MARTA LUPICA SPAGNOLO

\title{
Storie di confine
}

Biografie linguistiche e ristrutturazione dei repertori tra Alto Adige e Balcani

Romanistik

Franz Steiner Verlag 
Marta Lupica Spagnolo Storie di confine 


\section{SPAZI COMUNICATIVI}

KOMMUNIKATIVE RÅUME

Herausgegeben von Roland Bauer, Sabina Canobbio,

Mari D'Agostino und Thomas Krefeld

Band I6 
MARTA LUPICA SPAGNOLO

\section{Storie di confine}

Biografie linguistiche e ristrutturazione dei repertori tra Alto Adige e Balcani 
Publiziert mit Unterstützung des Schweizerischen Nationalfonds zur Förderung der wissenschaftlichen Forschung.

Pubblicato grazie al sostegno del Fondo nazionale svizzero per la promozione della ricerca scientifica.

Bibliografische Information der Deutschen Nationalbibliothek:

Die Deutsche Nationalbibliothek verzeichnet diese Publikation in der Deutschen Nationalbibliografie; detaillierte bibliografische Daten sind im Internet über $<$ http://dnb.d-nb.de > abrufbar.

Dieses Werk einschließlich aller seiner Teile ist urheberrechtlich geschützt. Jede Verwertung außerhalb der engen Grenzen des Urheberrechtsgesetzes ist unzulässig und strafbar.

(C) Franz Steiner Verlag, Stuttgart 2019

ab 09/202I: CC-BY-NC-N

Satz: DTP + Text Eva Burri, Stuttgart

Druck: Hubert \& Co., Göttingen

Gedruckt auf säurefreiem, alterungsbeständigem Papier.

Printed in Germany.

ISBN 978-3-5I5-I2290-o (Print)

ISBN 978-3-5I5-I2292-4 (E-Book) 


\begin{abstract}
A Nina e Sebastiano
Ogni azione da loro intrapresa sembrava ingenua e addirittura insensata. Misuravano qualche landa, segnavano degli alberi nei boschi, esaminavano le latrine e i canali, guardavano in bocca alle vacche e ai cavalli, indagavano sulle misure e sui pesi, si interessavano delle malattie della popolazione, del numero e del nome degli alberi da frutto, della qualità delle pecore e dei volatili. (Pareva che giocassero. A tal punto agli occhi della gente, erano incomprensibili, irreali e non serie tutte queste loro occupazioni.)
\end{abstract}

Ivo Andrić, Il ponte sulla Drina. 



\section{RINGRAZIAMENTI}

Nel presente volume è pubblicata una versione leggermente riveduta e ampliata della mia tesi di dottorato, discussa nel luglio del 2016 presso l'Università degli Studi di Pavia e la Libera Università di Bolzano. La ricerca sul campo condotta per il presente lavoro così come la scrittura della tesi, prima, e la redazione del libro, poi, hanno costituito una rottura (positiva) nella mia biografia scientifica e non solo. Vorrei ringraziare coloro che negli ultimi anni hanno supportato la mia attitudine a contare e coloro che l'hanno costruttivamente messa in discussione.

Sono molto grata per la guida accurata e partecipata e per le numerose discussioni sul manoscritto alla prima relatrice della tesi, Rita Franceschini, e agli altri lettori e lettrici: Silvia Dal Negro, Federica Guerini, Gabriele Iannàccaro e Gianguido Manzelli. Ringrazio profondamente anche la professoressa Anna De Fina per la sua grande disponibilità e per i preziosi suggerimenti durante il periodo di studio trascorso presso la Georgetown University. Un ringraziamento sentito va inoltre ai prof. Maria D'Agostino, Thomas Krefeld e Gabriele Pallotti per la proficua discussione e le osservazioni espresse durante la difesa della tesi di dottorato. Infine, vorrei esprimere la mia gratitudine al Fondo Nazionale Svizzero per aver generosamente finanziato la pubblicazione digitale di questo libro.

La ricerca ha inoltre beneficiato dei commenti incisivi di docenti, ricercatrici e ricercatori, incontrati lungo il percorso. Tra questi, ci sono i membri del Centro Competenza Lingue e del Comitato Scientifico dell'Università di Bolzano, in particolare, Marco Angster, Peter Auer, Camilla Bettoni, Simone Ciccolone, Chiara Meluzzi, Angelika Redder, Lorenzo Spreafico, Daniela Veronesi e Alessandro Vietti così come Alexandre Duchêne, Filippo Pecorari e i dottorandi e le dottorande del dipartimento di Linguistica dell'Università di Pavia. Consigli ed idee sono venuti anche dalla coordinatrice del programma di dottorato Marina Chini, di cui conservo un caro ricordo.

Un grazie speciale va a Edyta Chrzastek, Rahel Stoike-Sy, Francesca Caligiuri e Colin Arnaud, che hanno contribuito al presente lavoro con spunti di riflessione non solo da una prospettiva sociolinguistica e che mi hanno incoraggiato con la loro amicizia. Desidero anche ringraziare tutta la mia famiglia, in particolare, Caterina, Lucia, Franco, Mario e Giovanna, per il supporto costante e il coinvolgimento sentito in ciò che mi preme.

Infine, questo libro non sarebbe stato possibile senza la collaborazione delle persone che ho intervistato e l'aiuto di chi, insegnanti di lingua, operatori e operatrici, volontari e volontarie, ha agevolato la ricerca sul campo. Li ringrazio di cuore per aver accettato di partecipare al progetto e per avermi raccontato la storia delle loro vite. 



\section{INDICE}

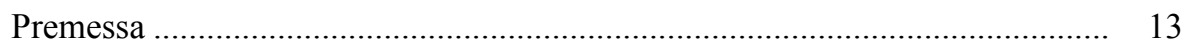

Capitolo I: Biografie linguistiche e repertori ………………………………..... 15

1 Approccio biografico al repertorio linguistico..................................... 15

$1.1 \quad$ Repertori plurilingui .............................................................. 15

1.2 Individui e comunità ................................................................. 17

1.3 Domini d'uso e tipi di repertori ................................................. 19

1.4 Usi linguistici reali e rappresentati ............................................ 20

1.5 Ristrutturazione dei repertori.................................................... 23

2 Biografie linguistiche: tra metodo e teoria ………………………....... 25

2.1 Dimensioni e realtà di un testo biografico ....................................... 26

3 Contestualizzazione delle domande di ricerca...................................... $\quad 30$

3.1 Unità di analisi ........................................................................... 33

3.2 Rilevanza della ricerca e contenuto del volume .......................... 35

Capitolo II: I contesti sociolinguistici di arrivo e di partenza............................ 39

1 Peculiarità sociolinguistiche dell'Alto Adige come meta

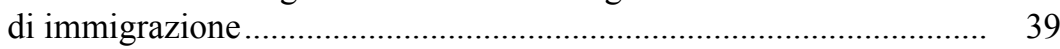

1.1 Minoranze autoctone: appartenenza linguistica e territoriale...... 40

1.2 Bilinguismo sociale e individuale................................................ 45

1.2.1 Competenze e uso della lingua seconda ........................... 47

1.2.2 La comunicazione tra gruppi ........................................... 48

1.2.3 Atteggiamenti verso il plurilinguismo.............................. 52

1.3 Le varietà di tedesco ................................................................ 53

1.3.1 Rapporti di differenziazione ............................................. 53

1.3.2 Allocazione.................................................................. 56

1.4 Le varietà di italiano ............................................................... 60

1.5 Il bilinguismo e la variazione intralinguistica per i cittadini

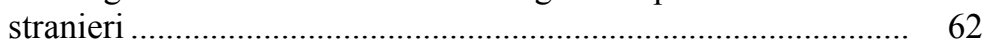

2 Immigrazione in Alto Adige: numeri ed etnografia ............................. 64

2.1 I cittadini stranieri in Alto Adige ................................................ 64

2.2 L'emigrazione dai paesi successori alla Jugoslavia..................... 68

2.3 Gli usi linguistici dei cittadini stranieri ..................................... 71

2.4 La querelle sull'apprendimento delle lingue ............................... 74

2.5 Attività di inclusione linguistica in provincia.............................. 78

2.6 Tipi di percorsi migratori........................................................ 84 
3 La situazione sociolinguistica di partenza .......................................... 86

3.1 Lo spazio linguistico slavo meridionale ..................................... 87

3.2 Plurilinguismo dei repertori d'origine ……………………........... 89

3.3 Lo status dei codici nei paesi di partenza ..................................... 90

3.4 Politiche linguistiche nei Balcani occidentali: breve storia......... 92

3.4.1 Purismo linguistico in Croazia ........................................ 93

3.4.2 Trilinguismo istituzionale in Bosnia-Erzegovina ............. 95

3.4.3 (Inter)nazionalismo linguistico in Serbia .......................... 95

3.4.4 Dibattiti intorno all'esistenza del montenegrino .............. 96

3.4.5 Legittimità delle lingue in Rep. di Macedonia ................. 97

3.4.6 Diglossia in Kosovo....................................................... 98

3.5 Controversie sui glottonimi e apposizioni .................................. 99

3.5.1 Denominazioni per una lingua in via di codificazione ..... 100

3.5.2 Denominazioni per una lingua "unitaria"........................ 101

3.5.3 Denominazioni per lingue in via di separazione .............. 102

3.5.4 Denominazioni e atti di posizionamento: la "nostra lingua" ......................................................... 106

Capitolo III: Corpus e metodi .................................................................. 109

1 Dati e possibili generalizzazioni ....................................................... 109

1.1 Modi di campionamento ............................................................ 109

1.2 Reticoli sociali e fasi di campionamento ……………………....... 113

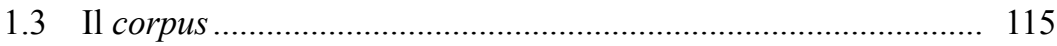

1.3.1 Fattori migratori........................................................... 116

1.3.2 Fattori pre-migratori ..................................................... 118

1.3.3 Fattori post-migratori.................................................... 120

1.4 Modi di conduzione delle interviste ........................................... 121

1.5 La lingua delle interviste e le competenze dichiarate dei partecipanti........................................................................ 123

1.6 Il ruolo dell'intervistatrice ........................................................ 125

2 Principi e strumenti di analisi .......................................................... 126

2.1 Analisi macro e supporti informatici ....................................... 126

2.2 Le convenzioni di trascrizione.................................................. 128

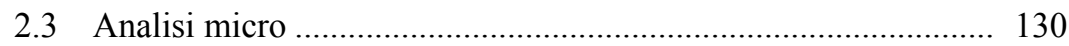

2.3.1 Identità narrative............................................................ 131

2.3.2 Rappresentazioni .......................................................... 132

2.3.3 Atti di posizionamento................................................... 134

2.3.4 Concetti affini: prese di posizione e footing ..................... 139

Capitolo IV: Denominazioni di lingua ............................................................ 141

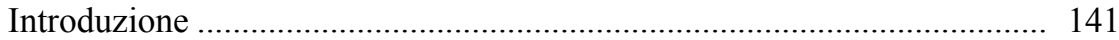

1 Denominazioni e rapporti di differenziazione tra i codici d'origine .... 143

1.1 Gli incipit delle interviste ......................................................... 144

1.2 Dimensioni di differenziazione................................................... 146 
1.3 Repertori d'origine monolingui ............................................ 149

1.3.1 Varianti e invarianti ................................................. 151

1.4 Repertori d'origine plurilingui............................................... 155

1.4.1 Il macedone come lingua co-ufficiale............................ 157

1.4.2 L'albanese come lingua di minoranza ............................ 160

1.4.3 Le varietà di rumeno come lingue non riconosciute......... 163

1.5 Repertori in situazioni di "schizoglossia"................................. 166

1.5.1 Glottonimi semi-concorrenti...................................... 168

1.5.2 Glottonimi concorrenti ................................................ 171

1.6 Conclusioni: identità dei codici d'origine................................. 176

2 Variazioni in famiglia ............................................................... 180

2.1 Selezione del campione ...................................................... 180

2.2 La dimensione interazionale ............................................... 182

2.3 Il tempo della storia ........................................................... 187

2.4 Codici endo- ed esocomunitari ............................................... 192

2.5 Conclusioni: rappresentazioni degli spazi (socio)linguistici di partenza...................................................................... 199

3 Denominazioni in divenire ........................................................... 201

3.1 Quasi-glottonimi: tentativi di definizione............................... 202

3.1.1 Da nomi generici a specifici in interazione .................... 203

3.1.2 Da nomi generici a specifici nel contesto macro ............. 205

3.1.3 La "madrelingua" ....................................................... 208

3.1.4 Le funzioni dei quasi-glottonimi nel corpus................... 209

3.2 Funzione elusiva e vergogna................................................. 212

3.3 Funzione enfatica e attrito linguistico..................................... 218

3.4 Funzione oppositiva e interventi di pianificazione ................... 227

3.5 Conclusioni: illegittimità di lingue e parlanti .......................... 233

Capitolo V: Narrazioni di interazioni ......................................................... 239

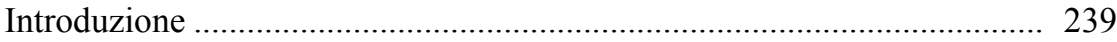

1 Terminologia intorno al concetto di repertorio narrato...................... 240

1.1 Per una definizione di narrazione ............................................ 241

1.1.1 Criteri di selezione.................................................... 242

1.1.2 Tipi di storie di dialoghi ............................................ 245

1.1.3 Narrazioni extra-linguistiche e metalinguistiche............. 249

1.2 Perché le narrazioni di interazioni? ........................................... 250

1.2.1 Polifonia.................................................................. 250

1.2.2 Interdiscorsività e intertestualità................................. 251

1.2.3 Partecipazione........................................................ 254

2 Modi di codifica: usi linguistici narrati e dichiarati........................... 255

2.1 Categorie emiche ed etiche .................................................... 256

2.2 I codici di comunicazione nel mondo della storia ..................... 258

2.3 Le unità narrative............................................................... 261

2.4 Le partecipanti e i repertori dichiarati .................................... 265 
2.4.1 L'intervista con VM......................................................... 268

2.4.2 L'intervista con DK ...................................................... 272

2.4.3 L'intervista con BV........................................................... 275

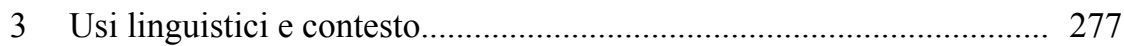

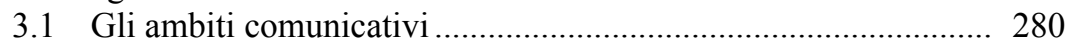

3.2 Lo spazio comunicativo narrato di VM ....................................... 282

3.2.1 Una storia "condivisa".................................................. 286

3.3 Lo spazio comunicativo narrato di DK........................................ 292

3.3.1 Una storia "abituale" e "generica".................................... 297

3.4 Lo spazio comunicativo narrato di BV ……………................... 301

3.4.1 Una storia "non-partecipata" .......................................... 304

3.5 Conclusioni: luoghi di interazione e usi linguistici soggettivi.... 308

4 Usi linguistici e ruoli interazionali .................................................... 311

4.1 Il discorso riportato................................................................. 315

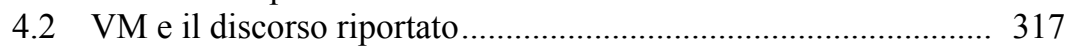

4.2.1 L'enunciazione mistilingue come pratica involontaria..... 319

4.2.2 Motivi e modi di acquisizione delle varietà di tedesco .... 322

4.2.3 La diffusione dell'italiano e dei codici d'origine ............. 328

4.2.4 Una parlante tedescofona nonostante il contesto

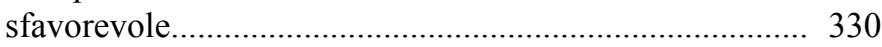

4.3 DK e il discorso riportato ……………………...................... 333

4.3.1 Le varietà di contatto e l'acquisizione non focalizzata.... 335

4.3.2 L'erosione delle competenze in albanese ........................ 338

4.3.3 Il plurilinguismo "interno" in varietà di tedesco .............. 340

4.3.4 L'ascolto occasionale di varietà di italiano........................ 345

4.3.5 Una parlante tedescofona stilisticamente competente ........ 347

4.4 BV e il discorso riportato........................................................... 350

4.4.1 Le varietà locali e non locali dei codici d'arrivo .............. 352

4.4.2 La selezione dell'italiano come "regola di default" ......... 357

4.4.3 I prestiti in funzione iconica e il ladino ........................... 360

4.4.4 L'inglese ........................................................................ 363

4.4.5 Una parlante "flessibile" senza potere di negoziazione

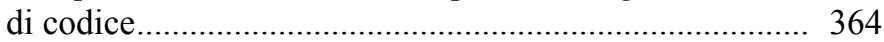

4.5 Conclusioni: il ruolo distintivo del tedesco …………………...... 367

Capitolo VI: Conclusioni: i repertori narrati................................................... 369

1 Tipi di parlanti nel contesto ........................................................... 369

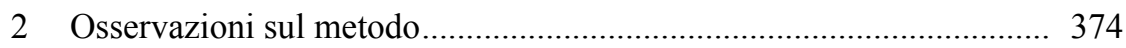

3 Narrazioni in intervista ................................................................. 377

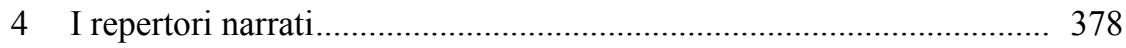

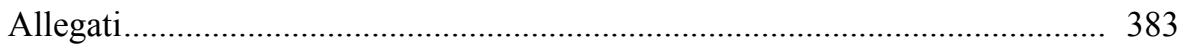

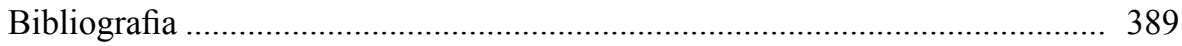




\section{PREMESSA}

Il presente lavoro, condotto nell'ambito del Dottorato di Ricerca in Linguistica dell'Università degli Studi di Pavia, ha beneficiato della supervisione di docenti in servizio presso l'ateneo pavese e presso le sedi consorziate della Libera Università di Bolzano, dell'Università degli Studi di Bergamo e dell'Università degli Studi di Milano-Bicocca. La borsa di studio, finanziata dall'ateneo bolzanino, era finalizzata a promuovere ricerche che investigassero fenomeni sul tema "Plurilinguismo e contatto linguistico".

Oggetto del volume sono le rappresentazioni degli usi linguistici propri e altrui di persone originarie dei paesi successori alla Jugoslavia e attualmente residenti in Alto Adige al momento di raccontare la storia della propria vita. Nel libro analizzo dunque a livello contenutistico e formale i discorsi epilinguistici e le prese di posizione su fenomeni di lingua di parlanti che hanno vissuto e vivono in spazi sociolinguistici altamente complessi.

Concetti chiave nel presente lavoro e nozioni guida nella formulazione delle domande di ricerca sono quelli di "repertorio linguistico" e "biografia linguistica". La nozione di repertorio pone al centro dell'attenzione la totalità delle risorse comunicative di individui e di gruppi, più o meno temporanei e territoriali, invece di assumere lingue singole come punto di partenza per l'analisi (cfr. Busch 2012). Perciò è particolarmente adatta per studiare le pratiche plurilingui di persone mobili e le relazioni tra codici in situazioni di contatto. In modo analogo, la ricerca di approccio biografico può essere definita, parafrasando Johnstone 1996, una (socio) linguistica non delle lingue, ma dei singoli parlanti. Infatti, si inserisce in quel filone di studi di approccio "soggettivista" che parte dall'individuo e dalle sue esperienze per formulare teorie sul linguaggio e sulla comunicazione (cfr. anche Franceschini 2010).

Senza per questo mettere in dubbio i risultati di ricerche condotte con altri metodi, la rilevanza di tali studi dipende almeno da due ragioni (cfr. Johnstone 1996: 178-188). Da un lato ricordano all'analista che i nessi tra fenomeni sociali e linguistici sono indiretti e mutevoli in quanto mediati dalle interpretazioni e dagli atti di identità dei locutori. Dall'altro invitano i ricercatori a concepire le scelte e gli usi linguistici individuali come il risultato dinamico di processi di allineamento a se stessi e agli altri durante specifiche interazioni. Nell'adottare un approccio umanistico e nell'includere il particolare e il non prevedibile tra gli oggetti di analisi scientifica, queste ricerche forniscono gli strumenti teorici e metodologici per capire meglio la tensione tra innovazione e convenzionalità che plasma forme e significati linguistici (cfr. anche Le Page \& Tabouret-Keller 1985/2011: 1-16, Tannen 1989/2007: 187-188).

Sulla scorta di questo approccio, uno dei fili conduttori dell'analisi, esposta nel presente volume, è il tentativo di mostrare come rappresentazioni comunitarie, nel senso di diffuse nei macro-contesti sociali di arrivo e di partenza, e rappresentazioni 
individuali, ossia sviluppatesi sulla base di esperienze personali e condizionate dallo specifico micro-contesto interazionale, si intreccino tra loro nel momento in cui i partecipanti danno un senso alla composizione dei loro repertori durante le loro biografie linguistiche. Inoltre, sebbene per interpretare le prese di posizione degli interattanti nei confronti dei rapporti di differenziazione tra codici conosciuti e degli usi linguistici propri e altrui abbia individuato unità di analisi specifiche, la prima entità presa in esame, a cui si riferiscono quelle successive, è costituita dai singoli parlanti. 


\section{CAPITOLO I: BIOGRAFIE LINGUISTICHE E REPERTORI}

\section{APPROCCIO BIOGRAFICO AL REPERTORIO LINGUISTICO}

Nella presente ricerca adotto un approccio biografico al repertorio linguistico (cfr. Busch 2013). Secondo questo paradigma è centrale rinvenire le tracce della dimensione diacronica, intesa come biografico-individuale e storico-collettiva, sulla configurazione sincronica di un repertorio nella prospettiva dei parlanti (cfr. anche Blommaert 2013). L'attenzione ai mutamenti avvenuti nel corso del tempo e l'adozione di un punto di vista "emico" - vale a dire che tiene conto delle rappresentazioni e interpretazioni dei locutori e delle comunità linguistiche, di cui si sta indagando, e non solo di categorie "etiche", vigenti nel discorso scientifico e/o proprie dell'osservatore esterno (cfr., per esempio, Iannàccaro 2002) - hanno diverse implicazioni. Da un lato, influenzano i modi di concepire le risorse linguistiche che compongono un repertorio e le interrelazioni tra gli usi linguistici individuali e quelli abituali in una comunità. Dall'altro, hanno conseguenze sul tipo di dati considerati rilevanti per lo studio dei rapporti tra codici e sull'interpretazione dei motivi che guidano un'eventuale riallocazione delle varietà linguistiche, conosciute o anche solo riconosciute dai locutori.

Seppur non esaustiva della letteratura a riguardo, la rassegna di studi nei prossimi cinque sotto-paragrafi ha lo scopo di enucleare alcuni assunti base della nozione di repertorio sottintesa nel presente volume (cfr. § I.1.1 e sgg.). Successivamente motivo la scelta sia teorica sia metodologica di raccogliere le "biografie linguistiche" dei partecipanti e illustro, sulla base di un esempio dal corpus, il potenziale e i limiti delle informazioni ricavabili da interviste biografiche (cfr. $§$ I.2 e I.2.1). Infine, ai § I.3 e seguenti, riepilogo le domande di ricerca, espongo come ho individuato le due specifiche unità di analisi e discuto il contributo che mi auguro il presente volume possa dare allo studio della ristrutturazione dei repertori in situazioni di contatto. ${ }^{1}$

\subsection{Repertori plurilingui}

Fin da una delle sue prime definizioni in Gumperz (1964: 137-138), il "repertorio verbale" (verbal repertoire) consiste della totalità delle forme linguistiche e dei modi di formulare messaggi regolarmente impiegati e accettati da una comunità per

1 Nei riferimenti interni a questo volume, la cifra romana indica il numero del capitolo, mentre i numeri arabi si riferiscono ai paragrafi al suo interno. Inoltre, sia qui notato che, nella prima parte di questo libro (fino al capitolo quarto compreso), ho prevalentemente usato il plurale maschile per indicare gruppi di persone composti sia da uomini sia da donne. Tuttavia, nel capitolo quinto, mi servo più spesso di nomi al femminile. 
la comunicazione quotidiana. Così il repertorio non è composto solamente di lingue riconosciute, standardizzate e/o con una tradizione scritta consolidata, ma comprende tutte le varietà linguistiche e di contatto, come dialetti, registri, stili, pratiche di commutazione di codice o fused lects, diffuse e ammesse in una collettività. Inoltre, costituivi di un repertorio sono anche i rapporti, talvolta bilanciati, talvolta gerarchici, tra codici, le loro norme di impiego e le interpretazioni dei parlanti riguardo a entrambi (cfr. anche Berruto 1995: 72-74, Gal 1987: 286, Dell'Aquila \& Iannàccaro 2004: 17-18).

Secondo approcci recenti, come quello olistico e biografico, le varietà linguistiche in un repertorio non sono strumenti autonomi gli uni dagli altri, di cui i parlanti hanno o non hanno competenza. Piuttosto i ricercatori si interessano anche di conoscenze linguistiche frammentarie e/o acquisite temporaneamente e/o in modo non focalizzato da un locutore. Tra i fenomeni esaminati ci sono, per esempio, le ragioni di competenze in singole parole in una lingua straniera, la capacità di riconoscere determinati codici pur senza saperli parlare o l'“adozione linguistica" (Sprachadoption) inconsapevole di espressioni alloglotte per esposizione (cfr. rispettivamente Blommaert \& Bakus 2012 e Franceschini 2003, 2012).

Inoltre, l'acquisizione di nuove forme linguistiche non è concepita in questi studi come un processo che semplicemente aggiunge risorse in un repertorio. Infatti, in conseguenza dei modi stessi in cui avviene l'apprendimento, le nuove conoscenze si intrecciano con quelle già acquisite in passato per essere capite e assimilate, eventualmente modificandole (cfr. Franceschini 2001, 2016 per dettagli sui fondamenti cognitivi di tale assunto). Infine, il valore strumentale e simbolico assegnato ai codici da un parlante e, quindi, la posizione più o meno "centrale" da loro occupata in un repertorio sono intesi come altamente dinamici (cfr. Franceschini 2001 per il modello di comportamento linguistico Centro-Periferia e anche Busch 2012, 2013). I rapporti tra varietà linguistiche conosciute $\mathrm{o}$ anche solo riconosciute si modificano infatti ripetutamente nel corso della vita di una persona, per esempio, in seguito ad esperienze di mobilità. ${ }^{2}$ Inoltre, slittamenti più o meno estemporanei nelle relazioni tra codici possono essere anche motivati situativamente e localmente, ad esempio dagli specifici interlocutori in una determinata conversazione.

In linea con questi approcci e con le prospettive di ricerca da loro dischiuse, nel presente lavoro non considero le varietà linguistiche conosciute e riconosciute dai partecipanti come entità date e separate $a$ priori, ma piuttosto come continua. Pur partendo da questo presupposto, non sottovaluto tuttavia l'influsso che categorie precostituite e comunemente associate a determinati codici, come per esempio quelle di "lingua standard" o "dialetto", hanno sui loro locutori. Uno degli scopi dell'analisi è infatti proprio quello di individuare i fondamenti storici e biografici dei rapporti di differenziazione tra codici nei repertori degli informanti.

2 La nozione di "mobilità" vuole essere più generale di quella di "migrazione". Questa cerca di catturare, tra l'altro, la diversità dei profili socio-economici e la complessità delle traiettorie e motivazioni, che caratterizzano lo spostamento di persone nelle società contemporanee (cfr., per esempio, László \& Adamo 2017 e § II.2 per più dettagli relativi alla situazione studiata in questo volume). 


\subsection{Individui e comunità}

Nella presente ricerca mi servo della nozione di repertorio per riferirmi alle risorse linguistiche sia di gruppi sia di singoli parlanti (cfr. per una definizione analoga, per esempio, Duranti 1997: 71-72, Gal 1987, Dell'Aquila \& Iannàccaro 2004: 17-18, Chini 2004, Guerini 2006a, ma non Berruto 1995: 74). La distinzione tra repertori individuali e comunitari è utile, se non indispensabile, per studiare gli usi linguistici di persone mobili. L'esperienza migratoria determina infatti una riorganizzazione delle competenze linguistiche e comunicative di singoli (o tutt'al più di piccoli gruppi di) locutori in conseguenza del loro entrare in contatto con i codici e le norme d'uso, vigenti in una comunità linguistica $\mathrm{o}$, più concretamente, in gruppi/aggregati di parlanti diversi da quelli presso cui è avvenuta la socializzazione primaria.

Seppur costitutivo della nozione di repertorio, ${ }^{3}$ il concetto di comunità (insieme a quello di minoranza) linguistica è estremamente controverso (cfr. Iannàccaro \& Dell'Aquila 2000, Dell'Aquila \& Iannàccaro 2004: $15-17$ anche per ulteriori riferimenti bibliografici). In particolare, i problemi di una definizione di questi termini secondo parametri esclusivamente etici trovano conferma e nuovi spunti di riflessione nelle ricerche di sociolinguistica della migrazione (cfr. Bagna et al. 2003, Chini 2009, Chini 2011 specificamente per osservazioni sui gruppi di cittadini stranieri in Italia). Da un lato, l'individuazione di eventuali comunità immigrate nei paesi d'arrivo e, quindi, l'implementazione di misure per la loro tutela non può basarsi esclusivamente sulla considerazione di unità amministrativo-territoriali come spesso avviene nel caso di minoranze storiche. Infatti, a differenza di queste ultime, i gruppi di cittadini stranieri sono per definizione de-territorializzati. Dall'altro, potenziali comunità immigrate non sono ovviamente neanche definibili sulla base dell'origine e/o dell'appartenenza nazionale dei nuovi arrivati. Lo spazio sociolinguistico di partenza, similmente del resto a quello d'arrivo, non è infatti unitario né i percorsi migratori sono lineari (cfr. Blommaert 2008 e, per esempio, Chini 2004 per un quadro dei diversi repertori d'origine di cittadini stranieri tra loro connazionali residenti in due città del Nord Italia). Inoltre, competenze in una lingua pluricentrica o la condivisione di una lingua seconda possono agevolare la comunicazione tra parlanti mobili in un contesto specifico e, quindi, favorire la costituzione locale di comunità non nazionali o di L2 dopo emigrazione (cfr. Clyne \& Kipp 1999, Chini 2009 e, per esempio, Andorno \& Interlandi 2004 per uno studio sulla comunità arabofona - e quindi non definita sulla base di criteri nazionali - a Torino). In conseguenza di ciò, gli studi di sociolinguistica della migrazione fanno emergere distintamente che interazioni regolari e frequenti, atteggiamenti e interpretazioni comuni di comportamenti comunicativi e, soprattutto, il sentimento o la volontà di appartenere a un gruppo definito su base linguistica siano criteri fondamentali per individuare una comunità di locutori immigrata e non solo (cfr. Dell'Aquila \& Iannàccaro 2004: 17).

Analogamente ai codici del repertorio, anche le comunità linguistiche dei partecipanti alla presente ricerca non sono concepite come date, ma come costruite in

3 Si confronti per esempio la definizione di Gumperz (1964) citata nel paragrafo precedente. 
interazione. ${ }^{4}$ Dato questo sfondo, mi interessa, da una parte, esaminare come l'appartenenza a gruppi (immaginati) di parlanti, localizzati nelle regioni sia d'origine sia d'arrivo, venga negoziata durante i colloqui dagli interattanti. Come si vedrà in seguito, tale negoziazione spesso avviene attraverso le rappresentazioni dell'allocazione e delle relazioni tra codici nei repertori individuali. Dall'altra parte, mi preme analizzare come i partecipanti rendano conto, nel corso delle loro interviste, di abitudini comunicative consolidate nella società altoatesina e di come queste ultime eventualmente influenzino pratiche linguistiche individuali, proprie o altrui, dopo il trasferimento in provincia di Bolzano.

La ricostruzione delle interrelazioni tra rappresentazioni metalinguistiche individuali e quelle diffuse in una comunità è centrale anche in un approccio biografico al repertorio linguistico. Infatti, i rapporti dei parlanti con le varietà linguistiche (ri-) conosciute sono concepiti in tale paradigma come caratterizzati da connotazioni sulla dimensione "corporale" (leiblich), "emozionale" e "storico-politica" (cfr. Busch 2013: 20-30). Le relazioni dei primi due tipi (ossia corporali ed emozionali) sono determinate rispettivamente dalle disposizioni, anche involontarie, dei parlanti verso i codici del proprio repertorio e dalle loro esperienze individuali nell'usare tali varietà. Invece i rapporti della terza specie sono condizionati dai discorsi metalinguistici e dalle categorizzazioni associate alle lingue a livello collettivo.

Un sentimento che è indicativo dell'influenza reciproca tra le dimensioni "emozionale" e "storico-politica" - e quindi tra connotazioni determinate dall'esperienza individuale e comunitarie - è quello della "vergogna". Infatti, un parlante si vergogna di un proprio comportamento e/o delle proprie competenze in un codice quando li valuta come violanti e/o non adeguati rispetto a norme linguistiche collettive, che ha interiorizzato come sue. Tale sentimento emerge spesso nelle interviste di parlanti una lingua minoritaria non riconosciuta (cfr. Busch 2006) o di apprendenti una lingua straniera (cfr. Busch 2013: 26-27). I partecipanti alla presente ricerca hanno spesso esperito entrambe le situazioni.

Inoltre, si noti che la sensazione di parlare una varietà linguistica non legittima - ossia non riconosciuta come da tutelare, talvolta, neanche a livello minoritario - o la sensazione di essere parlanti non legittimi di un codice - ossia dalle competenze non riconosciute, per esempio, come "native" - ha effetti sia sugli usi linguistici reali, sia sui modi in cui questi usi vengono rappresentati dai locutori. ${ }^{5}$ Il convincimento dell'illegittimità di una lingua può infatti portare a non usarla più in contesti pubblici, a sostituirla dopo migrazione e/o a non nominarla tra i codici del proprio repertorio. Infine è probabilmente la forza delle emozioni, più che semplicemente il loro essere positive o negative, ad avere un impatto decisivo sui processi di apprendimento linguistico (cfr. Franceschini 2003, 2004). La valutazione del

4 Nonostante siano concepite come altamente variabili, mi servo comunque, nel corso del volume, del termine di "comunità linguistica" (oltre a quello di "comunità di locutori"). Infatti, l'identificazione con tali entità, seppur immaginate, ha, come si vedrà, un effetto sull'allocazione dei codici nel repertorio. Per il concetto di "comunità immaginate", si veda l'omonimo libro di Anderson (1983/1991).

5 Sul concetto di "legittimità" di lingue e parlanti si confrontino Bourdieu (1982/2005: 49-55), Busch (2012) e il § IV.3 del presente volume. 
ruolo di queste ultime richiede di assumere una prospettiva soggettiva o emica, ossia di registrare le rappresentazioni metalinguistiche dei singoli parlanti per come possono essere espresse, tra l'altro, in interviste narrative in profondità (cfr. anche Franceschini 2010, Kramsch 2009: 16-22).

\subsection{Domini d'uso e tipi di repertori}

Numerose ricerche, sia di approccio variazionista, sia di etnografia della comunicazione, estendono gli assunti dell'analisi strutturale all'esame dei repertori (cfr. Gal 1979, 1987). Infatti, l'alternanza tra lingue o combinazioni di codici non è concepita come casuale, ma sistematica in quanto portatrice di significati sociali più $o$ meno intenzionali (cfr. anche $\S$ I.1.5). Inoltre, in considerazione del principio di economia, si assume che ogni codice definisca il proprio spazio d'uso e la propria funzione in relazione alle altre varietà linguistiche con cui entra in contatto (cfr. Fishman 1989: 181-202, Dal Negro \& Iannàccaro 2003).

Partendo da questi presupposti, alcuni ricercatori mirano a individuare la "configurazione di dominanza" tra codici di un repertorio sulla base dei contesti, del tipo di interlocutori e/o del tema in cui, con cui, da cui e per cui i parlanti li adoperano (cfr. Fishman 1972/1975: 110-156). Le situazioni comunicative e costellazioni di partecipanti, la cui rilevanza è appurata di volta in volta sul campo negli studi di approccio etnografico, sono solitamente raggruppate in domini d'uso, come famiglia, comunità, lavoro, mass media. I domini d'uso sono disposti su una scala da basso a alto (cfr. anche Mioni 1987, Rindler Schjerve 1996). I codici in L (ovvero i basiletti) sono usati in ambiti informali per conversazioni private, mentre quelli in $\mathrm{H}$ (o acroletti) sono impiegati in situazioni formali e pubbliche e/o sono destinati all'uso scritto.

La distribuzione funzionale di varietà linguistiche per domini permette di identificare tipi di repertori, ad esempio "diglottico", "dilalico", "diacrolettico" (cfr. Berruto 1995: 227-255, Dell'Aquila \& Iannàccaro 2004: 170-172). Come noto, la nozione di "diglossia", intesa nella sua accezione larga, si riferisce a una situazione sociolinguistica in cui due codici, geneticamente imparentati o meno, si dividono, senza sovrapporsi, il polo alto e basso del repertorio: l'uno essendo usato soltanto in ambiti formali e l'altro in ambiti privati. Invece, il concetto di "dilalia" indica una realtà in cui un codice con un alto prestigio (ad esempio, l'italiano in molte regioni della penisola) è adoperato in situazioni sia formali sia informali, mentre un altro codice (ad esempio, un dialetto italo-romanzo locale) è parlato solamente in domini bassi. Infine, il termine "diacrolettia" è coniato da Dell'Aquila \& Iannàccaro (2004: 171) per indicare uno spazio sociolinguistico, come per esempio quello della Catalogna, in cui una varietà linguistica, adatta a tutti gli ambiti, è affiancata da un'altra varietà usata solamente per la comunicazione in contesti alti (cfr. anche Iannàccaro \& Dell'Aquila 2007, Iannàccaro \& Dell'Aquila 2011).

Uno degli obiettivi del presente lavoro è quello di ricostruire (alcuni) tipi di repertorio d'origine e d'arrivo dei partecipanti attraverso: i) un'analisi dei nomi e delle apposizioni da loro usati, durante le interviste, per qualificare le varietà linguistiche di partenza e ii) un esame della distribuzione dei codici per contesti e interat- 
tanti nelle storie di dialoghi, ambientate in Alto Adige, da loro raccontate. Nel fare ciò, non parto da una lista predefinita di lingue, interlocutori e situazioni comunicative. Piuttosto mi propongo di risalire a quelli di volta in volta rilevanti per i singoli partecipanti e, quindi, più salienti da un punto di vista emico.

\subsection{Usi linguistici reali e rappresentati}

Le relazioni funzionali e il valore simbolico associato ai codici in un repertorio non dipendono da proprietà linguistico-strutturali a loro intrinseche, ma sono rintracciabili sulla base delle loro effettive condizioni d'uso e delle valutazioni spontanee dei parlanti (cfr. Dell'Aquila \& Iannàccaro 2004: 14). Dati per 1'analisi sia qualitativa sia quantitativa dei repertori sono perciò gli usi linguistici in conversazioni reali, rilevati, per esempio, tramite osservazione partecipante o auto-registrazioni degli informanti in assenza del ricercatore. In alternativa o in aggiunta a questi materiali, i ricercatori raccolgono anche le dichiarazioni dei locutori riguardo ai propri comportamenti linguistici, per esempio, tramite interviste semi-strutturate ofocus group o tramite questionari o diari etnografici. ${ }^{6}$

Le rilevazioni osservate ed elicitate spesso discordano. Questo è vero soprattutto quando si riferiscono a pratiche linguistiche o di contatto inconsapevoli, stigmatizzate o non riconosciute come legittime, tra cui la commutazione di codice (cfr. Gumperz citato da Franceschini et al. 1984: 55). Tuttavia, se si tiene conto del loro diverso valore conoscitivo per il ricercatore, entrambe le fonti sono utili per definire i rapporti tra codici in un repertorio. Infatti svelano aspetti differenti del comportamento linguistico di singoli e comunità.

In particolare, le auto-valutazioni sono indicative di come i parlanti credono che le lingue dovrebbero essere utilizzate. Queste forniscono quindi indicazioni sui contesti e/o sugli interlocutori, in cui e con cui i locutori considerano appropriato o normale l'impiego di un codice, per lo meno a livello di norme d'uso consapevoli (cfr. Dal Negro \& Iannàccaro 2003). Inoltre, come discusso nello studio appena citato, la loro rilevazione consente di definire la posizione emica delle varietà linguistiche in un repertorio e di ipotizzare linee di tendenza nell'evoluzione dei loro rapporti in un determinato contesto. In considerazione di ciò, lo studio dei giudizi metalinguistici dei parlanti è rilevante, da un lato, in quanto questi possono avere effetti sui comportamenti linguistici reali e aiutano a interpretarli. Infatti, i locutori si orientano a tali opinioni, per esempio, nel selezionare il codice socialmente ap-

6 Citando solo lavori sugli usi linguistici in contesto migratorio, ricerche che analizzano le auto-valutazioni dei parlanti sono, ad esempio, Franceschini et al. (1984), Clyne \& Kipp (1999, 2006), Chini (2003, 2004), Lawson \& Sachdev (2004), Extra \& Yagmur (2008), Guerini (2008). Invece, studi che considerano gli usi linguistici reali dei parlanti sono, tra gli altri, Auer (1984), Sebba \& Wootton (1998), che esaminano le funzioni e i significati sociali dell'alternanza di codice in interazione, o Dirim \& Auer (2004), Vietti (2005), Keim (2008), Cortinovis (2011), Freywald et al. (2011), che investigano la formazione di varietà di contatto, etnoletti o stili comunicativi sociali. Infine, per lavori che combinano entrambi i modi di rilevazione dei dati si confronti Guerini (2003, 2006a), Schader (2009). 
propriato in un determinato contesto o per definire le strategie da mettere in atto per l'apprendimento di una seconda lingua (cfr. rispettivamente Iannàccaro \& Dell'Aquila 2001 e Castellotti \& Moore 2002). Dall'altro, la loro analisi è indispensabile per pianificare misure di politica linguistica efficaci in quanto rispettose dell'ambiente sociolinguistico a cui sono rivolte (cfr. Dell'Aquila \& Iannàccaro 2006, Iannàccaro \& Dell'Aquila 2011).

Nella presente ricerca, mi prefiggo di ricostruire come i partecipanti rappresentano l'alternanza di codice e motivano la selezione di lingua propria e altrui nel narrare dialoghi, fittizi o reali, ambientati in Alto Adige. Inoltre, miro a individuare le categorie emiche da loro adoperate per definire e distinguere le varietà linguistiche (ri)conosciute nello spazio sociolinguistico di partenza. In particolare, i dati su cui si basano le analisi esposte nel presente volume sono "rappresentazioni" di fenomeni linguistici e "atti di posizionamento" (o "prese di posizione") nei loro confronti, messe in scena e portate a termine dagli interattanti durante interviste narrative. Le nozioni di rappresentazioni (sociali) e di atti di posizionamento saranno discusse più dettagliatamente al § III.2.2 e seguenti di questo libro. Per il momento basti qui anticipare che mi servo di questi due concetti, invece di quelli di "atteggiamenti", "verbalizzazioni" o "percezioni" riguardo alle lingue, in conseguenza del tipo di dati raccolti e dell'adozione di un approccio ispirato all'analisi della conversazione per esaminarli.

In primo luogo, una ricerca sugli "atteggiamenti linguistici” dei cittadini ex-jugoslavi in Alto Adige avrebbe perseguito fini diversi e avrebbe adottato metodi differenti da quelli adoperati nel presente lavoro. Da un lato, si sarebbe posta 1'obiettivo di individuare opinioni e (pre-)disposizioni riguardo a fenomeni linguistici, caratterizzate da una certa coerenza e stabilità a livello mentale (cfr. Gilles et al. 1987, Baker 1992: 8-21). Dall'altro, dal momento che gli atteggiamenti linguistici sono generalmente definiti come latenti, ossia non direttamente osservabili, si sarebbe avvalsa di tecniche di escussione dati non solo dirette, come questionari o interviste, ma anche indirette, come la matched guised technique o il differenziale semantico (cfr. Ciccolone 2010: 25-38, 70-76 per una descrizione di questi metodi e per ulteriori riferimenti bibliografici).

Tali atteggiamenti linguistici (coerenti e latenti) non sono invece ricavabili sulla base dei dati qui raccolti. Infatti, come sarà ampiamente illustrato al § I.2, tramite una sola intervista narrativa, incentrata sul proprio vissuto, non è possibile ricostruire con esattezza cosa una persona pensa(va) o percepisce(piva) o deside$\mathrm{ra}(\mathrm{va})$ riguardo alle lingue in senso assoluto. Piuttosto le biografie linguistiche del corpus permettono di valutare come il sapere riguardo alle lingue sia tramandato e (ri)costruito in modo dinamico in interazione. Infatti, nel corso dei colloqui, i narratori rappresentano, per esempio, gli usi e i comportamenti linguistici propri e altrui in Alto Adige in relazione a obiettivi interazionali concreti, come motivare tesi o far ridere. Lo stesso vale per le prese di posizione riguardo alla situazione sociolinguistica nel paese d'origine: queste ultime possono, in particolare, variare a seconda di ciò che il parlante presuppone che la ricercatrice sappia riguardo al tema.

Il fatto che le opinioni e i giudizi metalinguistici degli informanti siano contestualizzati e varino a seconda di specifici fattori interazionali non è considerato, nel 
presente lavoro, come un effetto collaterale o uno svantaggio del metodo di raccolta dati. Piuttosto tale ancoraggio è giudicato come normale anche in altre situazioni comunicative, oltre a in quella dell'intervista, e degno di essere oggetto di studio di per sé (cfr. De Fina \& Perrino 2011, Wortham et al. 2011 per approcci analoghi). Così, i modi in cui rappresentazioni e prese di posizione sulle lingue sono negoziate in interazione e condizionate dal contesto micro-situazionale e macro-sociale, in cui si svolge il colloquio, sono posti al centro dell'attenzione nelle analisi dei prossimi capitoli invece di essere accantonati.

In secondo luogo e in stretta connessione con ciò, preferisco le nozioni di "rappresentazioni" e "atti di posizionamento" anche a quelle di "dichiarazioni" o "verbalizzazioni" di giudizi metalinguistici. Le ultime sono infatti definite come "espressioni verbali globali di tutto il campione" e perciò sono solitamente analizzate e/o presentate al lettore come sganciate dal contesto in cui si realizzano (cfr. Iannàccaro \& Dell'Aquila 2007: 20). Al contrario, le rappresentazioni e le prese di posizione sono fondate discorsivamente: entrambe sono infatti concepite come (ri-) elaborate durante e tramite la conversazione e come emergenti sequenzialmente in interazione (cfr. rispettivamente Castellotti \& Moore 2002 e Lucius-Hoene \& Deppermann 2004: 196-212). In linea con ciò, anche secondo Py (2000: 9), non si può propriamente parlare di rappresentazioni sociali al di fuori di "un'esperienza pratica più o meno problematica di ciò che è rappresentato", né di "un'interazione verbale sufficientemente argomentata ed elaborata a riguardo di ciò che è rappresentato" (traduzione della scrivente). Così, secondo la terminologia adottata nel presente volume, l'analisi delle "rappresentazioni" metalinguistiche degli intervistati implica un esame di come queste siano da loro sviluppate tramite "atti di posizionamento" nel corso dei colloqui, vale a dire tramite attività comunicative e/o mosse discorsive di vario genere, volte a valutarle ed a esprimere l'allineamento o il disallineamento nei loro confronti.

Infine, sulla scorta degli studi di "linguistica percettiva delle varietà" (perzeptive Varietätenlinguistik), opto per distinguere il concetto di "rappresentazione" anche da quello di "percezione" (cfr. Krefeld \& Pustka 2010, 2014). Infatti, le percezioni sono il risultato del confronto di un parlante con un input linguistico concreto. Invece, le rappresentazioni sono parte del suo "sapere riguardo alle lingue" (Sprachwissen). Perciò, queste ultime possono essere richiamate alla mente anche senza uno stimolo linguistico specifico. In aggiunta, possono essere motivate da ragioni anche extra-linguistiche, in particolare, da fattori politici, storici o sociali. ${ }^{7}$ Nello specifico, secondo questo approccio, il rapporto tra percezioni e rappresentazioni è di influenza reciproca: infatti, una volta formatesi sulla base di (una serie di) percezioni concrete, le rappresentazioni guidano e filtrano queste ultime. Questa interrelazione è dimostrata, tra l'altro, dal fatto che i giudizi di somiglianza e di comprensibilità tra lingue a contatto, come, nel presente caso, tra varietà di ladino, italiano

7 Sia qui tuttavia notato che, nella ricerca di approccio biografico così come in altri ambiti della sociolinguistica, ad esempio, in dialettologia percettiva o in folk linguistics, il termine "percezione" è solitamente usato con un significato più ampio rispetto a come è adoperato in linguistica percettiva delle varietà (cfr. gli stessi Krefeld \& Pustka 2010 e anche Sinner 2014: 129-132). 
e tedesco in Alto Adige, siano talvolta spiegabili, più che dalle loro effettive affinità strutturali, dalla volontà più o meno consapevole dei loro parlanti di costruire e affiliare tra loro comunità linguistiche immaginate (cfr. Iannàccaro \& Dell'Aquila 2011: 272 e anche Carli \& Guardiano 2005). È proprio il loro essere al contempo sociali e mutevoli, collettive e individuali, pre-costruite e co-costruite in interazione (cfr. anche Py 2000), che rende la nozione di "rappresentazione" particolarmente adatta per riferirsi all'oggetto di studio della presente ricerca.

\subsection{Ristrutturazione dei repertori}

L'analisi della ristrutturazione dei repertori e delle sue cause è affrontata in una serie di ricerche da una prospettiva macro-sociolinguistica (cfr. Gal 1987). Secondo questo paradigma, tipi di repertorio sono concepiti come strettamente interconnessi con tipi di strutture sociali. Così, per Fishman (1989: 177-223), una situazione di diglossia stabile e il mantenimento di una lingua di minoranza hanno alla base una "società a comparti" (compartmentalized society). Vale a dire una società in cui i domini privati o etnicamente marcati, come ad esempio casa, comunità, ma anche luoghi di culto, rispondono a scale di valori diverse dagli ambiti pubblici. Invece, l'instaurarsi di una "dipendenza sociale tra gruppi" (intergroup social dependency), quale può per esempio verificarsi in seguito a processi di urbanizzazione o migrazione, determina un sovvertimento del sistema di premi e sanzioni associato con le competenze in un codice. Tale situazione è spesso causa di sostituzione di lingua da parte della comunità in posizione subalterna.

In altri approcci, l'influsso di fattori sociali macro sulla (ri)allocazione dei codici in un repertorio è invece inteso come mediato dall'identità sociale dei parlanti. Uno studio esemplare di questo paradigma è quello di Gal (1979). Secondo la ricercatrice, la selezione di tedesco o ungherese in determinati contesti è funzionale per alcuni locutori nella specifica comunità studiata a simboleggiare una certa rappresentazione di sé come "paesano" o "lavoratore". Le categorie identitarie rispetto a cui gli informanti possono e vogliono esprimere affiliazione sono condizionate dal loro reticolo sociale. Così, la sostituzione di lingua nella situazione esaminata si spiega con il fatto che le relazioni interpersonali dei parlanti più giovani sono più variegate di quelle degli informanti più anziani. Ciò accade, tra l'altro, anche in conseguenza di fenomeni sociali macro, come urbanizzazione e industrializzazione.

Parimenti a quanto avviene nello studio dei repertori di minoranze storiche, processi di sostituzione/mantenimento di lingua in sociolinguistica della migrazione sono spesso esaminati sulla base di un confronto tra prime e seconde generazioni di migranti (cfr. Clyne \& Kipp 1999, Clyne \& Kipp 2006 e in parte Andorno $\&$ Interlandi 2004). Come già accennato, un fenomeno peculiare in contesto migratorio è comunque la modificazione piuttosto brusca degli usi e competenze linguistiche dei singoli che avviene in conseguenza del trasferimento in un altro spazio sociolinguistico e luogo di interazione quotidiana. Ne consegue che l'analisi della ristrutturazione dei repertori di persone mobili richieda ancora più improrogabilmente di tener conto di fattori sia temporali sia spaziali. Da un lato, la distribuzione 
funzionale dei codici nei repertori individuali si modifica infatti più velocemente in contesto migratorio rispetto $\mathrm{a}$ in uno minoritario. Tale instabilità è probabilmente in parte dovuta alla (possibile) crisi dell'identità sociale dei parlanti e al minore potere simbolico dei gruppi immigrati, isolati e de-territorializzati (cfr. Lüdi 1996). Dall'altro, i reticoli sociali, la cultura comunicativa dell'ambiente circostante e/o le micro-zone di interazione quotidiana risultano centrali per fare ipotesi sia sul mantenimento/sostituzione dei codici d'origine (cfr. Chini 2004), sia sui modi di acquisizione (di alcune strutture) delle varietà linguistiche di arrivo (cfr. D'Agostino et al. 2003), sia sulla diffusione di queste ultime, per esempio, in ambito familiare (cfr. Franceschini 2011a). Inoltre, fattori spaziali sono rilevanti per spiegare il formarsi di varietà interferite, etnoletti o stili comunicativi sociali in contesto migratorio (cfr. Vietti 2005, Boario 2008, Cortinovis 2011). Infine, anche lo spazio sociolinguistico di partenza ha un influsso sui processi di ristrutturazione dei repertori dopo emigrazione. Infatti, secondo Clyne (2006, 2007), lo status e la funzione dei codici nei paesi d'origine, come ad esempio il loro essere lingue di minoranza o varietà in L, insieme all'esperienza di una situazione di plurilinguismo o di ideologie linguistiche puristiche prima della partenza, si intrecciano ad altri fattori "pre-migratori” nel condizionare pattern di mantenimento o sostituzione di lingua dopo mobilità in un paese straniero.

In particolare, il presente lavoro si ispira a un determinato filone di ricerche sulla ristrutturazione dei repertori. Questo indaga specificamente i modi in cui varietà e varianti linguistiche assurgono a indici di categorie identitarie (cfr. Gal 1993 e anche Gal 1996: 588-590 per una rassegna di studi al riguardo). Da tali lavori emerge che le categorie e il significato simbolico, assegnati dai parlanti alle risorse linguistiche conosciute o anche solo riconosciute intorno a loro, sono da un lato condizionati da discorsi metalinguistici e da "ideologie linguistiche", ossia da (insiemi di) "pratiche di significazione" (signifying practices) di fenomeni linguistici, diffuse in una collettività e funzionali agli interessi di specifici gruppi sociali o culturali (cfr. Woolard 1998 e anche Blommaert 1999, Irvine \& Gal 2000). ${ }^{8}$ Dall'altro, tali connotazioni sono influenzate dai "regimi linguistici", ossia dagli assetti che regolano l'uso linguistico a livello istituzionale, con cui si è entrati in contatto nel corso della propria vita (cfr. Busch 2013: 134-140). Ideologie e regimi linguistici sono storicamente fondati. Tuttavia i parlanti, partecipando a uno spazio comunicativo $\mathrm{o}$, nel caso di persone mobili, a più spazi comunicativi uno dopo l'altro o anche contemporaneamente tramite l'uso di internet e social network, scelgono individualmente quali categorizzazioni e norme far proprie e quali rigettare. In considerazione di ciò, la struttura di un repertorio non è lo specchio incondizionato dei rapporti di dipendenza in una società, ma piuttosto è il riflesso di come i parlanti

8 La nozione di "ideologie linguistiche" come "pratiche di significazione" presenta analogie con quella di "rappresentazioni" metalinguistiche, discussa nel § I.1.4. Infatti, rispetto ad altri concetti parimenti adoperati in letteratura - come "opinioni", "credenze", "idee" riguardo alle lingue e ai parlanti -, tale concezione enfatizza la dimensione interazionale alla base della loro formazione e trasmissione (cfr. anche $\S$ III.2.3.2). 
interpretano tali relazioni e si posizionano nei loro confronti, talvolta assoggettandosi, talvolta resistendo loro.

Anche nella presente ricerca, il collegamento tra rappresentazioni di scelte linguistiche, esperienze biografiche e fattori storico-sociali (o storico-politici) è inteso come mediato dalle categorie identitarie, salienti nell'ambiente circostante, a cui i parlanti vogliono o meno affiliarsi. Tuttavia, adottando un punto di vista parzialmente inverso rispetto per esempio a quello dello studio di Gal (1979), non miro a identificare la rappresentazione sociale di sé che i parlanti indicizzano tramite l'uso di determinati codici in conversazioni spontanee. Piuttosto, intendo ricostruire, attraverso un'analisi di diversi fenomeni linguistici nelle interviste raccolte, come i partecipanti rappresentano e costruiscono in interazione aspetti dell" "identità linguistica propria e altrui" e dell" "identità delle varietà linguistiche" conosciute e riconosciute (cfr. §I.2.1 per maggiori dettagli). La negoziazione di caratteristiche identitarie avviene, tra l'altro, reinterpretando le esperienze biografiche e storico-collettive, legate rispettivamente all'emigrazione e ai recenti interventi di pianificazione linguistica nei paesi di provenienza. Inoltre, si realizza in accordo o in opposizione alle opinioni metalinguistiche diffuse nei paesi d'origine e d'arrivo.

\section{BIOGRAFIE LINGUISTICHE: TRA METODO E TEORIA}

Con biografia linguistica si intende un racconto di vita (scritto o orale), incentrato sulle varietà linguistiche conosciute o riconosciute dai narratori, le modalità in cui queste sono state acquisite, il loro uso e mantenimento o sostituzione nel corso del tempo (cfr. Franceschini 2004: 124, Pavlenko 2007: 165).

Il metodo biografico è ampliamene adoperato in sociologia qualitativa ed è fondato su specifici assunti teorici (cfr. Lamnek 1988/2010: 594-645). Secondo tale approccio, le storie di vita offrono un accesso privilegiato ai modi in cui singoli orientano le proprie attività quotidiane e organizzano la propria esperienza, appropriandosi in modo individuale di schemi interpretativi diffusi nella collettività e motivati socialmente. I modelli di comportamento, fondati nei percorsi di vita dei singoli, sono rinvenibili secondo Rosenthal (2005) tramite un confronto tra la "vita narrata" e la "vita vissuta" dei biografi (erzählte ed erlebte Lebensgeschichte). Vale a dire sono ricostruibili paragonando la prospettiva del passato, quale emerge in passi chiave dell'intervista, con la prospettiva del presente, quale risulta dai modi in cui gli eventi sono selezionati e concatenati tra loro per elaborare un racconto coerente. L'interesse per il caso singolo è giustificato negli studi di approccio biografico dall'idea che nella storia di una persona si possano rintracciare schemi e strutture processuali esemplari, comuni a più corsi di vita. Il loro rinvenimento permette di ricostruire tipi di destini di vita, salienti in un determinato contesto sociale (cfr. Schütze 1983: 284).

In linguistica applicata, biografie linguistiche sono state raccolte tramite tecniche di elicitazione parzialmente diverse. Ad esempio, Busch (2013: 36-44) elabora un metodo che combina disegno e racconto orale, mentre in Nekvapil (2003) sono condotte più interviste a distanza di tempo con una stessa persona da ricercatori di 
diversa origine. Anche i metodi di analisi variano a seconda delle domande di ricerca degli studiosi. Questi si concentrano o sul contenuto o sulla forma o parimenti sul cosa e come del testo biografico. Analisi di contenuto sono spesso effettuate codificando i racconti di vita per categorie secondo procedimenti ispirati alla Grounded Theory (cfr. Strauss \& Corbin 1990/1996 e Pavlenko 2007 per ulteriori riferimenti bibliografici). Analisi narratologica e della conversazione sono invece combinate nel metodo della "ricostruzione dell'identità narrativa" proposto da Lucius-Hoene \& Deppermann (2004) e adottato anche nel presente lavoro (cfr. Franceschini \& Miecznikowski 2004, Bochmann \& Dumbrava 2007, 2009, Betten 2010 per studi che si servono anche, ma non esclusivamente di tale metodo).

Nonostante queste differenze, gli indirizzi di ricerca biografica in sociolinguistica hanno comunque in comune l'interesse per la prospettiva soggettiva dei locutori e per l'analisi del parlare e del riflettere intorno alle lingue (cfr. Fix 2010). In modo analogo agli studi in sociologia qualitativa, la convinzione di fondo è che atteggiamenti e rappresentazioni individuali testimonino modi collettivi e storicamente fondati di dare senso alla realtà (socio)linguistica e abbiano talvolta effetti su di questa (cfr. Franceschini 2010). Perciò, l'approccio teorico e metodologico delle biografie linguistiche mi sembra molto adatto per lo studio dei repertori linguistici, per lo meno nell'accezione esposta nei paragrafi precedenti (cfr. anche Busch 2013). Infatti, la raccolta di biografie linguistiche consente di individuare l'apporto di esperienze biografiche sulla conformazione delle risorse linguistiche di singoli parlanti e sul modo di interpretare i loro rapporti. D'altro canto, il loro confronto ha il fine di valutare l'influsso di fattori storico-sociali su queste rappresentazioni individuali e di identificare tipi di comportamenti linguistici, generalizzabili al di là del caso singolo.

In particolare, biografie linguistiche sono state tra l'altro utilizzate per analizzare esperienze di acquisizione e mantenimento/sostituzione di lingua in contesto migratorio (cfr. Franceschini 2003, Betten \& Du-Nour 2000, Betten 2010) e per raccogliere informazioni, filtrate dalle interpretazioni dei singoli, sui codici usati in diverse situazioni comunicative in comunità di minoranza (cfr. Nekvapil 2004). Inoltre sono state impiegate per studiare i rapporti tra lingua e identità in contesti plurilingui e talvolta "conflittuali" (cfr. Bochmann \& Dumbrava 2007, 2009 e Veronesi 2008a, 2008b, 2010, 2012 specificatamente su racconti di vita di parlanti altoatesini). Infine l'approccio è stato adottato anche per documentare in una prospettiva emica cambiamenti nell'uso linguistico conseguenti ad avvenimenti storici (cfr. Fix 2010). Tema del prossimo paragrafo sono proprio il tipo di informazioni che possono essere ricavate dall'analisi di un testo biografico.

\subsection{Dimensioni e realtà di un testo biografico}

Nell'analizzare singoli episodi o un racconto di vita nel suo complesso, è importante tener conto del compito che il narratore è invitato e mira a compiere così come del contesto in cui è portato a termine. Al momento di raccontare la propria vita, i partecipanti scelgono infatti tra un numero molto alto di esperienze quelle che considerano più significative. Tale significatività varia a seconda della prospettiva che i nar- 
ratori adottano attualmente rispetto al proprio passato e dal punto di vista situazionale, ossia in relazione al micro-contesto in cui l'interazione si svolge. A differenza di una cronaca, una biografia non documenta così una serie di eventi fattuali. Piuttosto ne è un'interpretazione e una ricostruzione coerente, finalizzata a motivare come e perché si è diventati una certa persona e a offrire una determinata rappresentazione di sé a destinatari, reali o immaginati (cfr. Lucius-Hoene \& Deppermann 2004).

Le biografie linguistiche raccolte per la presente ricerca sono state narrate in intervista. Da ciò segue che il racconto di vita sia il risultato di una specifica interazione tra partecipante e ricercatrice in un dato momento. Il testo elicitato può essere così analizzato da un lato nella sua dimensione "presentazionale", ovvero relativamente ai riferimenti a esperienze individuali e collettive che contiene. Dall'altro deve essere interpretato anche in relazione alla sua dimensione "interazionale", ossia tenendo conto di obiettivi comunicativi concreti e degli effetti dell'"orientazione all'interlocutore" (recipient design) sull'organizzazione della storia (cfr. Franceschini 2003: paragrafi 12-18). L'intreccio e il possibile divario tra la dimensione interazionale e presentazionale in un'intervista sono, per esempio, evidenti nel brano seguente. La sequenza in 1 è tratta dalla biografia linguistica di una donna (VM), intervistata per la presente ricerca. Qui come nel corso del volume, i nomi degli intervistati sono anonimizzati e indicati con due lettere maiuscole. I turni della ricercatrice sono invece preceduti dalla sigla INT. Per le convenzioni di trascrizione utilizzate si veda il § III.2.2.

\section{(es. 1)}

1 VM poveraccio quel professore perché a una classe eravamo (hh) - otto

2 VM noi da ex jugoslavia[=((riso))]

3 INT [= $\mathrm{mh} \mathrm{mh}]$

$4 \mathrm{VM} \quad<<$ ridendo che sai cosa si $>$

5 VM $\quad[-$ mio marito $<<$ bisbigliando in tono basso come si dice cosa]

6 INT $[(($ riso $))]$

7 VM [cosa mi ha chiesto $>$ ]

8 INT $[(($ riso $))]$

9 VM - non ti dico[ $-<<$ in tono basso dimmi cosa mi ha chiesto $>]$

10 INT

11 VM

12 INT

$13 \mathrm{VM}$

14 INT

$15 \mathrm{VM}$

16 INT

$17 \mathrm{VM}$

18 INT

[((riso) $)]$

$<<$ ridendo e l'altro hai scritto [((riso)) $]-$ haus $=$ gabe[ $[->$ s]:i [((riso)) $]-$ [ah ah]

si mio figlio mi ha detto $<<<$ ridendo scrivilo [((riso)) $]$ $[(($ riso $))]$

- dopo ha detto $>$ E:: voi[da ex jugoslavia $<<$ ridendo vi metto $[($ (riso) $)$

TUTTI così che non ti potete neanche guardare > ((riso))] ((riso))]

(VM_Ser_Mer, 42:15-42:42)

Nel brano in 1, l'intervistata mette in scena un dialogo tra sé e i compagni di un corso di lingua in Alto Adige. Nel fare ciò riporta alla riga 11 l'enunciato di un personaggio della storia in tedesco: "haus=gabe" (probabilmente una forma con- 
tratta di Hausaufgabe, tr. compito a casa). Tale inserzione non è necessariamente indicativa degli usi linguistici reali della donna nella situazione comunicativa descritta (dimensione presentazionale). La lezione è infatti di lingua italiana, mentre il marito e il figlio della partecipante non hanno competenze in tedesco. Piuttosto l'inserzione è verosimilmente motivata da obiettivi discorsivi e correlata ai partecipanti della conversazione (cfr. Auer 1984). Infatti l'uso di un termine in tedesco è funzionale a costruire un contrasto con gli altri enunciati riportati nel cotesto. Inoltre coinvolge specificamente l'intervistatrice, che conosce il tedesco, ma non la lingua prima della partecipante. ${ }^{9}$

A parte tra dimensione interazionale e presentazionale, gli studi sulle biografie linguistiche differenziano inoltre tra tre tipi di informazioni, tra loro più o meno interconnesse, che possono essere ricavate da un racconto biografico. Le analisi si concentrano solitamente sull'esame di alcune di queste.

In primo luogo, analizzando il contenuto di una biografia, si può risalire alla "realtà del soggetto", ovvero a come una persona esperisce determinati fenomeni e comportamenti linguistici (cfr. Pavlenko 2007, Nekvapil 2003). A seconda delle domande di ricerca, gli studiosi, interessati a questo aspetto, si concentrano su specifiche sequenze chiave di un'intervista. Tuttavia è importante tenere conto anche della "dimensione temporale" dell'identità narrativa (cfr. Lucius-Hoene \& Deppermann 2004: 56-61). ${ }^{10}$ Vale a dire di come i singoli episodi di vita vissuta siano interconnessi gli uni agli altri a livello della vita narrata nell'intera biografia (cfr. anche Rosenthal 2005).

In considerazione delle informazioni che contiene riguardo la "realtà del soggetto", il brano riportato in 1 è, per esempio, rilevante per ricerche sull'acquisizione di una lingua seconda (SLA) in contesto migratorio. Questo fornisce, infatti, informazioni soggettive sulle situazioni e sulle strategie di apprendimento, messe in atto da VM dopo il trasferimento in Alto Adige. La frequentazione di lezioni di italiano è valutata dalla partecipante come un'esperienza molto positiva in una sequenza di poco successiva a quella citata: il motivo dipende soprattutto dall'affabilità del professore incontrato. Tuttavia, se si prende in considerazione l'intera biografia linguistica, risulta che l'apprendimento di tale codice avvenga, nella prospettiva della donna, soprattutto in contesti spontanei durante interazioni con amici, parimenti parlanti italiano come lingua seconda. A questo riguardo, si noti che il mettere in scena legami interpersonali per motivare l'apprendimento di un codice costituisce, secondo Franceschini (2001: 119-120, 2004: 142), una "figura del raccontare biografico intorno alle lingue" (Figur sprachbiographischen Erzählens). In altre parole, è un motivo che ricorre in più biografie linguistiche a livello di contenuto e che

9 Non si può escludere che l'inserzione in tedesco in 1 sia determinata da un vuoto lessicale dell'intervistata. Anche in questo caso, sarebbe comunque motivata da ragioni interazionali. Per un'analisi più dettagliata della sequenza in 1 si veda $\S$ V.4.2.3.

10 Oltre che da una dimensione "temporale", l'identità narrativa secondo Lucius-Hoene \& Deppermann (2004) è caratterizzata anche da una dimensione "sociale" e da una "autoreferenziale" (cfr. § III.2.3.1 per maggiori dettagli). 
ha conseguenze anche sul piano formale (vedi, ad esempio, il suo dispiegamento in racconti di esperienze personali).

In secondo luogo, la ricerca biografica si prefigge anche di risalire alla "realtà della storia" o "della vita", ovvero a come fenomeni e avvenimenti linguistici erano o sono avvenuti (cfr. rispettivamente Nekvapil 2003 e Pavlenko 2007 che non concordano sul termine). Tale ricostruzione si basa sull'individuazione degli elementi comuni nei racconti di parlanti diversi. Così, dalla comparazione tra le interviste raccolte per la presente ricerca risulta, per esempio, che i partecipanti rappresentino frequentemente l'italiano come una lingua acquisita con successo in contesti spontanei. All'opposto, numerosi intervistati sentono il bisogno di frequentare corsi di lingua tedesca. Le informazioni così ottenute possono contribuire a validare per triangolazione i risultati di ricerche condotte con altri metodi, ad esempio con inchieste quantitative. Inoltre, sono particolarmente importanti per ricostruire la realtà comunicativa quotidiana di un passato recente, nel caso manchino altre fonti che lo documentino (cfr. Nekvapil 2003: 64 sugli usi linguistici della popolazione tedescofona in Cecoslovacchia dopo il 1945).

Tuttavia, sia qui ribadito che anche le informazioni, ricavabili dal confronto tra biografie linguistiche diverse, sono filtrate da schemi interpretativi collettivi e plasmate dal pubblico, reale o immaginato, a cui il narratore si rivolge. L'intento documentaristico, che talvolta indico come uno degli obiettivi della mia ricerca, deve essere quindi inteso in senso largo: quelle che sono documentate sono infatti le rappresentazioni dei parlanti rispetto al proprio passato e presente linguistico (e non veri e propri fatti). In linea con ciò, ritornando alle storie dei partecipanti del corpus, le rappresentazioni dei tipici modi di acquisizione dell'italiano e del tedesco non sono da intendersi come aderenti alla realtà della storia in senso assoluto, ma come riflettenti, almeno in parte, sistemi di credenze diffuse nella società di arrivo rispetto ai codici in questione e ai loro parlanti. Tra queste ci sono, per esempio, l'opinione di una maggiore facilità della lingua italiana rispetto a quella tedesca e/o di una maggiore affabilità e loquacità dei parlanti italofoni rispetto ai tedescofoni locali. Inoltre, nel presente caso, tali rappresentazioni sono eventualmente condizionate dal fatto che la ricercatrice sia parlante di italiano come lingua prima: gli intervistati possono essere infatti influenzati da questa consapevolezza nel mettere in scena strategie di apprendimento del codice. Come mostra Franceschini (2001: 120) analizzando le biografie linguistiche di parlanti tedescofoni svizzeri, le somiglianze invece delle differenze tra italiano e tedesco tendono ad essere poste in primo piano in un altro contesto, plasmato da rappresentazioni metalinguistiche collettive diverse.

In considerazione di ciò, per Lucius-Hoene \& Deppermann (2004: 91), non si arriva, tramite interviste narrative incentrate sul racconto del proprio vissuto, a rispondere alla domanda su che cosa abbia realmente giocato un ruolo nella storia individuale. Inoltre non si può neppure risalire al punto di vista che l'informante aveva nel momento passato, oggetto del racconto. Piuttosto, un loro esame permette di identificare i modi in cui i parlanti, nella situazione attuale e insieme agli interlocutori, rappresentano e ricostruiscono la propria esperienza e la propria identità narrativa con l'aiuto delle risorse biografiche e linguistiche a loro disposizione. 
Secondo il metodo proposto dai due autori è quindi fondamentale partire da quella che per Pavlenko (2007) e Nekvapil (2003) costituisce la "realtà del testo" biografico, ovvero da come fatti ed eventi sono narrati dagli informanti. Al centro dell'analisi ci sono, in particolare, i modi specifici in cui i partecipanti attribuiscono tramite pratiche comunicative concrete (es. aggettivi, prosodia, commutazione di codice) a se stessi e ad altri determinati attributi identitari (es. qualità, ruoli sociali, competenze linguistiche). In tal modo, si ricostruisce come i narratori si posizionano situativamente e sequenzialmente nei confronti di tali categorie, sia nel mondo della storia, sia in quello dell'interazione.

Il metodo della "ricostruzione dell'identità narrativa" sarà esposto più dettagliatamente nel terzo capitolo del presente volume. Qui sia tuttavia anticipato che questo approccio è elaborato per l'analisi delle rappresentazioni di sé in racconti di vita in generale. Dato che nella presente ricerca si sono raccolte biografie linguistiche, ci si concentrerà invece specificamente su due aspetti identitari che emergono dal testo interazionale delle interviste raccolte. Tale limitazione deriva dalla peculiarità delle esperienze storico-biografiche vissute dai partecipanti. Inoltre si basa su alcune riflessioni nella letteratura sui rapporti tra lingua e nazionalismo negli stati successori alla Jugoslavia. Da un lato, 1'analisi mira a ricostruire 1'“identità linguistica" (linguistic identity) degli intervistati al momento del colloquio (cfr. Bugarski 2012: 220). Con questo termine mi riferisco alle caratteristiche di una persona (o di un gruppo di persone) che sono negoziate in interazione tramite le rappresentazioni della allocazione dei codici nel proprio repertorio individuale e/o in quello della comunità d'origine o d'arrivo. Dall'altro, mi prefiggo di esaminare 1' "identità delle lingue" (language identity), conosciute e riconosciute dagli intervistati (cfr. sempre Bugarski 2012: 220). Vale a dire le funzioni strumentali e simboliche assegnate a questi codici e le relazioni di differenziazione istituite tra di loro dai loro parlanti.

\section{CONTESTUALIZZAZIONE DELLE DOMANDE DI RICERCA}

Gli obiettivi del presente lavoro sono già stati illustrati, seppur separatamente, nei paragrafi precedenti. Resta da motivare perché le biografie di parlanti provenienti dai paesi successori alla Jugoslavia in Alto Adige sono, a mio avviso, testi interazionali esemplari, tramite l'aiuto dei quali poter riflettere intorno alla nozione di repertorio linguistico (e a quelle correlate di varietà e comunità linguistica) così come per analizzare il lavoro identitario in discorsi epilinguistici.

A questo riguardo, si noti che, nella specifica situazione studiata, due esperienze possono avere influito in modo significativo sulle configurazioni dei repertori individuali e sulle connotazioni emozionali e ideologiche associate alle lingue conosciute o riconosciute dagli informanti. Entrambe le esperienze hanno determinato rotture nell'uso linguistico e una ridefinizione dei rapporti tra codici nel repertorio a livello biografico-personale. Inoltre, nel primo caso, hanno agito anche sul piano storico-collettivo.

In primo luogo, i partecipanti alla presente ricerca hanno più o meno durevolmente fatto esperienza degli interventi di politica linguistica, volti alla formazione 
di quattro codici standard successivi al serbocroato. Tali misure si sono susseguite nei paesi d'origine con diversa intensità almeno dai primi anni novanta fino al 2007. Ciò significa che gli intervistati del corpus sono stati ripetutamente sottoposti alla "violenza epistemica" di discorsi metalinguistici, finalizzati a giustificare l'esistenza della "propria" lingua e la sua diversità dagli altri codici divenuti ufficiali nella regione (cfr. Makoni \& Pennycook 2007b e §II.3 e seguenti per maggiori dettagli). In particolare, le misure di pianificazione e le argomentazioni metalinguistiche scismatiche, ${ }^{11}$ diffuse anche a livello massmediatico negli stati successori alla Jugoslavia, non hanno solo determinato l'elaborazione di nuove lingue standard. Queste hanno anche modificato i nessi (immaginati) tra pratiche linguistiche e categorie identitarie, ad esempio, nazionali e/o "etniche"12, con il fine di legittimarle (cfr. Irvine \& Gal 2000). Perciò, i parlanti di queste regioni possono avere l'impressione di non parlare o non saper più parlare la lingua "giusta" e/o di non appartenere a una comunità linguistica riconosciuta (cfr. anche Busch 2013: 2829). Il condurre interviste con persone che hanno subito in anni recenti una tale violenza epistemica - dai "regimi linguistici" e "metadiscorsivi"13 costruiti intorno alle varietà del loro repertorio - permette dunque di identificare i segni che tale violenza ha lasciato o non ha lasciato sul loro modo di rappresentare i rapporti di differenziazione tra le lingue conosciute. Inoltre, consente di valutare se e in che modo queste rappresentazioni siano collegate alla immaginazione/costruzione di determinate comunità linguistiche e non.

In secondo luogo, si tratta di investigare le storie di vita di parlanti che, avendo un repertorio linguistico complesso di partenza - provengono infatti da aree dove il plurilinguismo sociale e parzialmente quello individuale sono diffusi e in cui le varietà linguistiche locali hanno recentemente cambiato il loro status - si trasferiscono in una regione a trilinguismo istituzionale, l'Alto Adige, parimenti caratterizzata da rapporti tra codici complessi e difficili da individuare anche per la popolazione autoctona (cfr. Franceschini $2011 \mathrm{~b}$ e $\S$ II.1 e seguenti per maggiori dettagli). In modo simile alla sostituzione di un codice standard con uno nuovo a livello istituzionale, anche l'emigrazione in un paese straniero è un'esperienza di rottura.

11 Si confronti, a questo riguardo, anche il concetto di "glottotomia" in Goebl (1979). Questo termine si riferisce però solo ai tentativi esogeni, ossia esterni, di separare una comunità linguistica, specialmente in situazione di "schizoglossia". Come sarà spiegato meglio in seguito (cfr., in particolare, § IV.1.2), la nozione di "schizoglossia" indica invece una condizione di insicurezza linguistica dovuta alla presenza di più codici standard, oggetto di possibile identificazione.

12 I termini "etnicità" e "etnico" sono usati, qui e in seguito, tra virgolette per evidenziarne la problematicità. In particolare, per una critica all'uso del concetto di "etnicità" in sociolinguistica e alle responsabilità, seppur indirette, della letteratura scientifica nel diffondere e legittimare denominazioni discutibili, in quanto connotate negativamente, come appunto quelle intorno al concetto di "etnoletto", si confrontino Redder (2011) e Androutsopoulos (2011).

13 Come già accennato, con "regimi linguistici" si intendono gli assetti che regolano istituzionalmente il plurilinguismo (cfr. Busch 2013). Il concetto di "regimi metadiscorsivi" si riferisce specificamente alle rappresentazioni e ai discorsi sulla lingua stessa, a partire dai quali si basano e giustificano concrete forme di azione e potere politico (cfr. Makoni \& Pennycook 2007b). 
Questa può parimenti determinare la sensazione di essere parlanti illegittimi dei codici di arrivo e, in alcuni casi, anche delle lingue di partenza, ad esempio, a causa di erosione linguistica (cfr. sempre Busch 2013: 28-29 e in parte Gal 1996). ${ }^{14}$ Infatti, come già illustrato, le persone mobili si inseriscono in un nuovo spazio sociale, in cui vigono altre consuetudini linguistiche rispetto a quelle a cui sono abituati. Inoltre, nel nuovo paese di residenza, varietà linguistiche e competenze riguardo alle loro istruzioni d'uso non sono più senza sforzo immediatamente a disposizione, come invece avveniva prima nelle località d'origine.

In particolare, nel caso dei cittadini provenienti dalla ex-Jugoslavia in Alto Adige, è rilevante chiedersi se e, eventualmente, in che misura l'aver vissuto in situazioni plurilingui prima dell'emigrazione costituisca o, per lo meno, sia rappresentato come un vantaggio dagli intervistati al momento di raccontare come hanno gestito la nuova condizione di parlanti alloglotti e persone emigrate in un paese straniero. Inoltre, ci si può domandare se l'inserimento in una società plurilingue come quella altoatesina e l'apprendimento di uno o spesso di più codici d'arrivo (e delle relative norme di impiego) siano messi in scena come processi positivi o negativi dai partecipanti al momento di rendere conto alla ricercatrice della propria esperienza di mobilità dalla prospettiva attuale. Così, la specifica situazione studiata permette di esaminare non solo l'apporto dell'esperienza biografica in generale su quella linguistica, ma anche l'inverso. Vale a dire consente di analizzare i modi attraverso cui varietà e pratiche linguistiche, lungi dall'essere semplicemente strumenti di comunicazione, ci fanno essere o diventare quello che siamo (cfr. Romaine citata da Dell'Aquila \& Iannàccaro 2004: 19).

Considerato questo sfondo, il presente lavoro persegue, da un lato, uno scopo descrittivo. L'obiettivo è quello di illustrare i modi in cui i partecipanti caratterizzano i rapporti di differenziazione tra i codici di partenza e danno senso alle pratiche comunicative proprie e altrui nel nuovo contesto di residenza. Tramite un confronto tra le biografie linguistiche di diversi partecipanti, la ricerca si prefigge, d'altro canto, anche un fine esplorativo. In particolare, mira a formulare ipotesi sui "fattori" - intesi non come variabili oggettive e decontestualizzate, ma come motivi biograficamente, storicamente e situativamente fondati - che possono influenzare le rappresentazioni degli usi linguistici e delle relazioni tra codici da parte dei singoli secondo schemi comuni. L'individuazione di possibili invarianti nelle rappresentazioni e prese di posizione degli intervistati permette di ricostruire (alcuni) modelli di comportamento linguistico e (alcuni) tipi di repertori, validi in primo luogo per la specifica realtà studiata e poi eventualmente generalizzabili. Infine, il lavoro si propone di investigare, almeno in parte, anche la dimensione "autoreferenziale" (selbstbezüglich) dei dati raccolti (cfr. Lucius-Hoene \& Deppermann 2004: 67-76). In altre parole, intende esaminare anche quei processi di produzione di conoscenza,

14 La stessa Busch (2013) paragona la condizione delle persone mobili a quella di parlanti che hanno vissuto in periodi di bruschi cambiamenti linguistici, come in Germania dopo la caduta del muro o, appunto, in ex-Jugoslavia. In modo parzialmente analogo, anche Gal (1996) compara i processi di standardizzazione alla base del sorgere di lingue nazionali ai cambiamenti nel simbolismo linguistico che sono all'origine della sostituzione di lingua. 
che non sono precedenti, ma che avvengono nel corso e tramite l'atto del raccontare. In linea con ciò, sulla base dell'analisi del testo di alcune interviste, mi prefiggo, da un lato, di valutare se e, nel caso, in che modo i partecipanti, riflettendo intorno al proprio plurilinguismo, effettuino atti di resistenza contro categorizzazioni etnico-nazionali e/o discriminatorie, subite nei paesi d'origine o d'arrivo per via della configurazione dei loro repertori. Dall'altro lato, intendo illustrare come alcuni intervistati portino talvolta a termine una riqualificazione della propria storia personale $\mathrm{e}$, in particolare, della propria esperienza di mobilità tramite il racconto della loro acquisizione di codici diversi e del loro corrente agire con molteplici varietà linguistiche e di contatto nel nuovo contesto di residenza (cfr. Relaño-Pastor \& De Fina 2005, Baynham 2005 per studi con obiettivi analoghi).

\subsection{Unità di analisi}

L'identificazione delle unità di analisi è stata guidata dai dati, ovvero è avvenuta in seguito a un esame delle prime interviste raccolte finalizzato a stabilire la composizione dei repertori individuali degli intervistati. Nel tentativo di portare a termine questo lavoro ho riscontrato due problemi di natura pratica, ma con implicazioni anche di carattere teorico. Da un lato, in numerosi casi, i codici d'origine degli intervistati non sono identificabili in modo immediato ed eticamente univoco. Infatti, le denominazioni usate per chiamarli variano sia tra interviste diverse sia nel corso di uno stesso colloquio. Dall'altro, gli usi linguistici propri e altrui nel contesto d'arrivo non sono ovviamente descritti dai partecipanti una volta per tutte in un'unica sequenza dell'intervista. Piuttosto le rappresentazioni si precisano, generalizzano e, talvolta, apparentemente contraddicono durante le registrazioni, per esempio, in relazione a obiettivi interazionali perseguiti localmente dai narratori e/o alle richieste di chiarificazione dell'intervistatrice. In particolare, dal momento che ho raccolto interviste narrative, comportamenti linguistici e scelte di codice sono spesso messi in scena e motivati dai partecipanti raccontando dialoghi, reali o fittizi, a cui erano presenti o che sono stati loro riferiti. Da ciò segue che l'individuazione dei rapporti tra varietà linguistiche che compongono i repertori individuali degli intervistati non sia possibile dopo una semplice scorsa delle trascrizioni delle registrazioni. La loro identificazione e il loro confronto richiedono invece un esame piuttosto dettagliato del testo interazionale delle interviste del corpus.

In considerazione di ciò, la prima unità d'analisi della presente ricerca è costituita dalle "denominazioni di lingua" usate dai partecipanti per chiamare e/o per qualificare i codici d'origine nel corso dei colloqui. In questo volume, mi servo del termine "denominazioni linguistiche" come iperonimo per riferirmi a tre unità di analisi parzialmente distinte (cfr. anche Aronin et al. 2011). I "glottonimi" sono i nomi di lingua specifici, come "croato" o "serbocroato". Invece, le "apposizioni" sono gli attributi adoperati dai parlanti per categorizzare i codici nominati, ad esempio, "dialetto" o "lingua materna". Infine, dalle interviste raccolte emerge una terza categoria di denominazioni con caratteristiche intermedie tra le prime due. I "quasi-glottonimi" (Quasi-Glottonym) sono espressioni frequentemente adoperate da un 
partecipante in posizione isolata nel discorso come nomi di lingua specifici (cfr. Gröschel 2009: 31-35 per il termine). Tuttavia, la varietà linguistica da loro riferita non è immediatamente accertabile per l'interlocutrice $o$, in generale, da un punto di vista etico. Il motivo è che il significato di tali denominazioni è indessicale, ossia altamente dipendente dal contesto micro e macro.

Il presupposto su cui si basa l'analisi delle denominazioni di lingua, esposta nel capitolo IV del presente volume, è che queste non varino casualmente, ma che costituiscano una chiave di accesso per ricostruire i rapporti tra codici in una prospettiva emica, sia in generale, sia in special modo nella situazione studiata. Apposizioni, come per esempio "madrelingua" o "dialetto", sono infatti indicatrici del valore emozionale e dello status politico-sociale delle varietà linguistiche che qualificano. In connessione con ciò, permettono di risalire alla funzione simbolica e strumentale associata a questi codici da singoli e comunità (cfr. Goebl 1979, Tabouret-Keller 1997b, Iannàccaro \& Dell'Aquila 2007, Dal Negro 2009). Inoltre, i nomi di lingua specifici sono oggetto di controversie ricorrenti nello spazio sociolinguistico slavo meridionale e, in particolar modo, nei paesi successori alla Jugoslavia (cfr. Greenberg 2004/2008, Gröschel 2009). L'adozione di un determinato glottonimo o quasi-glottonimo, come ad esempio l'espressione "nostra lingua", può quindi contestualizzare - secondo modi e significati da identificare di volta in volta localmente - atti di posizionamento dei parlanti in affiliazione o in opposizione ai recenti interventi di pianificazione linguistica e/o alle istituzioni che li supportano.

La seconda unità di analisi è invece costituita dalle "narrazioni di interazioni". Con questo termine mi riferisco alle sequenze delle interviste in cui i partecipanti raccontano di dialoghi, ambientati in Alto Adige, specificando quale sia la varietà linguistica di comunicazione tra i personaggi nel mondo della storia. Talvolta, $\mathrm{i}$ narratori menzionano la lingua del dialogo incidentalmente. Così, si può ipotizzare che queste narrazioni rappresentino gli usi linguistici nella località di arrivo in modo meno mediato e più spontaneo rispetto, per esempio, alle dichiarazioni che seguono domande dirette della ricercatrice. Nella maggior parte delle storie, la lingua o la scelta di lingua sono tuttavia il tema principale del racconto. Le narrazioni "metalinguistiche" (in quanto incentrate su fatti di lingua) veicolano rappresentazioni sempre emiche dello spazio sociolinguistico d'arrivo. Ciò nonostante, in queste sequenze, la messa in scena degli usi linguistici propri e altrui persegue frequentemente anche specifici fini discorsivi, come ad esempio argomentare una tesi o divertire l'interlocutrice. Inoltre, contribuisce al lavoro di rappresentazione di sé e di altri come soggetti parlanti dopo l'esperienza di mobilità. Infine, in queste sequenze, nel tentativo di stabilire un'interpretazione comune con la ricercatrice del fenomeno linguistico narrato, i partecipanti attingono spesso a schemi interpretativi e a rappresentazioni metalinguistiche diffusi a livello collettivo. Così, le storie con argomento metalinguistico consentono specificamente di valutare come idee condivise su fatti di lingua si formino e riproducano in interazione (cfr. anche Johnstone 2006). Le narrazioni di dialoghi, ambientate in Alto Adige, sono esaminate nel quinto capitolo del presente volume.

In conclusione sia qui accennato che le due unità di analisi costituiscono ovviamente "oggetti" differenti da un punto di vista linguistico. Le denominazioni di lin- 
gua sono infatti nomi o sintagmi nominali (ma cfr. il capitolo IV per maggiori dettagli). Adoperando una nozione piuttosto controversa, le narrazioni di interazioni possono essere invece qui definite, almeno provvisoriamente, come "tipi di testo", ossia come fasci di caratteristiche linguistico-strutturali e situativo-funzionali, risultato di attività comunicative volte alla rappresentazione di eventi e accadimenti nella loro dimensione temporale (cfr. Lucius-Hoene \& Deppermann 2004: 141-159, De Fina \& Georgakopoulou 2012: 1-25 e il capitolo $V$ per una discussione più approfondita). Soprattutto l'esame delle sequenze narrative richiede inoltre di distinguere tra diversi livelli di significazione e di applicare metodi di analisi specifici, che saranno esposti più dettagliatamente nei capitoli successivi del presente volume.

Nonostante ciò, denominazioni linguistiche e narrazioni di interazioni svolgono frequentemente, per lo meno nelle interviste raccolte, una funzione simile, anche in quanto fondata su processi semiotici a mio avviso paragonabili. Così, per esempio, una delle controversie recenti nei paesi successori alla Jugoslavia riguarda l'impiego dei glottonimi "bosniaco" o "bosgnacco" per chiamare una delle varietà ufficiali della Bosnia-Erzegovina. Gli argomenti avanzati in favore o contro ai due nomi si riferiscono alle implicazioni che una loro adozione ha nel legittimare la portata comunicativa del codice così nominato e nel definire il numero e le caratteristiche identitarie dei suoi parlanti nativi. Infatti, il primo termine qualificherebbe il codice come lingua di tutti gli abitanti del paese. Invece, il secondo glottonimo lo caratterizzerebbe come la lingua esclusivamente dei residenti di fede musulmana (cfr. § II.3.4.3 per più dettagli). Da queste discussioni emerge che, sebbene il loro significato sia in alcuni casi opaco, i nomi di lingua sono frequentemente oggetto di contestazione in quanto costituiscono (anche) "racconti d'origine o racconti biografici" (récit d'origine ou récit biographique; cfr. Tabouret-Keller 1997b: 16). Vale a dire si riferiscono in modo ellittico e condensato a un testo narrativo (o narrativo-argomentativo), che illustra e al contempo giustifica l'evoluzione e le radici della pratica linguistica così nominata. In modo analogo, anche i racconti di dialoghi, specie quelli metalinguistici, sono spesso "formati" (framed) a livello di forma e contenuto tramite allusione a "matrici" di storie. Con l'espressione si intendono racconti diffusi in una collettività che ne rispecchiano in parte sistemi di credenze e/o modi convenzionali di narrare (cfr. Linde 2000: 614 e anche Johnstone 2006, De Fina \& Georgakopoulou 2012: 64-68). Perciò, entrambe le unità di analisi della presente ricerca permettono di valutare i meccanismi discorsivi, specialmente narrativi, attraverso cui parlanti e interlocutori prendono posizione e negoziano rappresentazioni comuni su fatti di lingua in una specifica interazione. In certi casi, gli interattanti riproducono, in altri casi contestano rappresentazioni di fenomeni linguistici condivise nel contesto macro in cui il colloquio si svolge.

\subsection{Rilevanza della ricerca e contenuto del volume}

La presente ricerca contribuisce allo studio del plurilinguismo nella misura in cui documenta (nel senso espresso sopra) le rappresentazioni e gli atti di posizionamento dei parlanti rispetto a fenomeni piuttosto consueti in contesti minoritari e migratori. 
Tra questi ci sono l'alternanza di codice a seconda della situazione comunicativa e/o dell'interlocutore così come i processi di mantenimento e sostituzione di lingue non maggioritarie. Al contempo, lo studio registra anche le opinioni e le prese di posizione degli intervistati rispetto ad eventi storicamente poco frequenti, come la "morte nominale" di un codice, il serbocroato, in seguito alla sua separazione in quattro varietà standard (cfr. Kloss 1984 citato da Greenberg 2004/2008: 14).

L'esame delle interviste raccolte consente, inoltre, di rivalutare i rapporti tra $\mathrm{i}$ codici in contatto nelle località d'origine e d'arrivo dei partecipanti da un'angolazione diversa rispetto a quella abituale. Tra i temi, che emergono dai colloqui e che sono dibattuti anche nella letteratura specialistica sullo spazio linguistico slavo centromeridionale e sui mass media, ci sono quelli del diverso status e riconoscimento di varietà di (dacu-)rumeno o delle somiglianze/differenze tra i codici a base neoštokava (cfr. § II.3). Relativamente al contesto altoatesino, questioni controverse sono invece, tra le altre, quelle della diffusione del plurilinguismo a livello individuale o del prestigio e della portata comunicativa dei dialetti tedeschi e italo-romanzi in provincia di Bolzano (cfr. § II.1). Il punto di vista, esposto nel presente lavoro, è originale in quanto, da un lato, è quello di chi reinterpreta le relazioni tra i codici di partenza a distanza, dopo il trasferimento in paese straniero. Dall'altro, è l'ottica di chi sta acquisendo le norme d'uso delle varietà linguistiche, parlate in Alto Adige, sulla base di un bagaglio linguistico-culturale differente da quello locale.

L'analisi concorre anche a una migliore "comprensione" ed eventualmente a una "spiegazione" delle strategie linguistiche adottate e dei problemi comunicativi affrontati, per lo meno, da alcuni (gruppi di) cittadini stranieri in provincia di Bolzano. ${ }^{15}$ Mettere a fuoco le esperienze soggettive dei migranti è importante in quanto queste persone e le loro comunità non hanno solitamente voce e sono frequentemente oggetto di pregiudizi o discriminazione nelle società di arrivo (cfr. De Fina 2003, Baynham 2005, King \& De Fina 2010 per un punto di vista analogo). Anche in Alto Adige, gli usi e le competenze linguistiche dei cittadini stranieri, soprattutto non provenienti dall'Unione Europea, sono tema di dibattiti politici e mass-mediatici. In particolare, la questione della prima lingua da loro appresa è talvolta strumentalizzata per argomentare in favore o contro misure di politica linguistica locale. Tuttavia ciò avviene spesso senza una previa ricognizione della situazione sociolinguistica reale della popolazione straniera in provincia di Bolzano (cfr. $\S$ II.2). Inoltre, si consideri che alcune delle persone intervistate per la presente ricerca hanno competenze in varietà linguistiche non legittime - ossia non riconosciute e non tutelate - non solo nella regione d'arrivo (questo vale per la maggior parte delle "lingue dei migranti" o "immigrate"; cfr. Bagna et al. 2003), ma già nei paesi d'origine (si vedano per esempio i parlanti di varietà di rumeno in Serbia e il $\S$ II.3 per maggiori dettagli). La raccolta delle loro esperienze è quindi doppiamente importante: le storie individuali di questi ultimi tendono infatti a non trovare spazio nei racconti ufficiali neanche nelle regioni di partenza degli intervistati.

15 Si confronti Lamnek (1988/2010: 216-218) sulla priorità, assegnata dalle ricerche qualitative, all'obiettivo di "comprendere" determinati fenomeni e secondariamente di "spiegarli". I due intenti ovviamente non si escludono a vicenda. 
Infine, la ricerca ha una rilevanza anche da un punto di vista più strettamente sociolinguistico. Questa dipende da alcuni assunti sulla relazione di interdipendenza tra lingua e ambiente sociale che condivido con studi, già in parte citati nel corso di questo capitolo, di antropologia linguistica e di linguistica del singolo, di analisi narratologica e di costruzione di identità in interazione così come di approccio biografico (cfr., per esempio, Irvine \& Gal 2000, Johnstone 1996, Makoni \& Pennycook 2007a, King \& De Fina 2010, Franceschini 2010, Busch 2013). Da un lato, questi approcci hanno in comune la concezione che le interpretazioni dei fatti di lingua da parte di singoli o di gruppi di parlanti abbiano un ruolo di mediazione nello stabilire e modificare le relazioni indessicali, "scientificamente" osservabili, tra forme e significati sociali. In questo senso, i giudizi e le opinioni metalinguistiche dei locutori condizionano la distribuzione di un fenomeno linguistico. Dall'altro, tali paradigmi sono accomunati dal conferire una particolare importanza al discorso, specie alle narrazioni, nella creazione e diffusione di orientazioni condivise. Le storie contribuiscono infatti a far prevalere un'interpretazione su un'altra, tramandando e consolidando i nessi tra forme e significati sociali, istituiti dai singoli.

È sulla base di questi presupposti che la riflessione metalinguistica e il "lavoro identitario" riguardo al tema lingua, quale si elicita tramite biografie linguistiche, è rilevante ai fini della ricerca sociolinguistica. Una loro analisi permette infatti di ricostruire le implicazioni (ideologiche ed emozionali) che un parlante associa all'occorrere di determinati fenomeni linguistici. Inoltre consente di intravedere i modi in cui queste connotazioni e interpretazioni sono tramandate discorsivamente in specifiche interazioni. Lo spostamento sulla prospettiva del parlante ha permesso, tra l'altro, di mettere a fuoco fenomeni, come la "diffusione di registro" (enregisterment) o l'"acquisizione di lingua non focalizzata" (unfokussierter Spracherwerb) (cfr. rispettivamente Johnstone 2006: 47-48 e Franceschini 2012). Tali nozioni contribuiscono, per esempio, a meglio definire, da un lato, i processi per cui una varietà linguistica non standard è tipizzata a socioletto o a dialetto e, dall'altro, i modi del cambiamento linguistico indotto dal contatto. Nel presente volume mi auguro che un approccio biografico consenta di capire meglio i processi che guidano la ristrutturazione dei repertori dopo mobilità in contesti che sono e che si concepiscono come già plurilingui. Inoltre, sullo sfondo della questione della responsabilità della ricerca scientifica che, nell'esplorare un fenomeno, crea le categorie che lo definiscono e al contempo lo immobilizzano in una determinata interpretazione, ${ }^{16}$ nel presente volume ci si propone anche di riflettere intorno ad alcuni concetti centrali della sociolinguistica odierna, come quelli di "repertorio", "comunità linguistica" e "contesto". L'adozione di un approccio emico contribuisce a una problematizzazione di tali nozioni e, eventualmente, offre spunti per una loro ridefinizione.

Il libro si compone di sei capitoli, a loro volta suddivisi in sezioni (o parti) e paragrafi. Nel prossimo capitolo, composto da tre sezioni, illustro la situazione so-

16 Emblematici a questo riguardo sono i concetti usati per descrivere le varietà linguistiche a base neoštokava, come "lingue per elaborazione" o "lingue pluricentriche". Un discorso analogo può essere fatto anche per le categorie "tedeschi", "italiani" e "ladini", in cui la popolazione altoatesina è solitamente suddivisa (per maggiori dettagli si veda il §II). 
cio-linguistica in Alto Adige e nei paesi successori alla Jugoslavia rispettivamente in ottica post- e pre-migratoria (cfr. § II.1 e § II.3). Inoltre, nella seconda parte del capitolo II, riporto alcuni dati sulla popolazione straniera residente in provincia di Bolzano (cfr. § II.2). Il terzo capitolo è invece dedicato alla descrizione generale del corpus di interviste raccolto (cfr. § III.1) e dei metodi impiegati per analizzarle (cfr. $\S$ III.2). Seguono i due capitoli più propriamente empirici del volume e che ne costituiscono il corpo principale, anche in termini di lunghezza. In questi discuto $i$ risultati dell'analisi delle denominazioni di lingua e delle narrazioni di interazioni nelle biografie linguistiche raccolte. In particolare, nella prima sezione del capitolo IV, confronto le apposizioni usate dai partecipanti per categorizzare i codici di partenza negli incipit dei loro colloqui (cfr. § IV.1). In aggiunta, nella seconda e terza parte, discuto alcuni motivi che guidano la scelta di denominazioni differenti tra membri di una stessa famiglia (cfr. § IV.2) e individuo le funzioni dell'impiego di apposizioni generiche come glottonimi specifici (o "quasi-glottonimi") in alcune interviste del corpus (cfr. §IV.3). D'altro canto, nel quinto capitolo, illustro dapprima la nozione di "narrazione" adoperata nella presente ricerca così come giustifico la scelta di concentrarmi sulle biografie linguistiche di tre partecipanti donne e descrivo i loro repertori dichiarati (cfr. §V.1 e V.2). In seguito, nella terza e quarta sezione del capitolo $\mathrm{V}$, esamino come le tre narratrici selezionate mettono in scena, nelle loro storie di dialoghi, la propria e l'altrui alternanza di codice in Alto Adige a seconda del variare i) della situazione comunicativa e ii) dell'interlocutore (cfr. rispettivamente $\S$ V.3 e V.4). Infine, nel sesto capitolo, riassumo i risultati della ricerca ed espongo alcune osservazioni conclusive di carattere etnografico, metodologico e sociolinguistico, relative ai repertori narrati dei cittadini ex-jugoslavi emigrati in una regione plurilingue, come la provincia di Bolzano. 


\title{
CAPITOLO II: I CONTESTI SOCIOLINGUISTICI DI ARRIVO E DI PARTENZA
}

\author{
1 PECULIARITÀ SOCIOLINGUISTICHE DELL'ALTO ADIGE \\ COME META DI IMMIGRAZIONE
}

L'Alto Adige si differenzia da altre mete di immigrazione in Italia e in Europa per alcune peculiarità della situazione linguistica e amministrativa. Da un lato i cittadini stranieri si trasferiscono in un territorio, caratterizzato dalla compresenza di varietà linguistiche più o meno standardizzate e con prestigio non sempre manifesto a contatto. Dall'altro si inseriscono in una comunità con un alto grado di consapevolezza sociolinguistica e metalinguistica, in cui la lingua è già - in parte in conseguenza dello speciale sistema scolastico e giuridico della provincia autonoma - uno dei principali veicoli di identità personale e di gruppo. Infine la struttura separata per gruppi linguistici della società altoatesina condiziona singolarmente il dibattito pubblico e le reazioni al fenomeno immigrazione.

Una descrizione preliminare della situazione linguistica e sociolinguistica in provincia di Bolzano è rilevante nella presente ricerca per dare un'idea della complessità dei rapporti tra codici che $\mathrm{i}$ cittadini stranieri devono gestire una volta arrivati in Alto Adige e di cui raramente sono a conoscenza prima di giungerci (cfr. ASTAT 2012: 206, Zanolla 2011: 190-192). Inoltre è indispensabile per valutare le rappresentazioni e le prese di posizioni espresse dai partecipanti durante le loro biografie linguistiche che saranno oggetto di analisi dettagliata nel capitolo V. In particolare, la complessità delle relazioni tra codici e gruppi linguistici autoctoni in provincia di Bolzano è testimoniata dalla presenza di una serie di questioni controverse in letteratura. Semplificando, tali questioni possono essere riassunte in quattro punti:

1) diffusione del plurilinguismo individuale, persistenza o meno di situazioni comunicative (caratterizzate come) esclusivamente monolingui e atteggiamenti verso la lingua seconda;

2) presenza di un continuum tra i dialetti austro-bavaresi locali e il tedesco standard regionale e sua eventuale descrizione;

3) rapporti funzionali tra varietà di tedesco e prestigio (occulto) dei dialetti tedeschi locali;

4) caratterizzazione dell'italiano regionale e diffusione dei dialetti italo-romanzi.

Il primo punto concerne la situazione sociolinguistica in Alto Adige e i rapporti tra gruppi linguistici autoctoni nel loro complesso, ossia visti come facenti parte di un'unica unità amministrativo-territoriale. La domanda di fondo, rilevante anche per analizzare le biografie linguistiche dei cittadini stranieri intervistati, è se e, eventualmente, con quali prospettive sia possibile vivere in provincia di Bolzano conoscendo solo una delle varietà linguistiche parlate sul territorio. A questo quesito 
sono dedicati i $\S 1.2$ e seguenti del presente capitolo. Le questioni formulate ai punti 2) e 3) sono tra loro correlate e riguardano invece la caratterizzazione dei repertori linguistici dei parlanti tedescofoni altoatesini, mentre il punto 4) concerne l'allocazione dei codici nel repertorio della popolazione italofona. Nel discutere questi temi ai $\S$ II.1.3 e II.1.4 intendo mettere in rilievo, da un lato, la molteplicità di varietà linguistiche, registri e varianti che i cittadini stranieri devono padroneggiare per risultare parlanti competenti anche solo di uno dei codici d'arrivo. Dall'altro mi interessa sottolineare lo status sociolinguistico ambiguo e l'alto valore simbolico che varietà linguistiche non standard, locali o non locali, di tedesco e italiano ricoprono frequentemente per la popolazione tedescofona e parzialmente per quella italofona residente in provincia di Bolzano. Tale prestigio è attribuito a codici non riconosciuti ufficialmente e/o privi di una funzione strumentale a livello globale (o semplicemente al di fuori dei confini provinciali). Perciò, i cittadini stranieri potrebbero avere difficoltà a riconoscere il valore di tali varietà linguistiche nel nuovo contesto di residenza. Infine, prima di affrontare le questioni controverse enunciate ai punti 1)-4), il prossimo paragrafo è dedicato all'esposizione dei modi in cui avviene la ripartizione della popolazione altoatesina per gruppi linguistici e alla distribuzione di questi ultimi sul territorio. Come si sarà notato, in questa sezione del capitolo II, mi concentro soprattutto sull'allocazione delle varietà di italiano e tedesco e sulla condizione delle rispettive comunità linguistiche in provincia di Bolzano. Lo status della lingua ladina e la situazione sociolinguistica della Ladinia Dolomitica non sono invece trattati sistematicamente. Il motivo è che, per non aggiungere un'altra variabile a quelle già numerose da considerare, ho scelto di non intervistare, per la presente ricerca, persone che hanno risieduto a lungo nelle valli ladine. In conseguenza del radicamento territoriale dei suoi parlanti, l'uso del ladino è infatti regolamentato solo in tali località nella provincia di Bolzano (cfr. Egger 2001: 36). Queste ultime presentano perciò una situazione sociolinguistica molto particolare. ${ }^{1}$

\subsection{Minoranze autoctone: appartenenza linguistica e territoriale}

Secondo i dati dell'ultimo censimento nel 2011, il 69,41\% degli altoatesini aventi diritto dichiara di appartenere e/o di aggregarsi al gruppo linguistico tedescofono, mentre la comunità linguistica italofona e ladinofona rappresentano rispettivamente il $26,06 \%$ e il $4,53 \%$ della popolazione totale, che consta di 453.272 persone (cfr. ASTAT 2013: 119). Da questo conteggio è escluso il 10,3\% (51.795) dei residenti in provincia di Bolzano che infatti è raggruppato sotto l'etichetta "altri”". Quest'ul-

1 Sui rapporti tra codici nelle valli "storiche" della Ladinia Dolomitica (ovvero Val Gardena e Val Badia in provincia di Bolzano, Val di Fassa in provincia di Trento, Livinallongo con Colle Santa Lucia e Ampezzo in provincia di Belluno) si confronti Iannàccaro \& Dell'Aquila (2000, 2011), Dell'Aquila \& Iannàccaro (2006, 2007), Vietti (2008). Per quanto riguarda il corpus di interviste raccolto, una sola partecipante ha abitato e lavorato in una località della Val Badia nei primi anni di soggiorno in Alto Adige, mentre un'altra informante è stata impiegata in un albergo della Val Gardena, pur risiedendo a Merano. 
tima categoria comprende nell'anno della rilevazione le dichiarazioni non valide, le persone temporaneamente assenti e i cittadini stranieri regolarmente residenti (cfr. ASTAT 2013: 118). Il numero delle persone categorizzati come "altri” è aumentato dal 2001 quando rappresentava il 7,4\% (34.308) della popolazione totale ed è probabilmente destinato a crescere ulteriormente, tra l'altro, proprio in conseguenza dei processi migratori (cfr. ASTAT 2013: 118). ${ }^{2}$

L'Alto Adige non è uno spazio sociolinguistico unitario. Il gruppo linguistico italofono è infatti concentrato soprattutto nei centri urbani, in particolare a Bolzano, e lungo le principali vie di comunicazione stradale e ferroviaria, per esempio a Fortezza e in misura minore a Vipiteno. La popolazione ladinofona risiede invece in prevalenza in Val Gardena e Val Badia, mentre i parlanti tedescofoni sono la maggioranza in 103 comuni, situati soprattutto nelle valli o in montagna (cfr. ASTAT 2003: 47). La cittadina di Merano rappresenta un'eccezione in quanto la percentuale di abitanti italofoni e tedescofoni si equivale. Inoltre anche le località della Bassa Atesina, ad esempio Salorno, Bronzolo e Laives, costituiscono casi particolari. Questi comuni sono infatti a maggioranza italofona, ma sono situati in un'area plurilingue da secoli. Infine, differenze nella distribuzione dei gruppi linguistici autoctoni si riscontrano anche a livello micro-areale. La concentrazione di popolazione italofona e tedescofona varia per esempio considerevolmente in relazione al quartiere bolzanino di residenza (cfr. Meluzzi 2014: 104).

Se quella appena delineata è la suddivisione generale per zone sociolinguistiche in provincia di Bolzano, i ricercatori non sempre concordano al momento di caratterizzare i repertori comunitari di alcune località "intermedie" tra mondo urbano e agro-montano. Inoltre, risulta molto complesso stabilire i fattori più rilevanti da un punto di vista sociolinguistico per spiegare la variazione diatopica nelle competenze e negli usi linguistici della popolazione autoctona. Così, Bressanone è talvolta considerata come una località semi-rurale e/o a maggioranza tedescofona e, quindi, rappresentativa di un altro tipo di situazione sociolinguistica rispetto a Bolzano, dove conoscenze in dialetto tedesco locale sono infatti meno diffuse (cfr. Måwe 2011: 181-182, Mioni 1990). Invece, in altri studi, il comune è paragonato al capoluogo di provincia in quanto località semi-urbana (cfr. ASTAT 2006), in cui almeno un quarto della popolazione appartiene al proprio gruppo linguistico e, dunque, competenze nella seconda lingua sono meno necessarie (cfr. Baur 2011: 167). Nel primo caso, i ricercatori individuano nella condizione di gruppo di maggioranza o minoranza assoluta un fattore determinante nel condizionare gli usi linguistici degli abitanti di un comune: i parlanti un codice localmente minoritario saranno più propensi a imparare la lingua dell'altro (ossia in questo caso il dialetto tedesco). Invece, per il secondo gruppo di studi, decisiva è la proporzione tra residenti appartenenti a gruppi linguistici diversi: se il numero di parlanti di entrambe le comunità è sufficientemente elevato (più di un quarto del totale), si tenderanno

2 In questo come nei prossimi paragrafi mi baso per i dati sulla popolazione autoctona e straniera in Alto Adige principalmente sulle pubblicazioni di ASTAT, l'Istituto Provinciale di Statistica. Questi dati sono infatti frequentemente aggiornati e confrontabili con quelli ISTAT a livello nazionale, di cui l'ente rappresenta un organo periferico. 
comunque a creare situazioni di chiusura, che influenzano negativamente l'acquisizione linguistica. Assunzioni differenti riguardo ai fattori che guidano la variazione diatopica hanno conseguenze importanti al momento di pianificare inchieste, per esempio, quantitative. Ciò ne rende talvolta difficile il confronto.

Oltre a variare diatopicamente, i rapporti tra varietà e comunità linguistiche in provincia di Bolzano si sono modificati anche diacronicamente. Tali variazioni sono avvenute in concomitanza con cambiamenti socio-economici e avvenimenti politici a livello locale, nazionale o internazionale (cfr. Eichinger 2001). Inoltre, anche i processi migratori e lo stabilirsi di popolazione alloglotta in provincia di Bolzano hanno determinato - per lo meno secondo le "percezioni" o le "rappresentazioni"3 di alcuni parlanti locali - variazioni nei rapporti tra codici e gruppi linguistici autoctoni.

In particolare, in provincia di Bolzano, la consistenza delle tre comunità linguistiche autoctone è rilevata ogni dieci anni in concomitanza con il censimento nazionale della popolazione, ma su foglio separato dal 1991 (cfr. ASTAT 2013: 87). I cittadini italiani residenti nella provincia autonoma hanno l'obbligo a partire dai 14 anni di indicare l'appartenenza a uno solo dei gruppi linguistici locali, ovvero a quello "tedesco", "italiano" o "ladino". 4 Le persone straniere con passaporto EU che si trasferiscono in Alto Adige compilano la dichiarazione fin dalla prima occasione. I cittadini extra-comunitari ne hanno invece diritto solo a partire dall'ottenimento della cittadinanza italiana (comunicazione dell'Ufficio Anagrafe di Merano). Dal 1991 è stata inoltre inserita nel documento l'opzione "altro": l'obiettivo era quello di facilitarne la compilazione alle persone cresciute in famiglie bilingui e, possibilmente, ai cittadini stranieri. ${ }^{5}$ Tuttavia, anche chi non vuole esprimere la propria "appartenenza" linguistica, deve comunque operare obbligatoriamente una seconda scelta e decidere di "affiliarsi" a uno dei tre gruppi linguistici autoctoni per usufruire di determinati diritti (cfr. Veronesi 2008a: 128-129, Medda-Windischer 2011: 20, nota a piè di pagina 7). La dichiarazione di appartenenza o di aggregazione a un gruppo linguistico ha infatti conseguenze di carattere legale. Sulla base dei risultati del censimento è regolato il sistema della "proporzionale etnica", ovvero il regime giuridico per cui i posti di lavoro pubblici e le risorse provinciali nei settori dell'educazione, cultura, affari sociali e parzialmente servizi assistenziali sono distribuiti proporzionalmente in base alla consistenza delle tre comunità linguistiche. Sebbene le dichiarazioni individuali siano segrete e dal 1991 scollegate da quelle rilevate in modo anonimo per il conteggio statistico, i singoli sono vinco-

3 Nel discutere, nel presente capitolo, la letteratura sulla situazione sociolinguistica di arrivo e di partenza, non distinguo nettamente tra i concetti di "percezioni" e "rappresentazioni" dei parlanti, ma adotto di volta in volta la terminologia usata nelle ricerche citate.

4 I genitori compilano la dichiarazione per i minori di 14 anni. Sono esonerati dallo scegliere per i propri figli qualora appartengano a due gruppi linguistici diversi.

5 Tuttavia, alcuni esponenti politici locali tentano (infondatamente) di distinguere tra le due condizioni tramite la coniazione di due termini diversi: le persone "mistilingui" sono nate da genitori appartenenti a due minoranze autoctone diverse, mentre quelle "bilingui" sono figlie di genitori stranieri (cfr. Carlà 2015: 76 e il § II.2.4 per più dettagli sulla strumentalizzazione del fenomeno "immigrazione" in discussioni di politica linguistica locale). 
lati alla propria dichiarazione nominale, conservata presso il Tribunale di Bolzano e modificabile, previa richiesta, solo trascorsi cinque anni dalla consegna (cfr. Pallaoro \& Coletti 2013: 118-119).

La proporzionale etnica e il censimento linguistico sono introdotti in provincia con il Secondo Statuto di Autonomia per il Trentino-Alto Adige del 1972 (decreto attuativo nel 1976 e prima rilevazione censuaria nel 1981). I provvedimenti fanno dunque parte di quell'insieme di norme finalizzate a garantire l'equiparazione delle tre lingue ufficiali e, in particolare, a compensare la "storica condizione di svantaggio" della popolazione tedescofona e ladinofona in Alto Adige (cfr. ASTAT 2006: 182183). La distribuzione ineguale di diritti e risorse era stata determinata da misure precedenti, promosse soprattutto durante il fascismo (cfr. Pichler 2008b: 108-110 e Veronesi 2008a: 126-130 per maggiori dettagli sugli interventi di questo periodo).

Tra le misure approvate dal secondo statuto - in cui confluiscono, tra l'altro, le norme del Pacchetto per l'Alto Adige del 1969 - c'è anche l'estensione dell'obbligo di un attestato di bilinguismo (e di trilinguismo nelle valli ladine) per tutti i lavoratori nel settore pubblico. ${ }^{6}$ Il cosiddetto "patentino di bilinguismo" si ottiene dopo il superamento di un esame di lingua, organizzato su quattro livelli corrispondenti al titolo di studio necessario per la professione aspirata. Lo Statuto di Autonomia conferma inoltre il modello scolastico tripartito, ossia suddiviso in scuole italiane, tedesche e ladine, e regola le modalità di insegnamento della lingua seconda in classe come materia curricolare obbligatoria (cfr. Pichler 2008a). Decreti di attuazione dello statuto sono emanati dalla provincia autonoma fino al 1992, anno in cui 1'ONU dichiara la questione altoatesina come risolta. Interventi di pianificazione linguistica, soprattutto nell'ambito della formazione, si susseguono comunque fino a oggi (cfr. Veronesi 2008a: 128-129).

Per descrivere la situazione sociolinguistica altoatesina nei prossimi paragrafi, considero anch'io la popolazione autoctona residente come facente parte di tre comunità linguistiche principali. Il gruppo linguistico costituisce del resto insieme a variabili tradizionali, come sesso ed età, una variabile indipendente attraverso cui enti provinciali e ricercatori descrivono e, talvolta, esplorano i dati demografici e socio-economici della popolazione locale. Sarebbe perciò difficile rendere conto dei risultati di molti studi tralasciando di effettuare questa distinzione. Tuttavia sia qui sottolineato che tali categorie sono intese nella presente ricerca come fondate esclusivamente su criteri linguistici. Per evidenziare ciò, preferisco usare in questo volume i termini "tedescofoni", "italofoni" e "ladinofoni” invece di tedeschi, italiani e ladini e l'espressione proporzionale "etnico-linguistica" al posto di proporzionale etnica. Infatti, sebbene le denominazioni citate per seconde siano le più diffuse in provincia, il loro impiego (specialmente quello di proporzionale etnica) è problematico in quanto tende a presentare i membri dei gruppi linguistici locali come accomunati da una presunta origine e/o "etnicità" comune. ${ }^{7}$

6 Precedentemente il certificato era obbligatorio solo per candidarsi ad alcuni posti di lavoro in enti pubblici (cfr. Coletti et al. 1992: 312).

7 A parziale supporto del punto di vista appena espresso, ASTAT (2006: 26-27) rileva una convergenza ampia, seppur non totale, tra le risposte degli informanti sulla propria madrelingua e 
Inoltre, sia qui messo in evidenza che l'adeguatezza di tali categorie e suddivisioni per descrivere la realtà presa in esame sia tutt'altro che da dare per scontata. A questo riguardo, le peculiarità amministrative ed educative della provincia autonoma, insieme ad avvenimenti storico-politici più o meno recenti, fanno inizialmente presupporre che i gruppi linguistici locali siano oggetto di forte identificazione da parte della popolazione autoctona (cfr. Baur 2000: 115 e sgg. sulla genesi e gli sviluppi di un'eventuale contrapposizione tra le comunità italofona e tedescofona in Alto Adige). La prima lingua costituisce infatti un marker di identità in diversi ambiti della società altoatesina, da quelli istituzionali e politici ai luoghi di ritrovo come bar o discoteche (cfr. anche Windischer 2011). In aggiunta, la quota di persone che usufruisce dell'opzione di "affiliazione" invece di "appartenenza" si assesta nel censimento del 2011 a solo 1'1,68\% (cfr. ASTAT 2013: 119). In linea con ciò, nonostante la scelta non vincolasse i partecipanti a livello giuridico, la percentuale di intervistati in ASTAT (2006: 20) che si dichiara come non appartenente a nessuna comunità linguistica è staticamente non significante, ovvero 30 informanti su un campione di 1.134 persone rappresentativo della popolazione di età uguale o superiore ai 19 anni. Per questo motivo, i ricercatori non considerano ulteriormente il sotto-gruppo al momento di analizzare i dati.

Sicuramente radicate nel discorso politico-istituzionale, tali categorie etnico-linguistiche sono tuttavia sempre più spesso oggetto di discussione e, talvolta, di contestazione da parte dei singoli. Tale resistenza "dal basso" emerge, per esempio, dalle biografie linguistiche raccolte da Veronesi (2008a) e Czernilofsky (2010). Al contempo, una certa insofferenza nei loro confronti si rileva anche nell'appena citato sondaggio ASTAT (2006: 181-187): da questo risulta infatti che gli informanti scelgano preferibilmente posizioni intermedie ("poco" o "abbastanza" d'accordo) nel valutare la proporzionale etnico-linguistica, mentre più sono giovani meno ritengono che tale sistema contribuisca a una convivenza pacifica tra gruppi.

A riguardo del sondaggio ASTAT, nel quadro del presente studio, è inoltre degno di nota il fatto che la maggior parte degli intervistati, indipendentemente dalla loro prima lingua, condivida l'opinione che la proporzionale e l'obbligo del patentino di bilinguismo costituiscano un vantaggio per la popolazione autoctona nel suo complesso nei confronti di quella proveniente da fuori provincia (cfr. ASTAT 2006: 187 e 280-281). Questi ultimi hanno infatti bisogno di acquisire un certificato specifico, valido solamente nella nuova regione di residenza. ${ }^{8}$ D'altro canto, il questionario rivela anche che il $67 \%$ dei partecipanti, interpellato sulla propria appartenenza "territoriale" ed "etnica", dichiari di sentirsi "sudtirolese" (Südtiroler/in), seguito da un 12,1\% che si definisce "italiano" (cfr. ASTAT 2006: 156-159). Le altre possibilità - tra cui "tedesco", ma anche "altoatesino" - non raggiungono in-

quelle sul gruppo linguistico di appartenenza. In particolare, la corrispondenza tra lingua materna e comunità dichiarata sfiora il $100 \%$ tra gli informanti tedescofoni (cfr. ASTAT 2006: 160-161). La madrelingua non coincide invece con il gruppo linguistico per 1'11\% degli intervistati ladinofoni, seguito dal $5,6 \%$ di quelli italofoni.

8 Recentemente la regione autonoma riconosce comunque oltre al "patentino" anche altri certificati di conoscenza della lingua italiana e tedesca, validi a livello europeo. 
vece singolarmente il $5 \%$ del campione. Sulla base di questi dati, si può ipotizzare che 1'origine locale (ossia l'essere "sudtirolese") costituisca un'altra categoria identitaria rilevante, a fianco di quelle linguistiche, per la popolazione residente nella provincia autonoma. Una ragione dipende dal fatto che specifici vantaggi siano associati e, effettivamente, derivino dalla condizione (eventualmente acquisibile a posteriori) di essere cittadini autoctoni. Di seguito descrivo lo spazio sociolinguistico altoatesino con l'obiettivo di rendere conto delle principali posizioni in letteratura rispetto alle questioni controverse formulate ai punti 1)-4) del paragrafo precedente. La rassegna non è esaustiva, ma si concentra specificamente sugli sviluppi degli ultimi venticinque anni. Particolare attenzione è data anche alle variazioni negli usi e negli atteggiamenti linguistici della popolazione autoctona a seconda del luogo di residenza. I cittadini stranieri intervistati per la presente ricerca si sono infatti trasferiti in Alto Adige in periodi differenti tra il 1992 e il 2014, mentre vivono in località caratterizzate da una diversa composizione linguistica.

\subsection{Bilinguismo sociale e individuale}

L'Alto Adige è un territorio a "plurilinguismo istituzionale" (cfr. Lüdi \& Py 1986/2003: 13). I residenti hanno infatti diritto a usare una delle lingue ufficiali (tedesco, italiano e ladino) nella comunicazione con le istituzioni, ad esempio negli uffici pubblici, negli ospedali o nei tribunali, e a usufruire di scuole e mass media in tali codici. Ne consegue che il diritto al "monolinguismo" (unilinguisme) dei singoli e della comunità provinciale sia garantito per legge, mentre non sussiste in via teorica la necessità assoluta di imparare le altre varietà linguistiche parlate sul territorio.

In concreto la situazione è ovviamente diversa. Lezioni di italiano e tedesco come lingua seconda sono introdotte via decreto nelle scuole dei due principali gruppi linguistici già dal 1945, mentre il secondo Statuto di Autonomia sancisce nel 1972 l'obbligatorietà di un loro insegnamento da parte di docenti madrelingua, almeno dalla seconda o terza elementare in avanti (cfr. Pichler 2008a: 63-64). ${ }^{9}$ Inoltre, la padronanza di entrambi i codici è spesso requisito ufficiale o ufficioso per l'ottenimento di un impiego in provincia di Bolzano e per il suo svolgimento, soprattutto nel caso di professioni a contatto con il pubblico e/o con altri enti o aziende (cfr. ASTAT 2006: 72 e già Egger 1990: 49). Come già notato, il conseguimento di un "patentino di bilinguismo" è indispensabile per ottenere un posto di lavoro nel settore pubblico. Inoltre tale certificazione è talvolta richiesta anche dai datori di lavoro privati (Osservatorio del Mercato del Lavoro 2009: 1). Così l'acquisizione di competenze nelle due principali lingue autoctone, oltre che nell'inglese, è promossa dalle istituzioni locali tramite iniziative formali e informali, mentre queste conoscenze risultano altamente vantaggiose nella vita quotidiana e professionale.

9 Le scuole ladine sono invece organizzate secondo un principio "paritetico". Tedesco e italiano sono lingue di insegnamento per un numero uguale di ore, mentre il ladino svolge la funzione di lingua di appoggio e di codice veicolare in un numero ridotto di materie (cfr. Franceschini 2011b: 148-149, Pichler 2008b). 
Per descrivere i repertori e le competenze linguistiche del gruppo tedescofono e italofono in Alto Adige è stata talvolta adoperata, per lo meno in riferimento al periodo precedente agli anni novanta, la nozione di bilinguismo "bicomunitario" e/o "intercomunitario" (cfr. Mioni 1982: 341-342, Berruto 1995: 251-252, Mioni 1990). Con tali etichette ci si riferisce a una situazione di plurilinguismo "sociale", in cui "pochi parlanti sono veramente bilingui e la comunità è ulteriormente suddivisa in due sotto-comunità separate, ciascuna con l'uso pressoché esclusivo di una delle due lingue al suo interno" (Berruto 1995: 251). Questa categorizzazione generale non è tuttavia, secondo i suoi stessi autori, sempre valida, ma necessita di ulteriori distinzioni in relazione al luogo di residenza dei parlanti.

In particolare, a variare diatopicamente sono le competenze della popolazione italofona in varietà colloquiali o locali di tedesco, mentre una maggiore o minore padronanza del tedesco standard dipende soprattutto dall'efficacia dell'insegnamento scolastico ricevuto (cfr. Mioni 1990: 23-24). Conoscenze nei dialetti locali o nei registri intermedi sono infatti (quasi) nulle per gli italofoni residenti in luoghi, come Bolzano o Merano, in cui il loro gruppo linguistico è maggioritario o piuttosto numeroso. Invece il repertorio dei parlanti italofoni della Bassa Atesina e dei comuni a prevalenza tedescofona (es. Brunico e, secondo lo studioso, anche Bressanone) comprende solitamente tali codici. I residenti di queste aree sono infatti quotidianamente a contatto con le varietà locali di tedesco e hanno quindi maggiori opportunità e/o necessità di usarle (cfr. anche Baur 2011 e Ciccolone 2010: 79-85 per conclusioni parzialmente simili con dati più recenti). In modo simile, anche Lanthaler (1990: 74-75) differenzia le competenze nella seconda lingua della popolazione tedescofona altoatesina in relazione al luogo di residenza. Le persone cresciute "nel dialetto", provenienti principalmente dalle zone "rurali" (ländlich), raggiungono mediamente un livello di padronanza di italiano inferiore alla classe media cittadina, cresciuta "con il dialetto", possibilmente perché i primi devono concentrarsi di più sull' acquisizione del tedesco standard durante il percorso formativo (cfr. ibidem: nota a piè di pagina 19).

Come già accennato, oltre che dal punto di vista diatopico, la caratterizzazione dei repertori delle due comunità linguistiche locali necessita di precisazioni anche in prospettiva diacronica. Dal confronto tra i risultati di ricerche recenti emerge infatti una situazione in parziale mutamento, rispetto a cui la qualifica di "bilinguismo bicomunitario" non è sempre senz'altro applicabile. Nello specifico, tre mi sembrano essere le questioni principali attraverso cui un'eventuale diffusione del plurilinguismo individuale tra la popolazione locale e possibili cambiamenti nei rapporti tra codici e minoranze di antico insediamento sono stati valutati. Queste sono:

1) il livello di competenza e la frequenza d'uso attivo e/o ricettivo della lingua seconda;

2) il codice selezionato per la comunicazione intergruppo in generale e/o in determinati contesti;

3) gli atteggiamenti verso i fenomeni di contatto e gli interventi di politica linguistica locale. 
Gli studi che discuto nei prossimi tre sotto-paragrafi adottano approcci diversi (qualitativi o quantitativi) e analizzano dati di natura differente, come auto-valutazioni elicitate con questionari o in interviste sociolinguistiche o ancora registrazioni di conversazioni spontanee, nell'affrontare questi tre temi.

\subsubsection{Competenze e uso della lingua seconda}

I parlanti italofoni dichiarano capacità di comprensione e produzione scritta e orale in tedesco mediamente inferiori rispetto ai locutori tedescofoni in italiano e ladinofoni nelle altre due lingue locali (cfr. ASTAT 2006: 138-153 e anche Franceschini 2011b: 145-146, Baur 2011). Tuttavia, la padronanza della seconda lingua da parte degli informanti più giovani è maggiore - soprattutto nelle famiglie italofone - rispetto a quella dichiarata dai genitori e/o dai parlanti più anziani (cfr. ASTAT 2006: 30-32). Inoltre, sempre secondo le auto-valutazioni raccolte, i contatti in età prescolare con le diverse varietà linguistiche parlate sul territorio si intensificano, ad eccezione che per gli idiomi ladini e per i dialetti italo-romanzi, in relazione al diminuire dell'età degli intervistati (cfr. ASTAT 2006: 32-36 e anche § II.1.4 per la diffusione delle varietà italo-romanze in Alto Adige). Così, i ricercatori concludono che "il plurilinguismo in Alto Adige abbia attualmente basi più ampie rispetto al passato" (ASTAT 2006: 32). ${ }^{10}$ Nonostante ciò, il parlare la lingua dell'altro risulta essere un'attività (rappresentata come) accidentale e/o praticata in un numero circoscritto di situazioni comunicative, soprattutto professionali (cfr. ibidem: 283). Infatti, se la maggior parte delle persone intervistate $(67 \%)$ valuta come frequenti interazioni in una varietà linguistica diversa dalla propria in contesto lavorativo, il $70 \%$ dei partecipanti allo stesso sondaggio afferma di condurre raramente conversazioni in una lingua seconda nella vita privata (cfr. ibidem: 125-128).

I risultati di questa indagine campionaria sono tendenzialmente confermati da quelli di altre ricerche che adottano approcci diversi. Anche i parlanti altoatesini, andati a scuola negli anni settanta e ottanta, di cui Veronesi ha raccolto le biografie linguistiche, valutano infatti i contatti con i bambini e i ragazzi dell'altro gruppo linguistico durante l'infanzia e l'adolescenza come rari. In aggiunta a ciò, qualificano come un obbligo e, quindi, piuttosto negativamente lo studio della seconda lingua in classe. L'appropriazione di tale codice avviene per gli intervistati di queste generazioni per iniziativa personale, soprattutto in seguito a viaggi all'estero e/o in concomitanza con l'entrata nel mondo del lavoro (cfr., in particolare, Veronesi 2008a: 130-139, Veronesi 2008b). Invece, i bambini e i giovani altoatesini costituiscono già per Egger (1990: 49) una categoria di persone sotto maggiore "pressione" al plurilinguismo. Attualmente, le nuove generazioni sembrano del resto godere di più occasioni, organizzate sia privatamente sia istituzionalmente, per migliorare le loro competenze linguistiche. Oltre ad essere stati promossi in via sperimentale programmi di scambio tra i due sistemi scolastici, si diffonde per esempio

10 L'incremento del plurilinguismo tra le generazioni più giovani è riscontrato anche da Iannàccaro \& Dell'Aquila (2011: 23) specificamente per le valli ladine. 
la prassi di iscrivere i figli in scuole con lingua veicolare diversa dalla prima lingua o da quella dell'istituto frequentato precedentemente. L'obiettivo è quello di far loro seguire un percorso formativo sia in italiano che in tedesco (cfr. Franceschini 2011b: 148 e Veronesi 2012 per biografie linguistiche di studenti che hanno partecipato al progetto di scambio "un anno in L2").

Tuttavia altre ricerche mettono in luce gli aspetti ancora problematici nei modi di insegnamento dei codici locali a scuola e nei rapporti tra minoranze storiche in provincia di Bolzano. Interpretando i risultati di studi condotti recentemente da enti provinciali e/o coordinati personalmente, Baur (2011: 169) nota per esempio che la competenza media nella seconda lingua dei ragazzi (soprattutto di madrelingua italiana) al termine delle scuole superiori si assesti tuttora a livello medio-basso. Questa è perciò inferiore alle aspettative calibrate sulle ore di insegnamento in classe. Gli studenti interpellati valutano, del resto, le occasioni di impiego dell'altro codice locale come scarse e i rapporti tra i due gruppi linguistici come rari, se non difficili, soprattutto nelle località in cui i parlanti di entrambe le comunità linguistiche sono numerosi (cfr. anche Baur 2000: 276-284 e le biografie linguistiche di due ragazzi, cresciuti in famiglie bilingui, analizzate da Czernilofsky 2010). In aggiunta, da uno studio sull'estremismo giovanile promosso dalla provincia di Bolzano e citato dallo stesso Baur (2011), risulta che gli insegnanti riscontrino negli ultimi anni un crescente atteggiamento di rifiuto nei confronti della lingua seconda e dei suoi parlanti (sia autoctoni sia stranieri). Questo sembra essere soprattutto vero nelle scuole tedesche delle zone rurali e negli istituti professionali. ${ }^{11}$

Infine, alcuni ricercatori discordano sugli effetti delle norme per la parificazione dei codici locali, sancite con il secondo Statuto di Autonomia nel 1972. Secondo Baur (2000: 78, nota a piè di pagina 44), il completo riconoscimento del tedesco come lingua ufficiale potrebbe aver determinato un calo - testimoniato dai risultati dell'esame di bilinguismo nel corso degli anni ottanta - nelle competenze in italiano del gruppo tedescofono. Invece, per Egger (1990: 47), la certificazione di bilinguismo, divenuta obbligatoria per accedere a tutti i posti pubblici proprio con l'entrata in vigore dello statuto, ha causato in generale una spinta all'apprendimento della seconda lingua. Questa ha avuto tuttavia effetti negativi, secondo il ricercatore, sugli atteggiamenti nei confronti della lingua seconda e dei parlanti dell'altro gruppo linguistico.

\subsubsection{La comunicazione tra gruppi}

Un secondo indice, usato per valutare la diffusione reale o rappresentata del plurilinguismo individuale, è il codice (più frequentemente) scelto per la comunicazione intergruppo e/o in situazioni comunicative "incerte", ovvero in cui non si conosce

11 La ricerca, citata da Baur (2011), si intitola "Das Phänomen Extremismus in Südtirol. Eine Erhebung im Auftrag des Runden Tisches gegen Extremismus in Südtirol, Juli 2009 - Mai 2010" ed è condotta dal Forum Prävention e dalla Libera Università di Bolzano sotto commissione della Provincia Autonoma di Bolzano, URL: < http://intranet.jugenddienst.it/download/ acc/extTQ72Gz.pdf>, p. 15 (18.10.2018). 
la prima lingua dell'interlocutore. Dalla selezione di codice, effettiva o dichiarata, in tali circostanze possono essere infatti dedotte le assunzioni e presupposizioni dei parlanti riguardo alle competenze linguistiche del proprio o dell'altro gruppo linguistico. Inoltre è possibile trarre considerazioni sull'allocazione funzionale di italiano e tedesco nello spazio sociolinguistico altoatesino. A riguardo di questo parametro valgono le seguenti osservazioni.

In primo luogo, secondo il già citato sondaggio ASTAT (2006: 129-135), gli informanti ladinofoni e tedescofoni dichiarano di condurre più spesso, sia al lavoro sia nella vita privata, conversazioni in una varietà linguistica diversa dalla propria. Invece, chi parla prevalentemente la sua madrelingua è italofono, anziano e con basso grado di istruzione. Ne consegue che i locutori ladinofoni e tedescofoni considerino 1'"adattamento linguistico" (language adaptation) come un comportamento più consono al proprio rispetto a quanto non facciano i parlanti italofoni (cfr. anche Franceschini 2011b: 143). Inoltre, analogamente a quanto notato precedentemente, non solo le competenze, ma anche la disponibilità - per lo meno dichiarata a parlare la seconda lingua sembrano variare a seconda dell'età dei partecipanti.

Una tendenza simile, vale a dire la propensione a commutare all'italiano in interazioni tra parlanti locali con diverse madrelingue, è constatata anche da Veronesi (2001) relativamente al contesto "riunioni di lavoro". Questo comportamento linguistico costituisce secondo la ricercatrice - che si basa su registrazioni di parlato spontaneo - una sorta di "regola di default". Infatti, disabilita l'influsso di altri fattori micro-contestuali sulla scelta di codice, come la lingua del turno di parola precedente e/o le competenze linguistiche effettive degli interattanti (cfr. più avanti in questo paragrafo per ipotesi sui motivi di questa (ri)selezione di "default" dell'italiano). Al contrario, nello stesso studio, Veronesi (2001: 320) nota che un uso alternato di più lingue caratterizzi le conversazioni a cui sono presenti parlanti non locali. I partecipanti "internazionali" alle riunioni osservate dalla ricercatrice sono insegnanti di lingua provenienti da paesi prevalentemente ad alto reddito. Perciò il loro status socio-economico e il loro eventuale potere di contrattazione nella scelta di codice non sono del tutto paragonabili a quelli della maggior parte degli intervistati per la presente ricerca. Tuttavia, tali osservazioni sono rilevanti dal momento che i modi di interazione tra parlanti autoctoni e alloctoni sono frequentemente tema di conversazione anche nelle biografie linguistiche raccolte.

In secondo luogo, secondo i dati ASTAT (2006: 196-200), è soprattutto la popolazione di madrelingua tedesca - insieme a quella ladina - ad affermare di essersi trovata frequentemente $(9,6 \%)$ o talvolta $(39,1 \%)$, nel corso dell'anno precedente all'inchiesta, nella situazione di non poter usare la propria lingua prima con gli addetti dei servizi pubblici. In particolare, difficoltà nel servirsi di tedesco o ladino sono riscontrate soprattutto al momento di interagire con 1) i carabinieri o i vigili urbani, 2) la polizia o la guardia di finanza e 3) negli ospedali. In linea con ciò, alcuni studi registrano il formarsi di correlazioni, per lo meno immaginate, tra codici, da un lato, e contesti/categorie di interlocutori, dall'altro. Così, Måwe (2011: 193) rileva - tramite questionari e osservazioni partecipanti - il consolidarsi di "norme linguistiche condizionate dall'ambiente" (milieubedingte Sprachnormen). Infatti, interazioni con sconosciuti in posta a Bolzano sono rappresentate ed effettivamente 
condotte (quasi) esclusivamente in italiano dai partecipanti, a differenza di conversazioni in posta a Bressanone o in altri contesti pubblici nel capoluogo di provincia (cfr. Måwe 2011: 185-187). Invece, secondo Dell'Aquila \& Iannàccaro (2007: 4), la situazione comunicativa "uffici pubblici" è prevalentemente associata all'impiego del dialetto tedesco locale nel comune a maggioranza ladinofona di Marebbe. D'altro canto, Vietti (2009: 210) - analizzando dati di parlato spontaneo elicitati tramite sondaggio rapido e anonimo - constata un diffuso "bilinguismo di base" in italiano e tedesco nelle città di Bolzano e Bressanone. Competenze elementari in entrambi i codici consentono infatti ai parlanti del capoluogo di provincia di adottare una strategia di accomodazione verso la lingua dell'interlocutore in situazioni comunicative parimenti "incerte", ovvero la richiesta di informazioni stradali da parte di sconosciuti. Una corrispondenza tra il codice della domanda e quello della risposta è presente, ma è invece meno pronunciata a Bressanone, dove il parametro si interseca con la variabile di genere. Infatti, gli informanti uomini scelgono più spesso una lingua diversa da quella della raccoglitrice, donna e di origine altoatesina, presupponendo così che quest'ultima abbia una competenza bilingue. Infine, seppur l'ipotesi sia ancora da verificare empiricamente, $i$ dati raccolti dal ricercatore fanno ipotizzare che la ri-selezione di una varietà di tedesco indipendentemente dalla lingua della domanda - e quindi anche a scapito di una mancata accomodazione - costituiscano l'opzione preferita in situazioni analoghe in contesti agro-montani (cfr. Vietti 2009: 211).

Dalle ricerche appena discusse emerge dunque che i parlanti altoatesini tendano ad associare, per lo meno a livello di rappresentazioni metalinguistiche, a certi contesti o costellazioni di partecipanti - ad esempio in posta, con le forze dell'ordine, in strada con gli sconosciuti - l'uso di solo una varietà linguistica locale (o italiano o tedesco). Il codice non sempre coincide da località a località, mentre lo status funzionale di tedesco e italiano e, quindi, la loro probabilità di utilizzo risultano essere bilanciati in altre situazioni comunicative o nelle stesse situazioni comunicative, ma in altri luoghi. Gli interventi di pianificazione linguistica, a partire dal secondo dopoguerra, hanno così indubbiamente determinato una riconfigurazione dei domini d'uso in modo tale che determinati ambiti o attività lavorative, tradizionalmente adibiti a un codice e/o a un gruppo linguistico - ad esempio il settore pubblico, ma anche l'industria o il terziario -, siano attualmente occupati da entrambi (cfr. Egger 1990). Nonostante ciò, alcuni contesti comunicativi hanno ancora una connotazione strettamente monolingue nello spazio sociolinguistico altoatesino. La presenza di nessi più o meno forti tra codici, contesti, e interlocutori sarà analizzata anche nella presente ricerca sulla base delle rappresentazioni e prese di posizione degli intervistati (cfr., in particolare, il $\S \mathrm{V}$ ).

In terzo luogo, è importante notare che la selezione dell'italiano per la comunicazione intergruppo ( $\mathrm{e}$, in parte, per le situazioni comunicative incerte) sia ricondotta in svariati studi all'impiego abituale dei dialetti austro-bavaresi locali da parte della popolazione tedescofona altoatesina e/o alla mancanza di una varietà colloquiale di tedesco in provincia (cfr., per esempio, rispettivamente ASTAT 2006: 280 e Moser 1982: 87). Come accennato sopra, la maggior parte dei parlanti italofoni studiano infatti l'Hochdeutsch a scuola, mentre non padroneggiano i dialetti locali 
né eventuali registri intermedi di tedesco. D'altro canto, gli altoatesini tedescofoni potrebbero essere "bloccati" nell'utilizzo del tedesco standard in contesti informali, preferendo così (ri-)selezionare l'italiano con i non dialettofoni (cfr. Lanthaler 1990: 73-75). Infatti, l'Hochdeutsch costituirebbe anche per loro una sorta di lingua seconda in $\mathrm{H}$.

In considerazione di ciò, già Mioni (1990: 25 e sgg.) riconduce le difficoltà nella comunicazione tra italofoni e tedescofoni in Alto Adige non solo alla differente composizione, ma anche alla diversa stratificazione dei loro repertori. In altre parole, le difficoltà dipenderebbero dall'asimmetria nel numero di codici da imparare per avere una comunicazione "naturale" con i membri dell'altro gruppo linguistico. Inoltre, Franceschini (2011b: 143-144) ipotizza un'eventuale "incomprensione diglottica" tra le comunità linguistiche locali. Infatti, i parlanti italofoni - probabilmente in conseguenza del poco prestigio solitamente attribuito ai dialetti italo-romanzi nello spazio sociolinguistico italiano - non sempre riconoscono lo status neutrale, se non alto dei dialetti austro-bavaresi locali per la popolazione tedescofona. In conseguenza di ciò, frequentemente sottovalutano l'importanza di una loro acquisizione. In aggiunta, secondo ASTAT (2006: 282), un certo "disagio" degli italofoni nei confronti delle varietà locali di tedesco dipenderebbe, oltre che dalle loro ridotte competenze e dall'alto valore simbolico di questi codici, anche dalla mancanza di un varietà dialettale autoctona di italiano, da contrapporre eventualmente come propria (cfr. però § II.1.4 su quest'ultima questione).

L'influsso di folk beliefs, stereotipi e discorsi metalinguistici condivisi sui modi della comunicazione intergruppo o, per lo meno, sulle loro rappresentazioni emerge, secondo Veronesi (2008a: 139-149), anche dall'esame delle tesi avanzate dai suoi intervistati per motivare competenze e abitudini comunicative altrui nelle loro biografie linguistiche. Infatti, nonostante i singoli partecipanti prendano talvolta posizioni autonome, le loro argomentazioni fanno spesso riferimento a caratteristiche piuttosto invariabili, se non stereotipate delle lingue locali, dei loro parlanti e della situazione socio-politica locale. ${ }^{12}$ In particolare, incomprensioni tra parlanti dei due gruppi linguistici sembrano frequentemente derivare da una diversa interpretazione della commutazione all'italiano in conversazioni precedentemente avviate in tedesco. Se la rinegoziazione è infatti considerata un "segno di gentilezza" dagli intervistati tedescofoni, tale comportamento è invece valutato come un mancato riconoscimento della propria competenza bilingue e come un "segno di esclusione sociale" da quelli italofoni (cfr. Veronesi 2008a: 150). Inoltre, dalle biografie linguistiche raccolte, risulta anche una grande pluralità di giudizi e di atteggiamenti nei confronti dei dialetti tedeschi locali, soprattutto da parte degli informanti italofoni (cfr. Veronesi 2008a: 146-149). Queste varietà sono infatti di volta in volta qualificate - in sequenze caratterizzate da riformulazioni, metafore, argomentazioni scherzose e/o riferimenti storiografici vaghi - come codici oggetto di "invidia", come mezzo di esclusione o come lingua ponte per una migliore comprensione

12 Tra queste caratteristiche più o meno presunte ci sono, ad esempio, la maggiore difficoltà del tedesco rispetto all'italiano, la minore paura di commettere errori da parte dei tedescofoni o la separazione degli edifici scolastici. 
della cultura dell'altro gruppo linguistico. ${ }^{13}$ A questo riguardo, anche Meluzzi (2014) rileva variazioni negli atteggiamenti verso il tedesco e i dialetti austro-bavaresi locali a seconda del quartiere di residenza e parzialmente dell'età dei suoi informanti (ossia parlanti italofoni residenti a Bolzano). Giudizi negativi verso le varietà di tedesco parlate in città si riscontrano infatti soprattutto tra gli intervistati più anziani, che abitano o hanno abitato in quartieri a maggioranza italofona. D'altro canto, la selezione del dialetto locale per la comunicazione intergruppo può essere una scelta dispreferita anche per alcuni parlanti tedescofoni: il motivo è che questa selezione può comportare il pericolo di essere considerati sostenitori di posizioni conservatrici, se non separatiste (cfr. Veronesi 2008a: 144 e anche Lanthaler 1990: 77). Come si vedrà meglio nel capitolo $\mathrm{V}$, la questione della diffusione delle varietà linguistiche locali di tedesco e italiano e delle difficoltà che il loro uso può provocare nella comunicazione tra parlanti autoctoni così come autoctoni e non autoctoni in provincia di Bolzano costituisce uno dei temi ricorrenti anche nelle interviste del corpus raccolto.

\subsubsection{Atteggiamenti verso il plurilinguismo}

Una terza tipologia di indicatori dei rapporti tra codici e tra comunità linguistiche autoctone in Alto Adige è costituita dagli atteggiamenti verso i fenomeni di contatto tra italiano e tedesco così come verso le misure di politica linguistica vigenti in provincia. Anche a questo riguardo, studi diversi mettono in luce tendenze parzialmente differenti.

Da un lato, secondo Mioni (2001), la "distanza" (Abstand) dalla pronuncia standard dell' italiano dei tedescofoni altoatesini è paragonabile a quella di parlanti in altre regioni della repubblica. Tuttavia, caratteristiche fonetico-fonologiche della loro interlingua - ad esempio la $\mathrm{r}$ uvulare o la resa poco fusa dell'affricata postalveolare sorda $\mid \mathrm{t} / \mathrm{l}$ - divengono per "elaborazione" (Ausbau) ideologica tratti diagnostici per caratterizzare un accento come "straniero" e/o una persona "come al di là di una frontiera etnic[o-linguistica]" (ibidem: 66). Dall'altro lato, secondo Ciccolone (2010: 122-123), fenomeni di contatto con l'italiano, soprattutto a livello lessicale, sono meno stigmatizzati che in passato in Alto Adige. Infatti, prestiti e calchi sono frequentemente accettati dai parlanti tedescofoni intervistati come "norma" sia in giudizi metalinguistici espliciti, sia a livello di atteggiamenti latenti. Perciò, il ricercatore conclude che per gli informanti "il contatto linguistico non rappresent[i] più una reale minaccia per la sopravvivenza della lingua tedesca, bensì il plurilinguismo sudtirolese [sia] visto [...] come un segno distintivo della propria identità" (Ciccolone 2010: 120).

Relativamente alla seconda questione, è rilevante notare che i partecipanti all'inchiesta ASTAT (2006) discordino notevolmente nel giudicare alcuni interventi di pianificazione linguistica e i loro risultati. La diversificazione delle risposte alle

13 Sulle ragioni psicologiche alla base degli atteggiamenti, frequentemente di rifiuto, della popolazione italofona verso le varietà locali di tedesco si confronti anche Baur (2000: 80-81). 
domande su tali temi - ad esempio, sui benefici della proporzionale etnico-linguistica, sulla riuscita della convivenza tra minoranze storiche o sulle cause della difficoltà di apprendimento della lingua seconda - è, secondo i ricercatori di ASTAT (2006: 284-286), segnale della loro problematicità e del persistere di una situazione di "incertezza" tra la popolazione locale. Nello specifico, i partecipanti non sono per esempio d'accordo sui motivi delle basse conoscenze nella lingua dell'altro gruppo linguistico: se per gli informanti tedescofoni e ladinofoni queste sono determinate da una scarsa volontà e da un mancato interesse nell'acquisirla, per gli intervistati italofoni sono invece da ricondursi a limiti del sistema scolastico, all'uso del dialetto tedesco locale ed, eventualmente, a una bassa volontà, ma non a un poco interesse per la lingua seconda (ASTAT 2006: 285). Dato questo sfondo, Franceschini (2011b: 149-150) nota tuttavia che i partecipanti all'appena citato sondaggio ASTAT tendano ad essere d'accordo al momento di valutare l'importanza di conoscere altre lingue oltre alla propria. Da ciò sembra emergere, secondo la ricercatrice, una "comunità" linguistica altoatesina unitaria, nel senso "che condivide opinioni e valori comuni” proprio nei confronti del plurilinguismo (ibidem: 150).

\subsection{Le varietà di tedesco}

Il numero e i rapporti tra le varietà di tedesco che compongono il repertorio dei parlanti tedescofoni in provincia di Bolzano sono di difficile precisazione. Schematicamente si può distinguere tra i dialetti tedeschi locali da un lato e il tedesco standard regionale dall'altro e definire le loro relazioni come diglottiche. Più controverse sono invece la presenza e l'eventuale caratterizzazione di varietà colloquiali di tedesco e/o di registri intermedi tra le prime due varietà, la cui distanza sarebbe infatti livellata da processi di "destandardizzazione" e "disglotizzazione" (cfr. Egger 2001: 53). Nel prossimo paragrafo discuto le caratteristiche delle varietà di tedesco usate in provincia di Bolzano da un punto di vista linguistico. Nel $\S$ II.1.3.2 esamino invece le categorie proposte in letteratura per qualificare il repertorio della popolazione tedescofona altoatesina sulla base della distribuzione di tali varietà per domini d'uso.

\subsubsection{Rapporti di differenziazione}

I vernacoli locali, adoperati frequentemente nella conversazione quotidiana in Alto Adige, appartengono al gruppo dei dialetti austro-bavaresi. Questi non costituiscono però una varietà "sudtirolese" unitaria (Südtiroler Dialekt), ma si differenziano tra loro in conseguenza di fattori geografici e storico-sociali (cfr. Moser 1982, Lanthaler 1990, Egger 2001: 44-51). Nello specifico, lo spazio dialettale altoatesino è percorso da numerose isoglosse che lo ripartiscono da est a ovest in almeno tre sotto-regioni (cfr. Lanthaler 1990: 61-63). I dialetti "occidentali", parlati in Val Venosta, Val d'ultimo, Alta Val di Non e Bassa Atesina, sono caratterizzati da peculiarità derivate dal contatto con l'alemanno, rispetto a cui costituiscono varietà di 
transizione. Invece, i dialetti "orientali" della Val Pusteria sono contraddistinti da tratti comuni con quelli bavaresi della Carinzia, con cui l'area ha per lungo tempo costituito un'unica unità amministrativa. Infine, le varietà della zona intermedia presentano alcune caratteristiche proprie e altre simili a quelle delle due regioni vicine.

Parallela a questa distinzione corrono anche l'opposizione tra varietà del Tirolo "centrale" (Zentraltirol) e "periferico" (Randtirol) da un lato e/o quella tra i dialetti di "valli di transito" (Verkehrstäler) e di "valli laterali" (Nebentäler) o villaggi di montagna dall'altro (cfr. anche Egger 2001: 44-48). Il numero di località isolate in Tirolo è diminuito. Nondimeno i dialetti delle Valli di Tures e Aurina presentano ancora molti tratti linguistici conservativi e sono, quindi, classificabili come periferici (cfr. Lanthaler 1990: 62-63). Infine, le frontiere nazionali tra Tirolo settentrionale e meridionale non hanno (ancora) un chiaro corrispettivo dal punto di vista linguistico (cfr. Egger 2001: 44-51). Tuttavia Moser (1982: 87) riconosce la presenza di un "confine pragmatico" in corrispondenza del Brennero determinato, tra l'altro, dalla maggiore o minore diffusione di registri intermedi e dal contatto con l'italiano.

Nonostante la frammentazione dello spazio dialettale sudtirolese appena delineata, cambiamenti socio-economici più o meno recenti - ad esempio la creazione di strade, la diffusione dei mass media, la frequentazione di internati, situati nei centri urbani, da parte di studenti provenienti dalle zone montuose - hanno determinato l'intensificarsi del (sempre presente) contatto tra parlanti locali. Nel fare ciò, hanno favorito la formazione, più o meno occasionale e consapevole, di "varietà di mediazione" (Ausgleichdialekte), improntate dallo sforzo di farsi capire (cfr. Lanthaler 1990: 64). Perciò, Lanthaler (2001: 138-142) ed Egger (2001: 52-55) si servono delle nozioni di "continuum dialettale" (Dialektkontinuum) e/o di "registri intermedi" (Zwischenregister) per descrivere in prospettiva sia diatopica sia diacronica l'insieme di codici, non suddivisibile in unità discrete, che va dai vernacoli parlati in famiglia o dialetti profondi di valle (Haussprachen o tiefe Taldialekte) alle varietà koinizzate a livello di comunità locali più o meno estese (es. Val Passiria, Merano) fino a un'eventuale "varietà colloquiale regionale" di tedesco (cfr. anche Ciccolone 2010: 47-52).

In realtà, la presenza di una "lingua colloquiale" (Umgangssprache) nel repertorio dei parlanti tedescofoni altoatesini così come i vantaggi di una sua promozione, ad esempio, per favorire la comunicazione intergruppo o la sicurezza linguistica dei suoi locutori sono (stati) oggetto di numerose discussioni (cfr. Moser 1982, Saxalber-Tetter 1982, Mioni 1990, Lanthaler 1990, Lanthaler 2001, Egger 2001). Anche in questo caso, nel valutare la letteratura a riguardo bisogna tener presente l'anno di pubblicazione delle ricerche e, quindi, gli eventuali mutamenti della realtà sociolinguistica presa in esame.

La mancanza di una competenza diafasica "continua" tra i tedescofoni altoatesini è sostenuta, per esempio, da Moser (1982: 85-87). Lo studioso adduce a prova di ciò esempi di interazioni in codici misti tra albergatori autoctoni e turisti stranieri, provenienti da altri paesi di lingua tedesca. Tuttavia, secondo Moser (1982), i tedescofoni bolzanini in posizioni dominanti dispongono già di una sorta di socio- 
letto comune, seppur non prestigioso, il cosiddetto "Bozner Deutsch" (cfr. anche Egger 2001: 54-55). Una descrizione analoga è fornita anche da Mioni (1990: 22), per cui una varietà di tedesco colloquiale vera e propria non esiste ancora, ma si sta lentamente formando. Il ritardo si spiega probabilmente con la composizione demografica del capoluogo di provincia, che propaga prevalentemente italiano piuttosto che una varietà urbana di tedesco. In apparente disaccordo con gli studi appena citati, gli intervistati in Saxalber-Tetter (1982: 196) dichiarano, al contrario, di servirsi in determinate situazioni sempre più spesso e preferibilmente di una "lingua colloquiale" al posto dei dialetti locali o del tedesco standard. Si noti tuttavia che le varietà linguistiche riferite con questa denominazione - proposta dalla stessa ricercatrice nel questionario - non coincidono verosimilmente tra gli informanti. Queste variano piuttosto a seconda del loro luogo di residenza o professione dei partecipanti (ibidem: 180-181).

Infine, deve essere qui anche menzionata la posizione di Lanthaler su questo tema (2001: 142-147). Secondo lo studioso, una varietà colloquiale di tedesco definita citando Bertagnolli 1994 "unfeines Hochdeutsch" (tr. letterale "tedesco sconveniente") - è divenuta nel corso degli anni novanta codice di interazione non solo tra élite politiche e amministrative, ma anche tra persone di tutti i ceti, indipendentemente dal grado di istruzione, in situazioni pubbliche o semi-pubbliche. Seppur (ancora) caratterizzata da alta variabilità interna, il tipo di denominazione e l'etichetta unitaria sono motivate dal ricercatore in considerazione di tratti linguistici distintivi e, soprattutto, dell'"intenzione dei parlanti" (Sprecherintention). Questi ultimi se ne servono infatti con la funzione di "varietà sub-standard intesa come standard" (Lanthaler 2001: 145, tr. della scrivente). Il tipo di contesti in cui tale codice è impiegato non permette così di equipararlo funzionalmente ai vernacoli sudtirolesi, per lo meno nelle percezioni dei locutori. D'altro canto, la presenza di numerosi tratti dialettali differenzia la "lingua colloquiale" dalla "varietà standard regionale" di tedesco, scritta e parlata in Alto Adige (cfr. più sotto in questo paragrafo). La diffusione di questo registro colloquiale è stata probabilmente favorita dalla presenza mediatica e dal conseguente prestigio dei suoi primi parlanti. Tuttavia, gli atteggiamenti piuttosto negativi nei suoi confronti ne rendono difficile, se non ne escludono, secondo lo studioso, una sua promozione a standard orale in provincia di Bolzano (cfr. ibidem: 145-146).

$\mathrm{Al}$ termine del continuum, formato dai dialetti locali e dalla eventuale varietà colloquiale di tedesco, si trova infine il già menzionato "tedesco standard regionale" (Südtiroler Hochdeutsch). Tale codice svolge la funzione di acroletto. Pur non differenziandosi notevolmente dall'Hochdeutsch o dai tedeschi standard scritti e parlati in altre regioni tedescofone, la varietà che in Alto Adige vale come norma è contraddistinta da peculiarità a livello fonetico-fonologico e semantico-lessicale. In particolare, secondo Lanthaler (2001: 147-149), certe caratteristiche soprattutto di pronuncia o il tipo di ipercorrettismi accomunano - in conseguenza della base dialettale comune - la lingua standard in Alto Adige a quella in uso in Austria e in Baviera. Tuttavia, alcune varianti sudtirolesi sono peculiari in quanto determinate dal contatto con l'italiano (cfr., per esempio, i prestiti e calchi per lemmi appartenenti ai campi semantici dell'amministrazione pubblica, dell'organizzazione scola- 
stica o della gastronomia). D'altro canto, in provincia di Bolzano si registra pure la diffusione di forme che valgono come norma in altri centri tedescofoni - soprattutto in Germania e parzialmente in Svizzera - a causa del loro prestigio (cfr. anche Ciccolone 2010: 59-66).

Nello spiegare ciò, è rilevante ricordare che, se la storia linguistica della regione prima dell'annessione allo stato italiano è simile a quella delle aree tedescofone meridionali (cfr. Eichinger 2001: 126-129), il tedesco standard di Germania più che quello austriaco - ha rappresentato il punto di riferimento per gli interventi di politica linguistica in Alto Adige a partire dal secondo dopoguerra (cfr. Daniel et al. 2001: 212 e sgg.). L'orientamento alla norma di Germania è testimoniato, tra l'altro, secondo i ricercatori, dai libri di testo adottati nelle scuole o dai luoghi di provenienza degli esperti convocati per la formazione dei conduttori televisivi. Così, il tedesco della repubblica federale può essere definito una "lingua desiderata" in Alto Adige, ossia un codice di riferimento culturale e ideologico. Tuttavia non è una varietà linguistica propriamente locale né è realmente usato sul territorio (cfr. anche Dal Negro \& Iannàccaro 2003: 434, Ciccolone 2010: 126). La dislocazione della lingua tetto al di fuori dell'area tedescofona meridionale ha possibilmente determinato una certa insicurezza linguistica tra la popolazione locale così come una svalutazione dei dialetti autoctoni (cfr. Moser 1982: 88). Nonostante ciò, anche nel caso dell'orientamento alla norma da parte dei tedescofoni altoatesini si riscontrano alcuni cambiamenti. Recentemente Ciccolone (2010: 125-126) nota infatti, per esempio, che i tedescofoni intervistati considerino migliori a livello di giudizi metalinguistici espliciti le forme standard di Germania. Tuttavia, preferiscano a livello di atteggiamenti - cognitivi, emotivi e conativi - le varianti comuni o regionali a quelle "federali" o austriache. Inoltre, secondo le rilevazioni di Måwe (2011: 193), lo standard regionale piuttosto che l'Hochdeutsch ha la funzione di veicolare gentilezza e competenza e costituisce la scelta di codice abituale per interagire con sconosciuti nel capoluogo di provincia. Indipendentemente l'uno dall'altro, i due ricercatori interpretano i risultati ottenuti come segni di un consolidamento dello status del tedesco standard regionale nello spazio sociolinguistico altoatesino rispetto a norme linguistiche alloctone (cfr., su questo tema, anche Eichinger 2001).

\subsubsection{Allocazione}

Il confronto tra i risultati di ricerche sui rapporti tra le varietà di tedesco parlate in Alto Adige è complicato dal fatto che non tutti gli studi considerati lavorano con le stesse categorie. I ricercatori non sempre suddividono infatti lo spazio sociolinguistico altoatesino sul versante tedescofono in un numero uguale di varietà linguistiche. Ad esempio, nel questionario ASTAT (2006) si distingue tra "tedesco standard" e "dialetto tedesco", mentre Saxalber-Tetter (1982) richiede agli informanti di valutare anche la frequenza di impiego della "lingua colloquiale". Infine, Måwe (2011: 183) classifica le interazioni osservate a seconda di quattro etichette, ovvero "standard", "standard regionale", "registri intermedi/lingua colloquiale" e "dialetto". In 
questo paragrafo mi concentro principalmente sull'allocazione di varietà "standard" e "non standard" di tedesco. Tale opposizione mi sembra essere infatti quella più rilevante e comune negli studi esaminati. Si tratta dunque di valutare la distribuzione per domini d'uso dei dialetti tedeschi locali, registri intermedi e/o della lingua colloquiale ${ }^{14}$ da un lato e di tedesco standard regionale ed eventualmente Hochdeutsch dall'altro.

In generale, sebbene si riscontrino differenze a seconda della località, le varietà non standard di tedesco hanno più o meno recentemente acquisito nuovi domini in Alto Adige (cfr. Lanthaler 1990: 63-64). I vernacoli locali e/o i registri intermedi continuano infatti ad essere usati in contesti privati a differenza di quanto per esempio avviene nel resto di Italia. Inoltre, costituiscono codice di comunicazione, indipendentemente dal grado di istruzione degli interattanti, anche in numerose situazioni semi-pubbliche $\mathrm{e}$, in modo più variabile e/o controverso, in ambiti pubblici (cfr. anche Baur 2000: 78-79). A questo proposito, più del $90 \%$ degli informanti tedescofoni di ASTAT (2006: 105-125) afferma di aver comunicato o di comunicare in dialetto tedesco locale non solo in famiglia e con gli amici, ma anche con $\mathrm{i}$ colleghi di lavoro e con i compagni di scuola. ${ }^{15}$ Inoltre 1' $80,5 \%$ di tutti i lavoratori intervistati, indipendentemente dalla prima lingua, indica tale codice tra le varietà linguistiche usate e/o sentite parlare sul posto di lavoro (ASTAT 2006: 72-73). Da ciò si può concludere che i vernacoli locali svolgano attualmente - per lo meno nelle rappresentazioni dei parlanti - la funzione non solo di basiletti, ma anche di mesoletti. Infatti sono (considerati come) normalmente impiegati in situazioni comunicative quotidiane "non necessariamente caratterizzat[e] come alt[e] o bass[e]" (cfr. Dell'Aquila \& Iannàccaro 2007 che si riferiscono però specificamente alle valli ladine).

Lo stesso sondaggio di ASTAT rileva, tuttavia, che la valutazione del valore funzionale e simbolico dei dialetti locali incorre in variazioni a livello diacronico e diatopico. Da un lato, conoscenze nel dialetto locale sono considerate più importanti per vivere bene in Alto Adige dalle generazioni di parlanti più giovani - tra $\mathrm{i}$ 19 e 39 anni - rispetto alle fasce di età più anziane (cfr. ASTAT 2006: 174-175). Questo è abbastanza sorprendente soprattutto se si tiene conto di altre situazioni sociolinguistiche nella penisola italiana. Dall'altro, solo un quarto degli intervistati bolzanini stima competenze nei dialetti locali fondamentali o abbastanza rilevanti, a differenza della maggioranza dei residenti nelle altre comunità comprensoriali (cfr. ibidem: 259). Variazioni temporali e areali nei giudizi di accettabilità di varietà locali di tedesco in contesti semi-pubblici e pubblici sono parzialmente confermate dal confronto tra i dati appena citati con quelli di altre ricerche. L'impiego del dialetto sul posto di lavoro risulta essere, infatti, poco frequente, soprattutto in città,

14 La definizione della lingua colloquiale è in realtà problematica in quanto, come illustrato nel paragrafo precedente, questa è una varietà linguistica non standard a cui è attribuita la funzione di standard dai suoi parlanti.

15 Nello specifico, la percentuale di intervistati che usa il dialetto in questi ambiti comunicativi e/o con tali costellazioni di partecipanti è sempre uguale o superiore al $95 \%$. Solo con il partner e con i figli si assesta rispettivamente al $91 \%$ e $94 \%$. 
secondo le dichiarazioni di parlanti tedescofoni al principio degli anni ottanta (cfr. Saxalber-Tetter 1982: 184-185, 196). ${ }^{16}$ Inoltre, nelle situazioni "incerte", l'uso di varietà non standard di tedesco sembra variare ancora più nettamente a livello diatopico. Così, Måwe (2011) nota, per esempio, che la probabilità di selezione sia dichiarata sia reale del dialetto tedesco locale invece dello standard regionale nell'avviare interazioni con sconosciuti in contesti pubblici - ad esempio negozi, banche, poste, interviste in televisione - dipenda, oltre che da fattori diafasici e micro-situativi, ${ }^{17}$ anche dalla composizione linguistica e/o grandezza delle località esaminate, ovvero Bolzano e Bressanone. Infatti, più numerosa è la popolazione tedescofona e più "rurale" è il macro-contesto, più gli informanti dichiarano o scelgono di usare il dialetto per comunicare in tali circostanze.

Dall'aumento (almeno rappresentato) e dal tipo di funzioni assegnate ai dialetti austro-bavaresi locali e/o ai registri intermedi si può desumere una loro buona "vitalità" in relazione alla lingua standard. ${ }^{18}$ Eventualmente si può inoltre ipotizzare un recente innalzamento del loro status nello spazio sociolinguistico altoatesino. ${ }^{19}$ In linea con ciò, si noti del resto che i dialetti locali sono spesso qualificati come "madrelingua" dai locutori tedescofoni e costituiscono il codice privilegiato per la comunicazione in-group (cfr. Veronesi 2008: 146-147). Perciò tali varietà linguistiche ricoprono un alto valore simbolico per i loro parlanti al momento di definire la propria identità individuale e di gruppo (cfr. anche Riehl 2004: 151, Ciccolone 2010: 129). Il prestigio dei dialetti locali in Alto Adige può dunque essere definito "occulto" (covert) o "interno" in contrapposizione a un prestigio "manifesto" (overt) o "esterno" (cfr. Edwards 1996: 706-707 e Franceschini 2011b: 144, nota a piè di pagina 12). Questo è infatti attribuito a varietà non standard ed è connesso al senso di solidarietà e di appartenenza a una comunità, piuttosto che essere motivato da funzioni strumentali o evocare particolari competenze e abilità di un parlante. Detto ciò, l'impiego di varietà non standard di tedesco in ambiti chiaramente marcati come alti - ad esempio negli uffici pubblici o sui media - non sembra essere tuttavia ancora riconosciuto come pienamente legittimo dalla popolazione locale.

16 Sia qui avvertito che lo studio di Saxalber-Tetter (1982) e quello di ASTAT (2006) sono solo parzialmente confrontabili. Come già accennato, la prima chiede infatti ai partecipanti di valutare la frequenza d'uso oltre che di dialetto, tedesco standard e italiano anche della lingua colloquiale. Inoltre la ricercatrice considera le risposte multiple congiuntamente sotto la categoria "combinazioni" (Kombinationen). Infine i partecipanti non bolzanini alla sua inchiesta risiedono quasi esclusivamente nella Bassa Atesina.

17 Tra i fattori micro-situativi che guidano la selezione di codice degli informanti di Måwe (2011: 185) ci sono la pronuncia o le scelte lessicali dell'interlocutore nel rispondere a un primo saluto standard e/o il suo aspetto. Tali strategie sono impiegate consapevolmente da molti intervistati che, infatti, le illustrano spontaneamente durante i colloqui.

18 Per una discussione sulla nozione di "vitalità linguistica" come concetto comparativo si confronti Iannàccaro \& Dell'Aquila (2011). Anche i due studiosi valutano la vitalità dei dialetti austro-bavaresi nelle località della Ladinia Dolomitica, in cui sono parlati, come "genericamente in ascesa, ma con modalità diverse a seconda della valle e talora del comune" (cfr. ibidem: 19 , nota a piè di pagina 14 ).

19 Sulla correlazione tra numero e tipo di funzioni di un codice e la probabilità che il suo status cresca si veda Mackey (1989: 15). 
Ciò è dimostrato dal fatto che le auto-valutazioni e gli usi linguistici reali dei parlanti tedescofoni altoatesini riguardo ai codici parlati in questi contesti spesso non coincidono. Così, per esempio, gli informanti di Saxalber-Tetter (1982: 185) discordano sulla norma linguistica a cui ci si dovrebbe attenere, mentre quelli di Måwe (2011: 187-188) dichiarano di utilizzare più frequentemente forme standard di quanto effettivamente non facciano.

Infine, alcune situazioni comunicative e/o costellazioni di partecipanti in Alto Adige sono tradizionalmente (rappresentate come) "riservate" all'uso di varietà standard di tedesco (cfr. Saxalber-Tetter 1982: 186). Si tratta delle interazioni con gli insegnanti in classe o della comunicazione rituale, ad esempio nelle cerimonie religiose o civili, o delle conversazioni con gli stranieri, in particolare con turisti provenienti da altre regioni tedescofone (cfr. anche Baur 2000: 78-79). Per quanto riguarda la prima situazione comunicativa, è opportuno ricordare che gli insegnanti erano, infatti, obbligati negli anni settanta a parlare esclusivamente Hochdeutsch con gli alunni dentro e fuori dalla classe. Tale vincolo derivava in larga parte dall'opinione, allora piuttosto diffusa, secondo cui il raggiungimento di un'alta competenza nella lingua standard fosse una condizione necessaria per salvaguardare l' $i$ dentità culturale e l'autonomia politica del gruppo tedescofono in provincia (cfr. Lanthaler 1990: 68-70 e anche Weisgerber 1990: 28, Daniel et al. 2001: 218-220, Baur 2008: 23-26). Gli effetti di tali misure di pianificazione nelle scuole sembrano essere ancora parzialmente visibili per lo meno nelle rappresentazioni dei parlanti. Infatti, la lingua di comunicazione prevalente con i docenti per gli informanti tedescofoni in ASTAT (2006: 120) è quella standard (82,8\%). Tuttavia più di un terzo degli intervistati, indipendentemente dall'età, afferma di comunicare o di aver comunicato anche in dialetto tedesco con gli insegnanti in classe (alla domanda era infatti possibile dare più risposte).

In letteratura sono stati proposti diversi termini per descrivere l'allocazione appena discussa delle varietà di tedesco nello spazio sociolinguistico altoatesino. A seconda del numero dei codici riconosciuti come parlati in provincia di Bolzano e della prospettiva enfatizzata dai ricercatori nel valutarne la distribuzione, i repertori della comunità di lingua tedesca in Alto Adige sono stati infatti definiti come caratterizzati, tra l'altro, da "diglossia" o "triglossia" (cfr. Mioni 1990: 22), da "diglossia mediale" (cfr. Lanthaler 1990: 63-65), da "poliglossia dinamica" (cfr. Weisgerber 1990, Måwe 2011: 179) e/o da "plurilinguismo interno" ed "esterno" (cfr. Baur 2000: 77 e sgg., Egger 2001: 41). Nello specifico, Mioni (1990: 22) definisce i germanofoni altoatesini "triglottici" nel caso si consideri già presente nei loro repertori una varietà di tedesco colloquiale oltre al tedesco standard e ai dialetti locali, mentre li qualifica come "bilingui" per le loro competenze in italiano. ${ }^{20}$ L'impiego di varietà non standard per interazioni orali in domini semi-pubblici e pubblici giustifica invece una qualifica di "diglossia mediale". Infatti, similmente a quanto avviene nella Svizzera tedesca, il canale di comunicazione (scritto o orale) più che la

20 Sia qui menzionato che il termine "triglossia" (Triglossie) è usato invece diversamente da Lanthaler (1990: 59-60) per riferirsi ai rapporti tra tedesco standard, dialetti austro-bavaresi locali e italiano in provincia di Bolzano. 
formalità della situazione comunicativa determina l'alternanza tra lo standard regionale e i vernacoli austro-bavaresi locali. Il concetto di "poliglossia dinamica" è inoltre adoperato per rendere conto della formazione di un continuum di registri intermedi tra la varietà in $\mathrm{H}$ e quella in L, usati uno accanto all'altro in diversi ambiti della comunicazione quotidiana (cfr. Wiesinger 1985: 1939-1941 che si serve del termine per riferirsi allo spazio tedescofono meridionale e in particolare all' $\mathrm{Au}$ stria). Infine, le espressioni "plurilinguismo interno" ed "esterno" si riferiscono specificamente ai repertori individuali dei tedescofoni altoatesini. Questi concetti indicano infatti rispettivamente la competenza diafasica in più registri di un'unica lingua e la padronanza di codici diversi da parte di uno stesso parlante.

\subsection{Le varietà di italiano}

La definizione dei rapporti tra varietà di italiano nello spazio sociolinguistico altoatesino ruota intorno a due domande principali. Negli studi a riguardo ci si chiede, da un lato, quali siano le caratteristiche peculiari dell'italiano regionale che si parla a Bolzano. Dall'altro, si mira a investigare quale sia la diffusione e l'eventuale funzione dei dialetti italo-romanzi tra la popolazione italofona.

Queste due questioni sono spesso trattate in letteratura come strettamente interconnesse. Infatti, seppur non sempre sulla base di dati empirici, la situazione sociolinguistica in provincia di Bolzano è stata spesso contrapposta a quella di altre regioni della penisola italiana in quanto l'origine composita della popolazione italofona - insediatasi nell'area in tempi relativamente recenti - ha determinato la compresenza di diversi dialetti italo-romanzi sul territorio. In questo contesto, l'uso di forme dialettali è stato valutato come meno frequente che altrove proprio a causa della mancanza di una varietà locale comune. In connessione con ciò, l'italiano parlato in provincia è stato per lungo tempo definito "neutrale", ossia privo di un particolare accento e conforme allo standard (cfr. Francescato 1975 citato da Egger 2001: 66-72).

Quella appena delineata è una descrizione ancora abbastanza diffusa del repertorio comunitario della popolazione italofona altoatesina che ha trovato fortuna non solo in ambito scientifico: l'idea che a Bolzano non si parli - per lo meno al di fuori della cerchia familiare - nessun dialetto italo-romanzo, ma soltanto italiano standard permea infatti frequentemente anche le rappresentazioni metalinguistiche dei parlanti locali e non locali in provincia. Tuttavia, secondo Meluzzi (2015: 4), possono essere individuate altre due tesi principali riguardo alla varietà di italiano usata a Bolzano e alla storia della sua formazione. Sempre a causa dell'assenza di un sostrato dialettale comune, questa varietà linguistica è stata infatti anche definita come "atipica" e "non viva" rispetto a quelle parlate in altre regioni della penisola $\mathrm{e}$, in un certo senso, anche rispetto allo standard. D'altro canto, più recentemente è stata avanzata l'ipotesi che l'italiano bolzanino sia il risultato di un processo di koinizzazione tra le varietà locali e regionali, usate dagli immigrati italofoni prima di trasferirsi in Alto Adige (cfr., per esempio, Coletti et al. 1992: 310-311 e la stessa Meluzzi 2015). Se quest'ultima tesi è vera, l'italiano di Bolzano non è dunque coincidente con lo standard, ma dovrebbe avere tratti dialettali e/o sociolettali propri. 
Nello specifico, tra le varietà "immigrate" di italiano presenti in provincia, i dialetti veneto-trentini potrebbero aver giocato un ruolo di rilievo nella formazione dello standard regionale. Il loro influsso sulla pronuncia è riscontrato, per esempio, da Mioni (2001: 67-68) in uno studio che confronta le variabili fonetico-fonologiche più significative nel parlato di ragazzi italofoni altoatesini versus padovani. Secondo il ricercatore, l'influenza di queste varietà si spiegherebbe con il fatto che la comunità di persone originarie da queste regioni è la più numerosa in Alto Adige. Inoltre si è trasferita stabilmente in provincia prima dei gruppi provenienti da altre zone di Italia. Il modo di parlare di veneti e trentini avrebbe quindi costituito un modello linguistico già consolidato al momento dell'arrivo degli immigrati di origine meridionale - soprattutto calabrese, ma anche pugliese, siciliana o campana a partire dal secondo dopoguerra (cfr., per un'opinione analoga, anche Coletti et al. 1992: 315-316). ${ }^{21}$ Così, sebbene i giovani della provincia di Bolzano si servano più frequentemente di varianti standard rispetto a quanto non facciano i loro coetanei veneti, l'italiano bolzanino appartiene, secondo Mioni (2001), al tipo generale degli italiani regionali settentrionali. Infatti, c'è coincidenza nel non realizzare certi tratti categorici tipici delle varietà centro-meridionali, come, ad esempio, le geminate o il raddoppiamento fonosintattico.

In uno studio precedente, Mioni (1990: 23-24) distingue inoltre tra tre tipi di repertorio della popolazione italofona in provincia di Bolzano a seconda che questa viva nei centri urbani, nella Bassa Atesina o nelle valli a maggioranza tedescofona (cfr. anche $\S$ II.1.2). A variare diatopicamente non sono tuttavia solo le competenze nelle varietà locali di tedesco, ma anche il numero di varietà non standard di italiano conosciute e/o usate dai parlanti di queste tre aree. In particolare, secondo lo studioso, il repertorio degli italofoni di città presenta l'italiano standard come acroletto, una varietà di "italiano regionale bolzanino" in via di formazione come mesoletto e, eventualmente, "resti dei dialetti" come basiletti (cfr. ibidem: 23). Questi

21 Durante il processo di "italianizzazione" dell'Alto Adige promosso dal fascismo negli anni venti e trenta e successivamente nel corso di una seconda ondata migratoria negli anni quaranta, la popolazione italofona che si trasferisce in provincia di Bolzano non proviene, in realtà, esclusivamente da Veneto e Trentino, ma anche da Lombardia, Emilia Romagna e Lazio (cfr. Mioni 2001: 66-67 e Meluzzi 2015: 3-4 anche per l'individuazione di tre fasi nella storia migratoria della popolazione italofona in Alto Adige). Tuttavia, gli immigrati dalle prime due regioni erano per la maggior parte parlanti dialettofoni di origine contadina, giunti per lavorare stabilmente nelle fabbriche di Bolzano. Inoltre, una predominanza di impiegati dal Nord-Est si riscontra anche, in quegli anni, nel settore della pubblica amministrazione. Al contrario, i lavoratori dalle altre tre regioni occupavano solitamente posizioni dirigenziali per lo più temporaneamente. In conseguenza di ciò, il loro influsso sulla formazione dell'italiano regionale potrebbe essere stato meno determinante. Infine, a partire dagli anni cinquanta, si registra un terzo flusso di migrazione interna verso l'Alto Adige. Questo è più composito sia per l'origine, sia per il grado di istruzione delle persone coinvolte, ma è comunque caratterizzato da una forte presenza meridionale. Nel secondo dopoguerra anche le attività lavorative degli italofoni in provincia di Bolzano si differenziano. In particolare, si assiste a una maggiore occupazione nel terziario e nelle libere professioni. Questo sviluppo è in parte una conseguenza della spartizione proporzionale dei posti di lavoro nel settore pubblico e, quindi, di una diminuzione delle possibilità di impiego in questo ambito per gli italofoni. 
ultimi sono infatti usati dalla popolazione più anziana, ma non sembrano essere conosciuti attivamente dai giovani. Il repertorio dei residenti nella Bassa Atesina si differenzia, invece, da quello appena delineato perché, oltre all'italiano standard e regionale, sono parlati tradizionalmente nella zona anche dialetti trentini locali. Infine, nei paesi in cui gli italofoni sono in netta minoranza, i dialetti italiani sono impiegati in modo molto ridotto, se non nullo.

In linea con le osservazioni di Mioni (1990), anche le dichiarazioni raccolte dal sondaggio ASTAT (2006: 32-36, 282) testimoniano un progressivo decremento nell'uso e nei contatti con i dialetti italo-romanzi - a differenza di quanto avviene per le varietà austro-bavaresi locali - a seconda dell'età degli informanti. Tuttavia, per Meluzzi (2015), varietà non standard di italiano svolgono ancora un ruolo importante per la popolazione italofona bolzanina al momento di definire la propria identità linguistica, per lo meno nel contesto multilingue cittadino. Le persone intervistate dichiarano, infatti, di usare (un gran numero di) dialetti per comunicare in famiglia e di sentirli intorno a loro specialmente se abitano in quartieri a prevalenza italofona. Inoltre, secondo le affermazioni dei partecipanti, alcune espressioni dialettali sono impiegate estesamente dai parlanti italofoni - indipendentemente dalla loro origine o da quella dei loro genitori - in situazioni informali anche al di fuori della cerchia familiare come, per esempio, per interagire con gli amici. Così, (alcune di) queste locuzioni sembrano costituire parte stabile di un codice di gruppo, definito dai suoi stessi locutori lo "slang di Bolzano" (cfr. Meluzzi 2015: 13). Tale varietà, parlata soprattutto dai bolzanini di 40-50 anni residenti nel quartiere a maggioranza italofona di Don Bosco, ricopre secondo la ricercatrice una funzione simbolica e probabilmente distintiva sia nei confronti del gruppo tedescofono, sia dei parlanti italofoni più anziani. Significativamente, i suoi locutori percepiscono questo codice come composto soprattutto da forme venete e, secondariamente, trentine.

\subsection{Il bilinguismo e la variazione intralinguistica per i cittadini stranieri}

Dal quadro delineato in questa sezione del capitolo II emergono alcune questioni chiave da tenere presenti al momento di analizzare le biografie linguistiche della popolazione straniera intervistata.

In primo luogo, considerando gli studi sul bilinguismo altoatesino (cfr. § II.1.2 e sgg.), ci si può chiedere in che misura il repertorio dichiarato dei cittadini stranieri dopo il trasferimento in Alto Adige vari a seconda della località di residenza ed eventualmente della loro età, dell'età al momento dell'immigrazione così come dell'occupazione svolta. Partendo dal presupposto che competenze in entrambi i codici siano vantaggiose, ma non necessarie per vivere in provincia di Bolzano, il bilinguismo italiano-tedesco potrebbe essere, per esempio, più frequente tra i giovani. Il motivo dipenderebbe dal fatto che questi ultimi frequentano la scuola in Alto Adige e usufruiscono di più attività organizzate istituzionalmente per l'apprendimento linguistico. Tuttavia, come è stato illustrato al § II.1.2.1, le occasioni di uso di entrambe le lingue d'arrivo e le probabilità di acquisizione dei dialetti austro-bavaresi locali aumentano per gli occupati in determinati settori e per i residenti in 
certi comuni. Invece, non sono (sempre) direttamente correlate con lo svolgimento di una parte o del completo percorso scolastico nella regione di arrivo.

In secondo luogo, è interessante valutare in quale lingua i parlanti locali si rivolgono principalmente ai cittadini stranieri secondo le rappresentazioni di questi ultimi. Da un lato, ci si può domandare se sia possibile riconoscere comportamenti linguistici comuni (o "regole di default") e se questi coincidano o meno con quelli (considerati come) abituali per la comunicazione tra gruppi autoctoni. Dall'altro, è rilevante chiedersi se anche i cittadini stranieri caratterizzino alcune situazioni comunicative nella regione d'arrivo come tendenzialmente monolingui e quale sia l'influsso di rappresentazioni metalinguistiche collettive su tali rappresentazioni. In considerazione della letteratura a riguardo (cfr. § II.1.2.2), l'attenzione sarà posta soprattutto sulle rappresentazioni della selezione di codice in contesti istituzionali e in interazioni con sconosciuti. Al contrario, mi aspetto che ambiti come il lavoro o le conversazioni con gli amici (autoctoni e alloctoni) tendano ad essere caratterizzate come plurilingui dai partecipanti del corpus.

Invece, sia qui avvertito che gli atteggiamenti verso i fenomeni di contatto tra italiano e tedesco e verso il sistema sviluppato per la tutela delle minoranze storiche in Alto Adige non sono oggetto diretto della presente ricerca. Tuttavia, le osservazioni effettuate nei paragrafi successivi hanno, a mio avviso, anche un valore per comprendere la situazione sociolinguistica più strettamente "locale". Infatti, il diversificarsi del plurilinguismo in seguito ai processi migratori ha talvolta determinato e ancora determina l'emergere di nuovi atteggiamenti verso la seconda lingua e verso l'"altro" gruppo linguistico anche tra i membri delle cosiddette minoranze storiche (cfr. § II.2.4 per più dettagli).

Un terzo gruppo di questioni emerge poi dalle riflessioni sui repertori dei parlanti tedescofoni e italofoni altoatesini, esposte ai § II.1.3 e II.1.4. A questo riguardo, risulta evidente che le persone mobili devono padroneggiare più varietà linguistiche e/o registri per comunicare se non efficacemente, almeno adeguatamente con la popolazione tedescofona nella regione di arrivo. Inoltre, sebbene i dialetti italo-romanzi siano parlati meno frequentemente $\mathrm{e}$ in un numero più circoscritto di circostanze dai locutori italofoni, questi non sono del tutto assenti né sembrano ricoprire un ruolo del tutto marginale nello spazio sociolinguistico altoatesino.

In considerazione di ciò, ci si può chiedere, da un lato, se i cittadini stranieri siano consapevoli del plurilinguismo "interno" della popolazione altoatesina - probabilmente meno evidente di quello "esterno" che riguarda appunto le lingue ufficiali - e, nel caso, come rappresentino l'allocazione di tali varietà, locali e non locali, di italiano e tedesco nella regione di arrivo. Dall'altro, ci si può domandare quali codici gli intervistati vogliano (o abbiano voluto) imparare dopo il trasferimento in Alto Adige e quali siano (state) le loro modalità di apprendimento. Infatti, competenze linguistiche e metalinguistiche in varietà non standard non possono essere solitamente acquisite formalmente, vale a dire ad esempio tramite corsi di lingua. $\mathrm{Al}$ contrario, conoscenze in varietà standard, ma non locali di tedesco $(\mathrm{ad}$ esempio in Hochdeutsch) e di italiano sono più accessibili e riconosciute a livello globale. Tuttavia, possono risultare meno vantaggiose da un punto di vista simbolico e talvolta anche strumentale nello specifico contesto studiato. 
Infine, sarà interessante valutare il prestigio assegnato dalla popolazione straniera specificamente ai dialetti austro-bavaresi locali e, eventualmente, alle varietà venete e trentine. Infatti, come discusso nei paragrafi precedenti, la valutazione dello status di questi codici e, quindi, dell'adeguatezza di un loro impiego in determinati contesti non è uniforme. Questa varia non solo tra la comunità italofona versus quella tedescofona, ma anche all'interno del gruppo italofono e, per di più, tra gli stessi parlanti di lingua tedesca in Alto Adige.

\section{IMMIGRAZIONE IN ALTO ADIGE: NUMERI ED ETNOGRAFIA}

La seconda parte del capitolo II è dedicata a un'illustrazione di alcuni aspetti socio-economici, sociolinguistici e discorsivi relativi al fenomeno "immigrazione" in Alto Adige. Dopo aver commentato nel prossimo paragrafo lo sviluppo demografico della popolazione straniera a partire dagli anni novanta a oggi, nel § II.2.2 descrivo specificamente la storia migratoria e le caratteristiche socio-economiche e abitative di (gruppi di) cittadini provenienti dai paesi successori alla Jugoslavia in provincia di Bolzano. Nel $\S$ II.2.3 discuto alcuni fattori che secondo la letteratura condizionano gli usi e le competenze linguistiche dei cittadini stranieri in Alto Adige, mentre oggetto del §II.2.4 sono le tesi avanzate nei dibattiti politici e mass-mediatici riguardo alla prima lingua da loro appresa dopo il trasferimento. Inoltre, nel $\S$ II.2.5 espongo i risultati di una piccola ricerca etnografica, condotta per il presente volume, sulle attività promosse dalla provincia autonoma per favorire l'inclusione tra popolazione autoctona e alloctona tramite l'apprendimento delle lingue. Il fine di questa sezione del capitolo II è quello di individuare i tipi di percorsi migratori, che i partecipanti alla presente ricerca potrebbero avere intrapreso per stabilirsi in Alto Adige, e di metterne in luce alcune delle possibili ripercussioni sul piano linguistico (cfr. § II.2.6).

\subsection{I cittadini stranieri in Alto Adige}

Secondo dati ASTAT (2015), i residenti "stranieri"22 in provincia di Bolzano al 31 dicembre 2014 sono 46.045 e costituiscono 1'8,9\% della popolazione totale. Nonostante le cifre assolute e percentuali siano inferiori a quelle di altre regioni e province italiane (ad esempio Lombardia, Lazio, Brescia o Prato), la quota dei cittadini stranieri è al di sopra della media nazionale, che è infatti pari al 8,3\%. Inoltre l'incidenza percentuale della popolazione straniera su quella italiana è spesso sovrastimata dalla popolazione locale. Questa percezione probabilmente dipende dal fatto

22 Secondo le definizioni di ISTAT (2011: 5), la popolazione "immigrata" non coincide con la popolazione "straniera". La prima è infatti composta da tutti i residenti sul territorio nazionale che sono nati all'estero con cittadinanza straniera, anche se hanno successivamente acquisto il passaporto italiano. Invece, i cittadini stranieri sono tutti i residenti che hanno cittadinanza straniera, anche se sono nati in Italia. 
che l'incremento demografico è avvenuto rapidamente in un arco di tempo relativamente breve (cfr. ASTAT 2012: 40-41). ${ }^{23}$

Come mostra il grafico 1, il numero dei cittadini stranieri in provincia di Bolzano è infatti cresciuto considerevolmente, anche se non costantemente negli ultimi venti anni. Tra questi è aumentato anche il numero delle persone con passaporto non italiano nate in Alto Adige e di quelle che vi risiedono da più di dieci anni. Queste rilevazioni sono importanti in quanto il numero degli stranieri nati in Italia e la durata del periodo di residenza sono tradizionalmente considerati, insieme ad altri, "indicatori di stanzialità" dei cittadini stranieri nel paese di arrivo (cfr. ISTAT 2011). Dal grafico in 1 emerge inoltre che l'aumento della popolazione straniera in provincia di Bolzano abbia seguito uno sviluppo irregolare nel corso del tempo. Questo andamento è stato verosimilmente condizionato da vari fattori e avvenimenti anche internazionali. Il picco di arrivi nel 2007 è per esempio in parte spiegabile con l'entrata di Bulgaria e Romania nell'Unione Europea e con la promulgazione di nuove normative in materia di permessi di soggiorno in Italia. Invece il

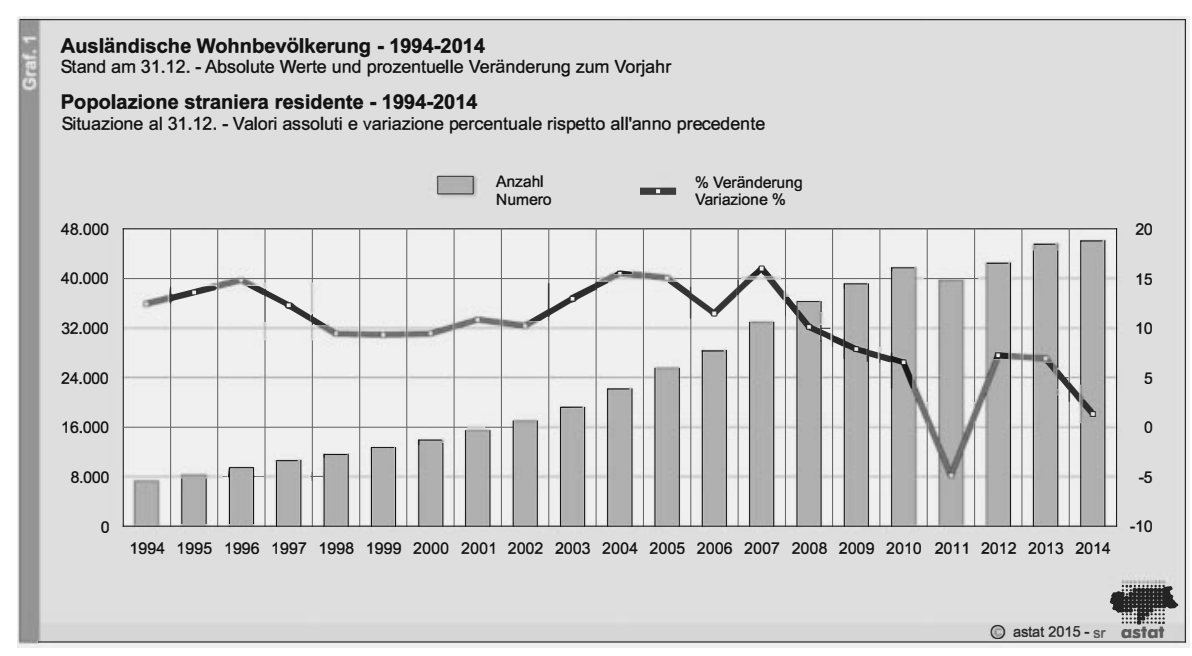

Grafico 1: Popolazione straniera residente in Alto Adige dal 1994 al 2014, valori assoluti e variazione percentuale rispetto all'anno precedente. Ristampato da: ASTAT (2015: 2), dati relativi al 31.12.2014.

23 La ricerca ASTAT (2012) può essere considerata per proporzioni il corrispettivo di ASTAT (2006), ma sulla condizione e gli atteggiamenti della e verso la popolazione straniera in provincia di Bolzano. I ricercatori hanno condotto "interviste dirette" ai partecipanti, supportate da questionari standardizzati e parzialmente confrontabili con quelli di un'inchiesta del 2002 (cfr. ASTAT 2012: 15-19). Gli informanti sia stranieri sia italiani sono stati contattati nella primavera del 2011 in modo da costruire due campioni rappresentativi della popolazione di età uguale o superiore ai 15 anni per sesso, età e comune di residenza (questi ultimi a loro volta stratificati per comprensorio statistico e percentuale di stranieri residenti). Le interviste effettuate sono tuttavia meno di quelle pianificate ( 565 con cittadini alloctoni e 730 con locali invece di circa 1000). L'alto tasso di non risposta tra gli stranieri potrebbe essere indicativo della loro mobilità stagionale e/o pendolare. 
calo relativo dei trasferimenti negli anni successivi è probabilmente riconducibile alla crisi economica (cfr. ASTAT 2015: 1-2). Nel 2014, per la prima volta da quasi trenta anni, il saldo migratorio in provincia di Bolzano è negativo. Il lieve incremento di residenti stranieri deriva esclusivamente dal loro saldo naturale positivo (cfr. ASTAT 2015: 2).

La popolazione straniera in Alto Adige si stabilisce preferibilmente nei centri urbani o semi-urbani. In particolare, i comprensori in cui si registra un tasso di immigrazione superiore o pari alla media provinciale sono quello di Bolzano, il Burgraviato (ovvero Merano e dintorni) e l'Oltradige/Bassa Atesina. A livello comunale, oltre a Bolzano e Merano, in alcune località minori, come a Fortezza, Salorno e Brennero, vive una percentuale di cittadini stranieri superiore al 10\% (cfr. ASTAT 2015: 5).

Nel 2014 i cittadini stranieri in provincia di Bolzano provengono da almeno 138 paesi diversi (cfr. ASTAT 2015: 9). Tuttavia, l'Alto Adige si distingue da altre regioni italiane per un'alta concentrazione di persone originarie da paesi europei, comunitari o non comunitari (cfr. Lupoli 2009: 30). A questo riguardo, i grafici 2, 3, 4 - elaborati su dati ISTAT al primo gennaio 2015 - permettono di paragonare la distribuzione della popolazione straniera per cittadinanza in Alto Adige, in tutta Italia e in alcune regioni del Nord-Est. ${ }^{24}$

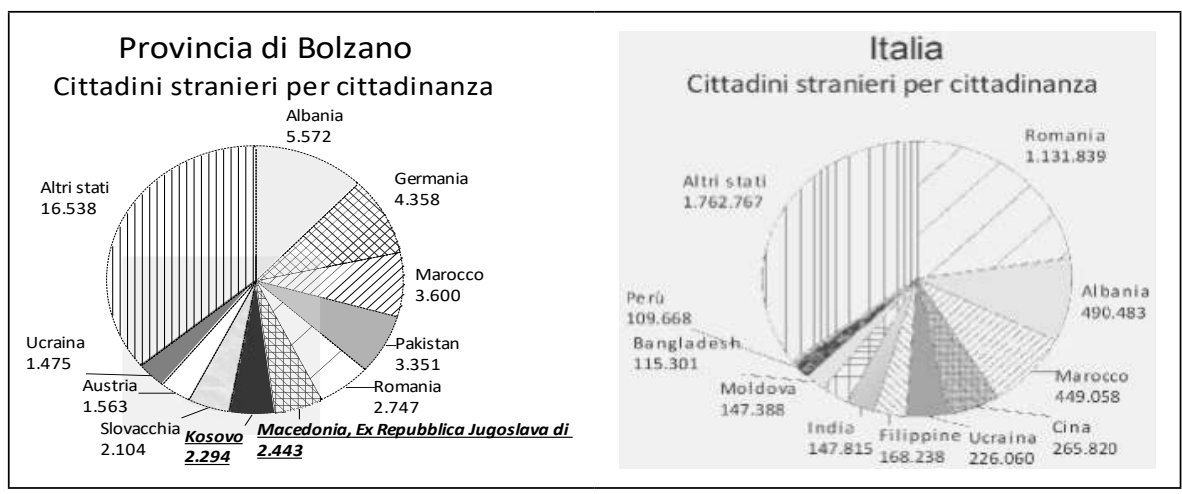

Grafico 2: Popolazione straniera per cittadinanza in provincia di Bolzano. Elaborazioni proprie su dati ISTAT al 01.01.2015.
Grafico 3: Popolazione straniera per cittadinanza in Italia. Elaborazioni proprie su dati ISTAT al 01.01.2015.

24 Sia qui avvertito di una differenza tra le pubblicazioni degli Istituti di Statistica Provinciale e Nazionale: i dati ASTAT sulla popolazione straniera sono solitamente al 31. dicembre, mentre quelli ISTAT al 1. gennaio. Perciò, in questo come nei prossimi paragrafi, paragono ad esempio rilevazioni ASTAT relative al dicembre 2014 con rilevazioni ISTAT relative al gennaio 2015 . Per i dati dei diagrammi in 2, 3, 4 si confronti il sito dell'ISTAT, URL: $<$ http://dati.istat.it/Index. aspx? DataSetCode=DCIS_POPSTRCIT1\&Lang $=$ it $>$ (18.10.2018). Dalle regioni, che secondo la definizione ISTAT costituiscono il Nord-Est, escludo per il grafico 4 l'Emilia Romagna. 


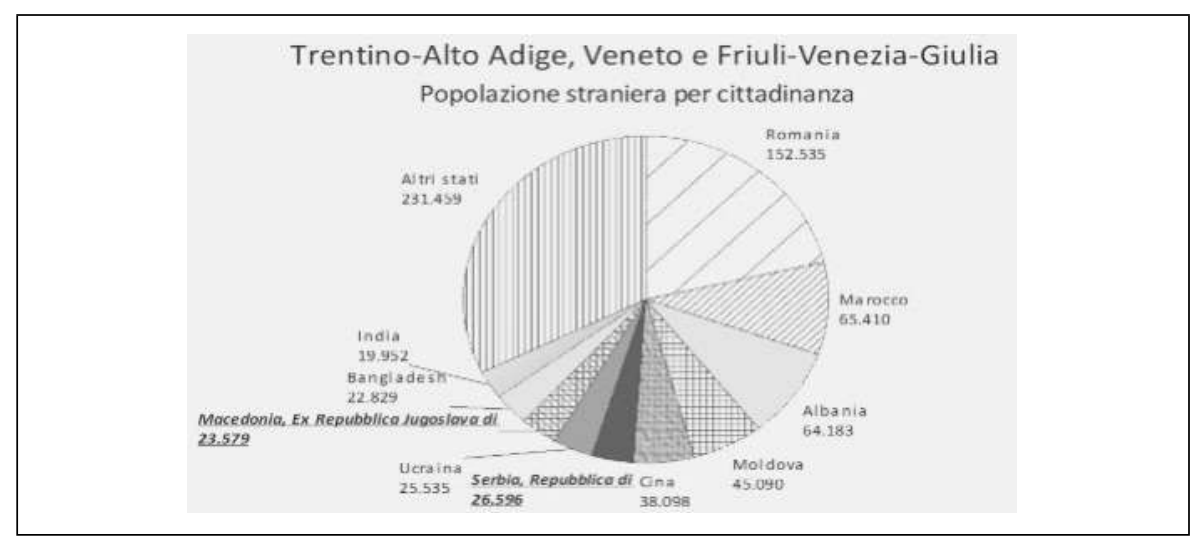

Grafico 4: Popolazione straniera per cittadinanza nel Triveneto. Elaborazioni proprie su dati ISTAT al 01.01.2015.

Similmente a nel resto della penisola (cfr. grafico 2 e 3), risiedono in provincia di Bolzano numerose persone originarie dall'Albania, dal Marocco e dalla Romania. Peculiare in Alto Adige rispetto alla situazione italiana generale è invece la presenza di un alto numero di cittadini provenienti, oltre che dal Pakistan e dalla repubblica Slovacca, da paesi europei tedescofoni, ossia Germania e Austria: fino al 1998, i cittadini EU sono infatti il gruppo più numeroso tra le comunità immigrate in provincia di Bolzano (cfr. ASTAT 2012: 42). Infine, è rilevante notare che, tra $\mathrm{i}$ primi dieci paesi di provenienza della popolazione straniera in Alto Adige, ci sono anche la Repubblica di Macedonia e il Kosovo.

I dati del diagramma in 4 confermano, d'altro canto, che le persone provenienti dai paesi successori alla Jugoslavia scelgano frequentemente di stabilirsi nelle regioni dell'Italia nord-orientale, in particolare nel Triveneto. Le cittadinanze serba e macedone sono infatti nel 2015 tra le dieci più rappresentate in Veneto, Friuli-Venezia Giulia e appunto Trentino-Alto Adige. Le ragioni di questa preferenza sono probabilmente da ricondursi alla vicinanza geografica e alla tradizionale offerta di lavoro nel settore dell'edilizia. La richiesta di manodopera edile ha infatti determinato fin dalla fine degli anni settanta il consolidarsi di catene migratorie di lavoratori jugoslavi, originariamente impegnati nella ricostruzione delle aree terremotate del Friuli (cfr. Macioti \& Pugliese 2003/2010: 30). Tuttavia, negli anni settanta e ottanta, la maggior parte degli emigrati dalla Repubblica Socialista Federale di Jugoslavia non risiedeva in Italia, ma in altri paesi europei. Mete preferite erano soprattutto la Germania - dove i cittadini jugoslavi erano solitamente impiegati come "lavoratori ospiti" (Gastarbeiter) -, l'Austria e, in misura minore, la Francia, la Svizzera, la Svezia e il Benelux (cfr. Fincati 2007: 5).

La concentrazione di alcune cittadinanze in modo disomogeneo sul territorio nazionale non è sorprendente, ma costituisce una caratteristica tipica del fenomeno migratorio in Italia (cfr. ISTAT 2011: 6-7). Seppur concentrata nel Triveneto, la presenza di cittadini ex-jugoslavi è comunque abbastanza diffusa in tutto il paese. A testimonianza della loro incidenza, per lo meno nel caratterizzare i flussi migratori 
verso la penisola durante gli anni novanta, gli studenti ex-jugoslavi costituiscono nell'anno scolastico 2001/2002 il terzo gruppo di iscritti stranieri nelle scuole dopo quelli di origine marocchina e albanese (cfr. Macioti \& Pugliese 2003/2010: 29).

Infine, in modo analogo a in altre regioni italiane, anche in provincia di Bolzano si registra la tendenza alla differenziazione delle professioni e dei tipi di contratti ad esempio stagionali o a tempo indeterminato - oltre che per sesso anche per area di provenienza dei lavoratori. Tale distribuzione ha causato una (almeno parziale) "specializzazione etnica" del mercato del lavoro italiano in generale e altoatesino in particolare (cfr. rispettivamente Ambrosini 2005 e Lainati \& Saltarelli 2007: 51-52, Lupoli 2009: 31-32). Con il termine ci si riferisce al fenomeno per cui (reti di) conterranei sono occupati in maniera significativa in una particolare attività lavorativa. Le professioni sono - in conseguenza della segmentazione del mercato del lavoro tout court - frequentemente a basso reddito e/o prestigio e offrono poche possibilità di avanzamento sociale (cfr. anche Macioti \& Pugliese 2003/2010: 58-61).

\subsection{L'emigrazione dai paesi successori alla Jugoslavia}

Tratteggiando i "modelli migratori" 25 di diversi gruppi nazionali in Italia, Macioti \& Pugliese (2003/2010: 38-44) notano che l'immigrazione dai paesi successori alla Jugoslavia sia difficile da descrivere come fenomeno unitario a causa della diversità dei motivi di trasferimento e del tipo di permessi di soggiorno rilasciati. Questi sono infatti inizialmente emessi soprattutto per ragioni umanitarie a persone che si spostano per la guerra, mentre successivamente sono prevalentemente accordati per motivi lavorativi. Nonostante ciò, considerando l'anzianità e la composizione demografico-sociale delle presenze, gli autori riconoscono alcune tendenze comuni nei progetti migratori delle persone di queste regioni. Tali piani sono in parte simili a quelli dei cittadini provenienti da altri paesi dei Balcani Occidentali. I cittadini da queste aree in Italia tendono infatti ad essere occupati principalmente nell'edilizia e a risiedere in prevalenza nel Nord-Est (cfr. anche $\S$ II.2.1). Inoltre, la loro ripartizione per genere è solitamente più equilibrata rispetto a quella delle persone provenienti dall'Africa da un lato o dall'Europa Centro-Orientale e dall'America Meridionale dall'altro, tra cui rispettivamente predominano presenze maschili e femminili. Infine, la durata del soggiorno dei cittadini ex-jugoslavi nella penisola è ten-

25 Sul concetto di "modello migratorio" o "modello di emigrazione" si veda anche Giddens (2009). In generale, questo ultimo ne distingue quattro: il "modello classico" verso paesi come Canada e Stati Uniti; il "modello coloniale", ovvero quello che contraddistingue, per esempio, l'emigrazione verso il Regno Unito fino agli anni '60; il "modello Gastarbeiter", ossia in seguito ad accordi per il reclutamento di manodopera tra paesi di arrivo e di provenienza; e il modello in cui l'emigrazione è trattata come "illegale". Inoltre, lo studioso nota come, dopo la caduta dell'URSS e il dissolvimento della Jugoslavia, sia aumentata la migrazione per principio di "affinità etnica". In studi recenti, i percorsi migratori dei singoli non sono del resto più visti come principalmente motivati da fattori push/pull. Piuttosto questi sono concepiti come determinati dall'interazione tra fattori "macro", ad esempio congiunture economiche, e fattori "micro", come la presenza di reti informali tra connazionali. 
denzialmente piuttosto lunga: questa è, per esempio, in media superiore anche a quella di altri gruppi nazionali di origine balcanica, come quello albanese (cfr. Macioti \& Pugliese 2003/2010: 41-42).

I dati della tabella 1 confermano queste osservazioni specificamente per l'Alto Adige. Considerati nel loro insieme, i cittadini dei paesi successori alla Jugoslavia in provincia di Bolzano sono 6.918 nel 2015 (senza contare gli eventuali naturalizzati). Questi costituiscono quindi il gruppo straniero più numeroso in provincia. Inoltre, alcuni di loro vivono in Alto Adige da più di venti anni. Oltre che in relazione ai primi e agli ultimi dati disponibili al momento della redazione di questo libro (rispettivamente 1998 e 2015), gli anni di riferimento riportati nella tabella 1 sono stati scelti, da un lato, in considerazione di alcuni momenti significativi nella storia migratoria della ex-Jugoslavia: il 2000 è per esempio l'anno in cui terminano, per lo meno ufficialmente, i (maggiori) conflitti in Kosovo. Dall'altro, sono stati selezionati sulla base di cambiamenti rilevanti nelle procedure di rilevamento demografico in provincia di Bolzano: i dati ASTAT del 2003 sono infatti i primi suddivisi per nazionalità (precedentemente la suddivisione era per aree di provenienza), mentre a partire dal 2008/2009 sono introdotte anche le cittadinanze kosovara e montenegrina nel conteggio. Le quote di donne e minori nella tabella 1 sono invece calcolate al 1. gennaio 2012 perché, al momento della redazione del presente volume, i dati relativi ad anni successivi non erano disponibili (n.d.). Per offrire un termine di paragone, sia qui menzionato che al primo gennaio 2012 i minori costitu-

Tabella 1: Composizione demografica per nazionalità dei cittadini provenienti dai paesi successori alla Jugoslavia in Alto Adige. Fonti: ISTAT, ${ }^{26}$ Lainati \& Salterelli (2007: 23), ASTAT (2013: 108-109).

\begin{tabular}{|l|c|c|c|c|c|c|c|c|c|}
\hline & $\mathbf{1 9 9 8}$ & $\mathbf{2 0 0 0}$ & $\mathbf{2 0 0 3}$ & $\mathbf{2 0 0 8}$ & $\mathbf{2 0 0 9}$ & $\mathbf{2 0 1 2}$ & $\mathbf{2 0 1 5}$ & $\begin{array}{c}\text { Donne } \\
\mathbf{( 2 0 1 2}\end{array}$ & $\begin{array}{c}\text { Minori } \\
\text { (2012) }\end{array}$ \\
\hline $\begin{array}{l}\text { Rep. di } \\
\text { Macedonia }\end{array}$ & - & - & 902 & 1.909 & 2.071 & 2.356 & 2.443 & $46,73 \%$ & $29,58 \%$ \\
\hline Kosovo & - & - & - & - & 894 & 1.868 & 2.294 & $47,64 \%$ & $36,24 \%$ \\
\hline $\begin{array}{l}\text { Rep. di } \\
\text { Serbia }\end{array}$ & - & - & - & - & 1.822 & 1.302 & 870 & $47,31 \%$ & $27,26 \%$ \\
\hline $\begin{array}{l}\text { Bosnia- } \\
\text { Erzegovina }\end{array}$ & - & - & 474 & 764 & 794 & 755 & 682 & $44,64 \%$ & $23,44 \%$ \\
\hline Croazia & - & - & 391 & 499 & 506 & 529 & 502 & $54,06 \%$ & $15,69 \%$ \\
\hline Montenegro & - & - & - & - & 49 & 35 & 95 & $54,29 \%$ & n.d. \\
\hline Slovenia & - & - & 15 & 22 & 20 & 23 & 32 & $69,57 \%$ & n.d. \\
\hline $\begin{array}{l}\text { Serbia e } \\
\text { Montenegro }\end{array}$ & - & - & 1.394 & 2.503 & - & - & - & - & - \\
\hline Totale & 2.221 & 2.777 & 3.176 & 5.697 & 6.156 & 6.810 & 6.918 & $47,43 \%$ & n.d. \\
\hline
\end{tabular}


iscono, secondo (ISTAT 2013: 1), il 23,9\% della popolazione straniera non comunitaria regolarmente soggiornante in Italia. ${ }^{27}$

Per quanto riguarda la storia migratoria della popolazione straniera in Alto Adige, i cittadini marocchini e tunisini sono tra i primi a stabilirsi nella provincia autonoma già dalla metà degli anni ottanta. Tuttavia, gli arrivi dai Balcani occidentali si registrano sempre numerosi a partire dagli anni novanta: questo incremento avviene inizialmente in corrispondenza delle crisi politiche e delle guerre in Croazia (1991-1992) e Bosnia-Erzegovina (1992-1995) (cfr. Lainati \& Saltarelli 2007: 26-30 e anche Girardi 2011: 78-81). Inoltre profughi albanofoni di nazionalità kosovara giungono in Alto Adige dal 1996 e, soprattutto, in conseguenza dei conflitti militari tra il marzo e l'agosto del 1999. In questo periodo, anche cittadini macedoni di lingua albanese o romaní, residenti nelle zone confinanti con il Kosovo, si trasferiscono in provincia di Bolzano (e di Trento). La consistenza dei flussi diminuisce nella seconda metà degli anni novanta in conseguenza delle politiche di rimpatrio intraprese dai paesi di partenza e di arrivo. Nonostante ciò, l'immigrazione da queste aree continua a essere consistente. Come mostra la tabella 1, il numero di cittadini ex-jugoslavi in Alto Adige è così più che raddoppiato tra il 1998 e il 2008, mentre, anche negli ultimi anni, si registra una crescita continua, seppur meno rapida.

Fenomeno spesso citato nel commentare lo sviluppo demografico della popolazione proveniente dai paesi successori alla Jugoslavia sono le oscillazioni nelle statistiche ufficiali dovute ai rivolgimenti politici nelle aree di partenza. Fino al 2008 serbi, montenegrini e kosovari sono per esempio conteggiati insieme (cfr. Medda-Windischer \& Girardi 2011: 22-23). In seguito al riconoscimento dell'indipendenza del Kosovo e all'introduzione della nazionalità montenegrina nel novero di quelle considerate, ${ }^{28}$ il numero dei cittadini kosovari - e in misura minore di quelli montenegrini - in Alto Adige aumenta non solo nel 2009, ma anche costantemente negli anni successivi. Invece la popolazione serba cala fino al 2013 in conseguenza di cambi di cittadinanza più che di reali movimenti di persone (cfr. colonne $6^{\circ}$ e seguenti nella tabella 1 ).

I dati nella tabella 1 mostrano anche che, seppur esistano differenze a seconda della nazionalità, la proporzione tra popolazione femminile e maschile proveniente dalle aree della ex-Jugoslavia è piuttosto bilanciata al 1. gennaio 2012. Inoltre la percentuale di minorenni sul totale è abbastanza alta (cfr. rispettivamente colonne $9^{\circ} \mathrm{e} 10^{\circ}$ ). L'incidenza di donne e di ragazzi in età scolare è, in parte, riconducibile ai modi di prima migrazione, avvenuta prevalentemente per gruppi familiari più $o$ meno estesi a causa della guerra. In parte, è determinata da ricongiungimenti familiari successivi (cfr. Lainati \& Saltarelli 2007: 38). Tali percentuali sono possibilmente indicative della stabilità del progetto migratorio dei cittadini ex-jugoslavi in

27 Per rappresentazioni grafiche, ma senza riferimento ai valori assoluti dell'andamento demografico della popolazione delle prime dodici nazionalità in Alto Adige - tra cui macedone, serba $\mathrm{e}$ più recentemente kosovara - negli ultimi venti anni si veda anche Medda-Windischer \& Girardi (2011: 43-61).

Il Montenegro è uno stato indipendente dal 2006. 
Alto Adige. Da un punto di vista sociolinguistico sono, quindi, rilevanti al momento di valutare la probabilità che le lingue parlate dai nuovi residenti entrino a far parte in modo stabile dello spazio linguistico della regione di arrivo (cfr. Bagna et al. 2003).

La popolazione proveniente dalla ex-Jugoslavia - similmente a quella dal Pakistan - risiede più spesso in località extraurbane rispetto ad altri gruppi stranieri (cfr. Lainati \& Saltarelli 2007: 25). Una tale distribuzione dipende, secondo gli studiosi, dai luoghi del loro primo insediamento in provincia di Bolzano, ovvero nei centri di accoglienza per profughi situati nelle ex caserme in zone montane. Nello specifico, considerando i dati per singole nazionalità al termine del 2009, è la popolazione di origine kosovara che preferisce le piccole località come luogo di residenza (cfr. Medda-Windischer \& Girardi 2011: 43-61). I cittadini macedoni abitano invece prevalentemente a Merano, Bolzano e in Bassa Atesina. Le persone di origine serba risiedono soprattutto nei comuni di Lana, Brunico e Bolzano.

Come nel resto della penisola, anche in Alto Adige un numero cospicuo di persone dalla ex-Jugoslavia è impiegato nell'edilizia. In aggiunta, i cittadini serbi, montenegrini e kosovari, residenti in provincia di Bolzano, sono frequentemente occupati nel settore alberghiero, soggetto a forti fluttuazioni stagionali (cfr. Medda-Windischer \& Girardi 2011: 57). Probabilmente per questo, dal confronto tra la durata dell'ultimo impiego e quella del soggiorno in Alto Adige risulta che gli informanti ex-jugoslavi siano i lavoratori meno stabili tra quelli delle comunità immigrate considerate (cfr. Lainati \& Saltarelli 2007: 53-54). ${ }^{29}$ I ricercatori interpretano questi frequenti cambi di occupazione come un potenziale indicatore di disagio.

Infine, sempre secondo lo studio appena citato, il livello di istruzione degli intervistati dai paesi successori alla Jugoslavia è inferiore a quello degli informanti dell'Europa dell'Est o dell'America Latina (cfr. Lainati \& Saltarelli 2007: 56-58). Solo un quarto dei partecipanti all'inchiesta ha ottenuto, del resto, il riconoscimento del proprio titolo di studio nel paese di arrivo. D'altro canto, similmente agli informanti di altre nazionalità, le reti sociali e i legami interpersonali tendono ad avere un ruolo abbastanza importante anche per i neo arrivati dalla ex-Jugoslavia. Questi rapporti sono infatti spesso determinanti sia al momento di scegliere l'Alto Adige come meta del primo trasferimento all'estero, sia al momento di trovare un impiego in provincia (cfr. ibidem: 31 e 55).

\subsection{Gli usi linguistici dei cittadini stranieri}

Una questione aperta in letteratura riguarda i fattori extra-linguistici che possono interagire sulle conoscenze, gli usi e gli atteggiamenti linguistici della popolazione straniera verso i codici storicamente parlati in provincia di Bolzano.

29 Lainati \& Saltarelli (2007) descrivono i dati raccolti ripartendoli in cinque macro-aree di provenienza, ovvero Albania, ex-Jugoslavia, Europa Centro-Orientale, Africa, Asia e America Meridionale. 
Il primo fattore ad essere solitamente menzionato è il comune altoatesino di residenza $\mathrm{o}$, più precisamente, la distribuzione di parlanti italofoni e tedescofoni in questa località. A questo riguardo, da una ricerca di Medda-Windischer et al. (2011: 71-81) risulta, per esempio, che la composizione linguistica del comune di residenza correli con la valutazione dell'importanza di padroneggiare il tedesco standard per vivere bene in Alto Adige. Tuttavia, il sondaggio registra trasversalmente e in particolare tra le intervistate donne - una volontà piuttosto bassa di imparare o migliorare le competenze nei dialetti tedeschi locali. Questo (presunto) atteggiamento - che parzialmente coincide con quello della comunità italofona altoate$\operatorname{sina}^{30}$ - contrasta con la frequenza d'uso dei dialetti tedeschi locali da parte della popolazione tedescofona in provincia di Bolzano. Similmente a quanto discusso nella prima parte del capitolo II, tale reticenza potrebbe essere quindi interpretata come un mancato riconoscimento del ruolo e del prestigio che tali varietà linguistiche ricoprono nell'interazione quotidiana in Alto Adige (cfr. anche Franceschini et al. 1984 per la descrizione di un atteggiamento analogo tra la popolazione immigrata di origine italiana nella Svizzera tedesca). Inoltre, dall'inchiesta di Medda-Windischer et al. (2011) emerge anche che molti cittadini stranieri vogliono acquisire entrambi i codici d'arrivo e/o desiderano che i propri figli li imparino indipendentemente da dove vivono. Al contempo, le competenze dichiarate in varietà di tedesco e la loro frequenza d'uso al lavoro, con gli amici e in famiglia sono in media inferiori rispetto a quelle dichiarate in italiano. Ciò vale anche per le persone straniere che abitano in comuni a maggioranza tedescofona. Solo il $15,1 \%$ e il 5,4\% degli informanti valuta infatti le proprie conoscenze rispettivamente in tedesco standard e nei dialetti austro-bavaresi locali come fluenti o buone contro il 58,7\% degli intervistati che afferma invece di comunicare correntemente in italiano (cfr. ibidem: 76). Da ciò segue che l'influenza del fattore "località di residenza" sui repertori della popolazione straniera in Alto Adige possa essere talvolta forte, ma non sia necessariamente cruciale.

Un secondo fattore che può in parte determinare le scelte e gli usi linguistici della popolazione straniera in provincia di Bolzano è il "lavoro svolto". A questo riguardo, la maggior parte dei cittadini stranieri in Alto Adige è impiegata nei settori dell'agricoltura e del turismo (cfr. ASTAT 2012: 84-85). ${ }^{31}$ Dal momento che queste

30 L'atteggiamento è solo parzialmente simile perché le ricerche sugli atteggiamenti della popolazione italofona verso i dialetti locali, discusse al § II.1.2 e seguenti, e lo studio di Medda-Windischer et al. (2011) non sono completamente confrontabili per il tipo di domande poste e per la rappresentatività del campione analizzato. Nello specifico, sia qui avvertito che Medda-Windischer et al. (2011) definiscono la propria ricerca non predittiva, ma solo descrittiva del campione preso in esame (476 intervistati tramite questionario). Oltre che per composizione linguistica del comune altoatesino di residenza, i ricercatori ripartiscono gli informanti anche per macro-area di provenienza, tra cui i "Balcani”. Tale variabile non è però considerata al momento di descrivere gli usi linguistici dichiarati dei partecipanti.

31 Questo è vero anche se il numero dei lavoratori stranieri impiegati nel settore agricolo è probabilmente sottostimato da ASTAT (2012: 84-85). Infatti questi, assunti solitamente con contratti stagionali per la raccolta di mele e uva, non si trovavano in Alto Adige al momento dell'inchiesta. 
attività lavorative sono tradizionalmente svolte da parlanti tedescofoni (cfr. ASTAT 2006: 82-83), si può supporre che conoscenze in tedesco e nei dialetti tedeschi locali siano per lo meno desiderate dai cittadini stranieri. Infatti, mancate o basse competenze in tali codici possono costituire un impedimento per i nuovi arrivati al momento di cercare un'occupazione e/o di interagire con colleghi e clienti in tali settori (cfr. Zanolla 2011: 190-192 per opinioni a riguardo in interviste qualitative con cittadini stranieri). Altri settori lavorativi, che frequentemente danno impiego alla popolazione immigrata, sono l'assistenza socio-sanitaria e, in misura leggermente inferiore, l'industria, l'artigianato e il commercio (cfr. sempre ASTAT 2012: 84). Come discusso nei paragrafi precedenti, tali attività sono poco specializzate per gruppo linguistico. Tuttavia, competenze in entrambi i codici sono sicuramente vantaggiose anche in questi settori. Così, in relazione alla ripartizione più o meno netta delle attività lavorative per comunità linguistiche locali, il tipo di occupazione svolta da un cittadino straniero può favorire o essere neutrale all'acquisizione di uno o più codici d'arrivo dopo il trasferimento in Alto Adige.

In terzo luogo, è talvolta possibile individuare comportamenti linguistici omogenei in relazione alla "storia" e agli "obiettivi migratori individuali" così come, almeno in parte, in relazione alla "comunità nazionale" e/o "linguistica" di appartenenza. Nello specifico, la presenza di orientamenti di gruppo comuni mette in evidenza, secondo Cortinovis (2011: 46-48), il ruolo delle catene migratorie sulle scelte linguistiche dei singoli dopo il trasferimento in provincia di Bolzano. Infatti, mentre i cittadini provenienti dal Pakistan e dal Kosovo - spesso giunti in Alto Adige dopo un primo soggiorno in un paese tedescofono - tendono ad imparare come prima lingua il tedesco, i migranti dall'Albania, dal Marocco, da altri paesi dell'ex-Jugoslavia e dalla Cina si concentrano inizialmente sull'apprendimento dell'italiano. Come la ricercatrice stessa afferma, tali generalizzazioni necessitano di essere prese con cautela e sarebbero da investigare in modo più dettagliato. Inoltre, più il progetto migratorio è stabile, maggiore sembra essere la consapevolezza tra la popolazione straniera del valore strumentale del bilinguismo nel contesto di arrivo. In connessione con ciò, cresce anche la volontà da parte dei singoli di acquisire entrambi i codici indipendentemente dai fattori sopra menzionati.

Sebbene li abbia appena discussi separatamente, sia qui infine rimarcato che questi fattori - composizione linguistica della località di residenza, lavoro svolto, storia e obiettivi migratori individuali, catene migratorie, comunità nazionale o linguistica di appartenenza - si intrecciano ovviamente spesso gli uni con gli altri. Infatti, legami deboli o forti tra connazionali che hanno una lingua in comune possono, per esempio, condizionare la scelta della (prima) località di residenza così come della (prima) occupazione. In questo modo, tutte queste circostanze insieme possono avere un influsso sulla (prima) lingua appresa dopo il trasferimento in Alto Adige. Perciò, nella misura in cui l'interazione tra fattori "macro" e "micro" è rilevante per spiegare le traiettorie migratorie individuali, questa lo è anche al momento di valutare le scelte e gli usi linguistici della popolazione straniera in un contesto plurilingue come quello della provincia di Bolzano. 


\subsection{La querelle sull'apprendimento delle lingue}

Il plurilinguismo determinato dai processi migratori è sempre più spesso oggetto di interventi di regolamentazione a livello politico. In conseguenza di ciò, riflessioni e dibattiti su questioni riguardanti "lingua e immigrazione" sono divenuti frequenti sui mass media europei, in generale, e italiani, in particolare (cfr. Stevenson 2006, 2011 e anche Orioles 2007 specificamente per la situazione in Italia).

Tali discussioni assumono una fisionomia particolare in provincia di Bolzano. Ciò dipende in parte proprio dal fatto che questa area sia un territorio a plurilinguismo istituzionale, dove i bisogni e i diritti linguistici delle nuove minoranze si intrecciano con quelli delle minoranze di antico insediamento. Dato questo sfondo, una serie di ricerche - condotte direttamente dall'Istituto sui Diritti delle Minoranze dell'Accademia Europea di Bolzano (EURAC) o con il suo supporto - hanno investigato se e, eventualmente, in che modo il sistema elaborato per la tutela delle minoranze storiche influenzi l'approccio alle questioni legate all'immigrazione e ai diritti linguistici dei cittadini stranieri in provincia di Bolzano. Questi studi si concentrano soprattutto su discorsi istituzionali e massmediatici, ovvero sulle prese di posizione (spesso programmatiche) di élite politiche e di una parte dell'opinione pubblica altoatesina. Tali opinioni sono espresse, tra l'altro, nei programmi elettorali, nei dibattiti del consiglio provinciale, sui giornali locali o siti internet. Dalle analisi emerge, da un lato, che l'esperienza nel regolamentare la diversità linguistica autoctona non abbia effetti chiaramente positivi al momento di gestire il plurilinguismo dei nuovi arrivati. Inoltre, proprio per il carico ideologico connesso a questioni linguistiche nella regione, risulta che diversi (gruppi di) attori locali abbiano una certa difficoltà nel formulare strategie coerenti e unitarie rispetto a interventi di politica linguistica per la popolazione immigrata (cfr. Wisthaler 2011, Medda-Windischer 2011).

Entrando più nei dettagli, la legislatura 2003-2008 è caratterizzata secondo Wisthaler (2011: 253-255) da un atteggiamento tendenzialmente positivo nei confronti del tema "immigrazione". Particolare attenzione è posta a questioni legate alla formazione e all'apprendimento linguistico dei cittadini stranieri. Nella primavera del 2004 è così, per esempio, eletta per la prima volta la "consulta degli immigrati/e" di Bolzano. Questo organo sottopone le istanze di cittadini non comunitari e apolidi all'amministrazione comunale. ${ }^{32} \mathrm{Nel}$ programma di coalizione si auspica, inoltre, una collaborazione tra gli assessorati di cultura dei gruppi linguistici italiano, tedesco e ladino per la promozione di attività finalizzate all'inclusione degli studenti stranieri nelle scuole. A questi fini è fondato nel 2007 un Centro Competenza, operante unitariamente per l'intero sistema scolastico provinciale (cfr. §II.2.5 per una descrizione delle sue attività e di quelle dei centri linguistici da esso coordinati).

La questione dell'inserimento degli studenti stranieri nel sistema scolastico altoatesino è spesso discussa, in quegli anni, anche sui mass media locali. A questo proposito, l'iscrizione a una scuola di lingua italiana è presentata di frequente come la scelta di default della popolazione alloctona. I motivi addotti sono, tra gli altri, una

32 Si confronti l'URL: <http://www.comune.bolzano.it/context.jsp?area=19\&ID_LINK=777> (18.10.2018). 
(presunta) maggiore facilità di apprendimento dell'italiano rispetto al tedesco e una (ipotetica) maggiore familiarità della cultura italiana per i nuovi arrivati (cfr. anche più avanti in questo paragrafo). ${ }^{33}$ Tuttavia, le differenze tra gli iscritti stranieri nelle scuole italiane e tedesche sono spesso sovrastimate nella percezione degli abitanti locali. Uno dei motivi è la consuetudine, seppur legittima, di fornire i dati degli studenti non italiani in percentuale. Infatti, il totale degli alunni nelle scuole tedesche è notevolmente superiore a quello degli iscritti negli istituti italiani o ladini cosicché la quota ne risulta spesso fortemente sproporzionata. Questo modo di rappresentazione rende inoltre poco evidenti cambiamenti di tendenza degli ultimi anni. Considerando i valori assoluti, il numero di minori stranieri frequentanti asili tedescofoni nell'anno scolastico 2009/2010 è infatti paragonabile a quello negli asili italiani: rispettivamente 790 (ossia il 6,8\% degli iscritti totali) e 778 bambini stranieri (vale a dire, però, il $21,2 \%$ degli alunni totali). Inoltre, l'incremento delle iscrizioni rispetto all'anno precedente è superiore negli asili e nelle scuole elementari tedesche rispetto a negli istituti italiani dello stesso livello: infatti, rispetto al 2008/2009 si registrano 135 nuove iscrizioni negli asili tedeschi e 81 in quelli italiani (cfr. Medda-Windischer \& Girardi 2011: 63-66 per i dati, originariamente raccolti da ASTAT).

Sempre in questa legislatura (2003-2008), si comincia inoltre ad assistere al fenomeno, per cui riferimenti a presunti nessi tra paese di provenienza, tipo di contratto (es. stagionale o a lungo termine) e competenze linguistiche dei cittadini stranieri siano adoperati per condizionare dibattiti pubblici su temi apparentemente non correlati con quello migratorio. Così, nell'aprile del 2005, tra gli argomenti avanzati contro una promozione del settore industriale cittadino al posto di quello agricolo c'è, per esempio, la tesi che incentivi in tale ambito possano richiamare un afflusso di lavoratori immigrati da paesi extra-europei, con progetto migratorio stabile, in quanto non sottoposti a contratti stagionali, e a più stretto contatto con il gruppo italofono, in quanto risiedenti a Bolzano (cfr. Medda-Windischer 2011: 26-27).

La campagna elettorale del 2008 e la legislatura successiva sono contraddistinte da prese di posizione (ancora) più restrittive nei confronti dei cittadini stranieri così come da una maggiore volontà di controllo anche rispetto alle loro scelte linguistiche. Nelle dichiarazioni programmatiche per la nuova legislatura del dicembre 2008 è avanzata per esempio la proposta, poi accantonata, di regolare i flussi migratori verso l'Alto Adige oltre che quantitativamente anche qualitativamente, ovvero di selezionare gli immigrati "secondo livello di istruzione, lingua e stile di vita" (cfr. Wisthaler 2011: 254). Sostenendo una posizione più estrema, alcuni partiti locali rivendicano, inoltre, la necessità di reclutare i lavoratori stranieri in base al luogo di provenienza - ovvero paesi tedescofoni o dell'Europa centro-orientale - cosicché i nuovi arrivati abbiano competenze in tedesco e/o siano culturalmente vicini alla po-

33 Queste motivazioni sono state identificate da Dorothy Louise Zinn in una relazione non pubblicata dal titolo "Migrants as New Linguistic Minorities in South Tyrol: Schooling and Language-group Incorporation", tenuta al convegno Interactions between indigenous and migrant minority languages in changing multilingual environments, città di Lussemburgo, 17-19 luglio 2013. Nell'intervento, la ricercatrice esaminava, in particolare, le strategie argomentative utilizzate per spiegare le (presupposte) preferenze dei cittadini stranieri al momento di scegliere la lingua in cui condurre la scuola dell'obbligo in Alto Adige. 
polazione locale (cfr. anche Carlà 2015: 83-84). In aggiunta, si richiede, senza conseguirla, che la frequentazione di corsi di lingua tedesca diventi una condizione per l'ottenimento di aiuti sociali, i quali devono essere comunque primariamente assegnati ai cittadini autoctoni (cfr. Wisthaler 2011: 256). Infine, a testimonianza di una certa incertezza nel trattare questioni legate all'immigrazione, sia qui ricordato che la provincia di Bolzano promulga solo nel 2011 - in ritardo rispetto alla maggior parte delle regioni a statuto ordinario e speciale in Italia - una legge provinciale per l'integrazione della popolazione straniera (cfr. Carlà 2015: 71).

Relativamente ai rapporti tra minoranze linguistiche autoctone e alloctone, è interessante rilevare che questioni legate all'immigrazione siano frequentemente strumentalizzate tra il 2008 e il 2013 da esponenti politici altoatesini, indipendentemente dal gruppo linguistico di riferimento del loro partito, per argomentare in favore o contro (una modifica delle) misure già adottate per la tutela delle lingue $\mathrm{e}$ minoranze storiche. Ad esempio, alcuni portavoce di frazioni a protezione della comunità tedescofona si posizionano contro la proposta di inserire un'opzione nella dichiarazione di appartenenza linguistica per i figli di coppie miste, strumentalizzando la tesi che la sua introduzione costituirebbe un precedente per eventuali rivendicazioni dei gruppi immigrati (cfr. Carlà 2015: 76). Al contempo, i rappresentanti di una formazione politica "italofona" attaccano il sistema scolastico tripartito della provincia autonoma, avanzando più o meno provocatoriamente il progetto di istituire una scuola separata anche per i minori stranieri (cfr. ibidem: 90). Così, la popolazione immigrata è spesso considerata, per lo meno nei dibattiti politici di questo periodo, come un "quarto gruppo" che si affianca con meno diritti a quelli autoctoni. Viceversa, a seconda degli obiettivi perseguiti, la comunità (immaginata) dei cittadini stranieri è talvolta affiliata a una locale, di solito quella diversa dalla propria (cfr. anche Wisthaler 2011, Baur 2011).

Alla base di numerose delle prese di posizione citate si rileva un argomento di tipo "demografico" (cfr. Carlà 2015). L'immigrazione è infatti considerata, più o meno esplicitamente, come un fenomeno che altera gli equilibri (anche numerici) tra gruppi linguistici locali. Perciò questa è valutata negativamente. In provincia di Bolzano, lo speciale regime giuridico della proporzionale etnico-linguistica può contribuire - tra altri fattori validi anche in altre regioni plurilingui - al desiderio di mantenere invariati tali rapporti. Nello specifico, secondo una catena argomentativa abbastanza diffusa, la regolamentazione degli arrivi è una misura imprescindibile per salvaguardare i diritti specificamente della popolazione tedescofona (e ladinofona) in provincia di Bolzano. Il motivo è che i cittadini stranieri sono spesso rappresentati come persone che apprendono di norma l'italiano come prima lingua dopo il trasferimento e, quindi, che probabilmente si aggregheranno alla comunità italofona una volta ottenuta la cittadinanza (cfr. Carlà 2015: 73-81). Partendo da queste assunzioni (spesso non fondate su dati reali), i sostenitori delle posizioni più estreme paragonano, in questo contesto discorsivo, i flussi migratori alle politiche di italianizzazione e "inforestierimento" (Überfremdung) del ventennio fascista e categorizzano i cittadini stranieri come "nuovi italiani” (cfr. Wisthaler 2011: 258, Carlà 2015: 82).

Alle argomentazioni demografiche si affiancano poi tesi di tipo più strettamente "politico" o "di potere" (cfr. sempre Carla 2015). Secondo queste ultime, l'immigra- 
zione provoca contrasti tra (i membri del) le minoranze linguistiche autoctone o tra la provincia autonoma, da una parte, e lo stato italiano, dall'altra, in materia di competenze politico-amministrative. ${ }^{34}$ Esemplare a questo riguardo è la questione dell' istituzione o meno di un test di conoscenza della lingua tedesca da sostenere in alternativa alla prova di lingua italiana, divenuta obbligatoria nel 2010 per richiedere un permesso di soggiorno CE di lungo periodo (cfr. Carlà 2015: 75-76, Dal Negro 2015: 38-39). Da un lato, le riserve del governo nazionale sono motivate dal fatto che tale norma condizionerebbe eccessivamente lo spostamento di persone all'interno del territorio nazionale: infatti, coloro che deciderebbero di sostenere un test di lingua tedesca in Alto Adige non avrebbero poi i requisiti linguistici necessari per trasferirsi in altre regioni della penisola. Dall'altro, la rappresentanza altoatesina in parlamento sostiene che un test esclusivamente in italiano violi la parità linguistica, sancita con lo Statuto di Autonomia: conoscenze in italiano sono infatti le sole richieste ai cittadini stranieri per ottenere un permesso di soggiorno valido per la provincia di Bolzano. Il dibattito assume ulteriore rilevanza se si considera che tali esami - introdotti in molti paesi europei solo per i cittadini non comunitari - contribuiscono a rendere la lingua un marker di esclusione/inclusione, stabilendo un nesso tra competenze linguistiche e diritti politico-civili (cfr. Stevenson 2006). In seguito a questa discussione, la provincia di Bolzano organizza classi opzionali e un test non obbligatorio di lingua tedesca per migranti (cfr. Medda-Windischer 2011: 21-22, nota a piè di pagina 13). ${ }^{35}$

I dibattiti a livello politico e massmediatico appena delineati non esauriscono i modi di concettualizzare la presenza di persone mobili in Alto Adige. Dati raccolti in altri contesti e/o con altri metodi mostrano atteggiamenti sia analoghi sia diversi. In parziale corrispondenza con le prese di posizione istituzionali, la padronanza di almeno uno dei codici d'arrivo è valutata, per esempio, dagli informanti sia autoctoni sia alloctoni in ASTAT (2012) come un criterio fondamentale per ritenere qualcuno "integrato" in provincia di Bolzano. In particolare, le competenze linguistiche sono per gli stessi cittadini stranieri indici di inclusione più rilevanti di avere un lavoro, di stringere amicizie con i locali e/o di godere di uguali diritti agli altoatesini in tutti gli aspetti della vita (cfr. ASTAT 2012: 114-115 e 171-173). Inoltre, similmente a quanto discusso sopra, alcuni studenti di una scuola superiore altoatesina tendono a contrapporre, durante interviste focus group, i cittadini stranieri ("loro") ai membri di una comunità regionale unitaria ("noi"), che comprende - in modo non scontato - i gruppi sia italofono che tedescofono (cfr. Dal Negro 2009). Tuttavia, si riscontrano anche opinioni diverse da quelle "dominanti". Così, gli stessi compagni alloglotti sono talvolta anche inclusi dagli studenti locali, almeno durante

34 A questo riguardo, si ricordi che allo stato italiano spettano competenze esclusive in numerose questioni legate all'immigrazione, come il controllo dei flussi attraverso le quote, la regolamentazione dei requisiti di residenza o cittadinanza, il conferimento dello status di rifugiato. Tuttavia, le regioni e le province a statuto ordinario e speciale sono responsabili della pianificazione e del coordinamento di attività finalizzate all'inclusione sociale, culturale ed economica dei cittadini stranieri in diversi ambiti, ad esempio sanità, istruzione, alloggi, partecipazione alla vita pubblica (cfr. Medda-Windischer 2011: 21-23).

35 Si confronti anche 1'URL: <http://www.provincia.bz.it/news/it/news.asp?news_action=4\& news_article_id $=345175>(18.10 .2018)$. 
le interazioni, nell'immaginare una "comunità di discorso" multietnica e plurilingue (cfr. sempre Dal Negro 2009: 238-239). In aggiunta, la presenza di un elevato numero di alunni originari di paesi diversi sembra determinare una nuova nozione di "madrelingua" e un nuovo status dei dialetti locali tra gli studenti autoctoni e alloctoni di un altro istituto bolzanino. In questo micro-contesto, alle varietà non standard è attribuita una funzione simbolica più importante rispetto a quanto non avvenga in ambienti paragonabili per la situazione sociolinguistica storica, ma dissimili per l'incidenza di popolazione straniera (cfr. Dal Negro 2011 che confronta le risposte a questionari di studenti frequentanti diverse scuole bolzanine con quelle di ragazzi residenti in alcuni paesi del Piemonte).

Dalle ricerche discusse in questo paragrafo risulta dunque che il diversificarsi del plurilinguismo in seguito a processi migratori possa modificare lo status delle varietà linguistiche locali nei repertori di singoli, di gruppi o dell'intera comunità linguistica altoatesina. Inoltre può determinare una messa in discussione, almeno a livello discorsivo, delle identità linguistiche tradizionali e dei rapporti consolidati tra minoranze autoctone. D'altro canto, la popolazione straniera in provincia di Bolzano non sembra essere particolarmente avvantaggiata dal fatto di risiedere in un contesto istituzionalmente plurilingue e caratterizzato da un'alta consapevolezza metalinguistica. Spesso solo determinati tipi di bilinguismo, ovvero quello italiano/tedesco o italiano/inglese, sono infatti considerati come legittimi, mentre competenze in altri codici non sono altrettanto valorizzate nel mercato linguistico locale neanche dagli stessi cittadini stranieri che li parlano (cfr. Dal Negro 2011: 193 e LINEE 2010: 45).

\subsection{Attività di inclusione linguistica in provincia}

Nonostante il ritardo nella promulgazione di una legge provinciale sull'immigrazione e nonostante l'atteggiamento ambiguo, se non restrittivo, di alcuni partiti locali discusso nel paragrafo precedente, diverse fonti - tra cui il CNEL nel 2010 valutano il grado di integrazione delle persone straniere in provincia di Bolzano come tra i più alti in Italia (cfr. Medda-Windischer 2011: 25). ${ }^{36}$ Inoltre, un miglioramento almeno percepito della propria condizione si riscontra anche nel sondaggio ASTAT (2012: 136): da questo risulta infatti che gli informanti stranieri percepiscano un'attenzione maggiore, sebbene ancora insufficiente, da parte dei politici e della popolazione locale per i loro problemi nel 2012 rispetto a quanto registrato nel 2002. In questo paragrafo descrivo alcune iniziative finalizzate all" "inclusione" tra la popolazione immigrata e altoatesina, ossia finalizzate ad aumentare il senso di

36 L'indice di "integrazione potenziale" è stato misurato dal CNEL sulla base di dieci indicatori che sono solitamente considerati come alcuni dei fattori "obiettivi" per valutare l'inclusione sociale e occupazionale. Tra questi ci sono, per esempio, accessibilità del mercato degli alloggi e il tasso di occupazione. Tuttavia, il grado di integrazione in provincia di Bolzano (tra quello delle altre province nel Nord-Est Italia) scende dal $13^{\circ}$ al $40^{\circ}$ posto su 103 nel 2011. In questo anno, l'indice è calcolato tenendo conto di 12 fattori. Tra gli indicatori nuovi, c'è anche quello della "competenza linguistica". Questo ultimo indicatore si basa sulla percentuale dei test di lingua italiana superati sul totale di quelli effettuati (cfr. CNEL 2013: 1-19). 
appartenenza e accettazione dei cittadini stranieri nel mercato del lavoro e nella compagine sociale del paese di arrivo. Queste attività sono di volta in volta organizzate da organi provinciali e/o da associazioni private locali e/o da organizzazioni di cittadini stranieri. Nella rassegna, pongo particolare attenzione, da un lato, alle misure intraprese per favorire l'integrazione tramite l'acquisizione e/o il perfezionamento di competenze linguistiche. Dall'altro, mi concentro specificamente sulle attività rivolte alle persone provenienti dai paesi successori alla Jugoslavia e/o finalizzate a trasmettere conoscenze su queste aree ai cittadini autoctoni. Le informazioni sono ricavate sia dalla consultazione di testi scritti reperiti soprattutto online, sia dalla raccolta di materiale etnografico sul campo (es. volantini, fotografie), sia dalla conduzione di interviste con alcuni operatori delle istituzioni coinvolte. In particolare, ho intervistato tra la primavera del 2013 e del 2014:

- la referente dell'associazione culturale "Trait d'Union" di Merano;

- il direttore della Mediateca Multilingue di Merano;

- il vicepresidente della scuola di lingue e casa editrice "Alpha-Beta Piccadilly" (sede di Merano) e la direttrice della scuola di lingua AZB di Bolzano;

- una mediatrice interculturale per le lingue tedesco, italiano, bosniaco-croato-serbo e macedone presso il Centro Competenza della provincia di Bolzano;

- un'addetta al prestito libri della Biblioteca Civica di Bolzano;

- una mediatrice culturale e insegnante di lingua tedesca

- la presidente e l'ex-presidente di un'associazione kosovara con sede a Bolzano;

- la presidente di un'associazione serba con sede a Brunico;

- gli ex-presidenti di un'ex-associazione serba e di un'ex-associazione macedone con sede a Merano.

Le attività di apprendimento linguistico in contesti formali (formal language learning), come per esempio a scuola o in corsi di lingua strutturati, sono prevalentemente organizzate dal già menzionato Centro Competenza che ha sede nell'Area Innovazione e Consulenza della provincia di Bolzano. Questo centro - che coordina sette Centri Linguistici distribuiti sul territorio - si pone 1'obiettivo di creare "le condizioni per l'accesso con pari opportunità delle/dei bambine/i e adolescenti con background migratorio all'offerta formativa del territorio". ${ }^{37}$ Partendo dal presupposto che una padronanza nei codici d'arrivo sia indispensabile per l'inserimento nel contesto sociale e istituzionale altoatesino, tali organi attivano laboratori linguistici per incentivare le conoscenze di italiano e tedesco tra gli studenti alloglotti. I corsi - inseriti in modo flessibile in orario curricolare e/o extra-curricolare - sono pianificati sulla base dei bisogni rilevati dalle scuole. In aggiunta a ciò, i centri organizzano anche corsi di italiano o tedesco per i genitori e lezioni per il mantenimento della lingua prima per i ragazzi.

Inoltre, il Centro Competenza mette a disposizione - con l'aiuto dell'associazione "Porte Aperte" e della cooperativa sociale "Savera" - servizi di mediazione interculturale nelle scuole. Nel documento di attuazione della delibera provinciale, datato 2008, le lingue considerate come più bisognose di mediazione sono "alba-

37 Cfr. URL: <http://www.bildung.suedtirol.it/index.php/referate/migration/> (18.10.2018). 
nese, bosniaco, serbo-croato, urdu, arabo, russo e spagnolo". ${ }^{38}$ I mediatori accompagnano bambini o adolescenti neo-arrivati e le loro famiglie al momento di inserirsi nel sistema scolastico altoatesino. Inoltre, organizzano progetti di educazione interculturale che coinvolgono intere classi. Queste lezioni hanno lo scopo di favorire l'avvicinamento reciproco di studenti locali e stranieri. Tra i seminari tenuti recentemente sui Balcani, la mediatrice intervistata nomina "Le lingue dei vicini", "Balkan-Express" e una lezione di presentazione della scrittura cirillica. Quest'ultima aveva lo scopo di sensibilizzare gli studenti sulle difficoltà di chi deve (ri-) imparare un nuovo sistema di scrittura dopo l'arrivo in provincia di Bolzano.

La provincia sostiene anche iniziative di istituti privati nel campo dell'insegnamento formale delle lingue. Per esempio, le scuole Alpha-Beta Piccadilly, Palladio e AZB organizzano con il suo supporto corsi di alfabetizzazione o di lingua italiana e tedesca per i cittadini stranieri. Le lezioni sono gratuite o di costo relativamente basso (30 euro). I corsi di livello A1 o A2 si tengono normalmente a Bolzano, Bressanone, Merano e Brunico, ma è prevista la possibilità di seguire lezioni in altre località qualora si iscrivano almeno otto studenti. Secondo la referente dell'organizzazione Trait d'Union di Merano, i partecipanti ai loro corsi di tedesco sono di solito meno numerosi di quelli alle lezioni di italiano. Inoltre, gli apprendenti di tedesco conoscono spesso già l'italiano, mentre è raro il contrario (cfr. però più avanti in questo paragrafo). Dal momento che la frequentazione di classi miste può costituire un problema, l'associazione culturale offre dal 2013 lezioni di lingua anche per sole donne. ${ }^{39}$

Nel programma della scuola AZB di Bolzano sono previsti anche "corsi di mantenimento della lingua madre" per bambini e ragazzi stranieri. Tra le lingue disponibili c'è anche "Serbo Croato" (cfr. foto 1 più avanti in questo paragrafo). La direttrice della scuola mi informa tuttavia che, ad eccezione di qualche classe di arabo, le lezioni per il consolidamento delle lingue prime hanno saltuariamente luogo. Le iscrizioni non raggiungono infatti il numero minimo di otto. In particolare, persone originarie dalla Serbia o dalla Croazia preferiscono, secondo la direttrice, concentrarsi sull'apprendimento di tedesco e/o italiano piuttosto che frequentare corsi di mantenimento dei codici d'origine probabilmente perché percepiscono un atteggiamento non del tutto positivo della popolazione locale verso tali lingue e i loro parlanti.

In alternativa alle lezioni in classe, alcune istituzioni promuovono attività per l'acquisizione linguistica in contesti non formali (non-formal language learning), vale a dire tramite attività che gli apprendenti intraprendono regolarmente, tra l'altro, con lo scopo di migliorare le proprie competenze linguistiche, ma che non sono governate da programmi di insegnamento rigidi né sono finalizzate all'acquisizione di certificati linguistici, spendibili per esempio nel mondo del lavoro. ${ }^{40}$ La mediateca di Merano e il centro multilingue di Bolzano coordinano, per esempio, il pro-

38 Cfr. il testo all'URL: <http://www.bildung.suedtirol.it/files/8613/7639/4134/Umsetzungskon zeptMai08.pdf $>$, pag. 12 (18.10.2018).

39 Cfr. URL: <http://traitdunion.oneminutesite.it/index.html $>$ (18.10.2018).

40 Sulla distinzione tra contesti e/o modalità di apprendimento linguistico "formali", "non formali" e "informali" si confronti la pagina del progetto "Linguistic Integration of Adult Migrants" del Consiglio d'Europa all'URL: <https://www.coe.int/en/web/lang-migrants/formalnon-formal-and-informal-learning $>$ (18.10.2018). 
getto di volontariato per le lingue "Parla con me ...". ${ }^{41}$ Gli operatori mettono in contatto cittadini stranieri che desiderano apprendere l'italiano o il tedesco con volontari che si impegnano a trasmetterli in almeno dieci ore di conversazione spontanea. Inoltre la mediateca, il centro giovani Papperlapapp e la scuola Alpha-Beta Piccadilly organizzano due volte al mese un caffè delle lingue o Sprachlounge a Merano e Bolzano. ${ }^{42}$ A diversi tavoli si parlano lingue differenti, tra cui tedesco, italiano, spagnolo, francese, portoghese e russo. Sebbene solo il primo progetto sia indirizzato specificamente ai cittadini stranieri, entrambe le iniziative offrono potenzialmente ai nuovi residenti occasioni per praticare i codici di arrivo.

Alcune biblioteche pubbliche mettono inoltre a disposizione materiali per 1" "apprendimento autonomo" (self-regulated learning) di italiano, tedesco e di alcune lingue "immigrate". Tra queste c'è la già menzionata mediateca multilingue di Merano. Secondo il suo direttore, la biblioteca coopera con l'ufficio di collocamento, situato nello stesso edificio. Le persone straniere in cerca di lavoro sono infatti informate della presenza di testi e materiali audio per lo studio dei codici d'arrivo al piano inferiore. La biblioteca civica di Bolzano ha invece istituito una sezione dal nome "Multi-Kulti". In questo reparto sono raccolti, tra l'altro, dizionari, guide culturali su singoli paesi, libri bilingui per bambini e romanzi nelle lingue dei nuovi residenti. Nel catalogo della biblioteca è possibile effettuare una ricerca delle pubblicazioni in "serbo-croato" e "albanese". Secondo un'addetta al prestito libri, la sezione "Multi-Kulti" è indirizzata sia a utenti stranieri sia altoatesini che desiderano conoscere di più riguardo alle rispettive lingue e culture. Gli utenti richiedono materiali in numerose lingue. In particolare, la bibliotecaria afferma che a domandare libri in lingue straniere sono soprattutto donne, mentre $\mathrm{i}$ bambini e i ragazzi si interessano di più per i materiali nei codici d'arrivo. L'emeroteca, situata al piano superiore, è abbonata tra gli altri a un giornale russo, a uno rumeno e al giornale degli albanesi in Italia.

All'ingresso delle biblioteche di Merano e Bolzano si trovano numerosi volantini informativi su corsi di lingua o altre iniziative di inclusione, organizzate dalla provincia, che non concernono solo l'apprendimento linguistico. Così, aderendo a un progetto nazionale, il museo archeologico dell'Alto Adige ha proposto, per esempio, una serie di visite guidate gratuite nelle quattro lingue straniere (o "aree linguistiche") più rappresentate sul territorio. Significativamente queste sono i) l'albanese, ii) l'urdu e hindi, iii) l'arabo e iv) il "bosniaco" e "serbo-croato". ${ }^{43}$ La guida della mediateca di Merano è inoltre tradotta in molte lingue straniere, tra cui, per esempio, in albanese e "serbo" (cfr. foto 2). In aggiunta, sebbene per il progetto "Bookstart" siano regalati ai nuovi nati pacchetti di libri solo in italiano e in tedesco, l'uso di codici diversi per pubblicizzare l'iniziativa ha l'obiettivo, secondo la bibliotecaria

41 Cfr. URL: < http://www.provincia.bz.it/formazione-lingue/lingue/volontariato-linguistico.asp> (18.10.2018).

42 Cfr. URL: < http://www.alphabeta.it/caffe_delle_lingue.html> (18.10.2018).

43 Per maggiori dettagli su questa e su altre iniziative culturali promosse dalla provincia per l'integrazione tra cittadini autoctoni e alloctoni si confronti il documento all'URL: <http://www. provincia.bz.it/cultura/download/BP_raccolta_risultati.pdf> (18.10.2018). 
intervistata, di avvicinare gli utenti stranieri al servizio (cfr. foto 3). Probabilmente per le stesse ragioni, sul logo della biblioteca civica di Bolzano sono riportati i nomi di alcune lingue di migranti, tra cui albanese e "serbocroato" (cfr. foto 4). L'addetta al prestito libri afferma che i glottonimi stampati sul marchio sono stati scelti consultando $\mathrm{i}$ dati ASTAT sulle nazionalità più numerose in provincia di Bolzano.

SERBO CROATO
AZB
- Corsi standard - corso - Bolzano, Bressanone, Brunico, Merano
- Corsi per viaggiare - corso - Bolzano, Bressanone, Brunico, Meranc
- Conversazione - corso - Bolzano, Bressanone, Brunico, Merano
- Corsi individuali - corso - Bolzano, Bressanone, Brunico, Merano

Foto 1: Corsi di "serbo croato" offerti dalla scuola AZB di Bolzano (foto della ricercatrice).

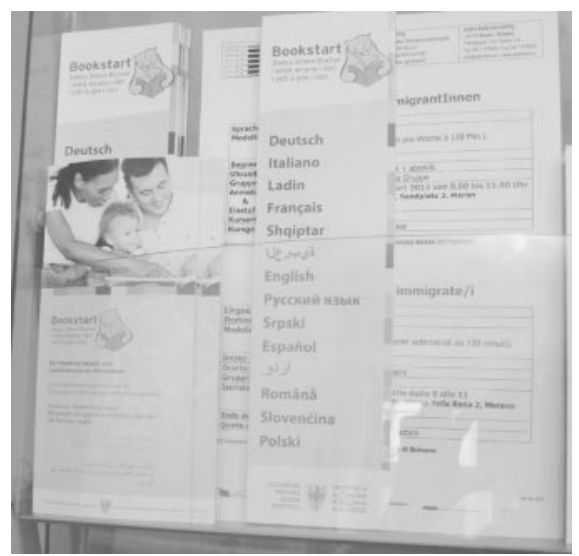

Foto 3: Volantino del progetto Bookstart all'ingresso della mediateca multilingue di Merano. Tra le lingue citate ci sono "Srpski" (serbo) e "Shqiptar" (lingua albanese [sostantivo]) (foto della ricercatrice).

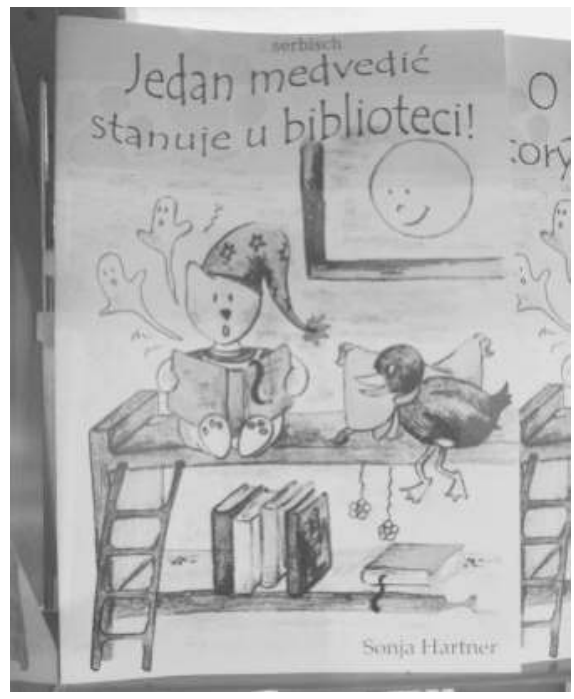

Foto 2: Guida della mediateca multilingue di Merano in "Serbisch" (serbo) (foto della ricercatrice).

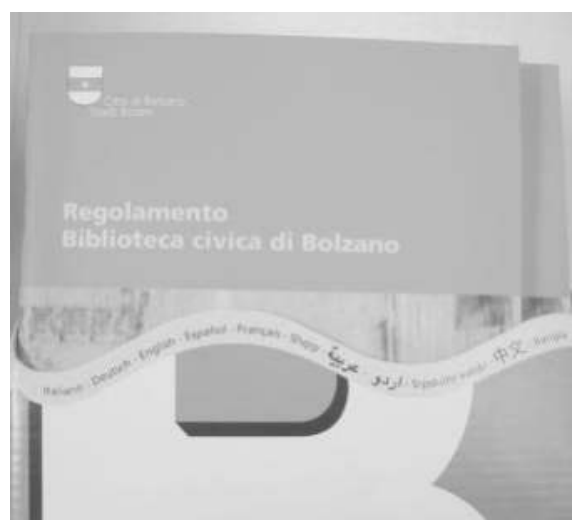

Foto 4: Logo della biblioteca civica di Bolzano. Tra le lingue citate ci sono "Srpskohrvatski" (serbocroato) e "Shqip" (albanese [aggettivo]) (foto della ricercatrice). 
Le iniziative appena discusse mostrano che le istituzioni locali (e, possibilmente, studenti, utenti della biblioteca, etc.) siano consapevoli della presenza di cittadini provenienti dai paesi successori alla Jugoslavia in Alto Adige. Tale percezione è documentata in parte anche da testi/scritte rintracciabili nel paesaggio linguistico altoatesino (cfr. le foto qui riportate). Tuttavia, si noti che le "tracce di uso linguistico esibito", rinvenibili nelle immagini 2,3 e 4 , non sono state direttamente prodotte da parlanti delle comunità immigrate coinvolte, ma da istituzioni della società d'arrivo. Così, non sono necessariamente indicative della vitalità delle lingue in questione nel contesto locale (cfr. Barni 2008: 193-194 sull'importanza di individuare 1'“autore" di testi/scritte in lingue straniere per lo studio del linguistic landscape). Considerata la storia recente delle varietà linguistiche parlate nei Balcani occidentali, non sorprende inoltre che dalle immagini (e dalla discussione appena condotta) si rilevi una variazione e, quindi, una certa incertezza nei glottonimi usati per nominarle.

Oltre ad istituzioni e organizzazioni locali, anche alcune associazioni di cittadini stranieri in Alto Adige sono impegnate, più o meno attivamente, nel promuovere attività per l'apprendimento dei codici d'arrivo e il mantenimento di quelli d'origine. Tali obiettivi sono perseguiti sia stimolando l'utilizzo di queste lingue in occasioni informali, sia organizzando corsi di lingua auto-gestiti. A questo riguardo, la lingua di comunicazione alle riunioni dell'associazione "Kosova" è esclusivamente l'albanese. Secondo alcuni partecipanti, gli incontri hanno infatti, tra l'altro, lo scopo di incoraggiare l'uso di tale codice tra i giovani. Anche i membri dell'associazione "Tamo Daleko" di Brunico - di nazionalità prevalentemente serba, ma anche montenegrina - parlano tra loro quasi esclusivamente nella lingua d'origine. Inoltre, durante le riunioni, i parlanti più esperti tengono lezioni informali di lingua tedesca per quelli meno esperti. Infine, l'associazione serba di Merano proponeva, secondo il suo ex-presidente, corsi di apprendimento di italiano e tedesco per adulti e di consolidamento della "lingua materna" per bambini. Tuttavia, l'intervistato afferma che l'organizzazione ha chiuso dopo soli due anni e mezzo di attività, proprio per mancanza di interesse e poca partecipazione da parte dei potenziali studenti.

Un'ultima questione riguarda se e come le persone straniere vengano a conoscenza delle attività di apprendimento linguistico organizzate sul territorio e quale sia il livello e/o il desiderio di partecipazione registrato. La maggioranza dei partecipanti all'inchiesta di Medda-Windischer et al. (2011: 45) è informata sull'offerta di corsi di lingua della provincia. Tuttavia, risultano più conosciute le iniziative a pagamento di quelle gratuite. Inoltre, secondo Lupoli (2009), il passaparola tra conoscenti è il maggiore canale di informazione sulle iniziative formative promosse istituzionalmente. Meno di un quinto degli intervistati ha infatti appreso dell'esistenza di un corso tramite materiale cartaceo. D'altra parte, secondo il sondaggio ASTAT (2012: 67-70), numerosi informanti, che vogliono migliorare la propria qualifica professionale $(61,8 \%$ del totale), desiderano portare a termine questo obiettivo iscrivendosi a un corso di lingua tedesca e/o italiana. In aggiunta, gli intervistati che, al momento dell'inchiesta, hanno già seguito un'attività formativa hanno scelto in prevalenza proprio un corso dedicato all'apprendimento dei codici d'arrivo (cfr. per risultati simili anche Lupoli 2009: 130-137). Tuttavia, dal con- 
fronto tra $\mathrm{i}$ due studi appena citati non è possibile trarre osservazioni univoche su quale sia la lingua più studiata e/o inizialmente appresa dai cittadini stranieri in provincia di Bolzano. In particolare, dal sondaggio ASTAT (2012) sembra che i corsi di italiano siano scelti per primi dopo l'arrivo in Alto Adige: solo in un secondo momento, gli informanti, soprattutto "extracomunitari", decidono infatti eventualmente di seguire anche un corso di tedesco. All'opposto, gli studenti di tedesco in Lupoli (2009) sono leggermente più numerosi di quelli di italiano. Una tale differenza nei risultati delle due inchieste potrebbe dipendere, tra l'altro, dal modo di campionamento utilizzato: la prima ha selezionato i partecipanti per estrazione casuale, mentre la seconda per centri di ritrovo.

Infine, se gli informanti di Lupoli (2009) concordano nel giudicare lezioni nelle lingue locali importanti, ${ }^{44}$ i giudizi sull'utilità di corsi per il mantenimento dei codici d'origine sono meno omogenei. Infatti, un quarto dei partecipanti li stima poco o per nulla rilevanti. Ciò è vero anche se i partecipanti condividono l'opinione che sia importante che i bambini imparino le lingue dei genitori. Secondo il ricercatore, il motivo di questa apparente contraddizione potrebbe dipendere dalla durata relativamente breve dell'esperienza di mobilità delle persone intervistate: in conseguenza di ciò, i partecipanti sono infatti confrontati con la questione del mantenimento dei codici di provenienza solo indirettamente.

\subsection{Tipi di percorsi migratori}

I dati e la discussione condotta nei paragrafi precedenti permettono di individuare alcuni tratti peculiari del fenomeno "immigrazione" in Alto Adige così come di delineare alcuni tipi di percorsi migratori, probabilmente seguiti dalle persone intervistate per la presente ricerca. Tali (gruppi di) esperienze hanno possibili ricadute anche a livello linguistico.

In primo luogo, i cittadini ex-jugoslavi in Alto Adige si sono trasferiti da paesi "non comunitari" in uno stato membro dell'Unione Europea. Perciò, la maggior parte di loro - ad eccezione recentemente di croati e sloveni - necessita di un permesso di soggiorno per abitare e lavorare in Italia per un periodo superiore ai 90 giorni. Inoltre, le persone originarie dalla ex-Jugoslavia devono risiedere regolarmente sul territorio nazionale da almeno dieci anni (contro i quattro necessari ai cittadini comunitari) per fare domanda di cittadinanza. Tuttavia, alcuni partecipanti sono arrivati in Alto Adige come rifugiati negli anni novanta. Questi ultimi hanno quindi seguito procedure diverse per regolarizzare la propria posizione. In aggiunta, si ricordi che i cittadini non comunitari devono sottostare a specifici requisiti anche da un punto di vista linguistico per abitare in Italia: come già menzionato nei paragrafi precedenti, dal 2010 è infatti necessario superare un test di conoscenza della

44 È interessante notare che, discutendo le risposte a questa domanda, Lupoli (2009: 135) chiami i codici d'arrivo "italiano" e "sudtirolese", mentre, nel questionario in appendice al libro, le due varietà linguistiche sono rispettivamente denominate "italiano" e "tedesco" (ibidem: 163). Tale discrepanza non è ulteriormente commentata dal ricercatore. 
lingua italiana di livello A2 per ottenere un permesso di soggiorno CE per soggiornanti di lungo periodo (cfr. ASTAT 2012: 199). ${ }^{45}$ Dal momento che il test di tedesco non è obbligatorio, tale norma potrebbe costituire un incentivo - e spesso è vista come tale da gruppi politici e di opinione pubblica locale - per l'apprendimento dell'italiano come prima lingua dopo l'arrivo in Alto Adige. Tuttavia, da un lato, essendo tale regolamentazione abbastanza recente al momento della raccolta dati, questa non ha necessariamente influenzato le scelte linguistiche della maggior parte degli informanti trasferitesi prima del 2010. Dall'altro lato, il livello linguistico richiesto dal test non impedisce un'acquisizione parallela e, eventualmente, più intensiva del tedesco.

In secondo luogo, i motivi di emigrazione dai paesi d'origine per i cittadini ex-jugoslavi sono molteplici. In alcuni casi, individui singoli o più spesso gruppi familiari si sono trasferiti all'estero a causa della guerra. Attualmente, i flussi migratori sono invece principalmente causati da difficoltà economiche, come dalla disoccupazione nelle regioni di provenienza. Parzialmente diversa da quelle appena tratteggiate, sono inoltre le esperienze di mobilità e di apprendimento linguistico di chi è arrivato in provincia di Bolzano da bambino o da adolescente insieme ai genitori o anche di chi si è ricongiunto con membri della famiglia, già residenti in Alto Adige. Infine, l'emigrazione da queste aree può essere anche motivata da ragioni di studio o dall'ottenimento di un posto di lavoro qualificato e/o desiderato. Gli atteggiamenti verso il mantenimento dei codici d'origine e la disponibilità a imparare uno o più codici d'arrivo - o alternativamente ad usare per esempio l'inglese come lingua franca - possono variare tra i partecipanti anche in relazione ai motivi di emigrazione in provincia di Bolzano (cfr. § III.1 e seguenti per maggiori dettagli).

In terzo luogo, ad eccezione delle persone arrivate per motivi di studio, i cittadini ex-jugoslavi risiedono di solito stabilmente e hanno un progetto migratorio di lunga durata in provincia di Bolzano. Tuttavia, singoli individui o nuclei familiari hanno talvolta seguito traiettorie migratorie piuttosto complesse. Alcuni intervistati hanno infatti abitato in località della (ex-)Jugoslavia diverse da quella di nascita e/o in altre regioni italiane e/o in altri paesi stranieri - spesso di lingua tedesca - prima di giungere in Alto Adige. Inoltre, soprattutto gli informanti più giovani, hanno in alcuni casi usufruito di programmi di scambio per studiare o lavorare all'estero e/o desiderano trasferirsi più o meno durevolmente in altri luoghi. Anche tali esperienze e progetti hanno sicuramente un influsso sulle lingue conosciute e desiderate dagli intervistati.

Infine, i viaggi di ritorno nei paesi d'origine per i cittadini dalla ex-Jugoslavia non sono impediti da una eccessiva distanza geografica e, dopo il concludersi dei conflitti, possono avvenire anche di frequente (cfr. Lainati \& Saltarelli 2007: 37). Perciò non sono da escludere fenomeni di mobilità stagionale - in generale piuttosto diffusi in Alto Adige (cfr. Medda-Windischer \& Girardi 2011: 98-99) - o flussi pendolari, ossia caratterizzati da spostamenti molto frequenti tra due o più paesi. Sia per via della vicinanza geografica, sia per via delle nuove tecnologie, alcuni

45 Cfr. anche l'URL: <http://www.provincia.bz.it/intendenza-scolastica/studenti/Certificazioni Stranieri.asp $>(18.10 .2018)$. 
partecipanti hanno quindi contatti piuttosto regolari con parenti o conoscenti residenti nelle regioni di partenza o in altri paesi stranieri. Durante questi scambi, gli intervistati continuano a parlare, più o meno frequentemente, le loro lingue di origine.

\section{LA SITUAZIONE SOCIOLINGUISTICA DI PARTENZA}

La scelta di concentrarsi sull'analisi delle biografie linguistiche di cittadini stranieri provenienti dalle regioni della ex-Jugoslavia non dipende solo dalla loro presenza numerosa e dal lungo periodo di residenza in Alto Adige, ma anche da considerazioni di tipo sociolinguistico. Le persone intervistate per la presente ricerca provengono da aree dove il plurilinguismo sociale e talvolta individuale è diffuso. Come accennato nel capitolo I, fattori sociolinguistici "pre-migratori" - come standardizzazione e status delle lingue d'origine - possono avere un influsso sugli usi linguistici dopo mobilità in un paese straniero (cfr. Clyne 2006, 2007, Busch 2006). Inoltre, per i cittadini provenienti da queste regioni, il mantenimento dei codici di partenza è probabilmente ostacolato non solo da una riduzione dei loro ambiti d'uso, ma anche da una perdita (o da un indebolimento) dei punti di riferimento linguistico-normativi, dovuta ai conflitti anche linguistici nei paesi di provenienza. Interviste con persone, le cui lingue sono diventate recentemente oggetto di numerosi interventi di pianificazione linguistica e discorsi metalinguistici, permette di comprendere meglio quali effetti politiche e rappresentazioni collettive hanno sui modi di rappresentare i rapporti tra codici da parte dei singoli.

Questa terza sezione del capitolo II è strutturata come segue. Ai § II.3.1, II.3.2 e II.3.3 descrivo lo spazio sociolinguistico slavo meridionale e l'allocazione dei codici che fanno parte dei repertori d'origine degli intervistati. I $\S$ II.3.4 e seguenti sono dedicati a una breve storia degli interventi di pianificazione linguistica volti alla codificazione degli standard successivi al serbocroato così come di macedone e albanese. Infine, nei §II.3.5 e successivi delineo le controversie sui glottonimi e sulle apposizioni per le varietà linguistiche a base neoštokava.

\subsection{Lo spazio linguistico slavo meridionale}

Le lingue slave meridionali si suddividono in varietà orientali e occidentali. Secondo Ethnologue, il primo gruppo comprende il macedone, il bulgaro e l'antico slavo ecclesiastico (lingua estinta che sopravvive solo in testi liturgici). Invece fanno parte della seconda schiera il croato-molisano (parlato in Molise), lo sloveno, il croato, il bosniaco, il serbo e attualmente anche il montenegrino. ${ }^{46}$ Sebbene ne indicassero lo status di "lingua nazionale" (national language) nella Repubblica di Montenegro, i ricercatori di Ethnologue consideravano invece, nel periodo in cui 
questa ricerca è stata condotta (ossia almeno fino al 2016), "montenegrino" un glottonimo alternativo di serbo. Perciò, non menzionavano tale codice nel novero delle lingue slave meridionali né gli attribuivano un codice ISO separato. ${ }^{47}$ Infine, il "serbocroato" ( $h b s)$ è definito una "macro-lingua" (macrolanguage) della Serbia che include bosniaco, croato e serbo. ${ }^{48}$

Le varietà linguistiche slavo meridionali sono parlate nella penisola balcanica dalle Alpi Giulie a nord-ovest fino al golfo di Salonicco (Tessalonica) a sud e alle coste del Mar Nero a est (cfr. Alexander 2000: 4, citata da Bugarski 2012: 223). Queste sono tradizionalmente descritte come formanti un continuum dialettale, la cui segmentazione in lingue diverse varia nel tempo in relazione a fattori extra-linguistici (cfr. Kordić 2004: 39, Busch \& Schick 2007: 217, Bugarski 2004: 23-24). Appena prima della seconda guerra mondiale, il numero dei codici riconosciuti nello spazio linguistico slavo meridionale ammonta per esempio a tre: lo sloveno, il serbocroato e il bulgaro. Dal 1944 a questi si aggiunge il macedone. La sua proclamazione a lingua distinta è piuttosto controversa (cfr. § II.3.4.5). Infatti, un fascio di isoglosse significante corre al confine tra Serbia e Bulgaria cosicché le varietà linguistiche di queste due zone sono tradizionalmente considerate distinte. Tuttavia, il passaggio da serbo a bulgaro avviene gradualmente a sud attraverso il territorio corrispondente all'odierna Repubblica di Macedonia (cfr. Irvine \& Gal 2000: 68, nota a piè di pagina 25 ).

Tre sono i gruppi dialettali principali o "macro-dialetti" (cfr. Bugarski 2012) parlati nella regione centrale, ossia nel territorio che attualmente corrisponde all'incirca a quello di Croazia, Bosnia-Erzegovina, Serbia e Montenegro. Il loro nome deriva dal modo di esprimere il pronome interrogativo non animato "che (cosa)", ovvero i) "ča" in čakavo, ii) "kaj" in kajkavo e iii) "što" in štokavo (cfr. Manzelli 2012: 394-395 su cui mi baso anche per le traslitterazioni delle denominazioni in italiano). A questi macro-dialetti si aggiunge il dialetto torlaceo o torlacco (torlačko), parlato nella Serbia meridionale e nelle regioni confinanti della Macedonia, Bulgaria e Romania. Dal punto di vista linguistico, un'ulteriore distinzione si intreccia con quella appena delineata. Le varietà štokave e čakave si suddividono infatti in dialetti jekavi (ijekavi), ekavi e ikavi a seconda dell'esito dello jat protoslavo, ad esempio in "mlijeko", "mleko" e "mliko", tr. latte (cfr. Manzelli 2012: 395). Inoltre, nella regione sono storicamente adoperati diversi sistemi di scrittura. Tra questi, gli alfabeti cirillico e latino - con l'aggiunta rispettivamente di alcuni grafemi speciali e di segni diacritici particolari - sono attualmente i più diffusi (cfr. Greenberg 2004/2008: 41-44 anche per maggiori dettagli sulle controversie ortografiche nell'area).

La distribuzione delle varietà linguistiche appena menzionate non è uniforme sul territorio (cfr. anche Dell'Aquila \& Iannàccaro 2004: 102, Voß 2007: 196 e

47 Attualmente, invece, il montenegrino ha ricevuto il codice ISO 639-3 "cnr" ed è stato inserito nell'elenco delle lingue slavo-meridionali sul sito di Ethnologue. Inoltre, tra i nomi alternativi del codice, è ora indicato il "serbocroato" (cfr. $<$ https://www.ethnologue.com/language/cnr $>$ (18.10.2018)).

48 Cfr. URL: $<$ http://www.ethnologue.com/language/hbs $>$ (18.10.2018). 
sgg.). I dialetti čakavo e il kajkavo sono infatti parlati rispettivamente sulla costa adriatica e nell'entroterra croato, per esempio, a Zagabria. Invece le varietà neoštokave - ossia caratterizzate da una ritrazione dell'accento tonale di una sillaba rispetto all'antico štokavo - hanno una maggiore diffusione nell'area slavo meridionale centrale. Questo è avvenuto sia a causa di migrazioni interne, per esempio, durante l'avanzata dell'impero ottomano, sia in conseguenza del supporto ad esse dato da interventi di politica linguistica. Per motivi in parte simili, i dialetti jekavi e ekavi sono parlati da un numero maggiore di persone rispetto a quelli ikavi.

Già 1'Accordo Letterario di Vienna del 1850 stabilisce infatti le varietà neoštokave come base per la lingua letteraria unitaria a discapito degli altri due macro-dialetti. La proposta è conforme a quanto auspicato nei decenni precedenti, oltre che dal linguista serbo Vuk Karadžič, anche dai principali esponenti del movimento illirico croato, tra cui Ljudevit Gaj. Il loro obiettivo era quello di promuovere l'unificazione linguistica e politica della popolazione slavo meridionale (cfr. Greenberg 2004/2008: 24-29, Kordić 2004). La decisione di privilegiare le varietà neoštokave è confermata anche dal successivo accordo di Novi Sad del 1954. Nel trattato - risultato di un incontro tra linguisti jugoslavi e ufficialmente non vincolante - si distingue ulteriormente tra due centri di diffusione dell'"unica" lingua scritta, condivisa da Serbi, Croati, Montenegrini. Questi sono Zagabria e Belgrado (cfr. Gröschel 2009: 23-24). Inoltre si riconoscono due "pronunce" (izgovora) ufficiali, la jekava e la ekava, e si sancisce uno status paritario degli alfabeti cirillico e latino. Le due varietà della lingua letteraria sono solitamente chiamate "varianti" (varijante) occidentale ed orientale, mentre le due pronunce sono proprie della seconda, ma non della prima varietà. La varietà occidentale è infatti solo jekava (cfr. Greenberg 2004/2008: 39-41).

Alcuni cambiamenti terminologici sono introdotti in seguito con la costituzione del 1974. La carta riconosce infatti quattro "idiomi" (izraz) standard regionali della lingua letteraria comune. Questi sono i) l'idioma standard croato, ii) l'idioma standard montenegrino, iii) l'idioma standard di Bosnia-Erzegovina e iv) la variante standard orientale con pronuncia ekava e jekava. Attualmente, i quattro codici successivi al serbocroato si basano tutti su una varietà neoštokava. Lo jekavo è parimenti il fulcro di bosniaco, croato e montenegrino, mentre in serbo è ufficiale anche la varietà ekava (cfr. anche Dell'Aquila \& Iannàccaro 2004: 100-103, Burgarski 2012).

\subsection{Plurilinguismo dei repertori d'origine}

Il concetto di continuum dialettale rende conto solo di una parte della situazione sociolinguistica della regione. Infatti nell'area sono storicamente presenti numerosi altri idiomi oltre a quelli slavo meridionali. Questi sono stati usati in periodi differenti, tra l'altro, come lingue dell'amministrazione, della liturgia, della letteratura e/o del commercio e detengono diverso potere strumentale e simbolico a seconda di sotto-comunità linguistiche più o meno estese (cfr. Neweklowsky 1997, Irvine \& Gal 2000, Voß 2007: 200). 
Considerando solo le regolamentazioni di politica linguistica recenti, nella Repubblica Socialista Federale di Jugoslavia (SFRJ), tre sono le lingue nazionali in cui si svolge la comunicazione con le istituzioni federali. Queste sono i) sloveno, ii) macedone e iii) serbocroato o croatoserbo (cfr. Bugarski 1990). Questi codici sono parlati come prima lingua da una o da più di una delle cinque "nazionalità" (narod) titolari delle sei repubbliche confederate, ovvero slovena, macedone, serba, croata, montenegrina e - secondo la terminologia introdotta a partire dal 1968 - anche musulmana. Inoltre, altri nove codici sono tutelati dal governo in quanto lingue di "minoranze nazionali" (narodnosti) riconosciute. Questi sono l'albanese, il magiaro/ ungherese, il bulgaro, il ceco, l'italiano, il rumeno, il ruteno, l'ucraino e il turco (cfr. Veiter 1983 anche per una caratterizzazione di queste varietà linguistiche e del loro status in SFRJ al momento della pubblicazione del suo articolo). In quanto parlati dalle minoranze linguistiche più numerose, albanese e ungherese sono talvolta impiegati anche per compilare atti a livello federale (cfr. Bugarski 2012: 226).

Le minoranze nazionali - che costituiscono secondo alcuni ricercatori circa un quarto della popolazione totale in SFRJ (cfr. Dell'Aquila \& Iannàccaro 2004: 100103) - sono variamente distribuite sul territorio e non dispongono di un'unità amministrativa di riferimento. Fanno eccezione le comunità albanofone, da un lato, e quelle ungheresi, rumene, slovacche e rutene, dall'altro. Queste abitano rispettivamente la provincia autonoma del Kosovo e quella di Voivodína, situata nel nord della Serbia. ${ }^{49}$ Ai parlanti delle lingue minoritarie sono riconosciuti in SFRJ diritti linguistici di tipo "personale" nell'educazione e "territoriale" nell'amministrazione (cfr. Dell'Aquila \& Iannàccaro 2004: 101). Se vivono in percentuale rilevante in un comune, è infatti garantita loro la possibilità di frequentare classi di insegnamento nella prima lingua ed eventualmente di utilizzare quest'ultima come varietà co-ufficiale a livello locale. Inoltre, sono previsti - almeno a livello ufficiale - finanziamenti pubblici per pubblicare giornali e trasmettere programmi televisivi nei codici in questione.

In aggiunta, sul territorio sono presenti anche varietà linguistiche non tutelate ufficialmente dal governo di SFRJ. Tra queste ci sono, per esempio, il tedesco, il romaní, l'istrioto, il veneziano coloniale, l'istrorumeno e l'arumeno (cfr. Veiter 1983, Manzelli 2012: 374). In particolare, tedescofoni, originari in prevalenza dalla Svevia, si stanziano dal 1722 soprattutto in Voivodína e Slavonia (cfr. Neweklowsky 1997: 1413-1414). Inoltre il tedesco costituisce varietà in $\mathrm{H}$ - insieme all'ungherese e precedentemente al latino - in Croazia all'epoca dell'impero austro-ungarico (cfr. Voß 2007: 200). Invece, parlanti di varietà italo-romanze risiedono in prevalenza nella penisola istriana in Croazia e Slovenia (cfr. Franceschini 2014). Nessuna delle persone intervistate per la presente ricerca parla(va) varietà di italiano e/o di tedesco in famiglia nel paese d'origine. Tuttavia, alcuni informanti comunicavano in certi domini in varietà non tutelate nel paese d'origine e/o con uno status molto basso (cfr. anche $\S$ II.3.3).

49 Il grado di autonomia di queste province varia durante gli anni della federazione e raggiunge il suo apice dopo la costituzione del 1974 (cfr. Neweklowsky 1997: 1408). Le lingue citate non sono le sole parlate in Voivodína. 
In conclusione, si consideri che, dagli anni settanta, i cittadini provenienti dai paesi della (ex-)Jugoslavia apprendono almeno due lingue straniere a scuola, rispettivamente a partire dalle classi corrispondenti alla terza e quinta elementare in avanti. A parte che per la possibilità di studiarle in contesti formali, l'acquisizione delle lingue straniere è inoltre agevolata dalla trasmissione di film e programmi televisivi in lingua originale alla televisione e nelle sale cinematografiche. Secondo Vučo (2003: 383-388), dopo la seconda guerra mondiale, gli alunni jugoslavi studiano prevalentemente il russo e, secondariamente, il tedesco e il francese come lingue straniere. Invece, negli anni sessanta e settanta aumentano le classi di insegnamento dell'inglese. Recentemente, si registra - specificamente in Serbia e in Montenegro - un incremento nell'interesse per il greco moderno, per lo spagnolo (a causa del successo di alcune telenovelas) e soprattutto per l'italiano. Lezioni di italiano, oltre che di tedesco, sono così disponibili in numerose scuole montenegrine e serbe, rispettivamente a partire dall'anno scolastico 1992-1993 e 2001-2002. In aggiunta, da un'inchiesta del 2003 risulta che studenti e adulti, formati per esempio come infermieri e ingegneri elettronici, si dedichino frequentemente allo studio dell'italiano in conseguenza della buona probabilità di trovare un'occupazione in Italia (cfr. Vučo 2003: 385-386). L'apprendimento di questo codice è infine favorito dal fatto che in Montenegro, soprattutto sulla costa, si riceva il segnale di emittenti radiofoniche e televisive italiane (cfr. ibidem: 387 ). Anche alcuni dei partecipanti alla presente ricerca hanno studiato italiano e/o tedesco prima di trasferirsi in Alto Adige.

\subsection{Lo status dei codici nei paesi di partenza}

Sebbene la costituzione del 1974 sancisse l'uguaglianza formale tra tutte le lingue, il loro status non è paritario in SFRJ né dal punto di vista funzionale né simbolico. Nello specifico, il serbocroato detiene un potere comunicativo e, talvolta, un prestigio maggiore non solo rispetto alle lingue non tutelate e a quelle minoritarie, ma anche alle altre lingue nazionali, ossia sloveno e macedone (cfr. Bugarski 1990, 2012: 226). Questo è infatti il codice di comunicazione dell'esercito federale e la principale lingua della diplomazia. Inoltre, costituisce solitamente la lingua franca tra i parlanti di varietà linguistiche di minoranza non mutualmente comprensibili (cfr. anche Schubert 1997). ${ }^{50}$ Il serbocroato è infatti appreso a scuola prima degli anni novanta dalla maggior parte della popolazione alloglotta, ad esempio, in Kosovo dove è insegnato sotto la denominazione di "seconda lingua materna" (drugi maternji jezik) (cfr. Pani 2006: 62). Classi di serbocroato sono istituite anche in comuni in cui risiedono pochi suoi parlanti primi (cfr. Dell'Aquila \& Iannàccaro 2004: 101).

50 Tuttavia anche altri codici svolgono talvolta la funzione di lingue franche a livello regionale. Così, la popolazione slovacca e rumena in Voivodína conosce oltre alla propria lingua e al serbo solitamente anche l'ungherese, mentre quella turca residente in Kosovo ha abitualmente competenze sia in albanese sia in serbo (cfr. Neweklowsky 1997: 1410). 
Le conseguenze di un mancato riconoscimento a lingua di minoranza in una specifica area e in un dato periodo possono essere invece esemplificate confrontando la situazione sociolinguistica delle varietà di rumeno nella repubblica federale, nei paesi ad essa successori e anche all'interno della stessa Serbia. A questo proposito, i censimenti ufficiali distinguono in SFRJ e poi in FRJ - vale a dire nella Repubblica Federale di Jugoslavia, formatasi nel 1992 dall'unione delle repubbliche di Serbia e Montenegro - tra rumeni, da un lato, e valacchi/vlacchi (vlaški), dall'altro (cfr. Neweklowsky 1997: 1409). Quest'ultimo termine si riferisce tradizionalmente sia i) ai parlanti daco-rumeni in Serbia orientale, sia ii) ai parlanti arumeni (o macedorumeni) e meglenorumeni in Rep. di Macedonia, sia iii) ai parlanti istrorumeni (o cicci) in Croazia (cfr. Arvinte 2003: 161-162). Solo questi ultimi due gruppi si servono tuttavia abitualmente dell'esonimo per chiamare se stessi e la propria lingua (cfr. anche Friedman 2004: 215, Banfi 2003: 626-628).

Come già accennato, le comunità di lingua daco-rumena in Voivodína sono riconosciute a livello ufficiale. Perciò, per esempio, dispongono dal 1974 di mass media nella prima lingua. Inoltre, il rumeno standard è insegnato in 33 scuole elementari bilingui e in alcuni istituti professionali (cfr. Veiter 1983: 159-160). Tuttavia, Nedeljkovic (2004: 46-47) nota che il numero dei giornali rumeni in Voivodína sia sceso da sette a uno dopo il conflitto del 1999. Inoltre, i ragazzi residenti nella regione sono solitamente poco motivati ad apprendere la prima lingua a scuola, preferendo concentrarsi sull'acquisizione del serbo. In questo caso, quindi, la tutela formale del codice non corrisponde a una sua vitalità alta o, per lo meno, stabile nella regione. Diversa è invece la situazione dei parlanti di arumeno (e meglenorumeno) in Rep. di Macedonia dove si assiste a una progressiva crescita di status della varietà linguistica in questione. Questi non godevano infatti di particolari diritti linguistici in SFRJ (cfr. Veiter 1983: 159). Dal 1991 iniziano però ad essere trasmessi programmi televisivi e radiofonici in arumeno in Rep. di Macedonia (cfr. Friedman 2004: 199, 215-218). Inoltre, il codice - per cui è in corso un processo di standardizzazione autonomo rispetto al rumeno di Romania - è attualmente insegnato in alcune scuole pubbliche. Infine, i parlanti di dialetti daco-rumeni - residenti nelle località della Serbia centro-orientale, ma al di fuori della provincia autonoma di Voivodína (ad esempio nel distretto di Braničevo e presso le valli del fiume Timok) - non ricevono fino ad oggi una formazione nella lingua parlata in famiglia. Queste persone dunque non sanno solitamente scrivere nel codice e lo usano solo oralmente in contesti informali (cfr. Neweklowsky 1997: 1410).

Differenze di status paragonabili si riscontrano anche tra le varietà di albanese parlate in Kosovo, in Rep. di Macedonia e in Montenegro, dove però il codice è insegnato a scuola (cfr. § II.3.4.4, II.3.4.5, II.3.4.6 per maggiori dettagli). Tali confronti sono rilevanti per la presente ricerca dal momento che la mancata standardizzazione e/o il basso prestigio di alcune varietà linguistiche parlate nell'area d'origine possono essere la causa di una loro omissione al momento di dichiarare le lingue parlate in famiglia (cfr. anche Busch 2006: 16). 


\subsection{Politiche linguistiche nei Balcani occidentali: breve storia}

Attualmente, i paesi costituitisi in seguito alla dissoluzione della Federazione Jugoslava riconoscono un numero piuttosto alto di minoranze nazionali al loro interno. Inoltre promuovono diversi interventi di corpus, status e talvolta acquisition planning, finalizzati rispettivamente alla standardizzazione delle varietà ufficiali, alla regolamentazione del loro impiego in determinati domini e all'incremento del numero dei loro parlanti potenziali (cfr. Dell'Aquila \& Iannàccaro 2004 per una definizione dei termini). Per Bugarski (1990, 2012), l'importanza della lingua nella progettazione di entità politiche autonome nella regione e nell'attribuzione a se stessi e agli altri di categorie identitarie ha variato nello spazio e nel tempo. La sua rilevanza è stata per esempio, secondo il ricercatore, bassa in Serbia e Montenegro e quasi nulla per gli abitanti della Bosnia-Erzegovina prima degli anni novanta. Tuttavia, negli ultimi venticinque anni, nessi tra lingua e identità nazionale sono divenuti rilevanti anche in questi ultimi paesi (per lo meno a livello istituzionale). Ciò è, per esempio, dimostrato dai dibattiti intorno alle caratteristiche costitutive dello standard serbo e dalla recente codificazione della lingua bosniaca e montenegrina (cfr. i paragrafi seguenti per più dettagli).

Gli atteggiamenti linguistici primari e secondari nei confronti dei codici parlati sul territorio (dialetti štokavi, čakavi e kajkavi, varietà urbane e rurali) così come la presenza di stereotipi linguistici verso le varietà non-native di serbocroato in SFRJ sono discussi per esempio in Kalojera (1985). Il loro formarsi si lascia probabilmente spiegare con il costituirsi di gerarchie e rapporti asimmetrici tra lingue e tra i loro parlanti, secondo modi e processi che spesso caratterizzano situazioni di contatto linguistico (cfr. Nelde 2007 e il concetto di conflitto linguistico "naturale"). L'entità di tali relazioni cambia, però, drasticamente in seguito alla dissoluzione della Federazione e alla volontà di far emergere quattro standard da un'unica area dialettale. In questo periodo, alcune caratteristiche linguistiche sono state reinterpretate, specialmente a livello istituzionale, come nazionalmente o "etnicamente" marcate, mentre ne sono state introdotte di nuove per contrassegnare una varietà in senso nazionale o "etnico" (cfr. sempre Nelde 2007 e il concetto di conflitto linguistico "artificiale", ossia fortemente ideologico e aizzato dall'alto). Così la fricativa glottidale sorda / $h$ / diventa, per esempio, marca del bosniaco, mentre l'uso dell'infinito dopo i modali, invece del congiuntivo, diventa marca del croato. Un'analoga funzione di marca di differenziazione linguistica acquistano anche le scelte lessicali $\mathrm{e}$, in particolare, i prestiti dalle altre lingue. In bosniaco si introducono perciò termini dal turco o dall'arabo, mentre in croato si eliminano tutti i forestierismi - soprattutto se percepiti come russismi o serbismi - sostituendoli con neologismi (cfr. Greenberg 2004/2008: 47-54). In aggiunta, se le politiche linguistiche di Croazia e Serbia sono rispettivamente guidate da una tendenza al rifiuto e all'accettazione di forme doppie nello standard, in Bosnia-Erzegovina sembra emergere recentemente - accanto a un approccio puristico filo-orientale - una concezione che vede nella variazione lessicale interna una marca peculiare dell'identità della lingua bosniaca e dei suoi parlanti (cfr. ibidem: 176). 
Come già emerge da questo breve resoconto, le misure $\mathrm{e}$ le innovazioni adottate per massimizzare le differenze tra i "nuovi codici" 51 seguono principi talvolta differenti. Questi interventi rispecchiano infatti, almeno in parte, le diverse forme che il nazionalismo politico ha assunto nei paesi dei pianificatori. Tali disparità lasciano ipotizzare che i conflitti linguistici nell'area della (ex-)Jugoslavia non siano stati tanto la causa scatenante degli scontri militari negli anni novanta. Piuttosto, come avviene anche altrove, questi rivelano e sono stati strumentali ad intensificare e perpetuare conflitti sociali, economici e/o politici già esistenti (cfr. sempre Nelde 2007, Bugarski 2012, Manzelli 2012: 373, ma Tollefson 2002 per un'opinione parzialmente diversa). Infine, è anche importante notare che i significati attribuiti dalla popolazione a determinate forme linguistiche variano a seconda delle esperienze personali e non sempre coincidono con quelli ufficiali. Alcuni parlanti possono essere "traumatizzati" nei loro usi e atteggiamenti linguistici in conseguenza degli effetti che l'impiego di un vocabolo "errato" poteva avere durante la guerra (cfr. Voß 2007: 201). D'altro canto, Busch \& Schick (2007: 221) rilevano che attualmente un uso "sbagliato" della lingua è frequentemente stigmatizzato in Bosnia-Erzegovina come "yugo-nostalgic", piuttosto che essere associato a una determinata "nazionalità/etnicità".

Nei prossimi paragrafi descrivo, seppur brevemente, i principali interventi di pianificazione linguistica e dibattiti metalinguistici condotti intorno alle lingue ufficiali in sei paesi successori alla Jugoslavia negli ultimi venticinque anni. Dalla rassegna è esclusa la situazione in Slovenia dal momento che nessuno dei partecipanti alla presente ricerca è originario di questo paese o parla lo sloveno come prima lingua. Inoltre, da un lato, illustro le eventuali radici e motivazioni dei recenti interventi di pianificazione in dibattiti e misure intraprese precedentemente alla dissoluzione della Federazione Jugoslava. Dall'altro, caratterizzo la situazione sociolinguistica attuale dei sei paesi, presi in esame, e riferisco delle regolamentazioni relative agli altri codici parlati sul loro territorio.

\subsubsection{Purismo linguistico in Croazia}

Le misure di pianificazione linguistica in Croazia dopo la dichiarazione di indipendenza nel 1991 si rifanno, almeno in parte, ai principi elaborati durante il movimento della cosiddetta "primavera croata" nella decade successiva al 1966 (cfr. Greenberg 2004/2008: 115-134). Nello specifico, questa corrente rivendicava una maggiore autonomia per la popolazione croata in SFRJ, tra l'altro, tramite la promozione di un'identità linguistica autonoma. Tra gli avvenimenti più importanti di questo periodo, c'è da un lato la firma nel 1967 della "Dichiarazione sul nome e posizione della lingua croata letteraria" (Deklaracija o nazivu i položaju hrvatskog

51 In questo e nei prossimi paragrafi, mi riferisco talvolta a croato, bosniaco, serbo e montenegrino come "nuovi standard" o "lingue in via di formazione" o "lingue neo-proclamate" in quanto standardizzate in tempi recenti secondo principi e modalità tendenzialmente innovativi. Questo vale, quindi, indipendentemente dal fatto che tali codici siano stati oggetto o meno di tentativi di codificazione nei secoli precedenti o durante la SFRJ. 
književnog jezika) da parte di organizzazioni linguistiche e culturali. Dall'altro, a partire dal 1971, iniziano a circolare le "Dieci tesi sulla lingua croata" (Deset teza o hrvatskome jeziku) del linguista D. Brozović, pubblicate poi a Spalato nel 1975. In reazione a questi documenti, un gruppo di scrittori a Belgrado sottoscrive una "proposta di considerazione" (Predlog za razmišljanje). I redattori della proposta approvano le istanze croate e, al contempo, rivendicano l'utilizzo del glottonimo semplice "serbo" per la lingua standard della propria repubblica. Tali movimenti e le loro petizioni sono tacciati di nazionalismo dal governo federale. Tuttavia, la costituzione del 1974 tiene conto di alcune delle loro rivendicazioni. Infatti riconosce ufficialmente un idioma standard croato in SFRJ (cfr. anche Bugarski 2012: 227).

Durante gli anni novanta, i pianificatori croati si concentrano principalmente sulla definizione di norme ortografiche per la lingua scritta in alfabeto latino. Inoltre, promuovono l'introduzione - ispirata da motivazioni puristiche - di neologismi soprattutto in campo lessicale (cfr. Greenberg 2004/2008: 118-125). In particolare, i dialetti kajkavi e čakavi acquisiscono, in questo periodo, un nuovo prestigio nella regione. Infatti, questi sono considerati distintivi specificamente della lingua croata rispetto agli altri codici elaborati successivamente al serbocroato. Sebbene raramente adoperati per tali scopi, linguisti e pianificatori li indicano così come fonti ideali di materiale per arricchire la lingua in via di formazione. Specialmente durante la presidenza Tuđman (1989-1999), i mass media sono inoltre strumentalmente impiegati per diffondere neologismi e nuove norme linguistiche tra la popolazione locale e anche tra i residenti all'estero (cfr. Busch 2004b: 191-218).

Attualmente, la situazione sociolinguistica nell'entroterra croato può essere definita come monolingue, mentre, sulla costa adriatica, è caratterizzata da "dialettia diatopica" tra croato standard da un lato e varietà slavo meridionali locali dall'altro (cfr. Dell'Aquila \& Iannàccaro 2004: 176). ${ }^{52}$ A fianco a quello latino, l'alfabeto cirillico (o anche altri alfabeti) possono essere talvolta adoperati per funzioni ufficiali in singole unità amministrative. Infine, nel paese sono riconosciute diciassette lingue minoritarie, tra cui l'italiano, il tedesco e il serbo. Nel 2001, queste varietà sono parlate da circa il 10,4\% della popolazione totale (cfr. Pan 2011: 33-34). ${ }^{53}$

52 Con la nozione di “dialettia”, Dell'Aquila \& Iannàccaro (2004: 172) si riferiscono a una situazione sociolinguistica in cui la varietà linguistica usata per scrivere e quella adoperata per parlare sono chiamate dai parlanti con lo stesso nome e, quindi, sono considerate tendenzialmente lo stesso codice. Tuttavia, sono presenti variazioni - socialmente necessarie e talora connotate positivamente - nell'uso orale a seconda dell'area geografica (dialettia diatopica; si pensi alla Toscana) o della classe socioculturale del parlante (dialettia sociale; si veda la situazione inglese).

53 Qui come nei prossimi paragrafi riporto indicativamente le percentuali di popolazione appartenente a gruppi minoritari sul totale dei residenti nei paesi successori alla Jugoslavia. Sia però avvertito che queste percentuali sono talvolta controverse. 


\subsubsection{Trilinguismo istituzionale in Bosnia-Erzegovina}

In seguito alla sua ri-proclamazione nel 1992 - una lingua chiamata bosniaca è infatti proclamata già durante l'impero austro-ungarico, mentre la costituzione del 1974 sancisce un idioma standard di Bosnia-Erzegovina -, controversie sulla lingua bosniaca riguardano soprattutto, da un lato, il glottonimo da usare per nominarla (cfr. Greenberg 2004/2008: 136-158 e anche § II.3.5.3). Dall'altro, si riferiscono alla presenza o meno di caratteristiche che la distinguano dagli standard croato e serbo. Inoltre, conflitti linguistici artificiali - vale a dire aizzati dall'alto - si verificano, in particolare, nel 1993 nella Republika Srpska, uno stato membro della Federazione della Bosnia-Erzegovina in cui la popolazione si dichiara in maggioranza "serba". In questo anno, i nazionalisti al potere impongono tramite decreto la pronuncia ekava agli abitanti della zona, che sono però parlanti nativi di jekavo. Il loro scopo è quello di accentuare il legame di questi ultimi con la popolazione serba residente in FRJ (cfr. sempre Greenberg 2004/2008: 78-79). Durante la guerra, scritte in alfabeto cirillico scompaiono invece dalle città a maggioranza croata.

Dopo gli accordi di Dayton (1995), tre lingue sono usate ufficialmente nei domini pubblici e sono sancite come codici dell'educazione a scuola in Bosnia-Erzegovina. Queste sono il croato e il serbo, per cui ci si orienta alle politiche linguistiche di Croazia e Serbia, e il bosniaco, la cui pianificazione si basa su interventi guidati da istituzioni interne (cfr. Busch \& Schick 2007).

Attualmente, la situazione sociolinguistica nel paese può essere definita di dialettia diatopica tra codici standard e dialetti neoštokavi locali, soprattutto jekavi e parzialmente ikavi (cfr. Dell'Aquila \& Iannàccaro 2004: 175 e 102). Entrambi gli alfabeti - latino e cirillico - sono ufficiali, ma il primo è solitamente adoperato per scrivere in bosniaco. Secondo Greenberg (2004/2008: 157), alcune difficoltà a livello amministrativo (ma non comunicativo) dipendono inoltre dal fatto che bosniaco, croato e serbo sono di fatto lingue di minoranza in determinate aree. Tuttavia, in quanto codici ufficiali della Federazione, non godono di una protezione particolare in questi territori. Nel paese sono riconosciute infine sei comunità linguistiche. Queste costituiscono nel 2011 l'intera popolazione residente dal momento che nessuna nazionalità è titolare (cfr. Pan 2011: 33-34).

\subsection{3 (Inter)nazionalismo linguistico in Serbia}

La lingua ufficiale della Repubblica Serba - sia come stato componente della Federazione di Jugoslavia (FRJ) dal 1992, sia come stato autonomo dal 2006 - è il serbo. Per il codice sono ammesse due pronunce o varianti ufficiali. La prima è identificata con il dialetto ekavo di Belgrado-Novi Sad, mentre la seconda con quello jekavo parlato in Montenegro e nella Serbia Occidentale (cfr. Greenberg 2004/2008: 6087). La costituzione del 1992 sancisce inoltre una situazione di digrafia sbilanciata in favore della scrittura cirillica. L'alfabeto cirillico è infatti definito ufficiale. Invece l'impiego di quello latino è ufficiale, ma secondo modalità da precisarsi per legge. Tale regolamentazione è in controtendenza con la diffusione della scrittura 
latina, specialmente nei centri urbani, in Serbia prima del 1991 (cfr. anche Brozović 1992: 374).

Secondo Greenberg (2004/2008: 65-68), tre fazioni principali si fronteggiano nei dibattiti riguardo alla codificazione della lingua serba nel corso degli anni novanta. La cerchia di linguisti intorno al dialettologo P. Ivić - composta soprattutto da ricercatori dell'Istituto della Lingua Serba presso l'Accademia di Scienze e Arti o da professori dell'Università di Novi Sad, tra cui ci sono anche alcuni curatori dell'influente manuale della Matica Srpska - considera il nuovo standard come naturalmente evolutosi dal serbocroato. Questa fazione è accusata di "ekavismo", vale a dire di voler abbandonare l'uso ufficiale dello jekavo, dalla seconda corrente Neo-Vukovita, i cui sostenitori sono invece in prevalenza studiosi serbi e montenegrini, affiliati alle Università di Belgrado e di Nikšić in Montenegro. I Neo-Vukoviti sostengono, in particolare, la parità di entrambe le varietà ekava e jekava. Dato che quest'ultima varietà è quella nativa di gran parte della popolazione "serba" residente al di fuori dei confini nazionali, una sua esclusione potrebbe infatti causare una diminuzione del numero di parlanti che si identificano con il nuovo standard. In aggiunta, propongono di introdurre nuovi grafemi latini per scrivere in serbo. Tale innovazione mira a una rottura con la tradizione della lingua letteraria unitaria e, perciò, alla creazione di un codice standard autonomo. Infine, una frangia estrema di linguisti "nazionalisti" - attiva soprattutto tra il 1998 e il 1999 - attribuisce un'identità serba a tutti i parlanti neoštokavi. Inoltre rivendica il ritorno a una scrittura cirillica "etimologica", ossia caratterizzata dall'uso di alcune lettere dell'antico slavo ecclesiastico. Tra i leader di questa fazione nazionalista, c'è anche il decano dell'Università di Belgrado.

Attualmente, in Serbia sono riconosciute undici lingue minoritarie, parlate nel 2011 da circa il 17,2\% della popolazione (cfr. Pan 2011: 33-34). Tra queste ci sono il bosniaco e il croato, ma non il montenegrino (cfr. Greenberg 2004/2008: 180-181).

\subsubsection{Dibattiti intorno all'esistenza del montenegrino}

Sebbene la costituzione del 1974 sancisse un idioma locale della lingua letteraria, le attività volte alla codificazione del montenegrino si intensificano dal 1993 quando il paese costituisce insieme alla Serbia una federazione bimembre (FRJ). Di questo anno è, infatti, la pubblicazione del primo manuale di ortografia e del primo volume di storia della lingua montenegrina ad opera del letterato/linguista Vojislav P. Nikčević, per lungo tempo, principale sostenitore tra pochi dell'esistenza del codice (cfr. Trovesi 2009, Manzelli 2012: 388-389). In particolare, la diversità del montenegrino dal serbo, croato e bosniaco è argomentata adducendo la presenza di tre (presunti) fonemi in più da scrivere con rispettivi nuovi grafemi. La distintività di tali foni non è però dimostrata da coppie minime (cfr. anche Greenberg 2004/2008: 88-108). Parallelamente alla codifica del nuovo standard si susseguono i dibattiti sul glottonimo da usare per chiamarlo (cfr. § II.3.5.3 per più dettagli).

Negli anni novanta e duemila, l'esistenza di una lingua montenegrina diversa dal serbo è osteggiata da numerosi linguisti. Questi sono sia residenti nel paese, 
come ad esempio il già menzionato gruppo Neo-Vukovita, sia abitano all'estero. La codifica del nuovo standard trova invece supporto tra alcuni intellettuali croati, probabilmente in funzione di una politica linguistica anti-serba (cfr. Gröschel 2009: 283). Disaccordo riguardo all'esistenza del codice emerge anche dai dati del censimento del 2003, anno in cui, tra l'altro, la Repubblica Federale di Jugoslavia diventa l'Unione Statale di Serbia e Montenegro. La maggioranza dei cittadini montenegrini $(63,49 \%)$ indica infatti il "serbo" come la propria madrelingua contro il 21,96\% che la definisce "montenegrino" (cfr. Trovesi 2009: 202).

Nel 2007 la costituzione della Repubblica di Montenegro - stato indipendente dal 2006 - sancisce infine la "lingua montenegrina" (crnogorski jezik) come ufficiale insieme a quella serba, bosniaca, albanese e croata (cfr. Greenberg 2004/2008: 180). Parimenti il documento ratifica una situazione di digrafia tra alfabeto latino e cirillico. In Montenegro sono attualmente riconosciute sei minoranze linguistiche, che costituiscono circa il 49,1\% della popolazione totale nel 2011 (cfr. Pan 2011: 33-34). Tra queste, parlanti di varietà gheghe di albanese risiedono soprattutto nel sud-est del paese lungo il confine con il Kosovo e l'Albania nei comuni di Plav/ Plava, Tuzi/Tuz e Ulcinj/Ulqin.

\subsubsection{Legittimità delle lingue in Rep. di Macedonia}

Sebbene già almeno dall'inizio del novecento la popolazione della regione rivendicasse un'autonomia politica e linguistica, la lingua macedone nasce ufficialmente nel 1944 in concomitanza con l'istituzione della Repubblica Federata di Macedonia in SFRJ (cfr. Dell'Aquila e Iannàccaro 2004: 151-154). Come accennato sopra, le varietà locali erano infatti precedentemente considerate o dialetti del serbo o dialetti del bulgaro o (addirittura) dialetti del greco dai linguisti e dalle istituzioni dei rispettivi paesi (cfr. Irvine e Gal 2000: 60-72). In particolare, le argomentazioni avanzate per l'una o per l'altra tesi tendevano ad accentuare affinità fonologiche $o$ morfologiche o lessicali tra i rispettivi codici, cancellandone le differenze. Così, per esempio, l'ipotesi di un apparentamento genealogico con la lingua greca si basava sulla presenza di numerosi prestiti e sulla teoria secondo cui parlanti grecofoni fossero stati assimilati da immigrati slavi giunti successivamente nella zona (cfr. Andriotes 1957: 15-16, citato da Irvine \& Gal 2000: 69).

La codificazione del macedone è avvenuta principalmente sulla base delle varietà linguistiche parlate nelle zone occidentali del paese, sia perché dotate di una tradizione letteraria scritta, sia per via della loro massima distanza dal bulgaro e serbocroato. I turchismi - che negli anni quaranta sono tendenzialmente sostituiti con parole slave - acquistano invece a partire dal 1989 un nuovo prestigio nella regione (cfr. Friedman 2004: 202). L'esistenza di uno standard macedone è a lungo contestata da altre entità nazionali. Il codice è ufficialmente riconosciuto come lingua distinta e indipendente da un governo bulgaro solo nel 1999, sebbene tale riconoscimento non si estenda alle comunità macedoni in Bulgaria (cfr. Friedman 2004: 201). Invece, la Grecia contesta tuttora (almeno fino alla data di redazione di questo volume) l'uso della denominazione "macedone" sia per la lingua, sia per lo stato. In 
conseguenza di ciò, si serve del termine "slavo" per chiamare questo codice, parlato anche all'interno dei suoi confini nazionali. ${ }^{54}$

Dopo la separazione dalla Jugoslavia nel 1991, la costituzione della Repubblica di Macedonia sancisce il macedone, scritto in alfabeto cirillico, come lingua ufficiale. Inoltre la carta, rivista nel 2001, riconosce il diritto ad usare la propria lingua negli uffici pubblici ai quei gruppi di parlanti alloglotti che costituiscono il $20 \%$ o più della popolazione totale (cfr. Dell'Aquila \& Iannàccaro 2004: 184-185). Così l'albanese ottiene, seppur implicitamente, lo status di lingua ufficiale regionale nella Rep. di Macedonia. Questioni di politica linguistica relative a quest'ultimo codice erano state oggetto di accese contese nel corso degli anni novanta e, in particolare, durante gli scontri tra attivisti albanofoni ed esercito nel 2000-2001 (cfr. anche Friedman 2004: 200-201). Altre lingue di minoranza parlate nel paese sono il turco, il romaní, l'arumeno e il serbo. La presenza mediatica dei primi tre codici così come il numero di classi per un loro insegnamento nelle scuole pubbliche aumenta, secondo Friedman (2004: 199-200), durante gli anni novanta. Per Pan (2011: 33-34), i parlanti una lingua di minoranza nella Rep. di Macedonia costituiscono nel 2011 il 35,8 \% della popolazione totale. La percentuale di persone albanofone è, tuttavia, estremamente controversa.

Infine, la conoscenza di una varietà neoštokava come lingua seconda o terza è diffusa tra la popolazione locale. Sempre secondo Friedman (2004: 210-211), i conflitti linguistici derivati dalla codificazione degli standard successivi al serbocroato non hanno avuto particolari ripercussioni nella Rep. di Macedonia. Per Greenberg (2004/2008: 165), gli abitanti albanofoni del paese hanno tuttavia opposto qualche resistenza al cambiamento della lingua communis dal serbocroato al macedone.

\subsubsection{Diglossia in Kosovo}

Gli interventi di pianificazione linguistica in Kosovo si orientano dal 1968 alla varietà di albanese tosca, lingua standard in Albania, abbandonando il tentativo, intrapreso nel secondo dopoguerra, di creare uno standard sulla base del dialetto ghego principalmente parlato nella regione (cfr. Friedman 2004: 203-206). Si delinea così una situazione di diglossia (mediale), in cui lo standard esogeno, scritto e parlato solo in contesti molto formali, non sostituisce l'albanese ghego nella comunicazione quotidiana. Il repertorio degli albanofoni kosovari è tuttora diglottico (cfr. Dell'Aquila e Iannàccaro 2004: 191).

Probabilmente in conseguenza delle diverse tradizioni di codificazione, in serbocroato sono usati, almeno fino alla metà degli anni settanta, due glottonimi differenti per riferirsi alla lingua albanese d'Albania (arbanaški o albanski jezik) da un lato e alla lingua albanese in Jugoslavia (šiptarski jezik) dall'altro. La prima designazione è quella impiegata correntemente, mentre la seconda ha acquisito una connotazione spregiativa (cfr. Byron 1985/2009: 66-67, Neweklowsky 1997: 1410).

$54 \mathrm{Si}$ confronti anche il sito di Ethnologue, URL: $<$ http://www.ethnologue.com/language/mkd $>$ (18.10.2018). 
Nel corso degli anni ottanta, si verifica una progressiva riduzione dei diritti linguistici in Kosovo, parallela alle limitazioni nel suo statuto di autonomia (cfr. Tollefson 1993: 82-86). Questa riduzione raggiunge il culmine negli anni novanta con la chiusura forzata di scuole, case editrici, giornali e con l'espulsione di studenti e docenti albanofoni dall'Università di Pristina, presso cui l'albanese era una lingua veicolare di insegnamento (cfr. anche Pani 2006: 61). In questo periodo, la proposta di rintrodurre alcune forme gheghe nella lingua standard - avanzata da linguisti originari soprattutto dal nord dell'Albania - è osteggiata dai rappresentanti kosovari alle conferenze di Tirana $(1992,1995)$. Il rifiuto è argomentato in nome della necessità di promuovere un'unità nazionale attraverso quella linguistica (cfr. Friedman 2004: 204-205).

Attualmente, i contatti (anche linguistici) con Tirana sono piuttosto frequenti, per esempio, per via dello scambio di programmi televisivi e radiofonici. Inoltre, numerosi cittadini kosovari si sono rifugiati durante la guerra in Albania o vi hanno risieduto successivamente per motivi di studio, entrando così in più stretto contatto con la varietà parlata nella regione. D'altro canto, la varietà ghega locale è usata in alcuni programmi televisivi e nelle pubblicità, mentre guadagna di popolarità, per esempio, tra i giovani a Pristina (cfr. Pani 2006: 71-72). Competenze in serbocroato come lingua seconda sono diffuse tra le persone più anziane e in particolare tra gli uomini, residenti in città o nelle località in cui vivono parlanti di entrambi i codici (cfr. Pani 2006: 62-63). Invece le generazioni, nate dopo gli anni settanta, hanno solitamente competenze inferiori nel codice. In Kosovo risiedono, tra le altre, una minoranza di parlanti turco e una di serbo(croato) (cfr. Neweklowsky 1997).

\subsection{Controversie sui glottonimi e apposizioni}

Il caso delle varietà parlate nello spazio linguistico slavo meridionale illustra in modo esemplare processi di creazione, soppressione e moltiplicazione di denominazioni linguistiche dall'alto (top-down) e dal basso (bottom-up), rispettivamente per fini di pianificazione linguistica e per esprimere affiliazione o opposizione nei loro confronti. Nei prossimi paragrafi riassumo le principali controversie riguardo ai glottonimi e alle apposizioni per chiamare e qualificare i codici a base neoštokava - ovvero il serbocroato e le lingue che gli sono succedute - a partire dal XIX secolo. ${ }^{55}$ Dall'esposizione seguente emerge che le denominazioni di lingua non hanno avuto solo la funzione di riferirsi in modo neutrale alle varietà linguistiche oggetto di interventi di pianificazione. Specialmente negli ultimi anni (ma anche in passato), queste sono state piuttosto determinanti anche per sancirne l'esistenza, prima o in concomitanza con la loro codificazione. Inoltre, i nomi di lingua sono (stati) adoperati per evocare e/o stabilire "genealogie", ossia racconti d'origine e rapporti di affiliazione tra $\mathrm{i}$ codici in questione. Il loro scopo era ed è quello di giustificare, tramite argomenti storici, rivendicazioni e progetti politici da attuare nel presente. Perciò, se il riconoscimento dei codici standard degli "altri” è spesso controverso dal momento 
che presuppone, almeno in parte, l'accettazione dell'entità politico-nazionale in cui la lingua è ufficiale, il rifiuto di queste "nuove" lingue e "nuovi" stati spesso si manifesta nel mancato riconoscimento della legittimità di un particolare glottonimo.

\subsubsection{Denominazioni per una lingua in via di codificazione}

Come abbastanza frequente, dibattiti e incertezze riguardo al nome con cui chiamare una lingua standard risalgono al periodo della sua codificazione, in questo caso al XIX secolo (cfr., per esempio, Seriot 1997 e Dell'Aquila \& Iannàccaro 2004: 65-66 per una ricostruzione delle diatribe onomastiche durante i processi di standardizzazione rispettivamente di macedone e norvegese). Nel 1850 i filologi serbi e croati, firmatari dell'Accordo Letterario di Vienna, non riescono per esempio a convenire su un nome da dare alla "lingua letteraria comune" che promuovono. Perciò si riferiscono al codice nel trattato solamente tramite l'espressione (ambigua) "nostra lingua" (cfr. Gröschel 2009: 11). Nei testi dell'epoca - ad esempio, grammatiche, dizionari, ecc.--, anche linguisti e pianificatori designano con nomi diversi la varietà linguistica che stanno codificando. Il glottonimo più frequente fino alla metà del 1850 è lingua "illirica". Tuttavia sono attestate, tra le altre, anche le denominazioni lingua "slavonica", "dalmata", "serba" e "croata" (cfr. Kordić 2004: 33, Gröschel 2009: 12-16).

La prima attestazione dell'aggettivo "serbocroato" si trova nella prefazione di J. Grimm alla propria traduzione del 1824 della "Grammatica della lingua serba" (Pismenica srpskoga jezika) di Vuk Karadžić, pubblicata nel 1814. Tale composto è perciò definito da alcuni filologi un esonimo. Tuttavia il neologismo è una combinazione di due etnonimi. Nel resto della grammatica, il traduttore chiama inoltre la lingua, come nel testo originale, esclusivamente serbo (cfr. Gröschel 2009: 12). Il termine "serbocroato" è invece usato chiaramente e sistematicamente in funzione di glottonimo per la prima volta dal linguista sloveno J. Kopitar nel 1836. La denominazione si diffonde nella seconda metà dell'ottocento anche in seguito alla pubblicazione della "Grammatica della lingua serbo-croata (illirica)" di P. Budmani nel 1867 a Vienna (cfr. ibidem: 12).

Differenze e variazioni nei glottonimi per la lingua in via di codificazione si riscontrano, in questo periodo, anche in ambito amministrativo. Nel 1868, in Serbia - stato indipendente dal 1878 - si sancisce come lingua ufficiale il "serbocroato" (cfr. Gröschel 2009: 13). Invece, il parlamento (Sabor) del regno asburgico di Croazia propone nel 1861 di chiamare lo standard unitario "lingua slava meridionale/jugoslava" (jugoslavenski jezik). La denominazione non è però approvata dalle autorità viennesi, che divulgano al suo posto i termini "serbo-illirico" o "croato o serbo" (cfr. rispettivamente Greenberg 2004/2008: 27 e Gröschel 2009: 15). ${ }^{56} \mathrm{Nel}$ paese è inoltre in uso semi-ufficiale anche il glottonimo semplice "croato" (cfr. Stančić 1986: 36-37 citato da Gröschel 2009: 15). In Bosnia-Erzegovina - protet-

56 Greenberg (2004/2008) e Gröschel (2009) discordano sul termine preferito dalla Hofkanzlei viennese. 
torato austro-ungarico tra il 1878 e il 1918 - la lingua di insegnamento nelle scuole elementari è a partire dal 1879 il "croato". Tuttavia, l'amministrazione dell'impero introduce ufficialmente dal 1890 il glottonimo "lingua bosniaca" (bosanski jezik o bozanski jazik). ${ }^{57}$ Tale innovazione avviene in concomitanza con il tentativo di promuovere un'identità regionale in funzione anti-serba (cfr. Gröschel 2009: 16, Dell'Aquila \& Iannàccaro 2004: 79-80, Pelusi 2008). In questo periodo, anche l'espressione indeterminata "lingua del paese" (zemaljski jezik dal tedesco Landessprache) è comunemente impiegata per riferirsi alle varietà linguistiche parlate dagli abitanti della Bosnia (cfr. Gröschel 2009: 15, Manzelli 2012: 393).

Tra il 1918 e il 1941 - durante il Regno dei Serbi, Croati e Sloveni e dal 1929 in poi Regno di Jugoslavia - la lingua ufficiale si chiama "serbocroatosloveno" (srpskohrvatskoslovenački). Tuttavia il governo non promuove misure concrete per elaborare uno standard unitario corrispondente a tale designazione (cfr. Gröschel 2009: 16-17). Il composto è inoltre spesso sostituito con la perifrasi (ambigua) "nostra lingua" anche in contesti pubblici (cfr. Bugarski 2012: 225). Dal 1941, durante l'occupazione tedesca, si ripristina invece in Serbia il glottonimo "serbo" (srpski), mentre lo Stato Indipendente di Croazia (1941-1945) intraprende interventi di pianificazione sulla lingua "croata" (hrvatski), ispirati da un approccio puristico (cfr. Gröschel 2009: 18-20). D'altro canto, l'amministrazione italiana conia nel 1941, insieme al glottonimo, anche il concetto di "lingua montenegrina". Tale denominazione ha la funzione di favorire, a vantaggio dei propri interessi di stato occupante, la separazione della varietà linguistica e, quindi, dei suoi parlanti dal resto della popolazione slavo meridionale (cfr. Gröschel 2009: 282-284 e il concetto di "glottotomia" in Goebl 1979). Infine, i documenti partigiani dell'AVNOJ fanno spesso riferimento a quattro codici, chiamati "serbo", "croato", "sloveno" e "macedone". Questi nomi sono probabilmente scelti in conformità all'uso onomastico più diffuso nella lingua parlata (cfr. Gröschel 2009: 20-22).

\subsubsection{Denominazioni per una lingua "unitaria"}

Come ratificato dall'accordo di Novi Sad nel 1954, l'amministrazione della Repubblica Socialista Federale di Jugoslavia dispone - piuttosto insolitamente rispetto ad altri stati dell'epoca - di diverse denominazioni ufficiali per riferirsi a una delle lingue nazionali a livello federale. ${ }^{58} \mathrm{Il}$ codice può infatti essere chiamato "srpskohrvatski" (serbocroato) o "hrvatskosrpski" (croatoserbo) a seconda del luogo (cfr. Gröschel 2009: 23-24). Ulteriori glottonimi autorizzati sono: "srpski i hrvatski" e "hrvatski i srpski" ("serbo e croato" e "croato e serbo") oppure "srpski ili/odnosno hrvatski" e "hrvatski ili/odnosno srpski" ("serbo o/ovvero croato" e "croato o/ovvero serbo"). Secondo il trattato di Novi Sad, i glottonimi devono essere scritti

57 In letteratura sono usate entrambe le varianti grafiche per il glottonimo.

58 Nella precedente costituzione federale del 1946 si trattano, invece, solo questioni linguistiche connesse alle minoranze nazionali (cfr. Gröschel 2009: 22). 
senza trattino (cfr. Greenberg 2004/2008: 31) ${ }^{59}$ La denominazione "serbocroato o croatoserbo" è adoperata anche per chiamare una delle lingue dei popoli jugoslavi nella seconda costituzione del 1963.

I composti appena citati appartengono comunque prevalentemente al linguaggio burocratico e scientifico. Invece, "serbo" e "croato" sono le denominazioni più diffuse nella lingua parlata (cfr. Kordić 2004: 35, Gröschel 2009: 29). Inoltre, si registra anche l'uso del glottonimo "jugoslavo" in contesti informali o all'estero, per esempio, per chiamare il codice insegnato ai figli dei migranti (cfr. Brozović 1992: 363, Gustavsson 2004: 252). Infine in questi anni, nella comunicazione quotidiana è frequente l'impiego della perifrasi "nostra lingua" (cfr. Gröschel 2009: 33-35).

Dispute sui glottonimi - specialmente sul diritto o meno di utilizzare i nomi semplici "croato" e "serbo" anche in contesti istituzionali - sono frequenti almeno a partire dagli anni sessanta (cfr. il già citato movimento della "primavera croata" e la reazione del gruppo di scrittori belgradesi). Queste diatribe sono concomitanti alle discussioni riguardo all'unità della lingua standard letteraria e riguardo alle apposizioni da adoperare per definire (i rapporti di differenziazione tra) le sue varietà. Tra queste ultime, ci sono i termini "variante" (varijanta), "pronuncia" (izgovor) o "idioma/espressione" (izraz) (cfr. Greenberg 2004/2008: 39-41). In conseguenza di tali dibattiti, la costituzione federale jugoslava del 1974 introduce l'apposizione "idioma" per definire tre dei neo-riconosciuti standard regionali della lingua scritta serbocroata o croatoserba. Nello specifico, l' "idioma standard croato" e l' "idioma standard montenegrino" sono designati tramite aggettivi (etnico-)nazionali. Invece la terza varietà, sancita come norma orale, è identificata attraverso un riferimento territoriale, ovvero come 1' "idioma standard di Bosnia-Erzegovina". Infine per l'ultima denominazione si mantiene la terminologia proposta dall'accordo di Novi Sad, ossia "variante orientale con pronuncia ekava e jekava" (cfr. Greenberg 2004/2008: 40).

\subsubsection{Denominazioni per lingue in via di separazione}

I dibattiti sui glottonimi e sui rapporti di differenziazione tra codici nello spazio linguistico neoštokavo si sono susseguiti, per lo meno a livello politico e mass-mediatico, nel corso degli anni novanta fino ad oggi. Tali diatribe hanno accompagnato la formazione degli stati attuali e la codifica delle quattro varietà standard successive al serbocroato o croatoserbo. Uno dei risultati è che queste ultime due denominazioni non siano più utilizzate a livello ufficiale in nessuno degli stati successori alla Jugoslavia. Seppur sostituiti nei domini pubblici, i nomi serbocroato o croatoserbo (o, alternativamente, la forma abbreviata es-ha) sono tuttavia, secondo Bugarski (2004: 16), occasionalmente ancora adoperati in situazioni informali. In tali contesti è anche in uso la perifrasi "nostra lingua".

59 In italiano tutte e due le ortografie sono possibili (cfr. URL: $<$ http://www.treccani.it/vocabolario/ ricerca/serbocroato/> (18.10.2018)). 
I glottonimi ufficiali per le lingue nazionali attuali sono invece "serbo", "croato", "bosniaco", "montenegrino". Come emerge dalla discussione nei paragrafi precedenti, nessuno di questi nomi è propriamente un neologismo. Tuttavia, la loro tradizione nella lingua sia orale sia scritta è diversamente consolidata, mentre il loro uso presenta, in conseguenza della loro storia, connotazioni diverse. In particolare, i glottonimi "croato" e "serbo" sono diffusi nella lingua parlata anche prima degli anni novanta. Il primo nome è inoltre, per esempio, in uso semi-ufficiale già nella Croazia asburgica (cfr. §3.5.1), mentre acquisisce valore ufficiale - in sostituzione del termine "croatoserbo" - in SFRJ con la costituzione del 1974 (cfr. Greenberg 2004/2008: 115-118, Bugarski 2004: 12 e §3.5.2). In conseguenza di questa tradizione, il glottonimo semplice "croato" non è oggetto di particolari contese nel corso degli anni novanta.

La denominazione "serbo" è invece adottata a livello ufficiale solo nel 1992, successivamente alla "secessione" di Croazia prima e di Bosnia-Erzegovina poi dalla federazione (cfr. Ivić 2001: 7-9) ${ }^{60}$ In Serbia, sono comunque soprattutto le apposizioni (invece che il glottonimo) per il codice ufficiale ad essere oggetto di diatribe negli anni novanta. Così, i curatori del manuale ortografico della Matica Srpska - tra cui ci sono alcuni linguisti intorno a P. Ivić - sono, per esempio, accusati dai compilatori di un prontuario rivale di evitare l'apposizione "lingua" per il codice. L'impiego da parte dei primi delle qualifiche "idioma" o "modo di parlare" è, nello specifico, contestato dai secondi perché antiquato e perché ricondotto alla loro riluttanza nel promuovere uno standard serbo autonomo (cfr. Greenberg 2004/2008: 67-68 e anche § II.3.4.3 per più dettagli sul contesto). In questo periodo, anche l'apposizione "pronuncia" - adottata nella costituzione di FRJ, in aderenza con l'uso vigente in precedenza, per riferirsi allo jekavo ed ekavo - è criticata da alcuni pianificatori e linguisti in Serbia. Il motivo è che tale apposizione minimizzerebbe le diversità tra le due varietà così definite, a differenza di una loro qualifica come "dialetti" (cfr. Greenberg 2004/2008: 78).

Le dispute maggiori di questo periodo riguardano comunque i nomi per chiamare le lingue standard in Bosnia-Erzegovina e in Montenegro. In Bosnia-Erzegovina, sono proposte due denominazioni alternative, entrambe già attestate nei secoli precedenti, per uno dei codici ufficiali (cfr. Greenberg 2004/2008: 139-142, Bugarski 2012: 228). Il primo glottonimo "bosanski jezik" (lingua bosniaca) è usato già dall'amministrazione austro-ungarica. Questo deriva direttamente dal toponimo Bosnia (Bosna) e significa, quindi, lingua parlata nella regione. Il secondo "bošnjački jezik" (lingua bosgnacca/bosniana) è invece affine a un'espressione coniata durante l'impero ottomano ("bosnakca"). Questo glottonimo è un derivato dell'espressione "Bošnjak" (Bosgnacco/Bosniacco), succeduta nel 1993 alla designazione "Muslimani" (Musulmani) per indicare una delle "nazionalità" (narod)

60 Si ricordi che P. Ivić partecipa ai dibattiti (meta)linguistici in Serbia negli anni novanta (cfr. $\S$ II.3.4.3). L'articolo citato polemizza, in particolare, contro gli interventi di pianificazione promossi dalle istituzioni croate e bosniache. 
slavo meridionali (cfr. anche Karadža 2004: 28). ${ }^{61}$ Il primo glottonimo è quello adottato dai pianificatori della lingua standard a cui si riferisce. Inoltre è stato riconosciuto dalla comunità internazionale. Tuttavia, tale denominazione è osteggiata da (alcuni) politici e linguisti serbi e croati, sia residenti in Bosnia-Erzegovina, sia stranieri. I suoi oppositori temono infatti che la scelta di un glottonimo che si basi su una qualifica territoriale possa giustificare una proclamazione del codice come unica lingua ufficiale del paese a discapito delle "altre" varietà linguistiche parlate dalle loro comunità. In conseguenza di queste polemiche, nella costituzione della Republika Srpska del 2002 sono evitati nomi di lingua specifici. Al contrario, i tre codici ufficiali sono chiamati rispettivamente lingua dei serbi, dei croati e dei bosgnacchi (cfr. Greenberg 2004/2008: 156). D'altro canto, i membri del Comitato per la Lingua Serba rifiutano nel 1998 non solo il glottonimo "bosniaco", ma anche l'apposizione "lingua" per il codice ufficiale nel paese confinante. Al posto di questa denominazione, è raccomandato l'uso dell'espressione "idioma bosgnacco" (cfr. ibidem: 142).

La sostituzione del termine "serbocroato" con il glottonimo "serbo" nella neonata Repubblica Federale di Jugoslavia dà avvio nel 1992 anche alle dispute onomastiche in Montenegro (cfr. Trovesi 2009: 202-204). Tra i numerosi glottonimi proposti dai codificatori del nuovo standard ci sono "montenegrino" (crnogorski), "montenegrino-serbo" (crnogorski-srpski), "montenegrino e serbo" (crnogorski $i$ srpski). Invece, gli oppositori al progetto di codificazione chiamano la varietà linguistica parlata nella regione "serbo" o tutt'al più riconoscono - conformemente a quanto sancito dalla costituzione del 1974 in SFRJ - un "idioma letterario montenegrino" (crnogorski književnojezički izraz) da intendere come varietà regionale del serbo.

In conseguenza di questa incertezza onomastica, denominazioni ambigue sono frequentemente adoperate nella regione anche in ambiti istituzionali. Dal 2004 nelle scuole e università del paese si insegna, per esempio, "Lingua materna e letteratura" (Maternji jezik $i$ književnost) invece di "Lingua serba e letteratura". La perifrasi permette infatti al governo di non prendere posizione sulla questione dei glottonimi: la scelta del nome della materia è così relegata agli alunni e ai genitori che possono decidere il glottonimo al momento di compilare le pagelle al termine dell'anno scolastico (cfr. Trovesi 2009: 203, Gröschel 2009: 307-309). Le denominazioni possibili per la lingua appresa a scuola - nella prima bozza dell'ordinanza non erano neanche specificate - sono poi fissate in "serbo", "montenegrino", "bosgnacco" (bošnjački) e "croato". Tale norma crea confusione nel sistema scolastico e tra la popolazione. Durante la primavera del 2007, i dibattiti sui glottonimi si intensificano inoltre anche a livello mass-mediatico: ciò avviene in concomitanza con i lavori per redigere la costituzione della neo-proclamata repubblica (cfr. Greenberg 2004/2008: 177-180 per una rassegna di alcuni articoli pubblicati sul giornale Pobjeda). Nell'ottobre 2007 si sancisce "montenegrino" come glottonimo per la

61 Interessante è che entrambi gli aggettivi sono usati secondo Manzelli (2012: 393) anche dai frati francescani della Bosnia per denominare la lingua dei cattolici residenti nella regione, che quindi oggi sarebbero considerati croati. 
lingua ufficiale. Le altre varietà neoštokave tutelate dalla legge sono chiamate "serbo", "bosniaco" (bosanski; a differenza di quanto prima stabilito per le scuole) e "croato".

Incertezze sulle denominazioni da adottare per le lingue a base neoštokava si registrano anche all'estero, mentre questa indecisione può creare confusione, se non avere effetti negativi specie nei paesi in cui risiedono molti espatriati. In particolare, nei corsi di lingua seconda o di eredità nelle università o nelle scuole, nelle biblioteche o nei tribunali, l'espressione più diffusa sembra essere attualmente "bosniaco/croato/serbo", abbreviata in BCS o BKS in tedesco (cfr. Kordić 2004: 38, Neweklowsky 2004: 245). Tuttavia, spesso, le scelte dei glottonimi non sono uniformi né tra paesi diversi né all'interno di uno stesso paese (cfr., per esempio, Gustavsson 2004: 251-254 e Neweklowsky 2004 rispettivamente per la situazione in Svezia e in Austria). Come illustrato al § II.2.5, le denominazioni usate per chiamare i codici in questione da parte di istituzioni locali variano anche in Alto Adige.

In conclusione, è rilevante notare che le dispute - specie quelle sulle apposizioni con cui definire i rapporti di differenziazione tra codici nello spazio sociolinguistico slavo meridionale - non riguardano soltanto il discorso politico e massmediatico, ma si estendono anche alla letteratura scientifica (o presunta tale). Così, le qualifiche "occidentale" e "orientale" sono state impiegate "eufemisticamente" (euphemistically), secondo Brozović (1992: 357), ${ }^{62}$ per chiamare due varianti definite piuttosto dal linguista-attivista come "nazionali", ossia il serbo e il croato. Da un punto di vista linguistico, queste appartengono, sempre secondo lo studioso, al "diasistema linguistico slavonico centro meridionale" (central south slavonic language diasystem). Inoltre, nella presentazione all'articolo appena citato, Clyne (1992: 2) nota che croato e serbo rappresentano un caso insolito di lingua "pluricentrica" in quanto parlata in uno stesso paese. Al contempo costituiscono un caso esemplare per valutare i limiti del concetto di "pluricentricità" - preso in esame nel volume - dal momento che "sono in una fase avanzata di sviluppo verso lo status di lingue per Ausbau", ossia per elaborazione (cfr. ibidem: 3, traduzione della scrivente). ${ }^{63}$ Una concezione di serbo, croato, bosniaco (e montenegrino) come lingue "per elaborazione" (Ausbau) è invece esplicitamente criticata da Kordić $(2009,2004)$. Secondo la ricercatrice, tali codici non presentano, da un lato, una "distanza minima" (Mindestabstand) tale per giustificare la qualifica di varietà standard distinte. Dall'altro, non si basano su dialetti diversi come invece solitamente fanno le lingue per elaborazione. Perciò i quattro glottonimi sono da considerarsi "sinonimi" (cfr. Raecke 1996: 21 citato da Kordić 2004: 34). Inoltre, la ricercatrice si oppone alla caratterizzazione da parte di alcuni linguisti del serbocroato come "diasistema" (cfr. la definizione di Brozović sopra). Questa apposizione si riferisce infatti tradizional-

62 Si ricordi che D. Brozović partecipa attivamente al movimento della primavera croata, elaborando il documento "Dieci tesi sulla lingua croata" nel 1971 (cfr. § II.3.4.1).

63 Secondo la terminologia introdotta da Kloss, le "lingue per elaborazione" (Ausbausprachen) sono quelle che hanno sviluppato un'ortografia e una grammatica standard, diversa da quelle delle lingue circostanti, per ragioni storiche, politiche e/o culturali. A questo concetto si contrappone quello delle "lingue per distanziazione" (o Abstandsprachen), le quali si differenziano nettamente tra loro per la loro struttura interna (cfr. Dell’Aquila \& Iannàccaro 2004: 14). 
mente a tutte le lingue slave meridionali. Il serbocroato costituisce piuttosto per Kordić (2004) una "lingua standard pluricentrica". Questa definizione vale non solo dal punto di vista strutturale, ma anche sociolinguistico: infatti, il codice in questione è sovra-regionale, largamente codificato e può essere opposto a diversi dialetti (cfr. Kordić 2004: 39).

Infine, secondo Bugarski (2004: 18-19), la questione dell'unità o diversità del serbocroato e dei successivi codici standard deve essere affrontata su almeno tre livelli distinti. Infatti, se dal punto di vista "politico" esistono quattro lingue, il serbocroato è ancora, per il ricercatore, una singola entità a livello "linguistico-comunicativo". Questa tesi è supportata dal fatto che le varietà di serbocroato, prima, e i quattro standard elaborati dal serbocroato, poi, siano tra loro intercomprensibili. Tuttavia, lo stesso studioso nota che la sostanziale intercomprensibilità tra queste varietà può essere, in taluni casi, ostacolata dall'incorrere di fattori psicologici o atteggiamenti negativi (cfr. Bugarski 1990 e anche Greenberg 2004/2008). ${ }^{64}$ Così, le opinioni, i sentimenti e le pratiche dei parlanti nativi "rispetto a quella che considerano essere la loro madrelingua e ai modi di chiamarla" costituiscono la terza prospettiva sulla questione, ossia quella "socio-psicologica" (cfr. Bugarski 2004: 18 , traduzione della scrivente). Questo ultimo punto di vista è anche quello principalmente investigato nel presente volume: in particolare, i passi delle interviste, in cui i partecipanti istituiscono rapporti di differenziazione tra i codici di partenza tramite l'uso di glottonimi e apposizioni, saranno oggetto di analisi specifica nel capitolo IV.

\subsubsection{Denominazioni e atti di posizionamento: la "nostra lingua"}

Dai dibattiti appena delineati emerge come fattori extra-linguistici condizionino l'adozione di glottonimi e apposizioni da parte di istituzioni, linguisti e parlanti nello spazio linguistico slavo meridionale. In particolare, convinzioni politiche e/o la volontà di esprimere o meno affiliazione nazionale possono influire, tra altri fattori, su tale scelta (cfr. Burgarski 2004: 17-18, Busch 2004a: 55, Gröschel 2009: 33-35, Greenberg 2004/2008: 8-9, Karadža 2004: 29). Specificamente per la popolazione espatriata, fattore rilevante potrebbe essere inoltre anche l'anno di emigrazione. Questo è infatti in parte correlato con l'esperienza diretta o meno di determinate politiche linguistiche nei paesi di provenienza. Tuttavia, le prese di posizione evocate dall'impiego di una determinata denominazione non sono univoche, ma dipendono dal contesto.

L'uso delle espressioni "naš jezik" (nostra lingua) e "naški" (nel nostro modo) in funzione di glottonimi può essere portato come esempio di tali variazioni contestuali. Queste espressioni costituiscono già prima degli anni novanta "locuzioni

64 D'altro canto, sia qui ricordato che la mutuale comprensibilità delle lingue a base neoštokava così come tra queste e il macedone e lo sloveno da un lato o anche tra varietà di albanese dall'altro - può essere vantaggiosa specie in contesto migratorio in quanto favorisce un loro utilizzo anche al di là della comunicazione tra connazionali. 
lessicalizzate" per nominare la lingua (cfr. Radovanović 1992: 93 citato da Gröschel 2009: 33). Tuttavia, la loro frequenza aumenta dopo i recenti interventi di pianificazione linguistica sia nei paesi successori alla Jugoslavia sia all'estero (cfr. Busch 2004a: 55). Tale incremento è probabilmente una conseguenza della loro acquisizione di nuovi funzioni e significati. Infatti, la perifrasi "nostra lingua" ricopre talvolta una funzione "elusiva" (evasive) perché consente al parlante di non menzionare il nome specifico del codice e, quindi, di non rivelare la propria nazionalità, ad esempio, durante interazioni con cittadini di altri paesi successori alla Jugoslavia (cfr. Gröschel 2009: 34). In altri contesti e/o con altre costellazioni di partecipanti, il termine può essere invece adoperato per riferirsi in modo mascherato al glottonimo "serbocroato". I suoi utilizzatori se ne servirebbero quindi non per prevenire un eventuale conflitto (linguistico), ma per prendere una posizione all'interno di questo e, in particolare, per opporsi ai glottonimi attuali (cfr. ibidem: $34)$.

In considerazione di quanto discusso in questa sezione del capitolo II, le denominazioni linguistiche sono così analizzate nella presente ricerca come segni attraverso cui ricostruire le rappresentazioni e le prese di posizione dei partecipanti relative ai rapporti tra i codici d'origine e tra questi e i loro parlanti al momento dei colloqui. Nel raffigurare il loro repertorio individuale e quello della "propria" o di "altre" comunità linguistiche, gli intervistati si riferiscono e sono parzialmente condizionati da opinioni metalinguistiche e discorsi politico-linguistici diffusi a livello collettivo. Nello stesso tempo, li rielaborano individualmente nella specifica situazione comunicativa "intervista" con una determinata interlocutrice. Perciò, secondo modi che saranno discussi più dettagliatamente nel capitolo IV, le denominazioni linguistiche costituiscono a mio avviso uno degli indicatori privilegiati per valutare l'interrelazione tra contesto macro e micro sulle rappresentazioni dell'identità delle lingue e dei loro parlanti nelle biografie linguistiche raccolte. 



\section{CAPITOLO III: CORPUS E METODI}

\section{DATI E POSSIBILI GENERALIZZAZIONI}

Il corpus si compone di 34 interviste singole o di coppia, condotte con 38 persone che negli ultimi venticinque anni si sono trasferite dai paesi successori alla Jugoslavia in Alto Adige. Il tipo di generalizzazioni che possono essere tratte dai dati è strettamente connesso al modo in cui questi sono stati raccolti e alle caratteristiche del campione. Modo di raccolta dati e conformazione del campione dipendono a loro volta dalle finalità della ricerca. La ricerca si propone di studiare qualitativamente come gli intervistati rappresentino e diano un senso alla ristrutturazione dei repertori individuali e comunitari in seguito a rotture storico-politiche nei paesi di provenienza e all'esperienza di mobilità in un paese straniero. Poiché l'approccio è qualitativo, l'indagine non mira a testare un'ipotesi precedentemente formulata, ma piuttosto a individuare, da un lato, schemi interpretativi di fenomeni e comportamenti linguistici e, dall'altro, a mettere in luce i fattori che li influenzano (eventualmente poi testabili in analisi quantitative successive). Alla base del metodo adottato c'è la convinzione che sia possibile trarre generalizzazioni tramite l'individuazione e la comparazione di casi tipici e non solo - come solitamente avviene in ricerche di approccio quantitativo - attraverso un esame di molti casi casuali (cfr. Lamnek 1988/2010: 166-167).

La presente sezione del terzo capitolo è strutturata come segue. Nel prossimo paragrafo espongo le modalità con cui ho contattato i partecipanti (cfr. § III.1.1), mentre al $\S$ III.1.2 illustro le relazioni che intercorrono tra di loro ed espongo le ipotesi di lavoro che hanno guidato le fasi di allargamento del campione. Successivamente descrivo gli intervistati sulla base di alcune caratteristiche migratorie e sociolinguistiche, a mio avviso, rilevanti per costruire sotto-corpora di confronto all'interno del campione totale (cfr. § III.1.3 e seguenti). Oggetto del § III.1.4 e del $\S$ III.1.5 sono, invece, rispettivamente il modo di conduzione delle interviste narrative e le competenze linguistiche dichiarate così come le lingue usate dai partecipanti nel raccontare la loro biografia linguistica. Infine, al § III.1.6, discuto il ruolo dell'intervistatrice nella raccolta e nell'interpretazione delle biografie linguistiche del corpus.

\subsection{Modi di campionamento}

Il modo in cui ho contattato i partecipanti è stato principalmente secondo i principi del "campionamento a valanga", mentre l'allargamento del corpus è avvenuto secondo i criteri del "campionamento teorico" (cfr. più avanti in questo paragrafo). La scelta delle modalità di reclutamento e campionamento degli intervistati dipende, 
da un lato, da alcune caratteristiche della popolazione studiata e da considerazioni di carattere pratico. Dall'altro, è motivata dall'approccio qualitativo scelto e dalle finalità esplorative della presente ricerca.

Nello specifico, la locazione "nascosta" della popolazione target e la sua condizione di gruppo di minoranza (spesso stigmatizzato) sono due delle ragioni che determinano la decisione di adottare un metodo di campionamento non-probabilistico come quello a valanga (cfr. Milroy \& Gordon 2003: 26-28, 30-33). Similmente a quanto avviene per cittadini stranieri provenienti da altre aree, è infatti difficile reperire i contatti e/o localizzare persone originarie dai paesi successori alla Jugoslavia residenti in provincia di Bolzano senza l'aiuto di guide interne alla comunità. Le liste dei certificati di residenza della popolazione immigrata per nazionalità non sono ovviamente consultabili nelle anagrafi dei comuni altoatesini. Inoltre, se tramite scuole di lingua, mediateche o istituzioni religiose è possibile entrare in contatto con persone straniere in modo semi-casuale, sarebbe stato poi necessario operare una seconda selezione a seconda del paese di provenienza dei contattati. Alcuni dei partecipanti alla presente ricerca hanno però vissuto esperienze traumatiche e di discriminazione a causa della guerra e dei pregiudizi o stereotipi (anche linguistici) diffusi nei paesi d'origine e d'arrivo. Perciò, non mi è parso opportuno avvicinare potenziali partecipanti in modo (quasi) anonimo, ad esempio, appendendo annunci nelle scuole o chiedendo agli insegnanti di presentarmi gli alunni ex-jugoslavi nelle loro classi.

Così, in linea con i metodi di campionamento abituali in numerosi studi di approccio biografico (cfr. Lamnek 1988/2010: 629-630), ho preferito scegliere un modo di contatto più personale. ${ }^{1}$ In particolare, ho conosciuto alcuni partecipanti "chiave" per il presente lavoro dopo aver scritto loro o in quanto presidenti di associazioni di cittadini stranieri in Alto Adige (LP, TF) o avendo ricevuto le loro e-mail da conoscenti in comune (BA, AF, DK). Queste persone mi hanno poi invitato alle riunioni delle organizzazioni e/o messo in contatto con altri potenziali partecipanti, di solito informandoli preventivamente dei modi e dei fini della ricerca. La modalità di contatto tramite istituzioni interne alla comunità o per canali privati - invece di enti della società di arrivo, come potrebbero essere le scuole di lingua - garantisce, da un lato, che i soggetti si sentano più liberi di partecipare o meno all'inchiesta. Indirettamente favorisce quindi una maggiore disponibilità degli intervistati a parlare di temi personali con una semi-sconosciuta. Dall'altro, sebbene non ne sia la condizione sufficiente, la raccomandazione da parte di conoscenti in comune agevola la costruzione di un minimo rapporto di fiducia tra intervistato e intervistatrice. Tale rapporto - che comunque è sempre condizionato dalla situazione comunicativa in via di svolgimento - è indispensabile per la conduzione di un'intervista narrativa in profondità. Ciò è vero anche se, secondo Lucius-Hoene \& Deppermann

1 Per ricerche sociolinguistiche di approccio biografico condotte su un corpus selezionato piuttosto casualmente (ovvero tramite annunci sul giornale) si confrontino invece le antologie curate da Betten (1995) e Betten \& Du Noir (2000). Secondo le ricercatrici, il campione raccolto è inoltre "rappresentativo" della popolazione studiata, ossia la generazione di popolazione ebraica rifugiatasi dalla Germania in Israele negli anni trenta. 
(2004: 298), ricercatore e partecipanti in inchieste biografiche devono essere al contempo sufficientemente estranei in modo da escludere inibizioni nel raccontare dovute, per esempio, alla frequentazione di spazi di attività quotidiana comuni - o resoconti poco dettagliati in quanto riferiti ad eventi conosciuti da entrambi gli interattanti. Nella presente ricerca, la registrazione delle biografie linguistiche è avvenuta, nella maggior parte dei casi, dopo una serie di incontri o scambi di e-mail tra partecipante e ricercatrice e/o attraverso la presentazione da parte di amici o conoscenti. $^{2}$

Dall'uso di una tecnica di campionamento a valanga segue che le persone intervistate per la presente ricerca siano state prevalentemente reclutate in modo "non casuale". In particolare, diciotto partecipanti sono stati contattati per luoghi di ritrovo piuttosto "esclusivi", ossia durante le riunioni di associazioni di cittadini stranieri fondate - almeno formalmente ${ }^{3}$ - sulla comune appartenenza nazionale dei loro membri. Inoltre, alcuni partecipanti mi sono stati presentati dal fondatore dell'ex-associazione serba di Merano (BA). Sebbene l'organizzazione non esista più proprio a causa del mancato interesse dei suoi membri, il suo ex-presidente continua ad essere un punto di riferimento per molte persone di origine serba nella cittadina altoatesina, per esempio, aiutandole nel risolvere questioni burocratiche o nella ricerca di un lavoro. Queste associazioni ed ex-associazioni promuovono (o hanno promosso) svariate attività culturali e linguistiche in provincia di Bolzano (cfr. § II.2.5). Considerato ciò, si può ipotizzare che l'appartenenza a tali gruppi sia interrelata con un impegno piuttosto attivo degli intervistati nel mantenimento dei codici d'origine in contesto migratorio e/o con un giudizio tendenzialmente positivo nei loro confronti. Per questo e per altri motivi (cfr. più avanti), il campione qui raccolto non è "rappresentativo" in senso statistico della popolazione ex-jugoslava residente in provincia di Bolzano, ma presenta piuttosto alcune imparzialità (o bias). Nel presente lavoro, il problema della parzialità del campione - quale è tipico del procedimento di selezione a valanga - è stato parzialmente risolto adottando una procedura di campionamento a più estrazioni parallele e, per quanto possibile, "mista". Da un lato, ho infatti seguito le diramazioni dei reticoli sociali di tre (più due) informanti, le cui esperienze pre- e post-mobilità variano per alcune caratteristiche significative secondo le mie ipotesi di lavoro iniziali (cfr. § III.1.2 e III.1.3 per maggiori dettagli). Dall'altro lato, ho raccolto le biografie linguistiche anche di alcuni individui isolati. Le esperienze di questi ultimi possono essere così comparate con quelle di persone che frequentano abitualmente associazioni di cittadini stranieri.

Dal momento che la presente ricerca adotta un approccio qualitativo e ha finalità esplorative, i modi di allargamento del corpus hanno inoltre seguito i principi del "campionamento teorico" (theoretical sampling) e non di quello "statistico" o

2 Eccezione è costituita dalle interviste con IP e RM. Questi due partecipanti sono stati contattati in quanto gestori di tavole calde di cucina balcanica e con loro ho svolto un'intervista al primo appuntamento.

3 L'associazione di Brunico si definisce "serba". Tuttavia i suoi membri provengono in realtà anche dall'attuale Repubblica di Montenegro. 
"per quote" (cfr. Lamnek 1988/2010: 167-177). Il presente studio non mira infatti né i) a valutare la distribuzione di determinati comportamenti o atteggiamenti linguistici a seconda di specifiche caratteristiche socio-anagrafiche dei partecipanti, né ii) a testare un'ipotesi precedentemente formulata. Piuttosto, come già detto nel capitolo I, il lavoro si pone l'obiettivo di identificare (alcuni) modelli di comportamento e (alcuni) tipi di repertorio - in primo luogo validi per la specifica realtà studiata e poi, eventualmente, generalizzabili - e di formulare ipotesi sui fattori che possano influenzarli.

La domanda di ricerca, formulata sotto il punto i), avrebbe richiesto la costruzione di un corpus "bilanciato" (o proporzionalmente stratificato) rispetto alla composizione della popolazione totale. Per condurre il secondo tipo di studio, sarebbe stato invece necessario costruire un campione "stratificato" relativamente a determinate variabili stabilite a priori come (probabilmente) significative (cfr. Biber 1993 per una comparazione tra diverse procedure di campionamento). ${ }^{4}$ Tuttavia, sebbene siano stati condotti alcuni studi sugli usi e gli atteggiamenti linguistici dei cittadini ex-jugoslavi in seguito dell'elaborazione dei codici standard successivi al serbocroato (cfr. §II.3 e seguenti), le dimensioni rilevanti di variazione - da un punto di vista sociolinguistico e, per esempio, dopo emigrazione in un paese straniero - non mi sembrano essere sufficientemente note. Lo stesso vale per i limiti dell'universo preso in esame. Infatti, se sono disponibili alcuni dati socio-demografici relativi alla popolazione immigrata in provincia di Bolzano, poche sono le informazioni di carattere linguistico. Tra queste mancano, per esempio, rilevazioni specifiche sulle lingue da loro conosciute prima di arrivare. Perciò, la costruzione di un corpus bilanciato è, nel caso studiato, di difficile realizzazione, mentre quella di uno stratificato, seppur non impossibile, mi sembra dovrebbe basarsi su criteri di selezione piuttosto arbitrari.

Al contrario, in un procedimento di campionamento teorico, il design della ricerca non è fissato fin dall'inizio. L'allargamento del corpus avviene piuttosto in fasi successive secondo domande di ricerca perfezionate e ricalibrate sulla base di analisi preliminari del materiale raccolto. In aggiunta, una parte dell'indagine consiste proprio nell'individuare le categorie localmente significative per costruire un campione "adeguato" alla situazione sotto esame. Tale strategia di raccolta dati "circolare" e "dialogica" (invece che "lineare") è particolarmente adatta, tra gli stessi metodi qualitativi, quando non si conosce molto su un tema (cfr. Lamnek 1988/2010: 171-172). ${ }^{5}$ In particolare, sebbene - come spesso avvenga in studi biografici (cfr. Lamnek 1988/2010: 629) - la selezione del campione sia stata anche

4 Nello specifico, la procedura del campionamento bilanciato è meno usata, per lo meno in linguistica dei corpora, di quella del campionamento stratificato. Il motivo è che i ricercatori non mirano tanto a stabilire la frequenza assoluta di un fenomeno, ma a individuare la sua dipendenza da determinate variabili e a identificare le caratteristiche linguistiche distintive di strati o varietà (cfr. Biber 1993: 347-348).

5 Altro metodo di campionamento dei dati in ricerche qualitative è quello "selettivo". Secondo tale tecnica, i ricercatori scelgono - sulla base dei risultati di studi condotti precedentemente casi significativi (spesso anomali o estremi) rispetto al fenomeno da analizzare (cfr. Lamnek 1988/2010: 171). 
nella presente ricerca in parte condizionata da vincoli pratici di fattibilità, ho mirato a costruire un corpus che, da un lato, massimizzasse alcune differenze tra i partecipanti e, dall'altro, sfruttasse i vantaggi del procedimento di estrazione a valanga per contattare coppie o triplette di informanti con esperienze biografiche molto simili (e dunque meglio comparabili). I rapporti tra i partecipanti così come le fasi di campionamento e le ipotesi di lavoro che le hanno guidate sono esposte più dettagliatamente nel prossimo paragrafo.

\subsection{Reticoli sociali e fasi di campionamento}

La figura in 1 mostra il "contenuto" e la "struttura" delle relazioni tra i 38 partecipanti intervistati per la presente ricerca. Con il contenuto di un legame (o proprietà interazionali di una rete) si intende il tipo di rapporto tra due nodi, in questo caso, di amicizia, di conoscenza o familiare. Le proprietà strutturali (o morfologiche di una rete) si riferiscono invece al modo in cui i legami sono interconnessi tra loro, ad esempio, se sono più o meno fitti (cfr. Vietti 2005: 54-62 e Vietti 2012, Milroy \& Gordon 2003: 116-130). Dai rapporti tra i partecipanti, rappresentati nella figura 1, emergono tre reticoli sociali principali da cui sono esclusi sei individui "isolati".

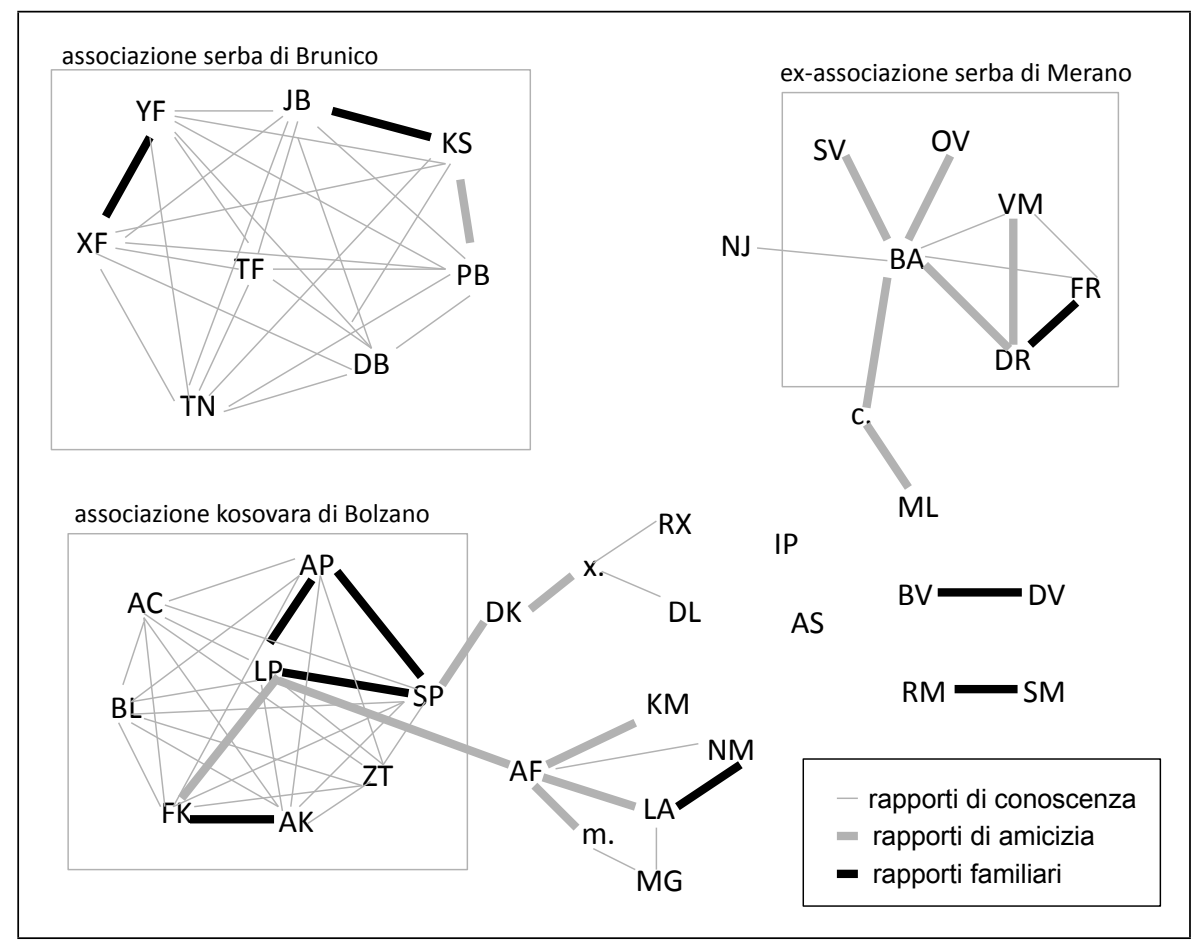

Figura 1: Diramazioni dei tre reticoli sociali principali lungo cui è avvenuto il campionamento a valanga. 
Tutte e tre le reti sono caratterizzate dalla presenza di legami sia deboli (ovvero di semplice conoscenza), sia forti (ossia amicali e familiari) tra gli informanti. Si ricordi che, nella figura 1 come altrove, mi riferisco ai singoli intervistati tramite due lettere maiuscole. Invece, con iniziali minuscole puntate indico le persone con cui non ho condotto un'intervista, ma che mi hanno aiutato nella raccolta dati.

Nello specifico, le due reti in alto nella figura 1 si equivalgono per numero di nodi, ma si differenziano tra loro per la densità dei legami. Infatti, il reticolo in alto a sinistra rappresenta un gruppo sociale coeso, ossia l'associazione serba di Brunico, in cui tutti i membri sono legati tra loro per lo meno da rapporti di conoscenza. La rete in alto a destra è invece una rete personale (o egocentrata) piuttosto che sociocentrata. Questa ritrae infatti alcuni rapporti personali di BA, fondatore dell'ex-associazione serba di Merano, con altri cittadini ex-jugoslavi residenti nella cittadina. Questi ultimi intervistati non necessariamente si conoscono tra loro. Infine, la rete in basso nella figura 1 è più estesa delle altre due e anche più composita per luogo di origine e residenza dei partecipanti. Questo reticolo si dirama lungo i rapporti personali di tre intervistate, ovvero LP, DK e AF. Sebbene le tre donne si conoscano tra loro, sono state da me contattate per vie diverse. La presenza di relazioni di amicizia, di conoscenza e familiari tra gli intervistati ha conseguenze sull'analisi dei dati e può essere valorizzata al momento di interpretarli. Tuttavia, si noti fin da subito che la presente ricerca non mira a valutare gli effetti di legami forti o deboli sulle rappresentazioni degli usi linguistici propri e altrui o sulla scelta dei glottonimi per i codici d'origine. I reticoli sociali sono infatti più il risultato del modo di campionamento che uno strumento di analisi.

Per quanto riguarda le fasi di campionamento, il primo gruppo di interviste è stato raccolto tra l'aprile e il maggio del 2013 principalmente grazie all'aiuto di tre partecipanti: LP, BA e, successivamente, DK. Al principio della ricerca le ipotesi di lavoro erano due. Volevo valutare le rappresentazioni dei rapporti tra codici e degli usi linguistici dei cittadini ex-jugoslavi dopo il trasferimento in Alto Adige, da un lato, i) a seconda della situazione politico-linguistica nei paesi di provenienza e della complessità dei repertori di partenza, dall'altro, ii) in relazione alla composizione linguistica del comune altoatesino di residenza (inizialmente Merano e Bolzano). Specificata la macro-area di provenienza, avevo tuttavia deciso di lasciare imprecisata la nazionalità così come la prima lingua degli intervistati. I motivi dipendevano sia dal fatto che il numero dei paesi da considerare varia nel tempo, sia che ero interessata a raccogliere ed esaminare diversi punti di vista sulla dissoluzione del serbocroato.

Una prima analisi dei dati ha consentito di rilevare l'impiego di denominazioni dal referente ambiguo (es. mia lingua, in lingua) e/o di glottonimi non ufficiali (es. jugoslavo, kosovaro) per chiamare i codici d'origine, propri o altrui, da parte degli intervistati. Inoltre ha permesso di identificare variazioni significative nel valutare $\mathrm{i}$ rapporti di differenziazione tra le varietà linguistiche slavo meridionali e l'allocazione dei codici di partenza e di arrivo nel proprio repertorio anche all'interno di una stessa famiglia, ad esempio, tra le sorelle FK e AK. Tali rilevazioni avvalorano l'ipotesi che fattori psicologici - come la volontà di dare una certa rappresentazione di sé - abbiano un influsso sugli usi e le competenze linguistiche per lo meno dichiarate al momento di un'intervista sociolinguistica (cfr. Betten 2010). 
Nella seconda fase di raccolta (novembre 2013 - gennaio 2014) ho dunque allargato il campione da un lato intervistando persone appartenenti a un medesimo nucleo familiare, sia della stessa generazione, sia di generazioni diverse (es. sorelle/ fratelli, genitori e figli). Dall'altro ho proseguito la raccolta dati per località di residenza, soprattutto ingrandendo il sotto-corpus di partecipanti di Merano. Sulla base della ricerca sul campo nella cittadina e delle interviste raccolte, ho potuto individuare alcuni luoghi di ritrovo (percepiti come) frequentati da ragazzi e adulti di origine balcanica. Questi "spazi di incontro" - ad esempio, un centro giovanile o un bar in una zona semi-centrale di Merano - possono costituire punti di partenza per pianificare ricerche successive.

Infine, nella terza fase di campionamento (marzo - maggio 2014), ho aggiunto, tramite il contatto con la presidente dell'associazione serba di Brunico (TF), un terzo polo di confronto. Questo è costituito dalle biografie linguistiche di residenti in paesi a netta prevalenza tedescofona, in particolare a Brunico e dintorni. Inoltre, grazie all'aiuto di AF, ho avuto modo di contattare persone non appartenenti ad associazioni di cittadini stranieri e, quindi, eventualmente più isolate nel proposito di mantenere i codici di partenza. Queste ultime sono originarie di Bosnia-Erzegovina e Croazia, mentre precedentemente il campione era composto esclusivamente di interviste con cittadini kosovari, serbi, montenegrini e macedoni.

In relazione alle domande di ricerca, è possibile dunque analizzare il campione nel suo insieme o selezionare alcune interviste dal corpus raccolto per creare sotto-corpora tra loro confrontabili. In particolare, la varietà delle esperienze raccolte giova al momento di interpretare i modi di qualificare i codici del proprio repertorio da parte dei partecipanti negli incipit delle loro interviste o di formulare ipotesi sulle funzioni dell'uso di denominazioni dal referente ambiguo nel corso dei colloqui (cfr. rispettivamente § IV.1 e IV.3). Invece, il paragonare le variazioni nei glottonimi per i codici d'origine in gruppi sociali piuttosto coesi - nello specifico, tra coppie di genitori e figli o zii e nipoti - permette a mio avviso di mettere meglio a fuoco l'influsso di fattori biografici e situazionali sulle scelte delle denominazioni di lingua (cfr.§ IV.2). Infine, il confronto tra le esperienze di partecipanti residenti in località altoatesine con diversa composizione linguistica è a fondamento dell'individuazione di BV, DK e VM come tipi ideali - e, al contempo, estremi tra di loro per l'analisi delle narrazioni di interazioni ambientate in Alto Adige (cfr. §V).

\subsection{Il corpus}

Come già accennato precedentemente, la raccolta dati non ha avuto come obiettivo la costruzione di un campione statisticamente "rappresentativo" della popolazione in relazione a determinati parametri predefiniti. Piuttosto il fine della selezione è stato l'edificazione di un corpus che rispecchiasse, secondo criteri di "adeguatezza" (Angemessenheit), la complessità della realtà presa in esame (cfr. Lamnek 1988/2010: 153, 172-173). I partecipanti sono stati dunque scelti in modo da rendere conto dell'eterogeneità delle traiettorie migratorie, dei repertori d'origine $\mathrm{e}$ delle condizioni di vita nel paese d'arrivo che contraddistingue l'universo studiato, 
ossia la popolazione ex-jugoslava in provincia di Bolzano. Di seguito presento alcune caratteristiche delle persone intervistate, facendo riferimento a tre gruppi di fattori che in letteratura risultano essere particolarmente significativi da un punto di vista sociolinguistico. Questi sono suddivisi in fattori migratori, pre-migratori e post-migratori. In generale, i partecipanti a questa ricerca hanno, al momento dell'intervista, un' età compresa tra i 18 e 59 anni, mentre il numero di intervistate donne (24) è superiore a quello dei partecipanti uomini (14). Per altre informazioni anagrafiche e socio-economiche relative ai singoli informanti (es. età, anno di emigrazione o occupazione svolta al momento del colloquio) si confronti invece la sezione della tabella dei metadati nell'allegato 1 del presente volume.

\subsubsection{Fattori migratori}

Come mostra la tabella 1, i partecipanti alla presente ricerca hanno lasciato il paese d'origine in periodi storici differenti e per motivi diversi. Inoltre, alcuni di loro avevano meno di 18 anni al momento dell'arrivo in Alto Adige. ${ }^{6}$

Tabella 1: Periodo, causa ed età al momento dell'emigrazione degli intervistati.

\begin{tabular}{|c|c|c|c|c|c|}
\hline & \multicolumn{4}{|c|}{ Motivi di emigrazione } & \multirow{2}{*}{$\begin{array}{c}\text { Totale } \\
\text { [di cui minorenni } \\
\text { all'arrivo in Alto Adige] }\end{array}$} \\
\hline & Guerra & Lavoro & $\begin{array}{c}\text { Con la } \\
\text { famiglia }\end{array}$ & Studio & \\
\hline Prima del 1991 (serbocroato) & - & 1 & - & - & 1 \\
\hline $\begin{array}{l}\text { 1990-1999 } \\
\text { (codifica di croato, bosniaco e } \\
\text { serbo e repressione linguistica } \\
\text { in Kosovo) }\end{array}$ & 13 & 3 & 5 & - & $\begin{array}{l}21 \\
{[9]}\end{array}$ \\
\hline $\begin{array}{l}2000-2009 \\
\text { (avvenuta codifica di croato, } \\
\text { bosniaco e serbo e codifica di } \\
\text { montenegrino) }\end{array}$ & - & 11 & 3 & 2 & $\begin{array}{l}16 \\
{[3]}\end{array}$ \\
\hline Totale & 13 & 15 & 8 & 2 & $\begin{array}{c}38 \\
{[12]}\end{array}$ \\
\hline
\end{tabular}

La causa di emigrazione è indicativa del progetto migratorio iniziale degli intervistati e correla con la loro condizione socio-economica nella società d'arrivo, per lo meno, all'avvio dell'esperienza migratoria (cfr. anche § II.2.6). Inoltre, i motivi di emigrazione possono avere anche effetti sulle competenze e gli usi linguistici dichiarati ed effettivi di persone mobili. A questo proposito, Schmid (2002: 192) rileva che fattori identitari - come la volontà di essere o non essere percepiti come

6 Nel caso di un'esperienza migratoria in più paesi, ma continua (ovvero ininterrotta), ho considerato la causa, l'età e il periodo al momento della prima migrazione. Invece, nel caso di un'esperienza migratoria in più paesi, ma discontinua (ovvero interrotta da un ritorno nel paese d'origine), ho considerato il motivo, l'età e il periodo al momento dell'ultima migrazione. 
membri della comunità linguistica d'origine - abbiano un forte impatto sull'attrito linguistico (in particolare, sul numero di interferenze dall'inglese) di parlanti tedescofoni ebrei emigrati negli Stati Uniti durante il nazismo. Infatti, la distinzione tra i partecipanti che hanno lasciato la Germania prima o dopo i pogrom del 1938 rende meglio conto delle variazioni nella padronanza della L1 nel suo corpus rispetto ad altre variabili (cfr. anche Schmid 2011: 96-106). In modo analogo, l'esperienza di eventi traumatici nel paese d'origine e, tra questi, un trasferimento a causa della guerra potrebbero determinare atteggiamenti negativi nei confronti dei codici di partenza anche tra i partecipanti alla presente ricerca (a differenza, per esempio, di chi si è trasferito principalmente per motivi economici o di studio).

$\mathrm{Nel}$ caso delle persone provenienti da alcune aree della ex-Jugoslavia - in particolare, Bosnia-Erzegovina, Croazia e Serbia prima, Kosovo poi - i motivi di trasferimento sono inoltre correlati con il periodo in cui questo è avvenuto (cfr. sempre tabella 1 per i dati relativi). Dall'anno di emigrazione dipende a sua volta, da un lato, il fatto che i partecipanti abbiano fatto esperienza più o meno diretta degli interventi di pianificazione linguistica e dei discorsi metalinguistici, volti all'elaborazione e alla legittimazione dei quattro codici standard successivi al serbocroato. In particolare, si possono identificare due gruppi principali: i partecipanti che hanno lasciato il paese d'origine - Bosnia-Erzegovina, Croazia, Serbia e Kosovo - negli anni novanta al momento di maggiore fervore delle politiche linguistiche e quelli che invece si sono trasferiti negli anni duemila quando i nuovi codici standard erano già tendenzialmente codificati e legittimati (una distinzione trasversale corre invece per gli intervistati montenegrini, la cui lingua standard è elaborata più tardi delle altre). Dall'altro lato, l'inizio dell'esperienza di mobilità è ovviamente correlato anche con la durata del soggiorno all'estero degli intervistati. Sia qui tuttavia notato che le traiettorie migratorie dei partecipanti non sono lineari, come del resto non lo sono neanche i processi di acquisizione, sostituzione ed erosione di lingua (cfr. sempre Schmid 2011: 71-80). Perciò, pur avendo lasciato la località d'origine da molti anni, alcuni intervistati potrebbero avere comunque poca familiarità con la situazione sociolinguistica altoatesina e/o essere stati esposti limitatamente ai codici d'arrivo e, quindi, aver competenze linguistiche inferiori rispetto a chi si è trasferito più recentemente, ma direttamente in Alto Adige (cfr. tabella 3 nel § III.1.3.3 per maggiori dettagli).

In terzo luogo, l'età al momento dell'emigrazione è un fattore tradizionalmente considerato importante nel descrivere i repertori dichiarati e gli usi linguistici reali di persone mobili. A questo riguardo, otto intervistati per la presente ricerca hanno lasciato il paese di partenza prima dei dodici anni, ovvero in una fase che secondo alcuni studiosi è "critica" - in senso sia positivo sia negativo - per l'acquisizione e il consolidamento di competenze nelle lingue seconde e prime (cfr. Selinker 1972 e anche Schmid 2011). Inoltre, la distinzione tra adulti e minori risulta, per esempio, significativa per spiegare il tipo di difficoltà comunemente incontrate nell'apprendimento delle lingue in contesto migratorio: in particolare, dai questionari raccolti in Chini (2004) emerge per esempio che gli adulti dichiarino maggiori difficoltà nel passare da competenze ricettive ad attive nella lingua seconda, mentre i minori affermino di avere più problemi nell'acquisizione di abilità scritte (lettura e scrittura) a confronto di quelle orali (ascolto e parlato). In aggiunta, gli informanti emigrati 
da adulti tendono ad avere una conoscenza più dettagliata dello spazio sociolinguistico di partenza rispetto a quelli arrivati da bambini o adolescenti: il motivo dipende anche solo dal fatto di aver trascorso un maggiore numero di anni nel paese d'origine (cfr. Andorno \& Interlandi 2004). Infine, la stessa Schmid (2011) plaude per riservare una maggiore attenzione non solo alle conseguenze del superamento del periodo "critico" nei bambini, ma anche agli effetti dei bisogni di "identificazione" (ad es. con gruppi di pari) negli adolescenti sullo sviluppo delle competenze linguistiche dopo mobilità in un altro spazio sociolinguistico.

Nello specifico, il presente lavoro si occupa di investigare l'influsso di rappresentazioni collettive sui modi dei singoli di dare un senso alle strategie di apprendimento e modalità d'impiego dei codici conosciuti. Perciò, oltre alla mera età di emigrazione, l'avvenuta scolarizzazione nel contesto di arrivo mi sembra essere un fattore particolarmente rilevante al momento di considerare le biografie linguistiche dei partecipanti. Infatti, gli intervistati arrivati da minori hanno appreso italiano e tedesco, durante il percorso formativo, in contesti anche istituzionali. Inoltre, come discusso nella prima sezione del capitolo II ( II.1 e sgg.), la frequentazione del sistema scolastico provinciale potrebbe costituire un periodo altamente "critico" per la formazione e la trasmissione di giudizi e opinioni condivise riguardo ai codici d'arrivo, mentre le scelte scolastiche dei minori stranieri sono oggetto di frequenti dibattiti a livello mass-mediatico nella società altoatesina (cfr. § II.2.4). Perciò nella tabella in 1 è indicato in parentesi quadre anche il numero di partecipanti che, essendosi trasferiti da minorenni, hanno frequentato la scuola in Alto Adige.

\subsubsection{Fattori pre-migratori}

La tabella in 2 mostra il paese di provenienza "attuale" degli intervistati, ossia secondo la ripartizione statale odierna e non al momento dell'emigrazione. Inoltre illustra schematicamente lo status sociolinguistico dei codici da loro parlati al momento della partenza per l'estero. Nello specifico, distinguo tra "codici ufficiali", "codici di minoranza" e "codici non riconosciuti". I codici ufficiali a livello nazionale parlati dagli informanti sono a seconda del luogo e del periodo: serbocroato (e/o bosniaco, croato, serbo, montenegrino) e macedone. Tra le varietà linguistiche di minoranza, ufficiali a livello regionale, conosciute dagli intervistati, ci sono invece, da un lato, l'albanese in Kosovo e anche nella Rep. di Macedonia e in Montenegro: infatti, sebbene il codice aveva e ha uno status parzialmente diverso in questi tre paesi, è parimenti insegnato a scuola e quindi gode di un certo riconoscimento a livello locale. Dall'altro lato, fa parte di questo gruppo il rumeno che è ufficialmente lingua di minoranza in Voivodína (Serbia). Al contrario, le varietà di daco-rumeno, parlate nella Serbia centro-orientale, non sono tutelate a livello ufficiale nè apprese a scuola e, quindi, appartengono alla terza categoria dei "codici non riconosciuti".

Come risulta dalla tabella 2, il corpus di intervistati rappresenta abbastanza adeguatamente la complessità dei repertori di partenza dell'universo preso in esame. Ho infatti raccolto esperienze di persone che parlano codici con diverso status e grado di standardizzazione nel paese d'origine. Inoltre, i partecipanti hanno 
esperito prima del trasferimento - ed esperiscono tutt'ora quando ritornano temporaneamente nelle località di nascita - diversi modi di gestione del plurilinguismo

Tabella 2: Paese di provenienza e situazione sociolinguistica nelle località d'origine degli intervistati.

\begin{tabular}{|l|c|c|c|c|c|}
\hline & $\begin{array}{c}\text { Uno o più } \\
\text { codici } \\
\text { ufficiali }\end{array}$ & $\begin{array}{c}\text { Uno o più codici di } \\
\text { minoranza \& uno o } \\
\text { più codici ufficiali }\end{array}$ & $\begin{array}{c}\text { Un codice di } \\
\text { minoranza }\end{array}$ & $\begin{array}{c}\text { Un codice non } \\
\text { riconosciuto \& un } \\
\text { codice ufficiale }\end{array}$ & Totale \\
\hline Serbia & 14 & 1 & - & 1 & $\mathbf{1 6}$ \\
\hline Kosovo & - & 4 & 6 & - & $\mathbf{1 0}$ \\
\hline Montenegro & 2 & 2 & - & - & $\mathbf{4}$ \\
\hline Rep. di Macedonia & 2 & 2 & - & - & $\mathbf{4}$ \\
\hline Bosnia-Erzegovina & 2 & - & - & - & $\mathbf{2}$ \\
\hline Croazia & 2 & - & - & - & $\mathbf{2}$ \\
\hline Totale & $\mathbf{2 2}$ & $\mathbf{9}$ & $\mathbf{6}$ & $\mathbf{1}$ & $\mathbf{3 8}$ \\
\hline
\end{tabular}

sociale e individuale a livello istituzionale. In particolare, c'è chi dichiara competenze esclusivamente in serbocroato e/o in uno o più codici standard a questo succeduti (cfr. seconda colonna nella tabella 2). Analoga, relativamente al fattore pre-migratorio "status del codice d'origine", è la situazione di altri due partecipanti che padroneggiavano, al momento di partire, due codici ufficiali nella regione d'origine, vale a dire serbo(croato) e macedone nella Rep. di Macedonia (cfr. sempre seconda colonna nella tabella 2). Invece, un gruppo piuttosto numeroso di intervistati parlava quotidianamente albanese (ossia un codice di minoranza), almeno in famiglia, prima di trasferirsi all'estero. Queste persone provengono dal Kosovo $(4+6$ partecipanti) e anche dal sud del Montenegro (2 partecipanti) o dal nord-ovest della Rep. di Macedonia (2 partecipanti). A seconda del periodo e del luogo di residenza, l'albanese detiene un diverso potere comunicativo nelle località d'origine degli intervistati. Inoltre l'acquisizione di altre lingue, oltre all'albanese, è più o meno necessaria. Così, sei tra gli informanti provenienti dal Kosovo hanno competenze solo nel codice di minoranza e non in quello allora ufficiale, vale a dire il serbocroato o serbo (cfr. quarta colonna nella tabella 2). Un tale repertorio tendenzialmente monolingue non è invece possibile per i parlanti albanofoni risiedenti in Montenegro o nella Rep. di Macedonia che infatti hanno sempre competenza, oltre che in albanese, in uno o più codici ufficiali (es. serbocroato e/o macedone). Infine, due partecipanti hanno competenze in varietà di daco-rumeno che godono di diverso status e riconoscimento istituzionale in Serbia. Da un lato, in Voivodína, il codice è tutelato e, per esempio, insegnato a scuola, anche se la sua vitalità non è particolarmente alta nella regione (cfr. anche §II.3.3). Dall'altro lato, nella Serbia centro-orientale le varietà locali di rumeno non sono invece standardizzate e sono parlate solo in famiglia (cfr. quinta colonna nella tabella 2$)^{7}$

7 Per un'analisi più dettagliata dei modi di rappresentare i repertori linguistici di origine da parte dei partecipanti si veda il capitolo IV del presente volume. 
Infine, si noti che anche il paese di provenienza potrebbe influenzare i modi di rappresentare i rapporti di differenziazione tra i codici di partenza da parte dei partecipanti. Infatti, i governi, le accademie e i mass media pianificano e dibattono politiche linguistiche principalmente a livello nazionale, mentre queste variano perciò da stato a stato (cfr. anche $\S$ II.3.4 e sgg.). La maggior parte degli intervistati proviene da località che attualmente si trovano in Serbia. Una diversa prospettiva rispetto alla dissoluzione del serbocroato potrebbe essere propria di quelle persone che hanno abitato in altre regioni della ex-Jugoslavia, vale a dire o in quelle a maggioranza di parlanti neoštokavi (ossia in Croazia, Bosnia-Erzegovina o Montenegro) oppure in zone dove il serbocroato era lingua ufficiale, ma non di maggioranza (ossia nella Rep. di Macedonia e in Kosovo). Tuttavia, dalle interviste del corpus emerge che il paese d'origine - così come l'età o l'anno di emigrazione - non siano sempre decisivi nel determinare l'appartenenza nazionale dichiarata dai partecipanti né il numero di codici da loro attualmente riconosciuti come standard.

\subsubsection{Fattori post-migratori}

Il corpus è adeguato anche in relazione ad alcuni fattori che, secondo altre ricerche, condizionano gli usi e gli atteggiamenti linguistici della popolazione straniera in Alto Adige. Come riportato nella tabella 3 , tra questi ci sono i) la molteplicità delle traiettorie di mobilità - semplificate qui in soggiorno precedente in un paese tedescofono, italofono o arrivo diretto in Alto Adige -, ii) la composizione linguistica della località di prima residenza in Alto Adige e iii) la durata del soggiorno in provincia di Bolzano.

Tabella 3: Traiettorie migratorie, composizione linguistica del comune altoatesino di residenza e durata del soggiorno in Alto Adige degli intervistati.

\begin{tabular}{|c|c|c|c|c|}
\hline & $\begin{array}{c}\text { Località a } \\
\text { prevalenza } \\
\text { italofona }\end{array}$ & $\begin{array}{c}\text { Località a } \\
\text { prevalenza } \\
\text { tedescofona }\end{array}$ & $\begin{array}{l}\text { Località con } \\
\text { equivalenza tra } \\
\text { gruppi linguistici }\end{array}$ & $\begin{array}{l}\text { Totale } \\
\text { [di cui residenti in Alto } \\
\text { Adige da } 10 \text { anni o più] }\end{array}$ \\
\hline Direttamente in Alto Adige & 8 & 6 & 6 & $\begin{array}{c}\mathbf{2 0} \\
{[17]}\end{array}$ \\
\hline $\begin{array}{l}\text { Paesi tedescofoni } \\
\text { (es. Germania, Austria, } \\
\text { Svizzera) }\end{array}$ & 4 & 5 & 1 & $\begin{array}{l}\mathbf{1 0} \\
{[8]}\end{array}$ \\
\hline $\begin{array}{l}\text { Altre regioni italiane } \\
\text { (es. Abruzzo, Campania, } \\
\text { Veneto) }\end{array}$ & 3 & 3 & 1 & $\begin{array}{c}7 \\
{[4]}\end{array}$ \\
\hline $\begin{array}{l}\text { Sia paesi tedescofoni sia } \\
\text { altre regioni italiane }\end{array}$ & 1 & - & - & 1 \\
\hline Totale & 16 & 14 & 8 & $\begin{array}{c}\mathbf{3 8} \\
{[29]}\end{array}$ \\
\hline
\end{tabular}

Alcuni partecipanti del corpus si sono trasferiti direttamente in Alto Adige dopo aver lasciato il loro paese d'origine. Questi spesso raccontano di non essere stati al 
corrente, al momento dell'arrivo, della situazione sociolinguistica della regione d'arrivo e, in particolare, di aver sottovalutato la diffusione delle varietà di tedesco nell'area. Invece, altri intervistati hanno vissuto in paesi tedescofoni e/o in altre regioni italiane prima di giungere in provincia di Bolzano. Perciò, hanno acquisito competenze in uno o in due codici d'arrivo in un altro contesto. Inoltre, i partecipanti alla presente ricerca si sono trasferiti in località altoatesine sia a maggioranza italofona, sia a prevalenza tedescofona, sia in cui vive un numero quasi uguale di persone appartenenti ai due gruppi linguistici (questo ultimo è il caso di Merano). Come illustrato nel secondo capitolo (cfr. § II.1.2 e II.2.3), la composizione linguistica del comune di residenza ha talvolta un influsso sulle possibilità di entrare in contatto (o di non entrare in contatto) con i codici d'arrivo e, quindi, sugli usi e gli atteggiamenti linguistici della popolazione straniera così come locale. Infine, la durata del soggiorno in Alto Adige è indicativa della stabilità dei progetti migratori degli intervistati. Dal punto di vista linguistico, questa può eventualmente correlare con una loro maggiore consapevolezza dei benefici dell'acquisizione di entrambi i codici di arrivo (sia italiano, che tedesco) per vivere bene in provincia di Bolzano (cfr. Cortinovis 2011: 46-48). D'altro canto, secondo alcuni studi citati in Schmid (2011: 71-80), i primi dieci anni di soggiorno all'estero sono cruciali nel determinare processi di erosione della lingua prima e, quindi, per esempio, se questa è estensivamente sostituita, per causare una sensazione di dimenticanza del codice.

\subsection{Modi di conduzione delle interviste}

Il corpus si compone di 34 interviste qualitative, la maggior parte delle quali condotte su modello di quelle effettuate per elicitare biografie linguistiche. La durata totale delle registrazioni è di 27 ore e 45 minuti, mentre i colloqui durano in media 44 minuti.

Il testo interazionale delle interviste narrative si compone idealmente di tre parti non necessariamente di uguale durata (cfr. Lucius-Hoene \& Deppermann 2004: 295-303, Schütze 1983: 285). Nella prima fase, la ricercatrice espone gli obiettivi dell'indagine e avvia l'intervista tramite una domanda il più possibile aperta, volta a generare un racconto biografico. Nel presente caso, il quesito iniziale è formulato all'incirca come segue: ${ }^{8}$

- vorrei chiederle se mi può raccontare delle lingue o dei dialetti che conosce o anche solo capisce o che sentiva parlare intorno a lei e se mi può raccontare di dove, come e quando ha appreso o è entrato/a in contatto con queste lingue o dialetti?

Dopo il primo quesito, il banco è assegnato al narratore o alla narratrice che inizialmente struttura il discorso come preferisce. Tra gli obiettivi dell'analisi, c'è infatti proprio quello di individuare $\mathrm{i}$ temi più rilevanti nella prospettiva degli intervistati riguardo all'argomento generale della conversazione così come quello di identifi-

8 Per esempi concreti degli incipit delle interviste del corpus si veda il § IV.1, dove questi sono analizzati nel dettaglio. 
care i principi formali e contenutistici secondo cui i singoli organizzano dapprima autonomamente i propri racconti biografici (cfr. anche $\S$ III. 2 e sgg.). Si noti che la distribuzione dei ruoli, negoziata all'avvio di una biografia linguistica, non è quella abituale nella situazione comunicativa "intervista", vale a dire in un colloquio tipicamente piuttosto formale tra una "ricercatrice" e un "informante". Perciò non è insolito che, nei primi minuti o nel corso dei colloqui, i partecipanti chiedano chiarimenti sul compito che devono svolgere e/o invitino l'interlocutrice a formulare domande più specifiche riguardo a ciò che vuole sapere (cfr. Lucius-Hoene \& Deppermann 2004: 200-201).

La seconda fase del colloquio inizia solitamente dopo una coda del narratore o della narratrice che ricongiunge il tempo della storia a quello presente. Questa parte dell'intervista è solitamente episodica, ovvero è caratterizzata da un intreccio di narrazioni del partecipante e di interrogazioni da parte dell'intervistatrice. Le domande di chiarimento tangenziali della seconda fase di un'intervista narrativa (tangentialer Nachfrageteil) incoraggiano l'informante a sviluppare alcuni temi affrontati in precedenza.

Infine, il colloquio si chiude con una "parte di bilanciamento" (Bilanzierungsteil). In questa sezione, la ricercatrice pone quesiti riguardo ad aspetti rilevanti per l'indagine, non menzionati spontaneamente dai narratori. Il formato delle domande in un'intervista narrativa è di preferenza aperto. Sono dunque evitate domande polari "sì/no" o domande che pongano alternative predefinite, direzionando così l'interlocutore verso una risposta "attesa" o preferita (cfr. Veronesi 2012: 68-73 e anche Lamnek 1988/2010: 357-363).

Le interviste raccolte per la presente ricerca seguono in concreto modelli di conduzione leggermente diversi dal tipo ideale appena tratteggiato. Queste variazioni dipendono in parte dalle fasi di campionamento, in parte sono da ricondurre al rapporto instauratosi tra ricercatrice e partecipante durante il colloquio o a preferenze comunicative individuali.

A causa dell'inesperienza con il metodo sopra esposto, le prime otto conversazioni registrate non sono propriamente interviste narrative. Queste sono piuttosto definibili come interviste "semi-strutturate" sulla base di una traccia di argomenti predefiniti. In questi colloqui, la prima domanda sul tema lingua segue quelle riguardo ai dati socio-anagrafici e al percorso migratorio dell'intervistato. Il quesito è formulato all'incirca come segue: "Quali lingue o dialetti ha imparato a casa dai suoi genitori prima dei sei anni?". Il testo elicitato da questi interrogativi è prevalentemente descrittivo-argomentativo. Le otto interviste semi-strutturate sono condotte rispettivamente con AC, AK, BL, FK, ML, ZT, BA, LP.

Già durante la prima fase della raccolta dati nella primavera del 2013, ho comunque optato per assumere uno stile di comunicazione più affine a quello delle "interviste morbide" (weiche Interviews), ovvero caratterizzato da un atteggiamento più neutrale, se non solidarizzante e da interventi sporadici da parte della ricercatrice (cfr. Lamnek 1988/2010: 313-314). Alcuni partecipanti hanno reagito adottando modi di comunicazione e rappresentazione prevalentemente narrativi, mentre altre interviste sono comunque caratterizzate soprattutto da sequenze argomentative o descrittive. In generale, la commistione di diversi tipi di testo non è 
sorprendente, ma è usuale nel realizzare concretamente un racconto biografico orale (cfr. Lucius-Hoene \& Deppermann 2004: 141-175, Betten 2010). Nei paragrafi successivi mi riferisco perciò alle 22 interviste del corpus raccolte con questo metodo tramite l'etichetta "interviste episodico-narrative". ${ }^{9}$ Dal momento che tali biografie linguistiche sono state spesso registrate nelle abitazioni dei partecipanti, è talvolta successo che altre persone - oltre al narratore e alla ricercatrice - fossero presenti in alcune fasi del colloquio e occasionalmente intervenissero nella conversazione (cfr. interviste con DV, OV, RM, VM).

Infine, ho condotto quattro "interviste di coppia", ovvero colloqui in cui, oltre alla ricercatrice, partecipavano altri due intervistati (cfr. Lamnek 1988/2010: 326, Lucius-Hoene \& Deppermann 2004: 299). Durante queste conversazioni, analogamente a nelle interviste focus group, gli informanti discutono tra loro dei temi proposti dalla intervistatrice/moderatrice. Nel fare ciò, prendono posizione su argomenti di lingua, allineandosi o disallineandosi l'uno rispetto all'altro in modo simile a quanto avviene nelle conversazioni quotidiane. La tecnica permette così di analizzare specificamente i processi di gruppo attraverso cui opinioni condivise si formano o sono contestate in interazione (cfr. Lamnek 1988/2010: 375-394 e Clyne \& Kipp 1999, Innàccaro \& Dell'Aquila 2007, Dal Negro 2009 per esempi dell'applicazione del metodo focus group in ricerche sociolinguistiche). A differenza che nelle interviste focus group vere e proprie, il numero limitato e il rapporto coeso dei partecipanti - massimo due intervistati, legati tra loro da legami familiari o di amicizia stretti - ha consentito comunque, nelle interviste di coppia condotte per la presente ricerca, di mantenere una situazione a basso potenziale di conflitto, più affine a quella di un'intervista narrativa in profondità. I colloqui a due sono quelli effettuati con DR e FR (madre/figlia), SP e AP (sorelle), YF e XF (marito/moglie), PB e KS (amiche).

\subsection{La lingua delle interviste e le competenze dichiarate dei partecipanti}

Prima di iniziare le interviste ho sempre chiesto ai partecipanti se preferissero raccontare la loro biografia linguistica in italiano o in tedesco. La maggior parte degli intervistati ha scelto l'italiano ( 27 persone), mentre nove partecipanti hanno preferito parlare in tedesco. Infine due persone mi hanno chiesto di svolgere la conversazione in inglese.

Il codice selezionato per il colloquio non coincide sempre con la prima lingua appresa in Alto Adige né con quella meglio conosciuta o preferita dall'informante. A questo riguardo, la tabella 4 incrocia i dati relativi alla lingua principalmente usata dai partecipanti durante l'intervista con quelli del primo codice da loro appreso dopo il trasferimento in provincia di Bolzano. È interessante notare che solo i partecipanti che hanno imparato come prima lingua il tedesco scelgano talvolta di condurre l'intervista in un altro codice. Questa scelta può dipendere da diversi fattori. Alcuni intervistati (es. FK, BA) hanno, per esempio, infatti dichiarato di aver

9 Le interviste episodico-narrative sono quelle con: NJ, DK, DL, RX, AS, OV, RM, SM, SV, VM, AF, BV, DV, IP, KM, DB, JB, LA, MG, NM, TF, TN. 
condotto l'intervista in italiano per accomodare la prima lingua dell'interlocutrice, ma che avrebbero scelto il tedesco con una ricercatrice tedescofona (cfr., sul ruolo dell'intervistatrice nella raccolta dati, anche il seguente §III.1.6). In altri casi, la scelta di codice dipende invece probabilmente dal modo del contatto, avvenuto tramite conoscenti che parlano di preferenza l'italiano, e/o dalla costellazione di partecipanti all'avvio dell'interazione, vale a dire in presenza di altri interattanti esclusivamente italofoni (es. AF, VM). In altri casi ancora, tale decisione può essere un segnale di insicurezza linguistica (cfr. BV e DV che conducono l'intervista in inglese). Sia qui comunque sottolineato che la lingua di conduzione dell'intervista è quella principalmente usata dai partecipanti, ma non l'unica adoperata durante $\mathrm{i}$ colloqui. Infatti, come sarà meglio illustrato nel capitolo $\mathrm{V}$, durante alcune registrazioni, sono abbastanza frequenti inserzioni e/o commutazioni di codice specialmente nell'altra lingua d'arrivo (ossia in italiano o in tedesco) e, talvolta, anche in inglese o nei codici di partenza.

Tabella 4: Lingua dell'intervista e prima lingua appresa in Alto Adige dagli intervistati.

\begin{tabular}{|c|c|c|c|c|c|}
\hline & \multicolumn{3}{|c|}{ Lingua principalmente usata nell'intervista } & \multirow[b]{2}{*}{ Totale } \\
\hline & & italiano & tedesco & inglese & \\
\hline \multirow{3}{*}{ 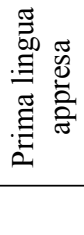 } & italiano & 22 & - & - & 22 \\
\hline & tedesco & 5 & 9 & 2 & 16 \\
\hline & Totale & 27 & 9 & 2 & 38 \\
\hline
\end{tabular}

Nella tabella 5 sono invece riassunti i dati relativi alle competenze linguistiche dichiarate dai partecipanti nei codici d'arrivo, ossia italiano, tedesco, e dialetti austro-bavaresi locali.

Tabella 5: Competenze linguistiche dichiarate dagli intervistati (auto-valutazioni).

\begin{tabular}{|l|c|c|c|}
\hline & Italiano & Tedesco & Dialetti austro-bavaresi locali \\
\hline Competenze alte & 27 & 14 & 7 \\
\hline Competenze medie & 6 & 4 & 2 \\
\hline Competenze basse & 2 & 13 & 3 \\
\hline Nessuna competenza & 3 & 7 & 23 \\
\hline
\end{tabular}

Preliminarmente possono essere fatte le seguenti osservazioni (cfr. §V per una discussione più dettagliata). In primo luogo, diversamente da quanto spesso argomentato nei discorsi politici e mass-mediatici locali (cfr. § II.2.4), conoscenze (alte, medie o basse) in tedesco sono comuni tra i partecipanti alla presente ricerca, almeno secondo le loro auto-valutazioni (31 su 38 intervistati). Tuttavia, gli intervistati del corpus sono in media più sicuri della propria padronanza dell'italiano: ben 27 persone affermano infatti di conoscere molto bene questo codice contro 14 che dichia- 
rano alte competenze in tedesco. Infine, la maggior parte degli informanti (23 su 35 - di tre partecipanti non ho infatti i dati) dichiara di non aver nessuna conoscenza in uno dei dialetti tedeschi locali, parlati in Alto Adige.

\subsection{Il ruolo dell'intervistatrice}

Per quanto riguarda il ruolo dell'intervistatrice, è importante notare che la sua persona ha un influsso sia al momento della raccolta dati - in quanto interattante con obiettivi e aspettative proprie nel corso delle interviste/conversazioni - sia come ricercatrice, che analizza successivamente i dati interazionali raccolti (cfr., su questo tema, Lucius-Hoene \& Deppermann 2004: 95-107, Lamnek 1988/2010: 19-25 e anche Slembrouck 2015 specificamente sull'influenza dell'analista sulla produzione, ma anche interpretazione di narrazioni in intervista).

Per quanto riguarda il primo aspetto, il fatto che le biografie linguistiche del corpus siano state raccontate a un'intervistatrice italofona, che non è originaria dei paesi di partenza dei partecipanti e che si presenta come membro di un'istituzione pubblica, seppur educativa, del paese d'arrivo (ossia il Centro Competenza Lingue dell'Università di Bolzano), ha sicuramente un influsso sul tipo di informazioni considerate rilevanti dagli informanti durante i colloqui. Tale condizionamento si manifesta, per esempio, da un lato, nelle presupposizioni che questi probabilmente fanno rispetto alle conoscenze pregresse dell'interlocutrice riguardo alla situazione sociolinguistica di partenza. D'altro canto, come in taluni casi esplicitamente affermato, potrebbe giocare anche un ruolo nel determinare la lingua di conduzione del colloquio o, eventualmente, nel plasmare alcune prese di posizione degli intervistati rispetto ai codici di arrivo. Quest'ultima evenienza non può essere sottovalutata, specialmente se si considera che i partecipanti risiedono in una società (apparentemente) piuttosto polarizzata dal punto di vista linguistico e sociolinguistico come quella altoatesina. Inoltre, anche nel corso della stessa intervista, la ricercatrice influenza il procedere della conversazione, tra l'altro, sia con domande esplicite, sia più indirettamente attraverso segnali difeedback, pause o attività paraverbali (come gesti, espressioni del viso, etc.).

Per quanto riguarda la seconda questione (ossia il ruolo della ricercatrice al momento dell'interpretazione dei dati), sia qui sottolineato che, sebbene, nell'approccio qualitativo adottato, l'analista si avvicini ai dati senza un'ipotesi a priori da verificare o falsificare, quest'ultima inizia ovviamente la sua ricerca con delle conoscenze preliminari e anche delle supposizioni su quelli che potrebbero essere i risultati. Questa costellazione determina il verificarsi del cosiddetto "paradosso del sapere" (Wissensparadox) (cfr. Lucius-Hoene \& Deppermann 2004: 106). La ricercatrice necessita infatti di diversi tipi di conoscenze preliminari di base (ad esempio, storico-etnografiche, linguistico-comunicative, teoriche) per condurre il suo studio. Al contempo, nel corso dell'analisi, deve mettere costantemente in discussione la loro rilevanza per l'interpretazione dei dati raccolti. Il tentativo è quello di evitare di raggiungere risultati parziali, che esclusivamente riproducano le proprie conoscenze (o stereotipi) di partenza. 
In particolare, secondo Lucius-Hoene \& Deppermann (2004: 97-99), per risolvere questa contraddizione in modo produttivo è importante seguire i principi della "centratura dei/sui dati" (Datenzentrierung) e dell'"attitudine alla ricostruzione" (Rekonstruktionshaltung) e metterli in relazione con le proprie conoscenze pregresse. In altre parole, da un lato, le interpretazioni devono basarsi sul testo interazionale delle interviste senza avanzare speculazioni su una possibile realtà psichica o oggettiva al di là di quanto effettivamente espresso dagli informanti. Anche in conseguenza di ciò, si è ripetutamente ribadito che l'oggetto della presente ricerca sono le rappresentazioni e le prese di posizioni dei narratori durante i colloqui e non i loro atteggiamenti o percezioni né, tantomeno, usi linguistici reali (cfr. anche i $\S$ III.2.3.2 e III.2.3.3). Dall'altro lato, al momento dell'analisi, ho cercato di adottare il più possibile un "atteggiamento di sospensione di giudizio" (suspensive Haltung), vagliando e soppesando molteplici interpretazioni possibili. Così, come sarà meglio illustrato nella prossima sezione del capitolo II e poi nei capitoli IV e V, la presente ricerca si fonda su uno studio dettagliato di alcune sequenze delle interviste, le quali sono trascritte e riportate nella loro interezza di modo che la loro interpretazione possa essere valutata autonomamente anche dai lettori. La convinzione è che fenomeni micro-linguistici, come le scelte lessicali, l'uso di determinate congiunzioni o avverbi deittici e l'attribuzione e i modi di mettere in scena il discorso riportato, siano segnali atti a ricostruire le rappresentazioni delle identità di lingue e parlanti nei contesti di arrivo e di partenza.

\section{PRINCIPI E STRUMENTI DI ANALISI}

Le unità di analisi della presente ricerca sono state già descritte nel primo capitolo. In questa seconda sezione del capitolo III illustro invece dapprima i principi generali e gli strumenti, di cui mi avvalgo per l'esame strutturale delle biografie linguistiche raccolte, così come il sistema di convenzioni scelto per trascriverle (cfr. §III.2.1 e $\S$ III.2.2). Successivamente, ai $\S$ III.2.3 e seguenti, discuto i concetti analitici di "identità narrative", "rappresentazioni" e "atti di posizionamento" e li distinguo da nozioni affini. Su questi concetti si fonda infatti l'interpretazione di alcune sequenze chiave delle interviste del corpus, effettuata durante l'analisi micro. Per ulteriori dettagli sui metodi adottati in specifiche fasi del lavoro rimando invece alle introduzioni dei capitoli IV e V.

\subsection{Analisi macro e supporti informatici}

Le interviste sono analizzate nella loro dimensione "presentazionale" e "interazionale" secondo il metodo interpretativo della "ricostruzione dell'identità narrativa" proposto da Lucius-Hoene \& Deppermann (2004) (cfr. anche Franceschini 2003). Seguendo la metodologia suggerita dai due studiosi, ho in primo luogo segmentato il flusso del parlato delle registrazioni sulla base di caratteristiche strutturali. L'analisi macro, o anche "nei tratti essenziali" (grob), delle interviste mira ad individuare 
i principi generali - contenutistici e formali (ad es. tematici, cronologici, testuali, retorici) - secondo cui i parlanti organizzano sequenzialmente la loro biografia linguistica. Nel fare ciò, particolare attenzione è posta ai "marcatori di struttura" (Gliederungsmarkierer), ossia agli elementi verbali o para-verbali che segnano i punti di transizione tra le unità o sotto-unità in cui il racconto è articolato (cfr. Lucius-Hoene \& Deppermann 2004: 109-140).

Oltre che per l'argomento trattato, Lucius-Hoene \& Deppermann (2004) propongono di suddividere il testo interazionale anche per il "tipo di testo", ovvero in "narrazioni", "argomentazioni" e "descrizioni". La segmentazione per "tipi di testo" (o "modi di rappresentazione") non è sempre facile dal momento che le tre tipologie spesso si intrecciano le une alle altre. In conseguenza di ciò, la loro individuazione richiede talvolta una disamina più dettagliata del testo delle interviste $\mathrm{e}$, quindi, deve essere posposta a cicli di analisi successive (cfr. ibidem: 319 ). Tuttavia, già in questa prima fase del lavoro, ho annotato il modo di rappresentazione prevalentemente adottato dal narratore in determinate sequenze. Soprattutto mi interessava registrare l'occorrere di racconti scenico-episodici o di narrazioni in funzione argomentativa (cfr. capitolo $\mathrm{V}$ per maggiori dettagli).

Il risultato del lavoro è una tabella a quattro colonne, compilata per ogni registrazione, in cui riporto i) il tema della conversazione, ii) i minuti corrispondenti e, eventualmente, iii) il tipo di testo così come iv) alcune note (o memos), per esempio, sui riferimenti degli informanti a temi ricorrenti - vale a dire menzionati anche in altre interviste - o sull'impiego di glottonimi particolari. Questo "protocollo di ascolto" funziona come una sorta di indice che facilita la visualizzazione del contenuto delle interviste e l'individuazione dei passaggi chiave su cui concentrare l'analisi micro o "dettagliata" (fein) (cfr. anche $\S$ III.2.3 e l'allegato 2 in fondo al volume per un esempio di protocollo d'ascolto).

Subito dopo gli incontri, ho anche stilato "protocolli di situazione" in cui documento, per ogni registrazione, informazioni etnografiche relative al contesto, ai partecipanti e ai modi di conduzione dell'intervista (cfr. Dittmar 2004: 229-230). In particolare, in questi protocolli sono annotati per esempio la data e il luogo del colloquio. Inoltre sono contenute informazioni sulle modalità del contatto, sui rapporti dell'intervistato con altri partecipanti così come sull'atmosfera durante l'intervista, sulla qualità dell'audio e sul tipo di registratore adoperato. In aggiunta, se rilevanti, trascrivo in questi documenti anche i temi di conversazioni avvenute prima o dopo l'accensione del registratore e/o in incontri precedenti o successivi (cfr. l'allegato 3 per un esempio di protocollo di situazione).

In contemporanea, ho anche compilato due tabelle in Excel. La prima, come già accennato, contiene i metadati relativi ai partecipanti (cfr. allegato 1 in fondo al volume). La seconda comprende alcune informazioni "standardizzate" sui codici che gli informanti dichiarano di aver usato o di usare in determinate situazioni comunicative nel paese d'origine e dopo il trasferimento in Alto Adige: tale tabella è alla base delle rappresentazioni dei "repertori dichiarati" dei partecipanti ai § V.2.4 e seguenti.

La segmentazione e poi la trascrizione delle interviste è stata effettuata tramite l'ausilio del programma ELAN. Alcune interviste sono state trascritte interamente, 
mentre in altri casi ho selezionato solo le sequenze dei colloqui su cui volevo concentrare l'analisi (cfr. Lucius-Hoene \& Deppermann 2004: 321-316 per il metodo). Inizialmente, il grado di dettaglio della trascrizione è basilare. Questo è stato poi eventualmente raffinato in fasi di lavoro successive (cfr. § III.2.2 per le convenzioni di trascrizione). In totale ho trascritto circa 13 ore di conversazione. La scelta di utilizzare ELAN rispetto ad altri programmi di trascrizione (es. EXMARaLDA, FOLKER, F4) è soprattutto motivata dalla sua diffusione in ricerche di linguistica applicata.

Infine, per un esame più approfondito (sia descrittivo sia esplorativo) delle interviste utilizzo MAXQDA, che è un software pensato per supportare l'analisi qualitativa di testi sia orali sia scritti (cfr. Kelle 2008 per un paragone tra diversi programmi di analisi qualitativa assistita dal computer). Nello specifico, MAXQDA è progettato per condurre analisi sulla base di approcci ispirati alla Grounded Theory. Secondo questo metodo, il confronto di passi con lo stesso tema e, quindi, codificati con le stesse categorie permette di individuare le "dimensioni" di tali categorie. Il fine del "paragone continuo" è la generazione di una teoria che sia radicata nei dati raccolti (cfr. Strauss \& Corbin 1990/1996).

MAXQDA facilita l'organizzazione e il confronto dei dati raccolti. Partendo dal testo delle interviste è possibile infatti stabilire una serie di categorie e sotto-categorie con cui codificare in modo uniforme le informazioni ivi contenute. Le sequenze categorizzate nello stesso modo - sia in un'intervista, sia in interviste diverse - sono poi recuperabili velocemente per essere paragonate tra loro. Il programma permette inoltre di creare tabelle incrociate con, da una parte, i metadati di un testo e, dall'altra, le dimensioni (o codici) delle categorie identificate. In questo modo si può per esempio visualizzare rapidamente quanti uomini e quante donne considerano "dialetto" (codice) la "lingua imparata a casa" (categoria). Come sarà meglio esposto nei capitoli IV e V, nella presente ricerca, ho codificato, in particolare, tramite MAXQDA i (tipi di) glottonimi e le apposizioni usati dai partecipanti per chiamare i codici d'origine durante i colloqui. Inoltre ho categorizzato le narrazioni di interazioni da loro raccontate per il contesto, il codice di comunicazione nel mondo della storia, il tipo di interattanti e il ruolo interazionale da questi svolto (es. ascoltatore/ascoltatrice o parlante) nel dialogo riportato.

\subsection{Le convenzioni di trascrizione}

Come convenzioni di trascrizione utilizzo un sottoinsieme delle convenzioni stabilite per l'Analisi della Conversazione (CA), integrato con alcuni simboli GAT (cfr. Jefferson 1984 e Dittmar 2004 per un'introduzione e un confronto tra sistemi di trascrizione). Il sistema di trascrizione GAT (Gesprächsanalytischen Transkriptionssystem), usato soprattutto in ambito tedesco, si ispira a quello CA e lo sviluppa. In particolare, sono introdotte ulteriori convenzioni per la riproduzione di caratteristiche prosodiche e sono sostituiti alcuni simboli per facilitare la realizzazione di trascrizioni al computer (cfr. Dittmar 2004: 160, Lucius-Hoene \& Deppermann 2004: 309-312). Nella tabella 6 sono riportate le convenzioni di trascrizione usate nel presente volume. 
La scelta di questo sistema di trascrizione dipende da un lato dalla volontà di conformarsi alle convenzioni usate per la banca dati del Centro Competenza Lingue della Libera Università di Bolzano, presso cui questa ricerca ha avuto luogo. Dall'altro, la sua adozione così come il tipo di fenomeni che ho deciso di trascrivere sono soprattutto motivati dalle mie specifiche domande di ricerca.

Tabella 6: Convenzioni di trascrizione, adattate da Jefferson (1984) e Dittmar (2004). Le convenzioni CA sono integrate da alcuni simboli GAT.

\begin{tabular}{|l|l|}
\hline INT, VM & intervistatrice, sigla del partecipante \\
\hline$[$ testo $]$ & inizio e fine di sovrapposizione tra parlanti \\
\hline$<$ testo $>$ & segmento pronunciato più lentamente rispetto al contesto \\
\hline$>$ testo $<$ & segmento pronunciato più velocemente rispetto al contesto \\
\hline${ }^{\circ}$ testo $^{\circ}$ & segmento pronunciato più piano rispetto contesto \\
\hline TESTO & segmento pronunciato più forte rispetto al contesto \\
\hline- & pausa breve \\
\hline$(($ pausa) $),(1,0)$ & pausa lunga. Se rilevante, sostituita con la durata della pausa in secondi \\
\hline test- & troncatura di un suono \\
\hline$(\mathrm{h})$ & respiro \\
\hline$:,::,:::$ & allungamento di un suono a seconda della durata \\
\hline$=$ & elisione all'interno di parola o tra parole \\
\hline$[=$ & continuità tra turni di parola di due interattanti, senza stacco \\
\hline$($ testo $)$ & espressioni dubbie \\
\hline xx & espressioni incomprensibili (una x per sillaba) \\
\hline$[\ldots]$ & materiale omesso nella trascrizione \\
\hline$(($ riso) $) ;$ & $\begin{array}{l}\text { commenti su attività non verbali (es. riso, tosse) e su attività paralingui- } \\
\text { stiche o extra-linguistiche che accompagnano il parlato (es. ridendo, } \\
\text { tossendo) }\end{array}$ \\
\hline$<$ ridendo $>$ & segnale di una linea di trascrizione significativa per l'analisi \\
\hline$\leftarrow$ &
\end{tabular}

In primo luogo, le convenzioni CA (e GAT) sono state sviluppate per riprodurre piuttosto fedelmente gli aspetti prosodici del parlato, come il volume e la velocità di pronuncia di un segmento rispetto al contesto o la presenza e la durata delle pause. Una trascrizione di questi fenomeni è importante in quanto questi elementi, fortemente espressivi, contribuiscono al significato di un enunciato e possono fungere da indicatori per l'importanza di un tema o per la sua problematicità. A questo riguardo, Lucius-Hoene \& Deppermann (2004) invitano a seguire, durante l'analisi di interviste narrative, il "principio della coerenza del testo" e quello della "presupposizione di senso". Secondo tali assiomi, proprio i passaggi di un'intervista che possono sembrare contraddittori e poco comprensibili devono essere analizzati con maggiore attenzione in quanto probabilmente indicizzano conflitti o dilemmi sottostanti. In particolare, questi due principi sono alla base della scelta di analizzare le 
denominazioni per i codici d'origine nelle interviste raccolte. Glottonimi e apposizioni si trovano infatti frequentemente in sequenze caratterizzate da interruzioni, pause e riformulazioni. Inoltre, tali assiomi giustificano, almeno in parte, l'assunto che la variazione nei nomi di lingua inter- e intra-parlante non sia casuale, ma indicativa di sistemi di senso sottostanti.

In secondo luogo, come già più volte illustrato, per interpretare un'intervista narrativa è di primaria importanza considerare la sua dimensione interazionale oltre che presentazionale (cfr. sempre Lucius-Hoene \& Deppermann 2004). Ciò significa analizzare, per esempio, non solo le risposte dei partecipanti, ma anche il modo in cui le domande sono state formulate cosi come i segnali di feedback dell'intervistatrice. Le convenzioni CA (e GAT) agevolano in questo proposito: queste sono state infatti sviluppate in modo specifico per trascrivere l'avvicendarsi dei turni di parola in un'interazione.

Infine sia qui menzionato che, in questo come nei prossimi capitoli, indico in calce ai brani citati delle interviste il nome del file e i minuti della registrazione. Dal nome del file si deduce il paese di provenienza dei partecipanti così come il luogo di residenza in Alto Adige. Nello specifico, i paesi di provenienza sono Serbia ("Ser"), Montenegro ("Mon"), Croazia ("Cro"), Rep. di Macedonia ("Mac"), Bosnia-Erzegovina ("Bos"), Kosovo ("Kos"). Le località di residenza più comuni tra gli intervistati sono abbreviate in "Bo" per Bolzano, "Mer" per Merano, "Bru" per Brunico e "Sar" per Sarentino. Negli altri casi riporto il nome del paese per esteso. I segmenti delle sequenze citate, discussi in corpo al testo, sono segnalati, come usuale, tramite una freccia $(\leftarrow)$ sul lato destro del brano. I glottonimi e le apposizioni nei brani citati nel capitolo IV sono in grassetto per essere più facilmente individuabili al momento di leggere gli esempi.

\subsection{Analisi micro}

Il metodo adottato nella presente ricerca per analizzare dettagliatamente singoli passi delle interviste si ispira a quello che impronta le ricerche di analisi della conversazione, ma non coincide del tutto con questo (cfr., per un'introduzione all'analisi della conversazione, Franceschini 1998 e anche Pallotti 2007). Similmente agli studi di CA, al momento di analizzare i dati, pongo particolare attenzione ai segnali e alle mosse interazionali, attraverso cui parlanti e interlocutori creano e mostrano come stanno interpretando localmente il contesto per conferire comunemente un senso e/o un ordine all'attività comunicativa in corso. Tuttavia, il mio approccio di analisi, a differenza di quello di CA, non è rigorosamente "analitico" (cfr. Franceschini 1998: 17-18, Cashman 2008). Infatti non mira esclusivamente a descrivere come la conversazione è organizzata sequenzialmente a livello micro, ma tenta di formulare anche ipotesi riguardo al perché di determinati comportamenti verbali tramite la considerazione del contesto sociale e politico più ampio.

Basandomi sul concetto di "identità in narrazione e/o in interazione", parto in particolare dal presupposto che varianti linguistiche costituiscano risorse indessi- 
cali adoperate dagli interattanti nell'hic et nunc della conversazione non solo per costruire ogni volta ex novo contesto e rappresentazioni di sé estemporanee. Piuttosto i partecipanti se ne servono anche per indicizzare e posizionarsi rispetto a categorie identitarie e rappresentazioni sociali, sia precostituite da loro stessi, per esempio, in interazioni precedenti, sia preesistenti, indipendentemente da loro, a livello collettivo (cfr. Lucius-Hoene \& Deppermann 2004, Bucholtz \& Hall 2005, Cashman 2008: 291-293, De Fina \& Georgakopoulou 2012: 166-183). Strumenti analitici fondamentali in questo approccio sono le nozioni interrelate di "identità narrative", "rappresentazioni (sociali)" e "atti di posizionamento".

\subsubsection{Identità narrative}

Il concetto di "identità" è piuttosto controverso in letteratura. Tuttavia, è al contempo centrale nella ricerca sociolinguistica non solo recente. Questo funge infatti da costrutto meso per descrivere l'interrelazione - intesa non come data, ma appunto come mediata - tra la lingua e le altre strutture sociali o, più esattamente, tra le pratiche comunicative in una specifica interazione e il contesto in cui questa ha luogo (cfr. Auer 2005, Günthner 2007: 437, De Fina 2003, Bamberg et al. 2007, Bamberg \& Georgakopoulou 2008, Holmes \& Marra 2008).

Gli studi appena citati hanno in comune la concezione secondo cui pratiche discorsive e variazione linguistica non codifichino direttamente significati sociali (es. sesso, età, etnicità). Queste sono piuttosto un mezzo privilegiato per fare "lavoro identitario", ovvero per esprimere e al contempo negoziare in interazione attributi personali, ruoli sociali e/o l'appartenenza a una comunità. In connessione con ciò, questi approcci intendono l'identità stessa non come un set finito di proprietà, possedute da un individuo (o da un gruppo) una volta per tutte. Piuttosto l'identità è concepita come un insieme complesso, dinamico ed emergente, di caratteristiche rivendicate o contestate dagli interattanti per sé o per gli altri in situazioni comunicative concrete per determinati fini. In tali approcci, l'uso di specifiche varianti non corrisponde inoltre in modo biunivoco a una particolare categoria identitaria. Il significato di tali varianti è infatti da interpretare localmente, mentre le categorie identitarie sono solitamente indicizzate tramite l'adozione non di una, ma di pattern di variabili linguistiche ed extra-linguistiche e, quindi, tramite l'appropriazione di un certo stile (cfr. Auer 2005: 404).

Gli aspetti di sé, che un narratore rappresenta e costruisce insieme all'interlocutore in quanto sequenzialmente e situativamente rilevanti per raccontare episodi della sua vita, costituiscono la sua "identità narrativa" (cfr. Lucius-Hoene \& Deppermann 2004: 47-76). L'identità narrativa è dunque secondo i due ricercatori ricostruibile empiricamente attraverso un'analisi delle storie concrete e situate che le persone raccontano (cfr. anche Deppermann 2013). Data la situazione comunicativa in cui si realizza e il compito perseguito dal parlante, l'identità narrativa in un'intervista biografica è costituita solitamente da una dimensione "temporale" e da una "sociale". Nel raccontare la propria storia, il narratore mira infatti a dare un senso e a organizzare la propria esperienza personale in modo coerente. Per fare ciò, da un 
lato, istituisce relazioni, temporali o causali, tra gli eventi vissuti; dall'altro si riferisce a modelli interpretativi e schemi culturali preesistenti a livello collettivo (cfr. anche Linde 1993). Inoltre, l'identità narrativa è caratterizzata anche da una dimensione "autoreferenziale" (selbstbezügliche). Come già accennato nel primo capitolo, durante l'atto del raccontare, il narratore riflette infatti sulle proprie esperienze, si confronta con il proprio passato e così, talvolta, approfondisce la propria conoscenza di sé (cfr. Lucius-Hoene \& Deppermann 2004: 67).

Alcuni approcci biografici all'identità narrativa partono dal presupposto che una buona vita e una personalità ben formata si lascino riconoscere dalla capacità di farne una narrazione coerente (cfr. De Fina \& Georgakopoulou 2012: 159-183 per ulteriori riferimenti bibliografici). Tuttavia, come risulta dalla rassegna di studi citata dalle due ricercatrici, ricerche recenti rivendicano l'importanza di considerare anche gli aspetti frammentari e relazionali della costruzione identitaria in interviste biografiche. Tale slittamento di prospettiva si realizza soprattutto tramite una ridefinizione in chiave interazionale della nozione di atti di posizionamento (cfr. $\S$ III.2.3.3 per maggiori dettagli).

\subsubsection{Rappresentazioni}

Nel presente volume il termine "rappresentazione" è usato con due accezioni leggermente diverse, ma tra loro compatibili. In primo luogo, sulla scorta degli studi sulle biografie linguistiche e sulle narrazioni, il concetto di rappresentazione, o quello correlato di dimensione presentazionale, è contrapposto a quello di performance, o di dimensione interazionale (cfr. Lucius-Hoene \& Deppermann 2004: 41-44 e anche Franceschini 2003, De Fina \& Georgakopoulou 2012). Come già precedentemente discusso, queste due nozioni si riferiscono a due aspetti concomitanti all'attività del narrare (cfr. § I.2). Da un lato, raccontando, un parlante fa infatti riferimento a un segmento di realtà - ossia a eventi, persone o situazioni di cui ha avuto esperienza - e lo rappresenta all'interlocutore per come se lo ricorda e/o per come ha imparato che tali esperienze possano/debbano essere ricordate, ad esempio, adoperando per interpretarle schemi narrativi appresi a scuola, al lavoro o in altri gruppi sociali. Dall'altro, tali rappresentazioni sono (ri)modellate in relazione agli obiettivi che il narratore si prefigge nella situazione comunicativa concreta. Infatti, raccontando, un parlante porta anche a termine una serie di atti performativi - ad esempio, si giustifica, ricerca approvazione, argomenta, spiega - indirizzati a se stesso o agli altri partecipanti della conversazione.

In secondo luogo, la nozione di "rappresentazione" è usata nella presente ricerca anche con un significato più specifico. Questa accezione si riallaccia al concetto di "rappresentazione sociale" adoperato in lavori di sociolinguistica o di analisi del discorso. In particolare, combinando riflessioni elaborate in psicologia e in sociologia costruttivista, questi studi si rifanno a una definizione di rappresentazione sociale come a una "forma di conoscenza, socialmente elaborata e condivisa, avente un'orientazione pratica e concorrente alla costruzione di una realtà comune a un gruppo sociale" (cfr. Jodelet 1989 citato da Castellotti \& Moore 2002, tradu- 
zione della scrivente). In connessione con ciò, le rappresentazioni tendono ad essere esplicitamente distinte, in alcune di queste ricerche, dalle nozioni per certi versi affini di "percezioni", "atteggiamenti" e "stereotipi" (cfr. rispettivamente Krefeld \& Pustka 2010, Castellotti \& Moore 2002 e Py 2000). Il motivo di questa distinzione dipende proprio dal fatto che le rappresentazioni sono motivate socialmente sotto due punti di vista. Da un lato, le rappresentazioni sono sociali in quanto diffuse in una comunità di locutori. Perciò, a differenza delle "percezioni", possono essere per esempio sganciate da un'esperienza diretta da parte del soggetto del fenomeno rappresentato. Dall'altro lato, le rappresentazioni sono sociali anche in quanto (ri)costruite dagli interattanti durante una conversazione. In conseguenza di ciò, diversamente da quanto tradizionalmente attribuito agli "atteggiamenti" e agli "stereotipi", le rappresentazioni non sono verbalizzate tramite singole proposizioni né compiutamente analizzabili al di fuori del contesto in cui sono formulate.

$\mathrm{Nel}$ descrivere il processo interazionale alla base della loro co-costruzione in un corpus di interviste focus group, Py (2000) distingue inoltre tra due tipi di rappresentazioni. Le "rappresentazioni di referenza" (représentation de référence) sono luoghi comuni, massime o credenze (ri)conosciute dai membri di un gruppo, indipendentemente dal fatto di aderirvi o meno. Una volta introdotte nella conversazione dai ricercatori, gli interattanti "si situano" (se situent) nei loro confronti tramite diverse attività discorsive - ad esempio, argomentando astrattamente o raccontando una storia - o tramite dispositivi di modalizzazione, attenuazione o dislocazione, tra cui, avverbi, denominazioni o citazioni di enunciati in discorso diretto. Nel fare ciò, gli interattanti costruiscono una "posizione personale" (position personnelle), o "rappresentazione in uso" (représentation en usage), rispetto al fenomeno trattato (cfr. ibidem: 13-14). In linea con il metodo biografico e in conseguenza dell'approccio esplorativo adottato nella presente ricerca, durante le interviste raccolte non ho elicitato in modo sistematico i giudizi dei parlanti rispetto a una lista prestabilita di opinioni metalinguistiche diffuse nella società di partenza o di arrivo. Perciò, nei prossimi capitoli, non distinguo nettamente tra $\mathrm{i}$ due tipi di rappresentazioni appena delineate. Tuttavia, le rappresentazioni metalinguistiche sono concepite, anche nel presente lavoro, come evolventesi nel corso del discorso tramite quelli che qui definisco "atti di posizionamento" degli interattanti. Come sarà meglio illustrato nel prossimo paragrafo, questi ultimi costituiscono i modi concreti in cui rappresentazioni collettive di comportamenti e usi linguistici sono indicizzate, negoziate e, eventualmente, riformulate in interazione dai singoli intervistati.

D'altro canto, il concetto di rappresentazioni è anche connesso a quello precedentemente tratteggiato di "identità" narrativa. Infatti le rappresentazioni collettive e la loro rielaborazione individuale concorrono in modo più o meno diretto alla co-costruzione delle identità di lingue e parlanti nel corso dei colloqui. In particolare, in quanto sistemi di valori e di conoscenze parzialmente determinate dall'alto, le rappresentazioni possono avere un potere normativo sui singoli locutori. Così, queste possono per esempio definire quale comportamento linguistico debba essere considerato appropriato dopo migrazione e/o quale parlante appartenga a quale comunità linguistica o, per converso, ne sia escluso. Proprio per il fatto che le rappre- 
sentazioni collettive hanno il potenziale di mettere in discussione la propria rappresentazione di sé, sono negoziate dai singoli in interazione. Perciò l'identità, soprattutto nella sua dimensione sociale, tende ad essere co-costruita in accordo o opposizione a queste (cfr. anche il concetto di soziale Positionierung, tr. posizionamento sociale, in Lucius-Hoene \& Deppermann 2004).

Infine, secondo Castellotti \& Moore (2002: 8-9), le rappresentazioni sociali si formano tramite "oggettivizzazione" (objectivation). Vale a dire si basano sulla selezione di una parte delle informazioni conosciute riguardo a un fenomeno, in questo caso linguistico. Il risultato di questa operazione è quello di offrire un'interpretazione meno dettagliata dell'evento rappresentato, ma in compenso più espressiva, maneggevole e facile da comprendere. In linea con ciò, le rappresentazioni sono spesso anche adoperate come chiave interpretativa, seppur semplificante, per dare un senso a fenomeni nuovi e, quindi, non ancora pienamente afferrati nella loro complessità. Per questi motivi, le rappresentazioni sociali di fenomeni linguistici operano in modo analogo alle "ideologie linguistiche", per lo meno secondo la definizione data loro da Irvine \& Gal (2000). Infatti, secondo le ricercatrici, le ideologie linguistiche sono "pratiche di significazione" di fenomeni linguistici, diffuse in una collettività per spiegare l'origine e il significato delle differenze linguistiche al suo interno. ${ }^{10}$ Queste operano, in particolare, sulla base di tre processi semiotici e sociali fondamentali; vale a dire i) 1' "iconicizzazione" (iconization), ovvero il processo per cui a un nesso tra un fenomeno linguistico e un gruppo sociale viene attribuito un valore di necessità assoluta quando invece questa relazione è tutt'al più storica, contingente o convenzionale; ii) la "ricorsività frattale" (fractal recursivity) che consiste nel proiettare un'opposizione, saliente ad un livello del nesso ideologico, a un altro livello, creando così una moltitudine di identità in opposizione dinamica tra loro; e iii) l'"elisione" (erasure), vale a dire la cancellazione e/o il rendere "invisibile" di fatti inconsistenti con lo schema interpretativo proposto dall'ideologia (ibidem: 37-39). Il concetto di "ideologie linguistiche" (o di "pratiche di significazione") è euristicamente molto utile, specialmente per il suo mettere in rilievo gli interessi di gruppo alla base di determinate interpretazioni dei rapporti tra codici in uno spazio sociolinguistico. Tuttavia, tale nozione è adoperata nel presente volume solo occasionalmente. Infatti, per un'individuazione delle ideologie linguistiche, l'esame delle interviste avrebbe dovuto essere affiancato da un'analisi più sistematica dei rapporti di forza tra gruppi nelle società di partenza e di arrivo e dallo studio di altri mezzi di diffusione di rappresentazioni metalinguistiche, come ad esempio i mass media.

10 Riassumendo la letteratura a riguardo, anche De Bres (2013: 58-62) definisce in modo analogo le "ideologie linguistiche" come sistemi di credenze tra loro correlate riguardo alla lingua e ai fenomeni linguistici, quali apparentemente descrittivi hanno in realtà una natura prevalentemente prescrittiva e valutativa così come sono funzionali agli interessi di un determinato gruppo sociale. 


\subsubsection{Atti di posizionamento}

Il concetto di "atti di posizionamento" si riferisce alla funzione, portata a termine da attività comunicative di vario tipo, di creare posizioni e attribuirle a se stessi e agli altri localmente durante una conversazione (cfr. Lucius-Hoene \& Deppermann 2004: 196-212, Deppermann 2013). Un atto di posizionamento discorsivo si realizza e dunque si manifesta in molteplici fenomeni verbali e para-verbali, tra cui categorizzazioni, caratteristiche prosodiche, discorsi riportati (cfr. anche più avanti in questo paragrafo). La corrispondenza tra le forme e i risultati di una presa di posizione non è comunque fissa dal momento che, come già accennato, le categorie identitarie indicizzate - talvolta esplicitamente, talvolta implicitamente - da un atto di posizionamento emergono localmente e sequenzialmente nel corso dell'interazione.

In particolare, ogni atto di posizionamento discorsivo è sempre duplicemente indirizzato a se stessi e agli altri (Selbst- und Fremdpositionierung). In altre parole, impegna contemporaneamente sia il parlante sia gli interlocutori nei confronti di attributi personali e/o di ruoli sociali e/o di valori morali (cfr. Lucius-Hoene \& Deppermann 2004: 196). Nel fare ciò, crea aspettative sui diritti e doveri dei partecipanti a una specifica interazione (cfr. anche Ribeiro 2006). Gli atti di posizionamento in una conversazione possono essere intenzionali o involontari. Questi ultimi si verificano, per esempio, quando il parlante indirizza la sua attenzione ad altri aspetti dell'enunciato senza mirare specificamente alla rappresentazione o al riconoscimento di attributi per sé o per gli altri (cfr. Lucius-Hoene \& Deppermann 2004: 200). Le posizioni, stabilite dalle attività comunicative di un locutore, sono poi a loro volta ratificate o confutate o ulteriormente precisate da quelle di altri interattanti in turni di parola successivi.

Conformemente agli assunti dell'approccio di "identità in interazione e/o narrazione", le prese di posizione non si esauriscono necessariamente nell'attribuzione momentanea a se stessi e agli altri di categorie identitarie, né sono interpretabili esclusivamente tramite la considerazione del contesto micro. Spesso gli atti di posizionamento di un parlante sono infatti parzialmente fondati nella sua storia biografico-personale.

Inoltre ricevono talvolta il loro significato anche da esperienze interazionali avvenute precedentemente in una collettività. Così, Wortham et al. (2011: 42) si riferiscono con l'espressione "atti di posizionamento abituali" (habitual positioning) alle prese di posizione dei singoli che rivelano - non solo in conversazioni informali, ma anche in intervista - modi consueti o tipici di rivendicare e costruire categorie identitarie da parte dell'intervistato e/o del gruppo sociale a cui l'individuo sente di appartenere.

In aggiunta, si consideri che il concetto di posizionamento richiede ulteriori specificazioni al momento di essere applicato all'analisi di narrazioni sia autobiografiche sia in terza persona. I piani su cui avviene il posizionamento di sé e degli altri e, quindi, il lavoro identitario si moltiplicano infatti durante l'atto del raccontare. Ciò avviene in conseguenza dello sdoppiamento tra il mondo dell'interazione e quello della storia. Perciò Bamberg (1997) distingue i seguenti tre livelli di posizionamento narrativo: 
1) il livello dei personaggi tra di loro durante l'evento riportato.

2) il livello del parlante nei confronti del pubblico al momento di enunciare la storia.

3) il livello del narratore nei confronti di se stesso e/o di opinioni diffuse in una collettività e/o di grandi racconti (master narrative). In particolare, le prese di posizione a questo livello sono secondo lo studioso finalizzate a costruire una risposta locale e situata, vale a dire appunto tramite la narrazione di un episodio specifico, alla domanda "chi sono?" (cfr. anche Bamberg \& Georgakopoulou 2008).

Questo modello è ridefinito da Lucius-Hoene \& Deppermann (2004: 202-212) che scompongono il primo e il secondo piano di analisi rispettivamente in ulteriori due e quattro livelli (cfr. anche Deppermann 2013). Si consideri la sequenza in 1 tratta dalla stessa biografia linguistica del corpus che ho citato nel primo capitolo del presente volume.

(es. 1)

1 VM sai gente si abituano che tu sbagli

2 INT $\mathrm{mh} \mathrm{mh}$

3 VM e trovano modo per ca- per capirti cosa volevi dire (h) e vai così

4 INT $\mathrm{mh} \mathrm{mh}$

5 VM tanto MEglio

6 INT $\mathrm{mh} \mathrm{mh}$

$7 \mathrm{VM}$ ((pausa)) correggere qualcuno fo:rse qualcosa rimane

8 INT ah ah

9 VM ((pausa)) fo:rse ((pausa))

10 INT si

$11 \mathrm{VM}$

$12 \mathrm{VM}$

$13 \mathrm{VM}$

$14 \mathrm{VM}$

15 INT

$16 \mathrm{VM}$

17 INT

$18 \mathrm{VM}$

19 INT

20 VM

$21 \mathrm{VM}$

$22 \mathrm{VM}$

23 INT

$24 \mathrm{VM}$

$25 \mathrm{VM}$

$26 \mathrm{VM}$

27 INT

28 VM

$29 \mathrm{VM}$

$30 \mathrm{VM}$

31 VM

32 VM

((pausa)) ma c=è uno nostro quello è disastro poveraccio ((pausa)) ma quello non ha senso per le lingue anche serbo lo parla male (h) ((pausa)) S:Empre e: da: - una cosa ti dice $<<$ sorridendo se ti dice buon giorno dice $>(\mathrm{h})-$ bon tag $[(($ riso $))]$

$<<$ ridendo mischia tutto $>[(($ riso $))]$

$[(($ riso $))]$

(h) tutto mischia ((pausa))

$$
[((\text { riso }))]
$$

mh:

e: con quello di sono scherzi scherzi e signore: chef chef miei

figli: cercano geld (h) - du muss du mir zahlen e: život kosta la

vita costa $[(($ riso $))]$

$$
[((\text { riso }))]
$$

$<<$ ridendo e dopo uno nostro ha chiesto suo capo $>$ (h) ma come lo capisci tu (h) non so io lo capisco tutto quello che dice ma scu:sa

lu- quello lo capisci tutto ((pausa))

$\mathrm{mh} \mathrm{mh}$

perché è c'è una correla- e: quanto io sono qua tredici ((pausa))

tredici pieni adesso - cominciano quattordici anni ((pausa)) (h) lui

un anno prima di me è venuto è sempre uguale posto - là e - loro

$<<$ ridendo più prima loro imparano serbo da lui prima

italiano o tedesco $>$ ((pausa)) ((sospiro))

(VM_Ser_Mer, 34:57-36:27) 
Nella sequenza in 1, l'intervistata VM non solo anima i personaggi del racconto, ma anche li posiziona strategicamente nel mondo della storia secondo la sua prospettiva attuale. Riportando alcuni enunciati in discorso diretto alle righe 24-26, VM mette in scena infatti le prese di posizione dei personaggi del racconto tra di loro (livello 1a, ovvero "posizionamento dei personaggi della storia uno rispetto all'altro"). ${ }^{11} \mathrm{Al}$ contempo, VM categorizza il protagonista (o l'antagonista) della narrazione come "disastro poveraccio" in quanto incapace di comunicare perfino nella sua prima lingua (cfr. riga 11). Nel fare ciò, da un lato, lo dequalifica per fini narrativo-argomentativi: la storia è infatti raccontata per fare un punto, espresso in apertura della sequenza alle righe 1-9. Dall'altro, legittima gli amici e i conoscenti che lo scherniscono e conferisce a loro e a se stessa l'autorità per formulare un tale giudizio (livello 1b, ossia "posizionamento dei personaggi della storia attraverso il design della narrazione").

Inoltre, sempre secondo il modello di Deppermann (2013), il narratore di una storia può attribuire anche al proprio io attuale (o "io narrante") determinate caratteristiche, in questo caso linguistico-identitarie. Così, tramite commenti retrospettivi o enunciati valutativi, colui che parla si può per esempio rappresentare come diverso da altri personaggi e/o cambiato rispetto al proprio personaggio di allora (o "io narrato") (livello 2a, ossia "auto-posizionamento del narratore tramite attività auto-riflessive extra- e meta-narrative"). Nella sequenza in 1, l'io narrante, paragonando per esempio alle righe 28-30 la durata del soggiorno in Alto Adige del protagonista alla propria, si disallinea dal comportamento mistilingue del conoscente. Nel fare ciò si posiziona indirettamente come persona che, pur avendo avuto un'esperienza migratoria simile, ha intrapreso e portato a termine un percorso di apprendimento linguistico diverso. A questo proposito, anche le ripetute inserzioni e/o commutazioni in tedesco e, talvolta, in serbo della partecipante contribuiscono, più o meno intenzionalmente, in questa come in altre sequenze dell'intervista, a rivendicare una rappresentazione di sé come parlante trilingue (cfr. righe 20-22 e capitolo V per maggiori dettagli). Contemporaneamente, tali scelte lessicali - insieme per esempio a caratteristiche prosodiche - sono anche funzionali a posizionarsi interazionalmente rispetto all'interlocutrice come intrattenitrice abile in grado di sfruttare le proprie risorse linguistiche per suscitare l'interesse del pubblico (livello $2 \mathrm{~b}$, ossia "posizionamento interazionale tramite il design della narrazione").

Infine, raccontando una storia, il parlante posiziona anche i destinatari, per esempio formulando assunti, dando spiegazioni o cercando la loro approvazione (livello 2c, ossia "posizionamento interazionale attraverso attività meta-narrative"). D'altro canto questi ultimi possono accettare o meno l'attribuzione di determinati ruoli da parte del narratore e partecipare alla loro negoziazione in interazione (livello $2 \mathrm{~d}$, "posizionamento interazionale del destinatario della storia attraverso attività fattuali"). Così, tramite il racconto in $1, \mathrm{VM}$ aspira ad ottenere la complicità della ricercatrice rispetto alla tesi dell'importanza di correggere gli apprendenti di una lingua straniera e, eventualmente, rispetto alla propria valutazione tendenzialmente negativa dell'enunciazione mistilingue. Al contempo, traducendo l'espressione dal serbo alle righe $21-22$, rivela alcune sue presupposizioni riguardo alle

11 Per le denominazioni dei livelli degli atti di posizionamento mi baso su Deppermann (2013). 
competenze linguistiche dell'intervistatrice, che infatti sa parlare il tedesco, ma non il serbo. Quest'ultima reagisce a sua volta accettando il ruolo di alleata e segnalando la sua posizione, per esempio, ridendo (cfr. righe 15, 17, 22).

Come già detto nel primo capitolo, nell'analizzare le biografie linguistiche del corpus mi concentro solo su alcuni degli atti di posizionamento degli interattanti. Questi sono quelli finalizzati a negoziare l'identità dei codici del proprio repertorio e la propria identità linguistica in interazione.

In particolare, nel capitolo IV, esamino le prese di posizione realizzate dagli intervistati tramite una specifica attività discorsiva, ovvero l'introduzione di categorie referenziali relative ai codici d'origine (cfr. Bucholtz \& Hall 2005: 594). Queste categorie sono concretamente realizzate, nelle interviste raccolte, tramite i glottonimi e le apposizioni scelte per le varietà linguistiche slavo meridionali. Nello sviluppare questa metodologia, mi sono ispirata a una procedura ampiamente diffusa in studi di analisi della conversazione, ossia l'"analisi delle categorie di appartenenza" (Membership Categorization Analysis o MCA; cfr. Sacks 1995 e De Fina \& Georgakopoulou 2012: 172-174 per ulteriori riferimenti bibliografici). Tale approccio studia come categorie (o collezioni di categorie) siano abitualmente adoperate dai parlanti in interazione per riferirsi a persone o oggetti, nel presente caso a varietà linguistiche, e per collegare a loro alcune attività gerarchizzate le une rispetto alle altre, qui connotazioni e funzioni. Il presupposto è che, nell'adottare determinate denominazioni, gli intervistati assegnino a questi codici connotazioni simbolico-emozionali e/o ruoli funzionali nei repertori individuali e comunitari. Al contempo, tramite la scelta del nome con cui chiamare i codici propri e altrui, i partecipanti si posizionano anche nei confronti di rappresentazioni metalinguistiche diffuse a livello collettivo. Nel fare ciò, eventualmente negoziano la propria appartenenza a comunità (immaginate), come per esempio a un certo stato-nazione. ${ }^{12}$

Invece, oggetto del capitolo $\mathrm{V}$ sono gli atti di posizionamento dei partecipanti portati a termine in sequenze narrative delle interviste. In particolare, mi concentro sulle loro prese di posizione nel mettere in scena dialoghi, immaginati o reali, ambientati in Alto Adige. Come le altre prese di posizione, anche quelle riferite alle competenze e agli usi linguistici propri e altrui possono contribuire alla rappresentazione e costruzione di un sé "agentivo" o di un sé "epistemico" (cfr. Bruner 1990 citato da Schiffrin 1996: 194, De Fina \& Georgakopoulou 2012: 167-171). ${ }^{13}$ Le prime caratteristiche identitarie - ossia quelle che vanno a costituire il sé agentivo emergono dalle affermazioni riguardo a ciò che un soggetto fa o può fare tramite l'apprendimento e l'uso di determinate varietà linguistiche. Al contrario, i tratti che interessano la costruzione di un sé epistemico sono strettamente correlati con ciò che il narratore sa, crede, vuole o sente rispetto a specifici codici.

12 Si confrontino anche De Fina (2003: 139-180) e Hansen et al. (2010) per studi su categorizzazioni finalizzate però a negoziare appartenenza specificamente a gruppi "etnici".

13 Sia qui notato che i concetti di "sé" (self) e "identità" non sono completamente sovrapponibili. Il primo termine si riferisce infatti solitamente a caratteristiche di natura psicologica o personale, mentre il secondo è di solito usato per indicare attributi con una valenza sociale (cfr. Shiffrin 1996). Nella presente ricerca non distinguo tuttavia tra le due nozioni. 


\subsubsection{Concetti affini: prese di posizione e footing}

La nozione di "presa di posizione" (stance) è frequentemente usata in letteratura in modo affine a quella di "atto di posizionamento" (positioning). Una presa di posizione è infatti definita da Du Bois (2007: 171-172) come un atto realizzato da un interattante che si ingaggia con quanto precedentemente detto da lui stesso (o da lei stessa) o da altri soggetti durante la conversazione in via di svolgimento e/o con quanto solitamente affermato nella comunità di discorso in generale. In particolare, l'atto unico di prendere una posizione si compone secondo Du Bois (2007) di tre azioni interrelate. Queste sono "valutazione", "posizionamento" e "allineamento". Chi prende una posizione (stancetaker) valuta infatti un oggetto (stance-object). Nel fare ciò si posiziona affettivamente e/o epistemicamente come soggetto e al contempo si allinea o disallinea rispetto ad altri soggetti (cfr. ibidem: 163). Questo processo è perciò definito dal ricercatore come "triangolo della presa di posizione" (stance triangle). Diversamente da Du Bois (2007), la nozione di posizionamento comprende invece, per Deppermann (2013: 9), quella di presa di posizione. Infatti, la prima è in grado di rendere meglio conto della doppia indessicalità temporale che contraddistingue le narrazioni (cfr. i livelli di posizionamento narrativo discussi nel paragrafo precedente). Dal momento che questa questione non è completamente risolta in letteratura né la distinzione tra i due termini è particolarmente importante per l'analisi esposta nel presente lavoro, nei prossimi capitoli adopero i concetti di atto di posizionamento e presa di posizione in modo interscambiabile. Tuttavia, mi servo della nozione specifica di "oggetto" di una presa di posizione nel caso mi sembri rilevante individuare al momento dell'analisi un elemento specifico nel discorso a cui è indirizzato un atto di posizionamento valutativo, affettivo o epistemico degli interattanti.

Anche la nozione di "footing", elaborata da Goffman (1981), è in parte correlata a quella di atti di posizionamento. I cambiamenti di "footing" sono infatti definiti dallo studioso come micro-slittamenti nell'allineamento dei partecipanti gli uni verso gli altri e/o verso il contenuto del proprio discorso. Questi si realizzano per esempio in seguito alla commutazione di pronomi personali e/o a variazioni di registro. Secondo Ribeiro (2006), i cambiamenti di footing contribuiscono alla realizzazione e al contempo sono influenzati da mosse interazionali più salienti, come gli atti di posizionamento. Anche secondo Deppermann (2013: 9), la terminologia proposta da Goffman è utile per l'analisi delle attività di posizionamento dei narratori. In particolare, nella presente ricerca mi servo del concetto di "footing" per ricostruire la "struttura di partecipazione" e i "formati di produzione" dei dialoghi riportati nelle narrazioni degli intervistati (cfr. sempre Goffman 1981 e $\S$ V.4 per maggiori dettagli). L'idea di fondo è che il ruolo interazionale, che il narratore prevalentemente attribuisce al proprio personaggio nelle storie raccontate (ad esempio, parlante, ascoltatore occasionale o destinatario ratificato), costituisca un atto di posizionamento di quest'ultimo rispetto, tra l'altro, alla propria capacità di negoziazione di codice dopo mobilità. In questo senso, l'esame della distribuzione dei ruoli interazionali nei singoli racconti permette di ricostruire alcuni aspetti della rappresentazione che il parlante dà della propria identità linguistica nel narrare la propria biografia linguistica in generale. 



\title{
CAPITOLO IV: DENOMINAZIONI DI LINGUA
}

\author{
INTRODUZIONE
}

Nel presente capitolo, esamino le variazioni nelle denominazioni, ossia nei glottonimi e nelle apposizioni, usate dai partecipanti per chiamare e qualificare i "codici d'origine" nelle interviste del corpus. Al centro dell'attenzione ci sono dunque i rapporti tra e con le varietà linguistiche parlate dagli intervistati nelle località di partenza, ovvero nei paesi successori alla Jugoslavia, e poi mantenute o sostituite dopo il trasferimento in Alto Adige.

Come già accennato al § I.3.1, le "denominazioni di lingua" sono definibili da un punto di vista linguistico come nomi o sintagmi nominali. Nel presente lavoro, fanno parte di questa categoria sia i "glottonimi", sia le "apposizioni", sia i cosiddetti “quasi-glottonimi”. In particolare, secondo Gröschel (2009: 31-35) e Aronin et al. (2011: 178), i glottonimi appartengono alla classe dei "nomi propri". ${ }^{1}$ Perciò si distinguono dalle apposizioni per le lingue che sono invece "nomi comuni". Oltre che per peculiarità ortografiche, morfosintattiche e pragmatiche, i nomi propri si differenziano da quelli comuni poiché denotano un contenuto, anche semanticamente opaco, invece di connotare un significato lessicale (cfr. Nicolaisen 1995). Tuttavia, l'applicazione di tale definizione specialmente ai nomi per le lingue è controversa. L'opposizione tra significato lessicale e contenuto onomastico non è infatti sempre binaria. Si considerino per esempio le denominazioni analogiche date in contesto coloniale (cfr. sempre Nicolaisen 1995) o i mutamenti di significato a cui termini come "creolo" o "lingua materna" sono stati sottoposti diacronicamente (cfr. Tabouret-Keller 1997b). Inoltre, in alcune lingue (come in italiano), i glottonimi non presentano caratteristiche distintive, per esempio, dal punto di vista ortografico - non sono infatti scritti in maiuscolo - che li distinguano dai nomi comuni. La questione dei modi di significazione e di referenza dei glottonimi è ovviamente centrale nel presente lavoro. Tuttavia, la ricerca non mira tanto a risolverla formulando una definizione delle denominazioni linguistiche e del loro modo di operare valida in senso assoluto. Invece si approccia al problema in modo empirico, valutando le funzioni e i significati concreti delle denominazioni nel discorso e non tralasciando di considerare i fenomeni limite o controversi. A questo riguardo, le denominazioni di lingua dal referente ambiguo (o quasi-glottonimi) rappresentano proprio un caso intermedio di espressioni in divenire o in fluttuazione tra nomi comuni e specifici.

La scelta di analizzare le denominazioni linguistiche, adoperate dai partecipanti nel raccontare le loro biografie linguistiche, si basa sulla convinzione che queste

1 In modo analogo anche Tabouret-Keller (1997b) e Dell'Aquila \& Iannàccaro (2007) distinguono tra nomi di lingua propri e comuni. 
costituiscano una chiave d'accesso alle loro rappresentazioni del plurilinguismo e dei rapporti tra codici nei repertori, sia in generale, sia in particolar modo nelle interviste del corpus. Il motivo è che i nomi e, tra questi, anche le denominazioni per le lingue svolgono non solo una funzione "referenziale" verso la realtà, ma anche "costruttivista" di tale realtà (cfr. Akin 2000: 34). Inoltre contestualizzano "atti di posizionamento", più o meno estemporanei, dei loro utilizzatori nei confronti delle pratiche linguistiche, oggetto del discorso (cfr. ibidem).

Le denominazioni per le lingue suddividono infatti lo spazio sociolinguistico in categorie. Da un lato, i glottonimi "identificano" - nel senso di individuano e classificano (cfr. Le Page \& Tabouret-Keller 1985/2011: 2) - le pratiche comunicative a cui si riferiscono in entità singole. Ricevendo un nome, queste sono immaginate come omogenee e unitarie, ossia appunto come codici distinti. Dall'altro, le apposizioni categorizzano tali varietà lungo diverse dimensioni, definendone così i rapporti di differenziazione. Perciò, l'introduzione (o la soppressione) di una denominazione contribuisce a sancire l'esistenza (o l'insussistenza) del codice nominato, assicurandone (o, per converso, compromettendone) l'accessibilità per lo meno a livello discorsivo. Nello stesso tempo, glottonimi e apposizioni rivelano giudizi e prese di posizione di singoli o gruppi nei confronti delle varietà linguistiche in questione (cfr. anche Goebl 1979, Tabouret-Keller 1997b e la nozione di categoria, presupposta dalla Membership Categorization Analysis in Sacks 1995). ${ }^{2}$

In conseguenza delle loro connotazioni a livello sociale ed emozionale, le denominazioni linguistiche sono state già analizzate, in altri studi, come indicatori per risalire all'allocazione emica dei codici in repertori individuali e comunitari (cfr. Iannàccaro \& Dell'Aquila 2007, Aronin et al. 2011 e, in parte, Hartley \& Preston 1999). Ciò è particolarmente evidente nel caso delle apposizioni. Infatti, attributi come, per esempio, "dialetto" o "lingua standard" segnalano lo status di un codice per un parlante e/o per la comunità linguistica a cui questo sente o vuole appartenere. In modo analogo, una (frequente) categorizzazione di una varietà linguistica come "mia lingua" o "madrelingua" punta al valore emozionale-identitario attribuitole da un parlante da un punto di vista emico. Inoltre, suggerisce la sua posizione di codice endocomunitario, eventualmente in opposizione ad altre varietà linguistiche del repertorio. Osservazioni simili valgono anche per i glottonimi, sebbene le loro connotazioni possano essere più opache rispetto a quelle delle apposizioni. Infatti, anche l'adozione di un determinato glottonimo ha talvolta implicazioni sulle caratteristiche riconosciute come proprie alle varietà linguistiche riferite. Così, secondo Bert \& Costa (2014: 200), alcuni attivisti preferiscono il glottonimo "arpitano" rispetto a "franco-provenzale" per il codice che promuovono. Il motivo è che il primo termine cancella ogni allusione all'idea di una varietà linguistica "mescolata" tra francese e provenzale. Al contempo, l'impiego di tale glottonimo contribuisce a presentare il codice come un oggetto linguistico discreto, dai confini esterni nettamente definiti.

2 Su questo tema è inoltre interessante Androutsopoulos (2007). Il ricercatore analizza circa venti denominazioni di etnoletti in Germania e nei paesi scandinavi dal punto di vista semantico-ideologico, vale a dire cercando di ricostruire i valori, le norme, gli stigmata e i rapporti di forza che queste proiettano sui loro referenti. 
Infine, si consideri che i motivi che determinano la scelta di specifiche denominazioni di lingua, specialmente in situazioni di conflitto linguistico, possono variare caso per caso e devono essere quindi interpretati localmente. Proprio a causa del loro valore simbolico e del loro ruolo nei processi di categorizzazione, le denominazioni linguistiche sono infatti spesso usate in una conversazione per compiere "lavoro identitario" o per portare a termine specifici "obiettivi interazionali" (cfr. Migge \& Léglise 2013: 162 e anche Léglise \& Migge 2006, Tofan 2007, Lazarenko 2009, Dal Negro 2009, Bert \& Costa 2014). In particolare, un glottonimo o un'apposizione possono assumere significati diversi a seconda di attori, gruppi e/o del contesto interazionale - e quindi anche per una stessa persona nel corso di una medesima intervista - in cui sono usati. Inoltre, la loro alternanza è frequentemente interrelata con atti di posizionamento dei parlanti rispetto a fenomeni sia linguistici, sia sociali. In connessione con ciò, l'analisi delle variazioni di glottonimi e apposizioni a seconda del contesto nei prossimi paragrafi mostra anche che le rappresentazioni dello spazio sociolinguistico e dei confini tra codici e tra comunità non sono stabili nelle menti dei parlanti, ma spesso negoziate in interazione.

Il presente capitolo è suddiviso in tre sezioni. Nella prima parte analizzo i glottonimi e le apposizioni utilizzate dai partecipanti negli incipit delle loro biografie linguistiche (cfr. §IV.1). La seconda sezione ha per oggetto le variazioni nelle denominazioni intra- e inter-partecipanti, ovvero nel corso di un'intervista o tra intervistati diversi, che appartengono a gruppi sociali coesi, ossia a una stessa famiglia (cfr. § IV.2). Infine, la terza parte del capitolo è dedicata alla descrizione dei modi d'uso e all'individuazione delle funzioni ricoperte dalle denominazioni dal referente ambiguo (o quasi-glottonimi) nelle interazioni registrate (cfr. § IV.3).

\section{DENOMINAZIONI E RAPPORTI DI DIFFERENZIAZIONE TRA I CODICI D'ORIGINE}

In questa prima sezione del capitolo IV analizzo i glottonimi e le apposizioni impiegate dai partecipanti per riferirsi e qualificare i codici d'origine negli incipit delle interviste del corpus. L'obiettivo è individuare le categorie emiche attraverso cui i parlanti differenziano le varietà linguistiche conosciute o riconosciute, nel proprio repertorio individuale e in quello comunitario delle località di partenza. Dal confronto tra gli incipit delle biografie linguistiche raccolte emerge un quadro delle identità dei codici parlati nei paesi successori alla Jugoslavia, vale a dire, per esempio, del loro status e valore emozionale-identitario nell'ottica degli intervistati. Inoltre, dal paragone risulta una descrizione - seppur sommaria in quanto tendenzialmente limitata alle sequenze iniziali dei colloqui - delle rappresentazioni e prese di posizione dei partecipanti nei confronti della situazione sociolinguistica di partenza e dei mutamenti incorsi in questa negli ultimi anni.

In particolare, ai §IV.1.1 e IV.1.2 motivo la scelta metodologica di concentrarmi sugli incipit delle biografie linguistiche raccolte e discuto le dimensioni di differenziazione individuate per ripartire le denominazioni di lingua, adoperate dai narratori. La suddivisione degli altri paragrafi segue il numero e il tipo di codici 
nominati all'avvio dei colloqui dai partecipanti. Così, inizialmente confronto le apposizioni usate dagli intervistati che nominano un unico codice d'origine (cfr. $\S$ IV.1.3 e sgg.). Invece, ai § IV.1.4 e seguenti, illustro i diversi modi di rappresentare il repertorio di partenza da parte di quei partecipanti che lo caratterizzano come originariamente plurilingue. Infine, tema dei § IV.1.5 e successivi sono i rapporti di differenziazione istituiti dagli informanti che si servono di più glottonimi - semi-concorrenti o concorrenti - per chiamare le varietà linguistiche a base neoštokava da loro (ri)conosciute.

\subsection{Gli incipit delle interviste}

Nei prossimi paragrafi mi concentro principalmente sulle denominazioni usate negli incipit delle biografie linguistiche raccolte. Con incipit intendo le sequenze delle interviste in cui i partecipanti rispondono alla prima domanda posta dall'intervistatrice sulle lingue di cui hanno competenza. Come già illustrato nel § III.1.4, il primo quesito posto dalla ricercatrice nelle interviste episodico-narrative mira a elicitare un racconto dell'intervistato riguardo a tutte le lingue o dialetti che conosce o anche solo capisce così come al luogo, tempo e modo del loro apprendimento. Invece, la domanda iniziale nelle otto interviste semi-strutturate del corpus concerne specificamente le varietà linguistiche imparate dai partecipanti prima dei sei anni. Nella maggior parte dei casi, l'incipit dell'intervista corrisponde effettivamente ai primi minuti della registrazione. Tuttavia, nel caso delle interviste semi-strutturate e di alcune interviste episodico-narrative avviate in modo diverso, ho considerato come incipit sequenze successive della registrazione (cfr. più sotto in questo paragrafo per i criteri di individuazione). Tutti i brani analizzati sono comunque formulati in risposta a domande paragonabili tra loro.

La confrontabilità almeno parziale di queste sequenze, avviate da domande simili, costituisce uno dei motivi della loro scelta come punto di partenza per l'analisi esposta nei prossimi paragrafi. Questa comparabilità mi permette infatti di fornire un quadro generale delle strategie - diverse, ma compresenti nel corpus raccolto e probabilmente anche nella comunità di origine degli intervistati - con cui i partecipanti danno un senso alla composizione, più o meno stratificata e complessa, dei loro repertori di partenza. Un'altra ragione è di carattere meramente pratico. Il numero limitato di brani da considerare mi consente di confrontare tra loro in modo dettagliato quasi tutte le interviste del corpus. ${ }^{3}$

3 In particolare, nei prossimi paragrafi, sono discusse le rappresentazioni dell'allocazione dei codici d'origine negli incipit delle biografie linguistiche di 36 intervistati. Due partecipanti, AP e ZT, sono invece esclusi dall'analisi. Infatti, la prima intervistata solamente conferma, all'avvio di un colloquio di coppia, la descrizione del repertorio data dalla sorella SP, senza aggiungere ulteriori informazioni (cfr. §IV.1.3.1). Invece, l'incipit dell'intervista semi-strutturata con ZT non è considerato in quanto piuttosto evasivo. Nessun codice è infatti esplicitamente nominato, mentre l'uso dell'apposizione "dialetto" è probabilmente determinato dal modo di formulare la domanda da parte della ricercatrice: "Int: che lingue o dialetti ha imparato prima dei sei anni-e dai suoi genitori [...] ZT: ma dialetti: io già quand- prima di venire in italia - avevo ventidue anni anni $[. .$.$] perciò i dialetti di paese del del kosovo li sapevo e quelli sono i dialetti miei”.$ 
Più importanti nel motivare la scelta di esaminare gli incipit dei colloqui sono comunque considerazioni di carattere teorico. A questo riguardo, secondo Lucius-Hoene \& Deppermann (2004: 134-135), gli enunciati iniziali di una biografia linguistica costituiscono sequenze altamente informative e punti nodali della conversazione in divenire. Infatti, nei primi minuti del colloquio, il parlante, ottenuto o vedendosi assegnato il banco, si presenta e si posiziona verso l'interlocutore o interlocutrice. Nel fare ciò, spesso anticipa, anche se in modo piuttosto convenzionale, temi e strategie di costruzione identitaria, sviluppati poi più dettagliatamente nel corso dell'interazione.

Date queste premesse, il fatto di considerare prevalentemente gli incipit dei colloqui rende necessari alcuni avvertimenti preliminari rispetto alla portata conoscitiva dell'analisi qui condotta. In primo luogo, il modo di organizzare le affermazioni contenute negli incipit è sì influenzato dalla ricercatrice e dal contesto interazionale immediatamente precedente. Tuttavia, tale influsso tende ad essere meno marcato rispetto a in sequenze successive del colloquio, mentre è probabile che $i$ narratori rappresentino, all'avvio delle registrazioni, il proprio repertorio di partenza nei tratti percepiti come essenziali e/o tipici. Al contempo, dato che i "rapporti di lingua" sono un tema estremamente controverso nei paesi d'origine degli intervistati, è però anche possibile che, all'inizio della conversazione, i narratori scelgano di rappresentare il proprio repertorio in un modo che è anche piuttosto convenzionale o ordinario. L'eventuale "tipicità" di queste descrizioni - nel loro essere sia essenziali, sia convenzionali - è a mio avviso interessante proprio in quanto indicativa di funzioni e valori attribuiti ai codici in questione dai singoli in accordo o in opposizione con rappresentazioni diffuse a livello collettivo (vale a dire nel macro-contesto sociale di provenienza). Ai fini di documentare le rappresentazioni dello spazio sociolinguistico di partenza in modo più dettagliato, rapporti di differenziazione - espressi successivamente dall'intervistato, ma significativi per specificare la prima categorizzazione effettuata - sono discussi nel corso dei rispettivi paragrafi. Tuttavia, le osservazioni di questa sezione del capitolo IV costituiscono solo un primo tentativo di approcciarsi alle rappresentazioni dei repertori d'origine degli intervistati e devono essere integrate con le considerazioni esposte nelle altre parti (cfr. §IV.2 e IV.3). Attraverso l'esame delle denominazioni di lingua così come di indicazioni sui domini d'uso e sul periodo di impiego delle varietà linguistiche nominate, l'obiettivo ultimo è quello non solo di descrivere, ma anche di formulare ipotesi sui fattori che possono entrare in gioco nel determinare l'istituzione di determinate relazioni di differenziazione tra $\mathrm{i}$ codici, parlati nelle aree di provenienza dei partecipanti.

I criteri di individuazione degli incipit delle biografie linguistiche del corpus si basano su caratteristiche sia contenutistiche sia formali (cfr. anche $\S$ III.2.1 per un'illustrazione dei modi di suddivisione delle interviste in segmenti e sotto-segmenti per l'analisi macro). In particolare, l'inizio della sequenza, qui definita “incipit" dell'intervista, è identificabile piuttosto facilmente. Ancorché lo stesso quesito dell'intervistatrice influenzi e quindi sia, in un certo senso, parte integrante dell'incipit, l'attacco di questo ultimo corrisponde propriamente al primo turno di parola del narratore dopo la domanda iniziale della ricercatrice sul tema lingua. Si noti che 
i partecipanti non reagiscono sempre nello stesso modo all'esortazione dell'intervistatrice. Differenze si riscontrano non solo dal punto di vista presentazionale (tipo e/o numero di codici menzionati, glottonimi e apposizioni), ma anche interazionale. Talvolta gli intervistati invitano infatti la ricercatrice a formulare domande più specifiche e/o negoziano il compito e il ruolo che è stato loro assegnato da quest'ultima (cfr., per esempio, gli incipit delle interviste con MG e DV, questo ultimo discusso al § IV.1.5.2). Più difficile è invece stabilire il punto finale dell'incipit di una biografia linguistica. Per l'analisi dei prossimi paragrafi ho considerato l'incipit concluso dopo l'occorrere di uno o più dei tre fenomeni seguenti:

1. l'intervistatrice prende la parola per porre una domanda di chiarificazione

2. il narratore cambia argomento o si riferisce ad avvenimenti/situazioni verificatesi in un altro momento storico-biografico

3. nel testo occorrono marcatori di struttura verbali o para-verbali, tra cui pause prolungate, intonazione discendente, elementi di commutazione di cornice (Rahmenschaltelemente), come "e poi", "e allora" (cfr. Lucius-Hoene \& Deppermann 2004: 110-111).

In conclusione, sia qui ricordato che, nei paragrafi successivi, indico in calce a ogni sequenza citata il nome del file - e, quindi, il paese d'origine e la località di residenza in Alto Adige dell'intervistato - così come i minuti della registrazione. Inoltre, in questa prima sezione del capitolo IV, riporto anche il sesso $[\mathrm{F} / \mathrm{M}]$ e, quando conosciuti, la zona di provenienza, l'età e l'anno di prima emigrazione del o della partecipante. ${ }^{4}$ L'eventuale rilevanza di queste informazioni è illustrata di volta in volta in corpo al testo. Infine, sebbene le sequenze trascritte siano talvolta piuttosto lunghe, ho sempre riportato anche la domanda iniziale dell'intervistatrice (ad eccezione che in due casi; cfr. es. 9 e $12 \mathrm{~b}$ più avanti). Infatti, come appena discusso, la considerazione di come il quesito è posto è imprescindibile per poter valutare adeguatamente le denominazioni scelte dai narratori per categorizzare i codici d'origine. Al contempo, permette al lettore di verificare l'interpretazione qui proposta.

\subsection{Dimensioni di differenziazione}

Nel valutare le denominazioni usate dai partecipanti per chiamare e qualificare i codici d'origine negli incipit delle loro interviste faccio riferimento a due proposte di classificazione presenti in letteratura. La prima è quella suggerita da Dal Negro \& Iannàccaro (2003). I ricercatori individuano - tra i parametri emici rilevanti per la descrizione e classificazione dei repertori linguistici in contesti minoritari - le categorie di "lingua" o "dialetto", da un lato, e di codici "endocomunitari" o "esocomunitari", dall'altro (cfr. anche Chini 2009 per una discussione sul valore conoscitivo di applicare queste categorie all'analisi di repertori "immigrati"). Il primo parametro correla con lo status associato a un codice in una determinata comunità linguistica. ${ }^{5}$

4 Tuttavia, per garantire l'anonimato, indico solamente l'area di provenienza invece del nome completo della località d'origine degli intervistati.

5 Si ricordi che Dal Negro \& Iannàccaro (2003) si riferiscono primariamente a repertori comunitari e non a quelli individuali. 
Invece, il secondo distingue tra codici considerati da un gruppo di parlanti (quindi sempre a livello emico) come propri o estranei, indipendentemente dalla loro funzione di acroletti o basiletti (Dal Negro \& Iannàccaro 2003: 435-440). Infine, un terzo ed ultimo parametro emico identificato dai due studiosi è quello dei "codici ideologici o Wunschsprache". La categoria si riferisce a lingue non conosciute attivamente, ma desiderate da una comunità "o per essere state anticamente parte, seppur marginale del repertorio, o perché legate a visioni o apparentamenti etnici di particolare seduzione" (cfr. ibidem: 437). Questo ultimo parametro non è stato rilevante per classificare i glottonimi e le apposizioni riscontrate negli incipit delle interviste raccolte. Il concetto di codice ideologico è tuttavia adoperato nella presente ricerca al momento di analizzare, sotto altri punti di vista, le denominazioni di lingua e rappresentazioni metalinguistiche dei partecipanti del corpus (cfr., per esempio, § IV.3.3 e V.3.4).

La seconda classificazione a cui mi ispiro è quella proposta da Aronin et al. (2011). Gli studiosi distinguono le denominazioni conferite alle varietà linguistiche, sia da istituzioni (top-down), sia dai loro locutori (bottom-up), sulla base di quattro dimensioni. Oltre alla categoria i) dei "nomi propri", 6 le denominazioni possono infatti appartenere ii) al "continuum gerarchico delle dimensioni socio-geografiche", iii) alla "scala emozionale-identitaria" o iv) al "continuum vicino-lontano" (cfr. Aronin et al.: 178, traduzione della scrivente). Una stessa qualifica può puntare a significati diversi a seconda del contesto linguistico e culturale del parlante, mentre a uno stesso codice può essere attribuita più di una apposizione. Nonostante queste premesse, i ricercatori insistono sull'importanza di un'analisi delle denominazioni per valutare il ruolo che le varietà linguistiche così riferite ricoprono per singoli e comunità e per studiare in generale la diversità linguistica (cfr. anche Aronin \& Singleton 2010).

Sulla base di queste due proposte di classificazione derivo sei categorie o dimensioni per categorizzare le denominazioni negli incipit delle biografie linguistiche raccolte. ${ }^{7}$ Queste sono:

1) i /glottonimi/

2) la dimensione /socio-geografica o socio-politica/

3) la dimensione /emozionale-identitaria/

4) la dimensione /biografico-acquisizionale/

5) la dimensione /storico-temporale/

6) la dimensione delle /prese di posizione riguardo ai rapporti di uguaglianza, somiglianza o differenza tra i codici d'origine/

La prima categoria è quella dei /glottonimi/, ovvero dei nomi per le lingue intese (o immaginate) come entità specifiche e separate. Tra questi ci sono sia nomi attualmente ufficiali (es. croato), sia nomi ufficiali in passato (es. serbocroato), sia nomi non ufficiali (es. kosovaro), sia termini scientifici (es. variante ekava o jekava).

6 Si veda, però, a riguardo della definizione dei glottonimi come "nomi propri" l'introduzione al presente capitolo.

7 Per altri spunti di classificazione si confronti anche Hartley \& Preston (1999) e Iannàccaro \& Dell'Aquila (2007). 
Invece, alla dimensione /socio-geografica o socio-politica/ appartengono quelle denominazioni che istituiscono una differenziazione tra codici in senso gerarchico. Così, una qualifica della varietà linguistica d'origine come "dialetto" punta, per esempio, al fatto che il parlante e/o la comunità linguistica di appartenenza attribuiscano a tale codice un prestigio e una portata comunicativa più bassi e limitati rispetto a una sua categorizzazione come "lingua standard" o "lingua nazionale". Anche le situazioni comunicative possono essere disposte su una scala gerarchica da basso ad alto (cfr., per esempio, Fishman 1972/1975: 116-122). Perciò, una differenziazione tra due o più codici a seconda dei domini d'uso da parte di un intervistato si riferisce, a mio avviso, parimenti a questa dimensione di differenziazione. Infatti, se ne menziona gli ambiti di impiego o di apprendimento, il parlante sente la necessità - spontanea o indotta dal contesto intervista e/o dal contesto macro-sociale in cui questa si svolge - di specificare l'adeguatezza dell'utilizzo di tale varietà a seconda degli interattanti, del loro ruolo e/o della formalità della situazione comunicativa. Così, sebbene non siano propriamente denominazioni di lingua (ma si veda per esempio l'inglese home language), le categorizzazioni del tipo "lingua usata a casa" o "lingua usata a scuola" sono considerate per l'analisi esposta nei prossimi paragrafi. Queste danno infatti informazioni importanti sulla funzione sociale ricoperta da un codice e/o sulla sua distribuzione diafasica nella prospettiva degli intervistati.

In modo analogo a quanto affermato da Aronin et al. (2011), alla terza dimensione /emozionale-identitaria/ appartengono, d'altro canto, quelle apposizioni che istituiscono relazioni tra i codici del repertorio in base al ruolo più o meno centrale, assegnato loro dal parlante, nel definire la propria identità per lo meno linguistica. Fanno parte di questo gruppo le qualifiche "mia lingua", "nostra lingua" e "madrelingua". Come già precedentemente accennato, queste apposizioni rimandano infatti al valore affettivo ricoperto dai codici in questione. Eventualmente sono anche spia di una loro rappresentazione come "codici endocomunitari" in opposizione ad altre varietà linguistiche nel repertorio di partenza e/o d'arrivo (cfr. Dal Negro \& Iannàccaro 2003).

Una quarta dimensione di differenziazione - non presente in letteratura, ma identificata sulla base degli incipit delle biografie linguistiche raccolte - è quella / biografico-acquisizionale/. Apposizioni come "prima lingua", "seconda lingua", "lingua straniera" danno infatti indicazioni sul momento, nella storia della vita di una persona, in cui un codice è stato appreso. In realtà, secondo la terminologia proposta da Aronin et al. (2011), le denominazioni del tipo "lingua nativa" (native language) o "lingua straniera" (foreign language) segnalano la posizione di un codice sul "continuum vicino-lontano". Tuttavia, mi pare che gli intervistati del corpus - forse in quanto invitati a raccontare la propria biografia linguistica - se ne servano con un'accezione soprattutto temporale piuttosto che spaziale. Le denominazioni che istituiscono rapporti di differenziazione lungo questa dimensione non sono molto frequenti negli incipit delle interviste raccolte. Inoltre, alcune di queste apposizioni hanno talvolta molteplici significati. Così, la qualifica "prima lingua" rimanda, per esempio, all'ordine di acquisizione di un codice. In aggiunta, a seconda del contesto, può metterne in rilievo il valore /emozionale-identitario/ in con- 
trapposizione a una "lingua straniera" e/o la posizione /socio-geografica o socio-politica/ privilegiata in una comunità plurilingue (cfr. anche Lüdi \& Py 1986/2003: 44-47 per una riflessione su queste denominazioni da un punto di vista etico).

Specificatamente rilevante per categorizzare le relazioni tra codici nelle interviste analizzate è anche la dimensione /storico-temporale/. Nello specifico, indicazioni temporali svolgono negli incipit dei colloqui una funzione di differenziazione tra i glottonimi e le varietà da loro riferite in conseguenza della storia politico-linguistica recente dei paesi di provenienza dei partecipanti. Perciò, specialmente tra coloro che si riferiscono alle varietà linguistiche a base neoštokava, sono frequenti categorizzazioni che appartengono a questa dimensione (es. "la lingua usata all'epoca", "una volta si parlava"). Si noti che, come nel caso dei domini d'uso, tali espressioni non sono propriamente denominazioni di lingua. Tuttavia, data la loro rilevanza nella specifica situazione studiata, sono prese in esame nell'analisi esposta di seguito.

Infine, sempre a causa della situazione sociolinguistica di partenza, alcuni intervistati si servono delle apposizioni "stessa lingua", "lingue simili" o "lingue diverse" per qualificare codici, chiamati all'avvio dei colloqui con glottonimi differenti. Tali /prese di posizione riguardo ai rapporti di uguaglianza, somiglianza o differenza tra i codici d'origine/ costituiscono la sesta macro-categoria, individuata sulla base dei dati raccolti, a cui appartengono le denominazioni di lingua negli incipit delle interviste del corpus. Insieme a quelle descritte precedentemente, queste denominazioni e prese di posizione consentono specificamente di dare una prima valutazione di come siano (stati) esperiti "dal basso" gli interventi di "glottotomia" e la correlata situazione di "schizoglossia", che ancora vige nei paesi di provenienza degli intervistati (cfr. Goebl 1979 per i termini). Nello specifico, con interventi "glottotomici" si intendono interventi di pianificazione linguistica esterni, manifesti od occulti, volti alla frammentazione di una comunità linguistica. Come già illustrato nell'introduzione al presente capitolo, l'introduzione o la soppressione - per esempio, tramite processi di "tabuizzazione" - di nomi di lingua può essere funzionale a scopi glottotomici in conseguenza del valore simbolico da questi ricoperto (cfr. Goebl 1979: 31-32). Con "schizoglossia" si intende invece una situazione di insicurezza linguistica, nelle sue manifestazioni sia oggettive sia psicologiche. Nel caso studiato, questa è dovuta alla presenza di più codici standard, oggetto di possibile identificazione da parte di una $\mathrm{o}$ di più comunità linguistiche nell'area di partenza (cfr. sempre Goebl 1979: 32-33, Haugen 1966: 280-282).

\subsection{Repertori d'origine monolingui}

La figura 1 mostra i glottonimi e le eventuali apposizioni utilizzate dai 17 partecipanti del corpus che nell'incipit dell'intervista nominano un solo codice come facente parte del proprio repertorio d'origine. Le denominazioni elencate sull'asse verticale sono suddivise a seconda delle quattro dimensioni di differenziazione, rinvenute in questo gruppo di colloqui. 


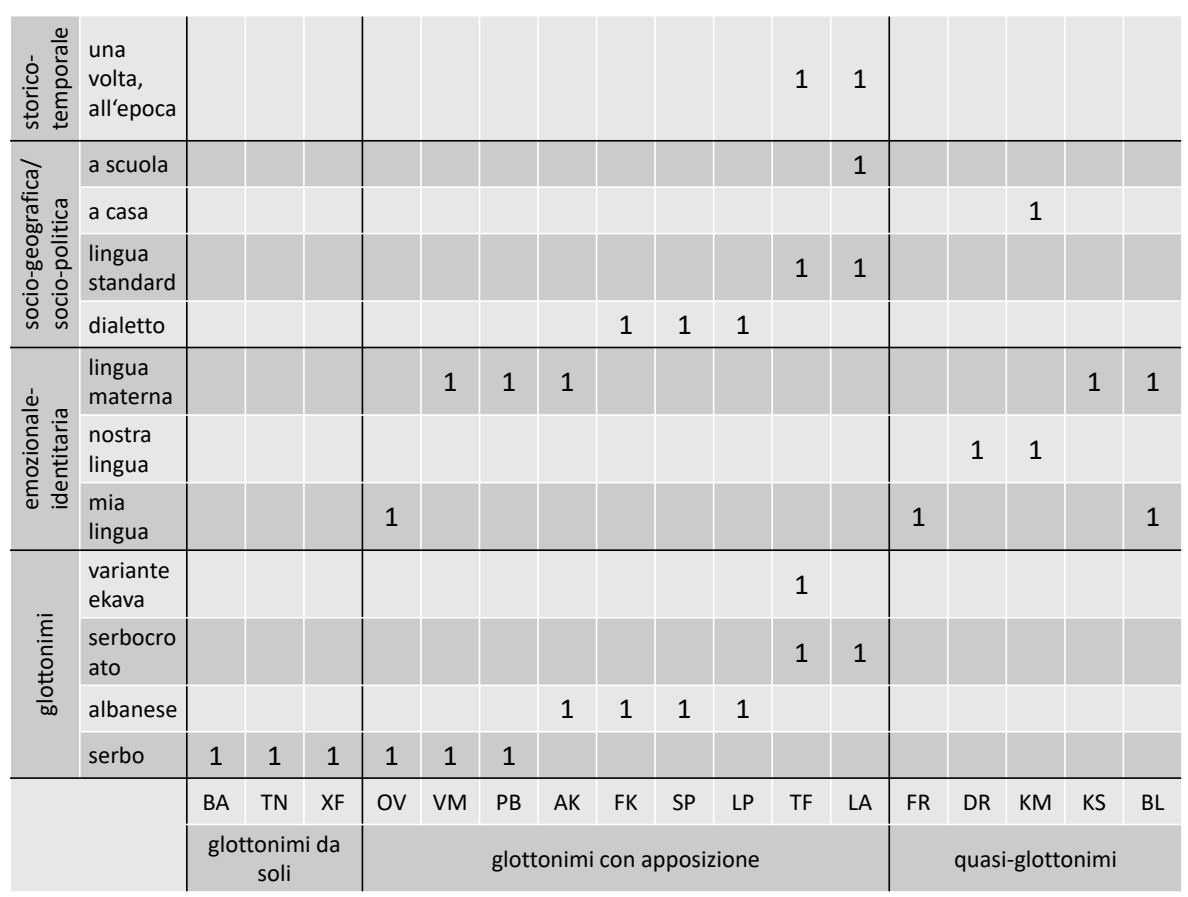

Figura 1: Glottonimi e apposizioni negli incipit delle biografie linguistiche dei partecipanti con repertorio d'origine monolingue.

Sulla base dell'immagine è possibile individuare alcune tendenze comuni nel qualificare determinati glottonimi e i codici da loro riferiti da parte dei singoli intervistati. Queste tendenze rimandano alla posizione che le varietà linguistiche in questione occupano nel repertorio comunitario dell'area di partenza. In particolare, al nome "serbo" è spesso associato un attributo relativo alla dimensione /emozionale-identitaria/. Invece, i codici denominati "albanese" e "serbocroato" sono inizialmente qualificati tramite categorie/socio-geografiche o socio-politiche/, ovvero rispettivamente come "dialetto" e "lingua standard". Infine, cinque partecipanti si servono esclusivamente di un nome di lingua dal referente ambiguo (o "quasi-glottonimo"), come "nostra lingua" o "lingua materna", per chiamare la varietà linguistica parlata nel paese d'origine all'inizio della registrazione (cfr. le colonne all'estrema destra della figura 1).

Esempi da questo ultimo sottogruppo di interviste non saranno discussi nei prossimi paragrafi. Per un'analisi dettagliata della funzione dei quasi-glottonimi nelle interazioni raccolte si rimanda infatti al §IV.2 e, in particolare, IV.3 e seguenti. Tuttavia sia qui menzionato, da un lato, che il codice riferito da tali circonlocuzioni è ambiguo soprattutto da un punto di vista etico. Infatti il referente di queste ultime non è immediatamente identificabile per la ricercatrice/interlocutrice. Lo stesso non vale però necessariamente per il parlante o per i membri della sua comunità linguistica di partenza. Dall'altro lato, i codici riferiti dai partecipanti tramite denomina- 
zioni ambigue non sono sempre gli stessi. Come emerge nel corso delle interviste, si tratta infatti di "kosovaro" nel caso di BL, di "serbo"/"montenegrino" nel caso di KS, di "serbocroato"/"bosniaco" nel caso di KM e di "serbo" nel caso di FR e DR. In aggiunta, alcuni intervistati, che nell'incipit della loro biografia linguistica chiamano i codici d'origine con nomi di lingua specifici, si servono poi durante il colloquio (o in sequenze significative di questo) prevalentemente di circonlocuzioni generiche analoghe. Infine, ancorché i quasi-glottonimi rinvenuti all'avvio delle registrazioni appartengano tutti alla dimensione /emozionale-identitaria/ (cfr. figura 1), i partecipanti adoperano talvolta nel corso delle interazioni anche perifrasi non connotate su questa scala.

\subsubsection{Varianti e invarianti}

Sei partecipanti del corpus, rispondendo alla prima domanda dell'intervistatrice, chiamano "serbo" l'unico codice del loro repertorio d'origine (cfr. figura 1 al $\S$ IV.1.3). Tra questi intervistati, BA, TN e XF non qualificano ulteriormente il codice in questione tramite apposizioni. Tuttavia, nei turni di parola iniziali delle loro biografie linguistiche, questi partecipanti rappresentano comunque il proprio repertorio attuale come plurilingue. Infatti, menzionano fin da subito i codici acquisiti durante l'esperienza migratoria, ovvero, in tutti e tre i casi, il "tedesco" prima e 1'"italiano" poi.

In particolare, la differenziazione tra il codice d'origine e quelli di arrivo in queste conversazioni è effettuata sulla base dei loro diversi domini d'apprendimento e d'uso. Così, XF distingue, all'avvio della sua intervista di coppia, tra "Serbisch" (serbo), da un lato, e "Deutsch"/“Italienisch" (tedesco/italiano), dall'altro. Questi codici sono rispettivamente categorizzati come lingua parlata a casa e come lingue usate al lavoro. Similmente, ma adottando il punto di vista cronologico elicitato dalla prima domanda dell'intervistatrice ("Int: eh:m quale:: lingue o dialetti ha imparato a casa dai suoi genitori prima: dei sei anni"), BA contrappone, all'inizio della sua intervista semi-strutturata, il "serbo", lingua usata in Serbia fino ai cinque anni, al "tedesco" acquisito "subito dopo in asilo - in Austria" (BA_Ser Mer, 08:05-08:27). Infine, TN illustra nei primi turni di parola della sua intervista episodico-narrativa le difficoltà riscontrate nell'apprendimento del tedesco durante il primo anno di scuola in Alto Adige. Inoltre racconta della successiva acquisizione dell'italiano al lavoro nella cucina di un hotel, per via dei numerosi colleghi italofoni. Solo dopo aver riferito delle modalità di apprendimento delle due lingue d'arrivo, TN afferma che in Serbia parlava solamente "Serbisch" (serbo) e ricorda di aver appreso un po' di "Französisch" (francese) a scuola. Il codice "serbo" è categorizzato dall'intervistato nel seguito della conversazione sulla dimensione /biografico-acquisizionale/ e parzialmente /emozionale-identitaria/ come la "erste Sprache" (prima lingua) da insegnare ai figli. Inoltre, al termine del colloquio, il partecipante introduce il glottonimo "Bosnisch" (bosniaco): tale nome è usato per chiamare una "lingua" che gli appare come un "dialetto" quasi uguale al codice "serbo" e che gli è divenuta familiare solo dopo il trasferimento in Alto Adige, grazie ad 
alcuni colleghi di lavoro. Così, dagli incipit di queste tre interviste, risulta che anche i partecipanti con un repertorio d'origine monolingue tendano a rappresentare il plurilinguismo come un valore: questi intervistati si posizionano infatti, fin dall'inizio delle loro biografie linguistiche, come parlanti (divenuti) plurilingui.

Le altre tre intervistate (OV, VM, $\mathrm{PB})$, che chiamano l'unico codice d'origine "serbo", lo qualificano immediatamente tramite le apposizioni "mia lingua", "lingua materna" e "Muttersprache" (madrelingua) (cfr. sempre figura 1 al $\S$ IV.1.3). Come emerge dall'esempio 1, queste apposizioni precisano la posizione del codice sulla dimensione /emozionale-identitaria/. Tale operazione è al contempo funzionale a differenziare la varietà linguistica in questione da altre lingue imparate successivamente, per esempio, a scuola nel paese di provenienza (cfr. righe 4-5).

(es. 1)

1 INT e: no appunto la prima domanda - è ampia in realtà ha già anche

2 INT risposto e: su tutte le lingue che sa come le ha imparate o anche

3 INT quelle che solo riconosce e::

4 VM ((sospiro)) sempre con il ((pausa)) serbo è lingua ma- e: lingua

5 VM materna - scuola ho imparato russo -

6 INT ah ah

(VM_Ser_Mer, 28:01-28:43, F, cittadina della Serbia occidentale, $46,2001)$

Nel prosieguo delle loro biografie linguistiche, le tre partecipanti adottano tuttavia strategie di denominazione differenti per chiamare e qualificare i codici d'origine. Inoltre prendono posizioni diverse rispetto ai codici elaborati successivamente al serbocroato. PB e OV utilizzano le apposizioni "mia lingua" e "lingua materna", introdotte nell'incipit della registrazione, anche in posizione isolata nel discorso in funzione di quasi-glottonimi. Possibilmente in connessione con ciò, queste due intervistate non prendono posizione, nel corso della conversazione, riguardo alle differenze/somiglianze del codice d'origine né con il "croato", "bosniaco" o "montenegrino", né con il "serbocroato".

Al contrario, VM si serve dell'apposizione "lingua materna" solo occasionalmente - in particolare, solamente nelle sequenze in cui descrive situazioni di erosione/dimenticanza di lingua propria o altrui - e sempre in concomitanza con il nome specifico "serbo". In aggiunta, la narratrice prende posizione, nel corso dell'intervista, rispetto alla mutuale comprensibilità dei quattro standard elaborati recentemente nell'area d'origine. Nello specifico, in risposta a una domanda dell'intervistatrice, la donna differenzia, al termine del colloquio, "serbo" e "serbocroato" sulla dimensione /socio-geografica o socio-politica/ e /storico-temporale/. Da un lato, VM paragona infatti lo spazio linguistico evocato dal termine "serbocroato" a quello nord-italiano e motiva la variazione diatopica che li contraddistingue con l'estensione del territorio. Inoltre, menziona il domino scuola come tipica situazione di utilizzo del codice. Dall'altro lato, il glottonimo "serbocroato" è usato per riferirsi a una varietà linguistica che esisteva in passato e che è stata recentemente oggetto di interventi di pianificazione, soprattutto a livello lessicale: "VM: a scuola 
[...] io avevo serbocroato insieme come una parola - serbo e croato ((pausa)) e adesso per fare $<<$ stringendo le labbra M:Olto più differenza si mettono nu:ove parole" (minuti 01:06:31-01:07:29).

A differenza del "serbo", al glottonimo "albanese" tende invece ad essere associata l'apposizione "dialetto". Questo vale per tre partecipanti su quattro che lo nominano come unico codice d'origine nell' incipit della loro intervista (cfr. FK, SP, LP nella figura 1 al $\S$ IV.1.3). ${ }^{8} \mathrm{Nel}$ brano in 2, l'apposizione "dialetto" è in realtà già adoperata dall'intervistatrice nella sua domanda (cfr. riga 1). Tuttavia, questa costituisce una categoria (divenuta) anche emica per qualificare il codice di partenza. Qui come altrove, la qualifica di "dialetto" è infatti funzionale a spiegare la differenza tra la varietà di "albanese", parlata nella località d'origine in Kosovo, e quella usata in Albania: differenza che diventa particolarmente rilevante in contesto migratorio (cfr. anche più sotto in questo paragrafo). Si noti che entrambe le partecipanti concordano nel caratterizzare i rapporti di differenziazione tra i due codici in questione tramite aggettivi appartenenti alla sfera della grammaticalità/correttezza (cfr. righe 8-9).

\section{(es. 2)}

1 INT e: okay allora:: - sarebbe sulle lingue e i dialetti che hai imp-

2 INT imparato quando eri piccola se mi puoi raccontare cioè se mi potete

3 INT raccontare come: se mi potete raccontare come: li avete imparati e

4 INT da chi e: ((pausa)) un po' che rapporto avete con queste lingue

5 SP quando ero: entrambe siamo sorelle innanzitutto $(\mathrm{h})$ - e:: siamo nate

$6 \mathrm{SP}$ in kosovo quindi:: sin da piccole siamo:: comunque abbiamo parlato

7 SP l'albanese - però:: n::on magari quello doc quello diciamo:: - u- u-

8 SP grammaticalmente:

9 AP corretto

10 SP si però una specie di dia- dialetto alla fine - e: e quindi questa

11 SP cosa per - tutto il periodo per cui abbiamo appunto:: cioè siamo

12 SP state in kosovo

(SP_AP_Kos_Bo, 00:10-01:04, F/F, paese del Kosovo occidentale, 24/22, 1998/1998)

Successivamente, SP e AP distinguono le due varietà di albanese anche sulla base di differenze estetiche, rappresentate come intrinseche, mentre discordano nel valutarne il grado di mutuale comprensibilità. AP definisce infatti il codice parlato in Kosovo "una sorta di dialetto" che "ha tanto dell'albanese", ma anche tante parole turche e serbe. Nel fare ciò, lo contrappone alla "lingua melodiosa" e "bellissima" parlata in Albania. La comunicazione tra parlanti delle due varietà è rappresentata inoltre come possibile, anche se solamente nei casi in cui gli uni si sforzino di parlare in maniera "più corretta" e gli altri rinuncino a "termini forbiti". SP è d'accordo con la descrizione della sorella e usa l'aggettivo "rigido" per qualificare il "dialetto" parlato in Kosovo. Al contrario di AP, la partecipante sottolinea tuttavia le difficoltà comunicative tra i parlanti delle due varietà, residenti in Alto Adige. Quando la

8 Fa invece eccezione AK che definisce la lingua "Albanisch" (albanese) come la propria "Muttersprache" (madrelingua) in contrapposizione a "Deutsch" (tedesco). 
donna comunica con albanofoni dall'Albania in contesto migratorio, è infatti piuttosto l'italiano "la lingua che un p- ((pausa)) ci unisce" (minuti 12:24-14:47).

Infine, due intervistate chiamano, all'inizio della loro biografia linguistica, l'unico codice del loro repertorio di partenza "serbocroato" (cfr. TF e LA nella figura $1 \mathrm{al} \S$ IV.1.3). Subitaneamente, le due partecipanti qualificano questa varietà linguistica anche sulla dimensione /socio-politica/ e /storico-temporale/: il "serbocroato" è infatti definito come la "lingua standard" o la "Hochsprache" (lingua alta o lingua standard) che si parlava in un'epoca passata. Nel brano in 3, TF si serve inoltre del termine "variante ekava" per definire la varietà di serbocroato diffusa a Belgrado. Tale concetto è adoperato anche da LA in sequenze successive del colloquio (cfr. righe 8-9). Nello specifico, la nozione è usata dalle due narratrici per concettualizzare la "leggera differenza" tra la varietà da loro usata e quella sentita parlare rispettivamente durante le vacanze estive in Croazia (TF) e da altri studenti durante gli anni di Università a Belgrado (LA).

(es. 3)

1 INT e:: ecco la prima domanda ((pausa)) in realtà è ampia - cioè i bv-

2 INT sar- l'idea sarebbe un: un racconto biografico e quindi e::

3 INT ((pausa)) come: e:: [come è]

4 TF [okay]

5 INT è diventata multilinguale o [quali] sono: - co- come è andata

$6 \mathrm{TF}$

$7 \mathrm{TF}$

$8 \mathrm{TF}$

$9 \mathrm{TF}$

$10 \mathrm{TF}$

$11 \mathrm{TF}$

$12 \mathrm{TF}$

$13 \mathrm{TF}$

[okay]

- okay (h) allora dal punto di vista linguistico quindi io sono nata

a belgrado dove si parla - serbocroato all'epoca ((pausa))

serbocroato è la vari- variante ekava - si parla a belgrado quindi ((pausa)) da noi non ci sono (h) - dia:letti insomma particolari a belgrado questo vuol dire si parla la lingua standard ((pausa)) (h) e io ho parlato naturalmente fino:: alla scuola ho parlato con i miei genitori - serbocroato ((pausa))

(TF_Ser_Falzes, 00:40-01:31, F, Belgrado, 49, 1994)

Nel corso delle loro interviste, le due partecipanti precisano la posizione del "serbocroato" nel loro repertorio individuale e comunitario di partenza. Nel fare ciò, si servono sempre di apposizioni che appartengono prevalentemente alla dimensione /socio-geografica o socio-politica/. Infatti, LA caratterizza il serbocroato, dal punto di vista della sua esperienza individuale, come la "lingua standard" (Hochsprache), da lei parlata a scuola, in contrapposizione al "dialetto dalmatino" (dalmatinischer Dialekt), "che si parla solamente quando si è proprio in compagnia di persone che parlano lo stesso dialetto" ("spricht man dann nur wenn man richtig mit den e:: e menschen umgegeben ist die die d- - den gleichen dia- dialekt sprechen"; LA_Cro Bo, 02:43-03:02). Inoltre, a livello di usi linguistici comunitari, il serbocroato è definito dalla donna come la "lingua dello stato/lingua nazionale" (Staatsprache), imparata obbligatoriamente a scuola sia dai parlanti di macedone e sloveno, sia dai parlanti di "lingue di minoranza" (Minderheitensprachen), tra cui "albanese" e "ungherese". In modo parzialmente analogo, TF definisce il serbocroato sulla dimensione /socio-politica/ e in parte /biografico-acquisizionale/ come la "prima lingua" 
che doveva essere appresa da tutti durante il percorso formativo in Jugoslavia. In ciò, il codice godeva di un trattamento privilegiato rispetto, per esempio, allo sloveno, lingua parlata dalla nonna, ma non trasmessa a TF da bambina. Infine, sia qui menzionato che LA qualifica il codice in cui sta parlando, all'inizio della sua biografia linguistica, anche con l'epiteto "mia lingua". Non è tuttavia chiaro a quale glottonimo la donna si riferisca in questa sequenza ("dobar dan ((riso)) ich beginne mit einer begrüßung weil: das wäre - meine sprache"; tr. "dobar dan (it. buon giorno) ((riso)) inizio con un saluto perché: questa sarebbe - la mia lingua"). ${ }^{9}$ L'apposizione "mia lingua" è utilizzata successivamente anche da TF. La partecipante la usa però, in modo piuttosto inconsueto rispetto agli altri intervistati del corpus, per riferirsi a un codice acquisito da adulta, ovvero l'"italiano".

Dal confronto esposto in questo paragrafo emergono così alcune correlazioni, per lo meno parziali, tra il tipo di glottonimo scelto per il codice d'origine e l'apposizione adoperata per qualificarlo. Questo vale preliminarmente per quegli intervistati che rappresentano, all'inizio della propria biografia linguistica, il proprio repertorio di partenza come monolingue. Tuttavia, l'analisi ha mostrato che tali rapporti di differenziazione si precisano e talvolta modificano in sequenze successive di una stessa conversazione. Inoltre, l'effettiva invariabilità e i motivi di tali categorializzazioni comuni possono essere precisati meglio sulla base di un esame degli altri incipit del corpus, in cui i narratori nominano più glottonimi - non concorrenti, semi-concorrenti o concorrenti - per i codici d'origine. Come sarà discusso più dettagliatamente nei prossimi paragrafi, alcune categorizzazioni rimangono infatti costanti, mentre altre variano possibilmente a seconda o in conseguenza del numero e dello status dei codici menzionati sequenzialmente dai narratori.

\subsection{Repertori d'origine plurilingui}

Dieci partecipanti nominano due o più glottonimi riferiti a codici (rappresentati come) tipologicamente diversi fin dall'inizio del colloquio. Nel fare ciò, presentano subitaneamente il proprio repertorio di partenza e la situazione sociolinguistica del paese di provenienza come plurilingue. La figura in 2 offre una panoramica dei glottonimi "non concorrenti" - in quanto riferiti a codici rappresentati dagli intervistati come diversi - e delle apposizioni impiegate per categorizzarli negli incipit delle dieci interviste in questione. A ogni glottonimo e alle relative qualifiche corrispondono numeri diversi a seconda dell'ordine in cui le varietà linguistiche sono menzionate dai partecipanti all'avvio dei colloqui. Le apposizioni elencate sull'asse verticale sono inoltre suddivise a seconda di quattro dimensioni di differenziazione. A differenza dei parlanti "monolingui" del primo gruppo (cfr. figura 1 al §IV.1.3), alcuni partecipanti con repertorio d'origine "plurilingue" si servono anche di categorializzazioni sulla dimensione /biografico-acquisizionale/ per distinguere i codici menzionati. Mancano invece, in questi incipit, le apposizioni relative alla dimensione /storico-temporale/.

9 Per un'analisi più dettagliata delle denominazioni, tra cui anche quasi-glottonimi, usate da LA nella sua intervista episodico-narrativa si veda il § IV.2.3. 


\begin{tabular}{|c|c|c|c|c|c|c|c|c|c|c|c|}
\hline \multirow{2}{*}{ 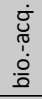 } & lingua seconda & 2 & & & & & & & & & \\
\hline & lingua prima & 1 & & & & & 1 & & & & \\
\hline \multirow{5}{*}{$\begin{array}{l}\dot{0} \\
\text { o } \\
\dot{0} \\
\dot{d} \\
0 \\
\dot{0} \\
\dot{0} \\
0\end{array}$} & nel quartiere & & & & & & 2,3 & & & & \\
\hline & a scuola & & 2 & 2 & 2 & 2 & & & 1 & & \\
\hline & a casa & & 1 & & & & & & 2 & & \\
\hline & lingua nazionale & 2 & & & & & & & & & \\
\hline & dialetto & & & & & & & 2 & & & \\
\hline \multirow{2}{*}{ 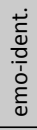 } & lingua materna & & & 1 & & 1 & 1 & 1 & 1,2 & & \\
\hline & nostra lingua & & & & 1 & & & & & & \\
\hline \multirow{8}{*}{$\begin{array}{l}\overline{\underline{\xi}} \\
\overline{0} \\
0 \\
\text { 음 }\end{array}$} & turco & & & & & & 3 & & & & \\
\hline & rumeno & & & & & & & 2 & 2 & & \\
\hline & jugoslavo & & & & & & & & & 1 & \\
\hline & serbocroato & 2 & 2 & 3 & & 2 & & & & & \\
\hline & serbo & & & & 2 & 2 & 2 & 1 & 1 & & 1 \\
\hline & kosovaro & & & & & 1 & & & & & \\
\hline & albanese & & & 1 & 1 & 1 & 1 & & & 3 & 3 \\
\hline & macedone & 1 & 1 & 2 & & & & & & 2 & 2 \\
\hline & & NJ & MG & AS & $\mathrm{ML}$ & $\mathrm{AC}$ & DK & $\mathrm{DL}$ & $\mathrm{DB}$ & IP & SM \\
\hline & & & & & glo & imi & conco & & & & \\
\hline
\end{tabular}

Figura 2: Glottonimi e apposizioni negli incipit delle biografie linguistiche dei partecipanti con repertorio d'origine plurilingue. I numeri si riferiscono all'ordine di menzione delle denominazioni.

Dalla figura 2 emerge che l'istituzione di rapporti di differenziazione, più o meno complessi, tra i codici d'origine sia una strategia comunemente usata dagli intervistati al momento di iniziare a narrare la propria biografia linguistica a un'intervistatrice semi-sconosciuta. Otto intervistati su dieci differenziano infatti nelle sequenze iniziali della registrazione i codici di partenza e la loro allocazione nel repertorio tramite apposizioni e/o descrivendone i diversi domini d'uso e d'apprendimento. Tale proporzione è significativa nella misura in cui queste categorizzazioni non sono esplicitamente elicitate dalla domanda della ricercatrice. Fanno però eccezione gli incipit delle interviste con IP e SM: questi ultimi due partecipanti non istituiscono infatti rapporti di differenziazione tra le varietà linguistiche menzionate all'avvio del colloquio (cfr. ultime due colonne nella figura 2). Inoltre, l'ordine di menzione dei codici di partenza non coincide, in queste due interviste, con quello di acquisizione. Come sarà precisato solo in sequenze successive delle registrazioni, $\mathrm{i}$ due partecipanti hanno infatti imparato come prima lingua 1'“albanese". Tuttavia, questo codice che è, invece, nominato, all'avvio del colloquio, come ultima varietà linguistica del repertorio, alla fine di un elenco di tre.

Le biografie linguistiche di IP e SM saranno analizzate più dettagliatamente ai $\S$ IV.3.2 e IV.2.4 del presente volume. Nei prossimi tre paragrafi, discuto invece gli incipit delle rimanenti otto interviste. Questi sono suddivisi in tre sotto-gruppi a seconda del codice che gli intervistati nominano per primo all'avvio dei colloqui, 
ossia rispettivamente "macedone", "albanese" e "serbo". Queste varietà linguistiche avevano - e frequentemente hanno ancora - un diverso status nello spazio sociolinguistico di partenza. L'analisi dei modi in cui sono chiamate permette di ricostruire la loro allocazione rispetto alle altre varietà linguistiche (ri)conosciute dai partecipanti e, così, di delineare i (tipi di) repertori individuali e comunitari di partenza, rappresentati all'avvio dei colloqui. Inoltre, l'esame degli incipit di queste interviste consente di confrontare i modi e le motivazioni addotte dai narratori per spiegare alla ricercatrice il plurilinguismo e la propria acquisizione di più varietà linguistiche nel paese di partenza, già prima dell'esperienza migratoria.

\subsubsection{Il macedone come lingua co-ufficiale}

Come mostrato nella figura 2 al § IV.1.4, MG e NJ nominano il "macedone" come primo codice del loro repertorio d'origine, mentre si servono dello stesso glottonimo, ovvero "serbocroato", per chiamare la seconda varietà linguistica da loro appresa nel paese di partenza. In particolare, nella sequenza in $4, \mathrm{NJ}$ concettualizza la differenza tra "macedone" e "serbocroato" tramite apposizioni appartenenti talvolta a più dimensioni contemporaneamente. La denominazione "seconda lingua" allude infatti nello stesso tempo i) al momento di acquisizione del codice, successivo a quello della "prima lingua", vale a dire alla dimensione /biografico-acquisizionale/ e ii) al suo status /socio-politico/ di seconda lingua usata ufficialmente nella comunità di partenza (cfr. anche l'apposizione "lingua nazionale" riferita sempre al "serbocroato"). Invece, la definizione di "macedone" come la lingua che si parla "da noi" (cfr. riga 7) può essere intesa sia da punto di vista /socio-geografico/, sia /emozionale-identitario/: infatti, dà un'indicazione, anche se piuttosto vaga, della sua area di utilizzo così come lo definisce implicitamente come codice endocomunitario. Infine, l'acquisizione di competenze in "serbocroato" è rappresentata nel brano in 4 come obbligatoria nella Repubblica di Macedonia nel periodo a cui $\mathrm{NJ}$ fa riferimento: alla riga 10, il narratore si serve infatti di verbi modali che esprimono deonticità per giustificarne l'apprendimento proprio e altrui ("bisogna", "dovevamo").

(es. 4)

1 INT ((pausa)) okay la prima domanda è sulle lingue e i dialetti che: ha

2 INT imparato e: nel suo paese d'origine

3 NJ mh: diciamo in ex jugoslavia -

4 INT si prima di venire: -

5 NJ si in ex jugoslavia ((pausa))

6 INT dai suoi genitori al le prime

7 NJ si: da noi si parla macedone no - e dopo: in macedonia cioè parlo di

8 NJ jugoslavia e: - lingua nazionale era serbocroato ((pausa)) così:

9 NJ macedone era prima lingua - serbocroato era anche - la seconda ma:

$10 \mathrm{NJ}$ ((pausa)) bisogna saper- si - dovevamo saperla tutti anche tutte

11 NJ repubbliche ((pausa))

(NJ_Mac_Mer, 00:00-00:58, M, paese della Rep.di Macedonia orientale, $40,1993)$ 
Una rappresentazione simile a quella in 4 è presente anche nell'incipit dell'intervista con l'altra partecipante proveniente dalla Repubblica di Macedonia, "al tempo della Jugoslavia". Anche MG usa infatti prevalentemente forme verbali impersonali per raccontare dei modi di apprendimento del "serbocroato" a scuola e attraverso i mass media: "visto che c'era un tempo della jugo:slavia a scuola si studiava anche s:erbo:croato [...] si:: leggevano i giornali la tivu". Tali forme contrastano con quelle in prima persona adoperate invece dall'intervistata per raccontare il processo di acquisizione dell'"inglese", sempre durante il proprio percorso formativo: "poi: alle scuole elementari ho iniziato con inglese ((pausa)) e poi:: ho continuato [...] e poi $>-$ ho iniziato a: insegnare inglese". Nel primo caso, MG lascia indeterminata la propria agentività nell'imparare un codice, il "serbocroato", la cui acquisizione è rappresentata quasi come un fenomeno di massa o collettivo. Nel secondo caso, la donna si presenta invece come agente attiva che sceglie autonomamente di acquisire una lingua, 1' "inglese", che del resto diventerà poi centrale nella sua biografia non solo linguistica. MG lavora infatti al momento dell'intervista come insegnante di inglese in una scuola elementare in provincia di Bolzano. Per quanto riguarda il "macedone", MG - riprendendo però una differenziazione per situazione comunicativa già presente nella prima domanda dell'intervistatrice - qualifica il codice come lingua parlata "a casa". Nel fare ciò, similmente a NJ nel brano in 4, lo differenzia dal "serbocroato" sulla dimensione /socio-politica/ e parzialmente /emozionale-identitaria/.

Così entrambi gli intervistati, che si posizionano come parlanti macedone come prima lingua all'avvio dei colloqui, descrivono la situazione sociolinguistica di partenza come caratterizzata da bilinguismo sociale a livello comunitario. Di questo bilinguismo mettono soprattutto in evidenza i tratti costrittivi, ossia l'obbligo di apprendere un secondo codice a scuola, e, nel migliore dei casi, gli aspetti legati alla sua dimensione istituzionale, ovvero, nel caso di MG, la possibilità di fruire di servizi, ad esempio di mass media, in codici diversi. ${ }^{10}$ In particolare, nel riferirsi in entrambi casi alla "Jugoslavia", i due partecipanti presentano, all'inizio delle loro biografie linguistiche, le proprie competenze linguistiche individuali come direttamente plasmate, se non necessariamente determinate, dal "regime linguistico" in cui hanno vissuto, ossia dall'assetto che regola(va) a livello istituzionale il plurilinguismo comunitario nel paese di partenza (cfr. Busch 2013: 134). Nello specifico, i repertori d'origine di MG e NJ possono essere definiti come "diacrolettici" (cfr. Iannàccaro \& Dell'Aquila 2004: 171). Questi sono infatti caratterizzati da ottime competenze in due codici, di cui il primo, il "macedone", è adatto a tutte le occasioni, mentre il secondo, il "serbocroato", è impiegato esclusivamente nei domini alti.

Tali rappresentazioni del repertorio individuale e comunitario di partenza sono ulteriormente specificate dagli intervistati in sequenze successive delle registrazioni. In questi brani - probabilmente sia perché i partecipanti fanno riferimento a codici diversi, sia perché si sentono più liberi di adottare modi di rappresentazione

10 Si confronti la già citata definizione di "plurilinguismo istituzionale" in Lüdi \& Py (1986/2003: 13) al § II.1.2. 
meno convenzionali -, MG e NJ riconducono il plurilinguismo del paese d'origine a (tipi di) motivazioni tra loro differenti. Da un lato, MG spiega le proprie competenze di base in "greco", codice definito dalla donna anche come "la lingua del vicino", tramite una ragione "geografica", ovvero in conseguenza della posizione della località di residenza a "tre chilometri dal confine con la Grecia" (cfr. MG_ Mac_Bo, 03:10-03:34). ${ }^{11}$ Invece, NJ si serve nel brano in 5 di una spiegazione "storica" per motivare la presenza di parlanti alloglotti "vlasi", con una lingua simile a "quelli di Romania", nel paese d'origine. ${ }^{2}$ La presenza attuale di tale codice sul territorio è infatti ricondotta alla presenza di discendenti di persone, rimaste nell'area dai tempi dell'impero romano. Nella sequenza in 5, il narratore attribuisce la paternità di tale affermazione a fonti scritte, ad esempio, statistiche e libri (cfr. righe 5 e 8). Nel fare ciò, mira implicitamente a convalidarne maggiormente la fondatezza e, al contempo, a non assumersene personalmente la responsabilità (cfr. anche la risata alla riga 7 che segnala una certa ironia (o incredulità) da parte dell'intervistato nell'usare questo tipo di argomentazione). La tesi è usata del resto per spiegare la presenza di un altro gruppo linguistico e la diffusione di una lingua non conosciuta personalmente dal parlante.

\section{(es. 5)}

1 NJ ci sono quelli: - zinzeri come si chiamano

2 NJ ((pausa)) non so da noi si chiamano vlasi - e: in lingua italiana

3 NJ non so però ${ }^{\circ}$ se l'avete voi ${ }^{\circ}$

4 NJ ((pausa)) lingua ce l'hanno come quelli di romania - ma da: alcune

5 NJ parti ho letto - che quelli sono quelli: - quando - una volta impero

6 NJ romano è stato lungo che quelli sono quelli romani che son rimasti

$7 \mathrm{NJ} \quad($ pausa) $)$ ((ridendo)) io non lo so come è come è giusto ma così ho

8 NJ sentito sai nelle statistiche nelle nei libri dove scrivono un po'

9 NJ di tutti i popoli - ho letto che quelli parlano lingua s:imile di

10 NJ quelli di romania - ma dicono che sono romani che sono rimasti

11 NJ quando era romano impero grande

(NJ_Mac_Mer, 05:33-06:09, M, paese della Rep. di Macedonia orientale, $40,1993)$

Indipendentemente dalla loro fondatezza o meno, è interessante notare che anche altri intervistati riconducono nel corso delle loro interviste l'apprendimento e/o la compresenza di codici diversi nelle regioni d'origine a ragioni "storiche" o talvolta "pseudo-storiche". Vale a dire, spiegano una situazione attuale raccontando o riferendosi a un racconto di un'esperienza passata, più o meno fattuale, vissuta non dal singolo, ma dalla collettività. Così, per esempio, TF fa riferimento all'impero austro-ungarico per

11 MG chiama la lingua "greco" senza far riferimento alla possibile presenza di codici misti tra greco e macedone.

12 Il nome "vlasi" ripara, nel brano in 5, l'etnonimo precedente "zinzeri" ed è usato dal partecipante per chiamare la popolazione valacca/vlacca. In questo caso, si tratta probabilmente di parlanti di una varietà di arumeno, dato che l'intervistato è originario della Rep. di Macedonia (cfr. anche $\S$ II.3.3). 
spiegare all'interlocutrice il fatto che la nonna sappia qualche parola in tedesco. Invece, RX motiva il proprio apprendimento del russo tramite l'allusione a un rapporto di fratellanza con la popolazione russa. Infine, DB - che a differenza di NJ ha competenze nel codice in questione (cfr. anche $\S$ IV.1.4.3) - riconduce la presenza di parlanti di varietà di rumeno o "vlaschi" in Serbia a migrazioni di persone avvenute "anni anni anni fa [...] dai carpati dalla russia" (DB_Ser_Bru, 05:09-06:02).

\subsubsection{L'albanese come lingua di minoranza}

Quattro partecipanti menzionano 1"“albanese" e/o il "kosovaro" come primo codice del loro repertorio plurilingue d'origine (cfr. AS, ML, AC e DK in figura 2 al $\S$ IV.1.4). A differenza degli intervistati che lo indicano come unico codice del repertorio di partenza, questi parlanti non si servono dell'apposizione "dialetto" per qualificare 1" "albanese" nell'incipit del colloquio. Invece, lo categorizzano fin da subito come "lingua materna" o "nostra lingua", differenziandolo così dai codici nominati di seguito sulla dimensione /emozionale-identitaria/. L'apposizione, assegnata dai singoli a una varietà linguistica che è di minoranza a livello collettivo, sembra dunque essere parzialmente correlata con il numero e/o il tipo di codici che vengono menzionati nel cotesto immediatamente successivo. Quando rappresentano il proprio repertorio come plurilingue, i narratori tendono infatti a stabilire fin da subito una differenziazione a livello /emozionale-identitario/ tra le varietà linguistiche conosciute. Una precisazione su questa dimensione è invece di solito tralasciata in favore di una sul piano /socio-geografico o socio-politico/ nel caso il repertorio sia presentato dapprincipio come monolingue (cfr. anche $\S I V .1 .3$ ). Si consideri ad illustrazione di ciò il brano in 6 , in cui AS caratterizza le relazioni tra $i$ codici nel repertorio trilingue di partenza.

1 INT ((pausa)) ${ }^{\circ}$ okay $^{\circ}$ - allora la prima domanda è:: ampia se mi puoi

2 INT raccontare delle lingue che:: sai - di tutte le lingue che sai

3 INT (h) e:: anche quelle che solo capisci - e:: quelle che hai imparato

4 INT eh:m se hai delle delle non lo so delle esperienze che sono legate a

5 INT queste lingue

6 INT (h) e:: se me le puoi raccontare e se: ehm e insomma così in

7 INT generale ((pausa))

8 AS allora ((pausa)) io parlo $1=$ albanese - che è madrelingua

9 AS - però a scuola noi: impariamo anche il maceDOne - viviamo li: e:

10 AS per forza dobbiamo saperlo

11 AS (h) - so anche un po' di serbocroato perch=é quasi come il maceDOne

12 AS ((pausa)) e poi un po' di $<<$ sorridendo italiano ((sorriso)) $>$

13 INT $\mathrm{mh} \mathrm{mh}$

14 AS $\quad-<<$ sorridendo solo questi $>$ ((pausa))

(AS_Mac_Bo, 00:00-01:00, F, cittadina della Rep. di Macedonia nordoccidentale, 24, 2006) 
La rappresentazione del repertorio di partenza di AS nella sequenza in 6 può essere confrontata con quelle di MG e NJ, discusse nel paragrafo precedente e parimenti relative alla situazione sociolinguistica nella Repubblica di Macedonia. Nonostante AS sia più giovane e si sia trasferita in Alto Adige piuttosto recentemente, anche lei si serve nell'incipit del colloquio di un glottonimo attualmente non ufficiale (ovvero "serbocroato") per chiamare uno dei codici d'origine. Inoltre, la donna caratterizza, analogamente agli altri due partecipanti, il plurilinguismo comunitario e individuale di partenza come promosso primariamente a livello scolastico-educativo: è infatti a scuola che l'intervistata apprende la seconda lingua, ossia nel suo caso il "macedone".

Tuttavia, le prese di posizione nei confronti delle varietà linguistiche di partenza e la loro allocazione nel repertorio individuale e comunitario non coincidono tra i tre intervistati. Da un lato, nel motivare l'apprendimento del "serbocroato", AS non menziona nel brano in 6 , diversamente da NJ e MG, la componente "costrittiva". Questo aspetto è invece messo in risalto nell'illustrare le condizioni di acquisizione del "macedone" (cfr. righe 9-10). Dall'altro lato, nel corso del colloquio, la partecipante descrive come tendenzialmente "diglottica" - e non diacrolettica - la situazione sociolinguistica della località di partenza. Nella cittadina di nascita, "macedone" e "albanese" si ripartiscono infatti rispettivamente il polo alto e basso della scala dei domini d'uso, mentre il "serbocroato" non è utilizzato in alcun ambito comunicativo. Ciò è vero anche se i rapporti tra codici nella comunità di partenza sono caratterizzati dalla donna come piuttosto instabili. In particolare, AS rappresenta l'impiego di "macedone" e "albanese" come parimenti possibile a seconda dell'interlocutore in situazioni comunicative semi-formali all'epoca in cui viveva nella Rep. di Macedonia. In aggiunta, la portata comunicativa della seconda varietà linguistica è vista come in aumento negli ultimi anni.

Un punto di vista, parimenti rilevante per ricostruire l'identità linguistica dell'albanese nell'area dei paesi successori alla Jugoslavia, è quello che emerge nell'incipit dell'intervista con DK, trascritto in 7. Nel descrivere il proprio repertorio individuale e quello comunitario nella città di origine in Kosovo, DK qualifica, similmente a AS, 1"“albanese" sulla dimensione /emozionale-identitaria/ come "Muttersprache" (madrelingua). In aggiunta, tramite l'apposizione "erste Sprache" (prima lingua), ne specifica lo status /socio-politico/ così come ne indica l'ordine di acquisizione abituale nella località di nascita.

(es. 7)

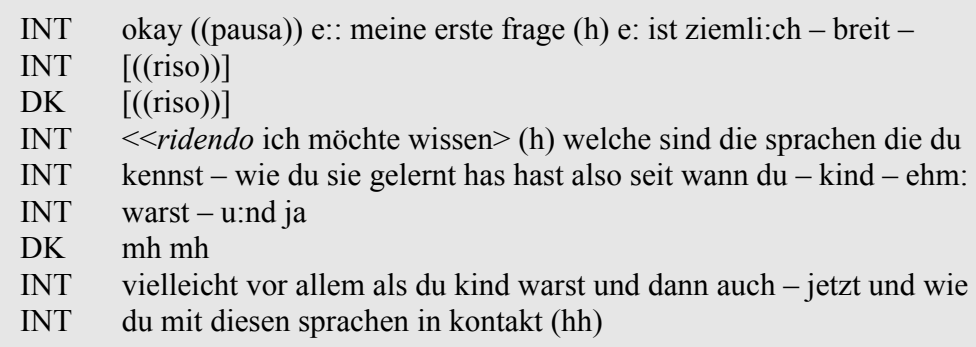




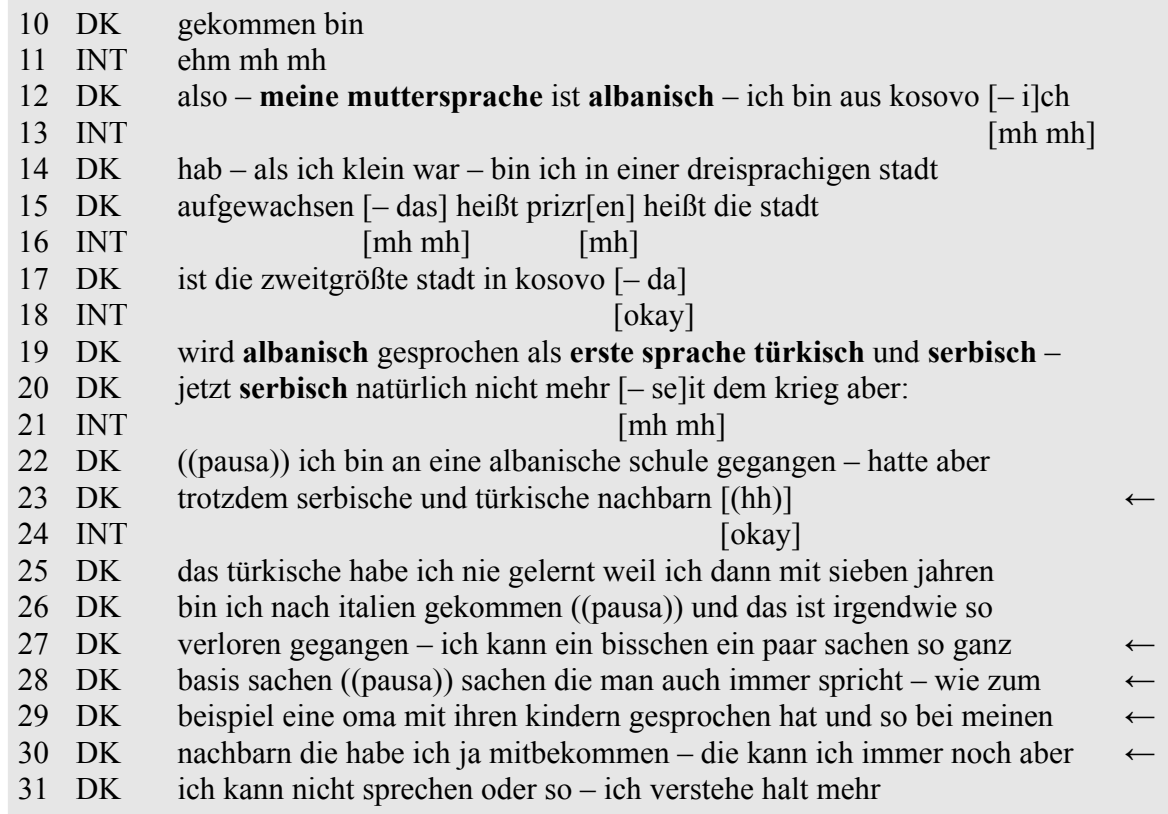

(DK_Kos_Sar, 00:00-01:21, F, 23, città del Kosovo meridionale,

Traduzione:

1998/99)

1 INT

2 INT

3 DK

4 INT

5 INT

6 INT

7 DK

8 INT

9 INT

10 DK

11 INT

12 DK

13 INT

14 DK

15 DK

16 INT

17 DK

18 INT

19 DK

20 DK

21 INT

22 DK

23 DK

24 INT

okay ((pausa)) e:: la mia prima domanda (h) e: è abbasta:nza - ampia $-[(($ riso $))]$ [((riso))]

$<<$ ridendo vorrei sapere $>$ (h) quali sono le lingue che conosci - come le ha hai imparate allora da quando tu - bambina - ehm:

eri-e: si

$\mathrm{mh} \mathrm{mh}$

forse soprattutto quando eri bambina e poi anche - ora e come sei con

queste lingue (hh)

entrata in contatto

ehm $\mathrm{mh} \mathrm{mh}$

dunque - la mia madrelingua è l'albanese - vengo dal kosovo [- ho] -

quando ero piccola - sono cresciuta in una città trilingue

$[\mathrm{mh} \mathrm{mh}]$

[ovvero] Priz[ren] si chiama la città

[mh mh] [mh]

è la seconda città più grossa del kosovo [- lì

si parla albanese come prima lingua turco e serbo - adesso serbo

ovviamente non più $[-$ dal]la guerra ma:

$$
\text { [mh mh] }
$$

((pausa)) ho frequentato una scuola albanese - tuttavia

avevo vicini di casa serbi e albanesi [(hh)] 


$\begin{array}{llll}25 & \text { DK } & \text { il turco non l'ho mai imparato perché poi a sette anni sono venuta in } & \\ 26 & \text { DK } & \text { italia ((pausa)) e in qualche modo è andato perso } & \\ 27 & \text { DK } & \text { - so un po' un paio di cose così cose del tutto base ((pausa)) cose } & \\ 28 & \text { DK } & \text { che si dicono sempre anche - come una nonna parlava con i suoi } & \leftarrow \\ 29 & \text { DK } & \text { bambini per esempio e così dai miei vicini quelle le ho si le ho } & \leftarrow \\ 30 & \text { DK } & \text { imparate involontariamente - quelle le conosco ancora ma non so } & \leftarrow \\ 31 & \text { DK } & \text { parlare o cose così - capisco di più } & \leftarrow\end{array}$

DK adduce, nel brano in 7, una motivazione di tipo "geografico-urbanistico" per spiegare perché attualmente ha qualche conoscenza di "turco". In particolare, l'acquisizione di competenze base nella lingua in questione è rappresentata dalla donna come avvenuta in modo spontaneo fin dall'infanzia nel quartiere dove abitava (cfr. righe 23 e 27-30). Inoltre, DK menziona anche il "serbo" tra le lingue parlate dai vicini di casa (cfr. sempre riga 23). Perciò caratterizza il repertorio comunitario nella località di partenza come "trilingue tricomunitario". Tuttavia, la frequenza d'uso del "serbo" così come la sua vitalità rispetto all'"albanese" sono viste dalla donna, qui come in brani successivi del colloquio, come in discesa.

Rappresentazioni analoghe si trovano anche in altre interviste del corpus, condotte con parlanti della stessa generazione di DK e/o trasferitisi all'estero al termine degli anni novanta: ciò vale indipendentemente dal grado di competenza dichiarata in "serbo" (cfr., tra gli altri, LP, AP, SP e anche ML). Al contrario AC, un parlante di 41 anni arrivato in Italia dal Kosovo nel 1992, rappresenta la varietà linguistica, chiamata talvolta "serbo", talvolta "serbocroato", come un codice parlato, insieme all'"albanese"/"kosovaro", in tutti i domini ad eccezione di quello familiare. In modo analogo ad AS (cfr. sopra in questo paragrafo), AC motiva le proprie alte competenze in tale codice riferendosi all'obbligo di "parlarlo a scuola".

\subsubsection{Le varietà di rumeno come lingue non riconosciute}

Due partecipanti nominano il "serbo" per primo tra i codici del repertorio plurilingue di origine. Entrambi lo qualificano come "madrelingua" (o "Muttersprache"), ossia sulla dimensione /emozionale-identitaria/. Diverso è però il modo in cui gli intervistati caratterizzano l'altro codice di partenza, denominato in entrambi gli incipit "rumeno" o "Rumänien" (Romania). In particolare, nella sequenza in 8, DL qualifica il "rumeno" come un "dialetto". Inoltre, dà una motivazione "geografica" per il suo apprendimento, ovvero il fatto di aver abitato vicino alla frontiera (cfr. righe 8-10). L'apposizione "dialetto" punta al basso prestigio del codice nel repertorio individuale e comunitario della località di partenza nella prospettiva dell'intervistato.

(es. 8)

$\begin{array}{lll}1 & \text { INT } & \text { ((pausa)) e::mh okay la prima domanda è sulle: se mi puoi raccontare } \\ 2 & \text { INT } & \text { di tutte le lingue che conosci come le hai imparate e dove le hai } \\ 3 & \text { INT } & \text { imparate ((pausa)) }\end{array}$




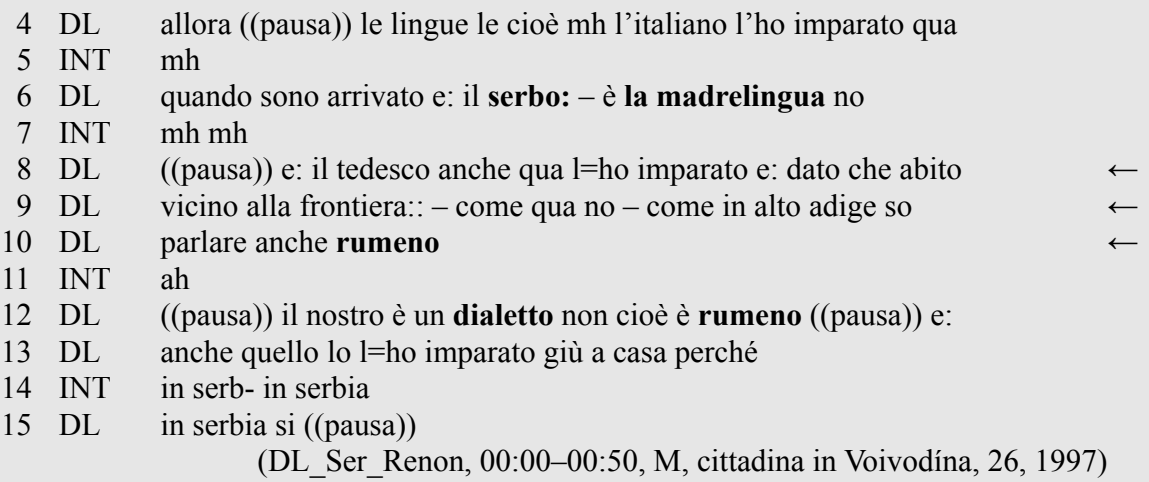

In sequenze successive della sua biografia linguistica, DL racconta di avere appreso "serbo" e "rumeno" simultaneamente in famiglia. ${ }^{13}$ Inoltre, dichiara di aver studiato entrambi i codici, seppur per un numero di ore diverso alla settimana, durante i primi cinque anni di scuola, trascorsi nel paese d'origine. Nello specifico, l'intervistato rappresenta il proprio repertorio di partenza come "dilalico" (cfr. Berruto 1995, Dell'Aquila \& Iannàccaro 2004: 171). "Serbo" e "rumeno" sono infatti entrambe lingue della socializzazione primaria. La prima varietà linguistica è usata però anche in domini formali e ricopre così un alto valore strumentale, oltre che simbolico-affettivo, per il partecipante (cfr. già l'incipit dell'intervista trascritto sopra in 8). Invece, il "rumeno" è sì studiato in modo guidato a scuola e ha, quindi, lo status riconosciuto di lingua dell'educazione. Tuttavia è rappresentato dall'intervistato, nel corso del colloquio, come non adeguato alla comunicazione negli uffici pubblici e come impiegato in prevalenza in situazioni informali, dove la commutazione di codice è dichiarata come frequente. Forse proprio in conseguenza di ciò, tale varietà linguistica è raffigurata come sostituita dopo mobilità. Infatti, DL afferma di comunicare attualmente quasi esclusivamente in "serbo" con i genitori e di aver dimenticato la grammatica del "rumeno".

Diversamente da DL, l'altra partecipante del corpus con competenze sia in "serbo", sia in "rumeno" attribuisce all'inizio della sua biografia linguistica ad entrambe le varietà linguistiche l'apposizione "Muttersprache" (madrelingua) (cfr. esempio 9 sotto). Tramite questa duplice qualifica, DB si posiziona nell' incipit del colloquio come parlante bilingue "bilanciata", vale a dire con uguali competenze in entrambi i codici. ${ }^{14}$ Nonostante ciò, la partecipante differenzia comunque subito dopo le due varietà linguistiche di partenza funzionalmente a seconda i) dei loro domini d'uso e ii) del modo e dei motivi di apprendimento. Il "Serbisch" (serbo) è infatti imparato in contesti formali a scuola, successivamente al "Rumänien" (Romania) appreso in famiglia (cfr. righe 6-7). In particolare, è la mancata standardiz-

13 Si confronti il modello di educazione plurilingue "mixed languages" discusso in Romaine (1989: 165-215).

14 Il termine "bilanciato" è da intendersi qui in senso neutrale. Per una critica del concetto si veda però Romaine (1989: 14, 235-236). 
zazione del "rumeno" a rendere necessaria anche l'acquisizione del "serbo", che è infatti l'unico codice che può essere utilizzato per la comunicazione scritta (cfr. righe $9-10$ e anche più sotto in questo paragrafo).

$(\text { es. } 9)^{15}$

1 DB $\quad(($ riso $))(($ pausa $))$ ba: $[(($ sorriso $))]($ h) e: ich komme aus: serbien

2 INT $\quad[($ (sorriso) $)]$

3 DB ich bin in: in italien in südtirol e: zehn jahre ((pausa)) ich hab

4 DB e: e:: ich habe zweiundvierzig jahre alt ((pausa))

5 DB (h) und mein muttersprache ist serbisch und rumänien (h) ((pausa))

6 DB e::: (h) meine muttersprache erste male ich lerne ich:: lernen e::

7 DB rumänien - und nach in der schule die schule e:: lernen serbisch

8 INT $\mathrm{mh}$

9 DB ((pausa)) e:: weil in ((pausa)) in rumänien nix:: $-<<$ in italiano

10 DB niente lettere niente per il scritto solo che si parlava in: in

11 DB casa>

12 INT mh mh okay

(DB_Ser_Bru, 00:00-00:59, F, paese nella Serbia centro-orientale,

42, 2004)

Traduzione:

1 DB ((riso)) ((pausa)) ba: [((sorriso))] vengo dalla serbia

2 INT [((sorriso))]

3 DB sono in: in italia in alto adige e: dieci anni ((pausa)) sono e: e::

4 DB sono quarantadue anni ((pausa))

5 DB (h) e la mia madrelingua è serbo e romania (h) ((pausa))

6 DB e::: (h) la mia madrelingua inizialmente imparo io:: imparo e:: romania $-\leftarrow$

7 DB e poi a scuola a scuola imparo serbo

8 INT $\mathrm{mh}$

9 DB ((pausa)) e:: perché in ((pausa)) in romania niente:: $-<<$ in

10 DB italiano niente lettere niente per il scritto solo che si parlava

11 DB in: in casa>

12 INT mh mh okay

Durante il colloquio, DB specifica ulteriormente le modalità di utilizzo e di apprendimento dei due codici a livello individuale e comunitario. Inoltre, introduce altri glottonimi per chiamarli. Pur avendo imparato "qualcosa anche in serbo" prima di iniziare la scuola, la varietà linguistica usata nella sua famiglia è esclusivamente il "vlaschi". ${ }^{16}$ Il motivo è che la nonna, nata nel 1928, conosce solo questo ultimo codice (minuti 06:53-09:53). D'altro canto, questo modello di educazione plurilingue non è il solo adottato nella comunità d'origine. In altre famiglie, specialmente quando i nonni e genitori sono di generazioni più giovani, il "serbo" è infatti scelto come codice per la comunicazione in casa. Secondo la partecipante, tale decisione

15 La prima domanda della ricercatrice non è qui trascritta perché precede l'accensione del registratore. L'intervista con DB è condotta fino al minuto 02:51 prevalentemente in tedesco. In seguito il codice principale della conversazione diventa l'italiano.

16 In questo caso, si tratta probabilmente di una delle varietà di daco-rumeno, parlate nella Serbia centro-orientale (cfr. § II.3.3). 
è presa nella convinzione di migliorare così l'acquisizione del "serbo" da parte dei bambini e di evitare che "quando parlano qualsiasi lingua si capisca [...] da quale zona vengono" (minuti 10:06-10:28). Il "rumeno" è invece usato talvolta al lavoro, in particolare, con alcune colleghe provenienti dalla Romania. Infine, il "serbo" è il solo codice impiegato a scuola e nei domini pubblici. Così, la situazione sociolinguistica della località d'origine è descritta da DB come "diglottica" con i codici "serbo" e "vlaschi" rispettivamente in funzione di acroletto e basiletto. Il glottonimo alternativo a quest'ultimo, ossia "rumeno", si specializza, inoltre, in sequenze successive del colloquio, per andare ad indicare un codice adoperato con parlanti non locali (cfr. anche il §IV.3.2 per un'analisi più approfondita della variazione delle denominazioni in questa intervista). A differenza che nel caso di DL, originario di una cittadina in Voivodína, le varietà di rumeno non sono infatti riconosciute nella località di nascita di DB, né come codice dell'amministrazione, né come lingua dell'educazione. In questo contesto, tali varietà linguistiche hanno un basso prestigio sia dal punto di vista strumentale, sia talvolta simbolico per i loro stessi parlanti. Perciò, come illustrato dalla narratrice, tendono ad essere sostituite per la comunicazione in famiglia già prima di un'eventuale esperienza di mobilità.

Nell'analisi degli incipit, discussi in questo e nei §IV.1.4.1 e IV.1.4.2, trova dunque conferma l'osservazione che i glottonimi usati per le varietà linguistiche d'origine non sempre coincidano tra parlanti (cfr. l'alternanza tra "serbo"/"serbocroato", "albanese"/“kosovaro"). D’altro canto, più frequentemente rispetto agli intervistati del primo gruppo (cfr. § IV.1.3 e sgg.), i partecipanti che si posizionano come originariamente "plurilingui" si servono di apposizioni che istituiscono rapporti di differenziazione sulla dimensione /emozionale-identitaria/ e/o /biografico-acquisizionale/. Questi attributi distinguono solitamente la prima varietà linguistica nominata da quelle menzionate in seguito. Infine, i narratori già "plurilingui" spesso spiegano all'interlocutrice, al momento di iniziare il proprio racconto biografico, le proprie competenze linguistiche individuali tramite una rappresentazione della situazione sociolinguistica di partenza a livello comunitario. A questo riguardo il caso di DB, appena descritto, costituisce un'eccezione. Il rapporto "gerarchico" tra i codici nel repertorio comunitario d'origine non corrisponde con quello "bilanciato" nel repertorio individuale della donna, per come è da lei rappresentato nell' incipit dell'intervista. Infatti, all'inizio del colloquio, DB assegna a due varietà linguistiche (serbo e rumeno) la qualifica di "madrelingua" (Muttersprache).

\subsection{Repertori in situazioni di "schizoglossia"}

Oggetto di questo e dei prossimi paragrafi sono i rapporti di differenziazione tra codici istituiti dai nove partecipanti che si riferiscono, negli incipit delle loro biografie linguistiche, alle varietà linguistiche a base neoštokava, parlate nei paesi successori alla Jugoslavia. Una panoramica delle denominazioni (ossia glottonimi e apposizioni) utilizzate da questi intervistati è offerta nella figura 3. I glottonimi adoperati sono "serbocroato", "croatoserbo", "bosniaco", "croato", "montenegrino", "serbo", variante "ekava" e/o "jekava". Oltre a qualificare i codici menzio- 
nati lungo (alcune del)le dimensioni di differenziazione già riscontrate nei paragrafi precedenti, i narratori di questo gruppo prendono anche spesso /posizione rispetto ai rapporti di uguaglianza, somiglianza o differenza tra i codici d'origine/. Come negli schemi precedenti, i numeri in figura 3 si riferiscono all'ordine in cui i glottonimi e le corrispondenti apposizioni sono menzionati dai partecipanti all'avvio dei colloqui.

\begin{tabular}{|c|c|c|c|c|c|c|c|c|c|c|}
\hline \multirow{3}{*}{ 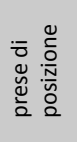 } & lingue diverse & 1,3 & & & & & & & & \\
\hline & lingue simili & & & & & $1,2,3,4$ & & & & \\
\hline & stessa lingua & & & & & & 1,2 & $1,2,3$ & $1,2,3$ & $1,2,3,4$ \\
\hline 它 & $\begin{array}{l}\text { indicazione } \\
\text { temporale }\end{array}$ & 2 & 2 & & & 4 & & & 1 & 1 \\
\hline \multirow{2}{*}{ io $\frac{\dot{0}}{\stackrel{0}{0}}$} & $\begin{array}{l}\text { lingua accettata / } \\
\text { imposta }\end{array}$ & & & & & & 1 & & & \\
\hline & dialetto & & & 2 & $2,3,4$ & & 2 & & 2 & \\
\hline \multirow{2}{*}{ 宅 } & mia lingua & & & & & & & 1 & & \\
\hline & lingua materna & & 1 & & 1 & & & & & \\
\hline \multirow{8}{*}{ 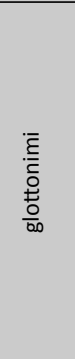 } & ljekavo & & & & & & 2 & & & \\
\hline & ekavo & & & & & & 1 & & & \\
\hline & serbocroato & 2 & 2 & 1 & 1 & & & & 1 & 1 \\
\hline & croatoserbo & & 2 & & & 4 & & & & \\
\hline & bosniaco & & & & 2 & 3 & 2 & 3 & & 4 \\
\hline & croato & 3 & & & 4 & 2 & & 2 & & 3 \\
\hline & serbo & 1 & 1 & & & 1 & 1 & 1 & 3 & 2 \\
\hline & montenegrino & & & 2 & 3 & & & & 2 & \\
\hline & & $\mathrm{YF}$ & $\mathrm{JB}$ & $\mathrm{RM}$ & BV & NM & DV & SV & $\mathrm{RX}$ & $\mathrm{AF}$ \\
\hline & & \multicolumn{5}{|c|}{ glottonimi semi-concorrenti } & \multicolumn{4}{|c|}{ glottonimi concorrenti } \\
\hline
\end{tabular}

Figura 3: Glottonimi e apposizioni negli incipit delle biografie linguistiche dei partecipanti con repertorio d'origine in situazione di schizoglossia. I numeri si riferiscono all'ordine di menzione delle denominazioni.

Considerando il tipo di relazione istituita tra le diverse denominazioni, è possibile individuare due sottogruppi tra i partecipanti. Gli intervistati del primo sottogruppo caratterizzano i rapporti tra il primo codice menzionato e quelli nominati successivamente sulla dimensione /socio-geografica o socio-politica/ e/o /storico-temporale/. I diversi glottonimi sono quindi in queste sequenze "semi-concorrenti": questi nomi si riferiscono infatti a codici rappresentati dagli intervistati come leggermente diversi (cfr. il quadrante di sinistra nella figura 3). Il secondo sottogruppo è invece costituito da quelle persone che prendono subito posizione sulla questione dei glottonimi e affermano che i codici da loro riferiti siano sostanzialmente la stessa lingua (cfr. quadrante di destra della figura 3). Alcuni di questi partecipanti esprimono una preferenza per una denominazione rispetto un'altra. Tuttavia, definisco i glottonimi usati in queste sequenze come tra loro "concorrenti" (o sinonimi) in quanto si riferiscono a codici che sono presentati dai partecipanti come uguali tra loro. 
Come indicato dalla linea tratteggiata nella figura 3, la separazione tra i due sottogruppi non è netta (cfr. l'incipit dell'intervista con NM, descritto al § IV.1.5.1). Inoltre è importante notare che, da un lato, i rapporti tra codici istituiti all'inizio del colloquio sono talvolta riformulati in sequenze successive dell'intervista. Dall'altro, una presa di posizione esplicita sulla questione dei glottonimi nell'incipit non esclude che poi gli intervistati alternino denominazioni diverse, anche in modo semi-concorrente, nel corso della registrazione (cfr. RX, AF). Pur tenendo conto di questi limiti, l'analisi dei prossimi paragrafi permette di delineare un quadro preliminare delle strategie adottate dai singoli partecipanti per dare un senso ai rapporti di differenziazione tra varietà linguistiche in situazione di "schizoglossia", ovvero rispetto a cui collidono rappresentazioni e prese di posizione contrastanti a livello collettivo.

\subsubsection{Glottonimi semi-concorrenti}

I rapporti di differenziazione tra codici riferiti da glottonimi "semi-concorrenti", ossia che si riferiscono a codici rappresentati come (leggermente) diversi, non sono caratterizzati nello stesso modo negli incipit delle interviste del corpus. I due partecipanti che nominano il primo codice del loro repertorio "serbo" lo contrappongono infatti a quello riferito con il glottonimo "serbocroato" sulla dimensione /storico-temporale/ (cfr. JB e YF). Invece gli intervistati che scelgono inizialmente la denominazione "serbocroato" differenziano tale varietà da "croato", "bosniaco" e "montenegrino" a livello /socio-geografico o socio-politico/ (cfr. BV e RM). Il confronto tra gli incipit delle interviste con YF, BV e NM illustra la diversità delle relazioni istituite dai partecipanti tra queste varietà linguistiche.

Sia in apertura, sia in chiusura della sequenza in 10 (cfr. righe 11-12 e 14-15), YF fa ricorso alla dimensione /storico-temporale/ per motivare la presenza di un glottonimo semi-concorrente ("Serbokroatisch", tr. serbocroato) per il codice d'origine, quale è denominato inizialmente "Serbisch" (serbo). Inoltre, nel brano, l'intervistato definisce i codici chiamati attualmente "Serbisch" (serbo) e "Kroatisch" (croato) come da sempre caratterizzati da alcune differenze (cfr. riga 13).

(es. 10)

1 INT ((pausa)) okay ((pausa)) es ist eine recherche für die: universität

2 INT bozen

3 YF ah ah

4 INT und es ist anonym e:: und ja es ist für mein doktorat

5 YF ja was wollen sie wissen

6 INT (h) ich will wissen - e: ihre sprachbiographie (h) eh::m alle also

7 INT wie sie: eh:m mehrsprachig geworden sind

8 YF ach so ((pausa))

9 INT <<in italiano si: $>$

10 YF ich bin geboren in serbien ((pausa)) habe ich serbisch gelernt

11 YF damals wa:r ((pausa)) $<<$ sorridendo vor fünfzig jahre ((sorriso)) wo 


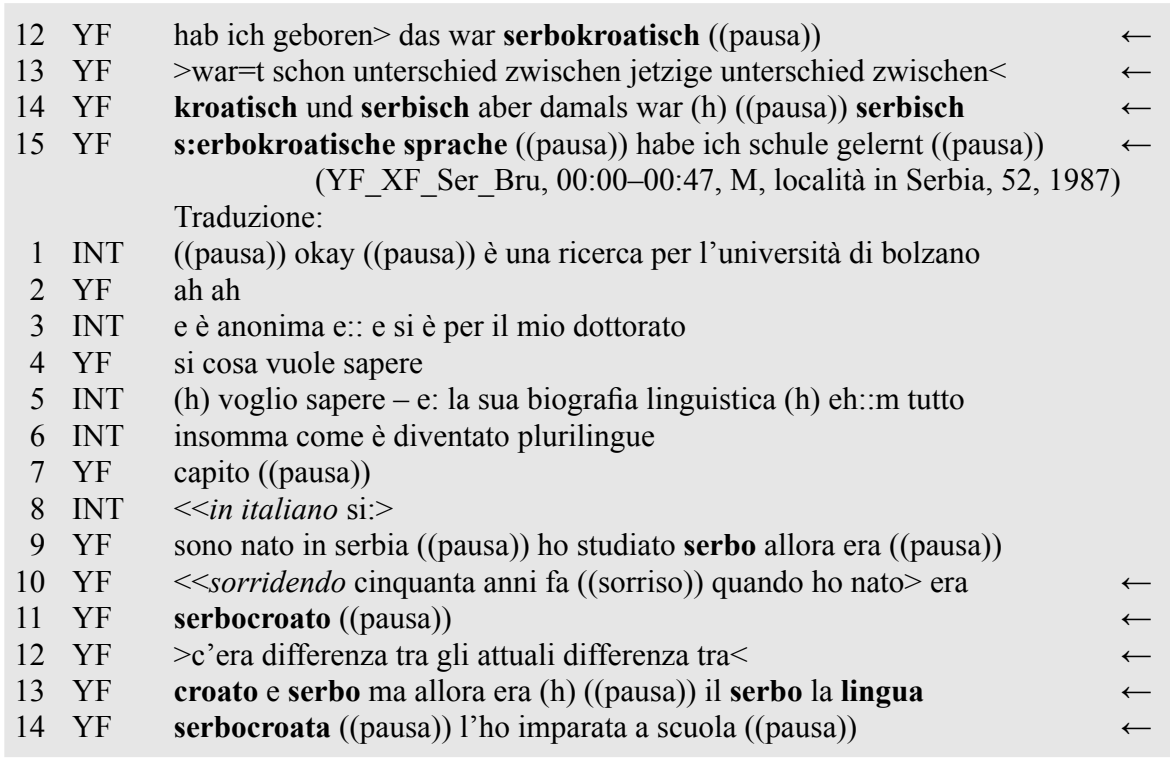

Nel corso della sua biografia linguistica, YF specifica la rappresentazione dei rapporti tra varietà neoštokave, tratteggiata nell'incipit, in un senso leggermente diverso. In particolare, l'intervistato riconduce, in sequenze successive della conversazione, la diversità tra i codici riferiti dai glottonimi attuali, ossia "Kroatisch", "Bosnisch", "Serbisch" e "Montenegro" (tr. croato, bosniaco, serbo e Montenegro), ${ }^{17}$ così come tra questi e altre lingue slave, "Mazedonisch", "Slowenisch", "Slowakisch" e "Bulgarisch" (tr. macedone, sloveno, slovacco e bulgaro), alla dimensione / socio-geografica/. La loro diversità è infatti concettualizzata come "meramente (una) differenza tra dialetti" ("rein dialektsunterschied"; minuti 17:32-18:18).

Diverse sono invece le relazioni istituite da BV tra i glottonimi introdotti nell'incipit della sua biografia linguistica così come tra lei, parlante, e i codici da questi riferiti (cfr. la sequenza in 11 più sotto). La prima varietà linguistica, nominata con qualche esitazione "Serbo Serbocroatian", è qualificata dalla partecipante come la propria "madrelingua" (mother language). Si noti che BV è l'unica intervistata del corpus che nell'incipit della sua biografia linguistica qualifica il "serbocroato" esplicitamente tramite un'apposizione appartenente alla scala /emozionale-identitaria/. ${ }^{18}$ L'impiego dell'avverbio "formally" (formalmente) alla riga

17 Dal momento che questa è l'unica occorrenza della denominazione nell'intervista, non mi è possibile stabilire se YF si serva abitualmente del toponimo "Montenegro" al posto del glottonimo "Montenegrinisch" (montenegrino). La variazione nei nomi dati a questo codice inter-partecipante è probabilmente legata alla sua standardizzazione relativamente recente (cfr. $\S$ II.3.4.4 per la storia del codice e, per esempio, anche l'intervista con KS al $§$ IV.3.4, dove la donna si serve del glottonimo non attestato "Montenegrisch", possibile tr. "montenegrese").

18 Anche altri partecipanti si servono di denominazioni appartenenti alla scala /emozionale-identitaria/ (ad esempio "mia lingua", "nostra lingua") per qualificare il "serbocroato". Questo tut- 
10 limita comunque la validità di tale attributo e, quindi, in un certo senso, l'identificazione della donna con la comunità linguistica (immaginata) che tale glottonimo evoca. Inoltre, BV afferma alle righe 13-17 di essere entrata allora in contatto, a causa della vicinanza della cittadina di residenza ai confini con altri paesi attuali, con numerosi "dialetti" (dialects), ora chiamati "lingue" (languages), ovvero "Bosnian", "Montenegrin" e "Croatian". La motivazione, addotta da BV per spiegare il plurilinguismo dell' area di provenienza, è quindi di tipo "geografico".

(es. 11)

1 INT ((pausa)) ja the first question is very: it's not - it's not a

2 INT question actually $<<$ sorridendo it's only $>$ if you can ((pausa)) tell

3 INT about your life but in the point of view of languages that you have

4 INT spo- spoken and e:: ja languages that you can recognize or languages

5 INT that you know the languages that you can ehm: - understand but maybe

6 INT not speak and so on

7 BV ah ah okay ((pausa)) language biography

8 INT ja language biography ((sorriso))

9 BV ((sbuffo)) e:: ((pausa)) i grow up in a country: that was once

$10 \mathrm{BV}$

11 BV

12 INT

13 BV

14 BV

$15 \mathrm{BV}$

$16 \mathrm{BV}$

17 BV

$18 \mathrm{BV}$

19 BV

20 BV jugoslavia so: $\mathbf{m y}$ - mother language formally is serbo- serbocroatian $\leftarrow$ ${ }^{\circ} i$ think $^{\circ}(($ pausa $))$ that $=s$ the name of the language $\mathrm{mh} \mathrm{mh}$

((pausa)) but i was exposed i would say in my - e: town which is near border with bosnia an:d $-<<$ cambiando tono di voce also near montenegro $>(($ pausa $))$ i was exposed also to many dialects and ((pausa)) to those ((pausa)) now so called languages like bosnian and montenegrin also croatian - pure croatian with dialects from different parts of croatian and i would say the th- the only two languages from the country that I was=nt really familiar with was macedonian and slovenian

21 INT $\mathrm{mh} \mathrm{mh}$

(BV_Ser_Bo, 00:00-01:30, F, città della Serbia occidentale, 29, 2009)

Traduzione:

1 INT ((pausa)) si la prima domanda è molto: non è - non è una domanda in

2 INT realtà $<<$ sorridendo è solo $>$ se puoi ((pausa)) raccontare

3 INT della tua vita ma dal punto di vista delle lingue che hai par-

4 INT parlato e e:: si lingue che sai riconoscere o lingue

5 INT che sai le lingue che sai ehm: - capire ma magari non parlare e così

6 INT via

7 BV ah ah okay ((pausa)) biografia linguistica

8 INT si biografia linguistica ((sorriso))

9 BV ((sbuffo)) e:: ((pausa)) sono cresciuta in un paese: che era una

$10 \mathrm{BV}$

11 BV volta jugoslavia così: la mia - lingua materna formalmente è serboserbocroato ${ }^{\circ}$ penso $^{\circ}$ ((pausa)) questo $=$ è il nome della lingua

tavia non avviene mai all'inizio dei colloqui. Negli incipit, questi narratori adoperano infatti piuttosto quasi-glottonimi (cfr., ad esempio, le biografie linguistiche discusse al § IV.3 e sgg. e, in particolare, quella di KM). 
12 INT $\mathrm{mh} \mathrm{mh}$

13 BV ((pausa)) ma sono stata esposta direi nella mia - e: cittadina che è

14 BV vicino al confine con la bosnia e: $-<<$ cambiando tono di voce anche

15 BV vicino al montenegro $>$ ((pausa)) sono stata esposta anche a molti

$16 \mathrm{BV}$ dialetti e ((pausa)) a quelli ((pausa)) ora così chiamati lingue

17 BV

$18 \mathrm{BV}$ come bosniaco e montenegrino anche croato - croato puro con dialetti $\leftarrow$

$19 \mathrm{BV}$

20 BV da parti diverse della croazia e direi le l- le uniche due lingue

21 INT del paese con cui non=avevo realmente dimestichezza erano il macedone e lo sloveno $\mathrm{mh} \mathrm{mh}$

Dall'uso che BV ne fa nel brano in 11 sembrerebbe, dunque, che il glottonimo "serbocroato" e i nomi di lingua attuali ("bosniaco", "montenegrino" e "croato") siano semi-concorrenti nell'ottica della donna: questi si riferiscono infatti a varietà linguistiche rappresentate come diverse dal punto di vista /socio-geografico o socio-politico/. Tra i glottonimi citati in 11 manca invece "serbo". A questo codice non è perciò esplicitamente attribuita da BV la qualifica di dialetto. In modo parzialmente analogo, la formulazione "croato puro croato con dialetti" (croatian pure croatian with dialects) alla riga 17 lascia supporre che anche tale codice sia visto dalla partecipante - a differenza di "bosniaco" e "montenegrino", che sono solo dialetti - come una lingua, a cui sono ascritti poi diversi dialetti. Altre sequenze del colloquio confermano questa interpretazione. In questi brani, BV racconta, per esempio, di saper imitare il modo di parlare tipicamente "croato" per il fatto di aver letto molti libri in "croato puro", pubblicati dagli editori di Zagabria e presenti nella biblioteca della città di nascita.

Infine, NM occupa una posizione intermedia tra il primo e il secondo sotto-gruppo di partecipanti. I codici nominati "serbo", "croato" e "bosniaco" sono infatti inizialmente categorizzati dall'intervistata come "tre lingue diverse", ma "veramente molto simili" dal momento che i loro parlanti provengono tutti dalla "ex-Jugoslavia" (NM_Cro_Bo, 03:15-03:32). In modo analogo a JB e YF, il "croatoserbo" è qualificato sulla dimensione /storico-temporale/ e parzialmente /biografico-acquisizionale/ come la varietà linguistica parlata durante l'infanzia. Tuttavia, in chiusura della sequenza, NM dichiara l'uguaglianza dei codici standard elaborati recentemente. Tale affermazione non è però presentata dalla donna come generalmente valida, ma esclusivamente come il proprio punto di vista: "per me era una lingua:: è uguale anche se non è [...] c'è serbo c'è croato c'è bosniaco [...] ma per me come da piccola $[\ldots]$ è tutto così per me era: una lingua" (minuti 04:25-04:36).

\subsubsection{Glottonimi concorrenti}

Come mostrato in figura 3 al $\S$ IV.1.5, quattro intervistati qualificano esplicitamente nell'incipit dell'intervista codici, riferiti da glottonimi diversi, come la "stessa lingua" (cfr. DV, SV, RX, AF). Tali glottonimi concorrono quindi per indicare quello che è rappresentato dagli intervistati come uno stesso codice. Pur sostenendo una 
posizione simile, gli intervistati di questo sottogruppo menzionano diversi nomi di lingua all'avvio dei colloqui. Inoltre descrivono e motivano l'introduzione, la soppressione e la compresenza di tali denominazioni nello spazio sociolinguistico di partenza in modo differente.

Tali disparità emergono per esempio dal confronto tra gli incipit delle interviste con DV e AF. Questi due partecipanti hanno età e livello di istruzione molto simili, ma sono arrivati in Italia in periodi diversi e sono rispettivamente originari di Belgrado e Sarajevo. Probabilmente anche in conseguenza del diverso modo di formulare la domanda da parte della ricercatrice, le sequenze iniziali delle due interviste sono strutturate in modo diverso. L'incipit della conversazione con DV, riportato in 12a, ha un attacco prevalentemente narrativo: "dunque il io sono nato [...]" (cfr. riga 6). Nel seguito del brano non mancano mosse argomentative (cfr. più sotto in questo paragrafo). Tuttavia, il narratore evita di menzionare opinioni diverse dalla propria riguardo alla questione dei rapporti tra codici a base neoštokava, mentre organizza il discorso facendo prevalentemente riferimento alla propria esperienza personale e familiare (cfr. anche la seconda parte dell'incipit citata in 12b).

$$
(\text { es. 12a) })^{19}
$$

1 DV i would like to have more $<<$ sorridendo concrete question $>$

2 INT ja okay maybe you can begin but it's also interesting how you

3 DV okay you want to investigate

4 INT ja i mean you can begin when you: live a in

5 DV in my home town - okay so ((pausa)) i would like to stay NN but okay

6 DV $<<$ sorridendo so you know my name [((riso) $)>]$ okay so the i was born

7 INT

8 DV [((riso)) $]$

9 DV $i-$ of course in belgrade you speak serbian language no [- th] $a t=s$

10 INT

11 DV

12 DV

13 DV

14 INT

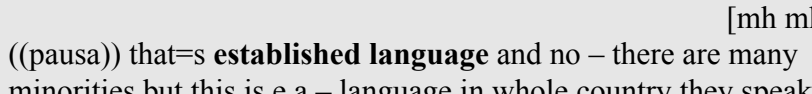

[mh mh]

minorities but this is e a - language in whole country
all minority $>$ let $=\mathrm{s}$ say $<$ they speak this language

ja mh mh

Traduzione:

(DV_Ser_Bo, 00:48-01:26, M, Belgrado, 29, 2009)

1 DV vorrei avere $<<$ sorridendo domande più concrete $>$

2 INT si okay forse puoi iniziare ma è anche interessante come tu

3 DV okay vuoi investigare

4 INT si voglio dire puoi iniziare quando tu: vivi a in

5 DV nella mia città natale -okay così ((pausa)) vorrei essere NN ma okay

6 DV $<<$ sorridendo tu sai il mio nome [((riso) $)>]$ okay dunque il sono nato

7 INT [((riso))]

8 DV a belgrado ((pausa)) dunque che è in serbia (pausa)) okay e lì i-

9 DV ovviamente a belgrado tu parli la lingua serbo no [-que]lla=è

10 INT

[mh $\mathrm{mh}]$

19 Per ragioni di spazio cito qui l'incipit dell'intervista con DV dal momento in cui il narratore invita la ricercatrice a formulare domande più specifiche rispetto a quella di avvio. 
11 DV ((pausa)) quella=è la lingua accettata e no - ci sono molte

12 DV minoranze ma questa è e una - lingua nell'intero paese parlano t-

13 DV tutte le minoranze $>$ si $=$ può dire $<$ parlano questa lingua

14 INT si mh mh

Le due tesi sostenute da DV nel brano in 12a sono quelle correlate della naturalezza (o ovvietà) del parlare il codice "serbo" (Serbian) a Belgrado (riga 9) e del suo ruolo di "lingua accettata/imposta" (established language) nel paese d'origine (riga 11). Questa seconda tesi è supportata dal fatto, usato nell'argomentazione come premessa, che "questa lingua" (this language) sia anche il codice parlato dalle minoranze linguistiche, residenti nel paese di provenienza (riga 13). L'apposizione "established language" rimanda al riconoscimento del "serbo" come lingua ufficiale e alla sua funzione di acroletto, anche presso comunità di parlanti alloglotti sul territorio. Nel prosieguo dell'incipit, citato sotto in 12b, DV sostiene inoltre che, ad eccezione che per alcune varianti diatopiche, "non c'è assolutamente differenza" tra il codice della madre parlato in Bosnia-Erzegovina e la lingua "serba" (Serbian), usata per esempio dal padre (cfr., in particolare, righe 18 e 38-39):

(es $12 b)$

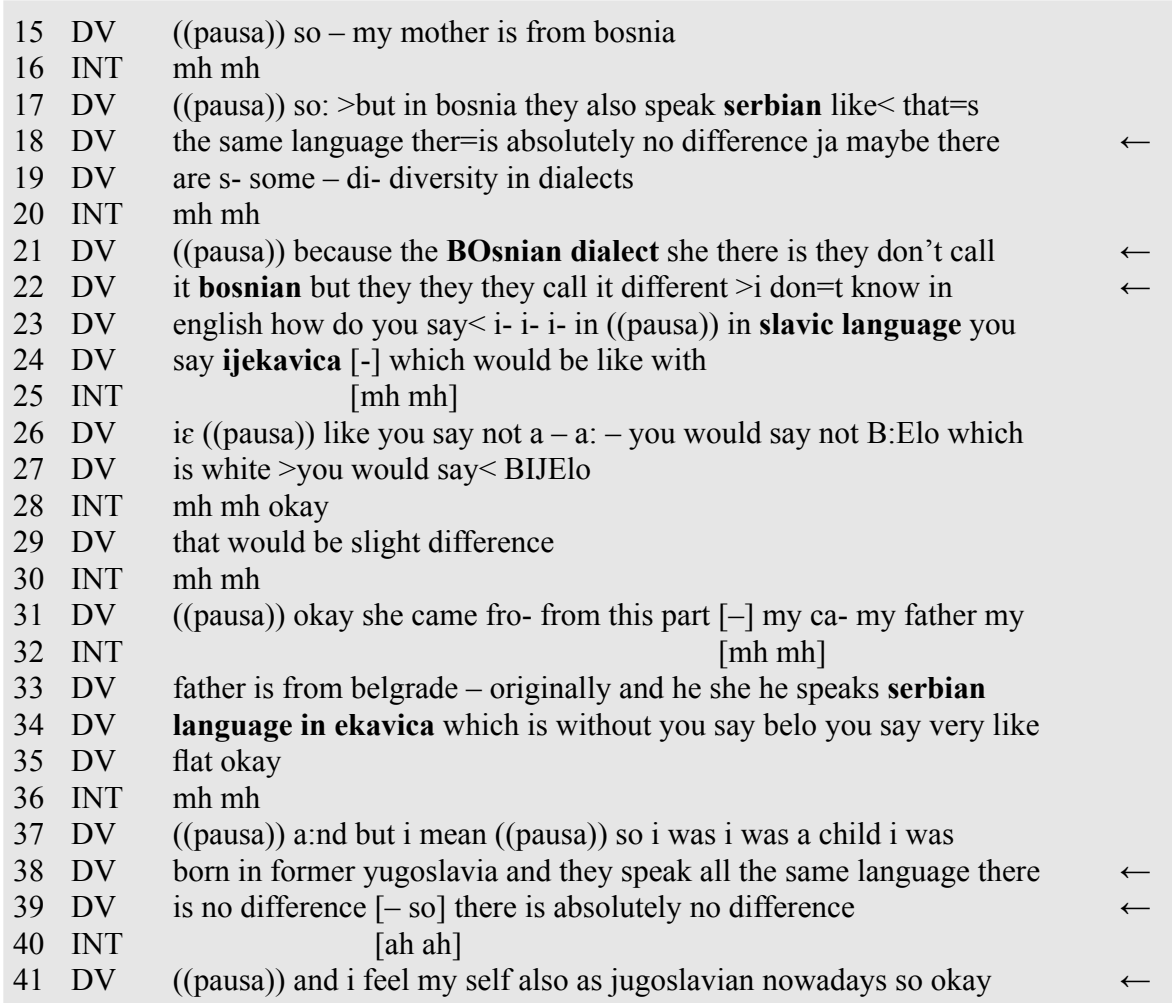

(DV_Ser_Bo, 01:26-02:24, M, Belgrado, 29, 2009) 
Traduzione:

15 DV ((pausa)) dunque - mia madre viene dalla bosnia

16 INT $\mathrm{mh} \mathrm{mh}$

17 DV ((pausa)) così: > ma in bosnia loro parlano anche come in serbo $<$ è la

18 DV stessa lingua non c=è assolutamente differenza si forse ci sono a-

19 DV alcune - di- diversità nei dialetti

20 INT $\mathrm{mh} \mathrm{mh}$

21 DV ((pausa)) perché il dialetto BOsniaco lei c'è loro non lo chiamano

22 DV

23 DV

24 DV

25 INT

26 DV

27 DV

28 INT

29 DV

30 INT

31 DV

32 INT

33 DV

34 DV

35 DV

36 INT

37 DV

38 DV

39 DV

40 INT

41 DV

bosniaco ma loro loro loro lo chiamano diversamente $>$ non so in inglese come si dice $<$ i- i- i- in ((pausa)) in lingua slava tu dici

ijekavica $[-]$ che sarebbe come con $[\mathrm{mh} \mathrm{mh}]$

ic ((pausa)) come non dici a-a: - non diresti B:Elo che è bianco

$>$ diresti< BIJElo

mh mh okay

questa sarebbe una sottile differenza

$\mathrm{mh} \mathrm{mh}$

((pausa)) okay lei viene d- da questa zona [-] mio ca- mio padre mio [mh mh]

padre è di belgrado - originariamente e lui lei lui parla la lingua

serba in ekavica che è senza dici belo dici molto

piatto come okay

$\mathrm{mh} \mathrm{mh}$

((pausa)) e: ma voglio dire ((pausa)) così io ero ero un bambino sono nato in ex jugoslavia e loro parlano tutti la stessa lingua non

c'è differenza [- così] non c'è assolutamente differenza [ah ah]

((pausa)) e io mi sento jugoslavo anche tuttora così okay

A proposito dei glottonimi e delle apposizioni usate da DV nel brano in $12 \mathrm{~b}$, è rilevante notare, in primo luogo, che l'intervistato qualifichi il codice "bosniaco" (Bosnian) come "dialetto" (dialect). Nel fare ciò, istituisce quindi, almeno inizialmente, una differenziazione sul piano /socio-geografico o socio-politico/ tra questo codice e la "lingua stabilita/accettata", ossia il "serbo". In secondo luogo, DV adotta denominazioni semi-specialistiche, vigenti anche in passato, per spiegare le differenze diatopiche tra i codici in questione: questi sono i termini con valenza scientifica di variante o pronuncia "jekava" e "ekava". L'utilizzo di tali concetti contestualizza l'autorità del narratore rispetto al tema (cfr. Lucius-Hoene \& Deppermann 2004: 252). In terzo luogo, è significativo che l'intervistato presenti i termini "jekava" e "ekava" come quelli emici, impiegati anche attualmente dalle persone residenti nell'area. A contrario, secondo DV, la denominazione "bosniaco" o "dialetto bosniaco" (bosnian dialect) non è utilizzata dalla popolazione locale: "they don't call it bosnian" (cfr. righe 21-22). Infine, il partecipante prende posizione alle righe 37-38 riguardo all'uguaglianza delle varietà linguistiche a base neoštokava, parlate nella regione. Subito dopo, alla riga 41, afferma di sentirsi ancora jugoslavo. Sembrerebbe dunque che ci sia una connessione tra questi due atti di posizionamento, ossia quello sull'identità del codice parlato nell'area di partenza e quello 
sulla propria identità politico-nazionale. Tuttavia, si noti che DV non ha bisogno di negoziare la propria appartenenza alla comunità nazionale di allora tramite l'impiego del glottonimo vigente all'epoca, ovvero "serbocroato". L'intervistato si serve infatti esclusivamente del glottonimo "serbo" durante la conversazione.

Diversamente da DV, AF non usa invece apposizioni particolari per qualificare i glottonimi concorrenti per il codice d'origine nell'incipit della sua biografia linguistica. Nel brano, riportato in 13, la donna esprime inoltre esplicitamente la preferenza per uno di questi glottonimi, ossia "serbocroato".

(es. 13)

1 INT si: cioè la mi- la mia prima domanda era molto ampia ed è soltanto

2 INT su: le lingue che sai e che riconosci e che

3 AF ((schiocco lingua)) si vabbè cioè allora ((pausa)) ((sospiro)) qu- e

$4 \mathrm{AF}$

$5 \mathrm{AF}$

$6 \mathrm{AF}$

$7 \mathrm{AF}$

$8 \mathrm{AF}$

$9 \mathrm{AF}$

10 INT

$11 \mathrm{AF}$

$12 \mathrm{AF}$

$13 \mathrm{AF}$

$14 \mathrm{AF}$

$15 \mathrm{AF}$

$16 \mathrm{AF}$

e la lingua:: mh serbocroato ((pausa)) per me è rimasta ancora -

$<<$ salutando un passante ciao $>-$ serbocroato anche se anche lì ci

sono molti dibattiti tutti dicono è serbo o è croato è bosniaco $(\mathrm{h})$

io non riesco a de- definirmi con questa definizione non riesco

((pausa)) per me non vuol dire ni:ente cioè sono solo delle: $\mathrm{m}$ -

((pausa)) manipolazioni li: politiche

$\mathrm{mh} \mathrm{mh}$

((pausa)) $\mathrm{mh}$ cioè vent=anni fa a scuola $\mathrm{c}=$ era il serbocroato $\mathrm{si}$

usava il la la:: la scrittura latina e il cirillico a s- una si

alternavano una settimana $(\mathrm{h})$ - cirillico una settimana la scrittura

latina ((pausa)) e:: abbiamo tutti parlato il serbocroato infatti

(h) - senza nessuna difficoltà: io riesco a comunicare con i serbi croati

17 INT $\mathrm{mh} \mathrm{mh}$

18 AF ((pausa)) e:: e bosniaci e:: non ho voglia di dire che: parlo il

$19 \mathrm{AF}$

$20 \mathrm{AF}$

bosniaco perché in realtà ((pausa)) cioè ((pausa)) non so

$<<$ sorridendo serbocroato mi sembra un po:' un territorio più ampio $>\quad \leftarrow$

(AF_Bos/Mon_Bo, 00:04-01:17, F, Sarajevo, 32, 1992)

A differenza dell'avvio del colloquio con DV (cfr. esempi 12a e 12b sopra), l'incipit dell'intervista con AF è dapprincipio strutturato in modo argomentativo. Solo, alle righe 14-15, la donna fa infatti riferimento alla propria esperienza personale e alle proprie competenze linguistiche. Nello specifico, la tesi principale sostenuta da AF nel brano in 13 è il perdurare del codice "serbocroato", per lo meno dal proprio punto di vista. Una potenziale obiezione a questa tesi è riportata subitaneamente dall'intervistata attraverso l'enunciato introdotto dalla congiunzione "anche se" ed è tratteggiata come comune da "tutti dicono" (cfr. righe 5-6). Preceduti da questa formula, i glottonimi attuali ("serbo", "croato" e "bosniaco") sono rappresentati dall'intervistata come collettivamente diffusi, al contrario di quanto fa DV all'inizio della sua intervista. Al contempo, tali nomi sono relegati a un fenomeno a livello di discorso più che a livello di realtà linguistica. Nel prosieguo della sequenza, AF menziona tre premesse in sostegno della propria tesi. L'introduzione dei glottonimi "serbo", "croato" e "bosniaco" è, da un lato, ricondotta i) a manipolazioni politiche 
(riga 9). Dall'altro, l'esistenza del codice "serbocroato" è giustificata ii) tramite il riferimento alla lingua comune usata a scuola venti anni prima (riga 11) e iii) alla mutuale comprensibilità dei codici parlati dagli abitanti dei tre paesi attuali (riga 15). Sulla base di queste premesse, AF esprime il suo rifiuto di chiamare il codice d'origine "bosniaco". Per sostenere questa sua presa di posizione, l'intervistata menziona in chiusura della sequenza un ulteriore argomento che, in quanto rinvia a una sua opinione personale, segue il modello del topos ad hominem (cfr. LuciusHoene \& Deppermann 2004: 250-253). La preferenza per il glottonimo "serbocroato" è infatti giustificata metaforicamente dall'intervistata per il suo rappresentare "un territorio più ampio" (cfr. riga 19).

\subsection{Conclusioni: identità dei codici d'origine}

Sulla base dell'analisi condotta nei paragrafi precedenti è possibile individuare alcune invarianti nei modi di categorizzare i codici riferiti da determinati glottonimi. Al contempo, l'esame illustra che il numero e l'ordine delle varietà linguistiche nominate nell'incipit abbia un influsso sul tipo di rapporti di differenziazione istituiti tra questi codici e, quindi, sulle categorie identitarie a loro assegnate dai parlanti. Si riconosce così, nelle sequenze iniziali delle interviste raccolte, il tentativo degli intervistati di rendere conto della situazione sociolinguistica d'origine facendo riferimento a collezioni (o serie) di categorie, talvolta in modo piuttosto convenzionale, talvolta, più innovativo.

In generale, vale che le apposizioni usate per certi glottonimi, tra cui "macedone" e parzialmente "serbocroato" e "albanese", non si discostano da quelle che probabilmente darebbero (o avrebbero dato) osservatori esterni per i codici in questione. Indipendentemente dalla loro corrispondenza alla realtà sociolinguistica e storica che qualificano, è comunque significativo rilevarne la sistematicità negli incipit dei colloqui. Infatti queste qualifiche non sarebbero necessarie, ma sono scelte autonomamente dai narratori. La convenzionalità di tali categorializzazioni è probabilmente un segnale dell'influsso di discorsi metalinguistici diffusi a livello collettivo sul modo di categorizzare le varietà linguistiche nei repertori comunitari e individuali di partenza.

Entrando più nel dettaglio, qualifiche sulla dimensione /socio-politica o socio-geografica/, /storico-temporale/ e parzialmente /biografico-acquisizionale/ occorrono frequentemente nelle sequenze iniziali delle interviste in cui il glottonimo "serbocroato" è quello prescelto per denominare la varietà linguistica d'origine. ${ }^{20}$ Inoltre, indipendentemente dall'ordine di menzione o di acquisizione, il "serbocroato" è spesso categorizzato, all'avvio dei colloqui, da intervistati diversi come codice usato a scuola. In particolare, nel caso si tratti di parlanti di altre lingue ufficiali o di lingue di minoranza nell'area di partenza, tale lingua è definita come una lingua obbligatoriamente appresa in contesto scolastico. ${ }^{21}$ Questo vale anche per i parteci-

20 Come si è detto, fa parzialmente eccezione l'incipit dell'intervista con BV (cfr. § IV.1.5.1).

21 In questo caso fa eccezione la rappresentazione di AS, discussa al § IV.1.4.2. 
panti che si riferiscono al periodo precedente agli anni novanta. Tale categorizzazione come codice tipicamente appreso e usato nel dominio scolastico è in linea con l'attribuzione al "serbocroato" di una identità di lingua istituzionale.

Invece, le apposizioni usate per definire l'"albanese" variano in misura maggiore a seconda che i partecipanti rappresentino i loro repertori di partenza come monolingui o plurilingui. Il numero di codici nominati nell'incipit dell'intervista sembra dunque determinare, almeno in parte, le apposizioni scelte dagli intervistati per qualificarli. L'“albanese" tende infatti ad essere caratterizzato subitaneamente sulla dimensione /socio-geografica o socio-politica/ come "dialetto" da chi lo menziona come unico codice d'origine. Al contrario, è spesso qualificato sulla dimensione /emozionale-identitaria/ come "madrelingua" da chi lo nomina per primo al momento di rappresentare il proprio repertorio di partenza come plurilingue. Ciò non toglie che in questi ultimi incipit si trovino talvolta anche apposizioni che definiscono l'"albanese" lungo altre dimensioni (cfr. § IV.1.4.2). Inoltre, anche i partecipanti con repertorio di partenza plurilingue tendono ad usare, in sequenze successive delle registrazioni, l'apposizione "dialetto" specialmente per istituire rapporti di differenziazione tra la varietà linguistica parlata nei paesi di partenza e quella adoperata in Albania. Interessante è però che la qualifica di "dialetto" e quella di "madrelingua" non compaiano mai in una stessa sequenza per riferirsi all'"albanese" all'avvio dei colloqui.

Infine, la scelta di alcuni glottonimi sembra elicitare l'istituzione di rapporti di differenziazione su un piano diverso rispetto a quello della realtà sociolinguistica osservabile. In particolare, al glottonimo "serbo" sono spesso associate dai partecipanti - che lo nominano come primo codice o che lo indicano come unico codice del repertorio di partenza - le qualifiche di "mia lingua", "lingua materna", "nostra lingua". Questi attributi puntano al valore /emozionale-identitario/ ricoperto dalla varietà linguistica in questione nella prospettiva del parlante. Tale valore si manifesta, per esempio, in opposizione ad altri codici acquisiti successivamente durante l'esperienza migratoria o, talvolta, anche contemporaneamente nel paese di partenza (cfr. il caso di DL al §IV.1.4.3). Dal confronto tra gli incipit risulta dunque che, quando i partecipanti scelgono il glottonimo "serbo", tendono poi a identificarsi affettivamente con la varietà linguistica così nominata.

Un secondo gruppo di osservazioni che emerge dalla discussione nei paragrafi precedenti concerne il fatto che i partecipanti utilizzino, nell'incipit così come nel corso dei colloqui, diversi glottonimi per le varietà linguistiche a base neoštokava in modo semi-concorrente o concorrente. Nel primo caso, le denominazioni non sono interscambiabili e si riferiscono a codici rappresentati dagli intervistati come leggermente diversi. In particolare, la differenza tra "serbo" e "serbocroato" è comunemente caratterizzata dai partecipanti sulla dimensione /storico-temporale/. Invece quella tra "serbocroato", da un lato, e "bosniaco", "montenegrino", "croato", dall'altro, è solitamente spiegata dal punto di vista /socio-geografico o socio-politico/, ovvero tramite l'adozione delle apposizioni "lingua" e "dialetto" (cfr. RM, BV, RX e parzialmente DV). Significativo è il fatto che al "serbo" non sia invece ascritto, in nessuno degli incipit delle interviste raccolte, l'attributo di "dialetto". Tale risultato potrebbe dipendere in parte dalla prevalenza di persone origi- 
narie dalla Serbia tra gli intervistati del corpus. In parte, potrebbe essere anche indicativo di un diverso status riconosciuto al codice in questione rispetto alle altre varietà linguistiche standardizzate, più o meno recentemente, nello spazio sociolinguistico slavo meridionale. Anche negli incipit di chi lo nomina come secondo codice, il "serbo" è del resto caratterizzato come codice usato prevalentemente in domini medio-alti (cfr. ML, DK).

$\mathrm{Al}$ contrario, i glottonimi per le varietà linguistiche a base neoštokava sono concorrenti quando si riferiscono a codici rappresentati dagli intervistati come la "stessa lingua". Il confronto tra gli incipit delle interviste con DV e AF ha mostrato diversi modi di strutturare testualmente questa presa di posizione così come ha illustrato strategie di argomentazione, fondate sia sull'esperienza personale, sia sull'allusione a distinzioni di carattere scientifico. Infine, dal paragone tra le biografie linguistiche risulta che una presa di posizione sull'uguaglianza dei codici nello spazio linguistico neoštokavo non sia necessariamente correlata con la preferenza per un determinato glottonimo. L'adozione di un nome non (più) ufficiale all'avvio delle interazioni, come per esempio "serbocroato", non sembra inoltre dipendere neanche dall'età, dal paese di provenienza, dall'appartenenza nazionale dichiarata e/o dall'anno di emigrazione dei partecipanti (cfr. la diversità di questi attributi per AS, NJ, MG, AC, TF, LA, DV). Alcuni dei fattori che entrano in gioco nello strutturare questi rapporti di differenziazione nel corso dei colloqui saranno discussi dettagliatamente nella prossima sezione del capitolo IV.

Come terzo risultato, l'analisi dei paragrafi precedenti ha consentito di formulare alcune ipotesi sui modi in cui i partecipanti organizzano le informazioni sui repertori e danno un senso alla realtà sociolinguistica da loro rappresentata. Dalle categorizzazioni effettuate negli incipit (e in sequenze successive) delle interviste emergono, in particolare, diversi tipi di repertori d'origine rappresentati. Questi sono definibili da un punto di vista etico come "diacrolettici", "plurilingui tricomunitari", "dilalici" o "diglottici" (questi ultimi caratterizzati da una maggiore o minore sovrapposizione funzionale degli acroletti e basiletti nei domini intermedi). A questi tipi di repertorio corrispondono diverse modalità di raffigurare i modi di apprendimento dei codici di partenza. Così, gli intervistati che descrivono la situazione di partenza come diacrolettica e diglossica hanno imparato una o più varietà in $\mathrm{H}$ in contesto scolare, successivamente all'acquisizione della prima lingua in famiglia (cfr. rispettivamente MG, NJ, AC e AS, DB). Invece, l'apprendimento dei codici d'origine in una situazione di plurilinguismo tricomunitario o di dilalia avviene, pur con risultati diversi, in modo non guidato e simultaneamente in contesti informali (cfr. le interviste con DK e DL).

La descrizione del repertorio comunitario della località d'origine è inoltre spesso funzionale, per lo meno all'avvio dei colloqui, a spiegare e talvolta a giustificare le modalità di acquisizione e i rapporti tra codici anche nei repertori individuali (cfr. MG, NJ, AC, ML, AS). Non sempre tuttavia un rapporto gerarchico tra varietà linguistiche a livello comunitario corrisponde con uno parimenti gerarchico a livello individuale o viceversa. Infatti, DB qualifica "serbo" e "rumeno" (poi definito anche "vlaschi") come entrambe "madrelingua", anche se li rappresenta al contempo come funzionalmente distinti, a seconda dei domini d'uso, nella cittadina 
d'origine. Invece, DL caratterizza il rumeno come "dialetto". Questo vale sebbene l'intervistato abbia imparato il rumeno anche a scuola in una località della Voivodína, dove il codice ha uno status riconosciuto come lingua dell'istruzione (ma non dell'amministrazione). Si registrano quindi talvolta, già all'avvio dei colloqui, modi idiosincratici di rendere conto dei repertori di partenza. Tuttavia, è piuttosto significativo che nessuno dei partecipanti plurilingui in partenza o in situazioni di "schizoglossia", usi categorializzazioni come "le nostre lingue" al plurale per definire i codici del proprio repertorio. ${ }^{22}$

Infine, dall'analisi esposta in questa sezione del capitolo IV risulta anche che gli intervistati spieghino alla specifica interlocutrice l'apprendimento o la compresenza di varietà linguistiche diverse nel paese d'origine, adottando talvolta schemi argomentativi differenti (cfr. Lucius-Hoene \& Deppermann 2004: 248-256). In alcuni casi sono addotte ragioni "geografiche" o "personali", mentre in altri si preferisce ricondurre la scelta o l'obbligo di imparare una lingua seconda a ragioni "politico-amministrative". In un modo ancora diverso, certi intervistati ricorrono invece a racconti "storici" o "pseudo-storici" per illustrare le ragioni del plurilinguismo proprio e altrui. Sulla base dei dati raccolti per questa ricerca non è possibile stabilire con certezza i motivi di questa variazione. Tuttavia si può qui notare che i cinque partecipanti, che fanno uso, più o meno frequente, di strutture argomentative storiche o pseudo-storiche, hanno tra i 40 e i 50 anni e hanno condotto nel paese d'origine l'intero percorso formativo fino all'università. Alcuni di questi hanno inoltre risieduto in collegi fuori casa con studenti originari da diverse località della federazione. In considerazione di ciò si può, seppur cautamente, ipotizzare che tali modi di rappresentazione individuali rispecchino schemi interpretativi tramandati per via scolastico-istituzionale all'epoca della Repubblica Socialista Federale di Jugoslavia (SFRJ). La loro funzione sarebbe stata quella di giustificare una situazione di contatto linguistico anche specifica, come quella che si crea, per esempio, tra ragazzi in uno studentato. E infatti, quando si tratta di argomentare un'affermazione riguardo alla realtà linguistica o sociolinguistica altoatesina, i partecipanti non si servono più di questi modelli argomentativi storici o pseudo-storici. Le premesse per giustificare la compresenza di codici diversi nel macro-contesto d'arrivo sono infatti piuttosto costituite da narrazioni "scenico-episodiche" o "abituali", vale a dire da storie di avvenimenti singolari o ripetutesi più volte, ma avvenute in un passato recente ed esperibili, dunque, dal narratore in prima persona e/o da altri personaggi intorno a lei o lui (cfr. capitolo $\mathrm{V}$ per maggiori dettagli).

22 Seppur molto raramente, denominazioni al plurale sono invece, talvolta, utilizzate nel prosieguo delle interviste. È questo il caso di LA che, in modo abbastanza innovativo, usa l'apposizione "madrelingue" al plurale in una sequenza della sua biografia linguistica (cfr. § IV.2.3). 


\section{VARIAZIONI IN FAMIGLIA}

In questa seconda sezione del capitolo IV analizzo la variazione delle denominazioni di lingua in un colloquio di coppia e in quattro interviste episodico-narrative del corpus. ${ }^{23}$ Le conversazioni sono condotte con tre coppie di persone che appartengono rispettivamente a tre famiglie differenti. Inoltre, le coppie intervistati sono di generazioni diverse. I motivi della scelta di queste biografie linguistiche tra quelle raccolte sono esposti al §IV.2.1. Invece, ai § IV.2.2, IV.2.3 e IV.2.4 discuto i risultati della ricerca.

Nello specifico, l'analisi di questa sezione del capitolo IV si concentra sull'alternanza dei glottonimi e delle apposizioni per i codici d'origine "intra-parlante", vale a dire durante una medesima conversazione da parte di uno stesso partecipante. Nel fare ciò, miro a individuare $\mathrm{i}$ fattori che guidano, più o meno durevolmente, la selezione dei nomi di lingua in interazione. I fattori emersi come rilevanti sono: i) la dimensione interazionale, ii) il tempo della storia e/o iii) la volontà di rappresentare le varietà linguistiche, oggetto del discorso, come codici endo- o esocomunitari. Inoltre, la ricerca punta a ricostruire - in modo più dettagliato rispetto a nella sezione precedente del capitolo IV - come alcuni partecipanti negozino e diano un senso alla composizione dei repertori individuali e comunitari di partenza durante l'intera intervista (e non solo all'inizio di questa). Il confronto "inter-parlanti", ovvero tra le rappresentazioni dei rapporti tra codici in biografie linguistiche diverse, suggerisce che gli intervistati non suddividano, per lo meno al momento del colloquio con la specifica interlocutrice, lo spazio linguistico d'origine nello stesso modo e sulla base delle stesse categorie.

\subsection{Selezione del campione}

Per l'analisi dei prossimi paragrafi, ho selezionato dal corpus di interviste raccolto le biografie linguistiche di i) una madre e sua figlia, ii) una zia e sua nipote e iii) un padre e suo figlio. Come già accennato nel capitolo III, il confronto tra parlanti di generazioni diverse appartenenti a gruppi sociali coesi, come appunto la famiglia nucleare o allargata, permette di mettere a fuoco gli effetti di specifici fattori micro sulle rappresentazioni dei rapporti tra codici. Il presupposto è che altre dimensioni di variazione a livello macro - come le condizioni socio-economiche di base e, probabilmente, anche alcuni atteggiamenti e credenze sul linguaggio in generale (cfr. Preston \& Niedzielski 1997 citato da Chini 2003: 225-226) - tendano ad essere sostanzialmente simili tra partecipanti legati da rapporti familiari. Ciò vale anche se, come Chini (2003) stessa ribadisce, non è comunque trascurabile l'influsso esercitato, soprattutto per i parlanti più giovani, dal gruppo dei pari e, in contesto migratorio, da associazioni di cittadini connazionali sulle rappresentazioni metalinguistiche in questione.

23 Una versione semplificata dell'analisi esposta in questa sezione del capitolo IV si trova in Lupica Spagnolo (2016). 
Nel presente caso, il paragone tra interviste condotte con coppie di membri di una stessa famiglia consente, da un lato, di valutare meglio se l'età dei parlanti correli o meno con l'uso di determinate denominazioni, ad esempio, con l'adozione di glottonimi non più ufficiali. Dall'altro, permette di esaminare più dettagliatamente l'apporto di fattori situazionali, biografici e identitari sulle rappresentazioni dei rapporti tra e verso i codici d'origine nel corso di un'unica intervista così come in colloqui diversi (cfr. anche Krefeld 2004 e Betten 2010 per ricerche sociolinguistiche in contesto migratorio, che usano la famiglia come unità di analisi privilegiata).

In particolare, le tre coppie di intervistati, selezionate per la presente analisi, sono comparabili le une con le altre in relazione ad alcune caratteristiche rilevanti da un punto di vista sociolinguistico (cfr. $§$ III.1.3 e sgg. per una discussione a riguardo). Come riassunto nella tabella 1, queste sono i) l'età, ii) il paese d'origine e iii) la situazione sociolinguistica delle località di partenza, iv) le cause e traiettorie (o percorsi) di emigrazione così come v) l'anno e l'età al momento del trasferimento. A riguardo dei parametri ii) e iii) (ossia località di partenza e situazione sociolinguistica d'origine), sia qui specificatamente notato che i sei partecipanti sono nati e, per un diverso lasso di tempo, sono cresciuti in luoghi che attualmente si trovano in tre paesi diversi, ossia Serbia, Croazia e Montenegro. Perciò hanno più o meno durevolmente esperito interventi di pianificazione linguistica differenti, volti alla codifica di tre lingue standard attualmente distinte a livello ufficiale, vale a dire "serbo", "croato" e "montenegrino". Inoltre, quando vivevano e, in seguito, al momento di ritornare temporaneamente nelle città o nei paesi di nascita, le tre coppie

Tabella 1: Sintesi di alcune caratteristiche biografico-migratorie delle tre coppie di intervistati.

\begin{tabular}{|l|c|l|l|l|l|}
\hline & Età & Località di partenza & $\begin{array}{c}\text { Situazione } \\
\text { sociolingui- } \\
\text { stica d'origine }\end{array}$ & $\begin{array}{c}\text { Cause e traiettorie di } \\
\text { emigrazione }\end{array}$ & $\begin{array}{c}\text { Anno ed età di } \\
\text { trasferimento }\end{array}$ \\
\hline $\begin{array}{l}\text { DR } \\
\text { madre }\end{array}$ & 59 & Belgrado (Serbia) & monolingue & $\begin{array}{l}- \text { in Alto Adige per } \\
\text { lavoro }\end{array}$ & -2001 a 46 anni \\
\hline $\begin{array}{l}\text { FR } \\
\text { figlia }\end{array}$ & 35 & Belgrado (Serbia) & monolingue & $\begin{array}{l}- \text { in Alto Adige per } \\
\text { lavoro }\end{array}$ & -2001 a 22 anni \\
\hline $\begin{array}{l}\text { LA } \\
\text { zia }\end{array}$ & 53 & $\begin{array}{l}\text { Dalmazia centro- } \\
\text { settentrionale (Croazia) }\end{array}$ & dilalia & $\begin{array}{l}- \text { in Austria per guerra; } \\
- \text { in Alto Adige per } \\
\text { lavoro qualificato }\end{array}$ & $\begin{array}{l}-1991 \text { a } 30 \text { anni } \\
-1998 \text { a } 37 \text { anni }\end{array}$ \\
\hline $\begin{array}{l}\text { NM } \\
\text { nipote }\end{array}$ & 29 & $\begin{array}{l}\text { Dalmazia centro- } \\
\text { settentrionale (Croazia) }\end{array}$ & dilalia & $\begin{array}{l}- \text { in Serbia insieme alla } \\
\text { famiglia per guerra; } \\
\text { in Alto Adige per } \\
\text { lavoro }\end{array}$ & $\begin{array}{l}-1994 \text { a } 10 \text { anni } \\
2004 \text { a } 20 \text { anni }\end{array}$ \\
\hline $\begin{array}{l}\text { RM } \\
\text { padre }\end{array}$ & 42 & $\begin{array}{l}\text { Sud del } \\
\text { Montenegro }\end{array}$ & bilinguismo & $\begin{array}{l}- \text { a Roma per guerra; } \\
\text { a Trento, in Svizzera, } \\
\text { in Alto Adige per } \\
\text { lavoro }\end{array}$ & -1992 a 19 anni \\
\hline $\begin{array}{l}\text { SM } \\
\text { figlio }\end{array}$ & 19 & $\begin{array}{l}\text { Sud del } \\
\text { Montenegro }\end{array}$ & $\begin{array}{l}\text { bilinguismo } \\
\text { a Roma, a Trento, in } \\
\text { Alto Adige insieme } \\
\text { alla famiglia }\end{array}$ & $\begin{array}{l}-1995 \text { a } 6 \text { mesi } \\
\text { circa }\end{array}$ \\
\hline
\end{tabular}


di intervistati sono entrati in contatto con diversi assetti e modi di gestione del plurilinguismo a livello istituzionale, vale a dire i) una città ufficialmente monolingue, ma in cui vivono numerose persone straniere come Belgrado, ii) un paese della Dalmazia centro-settentrionale in cui vige una situazione di dilalia ${ }^{24}$ e iii) una cittadina situata al sud del Montenegro con una maggioranza di parlanti albanofoni.

\subsection{La dimensione interazionale}

Il primo confronto è tra DR e sua figlia FR. Le partecipanti DR e FR sono due donne, rispettivamente di 59 e 35 anni, trasferitesi da Belgrado in Alto Adige per cercare un lavoro all'inizio del millennio. Ho condotto l'intervista di coppia con DR e FR nella loro abitazione a Merano nel febbraio del 2014. Il colloquio dura un'ora e 18 minuti. La lingua principale della conversazione è l'italiano.

Nelle tabelle 2 e 3, sono riportati il tipo e la frequenza dei glottonimi usati da DR e FR durante il colloquio per nominare il principale codice del loro repertorio di partenza, ossia il "serbo"/"nostra lingua". ${ }^{25}$ In altre interviste di coppia, i nomi per le lingue adoperati dagli intervistati - se già non coincidono all'inizio del colloquio tendono a convergere nel corso dell'interazione (cfr. SP \& AP, YF \& XF, KS \& PB). Al contrario, DR e FR adottano coerentemente, e spesso simultaneamente, glottonimi diversi fino alla fine della loro intervista. DR nomina il codice d'origine prevalentemente "nostra lingua", mentre FR lo chiama nella maggior parte dei casi "serbo".

Tabelle 2 e 3: Tipo e frequenza delle denominazioni concorrenti per il codice d'origine, impiegate rispettivamente da DR e FR durante la loro intervista di coppia.

\begin{tabular}{|l|c|}
\hline Denominazioni di DR & Frequenza \\
\hline nostra lingua & 13 \\
\hline serbo & 5 \\
\hline sua lingua & 1 \\
\hline Totale & $\mathbf{1 9}$ \\
\hline
\end{tabular}

\begin{tabular}{|l|c|}
\hline \multicolumn{1}{|c|}{ Denominazioni di FR } & Frequenza \\
\hline nostra lingua & 2 \\
\hline serbo & 17 \\
\hline mia lingua & 1 \\
\hline Totale & $\mathbf{2 0}$ \\
\hline
\end{tabular}

Dal confronto tra i tipi di glottonimi riportati nelle tabelle 2 e 3 emergono non solo differenze, ma anche alcune somiglianze nell'uso delle denominazioni di lingua da

24 Qui ci si riferisce specificamente alla dilalia tra i dialetti slavo meridionali locali e il (serbo) croato (cfr. § II.3.4.1). Si ricordi comunque che, oltre a varietà slave, nella regione sono parlate anche varietà romanze, albanesi e tedesche. Per una storia "dal basso" dei loro rapporti tra il 1797 ad oggi, in particolare, a Zadar si veda la ricerca di Barbarić (2015), anch'essa effettuata tramite biografie linguistiche.

25 Si potrebbe obiettare che i glottonimi nelle tabelle 2 e 3 potrebbero riferirsi a codici (rappresentati come) diversi sia intra- che inter-parlante. Tuttavia, come sarà argomentato nel corso del presente paragrafo, mi sembra che il codice riferito da DR e FR sia concepito come lo stesso, mentre la variazione nelle denominazioni si lasci ricondurre a fattori prevalentemente interazionali. 
parte di madre e figlia. In particolare, la variazione nei glottonimi è relativamente bassa in questa conversazione. Infatti, le due donne usano rispettivamente solo tre tipi di denominazioni in concorrenza tra loro, ossia "nostra lingua", "serbo" e raramente "mia"/"sua lingua". Tra queste, preferiscono chiaramente un'espressione sulle altre, vale a dire rispettivamente "nostra lingua", nel caso di DR, e "serbo", nel caso di FR. Infine, le due intervistate non si servono, durante il colloquio, né del glottonimo "serbocroato" né menzionano altre denominazioni, introdotte più o meno recentemente nei paesi d'origine, come "croato", "bosniaco" o "montenegrino". In connessione con ciò, nessuna delle due partecipanti si riferisce o prende posizione riguardo alla questione dei glottonimi e/o alle misure di pianificazione, volte alla codificazione delle varietà linguistiche a base neoštokava nello spazio sociolinguistico di partenza.

Considerato ciò, l'incipit dell'intervista con DR e FR illustra tuttavia una differenza qualitativa significativa tra madre e figlia nell'uso delle denominazioni di lingua (cfr. esempio 14 sotto). Questa concerne la probabile funzione e motivazione d'impiego della perifrasi composta dall'"aggettivo possessivo + lingua" per chiamare il codice d'origine. Nel brano in questione, DR elenca le varietà linguistiche conosciute dalle sue due figlie. Nel fare ciò, la donna si riferisce al codice di partenza tramite la circonlocuzione "nostra lingua" (cfr. riga 8). Si noti che questa è la prima volta che il codice d'origine è menzionato dalla partecipante durante la conversazione. Perciò il nome del codice è ambiguo, almeno per l'interlocutrice. Subito dopo, FR prende la parola. Pur confermando le affermazioni della madre, varia l'espressione "nostra lingua" in "mia [lingua]" alla riga 10.

\section{(es. 14)}

1 INT okay $(1,3)$ allora appunto la prima domanda è: ampia e: tutte le

2 INT lingue che:: - conoscete $(0,8)$ anche solo distinguete e: -

3 DR no:: tedesco poco e italiano $(0,9)$ ma hai sentito non so come parlo

4 DR non parlo si sente [ben ((pausa)) più o meno]

5 FR [più o meno ((riso))]

6 DR la figlia tedesco lo parla $(1,7)$ no come italiano e italiano lo

7 DR parla veramente benissimo quella più grande - parla inglese $(1,1)$

8 DR russo $(1,8)$ nostra lingua $(0,3)$ e lei parla una in più - spagnolo

9 FR anche $[=$

10 FR [=spagnolo si: io parlo - inglese spagnolo la mia e:: italiano

11 DR e russo hai dimenticato

(DR_FR_Ser_Mer, 00:06-00:48)

La variazione del possessivo da "nostra" a "mia" suggerisce che madre e figlia adottino la circonlocuzione "aggettivo possessivo + lingua" per ragioni e con funzioni differenti. Per quanto riguarda DR, la donna adopera, nella sequenza in 14, la perifrasi "nostra lingua" in posizione "isolata" nel discorso, ossia senza che ci sia un referente anaforico o cataforico esplicito nel cotesto precedente o seguente. Impieghi in contesti analoghi sono tutt'altro che occasionali nella conversazione con DR, che del resto si serve della circonlocuzione molto frequentemente durante il 
colloquio (cfr. tabella 2 sopra). La perifrasi sembra così funzionare per la partecipante nelle veci e/o in sostituzione di un nome di lingua specifico. Nello specifico, nel caso di DR, non si può escludere che l'intervistata si serva, durante la sua biografia linguistica, della circonlocuzione "nostra lingua" in modo semi-involontario come calco dalla lingua prima. Infatti, come già illustrato precedentemente, l'espressione "naš jezik" (nostra lingua) costituisce un sintagma lessicalizzato usato per chiamare i codici a base neoštokava da parte dei loro parlanti sia prima, sia dopo gli anni novanta (cfr., in particolare, § II.3.5.4). Tuttavia, e indipendentemente da una maggiore o minore intenzionalità, il suo impiego consente alla donna di non menzionare e, dunque, di non scegliere un nome di lingua specifico per il codice d'origine fino al 25esimo minuto della registrazione (e anche in quasi tutte le sequenze successive a questo). Soprattutto se si tiene conto della semi-formalità del contesto "intervista" e del suo essere condotta con una ricercatrice non serbofona, l'uso ripetuto dell'espressione "nostra lingua" da parte di DR risulta singolare. La sua adozione può essere però messa in relazione con la riluttanza della partecipante a posizionarsi rispetto ai dibattiti sui glottonimi, diffusi a livello ufficiale nei paesi d'origine. Così, se l'interpretazione qui proposta è giusta, l'impiego della perifrasi "nostra lingua" sarebbe motivato dal fatto che la donna - consapevole delle connotazioni ideologico-linguistiche e politico-linguistiche, associate ai nomi di lingua nelle comunità di partenza - non voglia prendere una posizione a riguardo.

L'espressione "nostra lingua" potrebbe avere dunque per DR una funzione "elusiva", ovvero sarebbe correlata con la volontà di evitare di auto-categorizzarsi di fronte agli interlocutori in modo univoco come parlante "serbofona". In alternativa potrebbe servire alla partecipante anche per fini "oppositivi" (cfr. Gröschel 2009: 34). Infatti, potrebbe contestualizzare la resistenza della donna ad adoperare glottonimi specifici in quanto (divenuti), suo malgrado, indicatori di appartenenza nazionale e/o di convinzioni politiche. La differenza è che in quest'ultimo caso, la partecipante non intende nascondere, ma piuttosto ribadire la propria condizione di parlante una lingua $-\mathrm{e}$ la propria appartenenza a una comunità linguistica - non più riconosciuta a livello ufficiale (per un'analisi più particolareggiata delle funzioni di perifrasi generiche analoghe, qui definite quasi-glottonimi, nelle interviste del corpus cfr. il § IV.3 e sgg.).

Diversamente dalla madre, FR usa invece la perifrasi "mia/nostra lingua" raramente durante l'intervista, mentre nella maggior parte delle occasioni si serve del nome specifico "serbo" (cfr. tabella 3). Nelle sequenze, in cui è adoperata, la circonlocuzione non ha dunque una funzione "elusiva" dato che è chiaro a quale codice la donna si stia riferendo. Inoltre, FR modifica l'espressione fissa "nostra lingua" in "mia [lingua]" nel brano citato sopra in 14. Questa variazione è spiegabile considerando la dimensione "interazionale" dell'intervista. Nel rispondere alla prima domanda di una ricercatrice italofona in Alto Adige, l'intervistata reinterpreta liberamente la locuzione semi-lessicalizzata adoperata dalla madre nel turno di parola precedente. In particolare, la commutazione del possessivo di prima persona plurale con uno in prima singolare rivela, a livello linguistico, che l'espressione abbia acquisito, almeno temporaneamente, per FR una nuova funzione. Il possessivo "mio" marca infatti in modo "enfatico" un nuovo confine linguistico. Questo è 
primariamente quello tra la narratrice e l'interlocutrice non serbofona nello specifico contesto interazionale. Eventualmente, può anche delimitare il confine tra la partecipante e la comunità linguistica di arrivo in generale, i cui membri per l'appunto non conoscono la lingua prima dell'intervistata (cfr. anche Bert \& Costa 2014 e il §IV.3.3 per maggiori dettagli su questa funzione dei quasi-glottonimi). Così, dall'analisi emerge che il contatto con codici e parlanti alloglotti, conseguente all'esperienza migratoria, può modificare le relazioni emiche anche tra le varietà linguistiche che facevano precedentemente parte del repertorio. Tali mutamenti sono rintracciabili nell'adozione di nuove denominazioni di lingua per rappresentarli.

La presenza di differenze nei modi di impiego e nelle funzioni delle denominazioni di lingua tra madre e figlia è confermata dall'esame di sequenze successive del colloquio. Anche le altre due occorrenze della perifrasi "possessivo + lingua" hanno infatti una connotazione prevalentemente enfatica nel discorso di FR. La donna se ne serve, da un lato, per specificare la lingua dei cartoni animati americani guardati da bambina ("guardavo quelli ((pausa)) nella nostra lingua con la nostra traduzione"; minuti 23:53-24:35). Dall'altro, la impiega per contrapporre il codice, parlato con i componenti della famiglia, alle lingue adoperate con altri interlocutori nella regione d'arrivo ("quando siamo noi parliamo nostra lingua"; minuti 27:10 27:18).

All'opposto di quanto appena illustrato per la figlia, la madre seleziona invece spesso proprio il glottonimo "serbo" per ragioni interazionali e, in particolare, enfatiche. Infatti, due occorrenze (su cinque) di questo nome si trovano proprio in una sequenza in cui DR rimarca la distinzione tra le varietà linguistiche adoperate fuori casa e quelle da mantenere in famiglia dopo migrazione. A queste ultime è conferito enfaticamente dalla donna un valore speciale nel simboleggiare l'identità non solo linguistica, ma anche "nazionale" di un parlante: "tu vai qualsiasi altro paese impari la lingua lì $[\ldots]$ ma in casa devi tenere la sua lingua $[\ldots]$ sai è inutile che tu impari serbo lì: e a casa devi parlare serbo cavolo sei italiana parli italiano"; minuti 25:44 26:06). Inoltre, anche il brano in 15 è significativo per tracciare le funzioni delle due denominazioni, "nostra lingua" e "serbo", nell'uso di DR. Nel porre una domanda all'intervistatrice sulle sue competenze linguistiche, la partecipante alterna sequenzialmente alla riga 5 i due glottonimi. Questa alternazione è a mio avviso correlata sia ai partecipanti della conversazione, sia parzialmente al discorso. ${ }^{26}$ In altri termini, la variazione da "nostra [lingua]" a "serbo" dipende, da un lato, dal fatto che la donna si stia rivolgendo all'intervistatrice, che è un'apprendente di "serbo" come lingua seconda e, dunque, non è un membro effettivo della comunità linguistica, identificata e/o identificabile con l'espressione "nostra lingua". Al contempo, la variazione ha probabilmente anche la funzione discorsiva di organizzare la conversazione. Questa segnala un mutamento nel tema e anche nei ruoli interazionali, pre-assegnati agli interattanti. Nella sequenza in 15 è infatti l'intervistata che pone una domanda alla ricercatrice e che, quindi, ribalta i ruoli finora svolti/assunti dai partecipanti nella conversazione.

26 Adotto qui per concettualizzare un fenomeno diverso le categorie elaborate da Auer (1984) per descrivere l'inserzione di codice in conversazione. 
(es. 15)

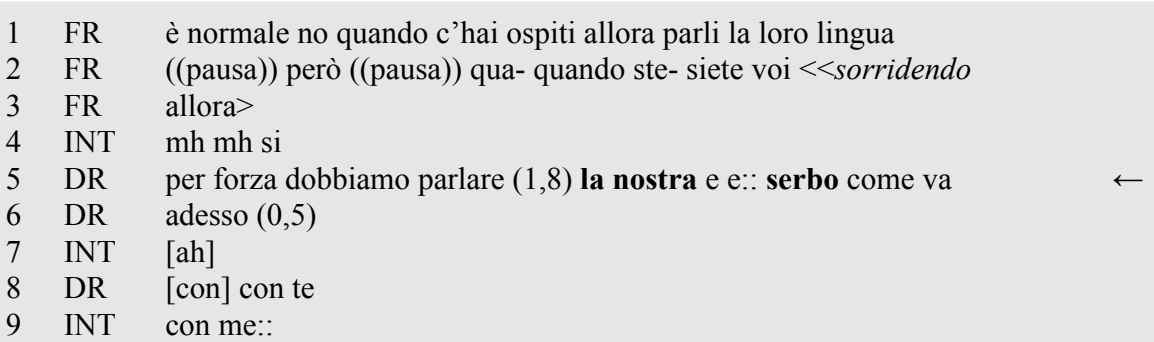

(DR_FR_Ser_Mer, 27:42-27:58)

Così, madre e figlia adottano rispettivamente glottonimi diversi per il codice d'origine nel corso di una medesima interazione e anche in turni di parola molto ravvicinati tra loro. Tale rilevazione mostra che le denominazioni scelte per le varietà linguistiche a base neoštokava possano non coincidere anche tra parlanti che appartengono a una stessa famiglia e che quindi condividono numerosi spazi di interazione quotidiana. In particolare, l'analisi qualitativa di alcuni brani della conversazione punta alle diverse funzioni svolte dalle perifrasi "possessivo + lingua" e dal glottonimo "serbo" per madre e figlia. La circonlocuzione "nostra lingua" è usata da DR indipendentemente dal contesto. La sua adozione è probabilmente motivata dalla volontà di non prendere posizione o di opporsi a uno dei nomi specifici per le varietà linguistiche a base neoštokava. Invece, la variazione nel possessivo da "nostra" a "mia" da parte di FR suggerisce che la donna reinterpreti la circonlocuzione per differenziare enfaticamente sulla dimensione emozionale-identitaria il suo codice da quelli di altri parlanti alloglotti in contesto migratorio. Così, una differenza tra i repertori di madre e figlia potrebbe concernere l'allocazione emica delle varietà linguistiche d'origine rispetto a quelle acquisite nella regione di arrivo dopo migrazione.

Detto ciò, le due partecipanti non rappresentano tuttavia durante il colloquio lo spazio linguistico e sociolinguistico nel paese d'origine in modo radicalmente diverso. Da un lato, il codice riferito con l'espressione "nostra lingua" sembra sostanzialmente coincidere con quello chiamato "serbo" nell'ottica di DR. Infatti, la donna ripara, in due sequenze della conversazione - le ultime due in cui occorre il glottonimo "serbo" -, l'espressione generica con il nome di lingua specifico e viceversa. Dall'altro lato, sebbene nell'incipit della loro biografia linguistica le due intervistate rappresentino il loro repertorio di partenza come originariamente monolingue (cfr. anche $\S I V .1 .3$ ), entrambe le partecipanti precisano, nel seguito della conversazione, questa prima rappresentazione. Nel fare ciò, si posizionano piuttosto come parlanti già plurilingui nel paese di partenza. Similmente a molti altri intervistati, DR e FR hanno infatti imparato due lingue straniere a scuola, ossia rispettivamente "russo"/"francese" e "russo"/"inglese". Quest'ultima varietà linguistica ha, in particolare, un forte valore emozionale-identitario per FR. La donna la descrive infatti come il codice segreto usato da lei e dalla sorella per comunicare da bambine e la qualifica come "un'altra lingua madre" (minuti 01:01:19-01:01:40). 
Pur lavorando, al momento del colloquio, in una lavanderia a Merano, l'intervistata è del resto insegnante abilitata di inglese e dichiara di avere attualmente maggiori competenze in questo codice che in italiano. In aggiunta, FR racconta di aver appreso anche lo "spagnolo" in Serbia in modo informale, per via della sua passione per le serie televisive prodotte in America Latina. Infine, per quanto riguarda il repertorio comunitario d'origine, entrambe le partecipanti descrivono Belgrado, nel corso della registrazione, come una metropoli plurilingue in cui è possibile sentire "di tutto" (minuti 30:52-31:51). Al contempo, pur avendoli esperiti quando ancora vivevano in Serbia, non fanno menzione dei "conflitti" e delle diatribe linguistiche, incorse negli anni novanta, in concomitanza con la formazione dei nuovi codici standard.

\subsection{Il tempo della storia}

I rapporti di differenziazione tra le varietà linguistiche d'origine sono rappresentati in modo diverso da LA e da sua nipote NM in relazione al "tempo della storia", ovvero a seconda del momento in cui gli eventi da loro raccontati nel corso dell'intervista hanno (avuto) luogo (cfr. Lucius-Hoene \& Deppermann 2004). ${ }^{27}$ In altre parole, il periodo, a cui le due donne si riferiscono nel raccontare, condiziona le rappresentazioni e le prese di posizione riguardo ai codici che compongono il loro repertorio. Tale influsso può essere dedotto dalla variazione nelle denominazioni di lingua. Inoltre, dall'analisi emerge che la configurazione, assunta nel corso del tempo dal repertorio d'origine individuale e comunitario, non coincide nelle rappresentazioni di zia e nipote.

LA è una donna di 53 anni, nata in una cittadina della Dalmazia centro-settentrionale. Nel 1991 si trasferisce in Austria per sfuggire alla guerra e dopo sette anni trasloca di nuovo a Bolzano per via di un'offerta di lavoro qualificato. Il colloquio con la donna si svolge nell'ufficio di quest'ultima nel maggio del 2014. La durata dell'intervista è di un'ora, mentre la conversazione è condotta prevalentemente in tedesco. Durante il colloquio, LA si serve di nomi diversi per i codici d'origine a seconda del periodo "storico" a cui si riferisce nel narrare esperienze passate. Al fine di illustrare questa variazione, la figura 4 mostra i tipi di glottonimi adoperati da LA nel corso della registrazione. La frequenza totale di ogni denominazione è indicata nella colonna a destra. In basso sono riportati il periodo e la situazione comunicativa, in cui si svolgono gli eventi raccontati.

Nel nominare i codici parlati dagli anni sessanta ai primi anni novanta nel paese d'origine e durante il primo periodo di residenza in Austria, LA usa alternativamente i glottonimi "serbo" (Serbisch), "croato" (Kroatisch), "serbocroato" (Serbokroatisch), "serbo o croato" (Serbisch oder Kroatisch) e "croato o serbo" (Kroa-

27 Si ricordi qui la distinzione tra "tempo della storia" (erzählte Zeit) e "tempo del racconto o della narrazione" (Erzählzeit). Con il primo concetto ci si riferisce al momento in cui i fatti narrati sono avvenuti, mentre con la seconda nozione si indica il momento in cui sono raccontati, ovvero l'hic et nunc dell'interazione (cfr. Lucius-Hoene \& Deppermann 2004: 25). 


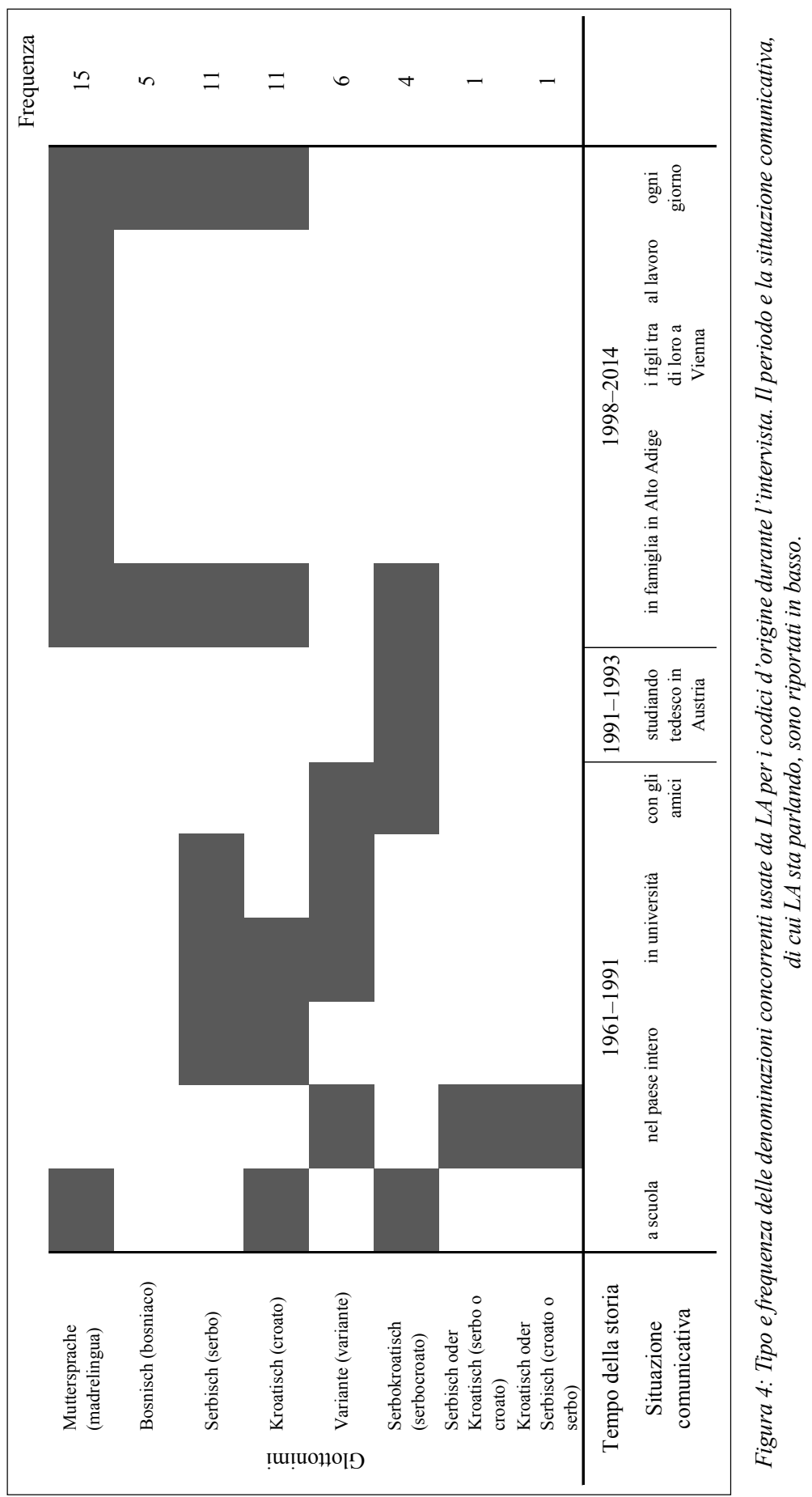


tisch oder Serbisch). Le denominazioni "serbo" e "croato" sono le più frequenti nella prima parte dell'intervista. La donna descrive le differenze tra queste due varietà come minime e ne rende conto tramite la nozione di "variante jekava" o "occidentale" (jekavische o westliche Variante), da un lato, e di "variante ekava" (ekavische Variante), dall'altro (LA_Cro_Bo, 12:14-14:00). ${ }^{28}$ La partecipante dichiara inoltre che all'epoca in cui frequentava la scuola "la giusta denominazione era (h) dunque eh:m serbo o croato croato o serbo" ("di:e richtige benennung war (h) also eh:m serbisch oder kroatisch kroatisch oder serbisch"; minuti 03:25-03:57). Questa è l'unica sequenza dell'intervista in cui le due locuzioni composte occorrono. All'opposto, quando racconta dei codici parlati attualmente in famiglia o al lavoro in Alto Adige, l'intervistata adotta prevalentemente l'espressione "madrelingua" (Muttersprache). La frequenza totale di quest'ultima denominazione, spesso adoperata in posizione isolata nel discorso, supera quella di altri nomi di lingua specifici. Questo vale anche se l'espressione occorre quasi esclusivamente nella seconda parte del colloquio (cfr. figura 4).

La denominazione "madrelingua" è ambigua da un punto di vista etico. Tuttavia, in due sequenze della registrazione, la partecipante discute specificamente a quali codici si riferisce con questo quasi-glottonimo. All'inizio della seconda parte del colloquio, LA esplica la circonlocuzione tramite la serie di glottonimi "bosniaco croato serbo" (Bosnisch Kroatisch Serbisch). Questi ultimi sono definiti come i nomi attuali per "la lingua" (minuti 31:53-32:22). La stessa sequela di glottonimi è ripetuta dalla donna al termine della sua biografia linguistica con la medesima funzione. Nel brano in questione, trascritto in 16, LA dichiara inizialmente di parlare sul lavoro tre lingue: "tedesco" (Deutsch), "italiano" (Italienisch) e la sua "madrelingua" (Muttersprache). Subito dopo, alle righe 5-6, l'intervistata ripara quest'ultima espressione. Nel fare ciò, conia più o meno estemporaneamente un nuovo glottonimo al plurale, ossia "madrelingue" (Muttersprachen).

(es. 16)

1 LA das ist meine arbeit sozusagen ich verwende meine muttersprache (h) e

2 LA auch bei der arbeit fast jeden tag (h) [21 secondi omessi]

3 LA jeden tag - m:uss ich sozusagen (h) eh:m $(0,8)>$ und ich mache es

4 LA gerne $<$ benutze ich $(1,5)$ ah:: diese drei sprachen - ich sage drei

5 LA also: - deutsch italienisch und meine $(0,7)$ mutterspraCHE oder

6 LA mutterspraCHEN

7 INT $\mathrm{mh} \mathrm{mh}$

8 LA ((sorriso)) (h) weil sind $-{ }^{\circ}$ bosnisch kroatisch serbisch ${ }^{\circ}$ und

9 LA MAZEdonisch also: (h) - mh: dieses bo ganz ähnlich ist (h) mit $(0,6)$

10 LA meiner muttersprache $(1,2)$ so

(LA_Cro_Bo, 52:30-53:38)

28 Si confronti anche il § IV.1.3.1 per un'illustrazione delle denominazioni adoperate da LA per categorizzare i codici d'origine nell'incipit e in alcune sequenze successive dell'intervista. 
Traduzione:

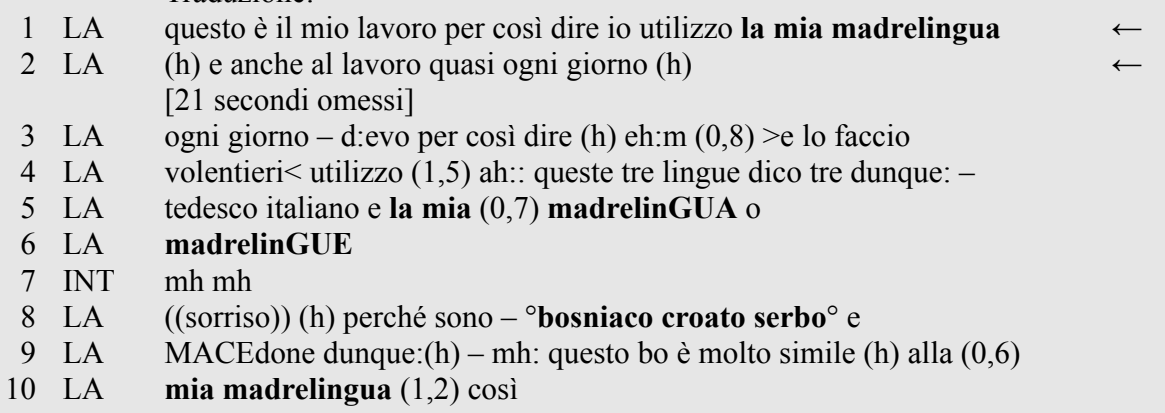

Perciò, il momento storico, che fa da sfondo alle circostanze e agli episodi narrati, condiziona la scelta delle denominazioni per le lingue e le rappresentazioni delle relazioni tra codici da parte della narratrice. Tuttavia, si noti che i nomi adottati da LA non sempre corrispondono ai glottonimi ufficiali nel periodo di riferimento. Infatti, l'apposizione "variante" è usata a livello istituzionale anche al tempo della Federazione Socialista Jugoslava (SFRJ) per distinguere tra le varietà linguistiche a base neoštokava. Invece, i nomi attualmente ufficiali sono per lo più sostituiti dall'intervistata con l'espressione "madrelingua".

Il tempo della storia ha un influsso sulla selezione delle denominazioni di lingua anche nell'intervista con NM. La partecipante, nipote di LA, è una donna di 29 anni, nata in una località della Dalmazia centro-settentrionale, che si è trasferita a Bolzano nel 2004 dalla zia, dopo aver trascorso dieci anni in Serbia. L'intervista con NM ha luogo nel suo appartamento nel maggio del 2014. Il colloquio si svolge prevalentemente in italiano e dura 49 minuti. In modo parzialmente diverso da sua zia, NM alterna tuttavia denominazioni di lingua differenti a seconda non tanto del periodo "storico", ma piuttosto del tempo "biografico" di cui sta parlando. Infatti, circostanze ed episodi della sua vita personale - in particolare, il luogo di residenza - hanno un forte impatto sui modi di rappresentare i rapporti tra codici. Ciò avviene piuttosto indipendentemente dallo sfondo storico, in cui questi eventi avvengono. Questa correlazione è esemplificata dal brano in 17. Le affermazioni di NM sono commentate direttamente a destra del testo.

Il pattern d'impiego dei nomi di lingua, che emerge nell'esempio 17, è mantenuto da NM durante l'intero colloquio in modo piuttosto coerente: il "serbocroato" è infatti il codice usato nei primi dieci anni trascorsi in Jugoslavia e negli ultimi dieci anni passati in Alto Adige, mentre il "croato" è la lingua parlata prevalentemente tra il 1994 e il 2004 nel periodo di soggiorno in Serbia. Trasversalmente al tempo biografico, si aggiungono così - e questo è soprattutto evidente per il tempo della storia recente, quando i viaggi avanti e indietro della donna nel paese d'origine sono più frequenti e la comunicazione con le persone che vi vivono è facilitata dall'uso di internet e dei social network - il fattore geografico-spaziale e, parzialmente, il tipo di interlocutore. Infatti, il luogo, in cui si svolgono le interazioni narrate, risulta parimenti importante nel condizionare la scelta del glottonimo appropriato. Il "serbocroato" - chiamato per una volta dalla donna all'inizio del col- 
(es. 17)

$1 \mathrm{NM}$ sono nata e ho vissuta la vita di là allora per

2 NM dieci anni: insieme in croazia in serbia

3 INT $\mathrm{mh} \mathrm{mh}$

4 NM $(1,2)$ era: serbocroato[- $i$ :] in quello periodo era

5 INT [mh $\mathrm{mh}]$

$6 \mathrm{NM}$ ancora: serbocroato $(0,3)$ e poi ci sono divisi

[27 secondi omessi]

$7 \mathrm{NM}$ e in serbia ho fatto la scuola $(1,0)$ e di là si

$8 \mathrm{NM}$ parlavo serbo - ma anche usavo mio croato

9 INT okay e c $[=$

$10 \mathrm{NM}$ [=perché per me non era::: facile adesso

$11 \mathrm{NM}$ quello

12 INT che ti parlavo sedi sjedi con la una lettera $(1,0)$

$13 \mathrm{NM} \mathrm{mh} \mathrm{mh}$

14 INT io ero abituata a parlare - più croato

$15 \mathrm{NM} \mathrm{mh} \mathrm{mh}$

16 NM $(1,3)$ e così anche a scuola io parlavo:: - croato

$17 \mathrm{NM}$ solo quando - era:: a scuola per esempio la

18 INT materia:: serbo <<in tedesco [serbisch] $>$ (h) a::

19 INT [mh mh]

$20 \mathrm{NM}$ quando si doveva scrivere [3 sec. omessi] un esame

21 NM di scritta-

22 INT $\mathrm{mh} \mathrm{mh}$

23 NM hai: un titolo - e tu devi scrivere questo e di là

$24 \mathrm{NM}$ dovevo stare molto attenta come scrivere [42 secondi omessi]

$25 \mathrm{NM}$ allora ho cominciato qui:: allora con il mio

26 NM serbocroato - ho cominciato:: imparare: sloveno con $\leftarrow$

$27 \mathrm{NM}$ la f- famiglia dove: lavoravo $(0,8)$

$$
\text { (NM_Cro_Bo, 04:51-07:08) }
$$

Riferendosi ai primi dieci anni della sua vita

$\leftarrow$ (1984-1994), quando Croazia e Serbia erano

$\leftarrow$ unite, NM chiama il codice "serbocroato".

Dopo 27 secondi, NM

$\leftarrow$ racconta degli usi linguistici durante il periodo trascorso in Serbia (1994-2004). Ora si serve dei glottonimi "serbo" e "croato"/ "il mio croato".

$\leftarrow$ In questo momento della sua biografia, le diffe-

$\leftarrow$ renze tra i due codici diventano infatti rilevanti

$\leftarrow$ per la narratrice. NM deve per esempio stare attenta agli errori di ortografia durante $\mathrm{i}$ compiti in classe.

L'intervistata parla delle

$\leftarrow$ lingue usate in Alto Adige, dove vive dal 2004. Qui adopera di nuovo il glottonimo il "mio serbocroato", nonostante questo non sia più ufficiale.

loquio anche "croatoserbo" - è, per esempio, il codice parlato con il marito, con il figlio e con alcune coppie di amici, tutti residenti in Alto Adige (minuti 12:32-14:18 e 33:18-35:09). Inoltre è la lingua di comunicazione adoperata nel corso di una visita guidata, organizzata per i cittadini stranieri, nel museo archeologico di Bolzano (minuti 31:19-32:08). ${ }^{29}$ Il "croato" è invece, tra l'altro, la varietà linguistica impiegata durante le vacanze estive "a casa" in Croazia o utilizzata dal figlio per interagire con i nonni, residenti nel paese d'origine (minuti 23:19-24:25 e 27:34 28:14). In altre parole, il primo glottonimo è (ancora oggi) usato per chiamare il

29 Gli organizzatori dell'iniziativa si servono invece contemporaneamente della denominazione "serbo-croato e bosniaco" per definire una delle quattro lingue straniere (o "aree linguistiche") in cui è possibile effettuare la visita guidata (cfr. anche $\S$ II.2.5). 
codice d'origine in contesto migratorio, mentre il secondo è quello più appropriato per la varietà linguistica parlata (o da parlare) quando si torna temporaneamente nella regione di provenienza e con le persone che vi abitano.

Talvolta, NM si serve inoltre anche dell'espressione "nostra lingua" - e più raramente "mia lingua" - in posizione isolata nel discorso. Al contempo, fa un uso molto frequente di aggettivi possessivi insieme a glottonimi specifici (cfr., per esempio, "mio croato o "mio serbocroato alle righe 8 e 25-26 nel brano in 17 sopra). In questo modo, qualifica più o meno intenzionalmente i codici riferiti o il suo modo di parlarli in modo enfatico sulla dimensione emozionale-identitaria.

Infine, al termine della conversazione, NM prende nuovamente posizione rispetto ai rapporti di differenziazione tra varietà linguistiche a base neoštokava, in particolare, tra "serbo", "croato" e "bosniaco". Queste varietà erano già state caratterizzate nell' incipit dell'intervista come "tre lingue diverse" dal punto di vista ufficiale, anche se "uguali" tra loro dal proprio punto di vista (cfr. anche § IV.1.5.1). Ritornando sulla questione alla fine della registrazione, la partecipante afferma di non saper comunicare perfettamente né in "croato" né in "serbo", ma di parlare una "lingua mescolata". Secondo il suo racconto, qualcuno, allo scoppio della guerra, subito "con la testa è andato:: in serbo". L'identificazione con questo codice è avvenuta, per esempio, a causa delle persone che si frequentavano e/o per ragioni politiche. Invece, qualcun altro ha continuato a parlare "la sua lingua". Anche NM, "se uno [le] chiede", dice che "sono tre lingue" distinte. Tuttavia, la partecipante dichiara di usare abitualmente la denominazione "serbocroato" per chiamare il codice d'origine perché si sente "ancora come ragazzina di queste cose" (minuti 46:16-48:58).

Così, benché comprendano le stesse varietà linguistiche da un punto di vista etico, i repertori di LA e NM, almeno per come sono da loro rappresentati durante il colloquio, non sono tra loro identici. La prima partecipante distingue i codici d'origine in relazione al momento storico di cui sta parlando. In particolare, qualifica "serbo" (Serbisch) e "croato" (Kroatisch) come "varianti" (Varianten), quando riporta di eventi e circostanze verificatesi nel periodo precedente alla metà degli anni novanta. Nel raccontare dei suoi usi linguistici attuali, l'intervistata chiama invece il codice di partenza quasi esclusivamente "madrelingua" (Muttersprache). Tramite questa espressione, la donna si riferisce contemporaneamente alle varietà linguistiche che sono ora ufficialmente denominate "bosniaco croato serbo" (Bosnisch Kroatisch Serbisch). Nel fare ciò, sembra contestare, tramite l'adozione di un quasi-glottonimo in funzione oppositiva, la validità o legittimità di una distinzione tra i tre nuovi standard, per lo meno dal punto di vista emico (cfr. sempre $\S$ IV.3 e seguenti per maggiori dettagli sull'uso dei quasi-glottonimi nell'interviste del corpus). Diversamente dalla zia, NM varia invece le denominazioni a seconda del tempo biografico e/o del luogo che fanno da sfondo alle circostanze e agli eventi nel mondo della storia. La distinzione tra "croato" e "serbo" è rilevante durante i dieci anni trascorsi in Serbia. Nel narrare esperienze precedenti e successive, la partecipante chiama invece la lingua prevalentemente "(mio) serbocroato". Eventuali differenze tra i due codici sopra menzionati perdono infatti di importanza al di fuori del paese d'origine e, in particolar modo, in contesto migratorio. Inoltre, il glottonimo "(mio) serbocroato" non si riferisce, in ultima istanza, a nessuno dei codici 
ufficiali. Questa espressione denomina piuttosto, nell'uso di NM, il proprio modo idiosincratico di comunicare nella varietà linguistica di partenza.

In conclusione, si noti che la variazione delle denominazioni di lingua intra-parlante - ossia nel corso di un'unica interazione da parte di uno stesso parlante - è maggiore nelle interviste, discusse in questo paragrafo, rispetto a nel colloquio di coppia condotto con DR e FR (cfr., per esempio, le tabelle 2 e 3 al $\S$ IV.2.2). Inoltre, sia zia, sia nipote si servono durante la conversazione del glottonimo "serbocroato" e prendono posizione rispetto alle somiglianze/differenze tra le varietà linguistiche a base neoštokava, parlate nei paesi d'origine. Così, il secondo confronto in famiglia, da un lato, conferma la possibilità che le denominazioni di lingua adoperate da persone legate da rapporti familiari piuttosto stretti non corrispondano tra loro. Dall'altro lato, mostra che una forte alternanza nei nomi scelti per i codici d'origine così come l'impiego di glottonimi non (più) ufficiali per chiamarli possano occorrere in interviste non solo con persone appartenenti alle generazioni più anziane - e che quindi hanno vissuto a lungo nella Federazione Socialista Jugoslava (es. DR e LA) -, ma anche con partecipanti di età piuttosto giovane e che, quindi, erano bambini o bambine allo scoppio della guerra (es. NM).

\subsection{Codici endo- ed esocomunitari}

L'ultimo confronto riguarda i glottonimi e le apposizioni usati nelle interviste con RM e suo figlio SM. Il primo partecipante è un uomo di 42 anni, nato in una cittadina a maggioranza albanofona, situata nel sud del Montenegro al confine con l'Albania. Nel 1992 RM si trasferisce prima a Roma per disertare la chiamata alle armi, poi a Trento e infine soggiorna dieci anni in Svizzera per motivi di lavoro. Da due anni vive a Bolzano con la famiglia. Con RM ho condotto due interviste, una nel novembre 2013 e l'altra nel marzo 2014, rispettivamente della durata di 24 e 39 minuti. I colloqui si sono tenuti presso la tavola calda di proprietà del partecipante. La lingua di comunicazione è prevalentemente l'italiano. Tuttavia l'intervistato si serve abbastanza frequentemente, soprattutto durante il secondo incontro, di espressioni in tedesco, in svizzero tedesco, in inglese, in spagnolo o in varietà linguistiche a base neoštokava. Tali inserzioni svolgono talvolta una funzione allusiva o scherzosa, talvolta sono adoperate per costruire un contrasto con altri enunciati del cotesto, per esempio, nel citare discorsi riportati altrui (cfr. Auer 1984 per alcune funzioni dell'alternanza di codice in interazione). Nel rivolgersi ai familiari presenti al momento del colloquio, RM seleziona invece prevalentemente l'albanese. Occasionalmente pratica comunque commutazione di codice in albanese/italiano o in albanese/italiano/varietà neoštokave. Infine, con i clienti della tavola calda l'uomo alterna italiano e tedesco a seconda della lingua prima dell'interlocutore.

Nel corso delle due interviste condotte con lui, RM rappresenta il proprio repertorio individuale e quello comunitario, al tempo in cui viveva in Montenegro, come plurilingui. Uno dei codici parlati nel paese d'origine e dichiarati come mantenuti dopo l'esperienza migratoria è chiamato dal partecipante alternativamente "serbo- 
croato", "montenegrino" e occasionalmente "croato". Per l'altra varietà linguistica di partenza, RM usa invece invariabilmente il glottonimo "albanese".

In particolare, le sequenze che hanno per tema le varietà linguistiche a base neoštokava sono caratterizzate da frequenti strategie di riparazione - ad esempio, pause e riformulazioni - e da un sovra-uso di glottonimi. Infatti il partecipante adopera sequenzialmente nomi di lingua diversi, talvolta anche in uno stesso turno di parola. Questi fenomeni segnalano l'insicurezza onomastica del parlante e sono indicativi di un suo (almeno iniziale) tentennamento nel prendere posizione riguardo al dibattito ufficiale sui glottonimi. Tuttavia, la denominazione appropriata tra "serbocroato", "montenegrino" e "croato" - non è a mio avviso di volta in volta selezionata da RM in modo casuale. Piuttosto, nel determinare la scelta del nome da parte del parlante gioca anche un ruolo la volontà - perseguita più o meno deliberatamente dall'intervistato - di istituire rapporti di differenziazione tra i codici d'origine (ri)conosciuti lungo diverse dimensioni.

Specialmente durante la prima intervista, RM tende infatti a distinguere il "serbocroato" e il "montenegrino" sulla base i) del loro status sociolinguistico e, in parte, ii) dei loro domini d'uso, vale a dire a seconda della situazione comunicativa descritta nel mondo della storia. ${ }^{30}$ All'inizio della conversazione, il narratore categorizza, per esempio, da un lato, il "montenegrino" come un "dialetto" del "serbocroato". Dall'altro, nella sequenza in 18, RM si serve di due perifrasi diverse per indicare rispettivamente il codice appreso a scuola ("nostra lingua serbocroata") e quello parlato a casa nel paese d'origine ("nostra lingua montenegrina $(1,0)$ serbocroato"). In modo analogo, nel rispondere a un'altra domanda dell'intervistatrice quasi al termine della prima conversazione, RM definisce il codice parlato a casa in Alto Adige "nostra nostr- nostra lingua < praticamente sarebbe quella montenegrina>" (minuti 19:17-19:46). Si noti che in questa sequenza, come nell'esempio in 18 (cfr. righe 5-6 e 11), la scelta del glottonimo è preceduta da diverse pause e riformulazioni.

(es. 18)

1 INT ha imparato a scuo[la]

2 RM

3 RM

l'alberghiera -

[si] - imparato alla scuola - ho fatto

4 INT

5 RM

che lingue ha imparato

6 RM

7 RM e:: ho parlato:: ne:: - cioè la nostra li- in inglese - e::: la

nostra lingua - serbocroata che ((pausa)) perché:: sulle navi

((pausa)) tanto si parla - li è una lingua che si parla: in generale

8 RM è l'inglese - no

[28 secondi omessi]

9 RM il mo- praticamente portano merce - queste navi portano merce in

10 RM giro ((pausa)) in giro per mondo ((pausa)) e::: - in casa si parlava

11 RM nella nostra lingua in ne- montenegrina $(1,0)$ serbocroato

(RM_Mon_Bo, prima intervista, 02:27-03:26)

30 A causa della brevità del primo colloquio di soli 24 minuti, non è possibile validare con certezza quest'ultima supposizione. 
Nella sequenza in 18 - così come in altri brani della prima intervista -, le varietà linguistiche a base neoštokava sono spesso qualificate da RM come "nostra lingua". A differenza che in altri colloqui (cfr., per esempio, quello con DR discusso al $\S$ IV.2.2), la perifrasi non è usata dal partecipante in posizione isolata nel discorso. Tuttavia, il suo impiego mi pare comunque avere una funzione. Questa denominazione è infatti usata per contrapporre - di volta in volta in modo più o meno intenzionale e manifesto - il "serbocroato"/"montenegrino"/"croato" all'altra varietà linguistica del repertorio di partenza, ossia l'"albanese", sulla dimensione emozionale-identitaria. I rapporti tra questi due (gruppi di) codici sono ribaltati durante la seconda conversazione (cfr. più sotto in questo paragrafo). Perciò, l'espressione "nostra/mia lingua" mi sembra ricoprire una funzione prevalentemente "elusiva" nella prima intervista con RM. In altre parole, l'intervistato se ne serve strategicamente per suggerire una determinata rappresentazione dell'allocazione dei codici nel proprio repertorio individuale di partenza, senza impegnarsi definitivamente ed esplicitamente con questa (cfr., in particolare, il §IV.3.2 per una discussione più approfondita di questa funzione dei quasi-glottonimi nelle interviste del corpus).

Nello specifico, durante la prima conversazione, rispondendo in modo non diretto a una domanda dell'intervistatrice sui modi di acquisizione del codice, RM rappresenta 1'“albanese" come la lingua parlata da un altro gruppo di persone, residenti nel paese di origine ("da noi a montenegro si parla anche l'albanese perché le l'etnia al- albanese ci sono - in montenegro"; minuti 03:42-03:52). Poco di seguito, l'intervistato adduce una ragione strumentale per motivare le proprie competenze nella varietà linguistica in questione. Il suo apprendimento è infatti riconnesso alla necessità e ai vantaggi di accomodare i clienti albanofoni al lavoro, per cui "noi ci siamo stati - abituati adeguati a loro" (minuti 04:29-05:01). A livello linguistico, RM tende dunque ad usare, in un primo momento, forme verbali impersonali (ad es. "si parla") per descrivere il proprio processo di acquisizione dell'“albanese". In questo modo, il narratore spersonalizza i modi del suo apprendimento (cfr. Lucius-Hoene \& Deppermann 2004: 223). Successivamente, l'impiego di pronomi personali in prima e terza plurale (noi $v s$ loro) contrappone e al contempo contribuisce a costruire due comunità linguistiche (immaginate come) distinte nella località di partenza. Infine, durante il primo colloquio, l'intervistato non menziona l'“albanese" tra le lingue parlate attualmente in Alto Adige. Nel fare ciò, suggerisce che il codice sia stato da lui sostituito dopo mobilità.

Tuttavia, nella seconda intervista, RM rinegozia con la ricercatrice l'allocazione delle varietà linguistiche nel proprio repertorio di partenza e di arrivo. Il partecipante (ri)definisce infatti il "serbocroato" e l'"albanese" come entrambe lingue della comunicazione in famiglia, sia prima, sia dopo l'esperienza migratoria. Inoltre, invitato dall'intervistatrice all'inizio del colloquio a rispiegare la differenza tra le varietà linguistiche usate a scuola e a casa in Montenegro, attribuisce nel brano in 19 all "“albanese" le apposizioni "mia/nostra lingua". In questo modo, RM ribalta la rappresentazione fornita durante il primo colloquio (si compari l'esempio 19 con il brano in 18 sopra): 1'“albanese" è infatti ora il codice endocomunitario, contrapposto sulla dimensione emozionale-identitaria a un' "altra/quella lingua là", ovvero il "serbocroato" (cfr., in particolare, righe 9-14). 
(es. 19)

$\begin{array}{rlll}1 & \text { INT } & \text { eh:m qu- cioè lei ha detto quando era giovane c'era una differenza } \\ 2 & \text { INT } & \text { quando era in montenegro tra la lingua - che aveva imparato a scuola } & \\ 3 & \text { INT } & \text { e quella in cui parlava a casa ((pausa)) e: mi può spiegare di nuovo } & \\ 4 & \text { INT } & \text { la differenza che non sono riuscita a capirla } \\ 5 & \text { RM } & \text { allora la differenza c'era praticamente perché a scuola io fa- fa- } \\ 6 & \text { RM } & \text { parlavo ((pausa)) il serbocroato ((pausa)) fino alle otto come qua - } & \\ 7 & \text { RM } & \text { fino alle medie ((pausa) e li mh praticamente - fino alle otto otto } & \\ 8 & \text { RM } & \text { anni fai: ((pausa)) poi vai superiori ((pausa)) io andavo } & \\ 9 & \text { RM } & \text { con la mi- mia lingua ((pausa)) praticamente c'era in albanese } & \leftarrow \\ 10 & \text { RM } & \text { ((pausa)) poi per andare superar- e:: i: scoli superiori poi c'era } & \leftarrow \\ 11 & \text { RM } & \text { un'altra lingua c'era ce- (h) che c'era serbocroato ((pausa)) e } & \leftarrow \\ 12 & \text { RM } & \text { andava in que- e andava in quell quella: lingua là no ((pausa)) e: } & \leftarrow \\ 13 & \text { RM } & \text { questa è il concetto che:: poi x si parlava:: la na- nostra lingua } & \leftarrow \\ 14 & \text { RM } & \text { cioè: I=albanese no } & \\ & & \text { (RM_Mon_Bo, seconda intervista, 00:00-01:11) }\end{array}$

Così, RM rappresenta durante il secondo colloquio 1'“albanese" come la propria lingua (o codice endocomunitario) in contrapposizione con quella altrui (o codice esocomunitario) che ora è (divenuta) il "serbocroato". Le denominazioni di lingua, insieme ai possessivi e all'alternanza tra forme verbali impersonali e in prima persona singolare o plurale, sono funzionali a portare a termine questa (ri)definizione dei rapporti tra i codici d'origine nel corso delle interazioni e, in particolare, nel passaggio dalla prima alla seconda intervista. Queste variazioni puntano al contempo alle difficoltà che RM incontra nel dare un senso alla composizione del proprio repertorio. Tali contraddizioni sono, in particolar modo, evidenti nel brano in 20 , tratto dalla seconda intervista.

(es. 20)

1 RM c=erano musulmani cristiani ((pausa)) e: ortodossi ((pausa)) sai

2 RM ((pausa)) ognuno aveva suo:: come qua per esempio no ((pausa)) non è

3 RM che:: cambiava tanto cambiava molto ((pausa)) come tutto il mondo no

4 RM - non è che ((pausa))

5 INT eh:

6 RM ((pausa)) perché un popolo ha solo una lingua - giusto ((pausa))

7 INT o anche più di una

8 RM ((pausa)) ((deglutisce)) si - però dico se sono lo- loro albanesi

9 RM loro hanno l'albane- e alba- parlano albanese e se sono montenegrini

10 RM

11 RM

12 RM

13 RM

14 RM

15 RM

16 RM

17 RM - da - da:: da podgoritsa per esempio loro parlano ((pausa)) montenegrino ((pausa)) sarebbe so- serbocroato ((pausa)) ecco ((pausa)) perché se v- loro parlavano: e:: - e:: i montenegri:ni parlavano soltanto una lingua (h) invece noi parlevamo due ((pausa)) perché ho - andavi un un trovavi un posto di lavoro - LI: ((pausa)) do- dovevi sapere albanese e serbro serbo s::erbo:: serbrocroato parlarci (h) invece per loro erano era un po' sai ((pausa)) ((deglutisce)) come tipo ignoranza loro che non sapevano parlare in 
18 RM in nostra lingua - albanese cioè ((pausa)) e ((pausa)) se se per

19 RM quello erav- eravamo più avanzati noi - co con le lin[gue]

20 INT

(RM_Mon_Bo, seconda intervista, 06:28-07:57)

Nella sequenza in 20, RM usa strategicamente due (insiemi di) ideologie linguistiche tra loro contrapposte per descrivere la situazione sociolinguistica della località di partenza. La prima sostiene che ci sia un collegamento ineludibile tra un popolo e una sola lingua (cfr. la tesi alla riga 6 e la sua spiegazione alle righe 8-11). Questa ideologia linguistica è "egemonica" nella misura in cui è fatta propria dal narratore sebbene sia a vantaggio del gruppo linguistico dominante, mentre vada tendenzialmente contro i propri interessi e/o quelli del gruppo locale, a cui RM dichiara in ultima istanza, nel brano in 20, di appartenere (cfr., per esempio, De Bres 2013: 61). Infatti, la popolazione albanofona della città, essendo bilingue, non sarebbe propriamente definibile come "popolo". In seguito, RM allude a una seconda ideologia linguistica quando definisce l'essere plurilingue in termini positivi come una situazione di maggiore "avanzamento" (cfr. righe 18-19). ${ }^{31}$ Quest'ultima tesi è invece favorevole alla propria condizione e a quella della minoranza albanofona in Montenegro. Si noti inoltre che, nel brano in 20 (come già in quelli citati precedentemente), il partecipante tentenni nel dare i nomi ai codici di partenza. Tuttavia, l'intervistato formula ora esplicitamente alla riga 11 una relazione di uguaglianza tra "montenegrino" e "serbocroato". In aggiunta, sebbene inizialmente si distanzi, tramite pronomi e verbi di terza persona plurale dalla popolazione "albanese" - e anche da quella "montenegrina" - residente nella località d'origine (cfr. righe 8-10), il narratore si serve poi, in conclusione della sequenza, dell'apposizione "nostra lingua" per 1'albanese. Nel fare ciò, si affilia in modo univoco alla comunità dei suoi parlanti.

La rappresentazione, appena delineata, del repertorio individuale e comunitario di partenza di RM non coincide con quella di suo figlio SM. Quest'ultimo si trasferisce in Italia insieme alla madre all'età di sei mesi per ricongiungersi al padre, emigrato precedentemente. Il ragazzo, diciannovenne al momento del colloquio, non ha soggiornato in Svizzera insieme al genitore, ma ha abitato con altri membri della famiglia in diverse città italiane, ossia a Roma, a Trento e da due anni a Bolzano. L'intervista con SM ha luogo nel gennaio del 2014 presso il ristorante dei genitori, in cui il ragazzo occasionalmente lavora. La registrazione dura 42 minuti. La lingua di comunicazione è l'italiano.

Nel corso del colloquio con SM, i nomi di lingua non variano quasi mai. L'intervistato chiama coerentemente le varietà linguistiche conosciute - oltre a "italiano" e "pochissimo [...] tedesco" - "serbo", "albanese" e "macedone". Solo in un'occasione si serve del glottonimo "montenegrino". Nella sequenza in questione, il codice

31 Per una discussione sulla compresenza, in anni recenti, di due discorsi ideologici sulla lingua l'uno che la vede in termini di "orgoglio" (pride) e che è ancora legato al ruolo giocato da questa nella formazione degli stati nazionali; e l'altro che la concepisce in termini di "profitto" (profit) ed è connesso con le trasformazioni economiche e politiche nelle società globalizzate si veda, in particolare, Heller \& Duchêne (2012). 
così riferito è comparato al "macedone" per motivare la facilità di apprendimento di quest'ultimo ("INT: il mac- - e il macedone come l=hai imparato SM: ma la m- il macedone é:: quasi uguale con: ((pausa)) come il montenegrino ((pausa)) praticamente perché lo ca- cambi solo $(\mathrm{h})-\mathrm{l}=$ accento $[\ldots]$ sai $[\ldots]$ però: - non cambia quasi niente"; minuti 05:06-05:19). In seguito, SM affermerà di usare il "macedone" con alcuni amici provenienti dalla Repubblica di Macedonia e, talvolta, anche con i genitori in Alto Adige. Tale codice non è invece menzionato come facente parte del proprio repertorio né d'origine né d'arrivo dal padre RM. Inoltre, all'opposto di quest'ultimo, SM non caratterizza i codici, di cui ha competenza, sulla dimensione socio-geografica o socio-politica né emozionale-identitaria. Per esempio, non utilizza mai spontaneamente, nel corso dell'interazione, l'apposizione "madrelingua". Al contrario, rispondendo a una domanda della ricercatrice a riguardo, afferma di non avere propriamente una madrelingua (minuti 19:50-20:11). In linea con ciò, nell'illustrare i modi di apprendimento del "serbo" e dell'"albanese" insieme alla madre e allo zio, SM qualifica, nella sequenza in 21 , tali codici come "lingue straniere", per cui provava curiosità (cfr. riga 12). Nel fare ciò, li posiziona come varietà linguistiche distanti (o esocomunitarie) dal punto di vista emozionale-identitario.

\section{(es. 21)}

1 NT

2 SM

3 INT

4 SM

5 INT

6 SM

7 INT

8 SM

9 SM

10 SM

$11 \mathrm{SM}$

$12 \mathrm{SM}$ l'albanese anche ((pausa)) e l'hai imparato QUI: o qua qua[ndo]

tu hai detto che ti sei trasferito qui quando avevi: sei me[si] [qua]

[si]

e: quando eri qui tua madre parlava con te sia in: in serbo che in esatto ((pausa))

ah okay perché mio padre non era qua allora: ((pausa)) perché anche mio zio sapeva no ((pausa)) e: tramite lui ho imparato un po' di parole perché: ero curi- anch'io ero curioso di come: ((pausa)) cosa significassero le parole e tutto perché: avev- come dirti era bello insegnare u cioè imparare lingue straniere magari ((pausa))

(SM Mon Bo, 01:28-02:07)

Infine, descrivendo e giustificando il plurilinguismo nella cittadina di nascita, SM non attribuisce alle lingue, presenti sul territorio, quel potere simbolico di sancire l'appartenenza a un gruppo, che invece sembra essere loro riconosciuto dal padre. Inoltre non si identifica particolarmente con la realtà (sociolinguistica) rappresentata. Piuttosto, il ragazzo istituisce raffronti con la situazione linguistica nel paese di residenza attuale, tendendo a metterne in evidenza somiglianze e differenze. Per esempio, secondo SM, "li”, nella località d'origine, "[loro] parlano:: ((pausa)) il serbo perché non sono tutti albanesi e magari: italiani" e/o per motivi turistici (minuti 01:11-01:26). Inoltre, nei ristoranti il ragazzo sente usare anche l'italiano perché "[loro] lo imparano l'italiano anche SAI ${ }^{\circ}$ perché ${ }^{\circ}$ fanno: magari la scuola parlan- parlano l'ITAliano" (minuti 05:40-06:22). Infine, "li”, nella cittadina montenegrina, "[loro] hanno una parabola [...] che prende tutti i canali ((pausa)) tutti i ca- 
nali:: serbi albanesi" (minuti 06:27-06:38). Così, attraverso apposizioni per le lingue che esprimono distanza dal punto di vista biografico-acquisizionale ed emozionale-identitario, deittici della lontananza (es. lì) e verbi coniugati in terza persona plurale (invece che in prima persona singolare o plurale), SM trasmette, nel corso del colloquio, un certo distacco dalla situazione sociolinguistica del luogo di nascita, divenuto attualmente località di vacanza.

Dalla discussione di questo paragrafo emerge dunque che RM e suo figlio SM rappresentano l'allocazione dei codici nel repertorio individuale e comunitario d'origine - così come i suoi mutamenti dopo emigrazione in diverse località straniere in modo diverso. Il primo partecipante classifica le varietà linguistiche di partenza sulla dimensione socio-geografica o socio-politica ed emozionale-identitaria. Nel fare ciò, le distingue in relazione al loro prestigio sia "manifesto" sia "occulto" (o "interno"). Vale a dire le differenzia rispettivamente a seconda i) della loro adeguatezza strumentale per comunicare in determinate situazioni ("serbocroato" vs "montenegrino") e ii) del loro valore simbolico come codici propri o altrui e, quindi, come marcatori di identità personale e di gruppo ("serbocroato"/"montenegrino"/"croato" vs "albanese") (cfr. anche Edwards 1996: 706-707). Inoltre, RM inizialmente sotto-specifica le funzioni e la posizione dell'“albanese" nel proprio repertorio. Le ragioni di questo comportamento dipendono verosimilmente dal basso status riconosciuto a questo codice dalla comunità linguistica d'origine e, eventualmente, da quella d'arrivo (cfr. Busch 2006 per esempi simili). Perciò, la rappresentazione dei rapporti tra i codici di partenza nel repertorio individuale di RM mi sembra essere significativamente condizionata dai modi in cui tali relazioni sono concepite, costruite e tramandate a livello collettivo. Anche la forte alternanza di glottonimi e apposizioni, insieme ad altre caratteristiche linguistiche (es. pause, riformulazioni), punta all'insicurezza del parlante rispetto a questioni di lingua. Tale incertezza è probabilmente una conseguenza della consapevolezza che le denominazioni di lingua e la configurazione dei repertori sono associate a e veicolano disposizioni e connotazioni, talvolta, stigmatizzanti nello spazio sociolinguistico di partenza. Il nesso ideologico tra (prima) lingua e appartenenza a una comunità, linguistica o nazionale, è parzialmente contestato da RM in una sequenza del colloquio (cfr. esempio 20 sopra). Tuttavia, l'allocazione di un codice, specialmente nel dominio famiglia, risulta essere (ancora) centrale per il partecipante al momento di negoziare la propria identità (almeno linguistica) in interazione.

Diversamente da suo padre, SM non differenzia invece i codici del suo repertorio tramite apposizioni appartenenti alla scala emozionale-identitaria e/o socio-geografica o socio-politica. Piuttosto qualifica, in una sequenza, le varietà linguistiche d'origine come "lingue straniere" e, quindi, tendenzialmente estranee dal punto di vista emozionale-identitario. Durante il colloquio, il partecipante raffigura inoltre il proprio repertorio individuale e quello comunitario nel paese di nascita come plurilingui, ma non come stratificati gerarchicamente. Infine, a differenza che in altre interviste analizzate nel presente capitolo, i nomi per le lingue non variano (quasi) mai durante il colloquio con SM. Ad eccezione di una volta, il ragazzo chiama la varietà neoštokava, da lui conosciuta, esclusivamente "serbo". Il glottonimo è attualmente in uso a livello istituzionale, diversamente per esempio da "serbocroato". 
Non è tuttavia quello sancito come ufficiale per la prima lingua parlata nel paese d'origine dell'intervistato, ossia "montenegrino".

\subsection{Conclusioni: rappresentazioni degli spazi (socio)linguistici di partenza}

In questa seconda sezione del capitolo IV, ho illustrato come le denominazioni di lingua si alternino, intra- e inter-parlante, in sei biografie linguistiche del corpus. Nel corso di una stessa interazione, i nomi valutati dai narratori come appropriati per chiamare i codici d'origine variano sequenzialmente. Perciò le ragioni che determinano la loro scelta devono essere interpretate localmente. Pur partendo da questo presupposto, la variazione delle denominazioni di lingua non avviene a mio avviso in modo del tutto casuale. Oltre alla volontà o alla riluttanza nel posizionarsi rispetto ai dibattiti ufficiali sui glottonimi, ho infatti individuato altri fattori - situazionali, biografici e identitari - che condizionano l'alternanza dei nomi di lingua e delle loro apposizioni in modo più o meno costante per uno stesso partecipante. Questi sono, da un lato, il contesto interazionale in cui il colloquio si svolge. Dall'altro, possono avere un influsso il tempo storico o biografico a cui il narratore si riferisce durante il racconto e, parzialmente, il luogo geografico, la situazione comunicativa o il tipo di interlocutore, riferiti nel mondo della storia (per questi ultimi parametri, si veda l'analisi delle interviste con NM e RM rispettivamente ai $\S$ IV.2.3 e IV.2.4). Inoltre, anche la volontà di presentare un codice come endo- o esocomunitario e di esprimere, così, affiliazione o meno a una determinata comunità linguistica può influire sulla scelta della denominazione appropriata. Tali fattori sono rilevanti per spiegare l'alternanza dei nomi di lingua intra-parlante in queste come in altre interviste del corpus.

La variazione delle denominazioni per le lingue e le sue motivazioni puntano, inoltre, al fatto che gli intervistati abbiano modi singolari e, talvolta, differenti tra loro di rappresentare i rapporti con i codici d'origine e di concepire le loro relazioni di differenziazione. In particolare, $i$ tre confronti, esposti in questa sezione del capitolo IV, mostrano che lo spazio linguistico e sociolinguistico di partenza non sia suddiviso secondo le stesse categorie - per lo meno al momento del colloquio con la specifica ricercatrice - neanche tra membri di una stessa famiglia. A questo riguardo, si ricordi che, come illustrato ai § I.1 e seguenti del presente volume, in un approccio "biografico" al repertorio linguistico, le varietà linguistiche (ri)conosciute dai parlanti non sono concepite come entità date e discrete a priori. In aggiunta, le dimensioni corporale, emozionale e storico-politica (o storico-sociale) dell'uso linguistico sono parti integranti di un repertorio. Perciò, anche se due repertori comprendono gli stessi codici da un punto di vista etico, la loro configurazione può variare in relazione, ad esempio, alle disposizioni e connotazioni affettive, simboliche o strumentali, ascritte a tali varietà linguistiche dai loro locutori nel corso del tempo.

In particolare, tra i fattori che possono condizionare una variazione inter-partecipante, l'età del parlante non risulta essere determinante nello spiegare i nomi prevalentemente scelti nelle interviste. Indipendentemente dalla generazione, i nar- 
ratori si possono infatti servire di glottonimi non più ufficiali, di denominazioni vigenti attualmente e/o di quasi-glottonimi per chiamare le varietà linguistiche di partenza. Inoltre, l'età non è neanche decisiva per rendere conto di una forte alternanza dei nomi di lingua in interazione e, quindi, di insicurezza onomastica. Per spiegare queste variazioni (ossia il tipo di nomi e la loro forte alternanza), altri aspetti meritano di essere considerati. I casi di NM e SM suggeriscono, nello specifico, che esperienze biografico-personali - come la traiettoria di mobilità e le cause di emigrazione, da un lato, e l'età al momento del trasferimento all'estero, insieme alle circostanze a questa correlate (es. scolarizzazione nel paese d'arrivo, minore conoscenza della realtà sociolinguistica di partenza), dall'altro (cfr. anche $\S$ III.1.3.1) - abbiano un certo influsso sull'occorrere o meno di tali variazioni. Infatti, la prima intervistata varia frequentemente i nomi di lingua a seconda dei luoghi di residenza e delle esperienze più o meno traumatiche che vi ha esperito. Invece, il secondo partecipante, emigrato insieme alla famiglia da neonato, usa coerentemente le stesse denominazioni nel corso del colloquio, mentre non sembra essere condizionato, nelle proprie rappresentazioni, dai rapporti di potere tra varietà e gruppi linguistici, vigenti nella località di origine.

Detto ciò, per spiegare la variazione dei glottonimi inter-partecipante mi sembra essere comunque soprattutto determinante, in primo luogo, il modo di posizionarsi del narratore o della narratrice nei confronti degli interventi di pianificazione linguistica e dei discorsi metalinguistici, diffusi nei singoli paesi di provenienza. Così, ad esempio, LA e NM, provenendo dalla Croazia, si sentono maggiormente in dovere di prendere posizione sui rapporti di differenziazione tra alcune varietà linguistiche successive al serbocroato e, in particolare, tra croato e serbo, da un lato, $\mathrm{e}$, secondariamente, tra queste e bosniaco, dall'altro. Lo stesso vale ancora più improrogabilmente per RM nei confronti della questione dell'esistenza o meno di un codice definito "montenegrino" distinto dal "serbocroato" (si noti, però, che per quest'ultimo partecipante la questione della legittimità degli altri codici standard non è rilevante né la sua rappresentazione dello spazio linguistico di partenza li comprende, per lo meno al momento del colloquio). Invece, DR e FR possono più facilmente tralasciare di posizionarsi rispetto a questo tema, facendo implicitamente riferimento a una tradizione di discorsi metalinguistici, diffusi in Serbia, che concepiscono il nuovo standard serbo come "naturalmente" evolutosi dal serbocroato (cfr. § II.3.4 e sgg. per un'illustrazione di queste diatribe).

In secondo luogo, significativo è anche il condizionamento dei modi di gestione del plurilinguismo a livello istituzionale nelle specifiche località di partenza degli intervistati e nei luoghi in cui hanno successivamente vissuto. In particolare, il grado di riconoscimento di un codice nella comunità linguistica d'origine e/o d'arrivo ha un forte influsso sulle rappresentazioni dei repertori dei singoli. Questo condizionamento è evidente specialmente nel caso di RM, ma anche parzialmente nelle prese di posizione enfatiche verso $\mathrm{i}$ codici d'origine, in contrapposizione a quelli appresi in contesto migratorio, da parte di altri intervistati, tra cui soprattutto FR. Tuttavia, sia qui ribadito che i singoli partecipanti possono sia fare proprie, sia contestare o rigettare le categorizzazioni attribuite a una varietà linguistica "dall'alto", vale a dire, ad esempio, da istituzioni o mass media a livello collettivo. 
Così, è anche possibile riconoscere dal "basso" (o a livello micro) modi individuali e creativi di rendere conto dei rapporti verso e tra codici che hanno recentemente cambiato il loro status. Tale aspetto sarà analizzato più dettagliatamente nella prossima sezione del capitolo IV.

\section{DENOMINAZIONI IN DIVENIRE}

In questa ultima sezione del capitolo IV analizzo i modi di impiego dei quasi-glottonimi nelle interviste del corpus. L'obiettivo è rendere conto di come e perché pratiche di denominazione generiche più o meno innovative siano negoziate in interazione e, eventualmente, si cristallizzino in glottonimi specifici durante una determinata conversazione. Ai $\S$ IV.3.1 e seguenti discuto alcuni criteri che a mio avviso sono segnali del fatto che un nome di lingua generico sia adoperato dai partecipanti come glottonimo specifico al momento del colloquio. Inoltre, illustro le ragioni di utilizzo di perifrasi analoghe da parte di parlanti originari dallo spazio sociolinguistico slavo meridionale o da altre regioni. Il resto del capitolo è dedicato alla descrizione delle tre funzioni, "elusiva", "enfatica" e "oppositiva", che i quasi-glottonimi ricoprono nelle interviste raccolte (cfr. rispettivamente §IV.3.2, IV.3.3, IV.3.4). Tali funzioni sono riconnesse a tre modi dei partecipanti di rapportarsi ai codici d'origine nel proprio repertorio.

\subsection{Quasi-glottonimi: tentativi di definizione}

Come già accennato nei paragrafi precedenti, studi onomasiologici sul campo dimostrano che la distinzione tra nomi comuni (o appellativi) e nomi propri non sia sempre netta, ma in alcuni casi graduale (cfr. Tamine 2013: 12 e anche Migliorini 1927: 1-14, Nicolaisen 1995, Tabouret-Keller 1997b). Nel presente lavoro mi servo del concetto di "quasi-glottonimo" proprio per indicare un nome di lingua in divenire o in oscillazione da generico a specifico nell'uso di un parlante.

L'individuazione dei casi d'uso di quasi-glottonimi nelle interviste del corpus non è sempre facile. Da un lato, i partecipanti possono adoperare una medesima espressione, come, ad esempio, "nostra lingua", sia da sola, sia in concomitanza con altre denominazioni durante una stessa conversazione. Così, tale espressione può presentare tratti che, talvolta la accomunano di più a un glottonimo specifico, talvolta di più ad un'apposizione generica, a seconda del contesto. Dall'altro lato, gli intervistati possono utilizzare circonlocuzioni generiche come glottonimi specifici in modo più o meno sistematico e frequente nel corso del colloquio. Alcuni se ne servono, infatti, fin da subito e in modo coerente durante l'intera conversazione per riferirsi sempre ai codici di partenza. Invece, altri le adoperano solo a partire da un certo momento della loro biografia linguistica o in specifiche sequenze di questa. Inoltre, un'altra ragione della difficoltà di individuare $\mathrm{i}$ casi d'uso di quasi-glottonimi nel corpus deriva dal fatto che né il tipo di denominazione adoperato, né il codice da questa riferito siano criteri sufficienti. Infatti, se, nelle interviste raccolte, predominano i quasi-glottonimi 
connotati sulla dimensione emozionale-identitaria (vedi "madrelingua" o "mia lingua"), gli intervistati si servono anche di espressioni generiche neutrali, come ad esempio "questa lingua" o "in lingua", in funzione di nomi specifici. D'altro canto, sebbene - come vedremo nel corso dei prossimi paragrafi - sia possibile individuare correlazioni tra la funzione dei quasi-glottonimi e lo status sociolinguistico del codice nominato, le varietà linguistiche riferite da una stessa denominazione non corrispondono tra gli intervistati. Così, la perifrasi "nostra lingua" è per esempio adoperata a seconda del partecipante per designare sia varietà linguistiche a base neoštokava, sia varietà gheghe di albanese, sia varietà di daco-rumeno.

Date queste variazioni, due fattori sono stati quindi preliminarmente presi in considerazione come potenziali indicatori a livello formale di processi di perdita di "significato" lessicale, proprio degli appellativi/apposizioni, e di possibile acquisizione di "contenuto" onomastico, caratteristico dei nomi propri, da parte di determinate espressioni generiche al momento dei colloqui (cfr. Nicolaisen 1995 per questa distinzione a livello semantico). Il primo parametro è un loro possibile utilizzo in posizione "semi-isolata" o "isolata" nel discorso, ossia senza un referente anaforico o cataforico esplicito rispettivamente i) in un solo turno di parola precedente e successivo o ii) in più turni di parola precedenti e successivi. ${ }^{32} \mathrm{Il}$ secondo parametro è la "frequenza" di occorrenza di tali denominazioni sul totale di quelle adoperate da un parlante per chiamare il codice di partenza. La tabella in 4 è un primo tentativo di descrivere, su queste basi, l'uso di potenziali quasi-glottonimi da parte degli intervistati del corpus. L'impiego di denominazioni generiche è descritto prendendo in considerazione due parametri scalari, ossia la frequenza da un lato e la posizione isolata, semi-isolata e non isolata nel discorso dall'altro. Ciò permette di comparare diversi gradi di cristallizzazione di nomi di lingua generici in specifici e, quindi, diversi stadi di impiego di quasi-glottonimi nelle conversazioni raccolte.

Tabella 4: Frequenza e posizione di potenziali quasi-glottonimi nelle interviste del corpus.

\begin{tabular}{|l|l|l|l|c|}
\hline & Posizione isolata & Posizione semi-isolata & Posizione non isolata & Totale \\
\hline$<\mathbf{2 0} \%$ & AC, FR, LP, SV, TF & AS, RM, XF, YF, ZT & AF, DL, IP, SP, VM & 15 \\
\hline $\mathbf{2 0} \%-\mathbf{4 0} \%$ & $\begin{array}{l}\text { BV, DB, LA, NM, } \\
\text { RX }\end{array}$ & ML, NJ & & 7 \\
\hline $\mathbf{4 0 \% - 6 0 \%}$ & JB, KM, PB & & & 3 \\
\hline $\mathbf{6 0} \%-\mathbf{8 0} \%$ & BL, DR, KS, OV & & & 4 \\
\hline Totale & 17 & 7 & 5 & 29 \\
\hline
\end{tabular}

32 Si ricordi che un turno di parola è lo spazio conversazionale assegnato a un parlante dagli interlocutori in una conversazione. Questo fornisce il contesto locale per l'interpretazione e la comprensione degli enunciati (cfr. Franceschini 1998: 30-35). Un turno di parola inizia e termina con uno scambio di ruoli tra gli interattanti. Così, nelle biografie linguistiche del corpus, questo è solitamente avviato e concluso da due domande della ricercatrice. I turni di parola delle interviste semi-strutturate, condotte all'inizio della raccolta dati, sono mediamente meno estesi e complessi di quelli delle interviste episodico-narrative, raccolte successivamente. 
Come si evince dalla tabella 4, ventinove intervistati su trentotto si servono potenzialmente di quasi-glottonimi per chiamare i codici di partenza durante le registrazioni. Si noti che nello schema in 4 sono riportati anche i partecipanti che adoperano denominazioni generiche abbastanza raramente $(<20 \%)$ e in posizione non isolata nel discorso, ossia in concomitanza con nomi di lingua specifici. Soprattutto in questi ultimi casi, non è sempre chiaro se ci troviamo di fronte a un nome di lingua in divenire da generico a specifico o a una semplice apposizione. Come sarà illustrato nel prossimo paragrafo, per risolvere questo problema bisogna prendere in considerazione un terzo parametro, a fianco a quelli già menzionati di frequenza e posizione. Questo è la funzione dei quasi-glottonimi nella specifica interazione e/o nel macro-contesto di partenza e di arrivo degli intervistati.

\subsubsection{Da nomi generici a specifici in interazione}

Le denominazioni linguistiche possono essere considerate come espressioni composte da un termine "generico" e da uno "specifico" (cfr. Stewart 1975: 20-25 per questa distinzione riferita però ai toponimi in diverse lingue del mondo). Il primo nome, definito nel presente lavoro anche apposizione, si riferisce alla categoria a cui il codice appartiene, ad esempio, "lingua" o "dialetto". Invece il secondo specifica più o meno univocamente la varietà linguistica riferita, ad esempio, "albanese" o "ghego". A seconda delle circostanze e/o della costellazione di partecipanti, i locutori possono tralasciare o l'una o l'altra componente della designazione. Così, si può ipotizzare che tedescofoni altoatesini, parlando tra di loro, si riferiscano prevalentemente alla lingua di comunicazione come a "dialetto". Invece al momento di paragonarlo al bavarese o allo svizzero tedesco la chiameranno probabilmente "sudtirolese". Infine la denominazione completa, ovvero "dialetto sudtirolese", sarà verosimilmente quella inizialmente selezionata in occasioni (semi-)formali e/o all'avvio di conversazioni con persone che non hanno competenza nella varietà linguistica in questione.

L'impiego di nomi di lingua comuni in posizione isolata nel discorso non è quindi di per sé sorprendente. Analogamente, anche in alcune biografie linguistiche del corpus, l'adozione da parte dei narratori di termini generici per chiamare i codici d'origine è in parte spiegabile dal contesto interazionale. Per esempio, è piuttosto frequente che gli intervistati rispondano alla domanda sulle varietà linguistiche, usate per pensare o parlate in famiglia dopo l'esperienza migratoria, con la "mia [lingua]" o la "madrelingua". Tali perifrasi sono talvolta usate in posizione isolata nel discorso. Tuttavia, il codice da esse riferito non è ambiguo per l'interlocutrice, né le apposizioni adoperate svolgono necessariamente la funzione di quasi-glottonimi. D'altro canto, in certe conversazioni, denominazioni generiche presentano alcune peculiarità dal punto di vista linguistico, indipendentemente dall'essere usate in posizione semi- o non isolata nel discorso. Così, un partecipante adopera, per esempio, l'espressione "nostra lingua" al singolare per riferirsi contemporaneamente a due codici diversi, ossia macedone e albanese. In altri casi, alcuni intervistati qualificano ripetutamente la varietà linguistica, oggetto della conversazione, 
come "nostra", sebbene il cotesto richiederebbe l'adozione di un possessivo di prima persona singolare, ossia "mia". Infine, in certe interviste, si riscontra un restringimento, per lo meno occasionale, del significato convenzionale di alcune espressioni, in particolare del termine "madrelingua". I tre fenomeni appena delineati puntano a una desemantizzazione delle apposizioni per i codici d'origine, ovvero a un'alterazione fino a una perdita del loro significato lessicale nell'uso degli intervistati. Perciò sono a mio avviso possibili segnali di un impiego, almeno temporaneo, di tali designazioni come quasi-glottonimi nelle sequenze in questione. Le denominazioni usate esclusivamente in posizione semi- o non isolata presentano comunque più tratti in comune con i nomi di lingua generici di quelle che appaiono anche in posizione isolata nel discorso.

Una collocazione opposta sul continuum tra apposizioni e nomi specifici hanno, invece, le designazioni generiche, il cui impiego non è giustificato dal contesto e/o dalla costellazione di partecipanti. Gli esempi più chiari sono quelli in cui i narratori chiamano la varietà linguistica di partenza "nostra lingua" all'inizio del colloquio. Se intesa nel suo significato lessicale, tale designazione è infatti inusuale all'avvio di una conversazione semi-formale con una ricercatrice semi-sconosciuta che, per di più, non è originaria dello spazio sociolinguistico di partenza dei parlanti, né padroneggia la varietà linguistica così riferita. Inoltre, come già illustrato nel paragrafo precedente, anche la frequenza di occorrenza di perifrasi generiche può essere indicativa di una loro cristallizzazione a glottonimi specifici nell'uso di un parlante. Tuttavia, si noti che un uso ripetuto di certe espressioni - in particolare, di "nostra lingua" - può essere anche segnale, nella specifica situazione studiata, di loro "uso fossilizzato". Con ciò intendo di una loro adozione scevra di una determinata funzione e tendenzialmente involontaria come calco dalla lingua prima (cfr. § IV.3.1.2 per maggiori dettagli). In questi casi, tali perifrasi sono adoperate dagli intervistati a tutti gli effetti come glottonimi specifici e non sono, quindi, denominazioni "in divenire". Il loro impiego è ambiguo per l'interlocutrice, ma non per il parlante.

In considerazione di ciò, un terzo parametro risulta essere rilevante per definire e, soprattutto, per descrivere i quasi-glottonimi nelle interviste raccolte. Questo è la "funzione" da loro ricoperta in interazione. In particolare, l'analisi sequenziale delle interviste raccolte consente di stabilire se i quasi-glottonimi siano adoperati strategicamente dagli interattanti e, eventualmente, in che misura la loro funzione sia determinata localmente dal cotesto interazionale, immediatamente precedente $\mathrm{o}$ successivo, o, in alternativa, si mantenga stabile nel corso del colloquio. La presenza o meno di una funzione permette di distinguere poi tra usi fossilizzati e non fossilizzati delle perifrasi generiche. Infatti, l'impiego strategico di queste ultime mostra che il loro significato non è del tutto opaco per il parlante e che, così, il nome di lingua è in divenire o in oscillazione tra comune e specifico. D'altro canto, l'individuazione dei motivi di utilizzo dei quasi-glottonimi consente di formulare ipotesi sul rapporto che gli intervistati hanno con i codici così riferiti e sulla loro allocazione nel repertorio da un punto di vista emico. A questi fini è utile considerare anche il contesto macro, in cui i colloqui si svolgono, e confrontarlo con situazioni analoghe in cui parimenti si fa uso di quasi-glottonimi. 


\subsubsection{Da nomi generici a specifici nel contesto macro}

Nelle località di origine degli intervistati del corpus, l'espressione "naš jezik" e l'avverbio "naški" - rispettivamente "nostra lingua" e "nel nostro modo" - costituiscono sintagmi lessicalizzati per denominare la lingua e il proprio modo di parlare già prima degli anni novanta (cfr. Gröschel 2009 e, in questo volume, §II.3.5 e sgg.). Modi di dire analoghi non sono inusuali tra comunità linguistiche diverse. Espressioni equivalenti o derivate dal pronome "noi", insieme a varianti dei sostantivi "popolo" o "uomini", sono usate abbastanza frequentemente come etnonimi e glottonimi da popolazioni, residenti in località anche distanti tra di loro (cfr. Stewart 1975: 68, Edwards 2012: 19-23). Tra queste ci sono, per esempio, le comunità parimenti di lingua slavo meridionale del Molise. In modo non ambivalente, questi parlanti chiamano infatti la varietà linguistica, usata soprattutto nei domini informali, naš jezik o na-našu/nanaš, ossia la "nostra lingua" o "nel nostro modo" (cfr. Breu 2002, Iannàccaro \& Dell' Aquila 2002).

In linea con ciò, sia qui ricordato che alcuni nomi di lingua, che fungono attualmente da glottonimi specifici, derivano o sono composti da espressioni originariamente generiche. ${ }^{33}$ Un esempio è "Deutsch" (tedesco), derivato dall'aggettivo "theudiscus", 34 che significa etimologicamente "volgare" o "lingua della gente" (cfr. Iannàccaro \& Dell'Aquila 2007: 14). La designazione è usata nell'VIII-X secolo per contrapporre questa varietà linguistica, parlata dalle comunità germaniche, alla lingua in $\mathrm{H}$, ossia il latino amministrativo. In aggiunta, tale glottonimo potrebbe avere acquisito, per le comunità tedescofone a contatto con parlanti di volgari romanzi, anche la funzione di demarcare il codice endocomunitario in opposizione alle varietà linguistiche esocomunitarie (cfr. ibidem). In modo simile, la denominazione inglese Welsh (gallese) deriva probabilmente dall'anglosassone "w(e) alh" tramite il tedesco antico "Wälsche", ossia da un nome generico con il significato di "straniero" o anche "barbaro" (cfr. Edwards 2012: 21). Anche la designazione "Vlah" o "Valah" (valacco), diffusasi dalle lingue slavo meridionali ad altre lingue balcaniche - ad esempio, greco, turco, albanese - per chiamare la popolazione romanizzata residente nella regione, ha probabilmente la stessa origine (cfr. Arvinte 2003: 161-162). Parlanti slavofoni l'hanno infatti verosimilmente adottata prima del VII-IX secolo in seguito al contatto con gruppi germanofoni. Invece è meno frequente tra i parlanti di arumeno (cfr. ibidem).

Il significato delle denominazioni appena menzionate può essere più o meno opaco per gli interattanti (si paragoni, per esempio, naš jezik a Deutsch). Tuttavia, queste designazioni tendono a funzionare a tutti gli effetti da glottonimi specifici. Non sono ambigue, né impiegate dai parlanti con una determinata funzione in interazione. Diversi sono, invece, i casi in cui nomi di lingua generici sono adottati

33 All'opposto anche nomi propri possono divenire, per esempio per antonomasia o metonimia, nomi comuni. Per riflessioni su tali processi deonomastici si confrontino Stewart (1975: 20-25) e Migliorini (1927: 1-14).

34 A sua volta probabilmente una latinizzazione dall'alto-tedesco antico *diutisk o dal sassone antico *thiudisk (cfr. Reiffenstein 2003: 2193). 
strategicamente dai locutori. In particolare, nei paesi successori alla Jugoslavia, la frequenza d'uso della perifrasi "naš jezik" (nostra lingua) aumenta, in concomitanza con la formazione dei quattro standard nazionali, probabilmente proprio in conseguenza della sua acquisizione di nuove funzioni (cfr. sempre Gröschel 2009, Busch 2004: 55, Bugarski 2004). In aggiunta a "nostra lingua", altre espressioni ambigue sono inoltre introdotte in questi anni per riferirsi ai codici di recente formazione. Tali denominazioni sono adoperate anche in ambiti istituzionali. Ad esempio, a scuola in Montenegro si insegna dal 2004 "lingua materna e letteratura". Questa circonlocuzione può essere sostituita dagli alunni con un glottonimo a scelta tra "bosniaco/bosgnacco", "croato", "montenegrino" o "serbo" sulla pagella a fine dell'anno scolastico (cfr. anche § II.3.5.3).

Come avvenuto nei paesi successori alla Jugoslavia, l'adozione strategica di designazioni generiche per chiamare le lingue non è un fenomeno inconsueto in situazioni di "schizoglossia" (cfr. Goebl 1979). A questo riguardo, lo studioso rileva, per esempio, la presenza di diverse circonlocuzioni - come "madrelingua", "lingua locale", da un lato, o "dialetto", dall'altro - per riferirsi in modo neutrale rispettivamente al "catalano" e all'"alsaziano" nella lingua scritta e parlata in diversi periodi storici (cfr. ibidem: 14 e 24). L'impiego di queste designazioni si spiega verosimilmente come una "strategia di evitamento" (Vermeidungsstrategie), dovuta alla formazione di tabù riguardo a uno o a più glottonimi tra loro concorrenti, vale a dire, tra gli altri, rispettivamente "valenziano" e "tedesco d'Alsazia". Denominazioni eufemistiche analoghe - tra cui "madrelingua", "lingua dello stato", "lingua del popolo", "nostra lingua" - sono adoperate anche in Moldavia. Secondo Condrea (2007), i parlanti si servono di tali perifrasi negli anni novanta per opporsi al nome ufficiale "lingua moldava". Attualmente, la loro adozione indica piuttosto la volontà dei locutori di astenersi dal prendere posizione sulla questione dei glottonimi e, quindi, dallo scegliere tra due denominazioni rivali, ossia "moldavo" e "rumeno". Similmente, anche il glottonimo "Landsmaal" (successivamente "Landsmål"), diffuso all'inizio del '900 in Norvegia, può essere utilizzato in modo volutamente ambiguo dai parlanti (cfr. Haugen 1966: 34). L'apposizione "land" può infatti qualificare la "lingua" ( $m a ̊ l)$ come varietà rurale/di campagna o come lingua del paese/della nazione. Infine, la frequente sostituzione della designazione specifica "Deutsche Unterrichtssprache" (lingua di insegnamento tedesca) con il nome generico "Unterrichtssprache" (lingua di insegnamento) nei programmi scolastici austriaci tra il 1945/46 e il 1951/52 è parallela e in parte motivata, secondo Goebl (1979: 23), dalla discussione sulla legittimità di una "nazione" austriaca in contrapposizione a quella tedesca dopo il nazionalsocialismo.

Analogamente a quanto appena illustrato per altre comunità linguistiche, i quasi-glottonimi, usati per chiamare i codici parlati nei paesi successori alla Jugoslavia nelle interviste raccolte, possono veicolare una molteplicità di significati. Questa polivalenza è confermata esplicitamente dalle dichiarazioni di alcuni informanti. Al termine di certi colloqui o di conversazioni non registrate, ho infatti chiesto ai partecipanti perché abbiano utilizzato un glottonimo invece di un altro o perché loro stessi o altre persone si siano serviti di denominazioni diverse e, talvolta, generiche per chiamare una varietà linguistica specifica. 
Alcuni intervistati non erano consapevoli di aver utilizzato denominazioni particolari nel corso delle interazioni. Così, per esempio, LP dichiara di non essersi accorta di aver ripetutamente adoperato l'espressione "in lingua" per riferirsi all'“albanese". Secondo le riflessioni della donna e delle sue sorelle parimenti interrogate, la designazione generica pare perciò essere un modo fossilizzato nell'idioletto della partecipante per chiamare il codice di partenza in determinate situazioni comunicative. LP afferma infatti di usarla inavvertitamente probabilmente solo con persone che, conoscendo la sua biografia linguistica, non possono equivocare a quale codice si stia riferendo.

Per quanto riguarda le varietà a base neoštokava, alcuni intervistati - che però non se ne servono personalmente - riconducono l'uso della circonlocuzione "nostra lingua" a variabili sociolinguistiche, come il basso livello di istruzione, l'origine contadina e/o l'età del locutore. Al contrario, altri partecipanti motivano l'impiego proprio o altrui di quasi-glottonimi, riferendosi al contesto micro e macro in cui l'interazione si svolge. Così, secondo AF, "nostra lingua" è un modo di dire "diplomatico" da lei adoperato al posto di "serbocroato" nel comunicare con persone provenienti da altri paesi successori alla Jugoslavia. In modo parzialmente analogo, questa perifrasi è usata, nell'ottica di DV, in prevenzione di conflitto e/o per gentilezza tra parlanti di diverse nazionalità, ma originari dell'area balcanica ${ }^{35}$ Il suo impiego potrebbe risalire per l'intervistato all'epoca della Repubblica Socialista Federale di Jugoslavia (SFRJ) con il significato di "lingua comune", "lingua del popolo". Infine, KM si serve della perifrasi "nostra lingua" nel corso del colloquio. Nelle sequenze finali di questo, la definisce come un modo di dire adoperato solo dalle generazioni più anziane per riferirsi alla varietà linguistica ufficiale (ossia il "serbocroato") e alla situazione socio-linguistica e politico-amministrativa di prima del conflitto (per una discussione più dettagliata di quest'ultima intervista cfr. §IV.3.4).

\subsubsection{La "madrelingua”}

L'uso dell'espressione "madrelingua" da parte di alcuni partecipanti del corpus merita una serie di osservazioni a parte. Nelle interviste raccolte, il termine è infatti talvolta adoperato come nome di lingua specifico, talvolta mantiene solo alcuni dei suoi significati lessicali, talvolta ne acquisisce di nuovi. Per spiegare queste variazioni, è utile ricordare che il concetto di "madrelingua" assume accezioni diverse, oltre che diacronicamente, anche a seconda di spazi sociolinguistici differenti.

In particolare, secondo Goebl (1986), il significato centrale di "Muttersprache" in tedesco è prevalentemente quello di lingua biologica, propria di un individuo specifico, in quanto insegnata dalla madre (cfr. anche Berić 1986). Invece, nelle lingue romanze spesso prevale, secondo il ricercatore, un senso del termine che enfatizza il rapporto tra il parlante e il territorio nativo. In alcuni contesti, la "madrelingua" è

35 Coerentemente con questa definizione, sia AF, sia DV non si servono del quasi-glottonimo "nostra lingua" nelle interviste raccolte. Piuttosto, AF utilizza durante il colloquio espressioni generiche e glottonimi specifici in funzione enfatica (cfr. § IV.3.3 per maggiori dettagli). 
inoltre definita come "la lingua imparata per prima" o "meglio conosciuta". Tuttavia, questa definizione non vale sempre da un punto di vista emico. Ciò risulta, per esempio, evidente dalle dichiarazioni di parlanti di codici con un prestigio non riconosciuto in contesti plurilingui e/o migratori. In questi casi, i parlanti tendono infatti a non attribuire al dialetto o alla varietà alloglotta da loro usata in famiglia - e quindi letteralmente alla "lingua parlata con la madre" - la qualifica di "lingua madre". Quest'ultima designazione è infatti adoperata esclusivamente per il codice standard o ufficiale. In particolare, il verificarsi di questo disaccordo è interpretato da Iannàccaro \& Dell'Aquila (2002) come un "indice di dialettalità percepita", ossia come un segnale della scarsa autonomia conferita da un parlante a una varietà linguistica rispetto a un'altra e, dunque, di un suo status relativamente basso nel repertorio (cfr. anche Dell'Aquila \& Iannàccaro 2006, Condrea 2007, Dal Negro 2011). A queste accezioni, si aggiunge infine che le varietà linguistiche, identificate da un locutore come lingua materna, possono essere più di una e/o mutare nel corso della vita di una persona o anche a seconda degli interlocutori (cfr. Romaine 1989: 22, Pavlinić-Wolf 1986: 175). Uno dei motivi è che i parlanti adoperano talvolta la nozione di "madrelingua" per esprimere affiliazione a una determinata comunità linguistica o gruppo di locutori. Ciò avviene indipendentemente dal fatto che padroneggino più o meno bene il codice in questione (cfr. sempre Romaine 1989: 18-22 e Tabouret-Keller 1997b). Questo ultimo significato di madrelingua come "lingua della comunità di (cui si vuole ribadire la) appartenenza" è spesso quello primario nell'uso di un gruppo di partecipanti del corpus. Questi intervistati si servono del termine "madrelingua" in funzione prevalentemente enfatica (cfr. § IV.3.3 per maggiori dettagli).

In conseguenza delle connotazioni appena delineate, il concetto di "madrelingua" non è adoperato nel presente lavoro con una valenza scientifica (cfr. anche Lüdi \& Py 1986/2003: 44-47 per una critica al termine). Tuttavia, proprio per le sue implicazioni ideologiche, l'esame di quali codici siano qualificati e, soprattutto, non siano qualificati come lingue materne dai partecipanti è molto rilevante per l'analisi esposta in questa sezione del capitolo IV. Infatti, permette di valutare lo status e il prestigio riconosciuto (o non riconosciuto) alle varietà linguistiche e alle comunità dei loro locutori a livello individuale e comunitario. Come sarà discusso più dettagliatamente nel prossimo paragrafo, 1" "illegittimità" o, meglio, il grado di "(de)legittimazione" di un codice e delle proprie competenze in questo mi sembra essere uno dei fattori a livello macro che concorre nel determinare l'adozione di quasi-glottonimi e nel plasmare le funzioni da questi assolte a livello micro nelle interviste raccolte.

\subsubsection{Le funzioni dei quasi-glottonimi nel corpus}

Dalla discussione dei paragrafi precedenti emergono diversi criteri per identificare i quasi-glottonimi e descriverne la funzione in una specifica interazione e/o da parte di una comunità linguistica. Nello specifico, nelle biografie linguistiche raccolte, una chiave per interpretarne l'uso è quella di metterli in relazione con le prese di posizione dei partecipanti rispetto al mantenimento e sostituzione di lingua propria e altrui in contesto migratorio. Questa operazione permette di individuare (almeno) 
tre possibili ragioni di utilizzo di quasi-glottonimi in interazione: queste sono la funzione "elusiva", "enfatica" e "oppositiva". A loro volta, tali funzioni sono strettamente interconnesse con il macro-contesto in cui si svolge l'interazione. Infatti, sono correlate a come i partecipanti si posizionano rispetto all'"illegittimità", intesa come mancato o basso riconoscimento, del codice così menzionato e/o delle proprie competenze in tale varietà linguistica da parte delle comunità di partenza e/o di arrivo. In questo senso, i quasi-glottonimi sono indicatori, nelle conversazioni raccolte, dello status e del prestigio di una lingua e/o dei suoi parlanti per i singoli e per le comunità in cui hanno vissuto. ${ }^{36}$

In particolare, alcuni partecipanti adoperano, nel corso dei colloqui, quasi-glottonimi in funzione "elusiva", vale a dire se ne servono come circonlocuzioni per evitare di dire il nome specifico del codice così riferito. Questi intervistati dichiarano inoltre di non usare tale varietà linguistica in famiglia e/o di averla completamente sostituita dopo l'esperienza di mobilità. La causa, espressa o lasciata implicita, è solitamente la vergogna. Infatti, le competenze e l'uso del codice in questione sono tabuizzate in quanto associate non solo da parlanti alloglotti, ma anche dai suoi stessi locutori a caratteristiche identitarie, sociali o etnico-nazionali, stigmatizzate e con cui non ci si vuole identificare.

In altre biografie linguistiche, l'impiego di espressioni generiche come nomi specifici ricopre invece una funzione "enfatica". La loro adozione mira infatti ad istituire un forte legame verso la varietà linguistica così menzionata. In questi casi, il referente della designazione generica non è necessariamente ambiguo per l'interlocutrice, mentre i narratori ribadiscono, durante la conversazione, il mantenimento di tale codice in contesto migratorio nonostante il rischio di una sua sostituzione per dimenticanza. Nel fare ciò, gli intervistati esprimono più o meno esplicitamente affiliazione al gruppo dei parlanti della varietà linguistica in questione. Il bisogno di prendere questa posizione può essere determinato da motivi prettamente interazionali: i narratori sentono le proprie competenze e la propria identità di parlanti del codice di partenza messa in discussione specificamente nella situazione "intervista". In aggiunta o in alternativa, può essere condizionato dal contesto macro più ampio: gli intervistati hanno esperito una tale delegittimazione da membri della comunità linguistica d'origine o d'arrivo.

Infine, sulla base dei dati raccolti si può identificare una terza funzione dei nomi di lingua generici come glottonimi specifici in interazione. Tale funzione, che definisco "oppositiva", è data da una combinazione di tratti caratteristici delle prime due. Alcuni partecipanti si servono infatti di apposizioni generiche in modo strategicamente ambiguo, ossia con il fine elusivo di non menzionare il nome specifico della varietà linguistica di cui stanno parlando. Nello stesso tempo, ribadiscono però enfaticamente nel corso del colloquio il mantenimento di tale codice in contesto migratorio e la sua posizione centrale nel proprio repertorio. In queste interviste, i narratori adottano quindi i quasi-glottonimi, da un lato, per posizionarsi contro (alcuni) nomi

36 Sul concetto di "legittimità" di lingue e parlanti si confrontino i già citati Bourdieu (1982/2005: 49-55) e Busch (2012). Sull'interrelazione tra il prestigio assegnato a un codice e il suo mantenimento/sostituzione si veda Edwards (1996). 
di lingua introdotti recentemente per i codici di partenza e, in connessione con ciò, contro (alcuni) interventi di pianificazione linguistica nei paesi di provenienza. Dall'altro lato, si oppongono, tramite l'uso di queste denominazioni, a processi di sostituzione di codice per vergogna o per dimenticanza di cittadini conterranei dopo migrazione in un paese straniero. Come risultato, gli intervistati del terzo gruppo si affiliano a una comunità linguistica non più riconosciuta a livello ufficiale.

La tabella in 5 ripropone lo schema riportato in 4 con alcune modifiche. $\mathrm{La}$ suddivisione dei potenziali quasi-glottonimi per righe rimane quella per intervalli di frequenza. Inoltre, le parentesi quadre e tonde indicano rispettivamente un impiego di espressioni generiche esclusivamente in posizione non isolata o semi-isolata nel discorso. Per converso, la mancanza di parentesi segnala l'uso di quasi-glottonimi anche in posizione isolata da parte dei partecipanti. I potenziali quasi-glottonimi sono poi ripartiti per colonne a seconda della funzione da loro svolta nelle interviste del corpus. Nell'ultima riga della tabella in 5, sono riportati infine (il tipo di) glottonimi usati con una determinata funzione: i numeri tra parentesi indicano quanti intervistati fanno uso di ogni designazione per gruppo. ${ }^{37}$ Sia qui notato che, da un lato, un narratore può servirsi, nel corso del colloquio, di denominazioni generiche differenti con una stessa funzione (es. "nostra lingua" e "mia lingua" nel caso di $\mathrm{OV})$. Dall'altro lato, uno stesso parlante può comparire in più di una casella se fa uso di denominazioni generiche con funzioni diverse. Questi ultimi sono i casi di i) AF che si serve di "madrelingua" in funzione enfatica e di "in lingua" in modo fossilizzato e di ii) DR che usa "nostra lingua" talvolta in funzione oppositiva, talvolta in modo fossilizzato (cfr. i paragrafi successivi per maggiori dettagli).

Tabella 5: Frequenza, posizione, funzione e tipo dei potenziali quasi-glottonimi nelle interviste del corpus.

\begin{tabular}{|c|c|c|c|c|}
\hline & $\begin{array}{c}\text { Funzione } \\
\text { elusiva }\end{array}$ & $\begin{array}{l}\text { Funzione enfatica } \\
\text { (contesto micro } \\
\text { o macro) }\end{array}$ & $\begin{array}{c}\text { Funzione } \\
\text { oppositiva }\end{array}$ & $\begin{array}{c}\text { Uso } \\
\text { fossilizzato }\end{array}$ \\
\hline$<20 \%$ & $\begin{array}{l}{[\mathrm{IP}]} \\
(\mathrm{RM})\end{array}$ & $\begin{array}{l}\text { [AF (madrelingua)], } \\
{[\mathrm{DL}],[\mathrm{SP}],[\mathrm{VM}]} \\
(\mathrm{AS}),(\mathrm{XF}),(\mathrm{YF}),(\mathrm{ZT}) \\
\text { AC, FR, TF }\end{array}$ & SV & $\begin{array}{l}\text { [AF (in lingua) }] \\
\text { LP }\end{array}$ \\
\hline $20 \%-40 \%$ & & $\begin{array}{l}\text { (ML), (NJ) } \\
\text { NM }\end{array}$ & BV, LA & DB, RX \\
\hline $40 \%-60 \%$ & & & $\mathrm{JB}, \mathrm{KM}, \mathrm{PB}$ & \\
\hline $60 \%-80 \%$ & & BL, OV & DR, KS & DR \\
\hline $\begin{array}{l}\text { Tipo di } \\
\text { denominazione } \\
\text { generica }\end{array}$ & $\begin{array}{l}- \text { nostra lingua/ } \\
\text { lingua nostra } \\
(2) \\
- \text { mia lingua (1) }\end{array}$ & $\begin{array}{l}- \text { mia lingua }(10) \\
- \text { nostra lingua }(8) \\
- \text { madrelingua/lingua } \\
\text { materna }(7) \\
- \text { lingua colloquiale/ } \\
\text { privata }(1)\end{array}$ & $\begin{array}{l}\text { - nostra lingua (6) } \\
\text { - madrelingua (4) } \\
\text { - mia lingua (3) } \\
\text { - lingua di casa }(1)\end{array}$ & $\begin{array}{l}\text { - in lingua (2) } \\
\text { - questa lingua/ } \\
\quad \text { questo (1) } \\
- \text { nostra lingua (2) }\end{array}$ \\
\hline
\end{tabular}

37 Per semplicità tutte le designazioni sono tradotte in italiano. Nei prossimi paragrafi, saranno comunque, di volta in volta, riportate anche le denominazioni in tedesco o in inglese. 
Date le osservazioni in questo e nei paragrafi precedenti, solo le espressioni usate strategicamente dai partecipanti - ossia in funzione elusiva, enfatica o oppositiva fungono propriamente da quasi-glottonimi nelle interazioni raccolte (tra questi, si possono poi distinguere diversi stadi di sviluppo da nomi specifici a generici in relazione al variare degli altri due parametri, frequenza e posizione). Non fanno invece parte di questa categoria quelle perifrasi generiche che sono adoperate in modo "fossilizzato" dagli intervistati (cfr. l'ultima colonna della tabella 5). Con ciò mi riferisco a quelle circonlocuzioni che non hanno una specifica funzione in interazione, ma il cui uso si spiega piuttosto come un tratto idiosincratico dell'interlingua del parlante, dovuto, per esempio, a un calco inconsapevole dalla L1 o all'imitazione involontaria dell'uso di denominazioni da parte di altri locutori.

L'individuazione delle funzioni dei quasi-glottonimi nelle interviste raccolte non è sempre facile. In connessione con ciò, lo schema in 5 si basa su una serie di scelte di codifica che sono necessariamente legate alla mia interpretazione dei dati e che potrebbero non essere condivise da altri analisti. Nei prossimi paragrafi, motivo la tassonomia da me proposta, illustrando le tre funzioni svolte dai quasi-glottonimi nelle biografie linguistiche del corpus e i modi di rapportarsi ai codici d'origine, con cui queste, a mio avviso, co-occorrono. Speciale riguardo sarà posto anche alla discussione di alcuni casi dubbi, come, per esempio, quelli di DB, AF o DR. L'analisi esposta è sia formale sia contenutistica. Oltre ad esaminare sequenze di occorrenza di perifrasi generiche, discuto infatti anche alcuni brani in cui i narratori motivano atti di posizionamento, propri o altrui, nei confronti delle varietà linguistiche di partenza e del loro mantenimento o sostituzione dopo mobilità.

\subsection{Funzione elusiva e vergogna}

Un uso dell'espressione "nostra lingua" in funzione elusiva si riscontra nelle interviste con IP e RM. Entrambi i partecipanti provengono da due cittadine a maggioranza albanofona, situate rispettivamente in Rep. di Macedonia e in Montenegro. I due intervistati adoperano le espressioni "nostra lingua" o "mia lingua" raramente nel corso dell'intervista $(<20 \%)$ e solo in posizione non isolata o semi-isolata nel discorso (cfr. tabella 5 al $\S$ IV.3.1.4). Tuttavia, l'impiego di queste perifrasi è strategico nel corso di questi colloqui: il loro uso consente, infatti, ai narratori di non prendere una posizione univoca sulle varietà linguistiche da loro parlate in determinati domini. Da ciò segue che la rappresentazione dei rapporti tra codici nei repertori individuali degli intervistati risulti, per gran parte della conversazione, ambigua per l'interlocutrice. La funzione elusiva delle perifrasi si riconosce esclusivamente a posteriori. In altre parole, emerge solo dopo che i partecipanti hanno rinegoziato la posizione del codice di partenza e l'affiliazione alla comunità linguistica dei suoi locutori, nel caso di IP, al termine dell'intervista e, in quello di RM, durante un secondo colloquio. ${ }^{38}$

38 La biografia linguistica di RM è stata già approfonditamente analizzata nel precedente § IV.2.4 e non sarà, dunque, ulteriormente trattata in questo paragrafo. 
IP è un uomo di 54-55 anni, nato in Rep. di Macedonia - allora parte della Federazione Socialista Jugoslava - e trasferitosi in Italia nel 1986-1987. Come già accennato al § IV.1.4, nell'incipit della sua intervista, IP enumera i codici d'origine, "jugoslavo", "macedone" e "albanese", in un ordine che da dichiarazioni successive risulta non essere quello di acquisizione. In seguito, rispondendo nel brano in 22 a una domanda della ricercatrice sulle varietà linguistiche parlate attualmente in famiglia, il narratore le chiama inizialmente "la nostra lingua normale". Questa perifrasi, usata al singolare, è esplicata subito dopo, alle righe 5-6, tramite due glottonimi specifici. Non è però chiaro se tale designazione si riferisca al "macedone", all'"albanese" o, eventualmente, a un codice misto tra i due. Si noti inoltre che, tramite l'aggettivo "normale", IP sembra voler ribadire che il proprio comportamento linguistico è simile a quello di altri parlanti nella comunità plurilingue d'origine (cfr. Iannàccaro \& Dell'Aquila 2007: 20 per usi analoghi del termine). Nonostante sia rappresentato come quello comunemente adoperato in ambito familiare nella comunità linguistica d'origine, il codice non è tuttavia specificato in modo univoco nel brano in 22.

(es. 22)

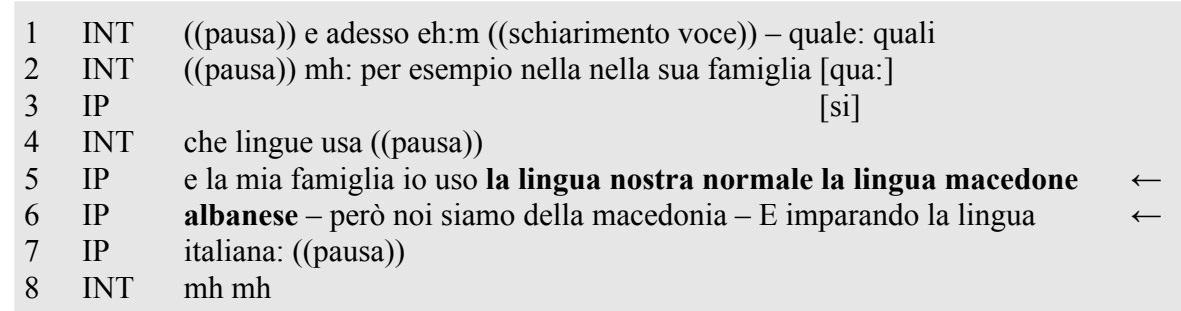

(IP_Mac_Mer, 03:07-03:27)

Durante il colloquio, l'intervistato menziona 1'“albanese" sempre in concomitanza con il codice "macedone". Entrambe le varietà linguistiche sono rappresentate senza esitazioni e ambiguità come lingue sia veicolari a scuola, sia di fruizione dei programmi televisivi, sia di comunicazione al lavoro nella località d'origine. Similmente a quanto fa RM nella sua intervista, IP sotto-specifica, dunque, al momento di raccontare la propria biografia linguistica, specificatamente i rapporti tra codici da lui usati nel dominio familiare. La rappresentazione dell'alternanza tra "albanese" e "macedone" in altri ambiti comunicativi è invece meno problematica per il partecipante.

La funzione elusiva dell'espressione "nostra lingua" emerge in special modo se si considera il brano in 23. In questa sequenza, tratta dalla fine del colloquio, il codice riferito dalla circonlocuzione "lingua nostra" è ambiguo. Ciò permette al partecipante di suggerire all'intervistatrice una configurazione del proprio repertorio di partenza senza impegnarsi irrevocabilmente con questa. 
(es. 23)

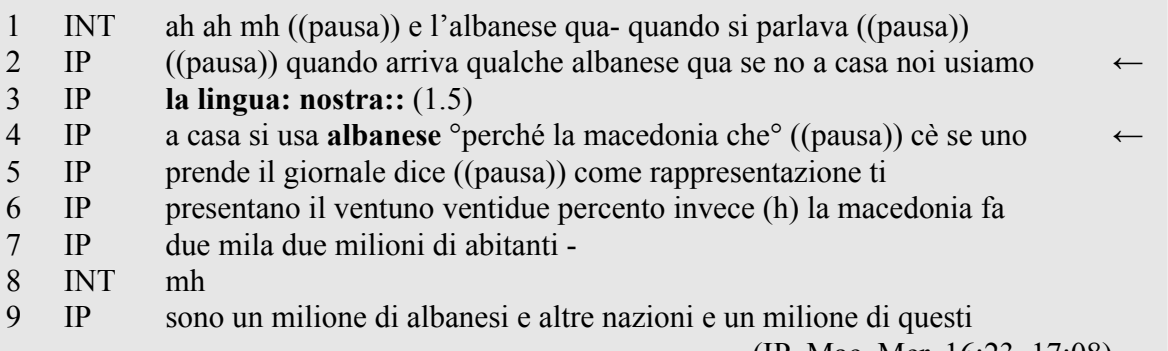

(IP_Mac_Mer, 16:23-17:08)

In particolare, all'inizio della sequenza in 23 , il parlante presenta 1'“albanese" come la lingua dell'accomodazione in situazioni presumibilmente semi-pubbliche: si parla tale codice "quando arriva qualche albanese". L'impiego del connettivo "se no" alla riga 2 implica convenzionalmente che l'intervistato si servisse, invece, solitamente di un altro codice, denominato appunto "la lingua: nostra::", per la comunicazione in famiglia. Tuttavia, dopo una pausa, IP ridefinisce l' "albanese" come l'unica varietà linguistica parlata a casa. Grazie all'ambiguità della perifrasi "lingua nostra", l'intervistato può riparare, alla riga 4, l'implicatura dell'enunciato precedente ("se no a casa noi usiamo la lingua: nostra::") senza contraddirsi e perdere la faccia. Si noti che la rinegoziazione della posizione del codice nel proprio repertorio è portata a termine dal narratore in un unico turno di parola.

Inoltre, è interessante che la presa di posizione sui codici parlati in famiglia sia seguita, nel brano in 23 , da un atto di posizionamento del narratore su una questione controversa nel paese d'origine, ovvero sulla consistenza demografica della popolazione albanofona in Rep. di Macedonia (cfr. righe 4-9 e il § II.3.4.5 per dettagli su questo tema). Ciò suggerisce che queste questioni siano, almeno in parte, correlate nella prospettiva dell'intervistato. In altre parole, fa ipotizzare che le ragioni per cui IP inizialmente sminuisca il ruolo dell'albanese nel proprio repertorio individuale siano connesse con lo status e il prestigio che il codice ha nel repertorio comunitario di partenza. Così, l'adozione del quasi-glottonimo "lingua nostra" in funzione elusiva si spiegherebbe con il fatto che la lingua prima dei parlanti albanofoni in Rep. di Macedonia sia "delegittimata" - vale a dire sia associata a caratteristiche stigmatizzate - a livello collettivo, almeno nella rappresentazione dell'intervistato. Il basso valore, per lo meno strumentale, del codice di partenza emerge, del resto, anche da una sequenza successiva del colloquio. In questo brano, IP contrappone la varietà di albanese da lui conosciuta, ossia quella parlata in Rep. di Macedonia, alla "lingua proprio pr=fessionale", usata in Albania e in Kosovo (minuti 18:4419:09). ${ }^{39}$ Si noti che la delegittimazione del codice d'origine ha effetto, nel caso di IP, anche dopo il trasferimento in spazi sociolinguistici diversi e a molti anni di di-

39 Per rappresentazioni diverse (dello status) dell'albanese in Kosovo versus in Albania - portate parimenti a termine tramite l'uso quasi-glottonimi, ma in funzione "enfatica" - si veda il § IV.3.3. 
stanza (si ricordi infatti che il partecipante emigra in Italia già nel 1986-87 e soggiorna in Abruzzo, Trentino, Lombardia, prima di arrivare in Alto Adige).

Ad eccezione di IP e RM, nessun altro partecipante del corpus fa uso di quasi-glottonimi in funzione elusiva nella sua intervista. ${ }^{40}$ Tuttavia, nelle biografie linguistiche raccolte, si riscontrano anche altre strategie per marginalizzare la posizione di un codice nel proprio repertorio. Tra queste ci sono la sua menzione al termine di un lungo elenco di lingue conosciute e/o l'adozione di forme verbali impersonali per descriverne l'apprendimento o l'uso. Così, ad esempio, all'inizio della sua intervista, SM menziona 1"“albanese" come quinto codice, di cui ha qualche competenza. Nel fare ciò, il ragazzo - che è figlio di RM e che, quindi, è parimenti originario di una città a maggioranza albanofona in Montenegro - sembra suggerire che tale varietà linguistica occupi una posizione piuttosto marginale nel proprio repertorio. Solo successivamente, l'intervistato la indicherà come uno dei codici prevalentemente usati in famiglia, pur assegnandoli occasionalmente l'apposizione di "lingua straniera" (cfr. il $\S$ IV.2.4 per un esame più approfondito di questo colloquio). Strategie di marginalizzazione analoghe sono individuate anche da Migge \& Léglise (2013) nelle interviste con bambini che parlano varietà stigmatizzate nello spazio sociolinguistico della Guyana francese. Invece, forme verbali impersonali sono usate, tra gli altri, da DL nel motivare l'apprendimento del "rumeno" nella località di nascita in Voivodína. La marginalità di questo codice nel repertorio emico del partecipante emerge anche dalle dichiarazioni sugli usi linguistici in famiglia dopo mobilità: il rumeno è infatti rappresentato come una lingua quasi completamente sostituita in Alto Adige. Al contrario, DL adopera talvolta denominazioni enfatiche per chiamare l'altro codice di partenza, ossia il "serbo", nell'incipit così come nel corso del suo colloquio (cfr., su questo ultimo punto, già il precedente § IV.1.3.2 e il successivo § IV.3.3).

Il basso status e prestigio di un codice nel paese d'origine possono dunque portare un parlante ad occultare le proprie competenze in questo e hanno un influsso sulla sua volontà di mantenerlo prima e, soprattutto, dopo un'esperienza migratoria. Tale fatto è confermato anche dai racconti di altri partecipanti del corpus. È il caso per esempio di DB, una donna di 42 anni, nata in un paese a maggioranza rumenofona nella Serbia centro-orientale e trasferitasi in Alto Adige nel 2004. Come già illustrato, l'intervistata qualifica nell'incipit della sua biografia linguistica "serbo" e "rumeno" come entrambe lingue materne (cfr. § IV.1.4.3). Nel corso dell'intervista, la partecipante alterna poi glottonimi diversi per riferirsi sia all'uno, sia all'altro codice. Tali denominazioni variano prevalentemente in relazione alla situazione comunicativa descritta e al tipo di interlocutori. Il glottonimo "serbocroato" è infatti adoperato al posto di "serbo" per chiamare specificamente la lingua appresa a scuola nella località di partenza. D'altro canto, DB definisce "rumeno" il codice parlato al lavoro, in particolare, con colleghe originarie della Romania nel paese d'origine così

40 A riguardo di IP e RM, sia qui menzionato che il loro uso di quasi-glottonimi in funzione elusiva potrebbe essere in parte determinato anche dai modi in cui sono stati contattati da parte della ricercatrice. Infatti, questi due intervistati sono gli unici due del corpus ad essere interpellati direttamente sul posto di lavoro senza previa presentazione da parte di amici o conoscenti e/o senza essere informati della ricerca via e-mail o in incontri precedenti (cfr. § III.1.1). 
come la lingua franca usata, per esempio, per comunicare con i compagni al corso di tedesco in Alto Adige. All'opposto, la varietà linguistica parlata in famiglia o con gli amici locali è denominata "vlaschi" o "questo"/"questa lingua". La distribuzione, appena delineata, del glottonimo "vlaschi" e "rumeno" è coerente con la qualifica del primo codice come "dialetto" del secondo. Tuttavia, è interessante da un punto di vista storico. Infatti, il termine "vlaschi", usato da DB per chiamare la lingua di comunicazione in ambiti privati, è originariamente un esonimo (cfr. Arvinte 2003). Invece "rumeno" (român) costituisce in principio l'endonimo.

Tornando alla questione dei quasi-glottonimi, l'intervistata si serve della denominazione generica "questo"/“questa lingua" con una frequenza medio-bassa durante il colloquio ( 5 occorrenze su un totale di 21 , ossia $20 \%-40 \%$ ). Talvolta, la usa però in posizione isolata nel discorso. Un esempio è l'enunciato "questo si parlava solo in casa o tra i (h) così:: tra gli amici" (minuti 09:53-10:06): il nome specifico "vlaschi" occorre infatti ben quattro minuti prima nella registrazione, a distanza di più turni di parola. Nonostante possa essere usata in autonomia, l'espressione "questa lingua" non funge però, a mio avviso, propriamente da quasi-glottonimo nell'intervista con DB. La perifrasi non svolge infatti una particolare funzione in interazione. Da un lato, la partecipante non la usa in modo elusivo dal momento che il codice così riferito non è mai ambiguo per l'interlocutrice. Dall'altro lato, adottando una denominazione dalla connotazione neutrale, la narratrice non istituisce un rapporto privilegiato a livello emozionale-identitario con la varietà linguistica in questione: la circonlocuzione non ha così valore né enfatico né oppositivo. Piuttosto il suo impiego mi sembra potersi spiegare come un tratto idiosincratico dell'interlingua dell'intervistata e costituire così probabilmente un caso di fossilizzazione (cfr. tabella 5 al $\S$ IV.3.1.4).

Il brano in 24 offre un esempio dell'uso dell'espressione "questa lingua" da parte di DB in posizione semi-isolata nel discorso. Il glottonimo "vlaschi" è infatti menzionato solo nel turno di parola precedente alla domanda della ricercatrice (cfr. righe 3-4). Nella sequenza, l'intervistata tematizza inoltre la vergogna di alcuni parlanti di rivelare competenze nel codice in questione e la loro resistenza a caratterizzarlo come proprio. Dopo essersi distanziata da questo comportamento (righe 20-21), DB ipotizza che tale vergogna derivi dalla mancata standardizzazione del codice d'origine (righe 23-26).

Nel brano in 24, DB si riferisce anche all'assunzione, rappresentata come diffusa nel paese di provenienza e da lei stessa in parte condivisa, che esista un nesso tra le competenze in "questa lingua" e la zona di nascita/provenienza del parlante (cfr. righe 16-17 e 20-21). Le conseguenze di tale associazione sono illustrate dalla donna in altre sequenze dell'intervista. Nello specifico, secondo la partecipante, conoscenze in "vlaschi" e una conseguente pronuncia peculiare, non facilmente occultabile, nel parlare "serbo" hanno effetti negativi sulla rappresentazione che un parlante dà di sé in interazione, per lo meno nel paese di provenienza. Attraverso un processo conforme a quello descritto da Irvine \& Gal (2000) come "iconicizzazione", gli interlocutori istituiscono infatti una correlazione tra i) queste caratteristiche linguistiche, ii) la provenienza da "quei luoghi di montagna" e iii) la bassa istruzione o classe sociale del locutore (minuti 10:06-10:57). Dalle dichiarazioni di 
1 DB non abbiamo nessun nessuna grammatica poi abbiamo anche (h) e: come

2 DB si dice le parole che le prendiamo dalle:: ((pausa)) dal serbo per

3 DB usarli che fo- - quelle parole che MANcano nella lingua:: questa

4 DB vla- e vlasca

5 INT vlasca ah ah okay

6 DB si si si si

7 INT e si parla solo in: in: in serbia ((pausa)) o

8 DB di quello che ho sentito ci sono alcuni paesi ((pausa)) mh: adesso

9 DB forse mi sbaglio verso la bosnia (h) - poi ci sono:: - in qualche

10 DB zona di machedonia ((pausa)) macedonia ((pausa)) e: in voivodina

11 DB peró - non e:: ((pausa)) non sono stata da quelle parti quello é

12 DB solo che ho sentito cosí perché non

13 DB ((pausa)) c'è la gente ((pausa)) ch- che volentieri parla questa

14 DB lingua anche qua come capita alcuni (h) invece altri che si

15 DB vergognano o parlan- dicono che non non conoscono que- che non: non

16 DB lo sanno invece lo sanno >che vengono da quelle zone è impossibile

17 DB che non $<[(\mathrm{h})$ pe]rò questo è: anche dalle persone dipende come:

18 INT [mh mh]

19 INT $\mathrm{mh} \mathrm{mh}$

20 DB ((pausa)) sono: >io non posso dire che non lo conosco perché lo

21 DB conosco sono nata lì in quella zona: $<$ quindi non ((riso))

22 INT ma e perché uno perché si mh:: uno si vergogna

23 DB

24 DB

25 DB

26 DB

27 INT ((pausa)) e: non lo so questo ((sorriso)) [9 sec. omessi] perchforse perché non non c'è la non c'è:: e non ci sono le lettere non ci sono:: come si dice non c'è niente in quello forse per quello non so $\mathrm{mh} \mathrm{mh}$

(DB_Ser_Bru, 12:00-13:36)

DB risulta, dunque, che alcuni parlanti nascondano le proprie competenze in "vlaschi" in conseguenza del suo status di "lingua illegittima" nelle rappresentazioni metalinguistiche non solo eso-, ma anche endocomunitarie, ossia non solo nelle rappresentazioni di parlanti alloglotti, ma anche della comunità dei suoi stessi locutori. ${ }^{41}$ In modo analogo a quanto raccontato da DB per i parlanti di "vlaschi", un mancato o controverso riconoscimento dello status dell'albanese nelle località d'origine di IP e RM può essere quindi la causa della loro adozione di quasi-glottonimi in funzione elusiva durante le biografie linguistiche raccolte per la presente ricerca.

Infine, si noti che la delegittimazione di un codice non deve per forza avvenire nel paese d'origine, ma può anche essere successiva all'esperienza di mobilità in un paese straniero. In questi casi, una varietà linguistica "legittima", ossia con uno status e prestigio riconosciuto nell'area sociolinguistica di partenza, perde tale riconosci-

41 Si confronti a questo riguardo anche il già citato lavoro di Busch (2006: 16). Secondo la studiosa, la popolazione di lingua "valacca" (qui "vlaschi"), trasferitasi a Vienna, dichiara frequentemente di parlare solamente il serbo in famiglia. Ciò è, per la ricercatrice, probabilmente una conseguenza della bassa standardizzazione e dello scarso prestigio del codice nello spazio sociolinguistico della ex-Jugoslavia. 
mento, agli occhi dei suoi stessi parlanti, nel nuovo contesto di residenza. Tale fenomeno è testimoniato tra l'altro dall'esperienza di TF, una donna di 49 anni, nata a Belgrado e trasferitasi prima a Roma nel 1994 e poi in una valle in provincia di Bolzano nel 2002. Nel corso della sua intervista, TF rivela di aver voluto mascherare le proprie competenze in "serbocroato"/"serbo" e, in questo modo, il proprio paese di provenienza durante i primi anni di soggiorno in Italia. In particolare, la partecipante racconta di aver deciso di sostituire completamente il "serbo" con 1" "italiano" per comunicare in famiglia in modo da non far riconoscere se stessa e la figlia come straniere e, nello specifico, serbofone. Infatti, tale identità è rappresentata dalla donna come particolarmente stigmatizzata all'estero negli anni novanta: "erano anni molto difficili in cui insomma farsi riconoscere serbo: insomma era una cosa molto molto negativa" (minuti 08:05-08:58). La partecipante ricorda inoltre che, a causa della rarità di utilizzo del codice, le sue competenze in "serbo" si fossero erose in quel periodo e che lei adottasse, più o meno volontariamente, un accento italiano nel servirsene. Perciò, TF era spesso scambiata per parlante non nativa da interlocutori serbofoni: "mi dicevano che io parlavo serbo con l'accento italiano come se fossi una persona che ha imparato serbo no" (minuti 09:34-09:55). Infine, TF racconta dell'invenzione di un toponimo immaginario, che suonasse come italiano, per sottrarsi alle domande di chi riconosceva dal suo modo di parlare un' origine non romana: "coMUNque anche se parlavo bene si notava la differenza che io non ero romana [...] e quindi mi ero inventata un posto da dove venivo che era camicino $(\mathrm{h})<<$ sorridendo e quindi dicevo no ma da dove vieni tu di-> dico da camicino" (minuti 24:15-24:39).

Questa vicenda conferma che i nomi, nel presente caso di luogo, possano essere usati strategicamente in interazione per evitare di rivelare agli interlocutori la propria origine e/o altre caratteristiche identitarie valutate come stigmatizzate. TF stessa non si serve tuttavia di quasi-glottonimi in funzione elusiva nel corso della sua biografia linguistica. L'espressione "nostra lingua" è infatti adoperata molto raramente dall'intervistata ( 2 occorrenze su un totale di 36 , ossia $<20 \%$ ) e in modo non ambiguo. Piuttosto la narratrice, che la impiega anche in posizione isolata nel discorso, si serve di questa perifrasi in funzione tendenzialmente enfatica (cfr. la tabella 5 al $\S$ IV.3.1.4 e il prossimo paragrafo per maggiori dettagli). Infatti la donna la usa al momento di enumerare, in due sequenze distinte, le peculiarità grafiche $\mathrm{e}$ morfologiche della "nostra lingua" rispetto all'inglese e al tedesco, codici appresi successivamente in ambiti formali. Del resto, al momento del colloquio, TF ha cambiato il proprio atteggiamento nei confronti del serbo e del paese di partenza e, per esempio, presiede attualmente un'associazione di cittadini serbi a Brunico in Alto Adige. Così, non ha più motivo di sotto-specificare o occultare i rapporti tra codici nel proprio repertorio. Si noti comunque che il fenomeno di sostituzione di una lingua maggioritaria per vergogna, a causa della perdita del suo status dopo mobilità in un paese straniero, non è inconsueto. Anche altri intervistati del corpus - di origine sia serba, sia bosniaca, sia montenegrina - attribuiscono ad alcuni amici o conoscenti una reticenza e una vergogna analoghe a quelle raccontate da TF nel parlare una varietà linguistica a base neoštokava dopo emigrazione in Alto Adige (cfr. VM, KM e RX). Tuttavia, questi ultimi tendono a discostarsi, se non ad opporsi fermamente a tale comportamento (cfr. anche $\S$ IV.3.4). 


\subsection{Funzione enfatica e attrito linguistico}

Un caso esemplare di uso di quasi-glottonimi in funzione enfatica è quello di BL, una donna di 18 anni originaria del Kosovo e trasferitasi con la famiglia in Alto Adige all'età di tre anni, con cui ho condotto un'intervista semi-strutturata. Durante la conversazione, la partecipante si serve di denominazioni generiche - in particolare, "mia lingua" e, secondariamente, "nostra lingua" e "lingua madre" - per chiamare il codice di partenza molto più spesso dei glottonimi specifici "kosovaro" e "albanese kosovaro" (26 occorrenze su un totale di 34 , ossia $60 \%-80 \%$ ). In connessione con ciò, tali denominazioni si trovano spesso in posizione isolata nel discorso. La loro alta frequenza di occorrenza e il loro contesto di utilizzo suggeriscono che queste perifrasi generiche - $\mathrm{o}$ almeno la più frequente di queste, vale a dire "mia lingua" 42 - non siano usate da BL semplicemente per evitare ripetizioni. Queste svolgono piuttosto una funzione in interazione. Perciò, secondo la definizione qui adottata, sono adoperate come quasi-glottonimi dalla partecipante, per lo meno durante la conversazione con la specifica intervistatrice.

La sequenza in 25 offre un esempio di impiego delle denominazioni "mia lingua" e "lingua madre" senza un referente anaforico o cataforico esplicito da parte della ragazza. BL ha parlato per circa sette minuti del proprio percorso migratorio abbastanza intricato. Dopo aver risieduto per tre anni in un paese tedescofono altoatesino, la sua famiglia decide infatti di ritornare in Kosovo per poi emigrare nuovamente, trascorsi soli sei mesi, in provincia di Trento. Quest'ultimo trasferimento è motivato dalla constatazione che la situazione nel paese d'origine non fosse affatto migliorata, né politicamente, né economicamente. Nonostante questa digressione, la narratrice risponde, alla riga 4, esclusivamente con le due circonlocuzioni generiche, "mia lingua" e "lingua madre", a una domanda della ricercatrice che introduce un nuovo tema, ovvero le lingue imparate prima dei sei anni.

(es. 25)

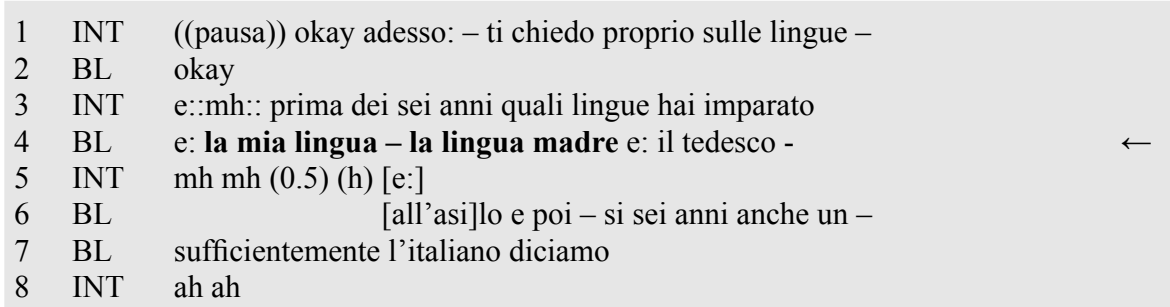

(BL_Kos_Laives, 07:50-08:13)

A differenza di IP e RM, BL non si serve di quasi-glottonimi per evitare di prendere una posizione univoca vis-à-vis con l'interlocutrice rispetto alle varietà linguistiche da lei parlate in determinati ambiti comunicativi. L'intervistata ribadisce,

42 L'espressione "mia lingua" è impiegata dall'intervistata 18 volte contro le cinque e tre occorrenze, rispettivamente di "nostra lingua" e "lingua madre". 
infatti, ripetutamente durante il colloquio l'allocazione centrale del codice così riferito nel proprio repertorio. Inoltre, la donna rappresenta la varietà linguistica d'origine come fortemente mantenuta in contesto migratorio. Oltre ad essere la lingua in cui spesso guarda la televisione e legge i giornali, la partecipante la indica come il principale mezzo di comunicazione in famiglia e con un gruppo di amici kosovari, residenti a Merano (minuti 19:12-19:29). Con i genitori e anche con le sorelle, BL afferma, d'altro canto, di parlare molto raramente e solo in determinate circostanze in "italiano" e in "tedesco", ossia "più che altro [...] quando si fanno i compiti" (minuti 15:00-15:26). Si noti che le rappresentazioni di BL discordano da quelle espresse da altri partecipanti del corpus o rilevate in altre ricerche, come, per esempio, in Chini (2004). Gli informanti emigrati da giovani dichiarano infatti solitamente di parlare spesso con i genitori e soprattutto con i fratelli nella lingua del paese d'arrivo. ${ }^{43}$ Del resto, secondo le dichiarazioni della donna, "la mia lingua" è anche quella da lei principalmente impiegata per la comunicazione interiore, ossia, per esempio, per "pensare", per "sognare" o per "scrivere per sé". Questi sono tutti ambiti i cui usi linguistici dichiarati sono tipicamente fortemente connotati dal punto di vista emozionale-identitario (cfr., per esempio, Schmid 2011: 81-96 sulle associazioni, non invariabili ma da valutare caso per caso, tra percezione di attrito e codici usati per le funzioni interne del linguaggio). Il fatto che $\mathrm{BL}$ sostenga tali posizioni è in linea con la sua volontà di costruire una rappresentazione di sé come parlante che ha mantenuto il codice di partenza nonostante aspettative contrarie nell'ambiente intorno a lei (cfr. più sotto in questo paragrafo).

L'identificazione di BL con il codice d'origine emerge anche dal fatto che, durante il colloquio, la donna prenda una posizione netta - diversamente dagli altri partecipanti del corpus - riguardo ai rapporti di differenziazione tra i) la sua lingua, ovvero il "kosovaro", e ii) l'“albanese". Scorrendo l'intervista sequenzialmente è interessante notare come la partecipante costruisca discorsivamente e negozi con l'interlocutrice le relazioni tra questi due codici, in parte, proprio attraverso l'adozione di denominazioni differenti. Il doppio processo di costruzione e promozione di un sapere che, secondo Tabouret-Keller (1997b: 11), è talvolta causato dalla messa in circolazione di un nuovo glottonimo è quindi visibile a livello micro in questa intervista. Così, rispondendo a una domanda della ricercatrice sulla propria lingua materna, BL chiama all'inizio della registrazione il codice d'origine "albanese kosovaro" o "kosovaro", distinguendolo dalla varietà linguistica parlata in Albania sulla dimensione socio-geografica ("kosovaro albanese [...] però se uno me lo chiede dico kosovaro perché tra l'albanese c'è un po' di dialetto in mezzo"; minuti 00:40-00:52). In seguito, la donna precisa questa caratterizzazione. In particolare, nel valutare le proprie competenze nei quattro codici conosciuti (ossia "ko-

43 Similmente a quanto raccontato da BV, la comunicazione con i connazionali tende invece ad avvenire nei codici d'origine anche nelle interviste discusse in Chini (2004). Sebbene sia meno carico dal punto di vista affettivo-identitario, tale dominio è quindi spesso, secondo la studiosa, più conservativo relativamente al mantenimento delle varietà linguistiche d'origine rispetto all'ambito familiare. 
sovaro", "italiano", "tedesco" e "albanese"), la partecipante riconduce le proprie difficoltà nel parlare perfettamente 1'“albanese" alla presenza di tratti dialettali che lo distinguono dalla sua "prima lingua", ossia il "kosovaro" ("e: poi: l'albanese quello:: - dove si parla in albania con un po' di dialetto e cose così [...] la parlo anche con un po' di difficoltà a volte però la parlo anche"; minuti 11:46-12:43). Infine, al termine dell'intervista, BL enumera la "mia lingua" e 1"“albanese" tra $i$ codici sentiti parlare nella cittadina di residenza in Alto Adige: "ho sentito pa- e: l'indiano ci sono alcuni indiani a laives si la mia lingua (h) l'albanese e anche il macedone tipo" (minuti 28:53-29:25). Si noti che, a questo punto del colloquio, la partecipante non ha più bisogno di giustificare ulteriormente la distinzione tra le varietà linguistiche menzionate rispettivamente con il quasi-glottonimo la "mia lingua" e con il nome di lingua specifico "albanese". A sua volta, l'intervistatrice inizialmente non adotta glottonimi emici nel formulare le sue prime domande. Nel corso della conversazione, quest'ultima converge tuttavia sulle espressioni "kosovaro" e "tua lingua", preferite dalla partecipante.

Come accennato sopra, BL è l'unica tra gli intervistati del corpus che attribuisca alla varietà di albanese parlata in Albania tratti dialettali rispetto a quella usata in Kosovo e non viceversa. Infatti, anche AC si serve del glottonimo "kosovaro", per esempio, all'inizio dell'intervista per illustrare proprio le differenze tra queste due varietà. Tuttavia, l'uomo afferma subitaneamente che una "lingua kosovara" vera e propria non esista. In modo analogo, AK e ZT chiamano nelle prime sequenze del colloquio la propria "lingua materna" rispettivamente "Albanisch Kosovarisch" (kosovaro albanese) e "kosovara albanese". In seguito, però, AK non utilizzerà più questa denominazione. Invece, ZT la userà solo occasionalmente - alternandola ai quasi-glottonimi in funzione enfatica "mia lingua" o "dialetti miei" (cfr. tabella 5 al § IV.3.1.4) - per riferirsi al codice di comunicazione in ambiti privati, in particolare, con la moglie e con gli amici. In linea con questa rappresentazione dei domini d'uso, il "kosovaro" è qualificato dall'intervistato come un "dialetto" dell'"albanese". Come si evince anche dal confronto con altre interviste, il pattern di denominazioni, usato da BL per chiamare il codice d'origine, è dunque indicativo del posto privilegiato che tale varietà linguistica occupa nel repertorio della donna da un punto di vista emico. Da un lato, tramite la ripetizione del quasi-glottonimo "mia lingua" (e delle varianti "nostra lingua" e "lingua madre"), la partecipante caratterizza il codice enfaticamente sulla dimensione emozionale-identitaria. Questo è infatti presentato come proprio a differenza di altre varietà linguistiche conosciute, ma acquisite in seguito. Dall'altro lato, l'adozione di un glottonimo specifico, vale a dire "kosovaro", e il rifiuto di qualificarlo come "dialetto" puntano al prestigio che la donna conferisce alla propria varietà linguistica, elevata appunto a lingua a sé (cfr. anche Dal Negro 2011 per esempi simili).

Restano da discutere le ragioni dell'adozione di quasi-glottonimi in funzione enfatica da parte di BL. Questa enfasi è, a mio avviso, motivata dall'impressione che la propria padronanza del codice di partenza - e, in connessione con ciò, la propria appartenenza alla comunità linguistica dei suoi parlanti - non siano pienamente riconosciute dalla ricercatrice nell'interazione in corso e/o, in generale, da potenziali interlocutori, residenti nel paese d'origine o d'arrivo. In alcune sequenze 
dell'intervista, BL rappresenta infatti la propria identità linguistica di parlante il "kosovaro" come contestata. In conseguenza di ciò, la donna sente la necessità di prendere posizione in sua difesa. Così, menzionando "la mia lingua" come unico codice sentito parlare nella cittadina di nascita, BL specifica di riuscire a comprenderla: "sentivo la mia lingua - e la capivo" (minuti 08:50-09:11). Inoltre, invitata dalla ricercatrice a identificare la propria lingua materna, la partecipante la definisce subitaneamente come il "kosovaro albanese". Al contempo, presenta le esortazioni a posizionarsi rispetto alla propria identità linguistico-nazionale come ricorrenti in contesto migratorio ("INT: quale consideri la tua lingua madre adesso BL: beh sicuramente il kosovaro albanese [...] anche se $(\mathrm{h})$ - cioè - $\mathrm{c}^{\prime}$ è gente che mi dice ma ti sei integrata ti senti italiana ma: cioè ((pausa)) [...] non mi sento italiana perché:: so chi sono le mie conosco le mie origini e quindi non [...] ((pausa)) non mi sento italiana"; minuti 10:09-10:34). In particolare, un evento nella biografia linguistica di BL potrebbe aver determinato - per lo meno per come è raccontato durante il colloquio - la sensazione di essere parlante "illegittima" (ossia non riconosciuta) del codice d'origine. Questo è il ritorno in Kosovo all'età di sei anni e la frequentazione di sei mesi di scuola in questo paese. L'esperienza è narrata due volte dall'intervistata. Nella prima sequenza, la donna racconta spontaneamente delle difficoltà incontrate in classe soprattutto nell'imparare a leggere. Curiosamente coniuga il verbo alla prima persona plurale: “all'inizio si abbiamo fatto un po' di difficoltà però: insomma <<sorridendo è passato $>$ " (minuti 11:22-11:46). Il secondo resoconto, riportato in 26 , segue una richiesta di chiarificazione della ricercatrice riguardo a questa vicenda.

(es. 26)

1 INT e: ((pausa)) ti semb- - prima dicevi che: quando sei andata a scuola

2 INT - e i pri- in questi sei mesi:

3 BL $\mathrm{mh} \mathrm{mh}$

4 INT e hai avuto delle difficoltà perché era da un po' che non

5 BL si beh ma per[ché comunque alla fine:]

6 INT [per per scriverlo]

7 BL - una bambina di [sei an]ni non è che

8 INT [mh mh]

9 BL (h) se sente parlare tedesco:

10 INT $\mathrm{mh} \mathrm{mh}$

11 BL a scuola - per tutto il tempo poi arriva a scuola deve parlare: la

12 BL lingua madre e ovviamente lì (h) è un po:' [messa] così diciamo

13 INT

(BL_Kos_Laives, 23:42-24:08) $[\mathrm{mh} \mathrm{mh}]$

La domanda dell'intervistatrice in apertura della sequenza in 26 elicita una storia di esperienza personale. Tuttavia, BL riformula la vicenda in terza persona. Nel fare ciò, la partecipante presenta la situazione narrata come generalizzabile al di là del suo caso singolo e la rende, perciò, più condivisibile per l'interlocutrice (un'interpretazione analoga potrebbe essere valida anche per l'uso di "noi" nel brano menzionato sopra, in cui BL racconta l'episodio per la prima volta). Al contempo, 
tramite l'uso di pronomi in terza persona, la donna si distanzia dal proprio personaggio di allora, categorizzato alla riga 7 come "una bambina di sei anni". Nel fare ciò, posiziona implicitamente il proprio io attuale come cambiato (cfr. anche Lucius-Hoene \& Deppermann 2004: 228). Inoltre, nel brano in 26, BL allude al motivo - ricorrente anche in altre interviste - del non saper parlare la "lingua madre" (cfr. le righe 11-12). Quest'ultima designazione è utilizzata dalla partecipante per qualificare un codice, con cui la donna ha, indipendentemente dal grado di padronanza, un forte legame emozionale-identitario ( $\mathrm{cfr}$. anche il concetto di codice ideologico o Wunschsprache in Dal Negro \& Iannàccaro 2003). Il restringimento del significato di "lingua madre" - la nozione va infatti a designare solo la "lingua della comunità di (cui si vuole ribadire la) appartenenza" e non anche il codice in cui si è più fluenti - ha l'effetto di presentare la situazione, vissuta e ora raccontata dalla narratrice, come paradossale, per lo meno ad occhi esterni. La donna si riferisce comunque con il quasi-glottonimo a una varietà linguistica specifica, ossia il "kosovaro albanese", in modo non ambiguo. Questo codice è enfaticamente contrapposto, nella sequenza in 26 , al tedesco, sentito parlare intorno a lei a scuola in contesto migratorio.

Il tema della sostituzione di lingua propria e altrui per dimenticanza (ossia per attrito linguistico) invece che per vergogna, appena esplorato nella biografia linguistica di BL, è affrontato da molti partecipanti del corpus indipendentemente dall'età, dall'anno di emigrazione e/o dalla composizione del repertorio d'origine. Nelle sequenze relative, i narratori si servono frequentemente di quasi-glottonimi in funzione enfatica in posizione isolata, semi-isolata o non isolata nel discorso (cfr. tabella 5 al §IV.3.1.4). In particolare, i partecipanti, trasferitesi in Alto Adige da adulti, caratterizzano solitamente il fenomeno come a loro estraneo e sembrano affrontare la questione soprattutto in conseguenza del micro contesto interazionale (cfr. AC, ML, NJ, OV, TF, VM, ZT, YF e parzialmente XF). ${ }^{44}$ In altre parole, questi narratori sembrano presupporre che una presa di posizione su tali temi sia più $\mathrm{o}$ meno esplicitamente richiesta nel corso di un' "intervista" sociolinguistica con una ricercatrice non appartenente alla loro comunità linguistica d'origine. Un caso esemplare della correlazione tra l'uso di quasi-glottonimi in funzione enfatica e affermazioni sul mantenimento di lingua da parte di partecipanti, emigrati da adulti, è quello di $\mathrm{OV}$, una donna di circa 36 anni originaria della Serbia e trasferitasi a Merano nel 2007 all'età di 29 anni. L'intervistata fa un uso molto frequente $(60 \%-80 \%)$ dei quasi-glottonimi "nostra lingua" $\mathrm{e}$ "mia lingua" in posizione isolata nel discorso. Queste denominazioni sono adoperate dalla donna per indicare il codice d'origine, altrimenti definito in modo non ambiguo "serbo". Come mostrano $\mathrm{i}$ brani in $27 \mathrm{a}$ e $27 \mathrm{~b}$, tali perifrasi sono ripetute dalla narratrice, in funzione enfatica,

44 Il caso di XF è particolare perché la donna sembra servirsi del glottonimo "Muttersprache" (madrelingua) parzialmente in funzione enfatica, parzialmente in modo non strategico per adeguarsi all'uso del marito YF, durante la loro intervista di coppia. L'uomo - che da bambino trascorreva le estati con i genitori Gastarbeiter (lavoratori ospiti) in Germania e che da adulto emigra a sua volta nello stesso paese, per poi ritornare per 5/6 anni in Serbia, prima di spostarsi nuovamente in Alto Adige - si serve occasionalmente di tale perifrasi generica per chiamare enfaticamente e in modo non ambiguo il codice "serbo". 
al momento di rispondere a una serie di domande della ricercatrice sui codici adoperati in determinati domini. Si noti che OV tende ad alternare l'espressione con il possessivo plurale "nostra lingua" a quella con il possessivo singolare "mia lingua" a seconda che si stia riferendo agli usi linguistici precedenti o successivi all'emigrazione in Alto Adige (si comparino, a questo riguardo, le situazioni comunicative nell'esempio 27 a versus quelle in $27 \mathrm{~b}$ ). Similmente a quanto rinvenuto, per esempio, nel colloquio con FR (cfr. §IV.2.2), la variazione nel pronome da "nostra" a "mia" sembra così marcare un nuovo confine linguistico dal punto di vista emico: questo è quello tra la partecipante e la comunità linguistica d'arrivo, divenuto rilevante dopo il trasferimento in un paese alloglotto.

(es. 27a)

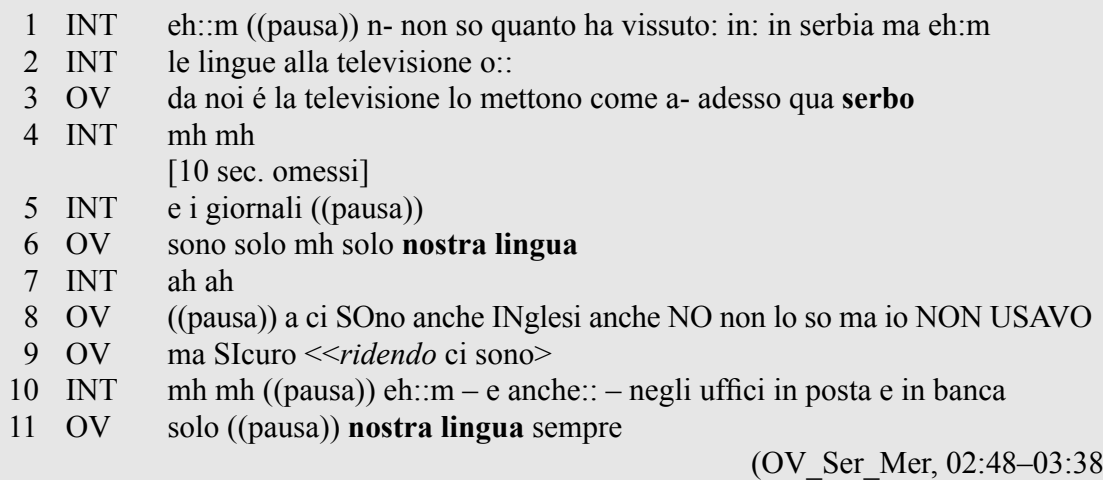

(es. 27b)

12 INT e adesso la lingua:: in cui guarda i programmi televisivi qual=é

13 OV <<ridendo e: non ti posso dire ((riso)) MIA>

14 INT ((riso))

15 OV $\quad<<$ ridendo - sempre mia si ((riso)) ((pausa)) si $>$

16 INT e: in cui legge libri o:

17 OV si sempre su mia lingua $<<$ ridendo che vuol dire che NON IMPARO

$18 \mathrm{OV}$ ((riso)) si sempre mia tutto su mia lingua $>$

(OV_Ser_Mer, 08:51-09:16)

In modo più urgente dei partecipanti trasferitesi da adulti, gli intervistati emigrati da giovani, specialmente in età prescolare, tendono invece a posizionarsi spontaneamente, fin dall'inizio dei colloqui, riguardo alla questione della sostituzione di lingua per dimenticanza. Nel fare ciò, spesso si servono parimenti di quasi-glottonimi in funzione enfatica (cfr. AS, SP, DL, AF, NM, FR sempre nella tabella 5 al $\S$ IV.3.1.4). Similmente a BL, alcuni di loro qualificano inoltre univocamente come "madrelingua" una specifica varietà linguistica, parlata nella località di partenza. Invece, altri, pur adoperando il termine spontaneamente nel corso dei colloqui, lo definiscono come problematico dal loro punto di vista. Infine, certi informanti si 
oppongono nettamente a tale nozione, non trovandola pertinente per caratterizzare i rapporti tra codici nel loro repertorio (cfr. il caso di SM, descritto al §IV.2.4, e quello di AF, illustrato più sotto). In tutti questi casi, il significato emico della nozione di "madrelingua" e, quindi, i criteri per una sua attribuzione sono variabili e possono discordare anche tra membri di una stessa famiglia. Così, per esempio, AK definisce 1"“albanese" la sua madrelingua perché a casa si è sempre parlato, oltre all'italiano e al tedesco, anche l'albanese per non dimenticarlo. Invece, secondo sua sorella maggiore FK, la lingua materna è il "tedesco" dal momento che la donna ha frequentato le scuole superiori in tedesco. Si noti che la rappresentazione di FK potrebbe essere in parte condizionata dalla volontà di definire come "madrelingua" un codice con un prestigio riconosciuto come alto da lei stessa e/o presupposto come tale agli occhi dell'intervistatrice. L" "albanese" parlato in Kosovo è invece ripetutamente qualificato dalla ragazza - che, a differenza della sorella minore, lo rappresenta però come unico codice di comunicazione con i genitori e, quindi, propriamente come unica "lingua parlata con la madre" - come una "specie di dialetto". Perciò, sembra avere un prestigio piuttosto basso nel repertorio rappresentato da FK e, di conseguenza, non poter assurgere allo status di lingua materna. ${ }^{45}$

Entrando maggiormente nel dettaglio, un punto di vista complementare rispetto a quello di BL sul tema della perdita di lingua per dimenticanza così come sul concetto di madrelingua è quello sostenuto da AF nel corso della sua biografia linguistica. La partecipante è una donna di 32 anni trasferitasi in Alto Adige nel 1992 da Sarajevo, ma nata in Montenegro da genitori già "lavoratori ospiti" (Gastarbeiter) in Germania. Nella sua intervista, AF si autodefinisce parlante senza "madrelingua". Per descrivere questa sua condizione e per qualificare il proprio modo di parlare, l'intervistata adopera denominazioni generiche e glottonimi specifici - talvolta diversi, talvolta simili a quelli individuati in altri colloqui - conferendo spesso loro un significato idiosincratico e innovativo. Già prima di iniziare la registrazione, AF chiama infatti genericamente il codice parlato da lei e dalla sua famiglia una "lingua privata", misto di quelle conosciute. In seguito, nel corso della conversazione, la donna porta esempi della "lingua: colloquiale" con "influenze dall'italiano dal tedesco e dall'inglese" usata nella comunicazione a casa (minuti 15:14 15:35). D'altro canto, fin dall'incipit del colloquio, AF dichiara di preferire il glottonimo specifico "serbocroato" ai nomi di lingua attuali, vale a dire "serbo", "croato" e "bosniaco" (cfr. anche $§ I V .1 .5 .2)$. In aggiunta, la narratrice si serve occasionalmente del glottonimo "montenegrino" nel corso della conversazione. Il nome non si riferisce però al codice recentemente standardizzato. Piuttosto, la partecipante usa la denominazione specifica per chiamare 1" "accento" peculiare dei genitori e dei fratelli, subito riconosciuti come parlanti non locali a Sarajevo, anche prima della guerra e dell'esperienza migratoria. ${ }^{46}$

45 Si confronti riguardo ai motivi della discordanza tra "lingua madre" e "lingua parlata con la madre" anche Iannàccaro \& Dell'Aquila (2002) e il loro "indice di dialettalità percepita", discusso al §IV.3.1.3.

46 Sia qui ricordato che, in modo simile a AF, un impiego parimenti innovativo di alcuni glottonimi specifici si riscontra anche nell'intervista con NM (cfr. § IV.2.3): il nome "mio serbocro- 
A livello di contenuto, AF ritorna frequentemente, durante la sua intervista, sul motivo della duplice sensazione di mancanza e di liberazione provocata dalla composizione del proprio repertorio, molto differente da quello di parlanti che non hanno vissuto un'esperienza di mobilità. Così, la partecipante illustra dettagliatamente le difficoltà incontrate in Alto Adige a causa di un repertorio caratterizzato da un'ottima padronanza in numerosi codici, ma privo di "madrelingua" (minuti 03:00-10:00). Infatti, non è ad esempio facile per lei decidere a quale gruppo linguistico affiliarsi al momento di compilare la dichiarazione etnico-linguistica, obbligatoria in provincia di Bolzano (cfr. §II.1.1 per dettagli su tale regolamentazione). Inoltre, la donna esprime la preferenza per "ambienti MI:sti", invece che "puri", dal momento che, nei primi, pratiche plurilingui "vengono valorizzate e non diventano un problema", a differenza di quanto invece avviene quotidianamente in altre circostanze nella regione di arrivo (minuti 12:00-13:16). In 28 è riportata la parte finale della sequenza in questione. Nel brano, la narratrice si posiziona come parlante dalle competenze non perfette e, quindi, non riconosciute come "native" da nessuna delle tre comunità linguistiche con cui è entrata in contatto.

(es. 28)

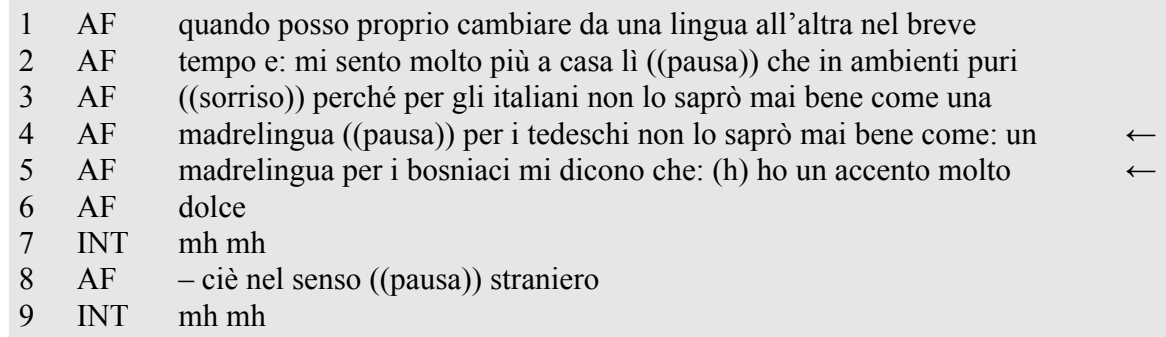

(AF_Bos_Mon_Vip, 13:00-13:16)

Il termine "madrelingua" non è impiegato da AF, alle righe 4 e 5 del brano in 28, come un nome di lingua specifico. Piuttosto, questo è qui usato per designare un tipo di "parlante" dalle competenze riconosciute come standard da una comunità di locutori. In connessione con questa definizione, l'espressione "madrelingua" è talvolta adoperata enfaticamente dalla donna, in altre sequenze del colloquio, per indicare un codice con una valenza simbolica peculiare nel repertorio (AF se ne serve tuttavia raramente $(<20 \%)$ e sempre in posizione non isolata nel discorso; cfr. tabella 5 al $\S$ IV.3.1.4). Proprio per il ruolo che gioca nel negoziare l'affiliazione a una determinata comunità di locutori e, in particolare, nel sentirsi parlante "legittimo" (nel senso di riconosciuto come parte) di questa comunità, l'avere una "madrelingua" è una caratteristica al contempo desiderata e rifiutata dall'intervistata.

Infine, sia qui menzionato che, oltre all'esperienza migratoria, anche le rotture nell'uso linguistico, determinate dai recenti interventi di pianificazione linguistica,

ato" si riferisce infatti per l'intervistata a una "lingua mescolata", non coincidente con nessuno dei codici ufficiali. 
costituiscono per AF una causa della sensazione di non padroneggiare perfettamente il codice d'origine. L'intervistata racconta infatti della frequente incomprensione di parole usate da parenti e amici a Sarajevo in quanto introdotte in seguito all'elaborazione di "bosniaco", "croato" e "serbo" per sostituire espressioni "serbocroate" (minuti 48:53-49:22). Inoltre la donna narra della situazione, ripetutasi più volte durante le vacanze nel paese di nascita, di essere interpellata in inglese dagli abitanti del posto. Ciò avviene talvolta anche quando AF stessa inizia la conversazione "in lingua" ("AF: un'altra volta ho parlato in lingua e mi hanno risposto in inglese: e volevo solo del pane [...] ho detto un pezzo di pane e lu- lui mi ha parlato in inglese allora ho detto e cioè qui c'è qualcosa che sta succedendo", minuti 48:33-48:53). Nel raccontare questa esperienza, la partecipante rappresenta se stessa, ancora una volta, come parlante "delegittimata" del codice d'origine (cfr. anche esempio 28 sopra). Infatti, le proprie competenze in tale lingua non sono riconosciute da parte della comunità dei suoi parlanti. Si noti che, anche in questo caso, la donna si serve di una denominazione generica, ossia "in lingua", per riferirsi al codice parlato a Sarajevo successivamente al serbocroato. Nel brano, questa perifrasi ha tuttavia una connotazione piuttosto neutrale e non svolge propriamente una funzione enfatica nel discorso. Piuttosto il suo uso si lascia probabilmente ricondurre a un tratto idiosincratico dell'idioletto della partecipante e sarebbe così fossilizzato.

\subsection{Funzione oppositiva e interventi di pianificazione}

Un terzo gruppo di partecipanti si serve, nel raccontare la sua biografia linguistica, di quasi-glottonimi in funzione "oppositiva". Tali denominazioni sono infatti usate in sostituzione dei nomi di lingua attuali per ribadire la propria condizione di parlanti di codici che erano ufficiali, ma che, in seguito a interventi di pianificazione linguistica dall'alto, non sono più riconosciuti a livello istituzionale. Similmente agli intervistati che usano quasi-glottonimi in funzione elusiva (cfr. § IV.3.2), durante questi colloqui, le denominazioni "nostra lingua" e "madrelingua" sono adoperate in modo ambiguo dai narratori per non prendere una posizione univoca sui (nomi specifici dei) codici che compongono il loro repertorio di partenza di fronte all'interlocutrice. Al contempo, gli intervistati ribadiscono, tuttavia, il mantenimento delle varietà linguistiche in questione e si distanziano da una loro sostituzione per vergogna o per dimenticanza (o attrito linguistico) in contesto migratorio. Nel fare ciò, in modo analogo ai narratori che usano quasi-glottonimi in funzione enfatica (cfr. § IV.3.3), esprimono più o meno esplicitamente affiliazione alla comunità linguistica dei parlanti del codice di partenza (pur non specificando, in questo caso, chiaramente quale questa sia). Nelle interviste del terzo gruppo, le sequenze che hanno per oggetto i codici d'origine sono inoltre spesso caratterizzate da un accumulo di denominazioni diverse, usate una di seguito all'altra, o per riparare quelle precedentemente menzionate o per specificare ulteriormente il codice così riferito. Tali fenomeni a livello formale rivelano il tentennamento del narratore nello scegliere il glottonimo appropriato. 
L'impiego di quasi-glottonimi in funzione oppositiva da parte di questo gruppo di informanti non è comunque omogeneo. Piuttosto il loro uso sia presenta alcune differenze tra intervistati diversi, sia può variare nel corso di una stessa intervista (cfr., in particolare, il colloquio con KM, discusso più sotto in questo paragrafo). In primo luogo, come già accennato, i codici riferiti dai quasi-glottonimi non sono, per esempio, sempre gli stessi. Ciò emerge, sia da dichiarazioni esplicite di alcuni partecipanti interpellati a riguardo, sia dall'esame delle condizioni di utilizzo delle denominazioni generiche nelle interviste del corpus. Inoltre (e in connessione con ciò), certi intervistati si servono di tali circonlocuzioni per chiamare i codici d'origine fin dall'inizio della conversazione, indipendentemente dal periodo storico a cui fanno riferimento o dalla situazione comunicativa descritta (cfr. KS, DR e KM). Altri narratori adottano, al contrario, denominazioni generiche solo dopo aver impiegato nomi di lingua specifici nella prima parte del colloquio. In queste ultime biografie linguistiche, i quasi-glottonimi sono usati, per esempio, quando gli intervistati devono descrivere interazioni attuali o rappresentare gli usi linguistici in determinati domini, come in famiglia o alla televisione (cfr. rispettivamente LA e JB). In altri colloqui o sequenze di questi, denominazioni generiche tendono invece ad essere adoperate quando il parlante si riferisce al codice di comunicazione con specifici interlocutori, ad esempio, con persone provenienti da altri paesi successori alla Jugoslavia e/o con persone che parlano una varietà neoštokava come L2 (cfr. $\mathrm{BV}, \mathrm{SV}$ e anche KM nella seconda parte della sua intervista). In aggiunta o in alternativa a ciò, alcuni informanti si servono di quasi-glottonimi in funzione oppositiva per motivi prevalentemente interazionali. In questi casi, l'impiego di perifrasi generiche può essere spiegato come un tentativo di adeguarsi alle conoscenze presupposte nell'interlocutrice e/o alle prese di posizione espresse da altri interattanti in colloqui di coppia (cfr. PB e ancora KM).

Entrando più nei dettagli, un uso di quasi-glottonimi in funzione oppositiva si riscontra, per esempio, nell'intervista di coppia, condotta con PB e KS. Le due donne sono due amiche rispettivamente di 35 e 40 anni circa, nate l'una in Serbia e l'altra in Montenegro. PB è arrivata direttamente in Alto Adige nel 2002. Invece KS si è trasferita insieme al marito JB - anch'egli intervistato per la presente ricerca prima in Austria nel 1992 e dopo in provincia di Bolzano nel 2000. Durante la conversazione, KS utilizza prevalentemente l'espressione "Muttersprache" (madrelingua) per chiamare il codice d'origine (16 occorrenze su 22, ossia 60\%-80\%). Come mostra il brano in 29 , la circonlocuzione è adoperata da questa partecipante quasi sempre in posizione isolata nel discorso come un nome di lingua specifico.

Nella sequenza in $29, \mathrm{KS}$ prende per la prima volta la parola nella conversazione in corso. Precedentemente il banco era infatti tenuto dall'amica PB, che ha illustrato alla ricercatrice le proprie competenze linguistiche in "Serbisch" (serbo) e nei codici d'arrivo. Nell'intervenire per la prima volta nella conversazione, KS chiama il codice di partenza "Muttersprache" (madrelingua), senza esplicitare ulteriormente a quale varietà linguistica si stia riferendo. La mancanza dell' articolo (o del possessivo) prima del quasi-glottonimo "madrelingua" alle righe 6 e 12 - così come nella maggior partedelle sequenze d'occorrenza in questa e nell'intervista con il marito JB - si lascia probabilmente spiegare come un transfer dalla prima lingua della narratrice. Tuttavia, 
(es. 29)

1 INT ((pausa)) und in ihrer stadt konnte mh: ko- konnten sie andere

2 INT sprachen hören

3 PB e: n:a nein ${ }^{\circ}$ wie hei- ${ }^{\circ}<<$ cercando una parola kreue- welch- welche -

4 PB welche>

$5 \mathrm{KS} \quad$ in serbien nicht viel

6 KS (0.3) bei uns sprechen wir oft mal nur mutterspra:che

7 KS (h) (0.4) u:nd (0.2) [manch]mal

8 PB $\quad[\mathrm{xx}]$

9 KS abe:r ganz selten (0.4) english

$10 \mathrm{KS} \quad(0.8)(\mathrm{h})$ das war=s auch bei mir so ich hab in: montenegro geboren

11 KS (h) dort auch schule gelernt

$12 \mathrm{KS}$ (h) ich habe immer in muttersprache gesprochen (h)

Traduzione:

(PB_KS_Ser_Mon_Bru, 02:46-03:18)

1 INT ((pausa)) e nella sua città poteva mh: po- potevate sentire altre

2 INT lingue

3 PB e: n:a no ${ }^{\circ}$ come si chia- ${ }^{\circ}<<$ cercando una parola kreue- com- come

4 PB come>

5 KS in serbia non tanto

6 KS (0.3) da noi parliamo spesso solamente madreli:ngua

7 KS (h) (0.4) e: (0.2) [a vol]te

8 PB $[\mathrm{x}]$

9 KS ma: molto raramente (0.4) inglese

$10 \mathrm{KS} \quad(0.8)(\mathrm{h})$ anche da me era così io ho nata in: montenegro

11 KS (h) là studiato a scuola

$12 \mathrm{KS}$ (h) ho sempre parlato in lingua materna $(\mathrm{h})$

tale omissione rende la denominazione generica ancora più simile a un nome di lingua specifico. Inoltre, sebbene nei turni di parola precedenti l'altra partecipante PB avesse chiamato esclusivamente "serbo" il codice di partenza, anche quest'ultima convergerà, nel prosieguo del colloquio, sulla denominazione generica, preferita dall'amica. In particolare, $\mathrm{PB}$ userà il quasi-glottonimo "madrelingua" meno sistematicamente di KS (40-60\% dei casi), ma, analogamente a quest'ultima, anche in posizione isolata nel discorso. Nel caso di PB, l'impiego di quasi-glottonimi in funzione oppositiva è determinato dunque in larga parte da motivi interazionali.

Ritornando al brano in 29, KS si serve della circonlocuzione "madrelingua", sia per indicare il codice sentito parlare in Serbia (cfr. riga 6), dove l'intervistata ha vissuto insieme al marito, sia per denominare la varietà linguistica usata in Montenegro (cfr. riga 12), dove la donna è nata e ha frequentato la scuola. Tale impiego suggerisce che la partecipante adotti la perifrasi ambigua per opporsi specificatamente alla distinzione, promossa recentemente a livello ufficiale in questi due paesi, tra i codici standard "serbo" e "montenegrino". Questa ipotesi è confermata anche dalle uniche due sequenze del colloquio, in cui KS si serve del quasi-glottonimo "madrelingua" in concomitanza con nomi di lingua specifici. Al momento di nominare i codici parlati in famiglia, la donna esplica infatti l'espressione "madrelingua" con il glottonimo "serbo mo-": "deswegen $[. .$.$] sprechen <<$ scandendo wir 
IMmer mit den kindern zu hause muttersprache $>>$ also das ist serbische $<$ mo(0.3) sprache" (tr. "perciò [...] parliamo $<<$ scandendo noi SEMpre con i bambini a casa madrelingua $>>$ dunque questa è serbo $<$ mo- (0.3) lingua", minuti 05:07$05: 15)$. In seguito, enumerando le lingue in cui si potevano comprare $i$ giornali in Montenegro, la donna ripara la perifrasi "madrelingua" con "serbi-", a sua volta sostituito con il glottonimo "Montenegrisch", qui tradotto con "montenegrese": "meistens in muttersprache (1.0) so ${ }^{\circ}$ serbi- montenegrish" (tr. "perlopiù nella madrelingua (1.0) così ${ }^{\circ}$ serb- montenegrese" ${ }^{\circ}$, minuti 07:44-07:49). Questa è 1'unica occorrenza del nome "Montenegrisch" nel corso dell'intero colloquio. Perciò, non mi è possibile stabilire se la narratrice si serva sistematicamente di questa denominazione idiosincratica al posto del nome ufficiale del codice, ossia "Montenegrinisch" (montenegrino). Indipendentemente da ciò, l'incertezza onomastica - indicizzata dall'uso di un glottonimo pronunciato in modo non corretto - suggerisce, a sua volta, un'insicurezza analoga nel prendere posizione rispetto all'esistenza o all'insussistenza della varietà linguistica in questione, la cui accessibilità è infatti già compromessa a livello discorsivo. Ciò vale soprattutto nel caso di KS. La donna ha infatti lasciato il paese d'origine nel 1992, quando i due codici non erano ancora distinti a livello istituzionale. Inoltre, tale incertezza è particolarmente comprensibile nel caso del "montenegrino", dato il suo riconoscimento a lingua ufficiale estremamente recente, ossia nel 2007 (insicurezze analoghe nei confronti del nome e dello status del codice si riscontrano, del resto, anche nell'intervista con YF, discussa al $\S$ IV.1.5.1, e in quella con RM, analizzata al § IV.2.4).

Così, l'adozione della denominazione generica "madrelingua" permette a KS di evitare di decidere, al momento di raccontare la propria biografia linguistica, tra una rappresentazione di sé come parlante di "serbo" o di "montenegrino". In connessione con ciò, la partecipante si riferisce verosimilmente con tale perifrasi al codice che esisteva precedentemente agli interventi di codifica di queste due varietà come lingue distinte. Si noti però che la "madrelingua" non coincide, a mio avviso, nell'ottica della partecipante con il "serbocroato", ma indica un codice (comunque) successivo a questo. Infatti, questo ultimo glottonimo - menzionato una sola volta da KS nel corso dell'intervista - non è posto in relazione di concorrenza con i primi due. Il codice, così riferito, è piuttosto differenziato dalla "madrelingua" sulla dimensione storico-temporale ("KS: serbien und montenegro das gehörte zu eine EX-jugoslawien und wir haben alle nur eine sprache gehabt das ist s:erbokroatische sprache", tr. "KS: Serbia e Montenegro - questo apparteneva a una ex-Jugoslavia e noi tutti abbiamo avuto solo un lingua questa è la lingua serbocroata; minuti 07:09-07:27). D'altro canto, è anche vero che, tramite l'uso del quasi-glottonimo "madrelingua", la narratrice sembra assegnare enfaticamente alla varietà linguistica in questione un forte valore emozionale-identitario. E infatti, nel corso del colloquio, la partecipante prende ripetutamente posizione in favore di un suo mantenimento in contesto migratorio. Nel fare ciò, ribadisce la posizione centrale di questo codice nel proprio repertorio ed esprime affiliazione alla comunità linguistica dei suoi parlanti. Nella terminologia sviluppata per la presente ricerca, KS usa dunque il quasi-glottonimo "madrelingua" in funzione oppositiva dal momento che sia la lingua (serbo-montenegrina), sia la comunità 
linguistica, a cui fa riferimento, non sono attualmente riconosciute come "legittime" a livello ufficiale.

Una funzione analoga hanno anche i quasi-glottonimi nell'intervista con KM. Il partecipante è un uomo di 42 anni, trasferitosi in Alto Adige nel 1995 da Sarajevo. L'intervistato si serve piuttosto frequentemente delle espressioni generiche "nostra lingua" e "mia lingua" in posizione isolata nel discorso (13 occorrenze su un totale di 32, ossia $40 \%-60 \%$ ). Nello specifico, le denominazioni date ai codici d'origine variano nel corso del colloquio, che può essere, perciò, suddiviso in tre parti. Durante la prima sezione (minuti 00:00-00:27), il narratore nomina molto raramente la varietà linguistica di partenza. Quando lo fa, usa esclusivamente l'espressione "nostra lingua". Tale perifrasi è impiegata in posizione isolata nel discorso e risulta così ambigua per l'interlocutrice. A quest'ultima non è infatti chiaro a quale codice l'intervistato si stia riferendo. Si confronti, a questo riguardo, il brano in 30 .

(es. 30)

1 INT si: - cioè per esempio se ((pausa)) per esempio qui: in alto adige

2 INT lei ha detto che ha una figlia (h) che lingua [parla con]

$3 \mathrm{KM}$

[due]

4 INT $->$ due ne ha<

5 KM due due due figlie NO ma a casa parliamo la nostra lingua perché è

$6 \mathrm{KM}$ ovvio [no]

7 INT $\quad\left[{ }^{\circ} \mathrm{mh}^{\circ}\right]$

$8 \mathrm{KM}$ hai tanta gente che: - si vergogna che magari non parla:: (0.6) la

$9 \mathrm{KM}$ loro lingua no

10 INT $\mathrm{mh} \mathrm{mh}$

$11 \mathrm{KM}$ però: io parlo a casa (1.2) la nostra lingua

(KM_Bos_Bo, 06:52-07:15)

Nella sequenza in 30, l'intervistato nomina per la prima volta il codice d'origine dopo aver illustrato, nei turni di parola precedenti, i modi di acquisizione di italiano e tedesco in Alto Adige. Nel brano, usi lessicalizzati e non lessicalizzati della perifrasi "possessivo + lingua" si alternano. KM si serve infatti dell'espressione "nostra lingua" per due volte come se fosse una locuzione fissa (cfr. righe 5 e 11). Ciò risulta soprattutto evidente dalla costruzione del secondo enunciato, dove l'aggettivo "nostra" non concorda nel numero con il soggetto del verbo "parlare" in prima persona singolare ("io parlo a casa (1.2) la nostra lingua"). In questo contesto, la circonlocuzione è quindi usata dal parlante invariabilmente, come se fosse un glottonimo specifico. Tuttavia, appena prima alla riga 9, il narratore adopera la denominazione "loro lingua" in senso generico. Tale variabilità, che si riscontra anche in altre interviste del corpus, punta alla polivalenza dei quasi-glottonimi in interazione. Questi ultimi infatti oscillano (o sono in divenire) da nomi generici a specifici.

Il brano in 30 è interessante anche perché esemplifica le prese di posizione piuttosto decise dei parlanti del terzo gruppo in favore del mantenimento del codice di origine dopo mobilità. Nella sequenza, KM si distanzia dalla sostituzione di lingua che deriva dalla vergogna di parlare una varietà linguistica alloglotta in conte- 
sto migratorio. Nel seguito del colloquio, l'intervistato esprime ripetutamente disapprovazione per chi parlante L1 o L2 della "nostra lingua" si rifiuta di usarla. Tra questi ci sono, secondo il narratore, persone sia che si sono trasferite all'estero da molto giovani, sia che si affiliano a una comunità linguistica di minoranza (come quella kosovaro-albanofona) nella regione di partenza. Il quasi-glottonimo "nostra lingua" non sembra avere quindi per l'intervistato tanto la funzione di occultare, quanto quella di ribadire la posizione centrale che il codice di partenza occupa nel suo repertorio individuale.

La seconda parte dell'intervista con KM (minuti 27:00-47:00) si apre con una presa di posizione esplicita del narratore sulla somiglianza tra i codici parlati nello spazio sociolinguistico neoštokavo. In questa sequenza, il partecipante dichiara di preferire il glottonimo "serbocroato" a quello attualmente ufficiale nel paese di nascita, ossia "bosniaco" ("KM: sai una volta dicevano ((pausa)) e: serbocroato ma è sempre quella sai adesso dicono che è bosniaco ma è sempre quella che parlav- sai ((pausa)) cioè ti dico sinceramente no ((pausa)) anzi sarei contento ancora se co- si chiama serbocroato cioè lo sai adesso bosnia poi deve essere per forza bosniaco"; minuti 27:30-28:02). A partire da questo momento, l'intervistato alterna queste due denominazioni ("serbocroato" e "bosniaco") a seconda del periodo storico a cui fa riferimento durante la narrazione. Inoltre, continua ad adoperare l'espressione generica "nostra lingua". Alcune sequenze di occorrenza puntano nuovamente alla perdita di significato lessicale di quest'ultima perifrasi e alla sua acquisizione di contenuto onomastico. Così, per esempio, KM chiama "nostra lingua" anche il codice usato da locutori non nativi e/o non provenienti dai paesi successori alla Jugoslavia in Alto Adige: "c'è un altro tedesco che lavora con me [...] che lui anche fa battute nella nostra lingua" (minuti 40:36-41:00). D'altro canto, la circonlocuzione "nostra lingua" non funge sempre da sintagma fisso neanche nella seconda parte del colloquio. Così, in una sequenza di poco successiva, KM la ripara, per esempio, con "mia lingua" probabilmente proprio in considerazione della dimensione interazionale dell'intervista. Il quasi-glottonimo è infatti preceduto da un inciso rivolto specificatamente alla ricercatrice: "ho conosciuto un ragazzo ((pausa)) e::: se ti: - può interessare che è tedesco ((pausa)) e adesso è: ((pausa)) tsk in austria però:: parla - perfettamente la nostra lin- la mia lingua" (minuti 41:51-43:01).

Infine, la terza parte del colloquio (minuti 00:47:00-1:03:00) segue le dichiarazioni, elicitate da una domanda dell'intervistatrice, sulla funzione del quasi-glottonimo "nostra lingua" nelle regioni di partenza. Il brano in questione è trascritto in 31 .

Nella sequenza in 31, KM conferma la definizione, suggerita dall'intervistatrice, secondo cui la perifrasi "nostra lingua" sia un "modo di dire". Inoltre attribuisce alle persone più anziane l'uso di tale termine. Perciò prevede una sua scomparsa tra i parlanti delle nuove generazioni, che non si ricorderanno infatti più di come era l'assetto linguistico-istituzionale precedente al conflitto. In connessione con ciò, nell'ottica dell'intervistato, il referente implicito della circonlocuzione "nostra lingua" è il "serbocroato": i tentennamenti nel formulare questa equivalenza puntano al fatto che il parlante sia consapevole delle connotazioni che tale presa di posizione ha nel paese d'origine e probabilmente anche in quello d'arrivo (cfr. righe 13-17). A differenza di KS, KM non adopera quindi il quasi-glottonimo 
(es. 31)

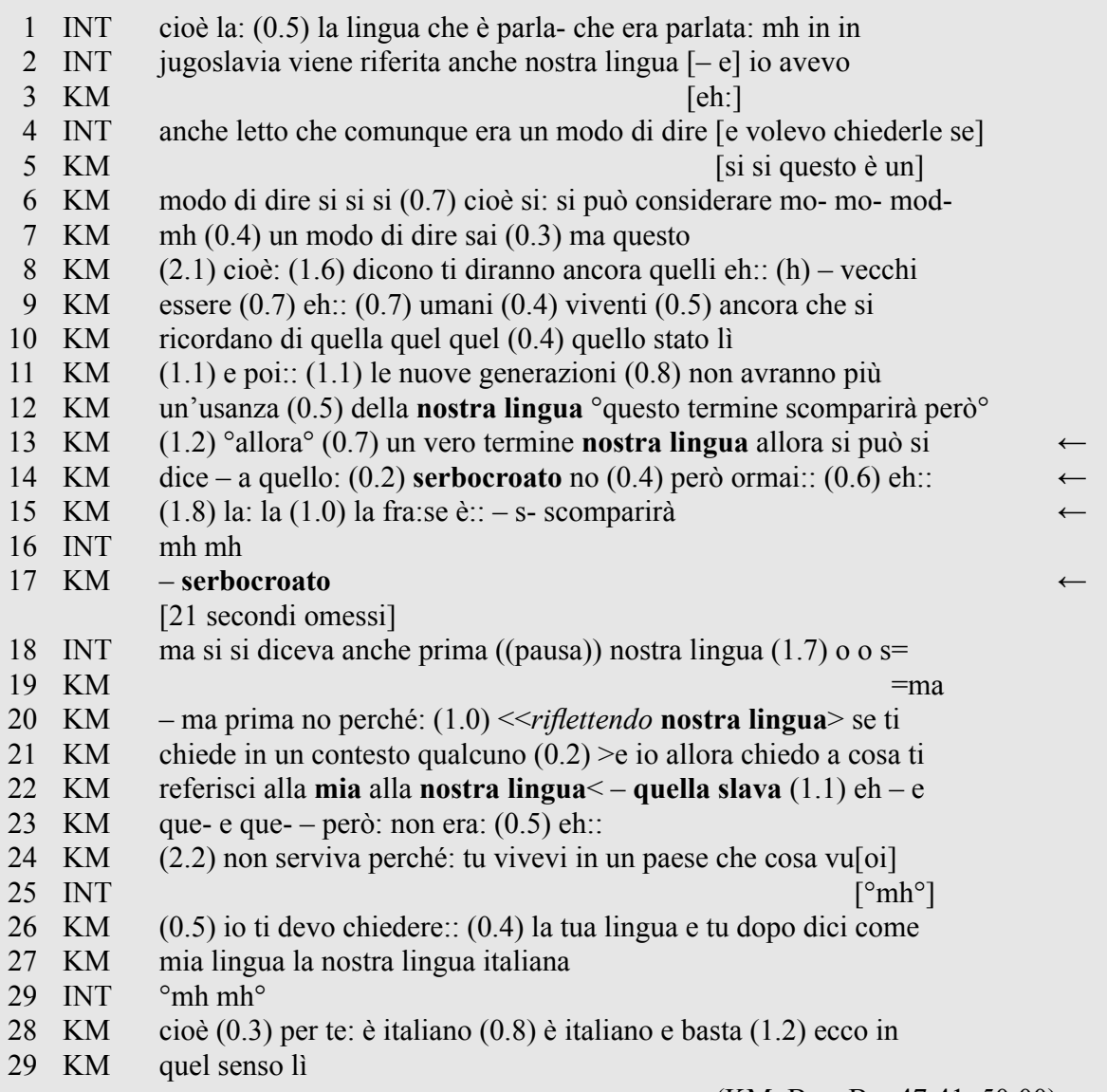

in opposizione ad alcuni, ma a tutti i nomi di lingua attuali. In particolare, il narratore se ne serve, da un lato, per evitare di riconoscere i codici elaborati recentemente come lingue tra loro distinte. Dall'altro, la sua adozione è funzionale a rappresentarsi sia come parlante di un codice "illegittimo", in quanto ufficialmente non riconosciuto, sia come parlante dalle competenze divenute "illegittime", in quanto quest'ultime si riferiscono e sono valide per stadi precedenti di standardizzazione. In chiusura del brano (righe 20-29), il parlante tematizza infine l'ambiguità che l'espressione "nostra/mia lingua" può avere per un interlocutore o un'interlocutrice durante una conversazione. Questa ambivalenza è del resto la principale ragione dell'utilizzo del quasi-glottonimo dopo l'elaborazione dei nuovi codici standard. Tale consapevolezza rende poco probabile che il partecipante si sia servito della circonlocuzione "nostra/mia lingua" inavvertitamente, nel corso della sua biografia linguistica, come calco dalla prima lingua. 


\subsection{Conclusioni: illegittimità di lingue e parlanti}

Dalla funzione assunta dai quasi-glottonimi a livello formale e dalle prese di posizione verso il mantenimento e la sostituzione di lingua a livello contenutistico emergono tre tipi o modi di rapportarsi con i codici d'origine da parte di cittadini ex-jugoslavi in Alto Adige.

L'impiego di quasi-glottonimi in funzione "elusiva" è proprio di persone che in conseguenza dell'assetto del plurilinguismo a livello istituzionale nei paesi di provenienza e/o dell'esperienza migratoria - valutano le loro "lingue illegittime". In altre parole, le associano con caratteristiche identitarie stigmatizzate a livello comunitario e perciò non vogliono identificarsi con queste. In conseguenza di ciò, $\mathrm{i}$ narratori sotto-specificano la posizione che questi codici occupano nel loro repertorio. Inoltre, tendono, almeno secondo i loro racconti, a sostituirli per vergogna dopo emigrazione in un paese straniero. I partecipanti del corpus, che si servono di quasi-glottonimi in funzione elusiva, sono solo due: IP e RM. ${ }^{47}$ Denominazioni dal referente ambiguo non sono comunque l'unico strumento impiegato, nelle interviste raccolte, allo scopo di sotto-specificare le competenze in un codice e/o di marginalizzare la sua posizione nei repertori individuali. Anche la menzione di una varietà linguistica al termine di un lungo elenco di lingue conosciute o l'adozione di forme verbali impersonali e, quindi, spersonalizzanti per motivarne l'apprendimento o per descriverne le situazioni d'uso possono concorrere ad obiettivi simili (cfr. sempre le interviste con IP e RM e anche quelle con SM e DL). Spesso, comunque, piuttosto che negare le competenze in un codice in modo assoluto, gli intervistati gli conferiscono o raccontano di avergli conferito un ruolo marginale nel proprio repertorio, per esempio, non menzionando il suo impiego in determinati domini. Nello specifico, i codici parlati in famiglia sono quelli che risultano essere $i$ più controversi. Infatti, anche da un punto di vista emico, sono quelli (rappresentati come) più carichi di connotazioni emozionali-identitarie.

Relativamente all'uso di quasi-glottonimi in funzione elusiva e alla sostituzione di lingua per vergogna, è inoltre importante notare che il mancato riconoscimento di un codice e, quindi, il suo divenire illegittimo agli occhi dei suoi stessi locutori può avvenire precedentemente o successivamente all'esperienza di mobilità. Da un lato, infatti, fanno parte di questo primo gruppo parlanti di una lingua "minoritaria" nella località d'origine, come di albanese in Montenegro e in Rep. di Macedonia o, eventualmente, di varietà di daco-rumeno/vlaschi in Serbia. Dall'altro lato, esperienze analoghe sono raccontate anche da locutori di una lingua "maggioritaria" nel paese di provenienza che diventa "minoritaria" in contesto migratorio, ad esempio, "serbocroato"/"serbo" a Roma. Sulla base dei dati a mia disposizione, non posso valutare approfonditamente gli effetti di tale delegittimazione sugli usi linguistici "reali" dei partecipanti. Tuttavia, le biografie linguistiche raccolte mostrano come la delegittimazione di un codice a livello comunitario abbia un forte impatto per lo meno sulla volontà dei singoli di mantenere o sostituire tale varietà 
linguistica in contesto migratorio. Detto ciò, il confronto tra le interviste del corpus dimostra comunque che la struttura di un repertorio individuale non dipende ovviamente solo dallo status e dal prestigio conferito alle varietà linguistiche conosciute dalle comunità in cui si ha vissuto. Alcuni partecipanti infatti interiorizzano, altri invece resistono alle stigmatizzazioni della propria lingua come illegittima (cfr. l'uso dei quasi-glottonimi in funzione oppositiva, descritto al §IV.3.4 e più avanti in questo paragrafo).

Al contrario, l'impiego di quasi-glottonimi in funzione "enfatica" contraddistingue quei partecipanti che sentono le proprie competenze nella lingua d'origine come messe in discussione dalla situazione "intervista" e/o, in generale, dalla comunità linguistica d'origine e/o di arrivo. Infatti, questi informanti sembrano interpretare l'interazione in corso come un'inchiesta, piuttosto formale, sul proprio livello di padronanza dei codici conosciuti. Inoltre, alcuni di questi narratori, specialmente se emigrati da giovani, raccontano spesso di avvenimenti che li hanno posizionati come "parlanti illegittimi" del codice di partenza, vale a dire come locutori dalle competenze non riconosciute - in quanto viste come incomplete e, quindi, non native da parte della comunità dei suoi locutori - della prima lingua appresa. Due sono le reazioni a questo (presunto) mancato riconoscimento, rinvenute nelle biografie linguistiche del corpus. Da un lato, numerosi narratori di questo gruppo si servono - più o meno frequentemente e in modo più o meno isolato nel discorso di quasi-glottonimi, connotati sulla dimensione emozionale-identitaria (ad es. "madrelingua", "mia lingua" e, talvolta, "nostra lingua"). La loro funzione è quella di mettere in risalto la posizione centrale della varietà linguistica così riferita nel proprio repertorio. Al contempo, questi intervistati rappresentano la "madrelingua" come un codice fortemente mantenuto in contesto migratorio ed esprimono così affiliazione con la comunità linguistica dei suoi parlanti, indipendentemente dal proprio grado di padronanza del codice (cfr. BL, OV, AS, YF, XF, ZT, SP, DL, VM, AC, FR, TF, ML, NJ). Dall'altro lato, altri intervistati, che hanno esperito situazioni di delegittimazione analoghe, si posizionano invece come parlanti senza "madrelingua". In aggiunta o in alternativa a ciò, caratterizzano il proprio modo di parlare il codice di partenza come una sorta di idioletto (es. "lingua privata" o "lingua mescolata"), non coincidente con nessuna varietà linguistica riconosciuta a livello ufficiale (cfr. AF e NM). Nel fare ciò, questi narratori si servono enfaticamente di denominazioni generiche o anche di glottonimi specifici (es. "montenegrino" o "mio serbocroato"), conferendo però loro un significato parzialmente innovativo.

In tutte le interviste del secondo gruppo, il codice d'origine non risulta comunque ambiguo per la ricercatrice. La sensazione, propria o presupposta negli interlocutori, di non padroneggiare perfettamente la lingua del paese di partenza dipende frequentemente - per lo meno secondo i racconti degli intervistati - da ritorni temporanei (per esempio, per le vacanze) nelle località di nascita, dopo un trasferimento avvenuto da bambini in un paese straniero. Tuttavia, il problema della sostituzione di lingua per dimenticanza e un conseguente uso di quasi-glottonimi in funzione enfatica per il codice di partenza si riscontrano anche nelle biografie linguistiche di informanti emigrati da adulti. In alcuni casi, tale sensazione di attrito è rafforzata dalle misure di pianificazione linguistica, volte all'elaborazione dei quat- 
tro codici standard ("bosniaco", "croato", "montenegrino", "serbo"), successivi al "serbocroato".

Infine, un uso di quasi-glottonimi in funzione "oppositiva" caratterizza le interviste con quei partecipanti che si identificano con varietà linguistiche che hanno recentemente subito processi di delegittimazione a livello istituzionale, in conseguenza di interventi di pianificazione linguistica avvenuti dall'alto ed ex abrupto. Tuttavia, tali codici - forse proprio per l'artificiosità di queste misure di codificazione - non hanno necessariamente perso il loro prestigio agli occhi di ogni loro singolo locutore. Gli intervistati del terzo gruppo sono parlanti di varietà neoštokave. Il modo di rapportarsi con i codici e la comunità linguistica d'origine da parte di questi informanti presenta somiglianze e differenze con quello dei partecipanti del primo e del secondo gruppo. Da un lato, questi narratori possono avere, infatti, la sensazione di parlare "lingue illegittime" in quanto non (più) riconosciute come ufficiali. Così, similmente ai parlanti del primo gruppo, sono reticenti nel nominare il nome specifico del codice di partenza e si servono, perciò, strategicamente di denominazioni generiche che risultano ambigue per la ricercatrice. Dall'altro lato, gli intervistati del terzo gruppo possono avere l'impressione che le proprie competenze nei codici d'origine siano delegittimate a livello comunitario dal momento che queste si riferiscono a stadi precedenti di standardizzazione. In reazione a ciò, analogamente ai "parlanti illegittimi" di un codice, affermano di aver mantenuto tale varietà linguistica in contesto migratorio e ne ribadiscono l'allocazione privilegiata nel proprio repertorio. I "parlanti illegittimi di lingue (diventate) illegittime" ribadiscono, quindi, a livello sia contenutistico, sia formale la propria identità linguistica di parlanti di un codice, senza specificare quale questo sia. Un tale comportamento "schizoglottico" (cfr. Goebl 1979) dipende verosimilmente dal fatto di aver esperito, nel corso della propria vita, il venire meno del riconoscimento a livello istituzionale della varietà e della comunità linguistica, rispetto a cui si vuole ancora esprimere affiliazione.

Gli interventi di pianificazione linguistica, volti ad elaborare i quattro codici standard successivi al serbocroato, hanno avuto luogo in momenti diversi e con tempi differenti nei paesi successori alla Jugoslavia. Così, anche i quasi-glottonimi possono essere adoperati in opposizione a glottonimi specifici diversi a seconda dei partecipanti. In particolare, alcuni narratori usano l'espressione "nostra lingua" per riferirsi al "serbocroato" (cfr. KM, BV, SV). In questi casi, la circonlocuzione con il possessivo "nostra" è, infatti, coerentemente adoperata per chiamare, tra l'altro, anche la lingua franca usata con parlanti di minoranze linguistiche nell'area di partenza e/o con parlanti di serbocroato come lingua seconda nella regione di arrivo. Invece, altri intervistati alludono con le denominazioni "madrelingua" e "nostra lingua" a varietà linguistiche ufficiali in fasi intermedie di standardizzazione, ossia successive al "serbocroato", ma comunque precedenti ai codici attuali. Così, nelle biografie linguistiche di $\mathrm{PB}, \mathrm{KS}$ e $\mathrm{JB}$, la varietà linguistica riferita tramite quasi-glottonimi è verosimilmente il codice comune di Serbia e Montenegro. Invece, nella sua intervista, LA si serve della circonlocuzione "madrelingua" per opporsi alla distinzione tra le varietà linguistiche attualmente chiamate "Bosnisch Kroatisch Serbisch" (bosniaco croato serbo). La situazione sociolinguistica a cui si 
riferisce implicitamente con questa denominazione è, tuttavia, una in cui "serbo" e "croato" sono categorizzate come "varianti" (cfr. anche § IV.2.3). Infine, il caso di DR è piuttosto difficile da interpretare. Da un lato, la donna alterna la denominazione generica "nostra lingua" esclusivamente al nome specifico "serbo", senza far mai riferimento, a differenza di altri partecipanti di questo gruppo, al codice "serbocroato". Dall'altro lato, similmente a questi ultimi, la partecipante sembra essere consapevole e, perlomeno a tratti, volersi opporre alle connotazioni che i nomi di lingua specifici, suo malgrado, hanno nell'area di partenza (cfr. anche § IV.2.2). In considerazione di ciò, DR adopera il glottonimo "nostra lingua", almeno in alcune sequenze dell'intervista, in opposizione al nome specifico "serbo". Questo è inteso - in conseguenza della storia specifica degli interventi di pianificazione linguistica in Serbia - come un codice naturalmente evolutosi dal "serbocroato". In altre sequenze del colloquio, la narratrice sembra invece servirsi del quasi-glottonimo "nostra lingua" in modo fossilizzato, ossia senza una specifica funzione in interazione. 



\title{
CAPITOLO V: NARRAZIONI DI INTERAZIONI
}

\author{
INTRODUZIONE
}

L'analisi delle denominazioni di lingua nel capitolo IV aveva il fine di illustrare i modi in cui i partecipanti si rapportano ai repertori individuali e comunitari di partenza al momento dei colloqui. Dall'esame è risultato che le rappresentazioni e le prese di posizione degli intervistati nei confronti dei codici d'origine non sono fisse, ma si evolvono sequenzialmente nel corso delle conversazioni, in parte anche in relazione a fattori micro-contestuali. Inoltre, si è potuto constatare che i rapporti di differenziazione tra tali varietà linguistiche variano anche in diacronia apparente. Questi si modificano infatti a seconda degli eventi e/o delle circostanze di vita a cui i partecipanti si riferiscono nel narrare.

Tema del capitolo V sono gli usi linguistici nel contesto d'arrivo per come sono messi in scena nei racconti di dialoghi delle biografie linguistiche raccolte. L'analisi, esposta nel presente capitolo, completa quella del capitolo precedente in primo luogo da un punto di vista descrittivo. Infatti, mira a ricostruire come i partecipanti si posizionano verso i modi e le norme di impiego di tutte le varietà linguistiche (ri)conosciute - sia d'origine, sia d'arrivo, sia di contatto - indipendentemente dal luogo in cui queste sono state apprese. Diversamente dal capitolo precedente, nei prossimi paragrafi mi concentro tuttavia solo sulle rappresentazioni degli usi linguistici in uno spazio-tempo circoscritto, ossia dopo l'emigrazione in Alto Adige. Nel fare ciò, presto comunque attenzione alle ragioni biografico-individuali e storico-collettive che influiscono sulla configurazione attuale dei repertori, per lo meno nell'ottica degli intervistati. Ciò mi permette di individuare alcuni tipi di repertori e alcuni modelli di comportamento linguistico, validi nella specifica situazione studiata.

In secondo luogo, l'analisi delle narrazioni di interazioni corrobora e consente talvolta di precisare i risultati ottenuti dall'esame di glottonimi e apposizioni. Da una parte, similmente all'indagine esposta nel capitolo precedente, mostra infatti che gli intervistati negoziano l'allocazione dei codici non solo d'origine, ma anche d'arrivo nel proprio repertorio. Nel fare ciò, hanno il fine, più o meno esplicito, di costruire insieme agli interlocutori una determinata rappresentazione di sé in interazione. Dall'altra parte, permette di confrontare le strategie argomentative e narrative adoperate dai partecipanti per rendere conto della situazione sociolinguistica di partenza con quelle da loro impiegate per dare un senso alla realtà sociolinguistica altoatesina. Queste ultime possono essere, inoltre, a loro volta paragonate con quelle adottate da parlanti autoctoni e analizzate in ricerche precedenti, talvolta di stampo biografico (cfr. § II.1 e sgg.). Quest'ultimo confronto consente di definire meglio come i singoli parlanti rielaborano in modo più o meno convenzionale $\mathrm{o}$, al contrario, creativo le rappresentazioni di fenomeni linguistici, condivise a livello collettivo, con cui sono entrati in contatto in diversi momenti della loro vita. 
Il capitolo V è strutturato in quattro sezioni. Dopo aver introdotto il concetto di repertorio narrato, nella prima sezione discuto la definizione di "narrazioni di interazioni", adottata nel presente volume, e illustro le ragioni per cui le sequenze narrative offrono, a mio avviso, un accesso speciale alle rappresentazioni delle esperienze linguistiche e ai giudizi metalinguistici dei partecipanti al momento dei colloqui (cfr. §V.1). Nella seconda parte, presento invece i criteri e i concetti analitici utilizzati per l'analisi delle sequenze narrative e motivo la decisione di concentrarmi specificamente sulle biografie linguistiche di tre intervistate donne (cfr. $\S$ V.2). ${ }^{1}$ Infine, i $\S$ V.3 e V.4 costituiscono il corpo centrale del presente capitolo, in cui è esposta l'analisi vera e propria. Nel corso di queste due sezioni, confronto come le tre partecipanti selezionate rappresentano, nelle loro narrazioni di dialoghi, la distribuzione delle varietà linguistiche usate in Alto Adige rispettivamente in relazione al contesto e agli interattanti. Al contempo, ricostruisco gli atti di posizionamento più salienti delle narratrici al momento di organizzare sequenzialmente, ma anche coerentemente la loro biografia linguistica insieme all'interlocutrice.

\section{TERMINOLOGIA INTORNO AL CONCETTO DI REPERTORIO NARRATO}

Le sequenze delle interviste analizzate nei prossimi paragrafi sono storie di dialoghi. Perciò chiamo l'insieme delle rappresentazioni e prese di posizione riguardo alle risorse linguistiche, ai loro rapporti e condizioni di impiego il "repertorio narrato" dei partecipanti. Al momento di metterne in rilievo l'articolazione spaziale, mi servo inoltre del termine "spazio comunicativo narrato".

Sia qui ribadito che il repertorio narrato di un intervistato non ritrae i suoi usi linguistici "reali" nel contesto d'arrivo. Inoltre, dal momento che la ricostruzione del repertorio narrato si basa sul testo interazionale delle interviste, l'analisi non permette nemmeno di individuare gli "atteggiamenti" linguistici dei partecipanti o il loro modo di "percepire" tout court la realtà sociolinguistica altoatesina. I repertori narrati sono invece piuttosto costituiti dalle "prese di posizione" e "rappresentazioni" - e non dagli atteggiamenti o percezioni - rispetto alle risorse linguistiche conosciute, riconosciute o desiderate dagli intervistati al momento del colloquio (cfr. anche $\S$ I.1.4 e $\S$ III.2.3).

D'altro canto, il repertorio narrato non coincide neppure con quello che potrebbe essere definito il "repertorio dichiarato" dei partecipanti. Intendo questo ultimo come la rappresentazione, bidimensionale e decontestualizzata, degli usi linguistici dei singoli che risulta, per esempio, dalle risposte a un questionario scritto $\mathrm{o}$ anche dalle affermazioni formulate in risposta a domande dirette della ricercatrice

1 Sia perché sono convinta dell'importanza della parità nell'uso del genere nel linguaggio, sia perché le biografie linguistiche analizzate nel presente capitolo sono raccontate da tre intervistate donne a una interlocutrice, utilizzerò prevalentemente forme al femminile per riferirmi alle partecipanti delle conversazioni. Non per questo, i tipi di repertori narrati, rinvenuti nel corso dell'analisi, non sono, in parte, generalizzabili ad altri intervistati del corpus. 
in un'intervista (semi-)strutturata. Come già notato, le dichiarazioni dei partecipanti riguardo alle modalità di impiego dei codici (ri)conosciuti si precisano, generalizzano e, talvolta, apparentemente contraddicono nel corso delle biografie linguistiche raccolte. Tale variabilità motiva la decisione di analizzare dettagliatamente le sequenze narrative delle interviste, in cui determinati fenomeni linguistici sono messi in scena.

La precisazione della distinzione tra "repertorio narrato" e "repertorio dichiarato" è uno degli obiettivi dell'analisi esposta in questo capitolo (e costituisce solo intuitivamente il suo punto di partenza). Tuttavia, sia qui anticipato che il repertorio narrato degli intervistati non coincide con il repertorio dichiarato per lo meno per tre ragioni. In primo luogo, la sua ricostruzione tiene conto del fatto che alcuni contesti e interattanti siano più "salienti" (nel senso di più rilevanti) di altri, nell'ottica dei singoli partecipanti, per raccontare la propria biografia linguistica. In secondo luogo, mira a mettere in evidenza come le rappresentazioni degli usi linguistici siano "negoziate sequenzialmente" in interazione e "contestualizzate" nella situazione comunicativa dell'intervista. Infine, partendo da una ricognizione di tutte le risorse linguistiche (ri)conosciute dai parlanti nell'ambiente circostante, l'analisi dei repertori narrati tenta di ricostruire come gli usi linguistici dei singoli e le loro prese di posizione su fatti di lingua siano condizionate (in positivo o in negativo) da abitudini linguistiche di altri (gruppi di) locutori e/o da opinioni metalinguistiche diffuse nella comunità. Ciò consente di aggiungere una terza dimensione al concetto di repertorio, accanto a quella individuale e comunitaria, che definisco "soggettiva". ${ }^{2}$ Il repertorio narrato integra questi tre aspetti tra loro correlati delle rappresentazioni degli usi linguistici propri e altrui, vale a dire quello della i) salienza, ii) sequenzialità e contestualizzazione e iii) soggettività. Nel fare ciò, offre, a mio avviso, una rappresentazione emica dei rapporti tra $\mathrm{i}$ codici peculiare rispetto a quella del repertorio dichiarato in quanto dinamica e polifonica.

\subsection{Per una definizione di narrazione}

In un'intervista narrativa (ma anche nella conversazione quotidiana), i tre "tipi di testo" (Textsorten) o attività comunicative che potremmo definire "ideali" - ossia quelli del "raccontare", del "descrivere" e dell'"argomentare" - sono frequentemente intrecciati tra loro e/o subordinati l'uno all'altro (cfr. Lucius-Hoene e Deppermann 2004: 171-174, Deppermann \& Lucius-Hoene 2006). Inoltre, la stessa specifica attività del narrare si realizza concretamente in forme testuali linguisticamente e strutturalmente eterogenee e non sempre univocamente delimitabili (cfr. Schwitalla 1997). Per distinguerle ci si basa, tra l'altro, i) sulla prospettiva adottata dal narratore nel raccontare un episodio, ii) sul modo in cui gli eventi sono concatenati tra loro e iii) sul tipo di attività valutative prevalenti in una storia. In conside-

2 Per una definizione del concetto "soggettività" in chiave sociolinguistica si confronti Busch (2013: 13-79) e Kramsch (2009: 16-22). La nozione sarà discussa, nel presente volume, anche al § V.3 e seguenti e al §VI.4. 
razione di ciò e in linea con altri studi che considerano la "narratività" una caratteristica scalare e non categoriale di un testo (cfr., per esempio, Carranza 1998, Ochs \& Capps 2001: 1-58, De Fina \& Georgakopoulou 2012: 108-121), la definizione di narrazione, adottata nella presente ricerca, si basa su criteri piuttosto "larghi". Questa è da intendersi come un'ipotesi di lavoro che, invece di essere stata "operazionalizzata" a priori e applicata ai dati, è stata ripetutamente modificata nel corso dell'analisi per adeguarsi a loro, seguendo un approccio induttivo e circolare (cfr. Lamnek 1988/2010: 107-127).

Nel prossimo paragrafo, illustro i parametri attraverso cui ho individuato i racconti di dialoghi nel testo interazionale delle interviste raccolte (cfr. §V.1.1.1). Per motivare più compiutamente la loro scelta, al $\S$ V.1.1.2, presento inoltre le funzioni, talvolta molteplici, che (tipi di) sequenze narrative possono assolvere nel cotesto locale e/o nel discorso biografico generale. Infine, al §V.1.1.3, differenzio sulla base del loro contenuto due categorie di narrazioni di interazioni rinvenute nel corpus, quelle con argomento "extra-linguistico" e quelle con argomento "metalinguistico".

\subsubsection{Criteri di selezione}

Nel porre le basi per un approccio linguistico all'analisi formale e funzionale delle storie orali di esperienze personali, Labov \& Waletzky (1967) formulano la seguente definizione di narrazione come "tipo di testo":

Narrative will be considered as one verbal technique for recapitulating experience - in particular, a technique of constructing narrative units that match the temporal sequence of that experience. Furthermore, we find that narrative that serves this function alone is abnormal: it may be considered empty or pointless narrative. Normally, narrative serves an additional function of personal interest, determined by a stimulus in the social context in which the narrative occurs. We therefore distinguish two functions of narrative: (a) referential and (b) evaluative.

(Labov \& Waletzky 1967: 13. Enfasi nell'originale)

Secondo la definizione citata, un primo criterio per distinguere le narrazioni da altri tipi di testo, che parimenti riepilogano esperienze passate, è l'organizzazione temporale degli avvenimenti messi in scena verbalmente dal narratore. L'ordine delle "unità narrative" di una storia - altrove chiamate anche "clausole narrative" (narrative clauses) - corrisponde, in particolare, alla sequenza temporale dei fatti riportati. In conseguenza di ciò, un racconto minimo contiene almeno una "giuntura temporale" (temporal juncture), ovvero due clausole ordinate cronologicamente tra di loro così da non poter essere invertite senza modificare 1' "interpretazione semantica" originaria della storia (cfr. Labov \& Waletzky 1967: 21 e, anche, Labov 1997, 2013: 17). In secondo luogo, secondo Labov \& Waletzky, una narrazione per essere tale non assolve esclusivamente la "funzione referenziale" di ricapitolare una serie di fatti, ma ne offre anche un'interpretazione in senso "valutativo" e una rappresentazione drammatica (cfr. anche Goffman 1974: 504-506). Infine e in connessione con ciò, Labov \& Waletzky delimitano, poco prima del passo riportato sopra, l'oggetto del loro studio ai soli racconti orali di esperienze personali. Tale scelta è mo- 
tivata dai due ricercatori inizialmente da ragioni pratiche, ossia dalla necessità di concentrarsi sulle strutture narrative più semplici a causa dell'arretratezza degli studi sul tema (cfr. ibidem: 12). Tuttavia, per Labov (1997: 397), la decisione di analizzare le narrazioni personali che trattano di accadimenti "seri e memorabili", "entrati nella biografia del parlante" (entered into the biography of the speaker), è giustificabile anche con ragioni di natura teorica. In misura maggiore rispetto a resoconti casuali, umoristici o triviali, queste storie, specie se raccontate in intervista, consentono infatti di esaminare come i narratori mettano con agio alla prova determinate tecniche narrative e trasformino i fatti esperiti, valutandoli emozionalmente e socialmente. ${ }^{3}$

Tale definizione di narrazione ha fortemente condizionato studi narratologici successivi, specie quelli di approccio biografico. Questi ultimi sono infatti frequentemente incentrati sull'esame di "storie grandi" (big stories), ovvero di ricapitolazioni ben formate e riflettute di episodi chiave nella vita di un parlante. La convinzione di fondo è che, principalmente, se non esclusivamente attraverso questi racconti, il ricercatore possa avere accesso alla rappresentazione di sé del narratore (cfr. De Fina \& Georgakopoulou 2012: 159-166 anche per ulteriori riferimenti bibliografici). Anche l'analisi, esposta nel presente volume, si basa esclusivamente su dati raccolti in interviste sociolinguistiche. Tuttavia, nei paragrafi successivi, considero come "narrative" un insieme più ampio di sequenze rispetto a quello che risulterebbe adottando i criteri appena delineati di Labov \& Waletzky. La decisione di includere diversi tipi di racconti dipende da ragioni teoriche oltre che etnografiche (cfr. anche $\S$ V.1.1.2). Infatti, deriva dalla convinzione che le rappresentazioni dei partecipanti riguardo alla realtà sociolinguistica locale debbano essere ricostruite anche sulla base della valutazione di prese di posizione parziali, più o meno estemporanee. Queste ultime sono tipicamente negoziate vis-à-vis con la ricercatrice in "storie piccole" (small stories). Con l'iperonimo "storie piccole" ci si riferisce, in particolare, ad attività narrative e/o con un'orientazione narrativa che non seguono la struttura archetipica delle narrazioni di esperienze personali, passate ed eccezionali. Il loro studio - che spesso, ma non esclusivamente, si basa su dati raccolti in interazioni quotidiane - mira proprio a rendere conto degli aspetti situativi e interazionali della costruzione di sé e di identità, più o meno transitorie, in relazione agli interlocutori e a obiettivi perseguiti localmente (cfr. Bamberg \& Georgakopoulou 2008 e, in particolare, Bernhard 2014 per un metodo che combina l'analisi di storie "grandi" e "piccole" in interviste biografico-narrative).

Sebbene non predominante, lo studio delle "narrazioni in interazione" ha comunque una tradizione di ricerca piuttosto lunga e non è del resto estraneo neanche ai lavori dello stesso Labov. Queste ricerche hanno soprattutto il merito di aver mostrato come obiettivi discorsivi e interazionali, insieme al contesto situazionale

3 Si rammenti che, come egli stesso ripetutamente ricorda, Labov raccoglie inizialmente narrazioni di esperienze personali come conseguenza indiretta del metodo sviluppato per elicitare dati di parlato vernacolare, non controllato. Le storie sono narrate dagli informanti in risposta a domande che provocano un alto coinvolgimento emotivo, ad esempio quella sul "pericolo di morte" (cfr. Labov 1997, 2013). 
e generale - in altri termini, insieme al contesto micro e macro - in cui l'attività narrativa si svolge, influenzino forma e contenuto di un racconto parimenti ai principi di organizzazione temporale. Così, il desiderio di assegnare lode o biasimo ai personaggi può portare, per esempio, il narratore a inserire eventi non strettamente necessari nella catena causale dei fatti riportati (cfr. Labov 1997, 2013). Similmente, il ri-raccontare una storia già conosciuta per sommi capi assolve talvolta la funzione di stabilire o contestare l'appartenenza del parlante o dei destinatari a gruppi di pari o a istituzioni, indipendentemente da una riproduzione fedele dello svolgersi della vicenda (cfr. Georgakopoulou 2005, Linde 2009). Al contempo, il tipo di relazione tra narratore e pubblico o la volontà di posizionarsi nel mondo della storia e/o dell'interazione possono, per esempio, influenzare il tipo di informazioni - ad esempio, fattuali o valutative - considerate rilevanti nel raccontare un episodio e le strategie di rappresentazione - ad esempio, scelte lessicali e pronominali, impiego di analessi o prolessi - adottate nel metterlo in scena (cfr. rispettivamente De Fina 2008, De Fina 2009, da un lato, e Bamberg 1997, Lucius-Hoene \& Deppermann 2004: 196-212, Deppermann 2013, dall'altro).

Le storie, analizzate in questo capitolo, sono così caratterizzate da diversi gradi di "narratività" e occupano posizioni diverse lungo i cinque continua o dimensioni di variazione, individuate da Ochs \& Capps (2001: 18-58), ossia quelle della i) "autorialità" (tellership), ii) "inclusione" (embeddedness), iii) "linearità" (linearity), iv) "raccontabilità" (tellability) e v) "posizionamento morale" (moral stance). Nello specifico, conformemente alla definizione di Labov \& Waletzky, le sequenze narrative considerate riferiscono sempre di una serie di (almeno due) accadimenti in successione temporale. Tuttavia, le storie del corpus trattano di eventi non solo vissuti dal narratore-autore in prima persona, ma anche da altri personaggi, fittizi o reali, e alla cui ricostruzione in forma narrativa partecipa, più o meno attivamente, anche l'intervistatrice, ad esempio, con segnali di feedback o gesti (cfr. il parametro dell'“autorialità"). ${ }^{4}$ I racconti esaminati presentano inoltre diversi gradi di agganciamento ("inclusione") con il cotesto circostante e con l'attività comunicativa in corso, ossia sono, per esempio, talvolta raccontati spontaneamente, talvolta in reazione a osservazioni della ricercatrice. Al contempo, gli avvenimenti riferiti sono organizzati in modo più o meno "lineare" dal punto di vista temporale e/o causale. Questi non sono del resto necessariamente singolari, puntuali o fattuali, ma possono anche essere ricorrenti e/o tra loro parzialmente concomitanti e/o non (ancora) verificatesi. In connessione con ciò, non tutte le narrazioni analizzate nei prossimi paragrafi sono altamente "raccontabili", in quanto incentrate intorno a un (unico) avvenimento culmine, inaspettato ed eccezionale, né veicolano necessariamente una sua interpretazione coerente e un atto di "posizionamento morale" nei suoi confronti da parte del narratore. A differenza delle "storie prototipo" per forma e contenuto, non è così sempre possibile identificare 1" "evento più riportabile" (the

4 Sulla rilevanza delle storie in terza persona per valutare gli atti di posizionamento dello stesso narratore si vedano anche Bamberg (1997: 342) e Günthner (2007: 435). 
most reportable event $)^{5}$ del racconto, vale a dire quella specifica azione o situazione che ha il maggiore effetto sui personaggi della storia e che è l'oggetto principale delle valutazioni dell'io narrante (cfr. Labov 1997: 404-406). Infine, nel presente capitolo, i termini "narrazioni", "racconti" e "storie" sono usati come sinonimi. Tuttavia sia qui accennato che il sostantivo inglese "stories" è solitamente impiegato per riferirsi alle narrazioni "prototipo" per forma e contenuto (cfr. De Fina 2003: 14) o alle storie "di default", vale a dire ai racconti che si collocano a un'estremità degli assi identificati da Ochs \& Capps (2001: 20), appena descritti.

Dopo aver individuato le sequenze con un'orientazione narrativa nel testo interazionale delle interviste, ho poi selezionato solo un sottogruppo di storie che definisco "narrazioni di interazioni" (o "storie di dialoghi"). In questi racconti, la narratrice mette in scena uno o più dialoghi e, quindi, riferisce di almeno un'attività comunicativa, frequentemente messa in scena in discorso diretto. In secondo luogo, nelle narrazioni prese in esame, il codice di comunicazione tra i personaggi nel mondo della storia è deducibile dal contesto. La lingua dell'interazione è infatti incidentalmente o deliberatamente nominata dall'intervistata e/o da lei imitata e/o da lei menzionata in seguito a una domanda della ricercatrice (cfr. § V.2.1 per maggiori dettagli). Infine, i racconti analizzati nei paragrafi successivi sono tutti ambientati in Alto Adige. La scelta di questi ultimi tre criteri di selezione è motivata dalle mie domande di ricerca. Le narrazioni di interazioni consentono infatti di valutare come le partecipanti rappresentino specificamente gli usi linguistici propri e altrui nel contesto d'arrivo al momento del colloquio.

Riassumendo, la selezione di storie condotta per l'analisi del presente capitolo si basa sulla seguente definizione di narrazione di interazione:

Le narrazioni di interazioni (o racconti di dialoghi) sono rappresentazioni di almeno due eventi, passati, futuri, ipotetici o contro-fattuali, eccezionali, abituali o familiari, organizzati temporalmente, ambientati in Alto Adige e messi in scena dalla prospettiva propria o di altri personaggi. Inoltre, in una narrazione di interazione, almeno uno degli avvenimenti riferiti è un'attività comunicativa, mentre la lingua del dialogo nel mondo della storia è deducibile dal contesto o perché nominata spontaneamente dalla narratrice o perché da lei imitata o perché da lei menzionata in risposta a una domanda della ricercatrice.

\subsubsection{Tipi di storie di dialoghi}

Come accennato nel paragrafo precedente, diversi tipi di storie, più o meno conformi al prototipo, sono risultati rilevanti da un punto di vista etnografico per ricostruire come le partecipanti si posizionano rispetto alla realtà sociolinguistica altoatesina e/o alla propria capacità di negoziazione di codice dopo mobilità in un paese straniero. Significative per questi fini sono, in primo luogo, le narrazioni "con-

5 Traduco "reportable" con "riportabile" e non con "raccontabile" perché il concetto non coincide con quello di "raccontabilità" (tellability) (cfr. Paternostro 2013a: 156-158 per una traduzione analoga e $\S$ V.2.3 per maggiori dettagli). 
tro-fattuali" e “ipotetiche” (cfr. Carranza 1998: 291-297). Queste sequenze narrative - rinvenibili sia da sole, sia inserite in storie di vicende fattuali più lunghe raccontano rispettivamente di eventi immaginari che non sarebbero potuti o potrebbero verificarsi. Il mettere in relazione avvenimenti accaduti con altri non (ancora) realizzatisi ha l'effetto di porre in evidenza, per contrasto o per analogia, determinati episodi di una storia e/o di motivare uno specifico corso di azioni (cfr. anche Labov 1972: 380-393, Labov 2013: 226-227). In conseguenza della loro funzione focalizzante ed esplicativa, i racconti contro-fattuali e ipotetici sono spesso usati per "fare un punto" (to make a point) e per supportare un'affermazione a fini argomentativi (cfr. sempre Carranza 1998: 291, 296-297). Nelle biografie linguistiche raccolte possono, per esempio, essere adoperati per presentare all'interlocutrice una determinata scelta di lingua in uno specifico contesto e/o con una determinata costellazione di partecipanti come irrealizzabile o desiderabile.

In secondo luogo, parimenti significative per rispondere alle mie domande di ricerca sono le narrazioni "abituali" e/o "generiche". Le prime sono storie di episodi, azioni, situazioni caratterizzate dal narratore come ricorrenti (cfr. Carranza 1998: 297-307). ${ }^{6}$ I racconti generici riferiscono invece di una sequenza di eventi, presentandola come tipica o emblematica per un gruppo di persone (cfr. Baynham 2005: 16-19 e anche De Fina \& Georgakopoulou 2012: 113). Le due categorie si sovrappongono qualora vicende ripetute siano raccontate in forma generica (cfr. Norrick 2000: 151-154). Queste narrazioni permettono di risalire agli usi linguistici valutati dal narratore o dalle persone appartenenti al suo reticolo sociale come normali e/o adeguati alla norma dopo l'esperienza di mobilità. Infatti il parlante vi mette in scena fenomeni linguistici considerati ordinari nei loro tratti essenziali. Inoltre, nella misura in cui vicende presentate come ricorrenti e/o collettive sono più difficili da questionare ed elidono esperienze singolari, questi tipi di storie veicolano e tramandano frequentemente interpretazioni "consolidate" (Carranza 1998: 306-307), se non "egemoniche" (Baynham 2005: 19-21) di questioni, nel presente caso, (meta)linguistiche.

In terzo luogo, anche le "storie ri-raccontate" (retold stories o retold tales) sono utili per ricostruire le rappresentazioni dei rapporti tra codici degli intervistati. La qualifica di "ri-raccontato" è stata adoperata in letteratura con un significato più o meno generale e/o in concorrenza con termini diversi. Per esempio, Linde (2009: 72-88) si serve del termine "storie ri-raccontate" (retold tales) per riferirsi soprattutto a quelle narrazioni che in studi precedenti aveva definito "non-partecipate", ossia alle storie in cui il narratore non era presente in prima persona, ma che gli sono state appunto (ri)raccontate, nel senso di riferite, da altri (cfr. Linde 1997). Invece, Georgakopoulou (2005: 224), in un articolo pubblicato nella sezione "retold stories" della raccolta di Quasthoff \& Becker (2005), sostituisce l'epiteto "ri-raccontato" con quello di "condiviso", conferendo perciò a quest'ultimo termine il valore di iperonimo. Infine, Norrick (2000: 67-103) distingue tra le storie meramente "ri-raccontate" in diversi contesti (retelling o retold stories) da quelle

6 In Lucius-Hoene \& Deppermann (2004: 125), le narrazioni abituali sono invece definite "racconti iterativi" (iterative Erzählungen). 
marcate e riconosciute come tali dagli interlocutori, mentre propone per queste ultime anche la designazione di "racconti familiari" (familiar o family stories). Al contrario, nel presente volume, in linea con la definizione data da De Fina \& Georgakopoulou (2012: 108-111), includo nella categoria delle "storie ri-raccontate" sia gli "aneddoti", sia le "storie condivise" (shared stories), sia le "narrazioni non-partecipate" (non-participant narratives). Pur presentando alcune caratteristiche differenti tra loro (cfr. sotto), questi tipi di racconti sono infatti accomunati dalla peculiarità - con ripercussioni non solo a livello contenutistico, ma anche formale - di riferirsi a (parti di) storie ripetute dal narratore o da altri locutori in circostanze diverse $\mathrm{e} / \mathrm{o}$ a vicende conosciute non solo dal parlante, ma anche da uno o più dei suoi interlocutori.

Nello specifico, le narrazioni cristallizzatesi in "aneddoti" sono rappresentazioni "scenico-episodiche", ossia messe in scena dal punto di vista dei personaggi nel mondo della storia, frequentemente ripetute dal narratore. Questo ultimo è quindi sicuro del loro effetto sul pubblico e spesso se ne serve per caratterizzare persone, eventi e/o circostanze, significative al di là del caso singolo (cfr. Lucius-Hoene \& Deppermann 2004: 152). Una storia ri-raccontata e divenuta un aneddoto può essere così verbalizzata, secondo Rosenthal (2006: 3), senza che sia innescato un processo mnemonico per recuperare gli eventi riferiti. Inoltre, specie se riguardante un episodio chiave nella vita di un individuo, un aneddoto entra a far parte della memoria, negoziata socialmente, di un parlante rispetto alla propria persona (cfr. Linde 2009: 72 e anche Linde 1993). Invece, le "storie condivise" sono narrazioni familiari agli interattanti o perché già raccontate in passato o perché concernono vicende conosciute da (alcuni di) loro, in questo ultimo caso, indipendentemente dal fatto di essere state precedentemente verbalizzate o meno (cfr. Georgakopoulou 2005: 224). Seppur non in modo omogeneo, queste narrazioni tendono a differenziarsi dalle storie prototipo sia i) per alcune peculiarità a livello strutturale, sia ii) per i modi in cui il parlante le introduce o si riferisce a loro nel corso dell'interazione, sia iii) per le routine con cui gli interlocutori segnalano di aver recepito il senso del racconto. Infine, come già accennato, i "racconti non-partecipati" narrano di episodi a cui il narratore non ha assistito personalmente, ma che gli sono stati riferiti da altri (cfr. Linde 1997). Queste storie sono quindi tipicamente raccontate in terza persona. Nei suoi studi, Linde si concentra specificamente su storie ripetute, nel corso del tempo, da parlanti diversi appartenenti a una stessa istituzione. In questo contesto, la ricercatrice distingue una storia effimera (ad es. un gossip) da una radicata nella memoria collettiva proprio per il fatto che la seconda sia fatta propria da (una nuova generazione di) narratori che non hanno vissuto l'episodio in prima persona (cfr. anche Linde 2000, Linde 2009: 72-75).

Sia gli aneddoti, sia le storie condivise, sia i racconti non-partecipati sono similmente condizionati nella loro forma e contenuto da esperienze di racconto in interazioni precedenti così come da aspettative presupposte nel e dal loro pubblico. Durante tali narrazioni, gli ascoltatori contribuiscono inoltre frequentemente - pur con diversi ruoli e gradi di partecipazione - alla rievocazione dell'episodio. Infine, caratteristica rilevante di questi tipi di racconti è il fatto di essere solitamente parte, più o meno stabile, del repertorio di storie di un individuo e/o di gruppi più o meno 
estesi e istituzionalizzati. La commistione tra elementi originali o ideati sul momento, da un lato, e riferimenti ad altri testi o discorsi, dall'altro, è dunque particolarmente visibile in questi tipi di storie. Nella presente ricerca, la loro analisi permette dunque, da una parte, di valutare come rappresentazioni metalinguistiche collettive e/o presupposte negli interlocutori interagiscano con quelle individuali, per esempio, nel co-costruire un'interpretazione comune di determinati fenomeni linguistici o nel rendere un'esperienza di apprendimento personale socialmente significante. Dall'altra parte, consente talora di esaminare come parlanti e destinatari ratifichino o invalidino la propria appartenenza alla comunità linguistica d'arrivo o a determinati milieu di questa (cfr. anche i § V.3.2.1 e V.3.4.1 per esempi concreti di narrazioni condivise e non-partecipate, tratti dal corpus).

In conclusione, sia qui accennato che, secondo De Fina (2009), le storie narrate in intervista sono spesso caratterizzate da una forte orientazione all'interlocutore e sono quindi classificabili sotto il tipo generale dei "resoconti" (accounts). Infatti, il destinatario principale, nel ruolo di intervistatore, detiene e/o si vede attribuito dal parlante - se non necessariamente, in media più frequentemente rispetto $\mathrm{a}$ in altri contesti interazionali - il potere o la responsabilità di valutare la legittimità e l'adeguatezza delle vicende riferite rispetto al tema della conversazione. Da ciò segue che le storie raccontate in intervista siano tendenzialmente contraddistinte da una forte componente dialogica ed esplicativa. Il motivo è appunto che è come se fossero costruite in risposta a una domanda (esplicita o implicita) del ricercatore (cfr. anche De Fina 2003: 98-100). Un'osservazione simile si ritrova anche in Lucius-Hoene \& Deppermann (2004: 145-159). Secondo i due ricercatori, i "racconti scenico-episodici" (szenisch-episodische Erzählung) sono infatti molto meno numerosi, nelle interviste biografiche, rispetto alle sequenze narrative da loro definite alternativamente "rappresentazioni informative" (berichtende Darstellungen) o anche "resoconti" (Berichte). Questo ultimo tipo di storie è caratterizzato dal fatto che avvenimenti, accaduti in periodi di tempo piuttosto lunghi, siano riassunti e valutati dal narratore dalla prospettiva presente. Infine, Lucius-Hoene \& Deppermann (2004: 145-159) individuano una terza tipologia di narrazioni, ossia quella delle "rappresentazioni in forma di cronaca" (chronikartige Darstellung). In queste, gli intervistati enumerano una serie di fatti in ordine cronologico senza però organizzarli dal punto di vista tematico o valutativo lungo un filo conduttore comune. Come sarà meglio illustrato nei prossimi paragrafi, i racconti di dialoghi, rinvenuti nel mio corpus di interviste, si lasciano ricondurre talvolta al primo modo di rappresentazione (ossia a quello dei "racconti scenico-episodici"), talvolta sono fortemente esplicativi e orientati all'interlocutrice e/o riferiscono di avvenimenti nei loro tratti essenziali dalla prospettiva attuale (cfr. il tipo dei "resoconti"), talvolta presentano caratteristiche comuni ad entrambi. Invece, i brani del terzo gruppo (ossia le "rappresentazioni in forma di cronaca"), seppur numerosi in alcune conversazioni, non sono oggetto della presente ricerca: questi non mettono infatti tipicamente in scena dialoghi in forma né diretta né indiretta (cfr. sempre Lucius-Hoene \& Deppermann 2004: 157). 


\subsubsection{Narrazioni extra-linguistiche e metalinguistiche}

In seguito a una prima disamina dei dati raccolti, distinguo tra ulteriori due categorie di narrazioni di dialoghi, questa volta, primariamente sulla base del loro contenuto. Queste due categorie sono da intendersi come tipi ideali, rispetto a cui le storie effettivamente raccontate dai partecipanti del corpus sono più o meno conformi. Da un lato, in certi racconti, i narratori specificano il codice dell'interazione incidentalmente (o perché lo chiede successivamente l'intervistatrice), ma riferiscono di una vicenda imperniata su un avvenimento extra-linguistico. Dall'altro, in alcune narrazioni, la lingua del dialogo e/o la scelta di codice costituiscono il tema principale o, nel caso sia presente, 1 '“evento più riportabile" della storia. ${ }^{7} \mathrm{Dal}$ momento che sono incentrate sul resoconto di fenomeni linguistici e/o sociolinguistici, definisco queste ultime storie "narrazioni metalinguistiche".

Nella tabella 1, indico il numero di narrazioni di interazioni con argomento extra-linguistico e metalinguistico, raccontate nel corso delle loro interviste dalle tre partecipanti (ossia VM, DK e BV), selezionate per l'analisi. La frequenza del secondo tipo di storie si spiega soprattutto con il fatto che le tre conversazioni analizzate sono biografie linguistiche. Inoltre potrebbe, in parte, anche dipendere dall'alta rilevanza ricoperta da questioni (meta)linguistiche nella società (già) plurilingue d'arrivo (cfr. anche § II.1 e II.2).

Tabella 1: Frequenza delle narrazioni di interazioni metalinguistiche e con argomento extra-linguistico nelle interviste di $V M, D K$ e $B V$.

\begin{tabular}{|l|c|c|c|}
\hline & $\begin{array}{c}\text { Narrazioni con argomento } \\
\text { extra-linguistico }\end{array}$ & Narrazioni metalinguistiche & Totale \\
\hline VM & 13 & 24 & 37 \\
\hline DK & 0 & 36 & 36 \\
\hline BV & 3 & 31 & 34 \\
\hline Totale & 16 & 91 & 107 \\
\hline
\end{tabular}

Nella presente ricerca, ricostruisco i repertori narrati delle tre partecipanti sulla base sia delle narrazioni con argomento extra-linguistico sia metalinguistico. Come sarà discusso più approfonditamente nel prossimo paragrafo, entrambi i tipi di racconti di dialoghi sono infatti a mio avviso adatti per studiare, nella loro complessità, le rappresentazioni e le prese di posizione degli intervistati rispetto agli usi linguistici propri e altrui in Alto Adige. Una distinzione tra i due tipi di storie è tuttavia importante, da un lato, perché le narrazioni con argomento extra-linguistico e metalinguistico presentano rispettivamente caratteristiche differenti a livello formale, dall'altro, perché veicolano, nell'hic et nunc dell'interazione, informazioni leggermente diverse sui repertori narrati degli intervistati.

7 Si ricordi che le nozioni di "riportabilità" e di "evento più riportabile" non sono applicabili a tutti i tipi di storie. 


\subsection{Perché le narrazioni di interazioni?}

La decisione di concentrarsi specificamente sulle sequenze narrative, invece che su quelle di carattere più descrittivo o argomentativo, dipende da alcune peculiarità delle storie di dialoghi nelle biografie linguistiche raccolte. ${ }^{8}$ Queste a loro volta si spiegano tramite tre caratteristiche tra loro correlate che contraddistinguono l'attività del narrare in genere, ovvero la realizzazione di i) "polifonia", ii) "interdiscorsività" e/o "intertestualità" e iii) "partecipazione". Tali proprietà sono discusse in dettaglio nei prossimi tre paragrafi.

\subsubsection{Polifonia}

La scelta di trattare un tema, anche parzialmente elicitato dalla ricercatrice, raccontando una storia implica che l'intervistato decida di approcciarsi alla questione in modo più personale e sia più interessato a stabilire un'interpretazione comune con gli interlocutori rispetto, per esempio, a quando semplicemente enumera le lingue parlate in un contesto in seguito a una domanda della ricercatrice (cfr., per riflessioni in linea con ciò, anche Bamberg \& Georgakopoulou 2008: 12-13 e Lucius-Hoene \& Deppermann 2004: 171). Inoltre, raccontando una storia, un parlante solitamente costruisce, insieme ai destinatari, un testo in cui rielabora in modo coerente esperienze (anche linguistiche) da una prospettiva che è al contempo "individuale" e "polifonica"9 (cfr. anche Goffman 1974, De Fina 2003: 6-7). Infatti, lo scarto temporale tra il mondo della storia e quello dell'interazione, insieme alla possibilità di animare altri personaggi oltre al proprio, consente al narratore (o "io narrante") non solo di presentare il proprio punto di vista riguardo a un evento o a un argomento. Al contempo, gli permettono anche di articolarlo in modo complesso e articolato, prendendo posizioni manifeste o latenti a diversi livelli del discorso e/o in relazione a opinioni differenti. In altre parole, un narratore veicola in una storia $i$ punti di vista singolari di diversi personaggi-soggetti e può posizionarsi nei loro confronti in modo implicito a differenza di quanto solitamente avviene in altri tipi di testo. Così, per esempio, nel mettere in scena atti linguistici altrui durante le loro biografie linguistiche, le narratrici possono indirettamente disallinearsi dai comportamenti riferiti, modificando il tono di voce e/o commutando il codice dell'interazione. Nel fare ciò, le partecipanti negoziano contemporaneamente per se stesse un'identità linguistica in negativo, ossia "si categorizzano en passant indicizzando chi sono in contrasto con le figure sociali animate" (cfr. Günthner 2007: 434, tr. della scrivente e, in generale, Goffman 1981). ${ }^{10}$

8 Sia qui ribadito che la distinzione tra sequenze narrative e non narrative di una biografia linguistica non è comunque netta e che, qui come altrove, mi riferisco a brani con un'orientazione narrativa.

9 In alternativa, questa prospettiva potrebbe essere definita anche "intersoggettiva", ossia che prende in considerazione il punto di vista di diversi soggetti (cfr. sotto).

10 Particolarmente rilevanti a questo riguardo sono le nozioni di "inclusione" e "dislocazione", adoperate da Goffman (1981) per illustrare i modi di citazione del discorso riportato proprio e altrui (cfr. $\S$ V.4 e V.4.1. per maggiori dettagli). 
La creazione di significati impliciti attraverso presupposizione e l'apertura a una molteplicità di prospettive e interpretazioni differenziano la narrazione come "modo di conoscenza" dai procedimenti di significazione logico-scientifici che si manifestano in forma prevalentemente argomentativa (cfr. Bruner 1986 citato da De Fina \& Georgakopoulou 2012: 16). Perciò, le sequenze con un'orientazione narrativa sono, a mio avviso, particolarmente adatte per studiare le rappresentazioni tutt'altro che univoche, ma intrecciantesi e giustapponentesi le une alle altre - anche nel discorso di un singolo individuo - di una realtà sociolinguistica complessa, come è quella altoatesina (cfr. anche Franceschini 2011b). Infatti, in conseguenza della loro "polifonia", le narrazioni sia con argomento extra-linguistico, sia metalinguistico offrono una rappresentazione emica dell'allocazione dei codici nel contesto d'arrivo, da un lato, meno mediata - nel senso di meno stereotipata, ma non per questo meno condizionata socialmente $-\mathrm{e}$, dall'altro, più elaborata dal punto di vista interazionale e contenutistico rispetto a quella che risulta, per esempio, dalle dichiarazioni non narrative formulate in risposta a domande dirette dell'intervistatrice.

Si noti tuttavia che i due tipi di storie di dialoghi sono concretamente caratterizzati da diversi gradi di (im)mediatezza ed elaborazione. In particolare, nelle narrazioni con argomento extra-linguistico, gli intervistati mettono in scena gli usi linguistici del proprio o di altri personaggi per come li ricordano al momento del colloquio. Nel fare ciò non sono influenzati, per lo meno situativamente, dalle aspettative e/o assunzioni rispetto a quanto costituisce una "risposta ragionevole" che, invece, una domanda al riguardo più o meno esplicitamente presuppone (cfr. Tracy \& Robles 2009: 132). Tuttavia, non essendo il tema principale della storia, le rappresentazioni e le prese di posizione dei partecipanti rispetto a fenomeni linguistici sono, di solito, meno sviluppate in questi racconti rispetto a in quelli metalinguistici. D'altro canto, le storie con argomento metalinguistico sono spesso, anche se non esclusivamente, narrate in seguito a una richiesta di chiarificazione e/o a una sollecitazione dell'interlocutrice. In questi casi, come sarà discusso più dettagliatamente nei $\S \mathrm{V} .3$ e V.4, i racconti metalinguistici non svolgono semplicemente la funzione di rievocare un'esperienza, ma sono frequentemente condizionati nella forma e nel contenuto anche da finalità argomentative e/o illustrative. ${ }^{11}$

\subsubsection{Interdiscorsività e intertestualità}

Sebbene ne abbia appena enfatizzato la maggiore immediatezza ed elaborazione, $\mathrm{i}$ resoconti di attività comunicative, sia con argomento extra-linguistico, sia metalinguistico sono comunque condizionati dal contesto micro-interazionale e macro-sociale in cui la conversazione si svolge (cfr. De Fina 2008). In altre parole, la loro (ri)

11 Si confronti anche Iannàccaro \& Dell'Aquila (2001) per riflessioni sul diverso valore - nella terminologia dei due ricercatori "ideologico" o "pragmatico" - degli spazi sociolinguistici rappresentati dai parlanti a seconda del contenuto e del modo, più o meno diretto, di formulare le domande da parte dei ricercatori. 
elaborazione nelle interazioni registrate è influenzata, tra l'altro, dal cotesto immediatamente precedente, dalla situazione semi-formale "intervista", dal rapporto co-costruitosi nel corso del colloquio tra partecipante e ricercatrice e dalle rappresentazioni (meta-)linguistiche diffuse nella regione di arrivo (cfr. anche De Fina \& Perrino 2011).

Come già ripetutamente affermato, i racconti di dialoghi non sono quindi un mezzo per investigare gli usi linguistici "reali" degli intervistati in Alto Adige, né ritraggono fedelmente avvenimenti linguistici e situazioni comunicative per come si sono oggettivamente verificati. Piuttosto, le narrazioni di interazioni consentono di risalire alle norme - intese come rielaborazioni più o meno personali di regole fondate storicamente e socialmente - che guidano, nell'ottica dei partecipanti, il proprio e l'altrui comportamento linguistico nel contesto d'arrivo. Infatti, nel rappresentare e commentare patterns d'uso, i narratori si riferiscono e prendono talvolta posizione rispetto alle presupposizioni che organizzano in modo più o meno manifesto lo spazio sociolinguistico in cui vivono (cfr. Hill 2005: 157 citato da Marra \& Holmes 2008: 398). Nella misura in cui (la messa in scena di) una regola di comportamento individuale è spesso condizionata dall'accettazione o dal rifiuto di norme e abitudini comunicative consolidate a livello comunitario, gli intervistati creano, tramite l'atto del narrare, testi "interdiscorsivi", ossia che si riferiscono a discorsi prodotti in altri milieu, e/o "intertestuali", ossia che rielaborano materiare presente in altri testi. In altre parole, i partecipanti fanno spesso riferimento nelle loro storie a (frammenti di) rappresentazioni metalinguistiche, talvolta precedentemente espresse in forma narrativa, talvolta non ancora verbalizzate in forma di racconto. Il loro obiettivo è quello di (ri)formulare la "propria" storia, in modo coerente e condivisibile per l'interlocutrice, nel qui e ora dell'interazione. ${ }^{12}$

In particolare, nel corpus raccolto, relazioni dialogiche tra sistemi di valori individuali e collettivi sono, a mio avviso, per esempio evidenti nei frequenti racconti di dialoghi sulla (progressiva) sostituzione dei codici d'origine o sull'enunciazione mistilingue. Queste storie rinviano, infatti, all'importanza che una presa di posizione su tali temi ha non solo per la singola intervistata, ma anche per i membri del suo reticolo sociale e/o per le istituzioni educative della regione d'arrivo (di cui la ricercatrice può essere vista come rappresentante). In modo analogo, alcune narrazioni sui tempi e le occasioni di apprendimento e d'uso delle varietà linguistiche locali mi sembrano essere influenzate, nella loro forma e contenuto, dai discorsi politici e massmediatici sulle pratiche comunicative abituali dei cittadini stranieri in provincia di Bolzano (cfr. anche $\S$ II.2.3 e II.2.4). Tuttavia sia qui sottolineato che le prese di posizione delle partecipanti nei confronti di fenomeni e giudizi metalinguistici più $o$ meno controversi nella regione d'arrivo non sono esclusivamente (pre)determinate dalle opinioni diffuse a livello collettivo. Infatti, rappresentazioni (semi)stereotipate dello spazio sociolinguistico altoatesino sono talora ri-contestualizzate dalle narratrici in una storia di esperienza personale per essere "resistite" o "rivalutate", per

12 Per una discussione più dettagliata delle conseguenze dell'orientazione all'interlocutore nella co-costruzione di racconti si confronti Linde (2009: 167-195), Linde (1993: 12-19) e anche il paragrafo successivo V.1.2.3. 
esempio, in funzione di una propria riallocazione sociale e/o morale. ${ }^{13}$ L'orientamento a discorsi o testi - diffusi precedentemente in forma orale o scritta nella collettività - da parte delle narratrici per farli propri o rigettarli e, quindi, 1 '“interdiscorsività" e, talvolta, l' "intertestualità" delle sequenze in questione motiva, come seconda caratteristica peculiare, anche se non esclusiva dell'atto del raccontare, il mio interesse per le storie di dialoghi delle interviste raccolte. ${ }^{14}$

Anche in questo caso è possibile riconoscere differenze tra tipi di racconti. Nello specifico, riferimenti a rappresentazioni di fenomeni linguistici, diffuse a livello collettivo, sono particolarmente evidenti nelle narrazioni metalinguistiche. In tali racconti, il parlante tende infatti spesso ad esagerare - per esempio, tramite iperboli, ripetizioni o un uso enfatico del tono della voce - l'invariabilità dei comportamenti linguistici riferiti e/o la validità dei giudizi metalinguistici espressi, alludendo a rappresentazioni condivise in modo drammatico, scherzoso o caricaturale. Le ragioni di questa enfasi sono soprattutto interazionali. Il narratore mira infatti ad aumentare e a giustificare la "riportabilità" o la "raccontabilità" di una vicenda incentrata su fatti di lingua tramite una messa in scena che ne veicoli un'interpretazione arguta e interessante per gli interlocutori (cfr. Johnstone 2006: 54 e anche $\S$ V.2.3). Data questa osservazione di carattere generale, sia comunque qui ricordato che non tutte le narrazioni metalinguistiche del corpus sono condizionate dallo stesso grado di necessità e/o volontà da parte del narratore di colpire i suoi destinatari. Piuttosto, le narrazioni metalinguistiche effettivamente raccontate presentano caratteristiche che le avvicinano o le allontanano dal prototipo. Inoltre, lo specifico contesto interazionale deve essere tenuto da conto al momento di analizzarne le caratteristiche formali e contenutistiche. Infatti, da una parte, durante un'intervista narrativa con un'interlocutrice incline ad ascoltare, i requisiti che un racconto deve assolvere per legittimare il mantenimento del banco sono minori in confronto a quelli in una conversazione quotidiana. In aggiunta, nei casi analizzati, la rilevanza di narrazioni incentrate su fatti di lingua è assicurata dall'esortazione iniziale della ricercatrice a raccontare la propria biografia linguistica. Dall'altra parte, come si è già notato, un parlante ha maggiore agio in un'intervista sociolinguistica per formulare compiutamente le proprie valutazioni e sviluppare la propria "posizione morale" rispetto a in altre circostanze (cfr. Labov 2013: 9). Perciò, le rappresentazioni e le prese di posizione, trasmesse nelle narrazioni metalinguistiche del corpus qui analizzato, sono frequentemente meno esagerate e dicotomiche, ma non per questo meno connotate ideologicamente o influenzate (positivamente o negativamente) da discorsi metalinguistici diffusi nella collettività di quelle veicolate nelle storie raccolte in interazioni spontanee, per esempio, da Johnstone (2006).

13 Per processi analoghi di resistenza o di riappropriazione con fini emancipativi (empowerment) da parte di singoli parlanti di rappresentazioni metalinguistiche (semi-)stigmatizzanti, diffuse in altri macro-contesti, si confrontino Relaño-Pastor \& De Fina (2005), Evans Davies (2007), King \& De Fina (2010). Nel presente lavoro si vedano in particolare i § V.4 e seguenti.

14 Come Linde (2009: 168) ricorda, interdiscorsività e intertestualità sono per alcuni studiosi, tra cui, Saussure e Bachtin condizione necessaria di ogni (tipo di) testo. 
Infine, sia qui ricordato che non solo le storie di vicende eccezionali, vissute in prima persona, danno accesso alle valutazioni dei narratori rispetto a determinati fenomeni linguistici. Come discusso al $\S$ V.1.1.2, anche altri tipi di racconti - ad esempio, narrazioni ipotetiche o contro-fattuali, abituali o generiche, e storie ri-raccontate - permettono, infatti, di risalire ai modi di posizionarsi dei singoli rispetto a modelli di comportamento e a schemi interpretativi salienti per gruppi sociali più o meno estesi. Come sarà illustrato approfonditamente nei $\S$ V.3 e V.4, altre strategie di rappresentazione - ossia non necessariamente basate sull'esagerazione quanto piuttosto, per esempio, su variazioni nei pronomi personali o nei deittici di luogo saranno verosimilmente adottate dagli interattanti in queste sequenze per trasmettere il proprio punto di vista e per allinearsi gli uni agli altri nell'interpretazione di un dato fenomeno.

\subsubsection{Partecipazione}

La rilevanza e, talvolta, la criticità di determinati comportamenti e/o scelte di lingua in Alto Adige sono segnalati, oltre che dal fatto di essere frequentemente tematizzati da parlanti diversi, anche dal lavoro interazionale, compiuto dalla narratrice, per co-costruire una posizione valutativa condivisibile con gli interlocutori così come dalle reazioni verbali e non verbali di questi ultimi nel corso e al termine del racconto. Questa considerazione rimanda all'ultima ragione che sta alla base della mia scelta di analizzare le storie di dialoghi nelle interviste raccolte. Narrando, un parlante crea "partecipazione" a livello personale, interpersonale e rispetto al tema trattato (cfr. Tannen 1989/2007). Ciò dipende dal fatto che il narratore impiega abitualmente in un racconto diverse "strategie di coinvolgimento" come, ad esempio, ripetizioni, accumulazione di dettagli, dialoghi riportati (o, nella terminologia della ricercatrice, dialoghi "costruiti”). In aggiunta, le narrazioni funzionano esse stesse come dispositivi che elicitano partecipazione, ossia, per esempio, suscitando adesione emozionale e, eventualmente, consenso o indignazione morale da parte degli interlocutori (cfr. ibidem: 40-41 e anche Günthner 1995).

Specialmente nei racconti scenico-episodici, il narratore mette in scena infatti una vicenda in modo tale che l'ascoltatore segua l'episodio dalla prospettiva esperienziale e dalle coordinate spazio-temporali del protagonista (cfr., per esempio, l'uso di espressioni deittiche traslate o del presente storico). Inoltre, forme linguistiche e paralinguistiche espressive come, ad esempio, quantificatori iperbolici, tropi, combinazioni di caratteristiche prosodiche, trasmettono la partecipazione emozionale del narratore rispetto all'episodio riportato e contemporaneamente "esigono" empatia e solidarietà da parte degli interlocutori (cfr. Lucius-Hoene \& Deppermann 2004: 157, Relaño-Pastor \& De Fina 2005). In questo modo, gli ascoltatori sono "trasposti" nel mondo della storia e assumono più frequentemente - rispetto, per esempio, ai destinatari di un testo argomentativo - il ruolo di "pubblico" (audience), che rivive l'esperienza riportata, piuttosto che quello di "contendenti" (contenders) del punto di vista veicolato (cfr. Schiffrin 1990 citato da De Fina \& Georgakopoulou 2012: 98). L'impatto del racconto sul pubblico è riconoscibile an- 
che dai segnali di ricezione di quest'ultimo, i quali a loro volta influenzano il proseguimento della narrazione.

Proprio in conseguenza dei loro effetti di coinvolgimento sugli interlocutorioltre che a causa delle esagerazioni determinate dai requisiti di raccontabilità illustrati nel paragrafo precedente -, le narrazioni di "incontri linguistici" sono rilevanti, secondo Johnstone (2006), per lo studio della variazione sociolinguistica. Il motivo è che, in aggiunta ad essere fonte di parlato spontaneo, queste storie svolgono un ruolo determinante nella formazione e riproduzione di idee condivise su fatti di lingua, come, per esempio, riguardo al prestigio di varietà linguistiche, ai loro rapporti di differenziazione o ai significati indessicali associati all'uso di determinate varianti. Infatti, in conseguenza della loro messa in scena in modo plastico e a forte impatto emotivo, è probabile che i destinatari facciano propri gli episodi raccontati o, almeno, l'interpretazione di questi fornita dal narratore. Tali vicende e valutazioni potranno poi essere riutilizzate al momento di dare un senso ad accadimenti o situazioni analoghe in conversazioni successive.

L'analisi esposta nel presente capitolo parte da considerazioni analoghe. Infatti, uno degli assunti su cui si basa è che le storie di dialoghi - specialmente quelle con argomento metalinguistico - permettano di fotografare, nelle fasi di trasmissione intermedie, i processi interazionali attraverso cui nessi precostituiti tra fenomeni linguistici e sociali si diffondono e trasformano in interazione. In linea con ciò, quando mi sarà possibile, cercherò nei prossimi paragrafi di stabilire, sulla base dei dati etnografici raccolti, quale sia la fonte precedente o originaria delle rappresentazioni veicolate dagli intervistati, ossia, ad esempio, se questi si riferiscono a discorsi massmediatici $\mathrm{o}$, piuttosto, a frammenti di narrazioni diffuse nel loro reticolo sociale. Inoltre, tenterò di valutare gli interessi di gruppo e, quindi, le ideologie linguistiche soggiacenti che possono motivare le interpretazioni dei rapporti tra codici così trasmesse. ${ }^{15}$

\section{MODI DI CODIFICA: USI LINGUISTICI NARRATI E DICHIARATI}

La presente sezione del capitolo $\mathrm{V}$ è dedicata alla descrizione degli specifici modi di codifica delle narrazioni di interazioni del corpus, finalizzata alla rilevazione degli usi linguistici narrati dei partecipanti, così come alla descrizione preliminare degli usi linguistici dichiarati da tre intervistate, sulle cui biografie linguistiche si è scelto di concentrare l'analisi delle sezioni successive. In particolare, nel prossimo paragrafo espongo i criteri e concetti analitici generali, adoperati durante l'annotazione, in modo tale da preservare il più possibile l'emicità delle categorializzazioni effettuate dai partecipanti e, al contempo, garantirne la confrontabilità a livello etico. Successivamente discuto le categorie utilizzate, da un lato, per codificare i codici e le attività non verbali, mezzo di comunicazione nel mondo delle storie e, dall'altro, per individuare sotto-unità a livello funzionale e strutturale in singole sequenze nar-

15 Si confronti per riflessioni sui modi di trasmissione delle rappresentazioni in un approccio sociolinguistico anche il numero speciale di Tranel curato da Py (2000) e, all'interno di questo, in particolare lo studio di Serra (2000). 
rative (cfr. rispettivamente i §V.2.2 e V.2.3). ${ }^{16}$ Infine, ai § V.2.4 e seguenti, riassumo le traiettorie linguistico-migratorie delle tre intervistate selezionate per la presente ricerca e descrivo i loro repertori dichiarati al momento dei colloqui.

\subsection{Categorie emiche ed etiche}

Dopo aver identificato le narrazioni di interazioni nel testo delle interviste, ho codificato il primo enunciato di discorso riportato o la prima attività comunicativa riportata secondo tre parametri. Questi sono:

1) la varietà linguistica o l'attività non verbale, mezzo di comunicazione nel mondo della storia, ad esempio "albanese", "enunciazione mistilingue in tedesco e serbo", "varietà di interlingua in italiano", da un lato, e "cercare le parole in tedesco", dall'altro;

2) il contesto in cui il racconto è ambientato, come "posto di blocco", "ospedale", "università";

3) gli interattanti, personaggi del racconto. Nello specifico, ho annotato:

a) il tipo di attori, identificati sulla base delle categorie sociali e/o relazionali usate dalle intervistate per qualificarli (es. "medico", "amico", "madre");

b) il ruolo interazionale da questi svolto nella conversazione riportata (es. "parlante", "destinatario", "ascoltatore occasionale").

La decisione di utilizzare gli enunciati o le attività comunicative riportate come unità di codifica dipende da una ragione in parte ovvia. Per identificare in modo preciso il contesto e, soprattutto, i ruoli interazionali dei personaggi di una storia, non posso considerare il racconto nel suo complesso, ma devo invece basarmi sugli specifici atti linguistici in esso riferiti. Inoltre, per l'esame dei prossimi paragrafi, considero solo la prima attività verbale riferita dalle narratrici. Il motivo è che voglio mettere specificamente a fuoco l'evento linguistico che, nella rappresentazione delle intervistate, dà avvio all'interazione. Una tale scelta ha implicazioni rilevanti soprattutto al momento di esaminare la distribuzione dei codici per interattanti. Infatti, consente di valutare se la partecipante si rappresenta più frequentemente come personaggio attivo nella selezione e negoziazione di codice nel contesto d'arrivo o, al contrario, come figura che risponde e, quindi, principalmente reagisce a scelte di lingua condotte da altri (cfr. $\S$ V.4 per maggiori dettagli). L'ambientazione di un dialogo riportato rimane invece di solito la stessa nel corso del suo svolgimento. Perciò, la scelta di codificare solo il primo atto linguistico riportato non ha conseguenze significative al momento di considerare la distribuzione di codici per contesti e, quindi, di ricostruire gli "spazi comunicativi narrati" delle narratrici (cfr. § V.3). Tuttavia, ho mantenuto la medesima unità di analisi per poter meglio confrontare le rappresentazioni della distribuzione dei codici per luoghi con quella per interattanti. Entrambe sono infatti così ricostruite sulla base dello stesso numero di osservazioni per partecipante. ${ }^{17}$

16 Per l'illustrazione del procedimento seguito per categorizzare "contesti" e "interattanti" si vedano invece rispettivamente i $\S \mathrm{V} .3$ e V.4 del presente volume.

17 Il numero totale di racconti di dialoghi non coincide invece tra le tre partecipanti. Tale varia- 
La ricerca esposta nei prossimi paragrafi combina un approccio "macro" con uno "micro" (cfr. anche § III.2.1 e III.2.3). Da una parte, considerando le narrazioni di interazioni nel loro insieme e, quindi, adottando una prospettiva di analisi "macro" relativa alla biografia linguistica nel suo complesso (cfr. Lucius-Hoene \& Deppermann 2004: 317-320), valuto il variare dei (tipi di) codici, mezzo di comunicazione nei dialoghi narrati, rispetto al modificarsi di "contesto" e "interattanti". Le risorse linguistiche menzionate dalle narratrici sono quindi paragonabili a una sorta di variabile dipendente, la cui distribuzione è ricostruita lungo queste due dimensioni di variazione. Tali dimensioni, ossia la situazione comunicativa e gli interlocutori, sono possibilmente significative da un punto di vista sia etico sia emico. Infatti costituiscono, insieme al tema di una conversazione, due principi generali rispetto a cui è rilevante mappare la (ri)allocazione dei codici in contesti storicamente plurilingui o dopo esperienza migratoria, sia in altri studi, sia specificamente nell'ottica di numerosi partecipanti del corpus (cfr., tra gli altri, Gal 1996, Dell'Aquila \& Iannàccaro 2006: 79-97, Chini 2004, Krefeld 2004: 25-36, Lawson \& Sachdev 2004). Il primo approccio d'analisi mira dunque a offrire una descrizione generale dei repertori narrati delle partecipanti per come sono rappresentati al momento dell'intervista.

Dall'altra parte, il punto di vista "macro" è integrato con un'analisi "micro", ovvero con un esame dettagliato di alcune sequenze narrative (cfr. Lucius-Hoene \& Deppermann 2004: 320-322). Gli esempi per l'analisi micro sono selezionati in quanto significativi per approfondire la discussione sulle rappresentazioni dei rapporti tra codici nei repertori narrati delle intervistate rispetto a specifiche domande di ricerca. In particolare, nelle storie discusse al § V.3 e seguenti, le tre donne istituiscono relazioni più o meno stabili tra i) varietà linguistiche, ii) situazioni comunicative e, talvolta, iii) interlocutori. L'esame di questi racconti a livello contenutistico e formale consente dunque di identificare, da un lato, alcuni fattori che guidano l'alternanza di codice situazionale propria e altrui nel contesto d'arrivo in una prospettiva emica. Dall'altro, mette in luce come le narratrici interpretino tali scelte di lingua in interazione insieme all'interlocutrice. Nel commentare i racconti del $\S \mathrm{V} .4$ e successivi, mi concentro invece sui modi in cui le partecipanti mettono in scena discorsi riportati, in particolare, tramite l'uso strategico della commutazione o dell'inserzione di codice. L'analisi dell'attribuzione di enunciati "costruiti" ai personaggi nel mondo delle storie permette infatti di considerare la dimensione "presentazionale" delle biografie linguistiche raccolte congiuntamente a quella "interazionale" e di renderne talvolta manifesto uno "scollamento" (cfr. Franceschini 2003). L'obiettivo è ricostruire prese di posizione interazionali, esplicite o latenti, di narratori e destinatari rispetto ai comportamenti linguistici o ai giudizi metalinguistici citati nelle storie. Segnatamente, tali atti di posizionamento conversazionali rivelano, talvolta, atti di posizionamento abituali, diffusi anche a livello comunitario (cfr. anche Wortham et al. 2011: 42).

Infine, un'ultima considerazione preliminare riguardo ai modi di codifica concerne i valori di volta in volta assegnati ai parametri "varietà linguistica", "conte-

zione non dipende dalla durata dei colloqui né mi sembra abbia conseguenze per l'analisi (cfr. anche $\S$ V.2.4 e sgg.). 
sto" e "interattanti". Questi sono, in un primo momento, un insieme potenzialmente infinito di categorie emiche. Infatti, corrispondono alle distinzioni effettuate dalle partecipanti nel corso delle narrazioni di interazioni (cfr., ad esempio, il contesto "posto di blocco" o il codice "lingua dal veneto"). Tuttavia, da tali categorie emiche di primo grado o "quotidiane" (Alltagsbegriffe) ho derivato concetti di secondo grado o "scientifici" (Wissenschaftsbegriffe) (cfr. Lamnek 1988/2010: 123-127). La sovrapposizione degli ultimi alle prime ha la funzione di guidare l'interpretazione dei dati. Così, per descrivere la distribuzione spaziale delle varietà linguistiche in Alto Adige mi servo, per esempio, della distinzione tra situazioni comunicative della "vicinanza" pragmatica o sociale, da un lato, e domini della "lontananza" o "anonimia", dall'altro (cfr. Krefeld 2004 e $\S$ V.3 per maggiori dettagli). In modo analogo, per valutare l'allocazione dei codici per interattanti ricostruisco la "struttura di partecipazione" degli enunciati riportati (cfr. Goffman 1981) e, quindi, utilizzo categorie non direttamente rinvenibili nel testo delle interviste, come, ad esempio, quella di "ascoltatore occasionale" o "destinatario ratificato" (cfr. § V.4).

\subsection{I codici di comunicazione nel mondo della storia}

Come già illustrato al $\S$ V.1.1.1, ho selezionato per l'analisi del presente capitolo solo le narrazioni di interazioni in cui il codice di comunicazione tra i personaggi nel mondo della storia è deducibile dal co(n)testo. I dati sono quindi costituiti da storie, in cui i narratori dicono più o meno esplicitamente in quale lingua si svolge il dialogo raccontato. La varietà linguistica indicata dal parlante è oggetto di codifica, non la lingua in cui il racconto è effettivamente narrato.

Nella maggior parte dei racconti considerati, la varietà o le varietà linguistiche di conduzione del dialogo sono espresse dalla narratrice spontaneamente oppure, meno frequentemente, sono menzionate in risposta a una domanda successiva della ricercatrice a riguardo. L'individuazione e la codifica della lingua di comunicazione in questi racconti avvengono solitamente senza particolari problemi sulla base di categorie emiche. Tuttavia non mancano alcuni casi dubbi. Così, quando la partecipante riporta di un'interazione in più lingue, ma specifica il nome solo di alcune di queste, ho assegnato alle varietà linguistiche non menzionate l'etichetta di "non identificabili" (n.i.).

La codifica dei codici di comunicazione di un gruppo (poco numeroso) di storie richiede invece fin dal principio l'adozione di categorie parzialmente descrittive e/o etiche da parte dell'analista (cfr. soprattutto l'intervista con VM). Da un lato, infatti, in certe narrazioni le partecipanti riferiscono di interazioni avviate da atti non verbali (es. "gesti") o riportano di attività metalinguistiche che coinvolgono determinati codici, ma che non sono propriamente in una varietà linguistica (es. "cercare le parole in tedesco", "esercitarsi in tedesco"). Dall'altro, in alcuni racconti, le narratrici imitano il modo di parlare dei personaggi nel citare un loro enunciato. In questi casi, la lingua di interazione non è identificabile tramite categorie "in vivo", ovvero sulla base di formulazioni usate dalle stesse informanti (cfr. Strauss \& Corbin 1990/1996). Tuttavia ho deciso di includere anche questi racconti nel corpus di storie analizzate in considerazione della loro rilevanza rispetto a determinati temi. 
Le storie di interazioni a gesti o di attività metalinguistiche affrontano infatti frequentemente questioni legate al fallimento o semi-fallimento di atti linguistici dopo migrazione in un paese straniero. Invece le narrazioni, in cui le narratrici imitano il modo di parlare dei personaggi, sono spesso interessanti per valutare la messa in scena di pratiche plurilingui nel contesto d'arrivo.

Per descrivere l'allocazione dei codici nel repertorio narrato delle partecipanti, raggruppo poi le singole varietà linguistiche menzionate dalle intervistate in insiemi più astratti a seconda di criteri, di volta in volta, rilevanti per le domande di ricerca. In seguito commento quattro categorie centrali per l'analisi dei $\S$ V.3 e V.4. Queste sono derivate dall'applicazione ai dati di tassonomie proposte in letteratura (cfr., in particolare, Dal Negro \& Molinelli 2002: 16-20, Auer 1984, Auer 1998b, Guerini 2006b per la ripartizione delle pratiche di contatto). Si noti che le categorie seguenti sono di natura etica e non emica. Inoltre la classificazione proposta, soprattutto quella relativa ai tipi di pratiche di contatto, è dibattuta in letteratura e non è l'unica possibile. La sovrapposizione di questi concetti di secondo grado a quelli usati dalle intervistate presuppone quindi già un'interpretazione dei dati da parte dell'analista. Tuttavia, offre a mio avviso una chiave (tra le numerose possibili) per esaminare e soprattutto per confrontare le rappresentazioni degli usi linguistici propri e altrui nelle narrazioni di dialoghi. La rassegna seguente funge anche da legenda per decifrare le figure dei prossimi paragrafi. ${ }^{18}$

$1^{\text {a }}$ categoria: varietà linguistiche

- deu, srp, hrv, aln, Nelle figure dei prossimi paragrafi uso le abbreviazioni ISO-639-2 per srp-hrv riferirmi in modo conciso alle varietà linguistiche menzionate dalle partecipanti (cfr. l'allegato 4 per una lista delle abbreviazioni utilizzate). La ragione è esclusivamente pratica. Una sigla breve è infatti vantaggiosa per motivi di spazio.

- lingua del veneto, montenegrino, nostra lingua, sdt

Tuttavia, nel caso l'intervistata si serva di un glottonimo per cui non esiste (o non esisteva al momento di conduzione di questa ricerca) un codice ISO-639-2, riporto il nome completo usato dalla partecipante. Si tratta frequentemente di denominazioni per varietà linguistiche non standard o solo recentemente standardizzate o di quasi-glottonimi in funzione "elusiva", "enfatica" o "oppositiva" (cfr. § IV.3). Per indicare le varietà di tedesco locali mi servo dell'abbreviazione "sdt".

- n.i.

Codici di dubbia identificazione.

18 Gli altri raggruppamenti effettuati sono piuttosto intuitivi e meno controversi di quelli discussi in corpo al testo. Per esempio, con l'obiettivo di valutarne la portata comunicativa e il grado di mantenimento rappresentati, mi riferisco alle varietà parlate e/o apprese nel paese di partenza nel loro complesso come ai "codici d'origine" delle intervistate. Invece, tedesco, italiano, dialetto tedesco locale e ladino costituiscono i "codici d'arrivo" delle partecipanti. Infine, le lingue parlate da persone trasferitesi recentemente in provincia di Bolzano sono qualificate come "lingue di nuovo insediamento", "varietà alloglotte" $\mathrm{o}$, nel caso in cui le narratrici le rappresentino come diffuse e radicate sul territorio altoatesino, "lingue immigrate" (cfr., per esempio, Bagna et al. 2003). 
$2^{\mathrm{a}}$ categoria: varietà di contatto

- ita e deu Pratiche di alternanza di codice situazionali e/o tra unità di discorso molto ampie. Le partecipanti narrano di attività comunicative (di solito abituali) in cui alternano codici diversi, per esempio, in conseguenza del modificarsi dell'argomento della conversazione.

- eng \& ita, srp \& slo

- hrv $\rightarrow$ ita

- srp/ita/deu
Pratiche di alternanza di codice non reciproca. Le intervistate raccontano di dialoghi in cui gli interattanti usano rispettivamente varietà linguistiche (rappresentate come) diverse per comunicare tra loro.

Qui come altrove adotto la terminologia proposta in Dal Negro \& Molinelli (2002: 16-20). Si ricordi comunque che la classificazione proposta non è l'unica possibile. In particolare, le ricercatrici definiscono il fenomeno dell'alternanza di codice non reciproca come un caso di alternanza di codice, inteso non dalla prospettiva del parlante, ma da quella dell'interazione (cfr. ibidem: 19). L'insieme delle competenze attivate dagli interattanti in questo tipo di comunicazione plurilingue è riferito in letteratura anche con il concetto di "lingua ricettiva" (cfr. Rehbein et al. 2011).

Pratiche di alternanza di codice non reciproca sono menzionate piuttosto frequentemente non solo nelle tre biografie linguistiche analizzate dettagliatamente nei $\S$ V.3 e V.4, ma anche in quelle di altri partecipanti. Interazioni in cui i locutori comunicano tra loro usando rispettivamente codici diversi si verificano soprattutto tra parlanti di varietà linguistiche slavo meridionali o slave (es. mac \& srp o srp \& slo).

Commutazioni di codice (o commutazioni di codice interfrasali o code-switching). Le intervistate narrano di atti comunicativi in cui uno stesso parlante passa funzionalmente e/o intenzionalmente da una lingua a un'altra in uno stesso discorso (cfr. Dal Negro \& Molinelli 2002: 19).

Le tre partecipanti non raccontano storie in cui i personaggi commutano il codice della conversazione consapevolmente e/o funzionalmente. Questa pratica costituisce inoltre molto raramente la lingua di interazione anche nei racconti di dialoghi delle altre interviste raccolte. Tuttavia, i narratori si servono talvolta di commutazioni e/o di inserzioni di codice reali durante il colloquio, per esempio, per citare discorsi riportati. Al $\S \mathrm{V} .4$ discuto le funzioni assolte da queste e altre pratiche di contatto nell'interazione in via di svolgimento.

Enunciazioni mistilingui (o commutazioni di codice intrafrasali o code-mixing). Le partecipanti raccontano di enunciati e/o di attività comunicative in cui il parlante impiega due o più codici in una stessa frase in modo non intenzionale e non funzionale (cfr. Dal Negro \& Molinelli 2002: 19).

Le intervistate narrano abbastanza frequentemente di dialoghi in cui gli interattanti passano involontariamente da una lingua all'altra in uno stesso enunciato. Lo stesso vale per gli altri partecipanti del corpus. Per lo meno al momento dei colloqui, l'enunciazione mistilingue sembra essere dunque un fenomeno più saliente a livello di consapevolezza metalinguistica rispetto a pratiche di commutazione di codice volontaria. 
$-\operatorname{aln}(+\mathrm{deu})$

Prestiti o inserzioni. Le partecipanti raccontano di interazioni in cui i locutori usano parole in un codice diverso dalla lingua principale della conversazione in funzione solo referenziale (prestiti) o stilistica (inserzioni). Ad esempio, le narratrici affermano che i personaggi delle loro storie si servono di termini in tedesco in un discorso in albanese per riferirsi ai documenti necessari per ottenere la cittadinanza.

Si ricordi che, secondo la tassonomia proposta da Auer (1984: 24-30) e leggermente modificata in Auer (1998b), i prestiti e le inserzioni si differenziano da altri fenomeni di contatto come la commutazione di codice per i seguenti motivi: 1) il materiale alloglotto ha confini prevedibili e, nel caso dei prestiti, è solitamente circoscritto a singoli lessemi; 2) l'alternanza di codice non ha il potere conversazionale di modificare la lingua base della conversazione (cfr. anche Guerini 2006b).

$3^{\mathrm{a}}$ categoria: varietà di interlingua o di apprendimento

- interlingua in ita Varietà di apprendimento (interlanguage). Le intervistate raccontano o, talvolta, imitano enunciati di parlanti "non nativi" di uno specifico codice.

Nel fare ciò, riproducono in modo più o meno accurato "fenomeni di fossilizzazione" (cfr. Selinker 1972), determinati in special modo da transfer(s) dalla L1 e/o da strategie generali di apprendimento e comunicazione (cfr., per esempio, l'emulazione di caratteristiche a livello fonologico e/o l'uso di morfologia e sintassi semplificate). Inoltre, le narratrici spesso categorizzano i parlanti nel mondo della storia tramite riferimento al loro paese di provenienza e/o prima lingua (es. compagni di corso cinesi, collega arabo). A questi enunciati ho assegnato la categoria etica di "interlingua", specificando la "lingua bersaglio" nel caso sia espressa dalla partecipante.

$4^{\text {a }}$ categoria: comunicazione non verbale

- gesti, Attività comunicative non verbali o attività metalinguistiche. Le interesercitarsi in deu vistate riportano e/o descrivono interazioni in cui i partecipanti comunicano non verbalmente o svolgono attività metalinguistiche che coinvolgono determinati codici, ma che non sono propriamente in un codice.

\subsection{Le unità narrative}

Le narrazioni, portate come esempi nei prossimi paragrafi, sono nella maggior parte dei casi suddivise in clausole e ripartite in sezioni secondo il modello proposto da Labov \& Waletzky (1967) e rielaborato da Labov in studi successivi (cfr. Labov 1972: 354-396, Labov 1997, Labov 2006, Labov 2013). L'individuazione dei modi di costruzione di una storia secondo tale schema ha infatti il vantaggio di offrire un punto di partenza per confrontare le narrazioni del corpus tra di loro (cfr. anche Labov 2013: 223-224). Inoltre, mi permette di identificare, per lo meno in modo preliminare, sotto-unità narrative a livello strutturale e funzionale da discutere durante l'analisi. Si noti, tuttavia, che l'applicazione di tale approccio ha nella presente ricerca scopi esclusivamente pratico-descrittivi. Perciò, quando la suddivi- 
sione strutturale delle sequenze narrative non è rilevante per il commento del brano o è di incerta individuazione, ho tralasciato di applicarla. ${ }^{19}$

Secondo Labov \& Waletzky (1967), unità di base nel processo di elaborazione di una narrazione sono le "clausole indipendenti" (independent clauses) con verbo di modo finito (cfr. anche Labov 2013: 15). Tra queste, gli autori distinguono ulteriormente tra clausole i) "narrative" (narrative), ii) "libere" (free) e iii) "ristrette" (restricted) tramite la nozione di "raggio di dislocazione" (displacement set), ovvero in relazione al punto fino a cui una frase può essere pre- o posposta in una storia senza modificarne il senso. Due clausole narrative hanno un raggio di dislocazione che non si include, anche se si può sovrapporre. Non sono quindi interscambiabili, ma separate da una "giuntura temporale" (temporal juncture). Invece, le clausole libere (cfr., per esempio, quelle orientative) e ristrette sono rispettivamente collocabili in qualunque punto della narrazione o spostabili in posizioni precedenti, ma non all'inizio della storia. In linea con l'approccio dei due ricercatori, anche le narrazioni di interazioni nei prossimi paragrafi sono inizialmente suddivise in clausole sulla base di criteri sintattici. Una tale segmentazione non sempre coincide con la suddivisione del flusso del discorso per "unità intonative" (intonation units), ovvero per segmenti di parlato con una curva intonativa in sé conclusa e al contempo verbalizzanti gruppi di informazioni (o "unità di idee") attive in un determinato momento (cfr. Chafe 1990: 88-89). Si noti, tuttavia, che queste ultime costituiscono parimenti unità organizzative a livello di produzione e ricezione, secondo cui una narrazione orale può essere trascritta e analizzata (cfr. Chafe 1990, De Fina 2003: 49).

Sulla base della distinzione tra tipi di clausole e dell'individuazione della loro funzione, Labov $\&$ Waletzky identificano poi unità narrative di livello più alto, realizzate da una o più frasi (cfr. anche De Fina \& Georgakopoulou 2012: 28). Di seguito descrivo, in ordine di apparizione usuale, le sezioni in cui una storia di esperienza personale nella sua forma ideale è strutturata. Di volta in volta, riporto anche le abbreviazioni che userò al momento di commentare gli esempi nei §V.3 e V.4. Sia comunque qui anticipato che le narrazioni di dialoghi delle interviste raccolte presentano piuttosto raramente tutte le componenti illustrate dal modello. Inoltre, un'unica clausola svolge talora più funzioni nell'elaborazione di un racconto e può essere, quindi, categorizzata contemporaneamente secondo unità narrative diverse (cfr., per esempio, il punto 3 più sotto sui modi di codifica del discorso riportato). Nei prossimi paragrafi, le clausole che, a mio avviso, hanno una funzione ambigua o sono classificabili come facenti parte di più unità narrative sono contrassegnate da più sigle rispettivamente separate da una "o" o da una "\&". Sezioni dello stesso tipo sono inoltre numerate in ordine di occorrenza (es. EV1, EV2, etc.).

19 Per una discussione sui problemi di codifica derivanti dall'impiego del modello di Labov \& Waletzky si confronti De Fina \& Georgakopoulou (2012: 27-36). Si veda, inoltre, Bamberg (1997), Norrick (2000: 1-46), Deppermann \& Lucius-Hoene (2006) per una discussione sul ruolo di fattori pragmatici, situazionali e performativi oltre che strutturali nella co-costruzione di una narrazione in interazione. 
1) Estratto (= abstract; $\mathrm{AB})$.

Il narratore riassume il tema della storia e/o anticipa il suo evento più riportabile senza specificare ulteriormente gli avvenimenti che lo hanno causato.

2) Orientazione (=orientation; OR).

Il parlante fornisce indicazioni sul luogo e il tempo, in cui si svolge la vicenda, sulle persone coinvolte e sulla loro condizione/attività all'inizio dell'episodio.

Si noti che tali informazioni hanno talvolta una funzione valutativa e/o esplicativa oltre che meramente descrittiva (cfr. Labov 2013: 28). Inoltre, creano coinvolgimento e aspettative rispetto al proseguimento della narrazione (cfr. De Fina 2003: 146-150). Una sezione orientativa segue di solito l'estratto. Tuttavia, clausole orientative sono talora posposte in punti successivi del racconto. Queste sono frequentemente caratterizzate dall'uso di verbi di stato o da forme verbali imperfettive e/o durative, come il passato progressivo (past progressive) in inglese o l'imperfetto in spagnolo (cfr. rispettivamente Labov 2013: 27 e Carranza 1998: 298-299).

3) Azione complicante (= complicating action; $\mathrm{CA})$.

È la serie di avvenimenti, ordinati cronologicamente, che costituisce il corpo della narrazione. Gli eventi riportati sono frequentemente connessi da rapporti di causa-effetto per aumentare la "credibilità" della storia (cfr. punto 3b). Tuttavia, i narratori talvolta omettono fatti o interrompono la catena causale riferendo di azioni strumentali. Facendo ciò, mirano a veicolare il proprio punto di vista e/o ad assegnare lode o biasimo ai personaggi (cfr. Labov 2013: 28-30).

Poiché il discorso riportato può svolgere molteplici funzioni in una narrazione, la sua codifica è spesso incerta (cfr. De Fina \& Georgakopoulou 2012: 32). Nell'analizzare le narrazioni di interazioni nel presente capitolo, ho considerato la maggior parte degli enunciati in discorso diretto e indiretto come parte dell'azione complicante. Infatti, tali attività comunicative hanno conseguenze sullo sviluppo della storia (cfr. De Fina 2003: 50 per una decisione analoga). Nello stesso tempo, il discorso riportato costituisce frequentemente anche un dispositivo di valutazione "incluso" (embedded), che consente al parlante di formulare giudizi senza interrompere la continuità drammatica del racconto (cfr. Labov 1972: 372_373). Perciò, gli enunciati riportati negli esempi dei prossimi paragrafi sono spesso doppiamente categorizzati, ossia al contempo come azioni complicanti ed enunciati valutativi.

Tenendo conto delle elaborazioni successive al modello proposto da Labov \& Waletzky (1967), distinguo ulteriormente gli eventi dell'azione complicante in:

3a) un evento matrice (= initiating event; $\mathrm{ME}$ ).

Consiste nell'avvenimento puntuale che dà avvio alla vicenda e che è valutato dal narratore come non necessitante di ulteriori spiegazioni (cfr. Labov 2013: 24-25).

$3 b)$ un evento più riportabile (=the most reportable event; $\mathrm{mRE}$ ).

È l'avvenimento culmine e meno probabile della storia. Questo (dovrebbe) giustifi$\mathrm{ca}(\mathrm{re})$ la riassegnazione automatica del ruolo di parlante al narratore fino al termine del racconto e determina in modo preponderante la sua struttura (cfr. Sacks 1968/1992: 3-5 citato da Labov 1997, Labov 2006).

La nozione di "riportabilità" (reportability) è piuttosto controversa. Il concetto è frequentemente contrapposto a quello di "credibilità" (credibility), mentre è talvolta sussunto o affiancato a quello di "raccontabilità" (tellability).

Riguardo alla prima distinzione, si noti che un racconto, almeno nella sua forma ideale, è spesso incentrato per ragioni cognitive e interazionali su un avvenimento o un climax di eventi inaspettati e/o difficilmente spiegabili (Chafe 1990: 83). Perciò, secondo Labov (1997, 2006, 2013: 23), "riportabilità" e "credibilità" sono due principi inversamente correlati che guidano i processi di "ricostruzione" mentale e "costruzione" verbale di una narrazione: questi mirano rispettivamente a suscitare inte- 
resse per la storia e a garantirne la verosimiglianza. In particolare, la credibilità di un racconto è avvalorata dalla creazione di "autenticità" e "coerenza". Pur essendo entrambe realizzate in modo collaborativo, "autenticità" e "coerenza" sono di solito perseguite dai (co-)narratori adottando strategie discorsive opposte (cfr. Ochs \& Capps 2001: 2-18). Una storia risulta infatti autentica se è messa in scena dalla prospettiva esperienziale dell'io narrato al momento del suo svolgimento. Così, l'(impressione di) autenticità aumenta se il narratore ha vissuto l'episodio riportato in prima persona o se lo riferisce fornendo un gran numero di dettagli. ${ }^{20} \mathrm{Al}$ contrario, la coerenza come proprietà "situativa" di un testo deriva dalle relazioni che le sue parti hanno tra di loro, con l'intero testo o con altri testi dello stesso tipo (cfr. Linde 1993: 3-19). Perciò, episodi in un racconto risultano essere coerenti se l'io narrante li connette, per esempio, evidenziandone le relazioni di causa ed effetto specialmente identificabili dalla prospettiva presente e/o li interpreta tramite riferimenti a sistemi di senso più o meno diffusi e, quindi, condivisibili con gli interlocutori.

Infine, per quanto riguarda le nozioni di "riportabilità" e "raccontabilità", si noti che un evento non è riportabile e/o raccontabile in senso assoluto. Piuttosto lo è in relazione al contesto interazionale e al suo pubblico. Così, "storie piccole" in conversazioni quotidiane possono trattare di pettegolezzi apparentemente insignificanti, ma essere lo stesso funzionali al lavoro interazionale dei partecipanti (cfr. Bamberg \& Georgakopoulou 2008: 5). Inoltre, secondo Norrick (2005), la raccontabilità non ha solo un limite inferiore, ma anche uno superiore. Infatti, un parlante può, per esempio, evitare di raccontare una vicenda scabrosa o immorale, seppur eccezionale, per non minacciare la propria faccia o quella degli interlocutori. In alternativa, può decidere di raccontarla lo stesso per modulare intimità con il pubblico. In considerazione di ciò, nella più recente teoria della narrazione di Labov (2013: 41-42), ${ }^{21}$ la "raccontabilità", intesa come l'adeguatezza di una storia rispetto agli interessi di rappresentazione di sé del suo narratore in una determinata circostanza, costituisce una terza massima nell'elaborazione di un racconto insieme a "riportabilità" e "credibilità".

4) Valutazione (=evaluation; EV).

Ha la funzione di trasmettere il punto di vista del narratore sulla vicenda e di rispondere anticipatamente alle potenziali domande del pubblico riguardo ai motivi per cui la storia è stata raccontata.

Frequentemente materiale valutativo è concentrato al termine della storia in prossimità dell'evento più riportabile. Tuttavia, dispositivi di valutazione di diversa complessità sintattica sono (anche) talvolta preposti e/o incassati nelle frasi narrative dell'azione complicante. A questo proposito, Labov (1972: 370-393) distingue le valutazioni "esterne", ovvero i commenti espliciti rivolti direttamente all'ascoltatrice che interrompono il resoconto dell'episodio, da quelle "incluse" (embedded) e/o interne (cfr. anche De Fina \& Georgakopoulou 2012: 29-30). Tra queste ultime ci sono, per esempio, ripetizioni, quantificatori iperbolici o prosodia espressiva. Queste caratteristiche enfatizzano, infatti, indirettamente l'importanza di certi eventi sugli altri. In modo analogo, anche l'inserzione di frasi negative o in modo irreale, di aggettivi coordinati o di clausole subordinate può avere rispettivamente una funzione "comparativa", "correlativa" o "esplicativa" e veicolare implicitamente una determinata interpretazione dell'episodio riferito, contrapponendo o paragonando avvenimenti fattuali e/o ipotetici tra loro.

20 Per una critica a questo assunto si confronti, tuttavia, De Fina \& Georgakopoulou (2012: 137141).

21 Tale distinzione non è però, per esempio, ancora presente in Labov (2006). 
5) Risoluzione (= resolution; RI).

È il risultato della serie di eventi riportati. Questa sezione e/o quella successiva possono mancare. In tal caso, la narrazione termina con l'evento più riportabile.

6) Coda (= coda; $\mathrm{CO})$.

1 narratore segnala la conclusione del racconto, indicando più o meno esplicitamente che nessuno degli eventi accaduti successivamente è rilevante per la sua messa in scena e interpretazione. Nel fare ciò, il parlante frequentemente istituisce un collegamento tra il mondo della storia e quello dell'interazione.

\subsection{Le partecipanti e i repertori dichiarati}

I repertori narrati, ricostruiti nei $\S$ V.3 e V.4, sono quelli che emergono dalle biografie linguistiche di tre partecipanti donne, ovvero VM, DK, BV. Oltre che per la loro abilità come narratrici, ho scelto le tre partecipanti per i seguenti motivi.

In primo luogo, le intervistate hanno ottime competenze in entrambi i codici d'arrivo, ossia italiano e tedesco, e dichiarano di disporre anche di conoscenze base o avanzate in dialetto tedesco locale. Dal momento che le tre donne hanno a disposizione un insieme di risorse linguistiche tendenzialmente simile, posso partire dal presupposto che le loro rappresentazioni dei modi, funzioni e condizioni di impiego di tali codici siano potenzialmente paragonabili tra loro. In particolare, nell'analizzare le prese di posizione delle partecipanti nei confronti delle lingue d'arrivo, posso escludere l'eventualità che queste dipendano in parte da una mancata acquisizione e/o dalla considerazione di uno dei due codici locali come assolutamente estraneo in quanto non conosciuto. Ciò mi permette, a sua volta, di mettere meglio a fuoco somiglianze e differenze nella configurazione dei repertori narrati al momento dei colloqui. Tali configurazioni sono specificamente intese come il risultato dell'interazione tra i) esperienze biografico-migratorie individuali, ii) rappresentazioni metalinguistiche collettive e iii) interpretazioni della situazione interazionale in via di svolgimento.

A questo riguardo, si può già anticipare una prima differenza significativa tra le biografie linguistiche di VM, DK e BV. Questa consiste nella lingua in cui le tre donne decidono di condurre l'intervista, ovvero rispettivamente in italiano, tedesco e inglese. La selezione di codice è in tutti e tre i casi relativamente marcata in quanto non coincide con la lingua in cui erano state condotte interazioni precedenti tra intervistata e ricercatrice (cfr. DK e BV) o con la prima varietà linguistica appresa dalla partecipante dopo il trasferimento in Alto Adige (cfr. VM). La scelta del codice in cui condurre il colloquio, insieme alle ragioni esplicitamente addotte o presumibili per la sua selezione, costituisce un primo atto di posizionamento delle intervistate come parlanti. Questo è talvolta confermato, talvolta parzialmente rinegoziato da prese di posizione successive nel corso dell'interazione (cfr. in particolare VM e BV). Inoltre, tale decisione è eventualmente indicativa del (tipo di) pubblico, reale o immaginario, a cui le partecipanti si rivolgono nel raccontare la loro biografia linguistica (cfr. Pavlenko 2007: 174). In questo senso, può costituire un punto di partenza per interpretare contenuto e forma delle narrazioni di dialoghi 
(cfr. le descrizioni delle singole partecipanti nei prossimi paragrafi per maggiori dettagli).

In secondo luogo, la scelta di costruire un campione omogeneo per genere e, quindi, di concentrarsi sulle biografie linguistiche di tre parlanti donne non è tanto finalizzata a escludere l'influsso di questa variabile, quanto piuttosto a mettere meglio a fuoco i suoi effetti. A questo riguardo, si ricordi che patterns femminili di mantenimento/sostituzione di lingua in contesti plurilingui e migratori sono socialmente e storicamente determinati dalla specifica condizione delle donne nelle comunità d'origine e/o d'arrivo (cfr. Milroy \& Gordon 2003: 214-216 per una recensione di ricerche sul tema). In tempi recenti, sono inoltre eventualmente condizionati dalla "femminilizzazione dei flussi migratori" (feminization of migration), ovvero dall'aumento del numero di donne che emigrano da sole nel ruolo di "apripista" (cfr. Giddens 2009: 668, Macioti \& Pugliese 2003/2010: 115-118 per la situazione in Italia e Lainati \& Saltarelli 2007: 26 specificamente per quella in Alto Adige). Così, interpretando i dati di una serie di ricerche condotte in Australia e Nuova Zelanda, Holmes (1993) riconduce, all'inizio degli anni novanta, il maggiore e il migliore mantenimento della lingua d'origine da parte di donne "immigrate" di prima e seconda generazione rispetto a uomini in situazione analoga a ragioni socio-culturali e attitudinali. ${ }^{22}$ Invece, sulla base di interviste qualitative condotte in provincia di Pavia in anni più recenti, Chini (2003: 242) registra, seppur preliminarmente, una maggiore propensione delle donne di prima generazione rispetto ai loro consorti all'uso delle lingue d'arrivo in famiglia. Infine, Guerini (2008) rileva che le motivazioni di apprendimento del dialetto locale e i giudizi metalinguistici sul suo uso siano piuttosto omogenei per sesso - oltre che per classe sociale ed età - tra gli intervistati ghanesi in provincia di Bergamo. La ricercatrice riconduce tale uniformità alla coesione interna della comunità studiata. Considerando i diversi risultati di questi studi, la ricerca, esposta nei prossimi paragrafi, si propone di porre l'esperienza e il punto di vista femminile in primo piano. Nel fare ciò, mira a confrontare i diversi ruoli e atteggiamenti che le donne possono assumere riguardo a questioni linguistiche legate all'emigrazione. La convinzione è che questi, oltre ad essere centrali per interpretare il presente, siano sintomatici di tendenze di cambiamento future ancora in nuce (cfr. Relaño-Pastor \& De Fina 2005, Baynham 2005, King \& De Fina 2011 per un approccio analogo).

Dati questi fattori comuni (ossia competenze nei codici d'arrivo e sesso) come "base di comparazione" (cfr. Lamnek 1988/2010: 206), le esperienze di VM, DK e $\mathrm{BV}$ si differenziano tra loro per almeno altre cinque caratteristiche significative in una prospettiva di sociolinguistica della migrazione e in considerazione delle peculiarità della realtà studiata (cfr. § II e III del presente volume e anche Chini 2004, Clyne 2006, Cortinovis 2011). Infatti, come mostra in modo schematico la tabella 2, le tre partecipanti si sono trasferite in provincia di Bolzano i) a età differenti, ii) per motivi diversi e hanno risieduto iii) più o meno durevolmente iv) in località al-

22 Tra i possibili fattori, Holmes (1996) cita il ruolo attivo svolto dalle donne nella socializzazione dei bambini, la diversa composizione dei loro reticoli sociali anche lavorativi e il riconoscimento della funzione "affettiva", svolta dai codici di partenza, nel loro repertorio plurilingue. 
toatesine con diversa composizione linguistica. Inoltre, VM, DK e BV descrivono v) il proprio repertorio di partenza come diversamente strutturato, ossia rispettivamente come prevalentemente monolingue (o diacrolettico dopo un primo trasferimento in Rep. di Macedonia), come diglottico e come dilalico.

Tabella 2: Dati biografico-migratori delle partecipanti scelte per l'analisi dei repertori narrati.

\begin{tabular}{|l|c|c|l|c|l|l|l|}
\hline Parlante & Sesso & Età & $\begin{array}{l}\text { Paese d'origine e } \\
\text { rappresentazione } \\
\text { dei repertori di } \\
\text { partenza }\end{array}$ & $\begin{array}{c}\text { Età al } \\
\text { momento } \\
\text { dell'emigra- } \\
\text { zione }\end{array}$ & $\begin{array}{l}\text { Località } \\
\text { d'arrivo }\end{array}$ & $\begin{array}{c}\text { Anno e } \\
\text { durata dell' } \\
\text { esperienza } \\
\text { migratoria }\end{array}$ & $\begin{array}{c}\text { Motivo di } \\
\text { emigrazione }\end{array}$ \\
\hline VM & F & 46 & $\begin{array}{l}\text { monolingue in } \\
\text { Serbia } \\
\text { (diacrolettico in } \\
\text { Rep. di Macedo- } \\
\text { nia) }\end{array}$ & 33 & Merano & $\begin{array}{l}13 \text { anni } \\
\text { (dal 2001) }\end{array}$ & lavoro \\
\hline DK & F & 23 & $\begin{array}{l}\text { diglottico in } \\
\text { Kosovo }\end{array}$ & 7 & Sarentino & $\begin{array}{l}16 \text { anni } \\
\text { (dal 1998/ } \\
1999)\end{array}$ & $\begin{array}{l}\text { con la } \\
\text { famiglia } \\
\text { presumibil- } \\
\text { mente per la } \\
\text { guerra }\end{array}$ \\
\hline BV & F & 29 & $\begin{array}{l}\text { dilalico in Serbia } \\
\text { (genitori monte- } \\
\text { negrini) }\end{array}$ & 25 & Bolzano & $\begin{array}{l}4 \text { anni } \\
\text { (dal 2010) }\end{array}$ & studio \\
\hline
\end{tabular}

Così, sebbene l'alto livello di competenza (dichiarata) nei codici d'arrivo e tra questi, soprattutto, nei dialetti tedeschi locali distingua le tre donne dalla media degli altri intervistati, ${ }^{23}$ VM, DK e BV costituiscono, a mio avviso, tre "prototipi" (Prototypen) rispetto all'intero corpus e, al contempo, tre "tipi estremi" (Extremtypen) tra di loro relativamente alle loro traiettorie di vita e mobilità (cfr. Lamnek 1988/2010: 205206). Nello specifico, la scelta dei tre casi singoli è avvenuta in seguito a un primo esame delle interviste raccolte. Dall'analisi preliminare è risultato che i tre casi selezionati siano particolarmente significativi per valutare (la messa in scena di) modelli di comportamento linguistico e giudizi metalinguistici nel contesto d'arrivo in forza della loro "rappresentanza" (Repräsentanz), anche se non "rappresentatività" in senso statistico, rispetto alla popolazione studiata (cfr. Lamnek 1988/2010: 167). La convinzione di fondo è che l'analisi dettagliata e il confronto tra le biografie linguistiche delle tre donne, oltre ad essere interessante di per sé, consenta (in un movimento all'indietro) di riflettere e possibilmente di specificare ulteriormente tendenze e meccanismi generali e generalizzabili ad altri partecipanti del corpus così come, eventual-

23 Sia comunque qui ricordato che quattordici persone tra le 38 intervistate dichiarano di padroneggiare mediamente o bene sia l'italiano, sia il tedesco. Inoltre, altri quattordici partecipanti affermano di aver competenze almeno base in entrambe le lingue d'arrivo. Così, l'acquisizione di conoscenze, seppur a diversi livelli, in italiano e tedesco dopo il trasferimento in Alto Adige non costituisce un'eccezione almeno tra le persone con cui ho parlato. Al contrario, meno diffuse sono competenze nei dialetti tedeschi locali: infatti, ben 23 partecipanti dichiarano di non conoscere per nulla il codice (cfr. anche $\S$ III.1.5). 
mente, ad altri parlanti migranti, trasferitesi in contesti a plurilinguismo istituzionale simili all'Alto Adige (cfr. Lamnek 1988/2010: 633, Schütze 1983).

Nei prossimi paragrafi, illustro i “dati” linguistico-biografici (Rosenthal 2005), ricavabili dalle storie di vita delle tre narratrici, con maggiore dettaglio e riporto alcune informazioni generali sui modi di conduzione delle interviste e sui tipi di narrazioni di dialoghi in queste prevalenti. Inoltre, descrivo brevemente i repertori dichiarati delle tre donne relativamente al periodo trascorso nel paese d'origine e d'arrivo. Nel fare ciò, pongo particolare attenzione ai contesti e alle modalità con cui diverse varietà linguistiche sono state acquisite. Infine, fornisco una panoramica dei fenomeni di contatto riscontrati nelle loro interviste.

\subsubsection{L'intervista con VM}

VM ha 46 anni (al momento dell'intervista nel 2014) ed è nata in una cittadina della Serbia occidentale al confine con la Bosnia-Erzegovina. VM è arrivata a Merano/ Meran da sola nel 2001 a 33 anni, passando per Ungheria, Austria e Friuli Venezia Giulia lungo un percorso seguito anche da altri intervistati (e fermandosi per qualche settimana a Vienna da conoscenti conterranei). La donna ha deciso di partire da un paese della Rep. di Macedonia al confine con la Grecia, dove viveva con il marito originario del posto e un figlio piccolo, per cercare lavoro. Secondo quanto lei stessa afferma, non poteva infatti "aspettare più", ma voleva finalmente "con tren trentatré - gua:dagnare per [s]e stessa ((pausa)) e per la [sua] famiglia". Dopo il trasferimento in Alto Adige, VM ha sempre vissuto a Merano, dove successivamente l'hanno raggiunta il marito, il figlio e altri componenti della famiglia allargata (la sorella con le nipoti e alcuni cugini). La partecipante lavora attualmente come addetta al servizio di ristorazione in una mensa a Merano.

L'intervista ha luogo nell'appartamento della donna e ha una durata di un'ora e tredici minuti. Oltre alla ricercatrice, un'amica di VM, parimenti di origini serbe, assiste ai primi trenta minuti del colloquio e talora partecipa alla conversazione (ma si rifiuta di condurre lei stessa un'intervista adducendo insufficienti competenze in italiano e/o tedesco). Il marito, tornato a casa dal lavoro, ascolta invece la parte conclusiva del colloquio, intervenendovi raramente. La presenza e, talvolta, l'interazione tra più partecipanti condizionano peculiarmente le sequenze iniziali e finali dell'intervista con VM. La donna detiene comunque il ruolo di parlante principale nel corso dell'intera conversazione, mentre la sezione centrale della registrazione segue più da vicino il modello di un'intervista narrativa a due interattanti.

L'appuntamento per l'intervista con VM è stato fissato telefonicamente il giorno precedente tramite l'aiuto di un'altra partecipante alla presente ricerca, ossia DR. Sia DR, sia l'amica di VM, che assiste all'inizio della registrazione, dichiarano di avere competenze quasi esclusivamente in italiano tra le varietà linguistiche d'arrivo. Così, la decisione spontanea e non argomentata di condurre l'intervista in tale lingua da parte della narratrice potrebbe dipendere, almeno in parte, dal modo del contatto e soprattutto dalla costellazione di partecipanti all'avvio dell'interazione. Tuttavia, VM rinegozia la rappresentazione di sé che deriva da questa iniziale scelta di codice nel 
corso del colloquio. Infatti, sebbene la principale lingua di comunicazione non cambi dopo la dipartita dell'amica, l'intervistata posiziona ripetutamente il suo personaggio nel mondo della storia come parlante (prevalentemente) tedescofono nel contesto d'arrivo. Inoltre, frequenti commutazioni di codice e/o inserzioni in tedesco puntano, nel corso dell'interazione, alla padronanza della narratrice della varietà linguistica in questione. In concomitanza con ciò, tali fenomeni di contatto eventualmente lavorano per (ri-)definire la selezione dell'italiano per l'interazione in corso come una scelta di codice non causata da necessità, ma occasionale e/o occasionata dalle circostanze (cfr. più avanti in questo paragrafo e anche $\S$ V.4.2 e sgg. per maggiori dettagli).

$\mathrm{Nel}$ corso della sua biografia linguistica, VM racconta molte narrazioni scenico-episodiche, ambientate sia in Alto Adige, sia in altre località in cui ha soggiornato più o meno temporaneamente (es. in Serbia, Rep. di Macedonia, Francia, Germania). Nello specifico, sebbene il colloquio con VM sia più breve di quello con $\mathrm{BV}$, il numero totale di racconti di dialoghi della donna supera quello delle altre due intervistate (37 narrazioni). Inoltre, seppur la partecipante non riferisca soltanto di esperienze personali, la maggior parte delle sequenze narrative nella sua intervista è per forma e contenuto simile alle storie prototipo. Perciò si lascia descrivere abbastanza bene tramite il modello proposto da Labov \& Waletzky (1967). I racconti della donna sono infatti frequentemente costruiti intorno a un evento culmine, accaduto nel passato, fortemente valutato dalla narratrice.

La figura 1 rappresenta tre momenti del repertorio dichiarato da VM al momento dell'intervista, ossia nel periodo in cui viveva in Serbia (in alto), in quello in cui abitava nella Rep. di Macedonia (al centro) e attualmente dopo il trasferimento in Alto Adige (in basso). Nel compilare l'immagine mi sono servita di tutte le dichiarazioni della partecipante, non solo di quelle formulate in sequenze narrative, indipendentemente dal loro grado di spontaneità. In particolare, nella figura indico con un "+" le varietà linguistiche menzionate dall'intervistata come presenti (ossia parlate o sentite parlare) nello spazio sociolinguistico di partenza o di arrivo. Inoltre, distinguo quattro livelli di competenza dichiarata nei codici (ri)conosciuti, ovvero i) nulla “-”, ii) bassa “*”, iii) intermedia “**” e iv) alta “***”. I simboli sono posti tra parentesi tonde quando la partecipante dichiara come molto raro l'impiego delle lingue in questione. Infine, le situazioni comunicative menzionate sono raggruppate in sei domini d'uso, disposti su una scala da basso ad alto. ${ }^{24}$

24 I domini d'uso considerati e le corrispettive situazioni comunicative sono: i) famiglia (padre, madre, fratelli/sorelle, partner, figli, parenti), ii) amici (es. connazionali, stranieri, italofoni, tedescofoni), iii) comunità (vicini di casa, negozianti, città), iv) lavoro/scuola (insegnanti/capi, compagni/colleghi), v) vita pubblica (uffici, medici, forze dell'ordine), vi) media (televisione, giornali, internet) (cfr. Fishman 1972/1975: 116-122, Mioni 1987, Dell'Aquila \& Iannàccaro 2007, Chini 2004). 


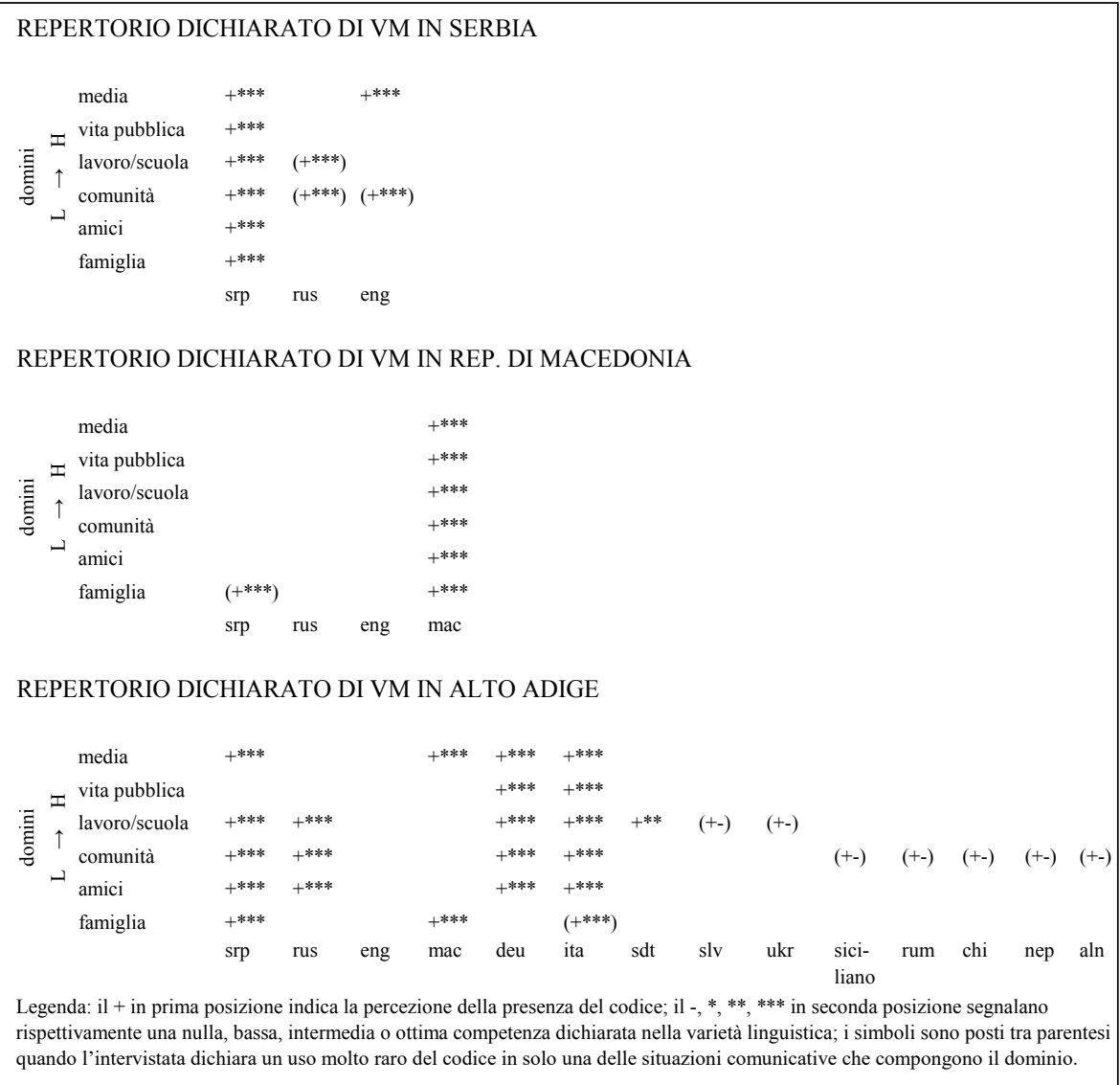

Figura 1: Tre momenti del repertorio dichiarato da VM durante l'intervista. I codici sono disposti da sinistra a destra in ordine di acquisizione.

Nella città di nascita, attualmente in Serbia al confine con la Bosnia-Erzegovina, VM dichiara di aver comunicato quasi esclusivamente in "serbo" 25 . Inoltre, ha appreso il russo a scuola e l'inglese in modo non guidato tramite film e canzoni. Invece, la partecipante afferma di essersi servita (quasi) esclusivamente di macedone durante gli anni trascorsi in Rep. di Macedonia. In questo periodo, l'intervistata comunica infatti in tale codice anche in famiglia. L'uso del serbo è invece limitato ai momenti di rabbia o alle interazioni con il figlio, ma solo dopo aver varcato la frontiera con la Serbia per andare a visitare i nonni. Del resto, le competenze dichia-

25 Durante l'intervista VM chiama la lingua d'origine quasi esclusivamente "serbo". Le espressioni "nostra lingua", "mia lingua" e "lingua materna" sono infatti usate come apposizioni e/o in modo non ambiguo dalla partecipante, mentre il glottonimo "serbocroato" è introdotto da una domanda dell'intervistatrice al termine del colloquio (cfr. anche § IV.1.3.1). Conformandomi all'uso della donna al momento dell'intervista, mi riferisco anch'io, in questo come nei prossimi paragrafi, al codice in questione principalmente con il glottonimo "serbo". 
rate di VM in macedone sono ottime: la donna paragona infatti le proprie conoscenze nel codice, già solo dopo tre mesi di matrimonio, a quelle in una "lingua materna". Arrivata a Merano, l'intervistata impara poi il tedesco come prima lingua prevalentemente in modo spontaneo (composizione linguistica della cittadina al censimento del 2011: 49,06\% italofoni, 50,47\% tedescofoni, 0,47 ladinofoni; dati ASTAT 2013: 120). Come sarà illustrato più dettagliatamente ai § V.4.2 e seguenti, la scelta di apprendere il tedesco come primo codice dopo l'arrivo in Alto Adige così come le sue modalità di acquisizione differenziano l'esperienza di VM da quella di molti altri intervistati del corpus. Successivamente la donna impara l'italiano, sia a corsi di lingua per cittadini stranieri, sia in contesti informali, come, ad esempio, a casa della sorella con le nipoti o con alcuni colleghi parimenti di origine straniera. In aggiunta, la partecipante dichiara di avere competenze intermedie anche in dialetto tedesco locale. I contatti con tale codice sono tuttavia occasionali e avvengono soprattutto al lavoro. Segnatamente, dalla figura 1 emerge anche che, dopo il trasferimento in Alto Adige, aumentino per la donna le occasioni di servirsi del russo, codice acquisito nel paese d'origine. Inoltre, pur non conoscendoli attivamente, la partecipante dichiara di sentire parlare nel contesto di arrivo un gran numero di codici non locali, ossia slovacco, ucraino, siciliano, rumeno, cinese, nepalese e albanese (cfr. anche § V.3.2).

In conclusione, fornisco una rassegna dei fenomeni di contatto nell'intervista con VM. Considerando tutte le narrazioni, non solo quelle ambientate in Alto Adige, VM si serve in sedici racconti di commutazioni di codice o inserzioni soprattutto in tedesco - ma anche in francese, serbo, dialetto tedesco locale, parole senza senso e varietà di interlingua di italiano - per riportare uno o più discorsi dei personaggi delle sue storie. Tra gli altri fenomeni di contatto, si rilevano transfer probabilmente involontari, sia dalla L1, sia dal tedesco. Tra questi ci sono i) quattro occorrenze di "chef" [ $[\varepsilon f]$ per capo, ii) la pronuncia dell'occlusiva come velare e della prima vocale anteriore come chiusa in "signale" [signale], iii) due occorrenze di "kurs" per corso, la seconda declinata al plurale secondo morfologia italiana "cursi" [korsI]. In questi specifici casi, si tratta verosimilmente di transfer occasionali, non fossilizzati, dal momento che VM si serve anche delle corrispondenti espressioni in italiano durante il colloquio. Infine, si riscontrano alcune inserzioni probabilmente intenzionali in tedesco, inglese e francese rispettivamente in quattro, una e una sequenza dell'intervista (cfr., per esempio, "Leber" per fegato e "Gallenstein" per calcolo biliare). Le inserzioni in tedesco mi sembrano essere "connesse alla partecipante" (cfr. Auer 1984). Infatti, VM pare reperire più velocemente termini in questo codice rispetto a in italiano, per lo meno nel parlare di certi argomenti. Le inserzioni sono talvolta segnalate da indicatori di correzione, talvolta semplicemente da pause (cfr. la descrizione del "time-out transfer" in Auer 1984: 57-59). Similmente alla commutazione di codice per citare discorsi riportati nelle narrazioni di dialoghi, queste inserzioni in tedesco potrebbero avere la funzione di (di)mostrare, più o meno intenzionalmente, le competenze linguistiche dell'intervistata in tale codice ai suoi interlocutori, siano essi reali o immaginati (cfr. §V.4.2 e sgg. per maggiori dettagli). 


\subsubsection{L'intervista con $D K$}

DK ha 23 anni (nel 2013) ed è nata in una cittadina medio-grossa, situata nel sud del Kosovo. Si è trasferita a Sarentino/Sarntal nel 1998-99 insieme alla famiglia all'età di sette anni. Secondo quanto affermato dall'intervistata, durante i suoi primi anni di soggiorno, la presenza di cittadini stranieri era molto bassa nel paese altoatesino: infatti vi abitava solo un'altra famiglia di nazionalità non italiana. La partecipante non racconta dettagliatamente delle ragioni per cui i genitori hanno deciso di partire dal Kosovo. Tuttavia, si può dedurre che il trasferimento sia stato principalmente causato dalla guerra o dalle sue conseguenze. Precedentemente, all'età di un anno, DK ha vissuto dodici mesi in Svizzera, dove il padre si era trasferito per lavoro. Attualmente la donna è studentessa e abita da qualche anno, insieme ai genitori e alla sorella maggiore, nel capoluogo di provincia (i due fratelli minori studiano invece a Vienna). Ha trascorso un periodo di studio a Lussemburgo. Il suo passaporto è kosovaro perché per ottenere la cittadinanza italiana "ci mettono troppo tempo".

L'intervista episodico-narrativa con DK si è svolta nello studio della ricercatrice e ha durata di circa un'ora. Ho preso appuntamento con la partecipante via email, dopo aver ricevuto il suo indirizzo da una docente dell'università frequentata dalla donna. Sebbene ci fossimo ripetutamente scritte in italiano e avessimo parlato in tale codice appena incontrate, DK mi dice prima di iniziare la registrazione che preferisce condurre l'intervista in tedesco. La scelta di lingua è motivata esplicitamente dalla partecipante adducendo una maggiore padronanza e sicurezza espressiva nel codice in questione.

Durante la sua biografia linguistica, la donna si serve abbastanza frequentemente di narrazioni - in particolare, di racconti abituali e/o generici - per illustrare usi linguistici propri o altrui e/o per argomentare in favore o contro giudizi metalinguistici diffusi a livello di gruppi sociali più o meno estesi, ad esempio, tra gli amici di "qui", gli studenti conosciuti in Erasmus o altri parlanti alloglotti in Germania. La ripetitività di fenomeni ed esperienze pare essere dunque per la narratrice uno dei presupposti per la loro "riportabilità" e/o "raccontabilità", per lo meno, nel contesto dell'intervista. In totale, DK racconta 36 narrazioni di dialoghi. La tendenza a narrare storie di eventi reiterati o (presentati come) tipici potrebbe essere in parte motivata dall'età della partecipante. Infatti, sulla base del corpus di interviste per l'Atlante di Sicilia, Paternostro (2013b) nota similmente una maggiore propensione degli informanti più giovani a raccontare storie abituali o generiche piuttosto che resoconti (accounts) o narrazioni scenico-episodiche (cfr. per osservazioni analoghe anche Paternostro 2013a: 226). Al contempo, la frequenza di tali tipi di racconti è, a mio avviso, anche indicativa del significato che la donna attribuisce all'interazione in corso. Infatti, l'intervistata sembra interpretare il colloquio come mirante a raccogliere non solo esperienze personali, ma, primariamente, conoscenze e informazioni fattuali riguardo alla realtà sociolinguistica della regione di partenza e d'arrivo. Tale interpretazione potrebbe essere determinata, tra l'altro, dalla locazione del colloquio (ossia l'ufficio dell'intervistatrice presso l'ateneo bolzanino), dal modo del contatto (via una docente universitaria) e/o dalla relativa poca espe- 
rienza della ricercatrice come intervistatrice (quella con DK è una delle prime interviste episodico-narrative da me condotte)

Nella figura 2 è rappresentato il repertorio dichiarato della partecipante prima e dopo il trasferimento in Alto Adige. In Kosovo (cfr. schema in alto nella figura 2), l'intervistata comunica principalmente in albanese. Inoltre acquisisce qualche competenza in "serbo" 26 e in turco in contesti informali. Dopo l'arrivo a Sarentino (cfr. figura 2 in basso), DK apprende simultaneamente dialetto tedesco locale e tedesco (quasi-)standard, rispettivamente in contesti informali e formali. Si ricordi che la composizione linguistica del paese al censimento del 2011 è 98,07\% di popolazione tedescofona, 1,82\% italofona, 0,10\% ladinofona (ASTAT 2013: 121). Con il passare del tempo, la donna impara anche l'italiano. Tale codice è appreso inizialmente a lezione di italiano a scuola oppure in contesti informali, vale a dire d'estate con un'amica brasiliana e i suoi figli. Infine, le competenze base di serbo, acquisite prima di partire, sono talvolta adoperate dall'intervistata anche attualmente in famiglia. Nello specifico, il codice è dichiarato come usato o da solo o in commistione con un'altra varietà linguistica, più recentemente acquisita, ossia lo slovacco (slo) (cfr. § V.4.3.1 per più dettagli).

In conclusione, fornisco qui un elenco dei pochi fenomeni di contatto riscontrati nell'intervista con DK. Sebbene il lemma "level" sia anche una parola tede$\mathrm{sca},{ }^{27}$ questo è pronunciato dalla partecipante in due occasioni in inglese durante il colloquio. In questi casi, potrebbe quindi costituire o un prestito non integrato oppure, nel caso sia usato in funzione stilistica, un'inserzione allusiva. Non ho rilevato invece fenomeni di contatto con l'italiano o il dialetto tedesco locale nella varietà di tedesco parlata da DK durante la registrazione. Fa eccezione 1'uso del termine "patentino", prestito dall'italiano con funzione referenziale, tendenzialmente "accettato" nelle varietà di tedesco locali (cfr. Ciccolone 2010). Infine, per alcuni turni di parola al termine della conversazione, DK commuta il codice base dell'interazione all'italiano. Questa alternanza di lingua è probabilmente elicitata dalla richiesta della ricercatrice di compilare un foglio scritto in italiano.

26 Dal momento che DK si serve (quasi) esclusivamente del glottonimo "serbo" nel corso dell'intervista, mi servo anch'io di tale denominazione in questo e nei prossimi paragrafi. In solo una sequenza, la partecipante impiega infatti il nome "Serbokratisch" (serbocroato). Nel brano in questione, DK sostiene la somiglianza di macedone, serbo e serbocroato in quanto lingue slave. Il modo di formulare il paragone sembra presupporre che, nella prospettiva dell'intervistata, "serbocroato" e "serbo" siano due codici simili, ma tuttavia distinti tra loro: "mazedonisch ist es auch - fast wie serbisch - serbokroatisch ist wiederum wie serbisch", tr. "il macedone è anche - quasi come il serbo - il serbocroato è a sua volta come il serbo" (minuti 06:19-06:35).

27 Il lemma "level" è per esempio registrato nel vocabolario Duden online. Qui come altrove consulto la versione in rete del dizionario Duden dal momento che questa include lemmi usati dall'intera comunità linguistica tedescofona ed è costantemente aggiornata dalla redazione sulla base di i) un corpus in continua espansione, ii) ricerche in internet e iii) segnalazioni di utenti (cfr. <https://www.duden.de/hilfe > (18.10.2018)). 


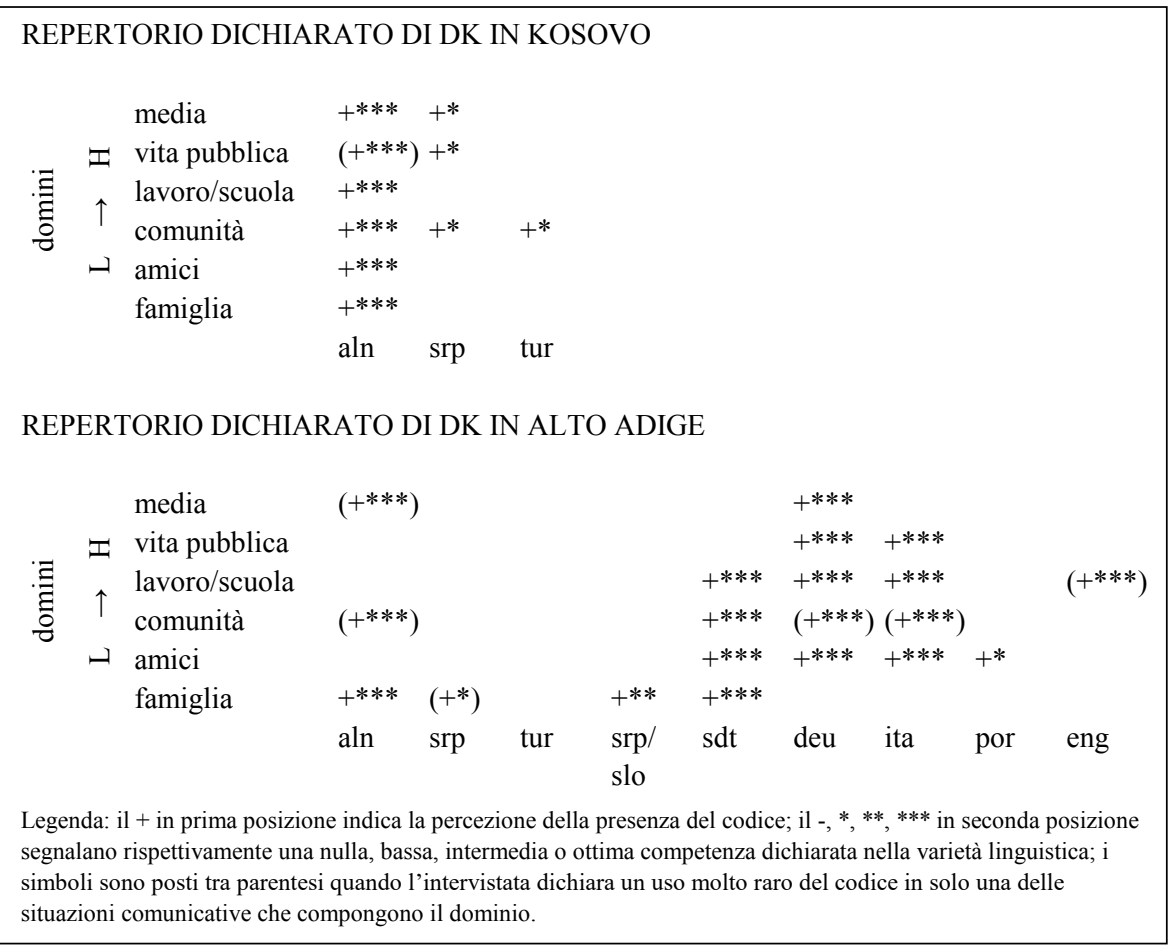

Figura 2: Due momenti del repertorio dichiarato da DK durante l'intervista. I codici sono disposti da sinistra a destra in ordine di acquisizione.

\subsubsection{L'intervista con BV}

L'ultima intervista, analizzata nei prossimi paragrafi, è quella condotta nel marzo del 2014 con BV. La partecipante è una donna di 29 anni, nata in una città medio-piccola della Serbia occidentale da genitori originari del Montenegro. BV si è trasferita nel 2010 a Bolzano/Bozen insieme al figlio di quattro anni e al marito, anch'egli intervistato per la presente ricerca, DV. Il motivo è che quest'ultimo ha ottenuto, in quell'anno, un posto di lavoro presso l'ateneo bolzanino. Prima di soggiornare in Alto Adige, la partecipante ha abitato sette/otto anni a Belgrado, dove si è laureata. Inoltre ha vissuto un anno (dal 2009 al 2010) a Vienna, dove il consorte ha lavorato sempre in un progetto accademico. Al momento del colloquio, BV è studentessa dell'università di Bolzano.

L'intervista narrativa con BV si è tenuta all'aperto nel capoluogo altoatesino e ha una durata di un'ora e trentasette minuti. Il primo incontro tra ricercatrice e intervistata risale all'anno precedente ed è occasionato dalla partecipazione a un progetto di "volontariato per le lingue", organizzato dal Centro Multilingue di Bolzano. Nonostante l'italiano sia la lingua di interazione abituale tra intervistata e ricercatrice, BV chiede, prima di iniziare la registrazione, di condurre l'intervista in 
inglese. Le ragioni di tale preferenza non sono ulteriormente specificate dalla donna. Questa potrebbe essere stata, in parte, influenzata dalla scelta di lingua analoga compiuta dal marito al momento di raccontare la sua biografia linguistica. Tuttavia, nel corso del colloquio, BV rinegozia, almeno in parte, la rappresentazione di sé che deriva da questa selezione di codice. Infatti, la partecipante mette in scena molto raramente il suo personaggio nell'atto di comunicare in inglese nel mondo delle storie. Piuttosto, la narratrice si posiziona come parlante "flessibile" di italiano e tedesco standard e come interessata ad acquisire competenze, almeno passive, nelle varietà locali e non locali di questi codici (cfr. § V.3.4 e V.4.4 e sgg. per maggiori dettagli).

Durante l'intervista, BV racconta abbastanza spesso storie di dialoghi per descrivere usi linguistici altrui o per citare giudizi metalinguistici di altri personaggi in supporto e/o in illustrazione di tesi diffuse nelle comunità di origine e d'arrivo. Solo occasionalmente, tali opinioni sono presentate esplicitamente dalla narratrice come (anche) proprie. In linea con ciò, i racconti della partecipante sono frequentemente narrazioni in terza persona o storie "ri-raccontate", ovvero resoconti di episodi a cui la narratrice non ha assistito personalmente, e hanno una funzione "argomentativo-esemplare" (cfr. anche $\S$ V.3.4.1). Il formato di storie prevalentemente raccontate punta, a mio parere, a un'interpretazione peculiare da parte di BV dell'interazione in corso. Infatti, questa sembra essere interpretata come una "situazione interpersonale", in cui la donna può e/o deve prendere posizione rispetto a rappresentazioni della realtà sociolinguistica locale, considerate da lei stessa tutt'altro che ovvie (cfr. anche Lucius-Hoene \& Deppermann 2004: 162-163). In particolare, l'attribuzione delle storie a fonti terze, spesso citate in funzione di autenticazione, permette alla partecipante di condividere la responsabilità di quanto sostenuto con altri personaggi, sia di fronte all'interlocutrice, sia, eventualmente, di fronte a un pubblico immaginario, possibilmente accademico, più ampio. Il numero totale delle narrazioni di dialoghi nell'intervista con BV è leggermente inferiore a quello delle altre partecipanti, ossia 34 storie.

La figura in 3 illustra due momenti del repertorio dichiarato da BV, rispettivamente in Serbia e in Alto Adige. 


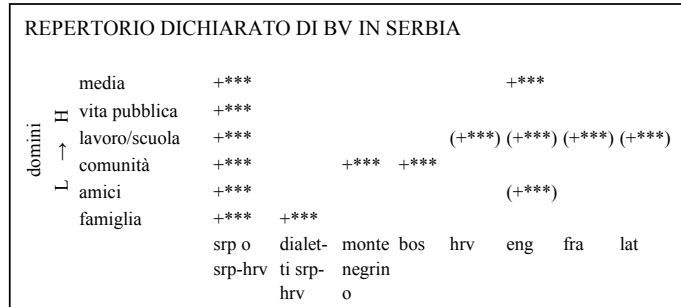

REPERTORIO DICHIARATO DI BV IN ALTO ADIGE

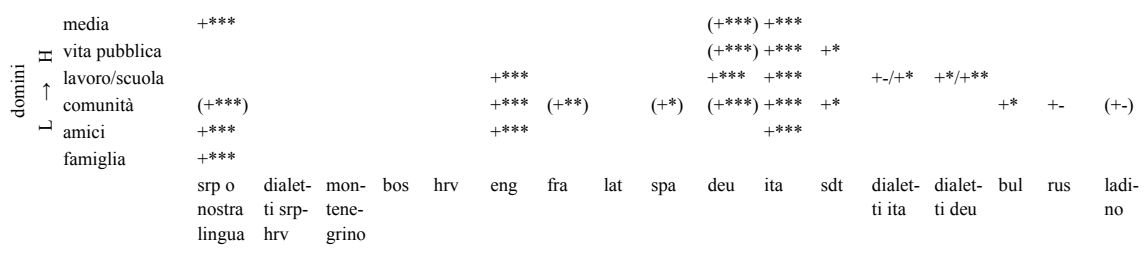

Legenda: il + in prima posizione indica la percezione della presenza del codice; il -, *, **,*** in seconda posizione segnalano rispettivamente una nulla, bassa, intermedia o ottima competenza dichiarata nella varietà linguistica; i simboli sono posti tra parentesi quando l'intervistata dichiara un uso molto raro del codice in solo una delle situazioni comunicative che compongono il dominio.

Figura 3: Due momenti del repertorio dichiarato da BV durante l'intervista. I codici sono disposti da sinistra a destra in ordine di acquisizione.

Al principio della sua biografia linguistica, l'intervistata descrive dettagliatamente i modi e i tempi di apprendimento dei codici attualmente conosciuti. Nella cittadina di nascita, "che si trova vicino ai confini con la Bosnia e anche vicino al Montenegro", BV parla in "serbo" o "serbocroato" ed entra in contatto con "molti dialetti [...] ora cosiddette lingue come bosniaco e montenegrino - anche croato". ${ }^{28}$ Inoltre, apprende l'inglese in contesti sia formali sia informali (ad esempio, a lezione o guardando film in televisione e ascoltando la musica), mentre studia il francese e il latino a scuola. In seguito, la donna - che appena si trasferisce a Vienna comunica esclusivamente in inglese - acquisisce competenze in tedesco, inizialmente studiando da sola e successivamente frequentando un corso di lingua intensivo. Sempre in Austria, BV segue dieci ore di lezioni private di italiano che consentiranno a lei, unica della famiglia, di "parlare [...] in modo base e organizzare tutto" appena trasferitasi a Bolzano (composizione linguistica della città al censimento del 2011: 73,80\% italofoni, 25,52\% tedescofoni, 0,68\% ladinofoni; dati ASTAT 2013: 120). Analogamente, anche i primi tre anni di residenza in Alto Adige, sono dedicati in modo più o meno intenso allo studio in internet o in classe delle tre lingue, ossia tedesco, italiano e inglese, necessarie per l'iscrizione all'università. Nell'anno ac-

28 BV usa nel corso dell'intervista alternativamente i glottonimi "serbo", "serbocroato", "nostra lingua", "madrelingua". La denominazione "serbo" è quella più frequente, mentre i rapporti di differenziazione più significativi sono quelli istituiti tra "serbo"/"serbocroato", da un lato, e "bosniaco", "croato", "montenegrino", dall'altro (cfr. § IV.1.5.1). In seguito mi riferisco perciò ai codici nel repertorio di partenza della partecipante con i glottonimi da lei, di volta in volta, usati nelle sequenze corrispondenti. 
cademico 2013-2014, BV è ammessa all'ateneo di Bolzano con tedesco come prima lingua (requisito di ingresso: $\mathrm{C} 1$ ), inglese come seconda (requisito di ingresso: B2) e italiano come terza (requisito di ingresso: test di conoscenza) ${ }^{29}$ Inoltre, in Alto Adige, la donna dichiara di sentir parlare intorno a lei, tra gli altri, numerosi dialetti italiani e tedeschi, non necessariamente locali. Questi sono parlati anche in contesti medio-alti, ossia tipicamente a scuola, in università o al lavoro (cfr. anche $\S$ V. 4.4.1).

Infine, oltre a un'inserzione in italiano in funzione allusiva, $\mathrm{BV}$ pronuncia sistematicamente, nel corso della sua intervista, toponimi e glottonimi nelle lingue d'arrivo (cfr. §V.4.4 e sgg. per maggiori dettagli). In aggiunta, adopera due prestiti dall'italiano con funzione referenziale nella sequenza seguente, tratta da una narrazione di interazione: "we go to questura to do permesso di soggiorno everyone speaks just italian" (minuti 58:02-58:32).

\section{USI LINGUISTICI E CONTESTO}

Nella terza sezione del capitolo V ricostruisco i rapporti tra codici e luoghi in Alto Adige per come sono rappresentati dalle intervistate e negoziati con l'interlocutrice al momento del colloquio. La concezione di spazio qui sottintesa rimanda a quella di spazio comunicativo "vissuto". Infatti, i modi di strutturazione e significazione dello spazio comunicativo da parte delle persone che lo abitano e lo vivono sono posti al centro dell'attenzione. Inoltre le rappresentazioni individuali sono concepite come parzialmente determinate e al contempo rimodellanti rappresentazioni collettive, culturalmente e socialmente sedimentate (cfr. Grassi 1981: 59-60).

Originariamente impiegato in studi di dialettologia e linguistica areale, il concetto di "spazio comunicativo vissuto" (gelebter Kommunikationsraum) ha trovato applicazione in ricerche di "sociolinguistica della migrazione" che adottano una prospettiva ecologica o emica per investigare pratiche linguistiche dopo mobilità (cfr. D’Agostino et al. 2003, Krefeld 2002, 2004, Melchior 2008, 2009: 199-204). I parlanti "migranti" hanno infatti in comune l'aver vissuto uno "sradicamento" territoriale: questa esperienza determina una ristrutturazione degli spazi sociali di attività quotidiana strettamente connessa a una riorganizzazione delle pratiche linguistiche in questi abituali (D'Agostino et al. 2003: 261). Ne consegue che lo studio dei rapporti tra lingue e luoghi così come la definizione degli strumenti analitici adatti a valutarli siano centrali nel caratterizzare la sotto-disciplina rispetto ad altri rami della linguistica (cfr. Krefeld 2004: 19-36).

I parlanti mobili ri-allocano le risorse linguistiche già acquisite e quelle con cui entrano in contatto nel nuovo ambiente in modo altamente complesso. Da un lato, come già illustrato nel capitolo I, si rileva una "particolarizzazione" negli usi lin-

29 I cittadini dell'Unione Europea non devono dimostrare competenze specifiche nella terza lingua ai fini dell'ammissione alla Libera Università di Bolzano. Invece, gli studenti non comunitari residenti all'estero, come BV, devono superare un test di conoscenza della lingua italiana, previsto per legge. L'intervistata passa l'esame con livello B2. 
guistici dei singoli anche all'interno di gruppi comunicativi coesi come la famiglia (Krefeld 2004: 54). Questa è, tra l'altro, condizionata dai modi di emigrazione (solitaria o in piccoli gruppi), dalla distribuzione a macchia di leopardo della popolazione alloglotta nelle località d'arrivo e dalla stretta connessione tra le risorse linguistiche di un parlante e le sue esperienze biografiche (cfr. anche Blommaert \& Backus 2012). Dall'altro lato, l'elaborazione di nuove routines linguistiche è comunque vincolata, specialmente nei domini formali (o in $\mathrm{H}$ ), da pratiche comunicative preesistenti. Inoltre, la progressiva implementazione di politiche linguistiche rivolte ai cittadini stranieri e la loro ricezione, spesso mediata da discorsi mass-mediatici su lingua e immigrazione (cfr. De Fina \& King 2010 e $§$ II.2.4 specificamente per la situazione in Alto Adige), possono influenzare dall'esterno motivazioni di apprendimento, scelte e rappresentazioni linguistiche individuali. Infatti, risorse, norme e modelli di comportamento linguistici, sebbene compresenti in uno stesso ambiente e altamente mutevoli, sono spesso gerarchicamente stratificati. Così alcuni "centri di autorità" risultano sistematicamente più influenti di altri (cfr. Blommaert 2010: 39-40 che definisce perciò "policentrici" gli ambienti nelle società globalizzate).

Per tratteggiare tendenze simili o divergenze nelle configurazioni dei repertori individuali, Krefeld (2004) propone una tipizzazione degli spazi comunicativi vissuti a seconda della portata comunicativa delle "lingue della vicinanza" (Nähesprachen), ovvero delle varietà linguistiche parlate in ambiti privati e con persone intime. Tale portata comunicativa può essere valutata a livello "areale" e "territoriale". Nello specifico, secondo il modello proposto dallo studioso, un criterio fondamentale per differenziare tra repertori è il fatto che i codici della vicinanza siano rappresentati o meno come impiegabili anche in altri ambiti, come nella comunicazione con sconosciuti, ad esempio, nel quartiere, nei negozi (ossia, nella terminologia del ricercatore, a livello areale) o in contesti istituzionali (vale a dire, come "lingua territoriale" (Territorialsprache)). Dopo mobilità extra-territoriale (ossia in un paese straniero), i codici usati nella cerchia familiare non coincidono generalmente con quelli adoperati nella comunità locale e dagli enti pubblici. Perciò, Krefeld (2004: 37) definisce, con una categoria astratta dalle dichiarazioni dei parlanti stessi, gli spazi comunicativi vissuti di persone mobili come "doppiamente dissociati". Similmente, ma adottando un termine diverso, Lüdi (1996) e Chini (2011) caratterizzano i rapporti tra le lingue d'origine e d'arrivo nei repertori delle "nuove minoranze" come tendenzialmente "diglottici". Krefeld (2004) individua poi sotto-tipi di spazi comunicativi vissuti o "glossotopi" in situazione migratoria, ad esempio, "isolanti", “conservanti" (konservierende), "koenizzanti". La distinzione è effettuata, tra l'altro, a seconda della portata comunicativa di varietà standard, regionali o locali dei codici d'origine solo in famiglia o anche con gli amici. Invece, Chini (2011: 66, nota a piè di pagina 7) suggerisce di descrivere la posizione delle varietà linguistiche conosciute nello spazio diglottico o poliglottico di persone mobili lungo diversi assi, ossia per esempio rispetto alla stabilità dell'allocazione funzionale delle varietà linguistiche nel repertorio, al loro modo di acquisizione, al loro prestigio manifesto o occulto e al loro grado di standardizzazione. 
Queste riflessioni costituiscono il punto di partenza per l'analisi esposta in questa sezione del capitolo V. Tuttavia, due considerazioni a livello terminologico e teorico sono ancora da precisare. In primo luogo, come già ripetutamene illustrato, usi linguistici reali e percepiti non sono direttamente ricavabili dall'analisi di un'unica intervista narrativa. Piuttosto, il compito di raccontare la propria biografia linguistica, seppur interpretabile e interpretato in modo parzialmente diverso, spinge le partecipanti a elaborare tramite una serie di storie piccole (small stories) un racconto grande (big story) e coerente della realtà linguistica esperita e dei propri comportamenti in diverse circostanze di questa (cfr. Bernhard 2014 e $\S$ V.1.1 e sgg.). I modi di tale "teorizzazione" del reale sono il tema generale della presente ricerca, mentre la ricostruzione degli spazi comunicativi delle partecipanti si basa specificamente sugli usi linguistici riportati nei racconti di dialoghi e sulle motivazioni addotte per spiegare l'alternanza di codice situazionale propria e/o altrui in alcune sequenze narrative. In considerazione del tipo di dati impiegati, chiamo dunque l'insieme delle rappresentazioni oggetto di esame gli spazi comunicativi "narrati" (e non "vissuti") delle partecipanti. ${ }^{30}$

In secondo luogo, uso il termine "soggettivo" - accanto a quelli di "individuale" e "comunitario"/ "collettivo" - per definire le articolazioni spaziali dei repertori narrati delle intervistate e alcune delle loro prese di posizione nei confronti dell'alternanza di codice. Il termine ha una duplice funzione (cfr. Busch 2013 per un uso analogo). Da un lato, serve ad indicare una terza dimensione, che si aggiunge a quelle dicotomiche di "individuale" e "comunitaria" (nel senso di relative a un singolo parlante o a un gruppo), nella descrizione degli spazi comunicativi ricostruiti delle partecipanti. Dall'altro lato, mi permette di rendere conto delle interrelazioni tra rappresentazioni "individuali", questa volta nel senso di basate sulla propria esperienza personale, e "collettive", ossia diffuse in gruppi sociali più $\mathrm{o}$ meno estesi, nella messa in scena di episodi di negoziazione di lingua in determinati contesti. Specificatamente a riguardo della dimensione "soggettiva" dei repertori, si consideri infatti che le partecipanti non mettono in scena gli usi linguistici individuali del proprio personaggio (o "io narrato") ${ }^{31} \mathrm{o}$ di altri personaggi come dispiegantesi in un vacuum. Piuttosto questi sono frequentemente rappresentati come occasionati e, talvolta, vanificati da abitudini linguistiche consolidate nel gruppo e nell'ambiente intorno a loro. In modo analogo, la messa in scena di episodi vissuti personalmente o ri-raccontati è spesso condizionata dalla volontà di supportare $\mathrm{o}$

30 Nonostante non corrispondano a quelli discussi nei prossimi paragrafi, siano qui menzionati altri due tipi di spazi ricostruiti sulla base di interviste sociolinguistiche con persone mobili. De Fina (2003: 93-138) studia rappresentazioni di sé e di altri come soggetti agenti attraverso un esame della distribuzione dello "spazio parlante" (speaking space) tra personaggi in storie di attraversamento della frontiera. Lo "spazio parlato" di persone immigrate a Palermo è invece analizzato da D'Agostino et al. (2003) sulla base del loro uso (più o meno innovativo) di verbi di movimento, tra cui "scendere".

31 I termini di "io narrato" e "personaggio dell'intervistata" da un lato, e quelli di "io narrante" e "io attuale" dall'altro, sono usati in modo interscambiabile nei prossimi paragrafi. 
confutare opinioni metalinguistiche diffuse a livello collettivo. È in accordo o in reazione a questi usi linguistici comunitari e rappresentazioni metalinguistiche collettive che le narratrici formano la propria rappresentazione di sé e di altri come "soggetti" parlanti nel corso delle interazioni.

\subsection{Gli ambiti comunicativi}

Come già illustrato precedentemente, nell'esaminare le interviste raccolte adotto un approccio sia macro che micro. In altre parole, considero la costruzione di senso sia a livello globale nell'intera biografia linguistica, sia a livello locale in singole sequenze narrative.

Nello specifico, per condurre la prima fase di analisi a livello macro, ho codificato il primo enunciato o attività comunicativa riportata in tutte le narrazioni di dialoghi delle tre partecipanti per la varietà linguistica, mezzo di comunicazione nel mondo della storia, e per il contesto, in cui è messo in scena il racconto. Il risultato della codifica è visibile alle figure $4,5,6$ dei $\S$ V.3.2, V.3.3, V.3.4. In tali immagini, sono indicate tutte le varietà linguistiche menzionate nelle narrazioni di interazioni, anche quelle sentite o solo riconosciute, ma non padroneggiate attivamente dalle partecipanti (cfr. Blommaert \& Backus 2012 per un approccio analogo). ${ }^{32}$ In questo modo, miro a fornire un quadro, il più completo possibile, di dove sono localizzate le attività comunicative riportate dalle tre intervistate nella regione d'arrivo.

La suddivisione per situazioni comunicative negli spazi comunicativi narrati delle partecipanti è emica, ovvero si basa sulle distinzioni effettuate dalle tre donne nelle loro narrazioni di interazioni. Tuttavia, nelle immagini dei prossimi paragrafi, ho poi raggruppato insieme (assegnando loro una stessa tonalità di grigio) ambientazioni che - secondo la mia interpretazione delle interviste o in considerazione della ripartizione in domini d'uso stabilita in altre ricerche ${ }^{33}$ - sono tra loro correlate. Tra queste ci sono, per esempio, quartiere e negozi (nel quartiere), da un lato, o carabinieri e questura, dall'altro. Inoltre, seguendo Krefeld (2004), distinguo i contesti menzionati lungo un continuum che va dagli ambiti della vicinanza pragmatica e/o sociale (ossia ambiti informali o in L) a quelli della lontananza o anonimia (ovvero ambiti formali o in $\mathrm{H}$ ) ${ }^{34}$ Infine, in considerazione della peculiare situazione sociolinguistica altoatesina, mi servo, durante l'analisi, della categoria di

32 Per informazioni sulla competenza dichiarata nelle varietà linguistiche conosciute e riconosciute dalle partecipanti rimando, invece, alle immagini dei repertori dichiarati ai precedenti $\S$ V.2.4.1, V.2.4.2, V.2.4.3. Nella prossima sezione del quinto capitolo ( $\$$ V.4), distinguo inoltre i codici i) che l'io narrato usa attivamente da quelli ii) con cui gli è rivolta la parola o iii) a cui è solo occasionalmente esposto nel mondo delle storie.

33 Si confrontino Fishman (1972/1975: 116-122), Mioni (1987), Dell'Aquila \& Iannàccaro (2007) e, in questo volume, il § I.1.3.

34 Sia qui ricordato che nell'individuare i rapporti tra codici mi baso, nei prossimi paragrafi, sulle rappresentazioni emiche delle partecipanti nelle narrazioni di interazioni. Perciò, per esempio, le lingue in $\mathrm{H}$ (o acroletti) sono le varietà linguistiche usate dai personaggi delle loro storie in 
"contesti istituzionali". Tale iperonimo raggruppa quelle situazioni comunicative in cui il plurilinguismo e il diritto al monolinguismo sono regolati per legge in provincia di Bolzano, ovvero, tra gli altri, in questura, in ospedale, a scuola o in università (cfr. Lüdi \& Py 1986/2003).

L'adozione di queste categorie di secondo grado è finalizzata a poter descrivere e, soprattutto, comparare la distribuzione delle lingue negli spazi comunicativi narrati delle tre donne da diversi punti di vista. L'obiettivo è rispondere alle seguenti domande di ricerca:

1) Quali luoghi di attività quotidiana costituiscono lo sfondo delle narrazioni di interazioni delle partecipanti? E, in particolare, quali sono le situazioni comunicative nominate più frequentemente e quelle meno menzionate e perché?

2) Quali contesti in Alto Adige sono rappresentati dalle narratrici come plurilingui e quali come monolingui?

3) In quali situazioni comunicative le intervistate raccontano di utilizzare/ascoltare i codici d'origine? E, quindi, quali sono la portata comunicativa (cfr. Krefeld 2004) e il grado di mantenimento/sostituzione di tali varietà linguistiche in prospettiva emica?

4) Quale è l'allocazione dei codici d'arrivo (varietà standard o non standard di italiano e di tedesco, ladino) nel repertorio narrato delle partecipanti? E, eventualmente, ci sono situazioni comunicative in cui è preferibile o necessario usare un determinato codice invece che un altro?

Partendo dal presupposto che il numero di narrazioni ambientate in un contesto sia correlato con la rilevanza di quest'ultimo, la prima domanda di ricerca mira a identificare i luoghi di interazione intorno a cui le singole partecipanti tendono ad organizzare il loro spazio comunicativo narrato al momento di raccontare la propria biografia linguistica. Il secondo quesito intende invece valutare la diffusione di pratiche plurilingui a livello comunitario e individuale - ossia diverse lingue in un unico contesto o diverse lingue nel discorso di un unico parlante - nell'ottica delle intervistate. Infine, le risposte alle ultime due domande puntano a tratteggiare i tipi di repertorio narrato delle tre donne. La loro tipizzazione avviene sulla base della portata comunicativa rappresentata dei codici d'origine, della diffusione sempre rappresentata delle lingue d'arrivo e, eventualmente, del fatto che queste varietà si specializzino a uniche lingue di comunicazione in determinati ambiti.

La seconda parte dell'analisi è dedicata all'esame dettagliato (o micro) di tre sequenze narrative, in cui le narratrici istituiscono relazioni più o meno stabili tra varietà linguistiche, luoghi di interazione, e talvolta (tipi di) destinatari (cfr. $\S$ V.3.2.1, V.3.3.1, V.3.4.1). Le lingue potenzialmente coinvolte nella scelta e i criteri stabiliti come cruciali nel motivarla variano tra le tre partecipanti. Tuttavia, le narrazioni considerate svolgono un'analoga funzione in interazione. Queste rendono infatti conto all'interlocutrice dei motivi della propria o dell'altrui selezione

ambiti formali in Alto Adige. Questo vale indipendentemente dal grado di standardizzazione di questi codici dal punto di vista etico. 
di codice nell'attuale regione di residenza. Un esame delle tre storie consente dunque di valutare gli specifici "mezzi" narrativi e le specifiche "forme" linguistiche con cui le intervistate risolvono un "lavoro" analogo (cfr. Hausendorf \& Quasthoff 2005: 121-124).

Tra le varie caratteristiche linguistiche prese in esame nel corso dell'analisi micro, le scelte e commutazioni dei pronomi personali si dimostreranno essere particolarmente significative. Tali variazioni permettono infatti alle intervistate di i) negoziare "agentività", ii) modulare "responsabilità" e iii) trasmettere "partecipazione" nel mondo della storia e dell'interazione. A questo riguardo, De Fina \& Georgakopoulou (2012: 75-83) riassumono i risultati di diversi studi sul tema. Da questi emerge, per esempio, che le interviste che vertono su storie di immigrazione siano spesso caratterizzate da un'alta frequenza di narrazioni in prima persona plurale o in forma impersonale (invece che in prima persona singolare). Questa predominanza può essere ricondotta, da un lato, allo specifico evento comunicativo "intervista", ossia a una conversazione con un ricercatore quasi-sconosciuto. Dall'altro, è significativamente probabilmente anche spiegabile dal contesto sociale più ampio; vale a dire, per esempio, dalle condizioni concrete in cui avviene l'emigrazione a catena (ossia in gruppi) e/o da alcuni discorsi, diffusi a livello collettivo, che colpevolizzano gli stranieri trasferitesi senza documenti. Soprattutto in conseguenza di questi ultimi, il narratore potrebbe preferire ridurre o condividere la propria agentività e responsabilità e, così, riferirsi alla propria esperienza migratoria in modo impersonale o come parte di quella di un gruppo. Inoltre, differenze nei modi abituali di costruire riferimenti personali nelle storie si riscontrano anche a seconda della prima lingua del parlante e sembrano, eventualmente, rispecchiare pratiche socialmente e culturalmente consolidate di rappresentazioni del sé. Così, Tannen (1989/2007: 205, nota a piè di pagina 13) rileva che l'adozione di forme in seconda persona singolare costituisca una strategia di coinvolgimento spesso utilizzata nei racconti di parlanti grecofoni. Invece, secondo Linde (2009: 72-88), storie in seconda persona sono raramente raccontate da locutori anglofoni negli Stati Uniti. Il loro impiego si limita infatti alla comunicazione con i bambini o tra amici, ad esempio, quando il narratore non è d'accordo con l'interpretazione di una vicenda vissuta dal destinatario.

\subsection{Lo spazio comunicativo narrato di VM}

La figura 4 rappresenta lo spazio comunicativo narrato di VM al momento dell'intervista. Questo è ricostruito sulla base delle 37 narrazioni di dialoghi che la donna racconta. I codici, mezzo di comunicazione nel mondo delle storie, sono raggruppati in cerchi a seconda dello scenario in cui si svolge il racconto. La grandezza dei cerchi è proporzionale al numero di narrazioni con una determinata ambientazione (il numero delle storie per situazione è indicato anche in ciascun cerchio in alto). Agli scenari tra loro correlati ho assegnato una stessa tonalità di grigio. Dalla figura 4 emerge che VM narra di dialoghi condotti sia i) in lingue cosiddette "standard" (es. tedesco, inglese), sia ii) in varietà regionali o locali dei codici d'arrivo (es. sici- 
liano, sudtirolese), sia iii) in varietà di contatto (es. italiano \& inglese, serbo/italiano ${ }^{35}$ sia iv) in varietà di apprendimento o interlingua (es. interlingua in italiano). Inoltre riporta anche di v) comunicazioni non verbali, riuscite o (parzialmente) fallite, e di attività metalinguistiche (es. gesti, cercare le parole in tedesco). All'interno di ciascun cerchio ho elencato i codici e/o le attività comunicative, menzionati dall'intervistata, indipendentemente dalla loro frequenza di occorrenza.

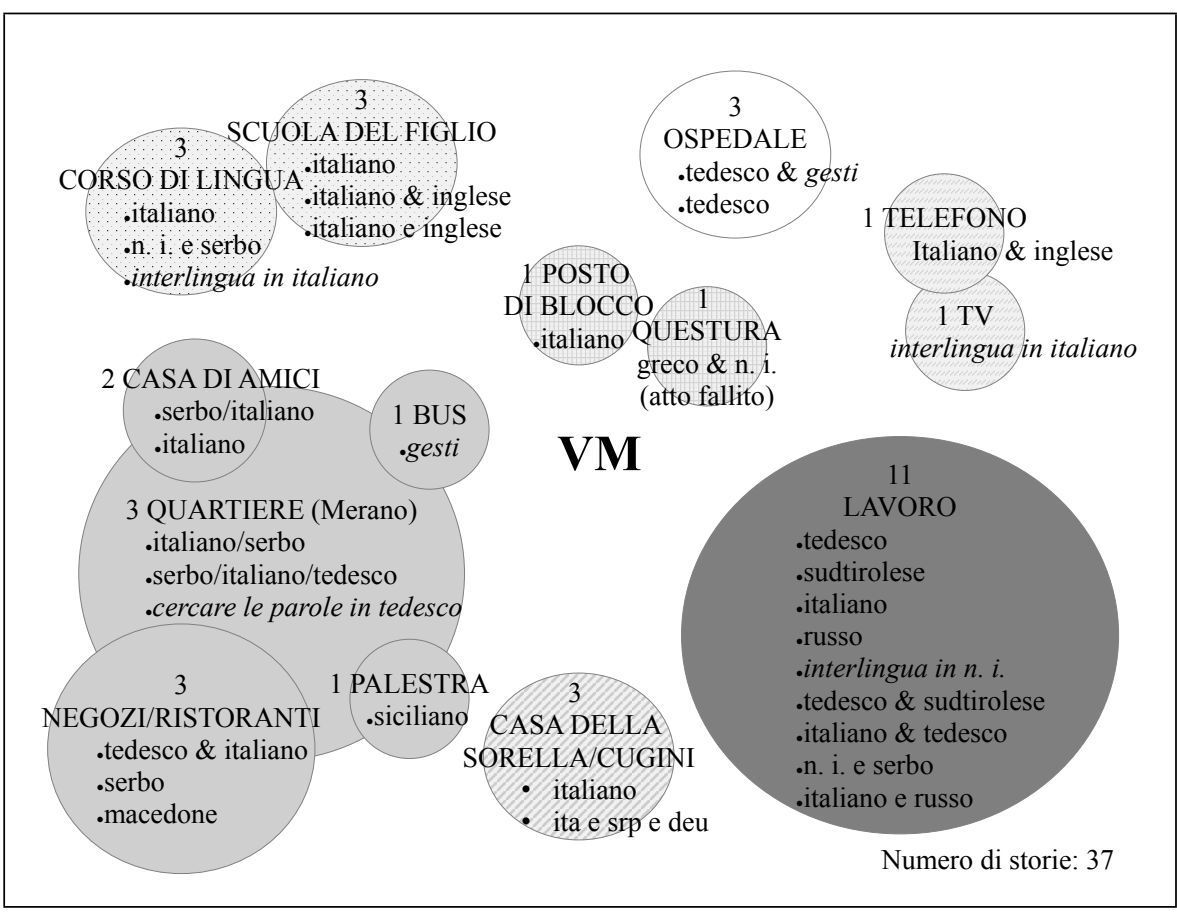

Figura 4: Codici usati nelle narrazioni di interazioni, ambientate in Alto Adige, dell'intervista con VM.

Una prima osservazione concerne la differenza tra il repertorio narrato di VM in figura 4 e quello dichiarato dalla stessa intervistata, per esempio, in seguito a domande dirette della ricercatrice (cfr. figura 1 al $\S$ V.2.4.1). A questo proposito, alcune situazioni comunicative non sono menzionate spontaneamente da VM come sfondo di narrazioni di interazioni in Alto Adige. Invece determinati scenari sono più citati di altri e, quindi, sembrano essere più rilevanti per la partecipante al momento di narrare la propria biografia linguistica. Nello specifico, tra le situazioni comunicative in figura 4, manca il contesto "casa". Rispondendo a una domanda sulle lingue impiegate in questo ambito, la partecipante dichiara di comunicare attualmente in serbo,

35 Si ricordi che pratiche di alternanza non reciproca tra due lingue sono indicate da una e commerciale (\&), mentre la barra diagonale (/) divide i codici usati in enunciazioni mistilingui. Per una legenda dei simboli utilizzati si veda il §V.2.2. 
macedone e, talvolta, in italiano con il marito e il figlio. Tuttavia, nonostante i due uomini siano personaggi di storie ambientate in altri scenari (cfr. anche $\S$ V.4.2 e sgg.), le lingue usate nel proprio nucleo familiare non sono oggetto né incidentale né diretto delle narrazioni di dialoghi della donna. Tutt'al più, l'intervistata riporta di interazioni avvenute nelle abitazioni di altri suoi parenti, a cui è legata da rapporti relativamente meno stretti e/o rispetto ai cui usi linguistici ha meno potere decisionale. Queste sono quelle a casa della sorella e di due cugini. All'opposto, l'ambito "lavoro" funge da sfondo alla maggior parte dei dialoghi riportati. Undici narrazioni sono infatti ambientate nelle due mense a Merano, in cui VM è stata ed è attualmente impiegata come addetta al servizio di ristorazione. A tali storie seguono per numero i racconti situati in modo piuttosto generico nel "quartiere" di residenza a Merano o in contesti a questo correlati (cfr. i cerchi in basso a sinistra in figura 4). Inoltre, VM narra abbastanza frequentemente di interazioni che hanno luogo in "ambiti istituzionali", ovvero in ospedale, in questura, presso un posto di blocco, a scuola del figlio e a un corso di lingua per apprendenti stranieri. La distribuzione quantitativa di narrazioni per contesti appena delineata dipende sicuramente in parte da motivazioni extra-linguistiche, come, ad esempio, la maggiore quantità di tempo trascorsa da $\mathrm{VM}$ al lavoro piuttosto che in questura. Non per questo è a mio avviso meno indicativa del modo di strutturare e di significare il proprio spazio comunicativo in Alto Adige da parte dell'intervistata al momento del colloquio. La singolarità dell'organizzazione spaziale del repertorio narrato di VM in relazione sia al tipo di ambiti omessi, sia a quelli più rilevanti emerge dal paragone con i contesti prevalentemente sfondo delle narrazioni di interazioni di DK e BV, ovvero "casa" e "università" (cfr. le figure 5 e 6 nei successivi $\S$ V.3.3 e V.3.4).

In secondo luogo, un esame della figura 4 rivela che, sebbene la donna associ ad alcuni contesti istituzionali l'uso di un unico codice (cfr. più sotto in questo paragrafo), VM rappresenta numerose situazioni comunicative in Alto Adige come plurilingui, per lo meno durante l'intervista. Ambiti estremamente plurilingui sono il lavoro e il quartiere alla periferia di Merano. In tali contesti, la donna ha infatti occasione di parlare e/o di ascoltare sia codici d'arrivo (italiano, tedesco e dialetto tedesco locale), sia lingue usate o apprese a scuola nel paese d'origine (serbo, macedone e russo), sia varietà di interlingua, sia pratiche di alternanza di codice non reciproca o di enunciazione mistilingue. Così, non solo la coesistenza di codici diversi in un determinato ambito (plurilinguismo a livello sociale), ma anche la compresenza di varietà linguistiche in uno stesso discorso, ossia l'occorrere di pratiche comunicative che presuppongano competenze in più lingue da parte di uno stesso individuo (plurilinguismo a livello individuale), risultano essere fenomeni almeno spazialmente pervasivi nel repertorio narrato della partecipante (ma cfr. il $\S$ V.4.2 e sgg. per una precisazione di tale osservazione in considerazione della distribuzione delle varietà di contatto per ruoli interazionali). Dal momento che tale rappresentazione differisce parzialmente da quella delle altre due intervistate si noti, tuttavia, che VM menziona, tra le varietà linguistiche di nuovo insediamento parlate e/o sentite nella regione d'arrivo, esclusivamente codici appartenenti al suo repertorio di partenza. I loro locutori si sono stabiliti in Alto Alto verosimilmente in conseguenza di emigrazione dovuta alla ricerca di lavoro. 
Una terza osservazione rispetto alla distribuzione dei codici per contesti in figura 4 riguarda la portata comunicativa e, indirettamente, il grado di mantenimento dei codici d'origine in Alto Adige, per come sono rappresentati da VM durante e tramite le sue narrazioni di interazioni. In particolare, le possibilità di impiego del serbo si estendono nello spazio narrato della partecipante al di là della cerchia familiare ad ambiti pragmaticamente più "distanti" e "semi-anonimi" (cfr. Krefeld 2004: 19-36, Melchior 2009: 199-202). Il codice è infatti mezzo di comunicazione con e da parte di amici, colleghi e conoscenti al lavoro, al corso di lingua italiana per stranieri e nel quartiere. Inoltre, una narrazione ha come evento matrice l'ascolto incidentale da parte dell'io narrato di un dialogo in "serbo"/"nostra lingua" tra sconosciuti in un ristorante. La storia suggerisce così la diffusione di tale codice in provincia di Bolzano e la sua condizione di "lingua immigrata" e non solo di "lingua di migranti" nella prospettiva dell'intervistata (cfr. per questa distinzione, per esempio, Bagna et al. 2003). ${ }^{36}$ Sebbene la lingua della vicinanza sia rappresentata come un codice che detiene un certo radicamento sul territorio, lo spazio comunicativo narrato di VM è comunque "dissociato" (Krefeld 2004: 33). Le varietà linguistiche di partenza sono infatti completamente sostituite da quelle d'arrivo per la comunicazione in ambiti istituzionali, ossia, ad esempio, a scuola del figlio, in ospedale, al posto di blocco.

In considerazione della discussione condotta finora, la distribuzione di serbo (e, parzialmente, di macedone) nello spazio comunicativo narrato della partecipante risulta singolare. Da un lato, come appena illustrato, i racconti di dialoghi della donna mettono in scena l'ampia portata comunicativa di tale varietà linguistica nella regione d'arrivo. Nel fare ciò, suggeriscono quindi un suo mantenimento a livello di repertorio "comunitario". Dall'altro, l'intervistata non menziona un contesto di solito centrale per la trasmissione delle lingue d'origine, ovvero quello familiare. Così, la partecipante sembra minimizzare l'impiego e la rilevanza dei codici di partenza a livello di repertorio "individuale". L'analisi della distribuzione di codici per interattanti e di alcune sequenze narrative dell'intervista permettono di precisare meglio questa prima impressione. L'io narrante, infatti, rappresenta raramente il proprio personaggio nell'atto di servirsi dei codici d'origine in qualità di parlante e si disallinea da un loro impiego da parte del marito in contesti pubblici, ad esempio, nei negozi (minuti 25:01-25:29). Tuttavia, in altri momenti della sua biografia linguistica, VM valuta affettivamente come "triste" ed epistemicamente come "sbagliata" la sostituzione di lingua da parte di un cugino parimenti residente in Alto Adige nel comunicare con i figli (minuti 39:10-40:21). Invece che segnale di un comportamento analogo, l'omissione dell'ambito "famiglia" nello spazio comunicativo soggettivo di VM mi pare essere, dunque, funzionale a prendere più fermamente posizione rispetto ad altri usi linguistici del proprio personaggio nel contesto d'arrivo. Infatti, la partecipante costruisce il proprio discorso biografico insieme all'interlocutrice intorno a una rappresentazione di sé come parlante preva-

36 Si noti che la comunità di parlanti serbofoni è anche elencata tra le possibili "nuove comunità linguistiche" in Italia, individuate preliminarmente in Chini (2011: 54) sulla base di criteri demografici e di dati raccolti in altre ricerche. 
lentemente tedescofona nonostante un contesto alloglotto (cfr. $\S$ V.4.2 e sgg. per più dettagli).

A proposito dell'allocazione delle lingue d'arrivo nella figura 4, tedesco e italiano costituiscono nel repertorio narrato di VM due acroletti, adoperabili in domini formali. Il loro uso è comunque presentato dalla narratrice come "normale" anche in situazioni comunicative informali, ad esempio, nel quartiere o con gli amici. Insieme a serbo e macedone, l'italiano costituisce inoltre (un) codice di socializzazione primaria a casa della sorella o dei cugini (cfr. sopra). Così, l'intervistata caratterizza le relazioni tra i codici conosciuti dopo mobilità come tendenzialmente "dilaliche": infatti, i codici d'arrivo sono usati in situazioni sia formali sia informali, mentre quelli d'origine sono adoperati solo in domini bassi (cfr., per esempio, Berruto 1995: 227-255). Si noti che, come frequentemente accade in situazioni di dilalia (cfr. Dell'Aquila \& Iannàccaro 2007), commutazioni di codice intrafrasali (es. italiano/serbo, serbo/italiano/tedesco) sono pratiche abbastanza diffuse nel repertorio narrato della donna. In aggiunta, la partecipante nomina, tra le lingue parlate o sentite al lavoro, anche i dialetti tedeschi locali. Il contatto con queste varietà linguistiche - che possono quindi fungere da mesoletti a livello comunitario - è, tuttavia, saltuario per la donna a differenza di quanto emerge dalle narrazioni di interazioni di DK e parzialmente di BV (cfr. figura 5 e 6 nei paragrafi successivi). D'altro canto, è interessante notare che l'uso dei codici d'arrivo si specializza nello spazio comunicativo narrato di VM a seconda di alcuni contesti in $\mathrm{H}$. L'ospedale è infatti un ambito comunicativo in cui la partecipante parla prevalentemente tedesco. Invece, presso il posto di blocco e a scuola del figlio, l'intervistata mette in scena dialoghi in varietà di italiano e/o di italiano e inglese. Il tipo di istituzione, più che la formalità della situazione descritta, sembra quindi condizionare la selezione dell'italiano o quella del tedesco in Alto Adige, per lo meno nella prospettiva della donna. Nel paragrafo seguente discuto alcuni fattori che, a mio avviso, condizionano tale allocazione dei codici d'arrivo. In particolare, tramite l'analisi dettagliata di una sequenza narrativa, valuto l'influsso di opinioni e narrazioni metalinguistiche, diffuse a livello collettivo nella regione di arrivo, sulla messa in scena dei propri usi linguistici individuali da parte della narratrice.

\subsubsection{Una storia "condivisa”}

La specializzazione dei codici d'arrivo per contesti istituzionali nel repertorio narrato di VM è condizionata, a mio avviso, in parte da fatti biografici, in parte da peculiarità amministrative del plurilinguismo in Alto Adige, in parte dall'interazione tra esperienze individuali, da un lato, e rappresentazioni di fenomeni linguistici condivise a livello locale, dall'altro. La serie di vicende in ospedale ha luogo, infatti, durante i primi anni di soggiorno di VM in provincia di Bolzano quando la donna ha competenze esclusivamente in tedesco. L'uso dell'italiano come principale lingua di interazione a scuola dipende, invece, dallo speciale ordinamento scolastico altoatesino e dalla frequentazione da parte del figlio di una scuola in lingua italiana. Infine, la scelta di tale codice per interagire con i carabinieri costituisce 
l'evento più riportabile di una breve narrazione di interazione, trascritta in $1 . \mathrm{Nel}$ racconto, la selezione di codice è presentata da VM come la conseguenza di un nesso (quasi) indissolubile tra lingua (= italiano), contesto (= posto di blocco) e interlocutori (= carabinieri).

\begin{tabular}{l|lr}
\multicolumn{1}{l}{$($ es. 1) } & & \\
OR \& & 1 & VM \\
ME & 2 & VM \\
EV & 3 & VM \\
mRE & 4 & VM \\
& 5 & INT \\
dopo & 6 & VM \\
sto- & 7 & VM \\
ria & 8 & VM \\
& 9 & VM
\end{tabular}

o quando una volta: $(1,0)$

carabinieri con la macchina

non dico $->$ adesso parlo tedesco $<<<$ forte no::: $>$

$<<$ forte e ridendo BUOna[sera $>$ ] ((riso))

$[(($ riso $))]$

$<<$ rivolgendosi sia al marito, presente durante la conversazione,

che alla ricercatrice $(\mathrm{h}) \mathrm{NO}$ o era incontro $(0,4)$ non si ricorda

$(0,8)(\mathrm{h})$ era incontro $>$

$(3,0)$ basta che lui non parlava greco $(1,4)$

(VM_Ser_Mer, 57:33-57:54)

Ho categorizzato il racconto in 1 come una narrazione metalinguistica, in cui VM nel ruolo di parlante si rivolge in italiano ai carabinieri presso un posto di blocco. La storia ha infatti per tema un evento linguistico, ovvero la negoziazione di codice in una determinata situazione comunicativa nella regione d'arrivo. Raccontata da VM quasi al termine della sua biografia linguistica, la narrazione in 1 segue un altro breve racconto della donna sulla sorpresa di un cameriere in un bar di Merano per la diversa scelta di lingua dell'io narrato e della sorella al momento di ordinare. Sebbene le due storie siano indirettamente elicitate da una domanda della ricercatrice sulle varietà linguistiche attualmente parlate nella cittadina altoatesina (minuti 57:11-57:18), l'argomento della narrazione in 1 è spontaneamente scelto dall'intervistata.

VM rappresenta la selezione dell'italiano da parte del proprio personaggio nel racconto in 1 non solo come un comportamento linguistico vantaggioso, ma anche come una reazione "tipica", ovvero una scelta di lingua invariabile e convenzionale, all'occorrere del particolare scenario riportato. L'influsso di opinioni metalinguistiche collettive sulla raffigurazione del proprio comportamento linguistico è riconoscibile, oltre che dal contenuto del racconto (cfr. più sotto in questo paragrafo), anche dalla sua struttura e dai commenti della narratrice nel dopo storia. In particolare, a livello formale, la convenzionalità della vicenda in 1 emerge, da un lato, dalla brevità della narrazione, composta da solo una "giuntura temporale". Infatti, la storia è formata da soli due eventi: quello matrice e quello più riportabile (ME e mRE). Dall'altro lato, risulta evidente dal modo selettivo in cui ambienta-

37 Ricordo qui le sigle usate per la segmentazione: $\mathrm{AB}$ (= abstract), OR (= orientazione), $\mathrm{ME}$ (= evento matrice), $\mathrm{CA}$ (= azione complicante), $\mathrm{mRE}$ (= evento più riportabile), $\mathrm{EV}$ (= valutazione), RI (= risoluzione), CO (= coda) (cfr. §V.2.3). Inoltre, le clausole con una funzione ambigua $\mathrm{o}$ facenti parte di più unità narrative sono contrassegnate da più sigle separate da una "o" o da una "\&". Infine, gli estremi di un'unità narrativa comprendente più righe sono segnati da una cornice nera intorno ai numeri di riga. 
zione e personaggi sono caratterizzati. A VM bastano pochi enunciati ellittici per mettere in scena la situazione comunicativa, motivare la propria scelta di codice, e coinvolgere ed allineare l'intervistatrice al proprio comportamento linguistico che, infatti, ride (cfr. riga 5). Nonostante la storia sia accennata piuttosto che raccontata, la rappresentazione di VM è selettiva nel senso che riporta con un alto grado di dettaglio alcuni particolari, apparentemente non tralasciabili per rievocare il culmine dell'episodio. L'io narrante specifica infatti l'attività lavorativa degli interlocutori, che sono carabinieri. In aggiunta, cita un enunciato del proprio personaggio in discorso diretto.

La struttura "scheletrica" del racconto in 1 e il modo con cui VM rinvia a questo tramite riferimento al suo "apice" (punchline) ricordano i processi di "de-narrativizzazione", "riduzione" e "congelamento dei modi di riferimento", a cui sono soggette le "storie condivise" (shared stories) tra persone intime (cfr. Georgakopoulou 2005: 230-233 e anche De Fina \& Georgakopoulou 2012: 108-121). ${ }^{38}$ Inoltre, in modo analogo alle routines di ricezione di tali "storie di gruppo", il riso dell'interlocutrice (di)mostra l'avvenuta comprensione e la sua familiarità con il tema, semplicemente alluso dalla narratrice (cfr. Georgakopoulou 2005: 231). In questo caso, partecipante e ricercatrice si incontrano però per la prima volta nell'occasione dell'intervista. Perciò, i presupposti della brevità e del non compromesso successo della storia devono trovarsi nella condivisione non di pratiche comunicative quotidiane, ma di motivi e temi a livello di comunità di discorso locale. In particolare, loro fondamento è la preesistenza di discorsi metalinguistici sull'indissolubilità del nesso tra lingua, contesto e interattanti, messo in scena nel mondo della storia. Infatti, se la collocazione del racconto al termine dell'intervista può in parte spiegare perché il rapporto instauratosi tra narratrice e ascoltatrice sia (ormai) piuttosto confidenziale, la narrazione non risulta essere raccontabile senza ulteriori spiegazioni a persone non familiari con (le rappresentazioni del) la situazione sociolinguistica altoatesina, a cui l'ho ripetuta. Infine, la peculiare struttura della storia in 1 potrebbe dipendere, oltre che dall'allusione ad opinioni metalinguistiche condivise, anche dal fatto di essere stata frequentemente ripetuta dalla narratrice in svariate circostanze. Nel presente caso, non dispongo tuttavia delle informazioni etnografiche necessarie per stabilire se è effettivamente così.

A livello di contenuto, VM allude nel brano in 1 a un'opinione che circola abbastanza diffusamente nella società d'arrivo. Secondo questo stereotipo, la maggior parte degli impiegati nelle forze dell'ordine in provincia di Bolzano sono parlanti di preferenza, se non esclusivamente, italofoni. In realtà, militari, carabinieri e polizia di stato in Alto Adige sono tenuti per legge al rispetto del "diritto alla madrelingua". Perciò, devono padroneggiare sia italiano sia tedesco, mentre sono esonerati dalla conoscenza della lingua ladina indipendentemente dal luogo in cui prestano servi-

38 Come già illustrato al $\S$ V.1.1.2, le "storie condivise" sono, secondo De Fina \& Georgakopoulou (2012: 108-121), tipi particolari di "storie ri-raccontate" (retold stories). Dal momento che la messa in scena di una storia è condizionata dalle aspettative (presupposte) nel suo pubblico e dalle esperienze di racconto precedenti, tali narrazioni spesso non seguono la struttura delle "storie" prototipo, discussa al § V.2.3. 
zio. Nello specifico, la garanzia di un uso parificato della lingua italiana e tedesca è regolata dalla norma di attuazione dello statuto speciale in Trentino-Alto Adige (decreto 574 del 15/7/88 del Presidente della Repubblica). Questa vale in Provincia di Bolzano specificamente "per le attività di polizia in genere, ossia per il controllo stradale e in tutti i casi in cui vengano compiuti atti, destinati ad avviare un'azione penale o che comunque provochino una sanzione". ${ }^{39}$ Per le comunicazioni interne alle istituzioni militari è invece previsto l'uso esclusivo della lingua italiana: 1'“obbligo al bilinguismo" non è quindi vincolante per gli addetti di polizia che lavorano negli organi amministrativi, senza entrare in contatto con la popolazione civile. ${ }^{40}$ Nonostante ciò, la presunta inottemperanza di questa disposizione e la conseguente proposta di istituire un corpo di polizia "locale" (ossia composto solo da gente del posto) sono questioni ampiamente dibattute in provincia di Bolzano, almeno fin dall'approvazione del pacchetto per l'Alto Adige nel 1969. Attualmente, tali rivendicazioni sono soprattutto sostenute da gruppi sociali locali profilati, ad esempio, partiti politici o liste civiche. Inoltre, trovano talvolta espressione in alcuni mass media provinciali. In particolare, da una breve ricerca condotta su siti internet e blog di associazioni e giornali altoatesini risulta che la violazione del "diritto alla madre lingua tedesca" sia giudicata, ancora nella primavera del 2015, come una costante delle relazioni tra cittadini e carabinieri da alcuni esponenti politici locali. Inoltre, la sospensione del servizio militare obbligatorio e 1" aggravarsi" dei requisiti di ingresso all'alma sono, per esempio, messi in relazione, sul sito di un'altra associazione altoatesina, alla diminuzione del numero di locali tedescofoni abilitati al servizio di polizia e alla conseguente assunzione di personale proveniente da altre regioni italiane, (presumibilmente) non bilingue. Infine, l'opinione di una preferenza per l'uso dell'italiano da parte di polizia e carabinieri è, almeno in parte, propagata anche da alcuni articoli e posts su blog locali, che riportano episodi di cronaca in forma narrativa. In tali racconti, agli addetti del controllo stradale sono, per esempio, attribuiti enunciati in discorso diretto che rivendicano la sovranità dello stato italiano in Provincia di Bolzano e giustificano così l'impiego esclusivo di tale codice (cfr. l'allegato 5 per due esempi di articoli di giornale che trattano di questo tema).

Nel racconto in 1, VM si appropria quindi di una rappresentazione metalinguistica o "pratica di significazione" condivisa (cfr. Woolard 1998), che è già diffusa in alcuni milieu altoatesini. Segnatamente nel brano in 1, il nesso tra lingua, contesto e interlocutore è rappresentato dalla narratrice come inamovibile soprattutto in conseguenza dell'enunciato valutativo della storia (cfr. riga 3). L'impiego di una doppia negazione, la seconda ulteriormente enfatizzata dall'allungamento della vocale finale ("non dico $->$ adesso parlo tedesco $<<<$ forte no::: $>$ "), caratterizza infatti

39 Cfr. il documento "Sprachgebrauch in öffentlichen Ämtern" all'URL $<$ http://www.provincia. bz.it/praesidium/download/Broschuere_Sprachgebrauch_dt.pdf $>$ : pag. 14, traduzione ed enfasi della scrivente (18.10.2018).

40 Cfr. il documento citato nella nota sopra a pag. 15 e anche il Decreto del Presidente della Repubblica 15 luglio 1988, n. 574 all'URL: <http://www.consiglio.provincia.tn.it/leggi-e-archivi/ codice-provinciale/archivio/Pages/Decreto\%20del\%20presidente\%20della\%20repub blica\%2015\%20luglio\%201988,\%20n.\%20574_591.aspx?zid=> (18.10.2018). 
l'ipotesi della selezione di tale codice nello scenario descritto come un evento "contro-fattuale" (cfr. Carranza 1998), appartenente a una "realtà alternativa" quasi impossibile. ${ }^{41}$ La "iconicizzazione" (iconization) di un nesso, tutt'al più storico o contingente, tra fenomeni linguistici e sociali e 1'“elisione" (erasure) di possibili eccezioni - in questo caso, l'eventualità di incontrare a un posto di blocco carabinieri tedescofoni e/o che preferiscano parlare in tedesco - sono due processi semiotici e sociali attraverso cui, secondo Irvine \& Gal (2000), le "ideologie linguistiche" acquistano significato e operano (cfr. anche $\S$ III.2.3.2). La sequenza in 1 offre, dunque, un esempio concreto del modo in cui tali forme di significazione collettive funzionano, attuando una semplificazione del campo sociolinguistico locale.

Nonostante la rappresentazione di VM sia condizionata dal retroscena discorsivo appena delineato, il rinvio intertestuale non implica comunque necessariamente una presa di posizione della partecipante in favore e/o in accordo con i gruppi e partiti politici sopra menzionati. La storia può assolvere, invece, contestualmente altre funzioni in interazione. A questo proposito, si noti, per esempio, che l'io narrante contestualizza l'atto di saluto riportato in discorso diretto $($ " $<<$ forte e ridendo BUOnasera ((riso)) >”) para-verbalmente e prosodicamente, vale a dire accompagnandolo con una risata e innalzando il tono di voce in funzione espressiva e contrastiva (cfr. Lucius-Hoene \& Deppermann 2004: 240-245, Günthner 1995: 154). Oltre a dimostrare le abilità di VM come narratrice, queste strategie di rappresentazione conferiscono all'intera vicenda una connotazione scherzosa invece che veicolare disappunto o critica. Inoltre, il riferimento a un'opinione diffusa nella comunità d'arrivo punta all'acquisizione da parte della partecipante di conoscenze riguardo alle rappresentazioni locali degli usi linguistici abituali in determinati domini. Tramite la messa in scena di una vicenda a questi conforme, l'io narrante posiziona così il proprio personaggio come parlante competente a livello pragmatico-comunicativo nella regione d'arrivo. In altre parole, si rappresenta come locutrice in grado di utilizzare strategicamente le risorse linguistiche del proprio repertorio per raggiungere determinati scopi. ${ }^{42}$ Perciò, l'esagerazione della necessità della selezione dell'italiano nello scenario descritto in 1 ha, a mio avviso, prevalentemente fini pratici nel mondo dell'interazione. L'enfasi sull'invariabilità di tale scelta di lingua rende infatti la storia interessante e divertente per l'interlocutrice. In aggiunta, il racconto contribuisce al "lavoro identitario" della partecipante, finalizzato ad offrire una specifica rappresentazione di sé come soggetto parlante nel mondo delle storie (cfr. anche Norrick 2005). Nello stesso tempo, però, proprio nel momento in cui VM ricostruisce in tal modo la vicenda per narrarla più efficacemente - ossia per aumentarne la riportabilità e giustificarne la rilevanza in relazione a situazione, pubblico e tema di conversazione -, la narratrice non solo allude all'idea metalin-

41 Sull'evocazione da parte del narratore di universi paralleli a quello reale in funzione valutativa tramite frasi negative e/o verbi coniugati nei modi dell'irrealtà si confronti anche Labov (1997: 403-404, 2013: 226-227).

42 Sulle diverse funzioni argomentative dei riferimenti a "discorsi diffusi culturalmente" in un'intervista biografica e sulla loro rilevanza per ricostruire i modelli interpretativi che soggiacciono all'elaborazione dei racconti di vita si confronti il già citato Lucius-Hoene \& Deppermann (2004: 254-256). 
guistica in questione, ma anche la mette in scena in una forma tale che ne favorisce la consolidazione e trasmissione (cfr. Johnstone 2006).

A questo riguardo, pur senza voler qui discutere la fattualità o meno dell'episodio riportato, si noti che la storia è formulata da VM in prima persona. Il formato della narrazione di esperienza personale assicura la proprietà/paternità (ownership) della vicenda alla narratrice e, quindi, contribuisce alla creazione di "autenticità" (cfr. De Fina \& Georgakopoulou 2012: 147-149). ${ }^{43}$ Inoltre, come emerge dagli articoli in blog e giornali locali discussi sopra, VM non adotta nella sequenza in 1 un tipo di testo inusuale nel contesto d'arrivo. La rappresentazione del nesso tra italiano, posto di blocco e carabinieri circola infatti già nella società altoatesina (o in alcuni milieu di questa) specificamente in forma di narrazioni scenico-episodiche. L'adozione di una prospettiva personale nel riportare l'episodio suggerisce, quindi, l'avvenuta "appropriazione" (induction) da parte della partecipante non solo di una rappresentazione metalinguistica condivisa, ma anche di una "trama" (plot), diffusa nella comunità di arrivo per lo meno a livello mass-mediatico (cfr. Linde 2000, Linde 2009: 167-195 e anche Johnstone 2006: 51). ${ }^{44}$ A conferma di questa ipotesi, sia qui menzionato che, oltre che nei mass media locali, ho individuato narrazioni similmente costruite anche in altre interviste del corpus. Nello specifico, il nesso tra "italiano", "forze armate" e/o "questura" è alluso in sequenze narrative di altri due partecipanti (BV e JB). Analogamente alla storia di VM, i due racconti di dialoghi enfatizzano l'inamovibilità del rapporto tra lingua, contesto e/o tipo di interlocutori, tra l'altro, tramite ripetizioni, formulazioni iperboliche e prosodia.

Infine, il processo di "ri-contestualizzazione" della storia nell'esperienza personale dell'intervistata e, dunque, la sua appropriazione da parte della narratrice sono, a mio avviso, resi ulteriormente evidenti dagli eventi comunicativi nel dopo-storia (cfr. righe 6-9). Sebbene la scena non sia ricostruibile con sicurezza in quanto fuori dalla visuale della ricercatrice, il marito sembra mettere non verbalmente in dubbio la (completa) aderenza alla realtà della rappresentazione della moglie, ad esempio, scuotendo la testa o sorridendo. In reazione a un tale gesto o espressione, VM sente infatti la necessità di smentire, rivolgendosi prima al consorte e subito dopo alla ricercatrice. Nel fare ciò, l'intervistata coinvolge, da un lato, il marito come co-personaggio del racconto, attribuendo la mancata convalida dell'episodio da parte di quest'ultimo a un vuoto di memoria ("'no era incontro non

43 Su questo tema è interessante anche Bauman (1986: 20), che individua diverse dimensioni del mentire in narrazioni di commercio di cani. In particolare, il ricercatore differenzia tra "frottole" (tall tale) e "fabbricazioni" proprio sulla base dell'uso di una voce in terza o prima persona.

44 Nei due studi citati, Linde $(2000,2009)$ esemplifica i processi di appropriazione di un parlante da parte di una storia e di una storia da parte di un parlante nella comunità testuale di un'agenzia di assicurazioni statunitense. A differenza che nelle ricerche di Linde, non mi è possibile risalire però qui a una precisa "storia preferita" (preferred narrative), sempre che questa esista, che funga da modello a VM per il racconto in 1. L'articolo di Johnstone tratta, invece, dei modi in cui "trame" e/o "impalcature semantiche" (semantic scaffolds) circolano anche tra sconosciuti per rendere specificamente conto di fenomeni linguistici. 
si ricorda"; cfr. Ochs \& Capps 1997 sul ruolo del verbo "ricordare" (remember) nel lavoro del narratore per conferire "autenticità" alle proprie storie). Dall'altro, la partecipante crea "coerenza" a livello dell'intero testo (cfr. Linde 1993: 12-14, Lucius-Hoene \& Deppermann 2004: 56-61), citando l'evento più riportabile di una narrazione raccontata all'inizio della propria biografia linguistica (minuti 02:25-03:34). L'enunciato "basta che non lo parlava greco" allude infatti all'apice di un precedente racconto. Nella storia in questione, il consorte, appena trasferitosi in Alto Adige dalla Rep. di Macedonia, si rivolge in greco ai poliziotti in questura. Pur essendo consapevole dell'inefficacia strumentale di una tale scelta di codice, l'uomo se ne serve, secondo la valutazione della narratrice, per ragioni simboliche, ossia per dimostrare le proprie competenze in (almeno) una lingua straniera. Tramite questo riferimento intratestuale, VM consegue, a mio avviso, complicità specificamente con la ricercatrice (il marito non era infatti presente all'inizio della conversazione). Inoltre, rinforza così la "coesione" e, indirettamente, l'attendibilità della propria versione. La variazione nel numero di personaggi (divenuti) rilevanti per rievocare l'episodio e il riferimento a un evento precedentemente narrato con protagonisti simili puntano ai diversi modi in cui eventi passati esperiti personalmente e/o intrecciantesi con rappresentazioni collettive sono ricordati e messi tra loro in relazione dalla narratrice in funzione di obiettivi interazionali presenti (cfr. Rosenthal 2006 sul rapporto dialettico tra presente, passato e futuro in un'intervista biografica).

Riassumendo, nonostante la sua ellitticità, il racconto in 1 ha successo poiché è formato sulla base di idee e narrazioni metalinguistiche diffuse riguardo a una tipica situazione di utilizzo dell'italiano in Alto Adige. Così, le sue peculiarità strutturali e contenutistiche dipendono strettamente dal macro-contesto in cui la storia è narrata. Al contempo, la partecipante mette in scena i propri usi linguistici e la propria alternanza di codice situazionale nella regione d'arrivo. In questo senso, la narrazione non solo ripete, ma si aggiunge a un insieme di storie "condivise" che veicolano una determinata interpretazione dell'allocazione dei codici nello spazio sociolinguistico altoatesino (ossia la necessità di rivolgersi in italiano ai carabinieri presso un posto di blocco). In particolare, il formato del racconto di esperienza personale contribuisce ad autenticare il punto di vista della narratrice e a facilitarne la trasmissione agli interlocutori. In conseguenza delle strategie di rappresentazione adottate, i destinatari assumono infatti il ruolo di compartecipanti della vicenda riferita. Invece, potenziali dubbi o contestazioni rispetto alla veridicità dell'episodio raccontato sono invalidati dalla narratrice nel dopo-storia.

\subsection{Lo spazio comunicativo narrato di DK}

La figura 5 illustra la distribuzione di codici per contesti nelle 36 narrazioni di interazioni, raccontate da DK durante la sua biografia linguistica. Similmente a nella figura 4 , le varietà linguistiche, di contatto e di interlingua, mezzo di comunicazione nel mondo delle storie, sono raggruppate in cerchi a seconda dello scenario altoatesino in cui il dialogo si svolge. 


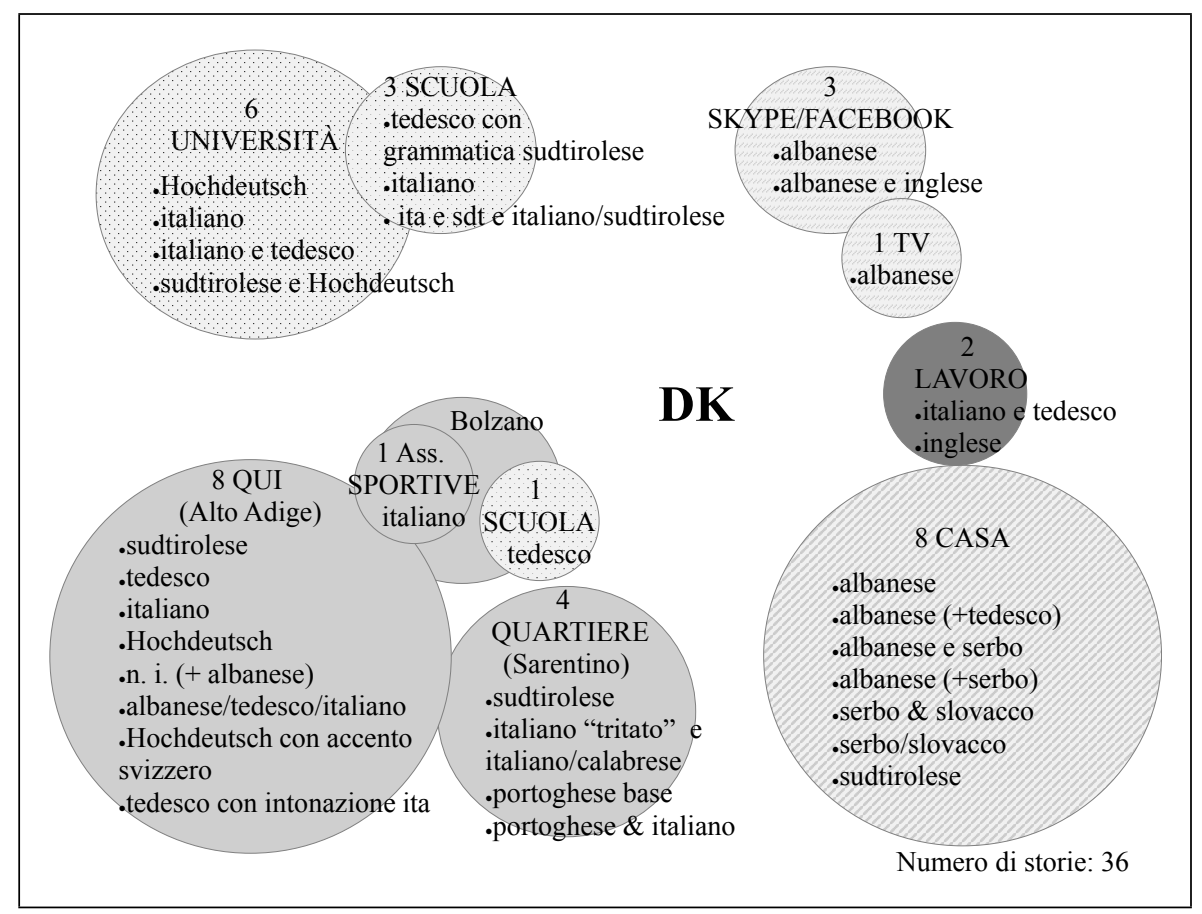

Figura 5: Codici usati nelle narrazioni di interazioni, ambientate in Alto Adige, dell'intervista con DK.

Dal confronto tra l'immagine 5 e la figura 4 al $\S$ V.3.2 risulta che altri ambiti comunicativi siano, almeno quantitativamente, più rilevanti per $\mathrm{DK}$ rispetto a $\mathrm{VM}$ al momento di narrare la propria biografia linguistica. Nello specifico, la minore centralità del dominio "lavoro" così come l'introduzione di nuovi media, ovvero "Skype" e "Facebook", nello spazio comunicativo narrato di DK sono probabilmente spiegabili tramite l'occupazione, l'età o le inclinazioni personali dell'intervistata. La partecipante è infatti una studentessa di 23 anni, che svolge attività lavorative parallele all'università solo occasionalmente e che si serve quotidianamente di internet per studio e svago. Invece, il fatto che DK precisi frequentemente i codici usati per la comunicazione in famiglia contrasta, senza un'apparente ragione socio-anagrafica, con l'assenza di una tale specificazione nel caso di VM. Come accennato precedentemente, questa differenza nell'articolazione dello spazio comunicativo narrato delle due donne dipende probabilmente dalla loro volontà di allinearsi a comportamenti linguistici differenti e di presentare diverse immagini di sé al momento di narrare la propria biografia linguistica alla specifica interlocutrice. Infatti, i modi di acquisizione e d'uso del tedesco sono un tema centrale nell'intervista con VM. Invece, un motivo ricorrente nella conversazione con DK è il proprio impiego abituale, seppur circoscritto a determinati ambiti comunicativi, dell'albanese anche dopo il trasferimento in Alto Adige. Nel ribadire ciò, la partecipante mira a costruire una rappresentazione di sé come interattante 
albanofona nonostante 1'emigrazione avvenuta da bambina (cfr. § V.4.3 per maggiori dettagli).

A differenza delle storie prevalentemente scenico-episodiche di VM, le narrazioni di DK riportano spesso dialoghi abituali e/o generici in funzione argomentativo-esemplare, ovvero sono raccontate con l'obiettivo di presentare un fatto come universalmente valido invece che singolare. Probabilmente in connessione con ciò (cfr. Lucius-Hoene \& Deppermann 2004: 153 per l'individuazione di una correlazione analoga), un gruppo abbastanza numeroso di storie nell'intervista con DK è caratterizzato da riferimenti temporali e spaziali piuttosto vaghi. Infatti, gli episodi narrati dalla partecipante sono spesso ambientati in contesti altoatesini poco specificati dal punto di vista descrittivo e, tutt'al più, localizzati tramite espressioni spaziali "intrinsecamente relazionali", ovvero che richiedono un punto di riferimento deittico e/o anaforico per essere interpretate (cfr. Vanelli \& Renzi 2001: 261-375 e il § V.3.3.1 per un esempio). ${ }^{45}$ Nello specifico, in modo non sorprendente, l'intervistata impiega avverbi di luogo indicanti vicinanza all"“origo deittico" (es. "hier", tr. “qui") per contrapporre l'attuale regione di residenza a paesi esteri, in cui ha vissuto durevolmente, ha abitato per sei mesi o che ha solo visitato. Questi sono rispettivamente il Kosovo, il Lussemburgo e la Germania. Inoltre, la partecipante si serve di marcatori di luogo per contrapporre, nel proprio spazio comunicativo narrato, il quartiere di Sarentino, dove ha risieduto con la famiglia appena dopo il trasferimento in Alto Adige, al capoluogo di provincia Bolzano. La distinzione tra questi due scenari urbani locali si basa soprattutto sui codici sentiti parlare da bambini e conoscenti, ossia in domini sì informali, ma piuttosto anonimi (cfr. cerchi in basso a sinistra in figura 5).

Per quanto riguarda gli altri contesti interazionali rappresentati nella figura 5, si noti che le "associazioni sportive" (Sportvereine) di Bolzano costituiscono una situazione comunicativa a sé stante nello spazio comunicativo narrato di DK. La partecipante associa infatti a questo contesto l'impiego quasi esclusivo di varietà di italiano tanto che, in conseguenza di ciò, i bambini bolzanini, anche se iscritti a scuole tedesche, hanno la possibilità di imparare a parlare fluentemente nella seconda lingua (minuti 32:22-32:53). Prese di posizione analoghe sono presenti anche in altre interviste del corpus. Così JB sostiene, per esempio, in una narrazione di interazione di dover parlare per forza in italiano con i compagni della sua squadra di calcio, nonostante abiti in una località a maggioranza tedescofona. Inoltre, la stessa VM narra una breve storia in cui il figlio comunica in siciliano nella palestra

45 In particolare, Vanelli \& Renzi (2001) distinguono tra marcatori spaziali intrinsecamente relazionali "inerentemente deittici" e "contestualmente deittici". I primi (es. "hier", "qui") sono interpretabili, in ogni loro occorrenza, solo tramite il riferimento alle coordinate personali e spazio-temporali del parlante al momento dell'enunciazione. Invece, i secondi (es. "drin", "dentro") richiedono talvolta una lettura deittica, talvolta sono decifrabili in senso solo anaforico, vale a dire esclusivamente sulla base del ricorso al co-testo linguistico (ibidem: 264). Infine, alcune espressioni spaziali necessitano di essere "saturate" da informazioni sia deittiche sia anaforiche per permettere l'individuazione del referente (ibidem: 332-333). Tra queste, ci sono gli avverbi che si riferiscono a una posizione localizzata negativamente rispetto al centro deittico (es. "da", "qua/là"). 
di kickboxing a Merano. Similmente alla comunicazione con le forze dell'ordine, tali coincidenze fanno supporre che anche le pratiche linguistiche abituali in contesti sportivi siano oggetto di discorsi metalinguistici diffusi nella società di arrivo.

Sulla base della figura 5, è possibile farsi inoltre un'idea della diffusione del plurilinguismo nella regione d'arrivo nell'ottica di DK. Ad eccezione delle associazioni sportive, tutti i contesti altoatesini sono rappresentati dall'intervistata come plurilingui a livello sia sociale sia individuale (vale a dire non sono solo caratterizzati dalla compresenza di codici diversi, ma anche dall'impiego di lingue differenti da parte di uno stesso parlante). Nello specifico, la donna riferisce di interazioni in lingue sia di antico, sia di nuovo insediamento, sia in pratiche di contatto, sia in varietà di interlingua parzialmente idiosincratiche, come, ad esempio, italiano "tritato" o tedesco con intonazione italiana. ${ }^{46}$ Tra le lingue alloctone sentite e/o usate in Alto Adige, DK menziona, diversamente da VM, non solo codici appartenenti al proprio repertorio d'origine (ovvero albanese e serbo), ma anche lingue di altri migranti, come lo slovacco e il portoghese. Dalla gamma di varietà linguistiche menzionate emerge che il plurilinguismo altoatesino sia per la donna il risultato di processi di mobilità compositi. Questi coinvolgono parlanti, sia provenienti da altre regioni italiane, sia da paesi esteri, sia trasferitesi in Alto Adige per lavoro, sia per studio (cfr., per esempio, l'impiego di "italiano/calabrese" nel quartiere e di "Hochdeutsch" in università).

La portata comunicativa dei codici di partenza è tuttavia minore nello spazio comunicativo narrato di DK rispetto a in quello di VM. A questo proposito si ricordi che, prima di arrivare in Alto Adige, la ragazza ha competenze, seppur a livelli molto diversi, in due codici, ovvero in serbo e in albanese (cfr. anche il repertorio dichiarato al § V.2.4.2). Il serbo è una "lingua seconda" ("Zweitsprache"), appresa a scuola e ben padroneggiata dai genitori della partecipante così come, in generale, dalle generazioni più anziane in Kosovo (minuti 09:50-10:31). Dal momento che il suo insegnamento formale è stato "abolito" ("abgeschafft") prima dell'iscrizione dell'intervistata a scuola, DK dichiara di essere stata esposta solo in contesti informali a questo codice, sia nella città di provenienza, sia successivamente in Alto Adige. In una narrazione ambientata nella città di nascita e quindi non considerata al momento di compilare la figura 5, DK racconta, per esempio, di come la nonna le insegnasse alcune parole in serbo utili per fare la spesa (minuti 07:16-07:49). Attualmente il serbo è usato in famiglia in funzione espressiva o per comunicare con parenti acquisiti di origine slovacca (cfr. anche $\S$ V.4.3.1). Invece, l'apprendimento dell'albanese da parte della partecipante avviene fino ai sette anni in modo "globale" (comprehensive) ${ }^{47}$ sia in contesti informali, sia a scuola. Dopo l'esperienza di mobilità, un ruolo di rilievo per il mantenimento di questa lingua è specificamente ricoperto nell'ottica dell'intervistata non solo dalla comunicazione in casa, ma anche da quella in rete. In una narrazione di interazione, la donna racconta infatti di come il fratello più giovane, arrivato in Italia all'età di tre anni, abbia im-

46 L'italiano è "tritato" ("gehackt") in quanto suona come il tedesco.

47 Per questo termine e per una rassegna, seppur provvisoria, di diversi modi di apprendimento linguistico si veda Blommaert \& Backus (2012: 9-16). 
parato a scrivere perfettamente in albanese, "chattando" ("durch chatten") con gli amici in Kosovo (minuti 37:46-38:40). In altri contesti l'albanese è invece raramente utilizzato. Nel caso lo sia, non costituisce, del resto, l'unica o la principale lingua di comunicazione. In un racconto elicitato da una domanda della ricercatrice sulle varietà linguistiche usate con possibili conoscenti originari dell'Albania in Alto Adige, DK narra, per esempio, di conoscere eventualmente ("wenn dann") solo persone dal Kosovo. Con loro, solitamente "si mescola" ("man mischt") albanese e tedesco e/o italiano (minuti 33:11-33:30). Oltre ad essere parlato in pochi ambiti comunicativi, l'albanese è utilizzato da DK solo con determinati interlocutori dopo il trasferimento in provincia di Bolzano. Nelle narrazioni della donna, il codice è infatti la lingua di comunicazione con i genitori e i parenti residenti nel paese d'origine, ma è sostituito nei dialoghi con i fratelli e le sorelle (cfr. il racconto discusso nel prossimo paragrafo per i modi in cui la partecipante giustifica questa alternanza di lingua). Così, l'albanese è una varietà linguistica usata esclusivamente in ambiti comunicativi pragmaticamente vicini, mentre non è adoperabile né in ambiti istituzionali né con gli amici o con gli sconosciuti nel quartiere. In conseguenza di ciò, lo spazio comunicativo narrato di DK è doppiamente "dissociato" (cfr. Krefeld 2004).

Un'ultima considerazione, che può essere tratta dalla figura 5, riguarda l'allocazione dei codici d'arrivo - ossia dialetti sudtirolesi, italiano e, in parte, Hochdeutsch (quest'ultimo codice non è infatti propriamente considerato dalla partecipante una varietà locale) - nel repertorio narrato dell'intervistata. Il dialetto tedesco locale ha una portata comunicativa molto più ampia nella rappresentazione di DK rispetto a in quella di VM e parzialmente a in quella di BV (cfr. anche § V.3.4). Tuttavia, la distribuzione delle varietà linguistiche di tedesco nello spazio comunicativo narrato della donna tende a diversificarsi a seconda della situazione comunicativa raccontata. L" "Hochdeutsch" è usato in domini medio-alti, ovvero al lavoro e in università (e con amici provenienti dalla Germania anche in situazioni colloquiali). In famiglia, a Sarentino e a scuola, l'intervistata racconta invece di interazioni condotte prevalentemente in dialetto tedesco locale e/o in un tedesco marcato regionalmente (tedesco con grammatica sudtirolese) ${ }^{48}$ In questo senso, gli usi linguistici soggettivi della partecipante riflettono, in larga parte, i rapporti diglottici tra varietà di tedesco nel repertorio comunitario d'arrivo. La corrispondenza non è comunque totale perché le abitudini comunicative di DK si modificano con il trascorrere del tempo. In particolare, l'iscrizione all'università costituisce nell'ottica della partecipante un periodo di "transizione". La frequentazione dell'ateneo bolzanino determina infatti l'entrata in contatto dell'intervistata con "sehr viele deutsche aus Deutschland" (tr. "moltissimi tedeschi dalla Germania") e, in conseguenza di ciò, (l'impressione di) un "miglioramento" delle proprie competenze in tedesco standard (cfr., per esempio, minuti 19:27-20:02 e anche $\S$ V.4.3.3). Invece, l'italiano è parlato e/o sentito parlare in un numero più circoscritto di scenari. Il codice non è

48 L'uso del dialetto tedesco locale a scuola tra i compagni è confermato dai racconti di un'altra partecipante, SP, compagna di classe di DK durante l'anno di scambio trascorso da quest'ultima in una scuola superiore italiana. 
infatti né lingua di comunicazione in famiglia né di fruizione dei mass media. Tuttavia, anche la distribuzione delle varietà di italiano, similmente a quelle di tedesco, si diversifica nello spazio comunicativo narrato di DK a seconda della formalità della situazione comunicativa. Nel quartiere a Sarentino e nella scuola tedesca, la donna è infatti esposta a varietà di interlingua, regionali, di contatto e/o semplificate del codice. Solo durante l'anno di scambio nella scuola superiore italiana e all'università, la partecipante narra di dialoghi in italiano ricercato, soprattutto dal punto di vista lessicale. Si noti che tale raffigurazione del repertorio d'arrivo contrasta con quella di $\mathrm{BV}$, che sarà discussa al $\S$ V.3.4. Nella prospettiva di quest'ultima, alcuni domini in $\mathrm{H}$, tra cui, in particolare, l'università, sono infatti frequentemente scenario di interazioni in varietà regionali o locali di tedesco e italiano.

Così, lo spazio comunicativo narrato di DK risulta essere caratterizzato da diglossia ad almeno tre elementi (cfr. Iannàccaro \& Dell'Aquila 2007), mentre la compresenza di svariati codici a diversi livelli spiega, almeno in parte, la frequenza di pratiche di contatto nei dialoghi messi in scena dalla donna. Rapporti diglottici si riscontrano, infatti, i) tra varietà di tedesco, ii) tra varietà di italiano, e iii) tra l'albanese e le lingue d'arrivo. Inoltre, le relazioni tra i due principali codici in L, ovvero albanese e dialetto tedesco locale, sono piuttosto complesse nel repertorio narrato di DK. Nel prossimo paragrafo, illustro come la partecipante rappresenta i rapporti tra questi ultimi due codici sulla base dell'analisi dettagliata di una sequenza narrativa. In questo brano, l'intervistata riconduce la propria abitudine a comunicare in dialetto tedesco locale con i fratelli e le sorelle al fatto che le loro interazioni avvengano frequentemente, dopo emigrazione in Alto Adige, fuori casa nel quartiere di residenza a Sarentino, vale a dire in contesti semi-pubblici.

\subsubsection{Una storia "abituale" e "generica"}

Nella sequenza in 2, DK illustra le ragioni della propria alternanza di codice a seconda del componente della famiglia tramite due brevi racconti di attività comunicative abituali. Nella prima storia (righe 1-7), la partecipante rappresenta l'impiego dell'albanese da parte del proprio personaggio con i genitori come un comportamento principalmente determinato dall'insistenza di questi ultimi. Inoltre, DK accenna a un tema ricorrente nella sua biografia linguistica, ovvero al rischio di dimenticare la lingua d'origine. Similmente a in altre sequenze del colloquio, l'espressione di tale paura è attribuita dalla donna, nel brano in 2, ai propri genitori. Questi ultimi si fanno così, in un certo senso, garanti del mantenimento dell'albanese dopo migrazione (cfr. anche $\S$ V.4.3.2). Nella seconda parte della sequenza (righe 9-17), l'intervistata mette in scena un altro episodio, sempre caratterizzato come abituale, in funzione "argomentativo-esemplare" (cfr. Günthner 1995, De Fina \& Georgakopoulou 2012: 98-105). Il suo fine è infatti quello di rappresentare e, al contempo, di motivare la propria selezione del dialetto tedesco locale per comunicare con i fratelli. Nell'orientazione della storia, l'io narrante sembra dapprima ricondurre tale scelta di lingua al tipo di interlocutore con cui interagisce. Tuttavia, nel prosieguo del racconto, DK attribuisce al contesto di interazione abi- 
tuale un ruolo cruciale per spiegare l'origine e il consolidarsi di tale comportamento linguistico, sia da parte del proprio personaggio, sia da parte di persone in una situazione analoga alla sua.

(es. 2)

\begin{tabular}{|c|c|c|c|}
\hline & 1 & DK & jetzt spreche ich mit den eltern ((pause)) albanisch fließend immer \\
\hline & 2 & DK & weil m:eine eltern legen sehr viel wert darauf dass wir immer \\
\hline & 3 & DK & zuhause wenigstens albanisch sprechen[- W]EIL WIR den ganzen tag \\
\hline & 4 & INT & {$[\mathrm{mh} \mathrm{mh]}$} \\
\hline & 5 & DK & irgendwie nur mit deutsch und italienisch beschäftigt sind $[-\mathrm{s}] \mathrm{ie}$ \\
\hline & 6 & INT & {$[\mathrm{mh} \mathrm{mh}]$} \\
\hline & 7 & DK & haben angst dass wir das dann ve:rgessen \\
\hline & 8 & INT & $\mathrm{mh} \mathrm{mh}$ \\
\hline OR & 9 & DK & $(($ pause $))(\mathrm{h}) \mathrm{zu}$ hause $\mathrm{d}=$ in und - albanisch und $>$ wenn ich dann mit \\
\hline OR & 10 & DK & meinen geschwistern da mal spreche $=$ ch immer $<$ deutsch südtirolerisch \\
\hline & 11 & INT & mh mh okay \\
\hline EV1 & 12 & DK & - das ist automatisch so seit wir klein sind \\
\hline ME & 13 & DK & weil dann gehst du raus \\
\hline $\mathrm{CA}$ & 14 & DK & spielst du mit den ki:ndern \\
\hline mRE\& & 15 & DK & da (h) willst du dass alle kinder verstehen was du mit deiner \\
\hline EV2 & 16 & DK & schwester sprichst \\
\hline EV3 & 17 & DK & und dann[es] ist automatisch so - \\
\hline & 18 & INT & {$[\mathrm{mh} \mathrm{mh}]$} \\
\hline & 19 & INT & okay ((pause)) \\
\hline & & & (DK_Kos_Sar, 04:51-05:22) \\
\hline & & & Traduzione: \\
\hline & 1 & DK & ora parlo con i miei genitori ((pausa)) albanese fluentemente \\
\hline & 2 & DK & sempre perché i m:iei genitori danno molta importanza al fatto che \\
\hline & 3 & DK & almeno a casa parliamo sempre in albanese[- P]ERCHÉ NOI siamo tutto \\
\hline & 4 & INT & {$[\mathrm{mh} \mathrm{mh}]$} \\
\hline & 5 & DK & il giorno impegnati solo con il tedesco e l'italiano[- $\mathrm{h}]$ anno \\
\hline & 6 & INT & {$[\mathrm{mh} \mathrm{mh}]$} \\
\hline & 7 & DK & paura che poi lo di:mentichiamo \\
\hline & 8 & INT & $\mathrm{mh} \mathrm{mh}$ \\
\hline OR & 9 & DK & $(($ pausa $))$ dent $=$ o a casa $\mathrm{e}-$ albanese $\mathrm{e}>$ quando poi con $\mathrm{i}$ miei \\
\hline OR & 10 & DK & fratelli e sorelle lì poi parlo sempre $<$ tedesco sudtirolese \\
\hline & 11 & INT & mh mh okay \\
\hline EV1 & 12 & DK & - è automatico così da quando siamo piccoli \\
\hline $\mathrm{ME}$ & 13 & DK & perché poi vai fuori \\
\hline $\mathrm{CA}$ & 14 & DK & giochi con i bambini \\
\hline mRE\& & 15 & DK & e là vuoi che tutti i bambini capiscano quello che stai dicendo con \\
\hline EV2 & 16 & DK & tua sorella \\
\hline EV3 & 17 & $\mathrm{DK}$ & e poi[è] automatico così \\
\hline & 18 & INT & {$[\mathrm{mh} \mathrm{mh}]$} \\
\hline & 19 & INT & okay ((pausa)) \\
\hline
\end{tabular}

Nelle due narrazioni metalinguistiche in 2 , l'io narrato in qualità di parlante si rivolge rispettivamente in albanese ai genitori, in casa, e ai fratelli e alle sorelle in 
dialetto tedesco locale, fuori. La messa in scena della seconda storia, l'unica che ho suddiviso strutturalmente, è a mio avviso interessante almeno sotto tre punti di vista. In primo luogo, DK caratterizza in senso regionale la varietà di tedesco parlata con i fratelli e le sorelle tramite il glottonimo "Deutsch Südtirolerisch" (tr. "tedesco altoatesino"; cfr. riga 10). Tale denominazione è introdotta per la prima volta proprio nel brano sopra citato ed è, quindi, utilizzata spontaneamente dalla donna fin dall'inizio della conversazione. Nell'impiegarla, la narratrice allude, per contrasto, alla presenza di altre varietà di tedesco, regionali e non regionali, nel proprio spazio comunicativo narrato. Anche nel seguito del colloquio, la partecipante ribadisce frequentemente, e in modo più netto rispetto ad altri intervistati, la presenza di differenze tra le varietà di tedesco adoperate intorno a lei. Tale differenziazione è portata a termine, tra l'altro, proprio attraverso l'adozione di diversi glottonimi (cfr. $\S$ V.4.3.3 per maggiori dettagli).

In secondo luogo, DK si serve, nella sequenza in 2, di una serie di marcatori spaziali, molti dei quali "intrinsecamente relazionali", per enfatizzare il passaggio dall'albanese al dialetto tedesco locale a seconda dell'ambientazione del dialogo riportato. Così, nell'orientazione del racconto, il gruppo preposizionale "a casa" ("zu hause") è per esempio ulteriormente specificato dall'avverbio di luogo posposto "dentro" ("d=in"). In seguito, la narratrice impiega il verbo di movimento "andare fuori" ("rausgehen") per verbalizzare l'evento matrice della vicenda (cfr. riga 13). In questo modo, la direzione del moto deve essere interpretata in modo anaforico, facendo riferimento a uno "sfondo contenitore", ovvero lo scenario casalingo delineato precedentemente alla riga 10. Infine, DK si serve dell'avverbio "da" (tr. "qua/là") per riferirsi nuovamente, alla riga 15, alle situazioni comunicative all'esterno della casa. Tramite questo avverbio, lo spazio riferito è denotato dalla narratrice come una "distanza vicina", rispetto al quale la posizione dell'origo deittico, costituito dall'io narrato, è lasciata piuttosto indeterminata. In altre parole, non è chiaro se quest'ultimo si trovi o meno nello spazio così tratteggiato. ${ }^{49}$ Tramite l'uso di questi locatori, DK struttura, da una parte, il racconto a livello discorsivo-testuale, concatenando le clausole narrative tra loro. Dall'altra, ri-attualizza le coordinate spazio-temporali dell'evento riportato a fini di coinvolgere l'interlocutrice (cfr. Lucius-Hoene \& Deppermann 2004: 229). Infine, àncora la scelta di lingua agli scenari descritti. In questo modo, spiega la propria attuale alternanza di codice per membro della famiglia tramite la contrapposizione tra le situazioni comunicative "a casa" e "fuori" (dove questo "fuori", presumibilmente, corrisponde al quartiere di Sarentino in cui l'intervistata ha vissuto dai sette ai 19 anni). L'esame dell'intera biografia linguistica conferma la centralità dei luoghi di attività quotidiana per

49 Per una discussione sull'interpretazione di tali deittici di luogo si confrontino il già citato Vanelli \& Renzi (2001: 261-375) così come Fricke (2007: 92-94, 101-102) e Ehrlich (1992: 13-16). Questi ultimi adottano un approccio alla deissi spaziale del tedesco rispettivamente come sistema binario e ternario. L'esame dei localizzatori nell'intervista con DK è qui esclusivamente finalizzato a individuare situazioni comunicative distinte nello spazio narrato della donna. Tuttavia, sia accennato che la scelta dei locativi per l'“altrove", oltre ad essere determinata dalla posizione geografica dei luoghi in questione, veicola talvolta anche giudizi valutativi nei loro confronti (cfr. Bletzer 2013). 
DK - maggiore che per le altre due intervistate - al momento di rendere conto degli usi linguistici propri e altrui in Alto Adige.

In terzo luogo, è interessante notare che DK metta in scena nella sequenza in 2 una storia abituale di esperienza personale nel formato "misto" di una narrazione in prima e seconda persona. Infatti, la partecipante impiega, nella sezione orientativa e nel primo enunciato valutativo del racconto, forme pronominali e verbali in prima persona singolare e plurale (cfr. righe $9,10,12) .{ }^{50}$ In seguito, al momento di riportare l'azione complicante e di esprimere le valutazioni conclusive dell'episodio, passa però a forme in seconda persona singolare (cfr. righe $13,14,15,16) .{ }^{51}$ Questa commutazione nei pronomi personali punta, da un lato, al "lavoro interazionale" svolto da DK per rendere la selezione del dialetto tedesco locale nella circostanza descritta una scelta di lingua "nomale" e generalizzabile al di là del proprio caso singolo e della specifica vicenda riportata (cfr. Carranza 1998: 302, De Fina \& Georgakopoulou 2012: 98-105). Infatti, i personaggi, che agiscono nel mondo della storia e che inizialmente corrispondono all'io narrato e ai suoi fratelli e sorelle (cfr. 1'uso del "noi inclusivo" alla riga 12), diventano successivamente un soggetto generico. Quest'ultimo include, possibilmente, tutte le persone che si trovano in una situazione analoga a quella della narratrice. Dall'altro lato, la scelta di forme in seconda persona singolare - invece, per esempio, della selezione di un pronome parimenti de-personalizzante come "man" (tr. "uno"/“si") - coinvolge specificamente l'interlocutrice. Quest'ultima è infatti implicitamente invitata ad allinearsi al comportamento linguistico dell'io narrato e, in particolare, alla valutazione della sua condotta da parte dell'io narrante come motivata dalle circostanze (riga 15) e "automatica" (riga 17). Così, l'alternanza nei pronomi personali rinvia anche al "lavoro morale" (moral work), intrapreso dalla partecipante, per co-costruire "una presa di posizione valutativa" (evaluative stance) coerente nei confronti del pattern d'uso linguistico descritto da condividere con l'interlocutrice (cfr. Günthner 1995: 150, 156). Nella misura in cui la narratrice presenta un episodio ricorrente della propria esperienza personale come generalmente valido ed è interessata all'allineamento, se non all'approvazione, della ricercatrice, la storia narrata in 2 svolge la funzione di "esempio" (cfr. Günthner 1995). Infatti, il racconto non solo supporta la tesi dell'inevitabilità della selezione del dialetto tedesco locale con i fratelli e le sorelle, illustrandone un'occasione concreta, ma anche lavora per definire l'uso linguistico in questione come una regola di comportamento generale e, quindi, più difficilmente questionabile dagli interlocutori, reali o immaginati.

La funzione "argomentativo-esemplare" del racconto in 2 emerge non solo dalla variazione nei pronomi personali, ma anche da altre sue caratteristiche linguistiche e strutturali. A questo riguardo, l'evento matrice della storia ("weil dann gehst du raus") alla riga 13 è verbalizzato dall'io narrante tramite una proposizione

50 Ovvero: ">wenn ich dann mit meinen geschwistern spreche=ch immer $<$ ", "seit wir kinder sind" (tr. ">quando poi con i miei fratelli/sorelle (io) parlo sempre<", "da quando (noi) siamo piccoli").

51 Ovvero: "gehst du raus", "spielst du", "willst du", "was du mit deiner schwester sprichst" (tr. "(tu) vai fuori”, "(tu) giochi”, “(tu) vuoi”, "quello che (tu) stai dicendo con tua sorella"). 
causale, introdotta dalla congiunzione subordinante "weil" (tr. "perché") e verbo in seconda posizione (V2). Questo "modo di frase" (Satzmodus), diffuso soprattutto nel tedesco parlato colloquiale, si differenzia da quello standard con verbo di modo finito al termine destro dell'enunciato non solo per la sua distribuzione diafasica. Nei registri in cui entrambe le costruzioni co-occorrono, il suo impiego, oltre a essere vincolato da specifiche costrizioni sintattiche, ha infatti implicazioni semantiche e pragmatiche. In particolare, l'uso di "weil" con verbo in seconda posizione caratterizza l'evento riferito dalla frase da cui dipende come fattuale. Così, la funzione della proposizione introdotta da "weil" è solitamente "giustificante" (rechtfertigend). In altre parole, piuttosto che esprimere la "causa" (Ursache) del contenuto proposizionale dell'enunciato precedente, motiva l'atteggiamento epistemico del parlante o la funzione comunicativa, espressi nell'enunciato matrice, attraverso argomenti discorsivi (cfr. Pasch et al. 2003: 403-411). In linea con ciò, DK presenta la vicenda narrata in 2 all'interlocutrice come un fatto che, oltre a motivare la causa, soprattutto legittima la propria precedente valutazione dell'alternanza di codice per componente della famiglia come automatica (cfr. riga 12). Si noti, del resto, che la tesi della meccanicità di tale scelta di lingua è ribadita dall'io narrante in chiusura del brano alla riga 17. Così, la sequenza in 2 è costruita in modo circolare, seguendo una struttura tipica delle argomentazioni in cui le storie esemplari sono solitamente incassate (cfr. De Fina \& Georgakopoulou 2012: 98, Carranza 1998: 302). Infine, le tre clausole narrative alle righe 13,14 e 15 - che costituiscono il nucleo centrale della vicenda riferita da DK - sono enumerate dall'io narrante per asindeto (cfr. la posizione incipitaria del verbo finito in "spielst du mit den kindern", risultante probabilmente dall'elisione di una congiunzione o di un avverbio precedente). Queste strategie di rappresentazione contribuiscono a rendere la messa in scena di DK veloce e incalzante. Nel fare ciò, veicolano, al contempo, iconicamente l'inevitabilità dei comportamenti linguistici dei personaggi della storia e contribuiscono a creare le basi per una loro condivisione da parte della ricercatrice.

\subsection{Lo spazio comunicativo narrato di BV}

L'ultimo spazio comunicativo che discuto è quello narrato da BV nel corso della sua biografia linguistica e rappresentato nella figura 6 .

Durante la sua intervista, BV racconta numerose narrazioni di interazioni che si svolgono in contesto universitario. Le ragioni della preminenza di questa situazione comunicativa sulle altre sono verosimilmente biografiche. Il raggiungimento dei requisiti linguistici necessari per iscriversi all'ateneo bolzanino ha infatti impegnato notevolmente l'intervistata nei due/tre anni precedenti al colloquio. Attualmente lo studio alla facoltà di economia costituisce, inoltre, la principale occupazione della donna. Se si considerano anche le storie ambientate nella "scuola" elementare del figlio e ai "corsi di lingua" (tedesca, inglese e serba) frequentati dall'intervistata o dal bambino, gli ambiti istituzionali, adibiti alla formazione, risultano essere centrali per la partecipante al momento di ricostruire insieme alla ricercatrice il proprio spazio comunicativo narrato in Alto Adige (cfr. i cerchi in alto a sinistra in figura 6). 


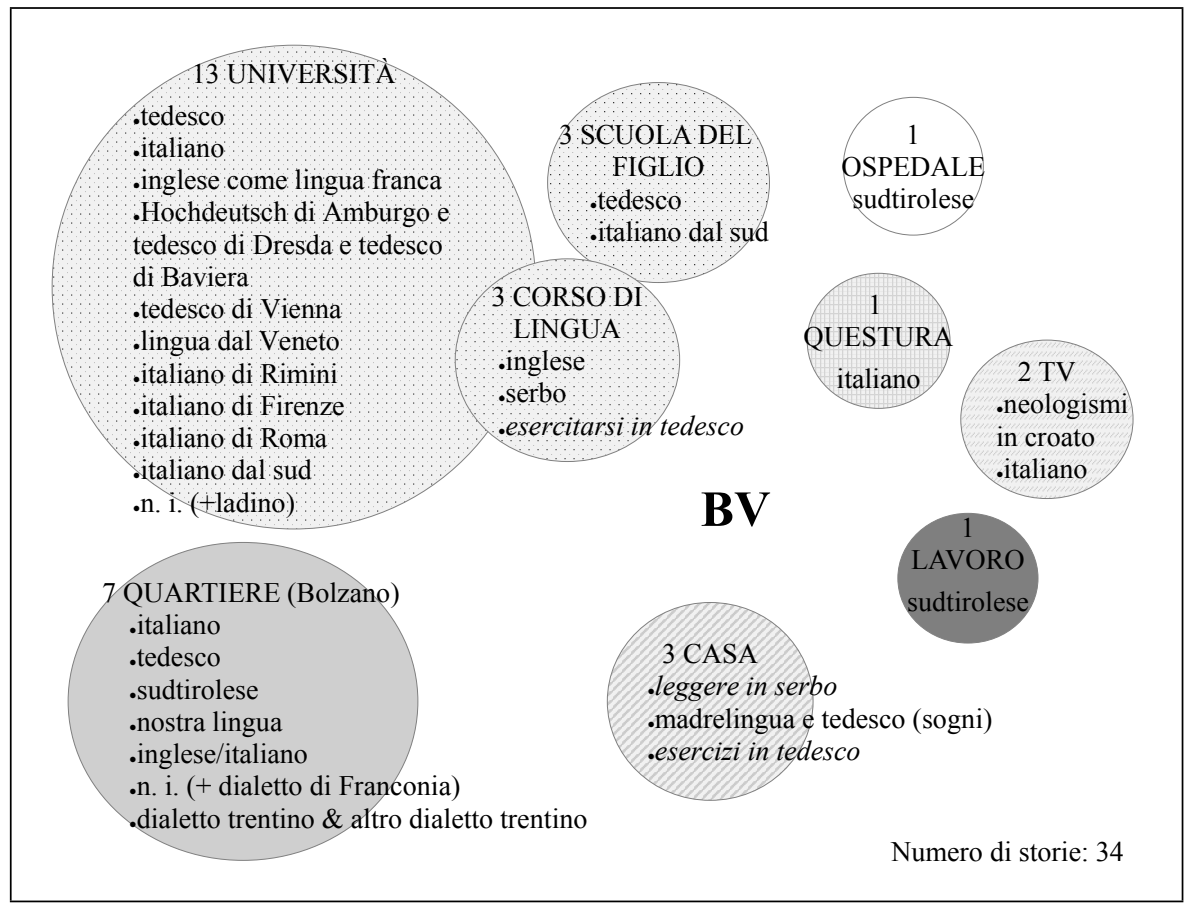

Figura 6: Codici usati nelle narrazioni di interazioni, ambientate in Alto Adige, dell'intervista con $B V$.

Altre situazioni comunicative rilevanti sono il "quartiere" di residenza nel centro di Bolzano e, in misura minore, la "casa". Gli usi linguistici in famiglia non sono infatti altrettanto importanti nell'ottica di BV per caratterizzare il proprio repertorio narrato come lo erano in quella di DK. In aggiunta, tre narrazioni di dialoghi hanno per tema le lingue parlate in "questura", al "lavoro" e nell'amministrazione di un "ospedale". Analogamente a VM, la partecipante caratterizza l'uso dell'italiano in commissariato come una scelta non negoziabile. Infatti, riportando per sommi capi un episodio vissuto personalmente, l'intervistata enfatizza l'impossibilità di servirsi di altre lingue in tale contesto tramite ripetizioni, quantificatori indefiniti iperbolici e variazioni nel volume della voce: "we go to questura to do permesso di soggiorno everyone speaks just italian - >nothing else $<$ JUST - JUST just just italian" (tr. "andiamo in questura per fare il permesso di soggiorno tutti parlano solo italiano $>$ niente altro $<$ SOLO - SOLO solo solo italiano", minuti 58:14-58:21). La selezione del dialetto tedesco locale per comunicare al lavoro e in ospedale è invece rappresentata dalla narratrice come la migliore, ma non come l'unica scelta di lingua possibile in due narrazioni metalinguistiche, raccontate una di seguito all'altra. Queste storie (di)mostrano l'importanza di acquisire competenze in dialetto tedesco locale in Alto Adige. Il nesso tra lingua e luoghi di interazione non è tuttavia caratterizzato come inamovibile dalla donna, a differenza di quanto fatto da VM nella storia analizzata precedentemente (cfr. § V.3.4.1 per maggiori dettagli). 
Similmente alle altre due partecipanti, BV rappresenta, al momento del colloquio, numerose situazioni comunicative in Alto Adige come plurilingui (fanno eccezione la "casa" e la "questura" che sono al contrario esplicitamente qualificate dalla donna come ambiti monolingui). Tuttavia, i codici parlati e/o sentiti dall'intervistata nella regione d'arrivo hanno uno status sociolinguistico globalmente o localmente più riconosciuto rispetto a quelli menzionati nelle storie di VM e DK. Da un lato, c'è infatti l'inglese che, essendo usato sia in università sia nel quartiere, ha una portata comunicativa piuttosto estesa nello spazio comunicativo narrato di BV. Dall'altro, ci sono numerose varietà diatopiche di tedesco e italiano, come, ad esempio, italiano di Rimini o di Firenze, tedesco di Baviera o di Vienna. L'origine di questi codici non è necessariamente "locale", ossia non si tratta di varietà storicamente parlate in Alto Adige. Tuttavia il loro prestigio è comunque rinforzato dal fatto di essere usati da compagni e professori in università. Invece, ad eccezione del serbo (cfr. più sotto in questo paragrafo), BV non menziona mai spontaneamente, nelle sue storie di dialoghi, le lingue di altri parlanti emigrati recentemente per lavoro o per motivi politici in provincia di Bolzano. ${ }^{52}$ In conseguenza di ciò, sembrerebbe che, nella prospettiva della donna, la compresenza di codici diversi nella regione di arrivo sia prevalentemente il risultato del contatto tra minoranze storiche e/o della mobilità di parlanti trasferitisi per ragioni di studio da altre regioni italiane, dall'Austria o dalla Germania. A questo si aggiunge che l'intervistata riferisce di un solo dialogo in una varietà di contatto (nello specifico in enunciazione mistilingue italiano/inglese). Il multilinguismo altoatesino nello spazio narrato di BV è dunque sociale, ma non necessariamente individuale. Quest'ultimo non presuppone infatti che uno stesso individuo abbia competenze in codici diversi.

L'intervistata narra di poche interazioni in serbo/nostra lingua. Dalla figura 6 risulta però che tali dialoghi siano condotti non solo in casa con i membri della famiglia, ma anche nel quartiere con alcuni conoscenti originari della Serbia o di altri paesi successori alla Jugoslavia. Nell'ottica della partecipante, i recenti interventi di pianificazione linguistica non minano infatti la comunicazione tra gli espatriati. Piuttosto complicano i contatti con i paesi d'origine, rendendo più difficile la fruizione dei media. A questo proposito, in una narrazione metalinguistica, BV attribuisce a un'amica istriana, residente in Alto Adige, un enunciato in discorso indiretto che lamenta l'incomprensibilità dei programmi televisivi, trasmessi in Croazia, a causa dell'introduzione di neologismi a lei sconosciuti. Inoltre, sebbene li giudichi mal organizzati - in quanto non calibrati in relazione all'età e alle competenze linguistiche degli studenti -, la partecipante racconta anche della temporanea frequentazione da parte del figlio di un corso di serbo come "lingua di eredità" (heritage language). Da ciò emerge che la portata comunicativa di tale lingua per BV sia maggiore in confronto a quella di albanese e serbo nel repertorio narrato di DK. Al contrario, la sua diffusione in Alto Adige è comunque rappresentata dalla donna come meno capillare e sembra essere più transitoria rispetto a nello spazio comunicativo di VM.

52 La partecipante accenna alla presenza di altre lingue "immigrate" in Alto Adige, come bulgaro e russo, solo dopo domanda diretta della ricercatrice (cfr. il repertorio dichiarato al § V.2.4.3). 
Infine, l'intervistata caratterizza i rapporti tra serbo (unico codice usato in famiglia) e le lingue d'arrivo come diglottici nel proprio repertorio. D'altro canto, in modo non convenzionale, raffigura il repertorio di parlanti italofoni e tedescofoni in Alto Adige come diacrolettico. Infatti, come già accennato, varietà regionali, locali e non locali, di tedesco e italiano sono usate oltre che in contesti informali anche in domini istituzionali, ad esempio, in università o nell'amministrazione di un ospedale. In conseguenza di ciò, le risorse linguistiche (rappresentate come) necessarie per comunicare nella regione di arrivo si moltiplicano nello spazio narrato di BV lungo il continuum che va dagli ambiti della vicinanza a quelli della lontananza (cfr. Krefeld 2004). In altre parole, diventano più numerose con l'aumentare della formalità della situazione descritta. Inoltre, proprio a causa del prestigio a loro riconosciuto nella regione di arrivo, l'acquisizione di competenze in varietà "non standard" è "desiderata" da BV a differenza di quanto avvenga per DK. Ciò è mostrato nelle due narrazioni di interazioni, analizzate nel prossimo paragrafo. In queste storie, la donna illustra infatti i vantaggi della selezione del dialetto tedesco locale in due contesti altoatesini. Nel fare ciò, sostiene la tesi dell'"importanza cruciale" di una acquisizione di tale codice dopo il trasferimento in provincia di Bolzano.

\subsubsection{Una storia "non-partecipata”}

BV valuta l'acquisizione di competenze in dialetto tedesco locale da parte dei cittadini stranieri come fondamentale per fare carriera e, in generale, per agevolare la propria permanenza in Alto Adige. Questa tesi è espressa, per esempio, in apertura della sequenza in 3 ed è supportata, subito dopo, da due narrazioni di dialoghi in terza persona. In questi racconti, uno stesso personaggio, ossia un conoscente di origini serbe, si serve in azienda e con il personale di un ospedale del dialetto tedesco locale. Grazie a questa scelta di lingua, il protagonista delle storie raggiunge facilmente e con successo i propri obiettivi, pur partendo da una situazione caratterizzata precedentemente dalla narratrice come svantaggiata e anomala. L'intervistata racconta le due narrazioni metalinguistiche in 3 in risposta a una domanda dell'intervistatrice riguardo al ruolo del dialetto tedesco locale per stringere rapporti di amicizia nella provincia di Bolzano. Il tema delle storie è quindi parzialmente elicitato dalla ricercatrice. Attraverso i due racconti, la partecipante sviluppa comunque l'argomento in modo piuttosto personale e autonomo.

(es. 3)

\begin{tabular}{|c|c|c|}
\hline \multirow[t]{2}{*}{ tesi } & $1 \mathrm{BV}$ & that's of a cru:cial meaning $(\mathrm{h})$ \\
\hline & $2 \mathrm{BV}$ & because we met a a man from serbia who lived in frankfurt (h) a:nd \\
\hline OR \& & $3 \mathrm{BV}$ & he: eventually he has just high school - he is here CHIEF - CHIEF \\
\hline \multirow[t]{4}{*}{ EV } & $4 \mathrm{BV}$ & in technical firm[-]so with the high school[-] \\
\hline & 5 INT & {$[\mathrm{mh} \mathrm{mh}]$} \\
\hline & $6 \mathrm{BV}$ & but he knows ONly dialect [a]nd bad and bad italia[n-] \\
\hline & 7 INT & [mh mh] \\
\hline
\end{tabular}




\begin{tabular}{|c|c|c|c|}
\hline ME & 8 & BV & so he told us - okay when I - came to that firm - \\
\hline CA & 9 & BV & I just said ((pause)) let's speak dialect I must learn that $\mathrm{it}=\mathrm{s}$ it is \\
\hline CA & 10 & BV & important ((pause)) \\
\hline RI & 11 & BV & and ((pause)) he speaks dialect \\
\hline OR & 12 & BV & so he he also explains us some situations $>$ you know $<-$ help care \\
\hline OR & 13 & BV & institution where (h) ((pause)) eh there are some problems with: \\
\hline OR & 14 & BV & some: numbers in his ID \\
\hline EV & 15 & BV & I don't know $>$ because our country changing $<$ name every two three \\
\hline \multirow[t]{2}{*}{ EV } & 16 & BV & $\begin{array}{l}\text { years [so:] we change also codes so: }\left[{ }^{\circ} \text { al }\right] \text { ways some problems }{ }^{\circ} \\
{[\mathrm{mh} \mathrm{mh}]}\end{array}$ \\
\hline & $\begin{array}{l}17 \\
18\end{array}$ & $\begin{array}{l}\text { INT } \\
\text { BV }\end{array}$ & $\begin{array}{c}{[\mathrm{mh} \mathrm{mh}] \quad[\mathrm{mh} \mathrm{mh}]} \\
\text { (h) }- \text { he said I was speaking you know in a hard dialect }\end{array}$ \\
\hline \multirow[t]{4}{*}{$\mathrm{mRE}$} & 19 & BV & and uo it's okay okay we are making something xx \\
\hline & 21 & INT & $\mathrm{mh} \mathrm{mh}$ \\
\hline & & & (BV_Ser_Bo, 37:36-38:29) \\
\hline & & & Traduzione: \\
\hline \multirow[t]{2}{*}{ tesi } & 1 & BVV & è di importanza cru:ciale $(\mathrm{h})$ \\
\hline & 2 & BV & perché abbiamo incontrato un un uomo dalla serbia che ha vissuto a \\
\hline OR \& & 3 & BV & francoforte (h) e: lui: alla fine ha solo la scuola superiore - lui \\
\hline \multirow[t]{4}{*}{ EV } & 4 & BV & è qui CAPO - CAPO in un'azienda tecnica [-]così con la scuola \\
\hline & 5 & INT & {$[\mathrm{mh} \mathrm{mh}]$} \\
\hline & 6 & BV & superiore [-] ma conosce SOlo dialetto [e] male e male italia[no -] \\
\hline & 7 & INT & {$[\mathrm{mh} \mathrm{mh}] \quad[\mathrm{mh}:] \quad[\mathrm{mh} \mathrm{mh}]$} \\
\hline ME & 8 & BV & così lui ci ha detto - okay quando - sono venuto in quella azienda - \\
\hline $\mathrm{CA}$ & 9 & BV & ho solo detto ((pausa)) parliamo dialetto devo impararlo è è \\
\hline CA & 10 & BV & importante ((pausa)) \\
\hline RI & 11 & BV & e ((pausa)) parla dialetto \\
\hline OR & 12 & BV & così lui lui ci ha anche spiegato di alcune situazioni $>$ sai $<-$ \\
\hline OR & 13 & BV & istituzioni di cura dove (h) ((pausa)) eh ci sono problemi con: \\
\hline OR & 14 & BV & alcuni: numeri nel suo documento \\
\hline EV & 15 & BV & non so $>$ perché il nostro paese cambia $<$ nome ogni due tre anni \\
\hline \multirow[t]{2}{*}{$\mathrm{EV}$} & 16 & BV & [così:] cambiamo anche codici così: $\left[{ }^{\circ}\right.$ se]pre qualche problema ${ }^{\circ}$ \\
\hline & 17 & INT & {$[\mathrm{mh} \mathrm{mh}]$} \\
\hline & 18 & BV & (h) - ha detto stavo parlando sai in un dialetto duro \\
\hline \multirow{2}{*}{$\mathrm{mRE}$} & 19 & BV & e uo è okay okay facciamo qualcosa $\mathrm{xx}$ \\
\hline & 21 & INT & $\mathrm{mh} \mathrm{mh}$ \\
\hline
\end{tabular}

Nella sequenza in 3, BV non presenta la selezione del dialetto tedesco locale come determinata necessariamente dalle situazioni comunicative, sfondo delle due storie, ovvero lavoro e ospedale. Piuttosto la caratterizza, più in generale, come la scelta di lingua migliore da fare, contro ogni aspettativa, per avere successo in svariate circostanze in provincia di Bolzano. In particolare, per illustrare questa tesi, la partecipante narra nel brano in 3 due "storie non-partecipate" (non-participant narratives), vale a dire riferisce di due episodi a cui non ha assistito personalmente neanche come personaggio secondario, ma che le sono stati a sua volta riferiti da altri (cfr. Linde 1997 e anche Norrick 2000: 149-151). ${ }^{53}$ Tali narrazioni in terza persona

53 Si ricordi che, in un lavoro successivo, Linde (2009: 72-88) sostituisce l'etichetta "narrazioni non-partecipate" con quella di "storie ri-raccontate" (retold tales). Come discusso al § V.1.1.2, 
non sono inusuali in interazioni quotidiane. Uno dei loro vantaggi è infatti quello di consentire al parlante di riferire determinati avvenimenti, assumendo una prospettiva piuttosto neutrale nei confronti di questi e del messaggio da loro veicolato (cfr. anche Lucius-Hoene e Deppermann 2004: 138-139). Tuttavia, è importante notare che le storie di questo formato corrono un rischio maggiore di quelle di esperienze personali di essere questionate riguardo alla loro "riportabilità" e "autenticità" (cfr. sempre Linde 2009: 72-88 e De Fina \& Georgakopoulou 2012: 147-148). ${ }^{54}$ In conseguenza di ciò, specialmente se il protagonista non è conosciuto dai destinatari nel mondo dell'interazione, gli eventi riferiti in questi racconti devono dimostrarsi particolarmente rilevanti rispetto all'argomento della conversazione. Inoltre, e in connessione con ciò, la loro messa in scena è spesso contraddistinta da marcatori di evidenzialità che indicano la fonte della storia e il modo in cui il narratore ne è venuto a conoscenza.

Ritornando al brano in 3, BV lavora per garantire la riportabilità delle vicende riferite rispetto al tema della conversazione fin dall'inizio della sequenza. A questo riguardo, si noti che le informazioni riportate nella sezione orientativa del racconto (righe 2-6) veicolano prese di posizione altamente valutative nei confronti del suo personaggio principale (cfr. anche $\S$ V.2.3 sulla funzione valutativa di alcune clausole orientative e sul loro ruolo nella creazione di aspettative riguardo al prosieguo della storia). Oltre a menzionarne la nazionalità e ad alludere (al tipo di) percorso migratorio da lui compiuto, ${ }^{55}$ la partecipante categorizza infatti il protagonista della narrazione tramite un riferimento al livello di istruzione "alla fine" (eventually) raggiunto. Ripetizioni e variazioni nel tono e nella qualità della voce concorrono ad enfatizzare il contrasto tra l'attuale posizione lavorativa del personaggio e la sua precedente formazione scolastica, rappresentandolo come (apparentemente) inspiegabile (cfr. righe 3-4). In chiusura dell'orientazione, la partecipante descrive infine brevemente le competenze linguistiche del conoscente, introducendo l'enunciato tramite la congiunzione avversativa "but" ("but he knows ONly dialect and bad and bad italian"). In questo modo, BV anticipa la rilevanza di tali abilità linguistiche per spiegare la circostanza inusuale appena tratteggiata. L'enfasi dell'intervistata nel caratterizzare il protagonista del racconto ha dunque più funzioni. Da un lato, consolida, tramite dettagli, l'autenticità degli avvenimenti riferiti e coinvolge l'interlocutrice. Dall'altro, come già accennato, mira a validare la tesi metalinguistica formulata alla riga 1 . La tensione costruita dalla narratrice tramite le categorizzazioni, espresse nella sezione orientativa della storia, e il suo parziale risolversi al termine di questa sono riconoscibili anche dall'addensarsi dei segnali di ricezione dell'interlocutrice alle righe 5 e 7.

la seconda designazione è usata in questo volume come iperonimo per riferirsi anche agli "aneddoti" e alle "storie condivise".

54 Sia qui ricordato che, in un approccio narratologico, 1' "autenticità" di un racconto non è intesa in senso assoluto. Questa è piuttosto il risultato di un lavoro interazionale. La creazione di "autenticità" insieme a quella di "coerenza" mira ad avvalorare la "credibilità" di una storia e costituisce, così, uno dei principi - accanto a "riportabilità" e "raccontabilità" - che guida i processi di verbalizzazione narrativa (cfr. §V.2.3). Ossia via un precedente soggiorno in Germania. 
Gli avvenimenti narrati in seguito hanno la funzione di esemplificare i vantaggi strumentali dell'acquisizione e della selezione del dialetto tedesco locale nella regione d'arrivo. A differenza di $\mathrm{VM}, \mathrm{BV}$ non istituisce però un rapporto inamovibile tra lingua, contesti e interlocutori. Infatti, in contrasto con il protagonista della storia, questi ultimi non sono definiti precisamente dalla donna, ma lasciati piuttosto indeterminati. Inoltre, la partecipante riferisce di due episodi, uno abituale e l'altro singolare. Nel fare ciò, istituisce, ad illustrazione della sua tesi, una serie in climax (cfr. Günthner 1995: 158) che può essere potenzialmente ampliata. Uno dei risultati è che, sebbene non siano vissute in prima persona, le vicende "ri-raccontate" da BV risultino essere riportabili in quanto inaspettate e, nello stesso tempo, generalizzabili. In questo senso, le storie svolgono, similmente ai racconti di DK analizzati al $\S$ V.3.3.1, una funzione "argomentativo-esemplare". Infatti, illustrano una regola in modo vivido attraverso la messa in scena di casi concreti (cfr. Günthner 1995). A differenza di DK, BV non lavora tuttavia per costruire insieme alla ricercatrice una valutazione dei rapporti tra codici raffigurati come conformi a una norma universalmente valida. Piuttosto enfatizza, tramite le categorializzazioni e le strategie di rappresentazione sopra menzionate, l'eccezionalità del prestigio del dialetto tedesco locale nello spazio comunicativo altoatesino. La sorpresa per l'alto status di questo codice nasce presumibilmente dal confronto - qui implicito, ma formulato espressamente in altre sequenze dell'intervista - con altre situazioni sociolinguistiche in cui la donna ha vissuto (cfr. § V.4.4 per maggiori dettagli).

Infine, come accennato sopra, il formato delle "storie non-partecipate" consente alla partecipante di modulare distacco e partecipazione rispetto agli eventi riferiti. A questo proposito, la tesi o morale delle narrazioni, riformulata alle righe 9-10, è attribuita da BV in forma di discorso diretto al suo protagonista ("I just said ((pause)) let's speak dialect $\mathbf{I}$ must learn that $\mathbf{i t}=\mathbf{s}$ it is important"). Perciò, un soggetto terzo condivide, se non si assume, la responsabilità di questo giudizio metalinguistico che, infatti, è solo citato dalla narratrice. Inoltre, l'intervistata sembra voler ribadire il proprio distacco, da un lato, introducendo ripetutamente le azioni e le parole del personaggio principale della storia tramite verbi di dire in terza persona al passato (cfr. righe $8,12,18$ ), dall'altro, rallentando lo svolgersi della vicenda e rompendo la finzione drammatica attraverso enunciati valutativi, espressi dalla prospettiva presente (cfr. righe 15-16). Tuttavia, al contempo, la donna si serve, nel brano in 3 , anche di alcuni dispositivi di rappresentazione e coinvolgimento che ricreano la scena - a cui l'io narrante non ha partecipato personalmente - dalla prospettiva del protagonista e "traspongono" l'interlocutrice nel mondo della storia. Così, l'evento più riportabile della seconda narrazione è, per esempio, messo in scena drammaticamente dalla narratrice, la quale "costruisce" un dialogo tramite l'uso del discorso diretto, del tempo presente e di interiezioni ("uo it's okay okay we are making something"). ${ }^{56} \mathrm{Nel}$ fare ciò, $\mathrm{BV}$ risolve, più o meno intenzionalmente, il problema di argomentare in favore di una rappresentazione della situazione sociolinguistica d'ar-

56 Su questo aspetto si confronti Tannen (1989/2007: 102-119). La ricercatrice propone infatti di riferirsi al discorso riportato con il termine "dialogo costruito" proprio per mettere in evidenza la relazione dinamica e trasformativa tra ogni enunciato (anche quelli presentati come citazioni 
rivo, da lei stessa valutata in altre sequenze dell'intervista come insolita. Il formato delle storie non-partecipate le permette infatti di condividere la responsabilità della tesi metalinguistica espressa con una terza persona, senza che le vicende riferite perdano, per questo, di forza argomentativa.

\subsection{Conclusioni: luoghi di interazione e usi linguistici soggettivi}

Dalla ricostruzione degli spazi comunicativi narrati, discussi nei paragrafi precedenti, possono essere tratte alcune considerazioni conclusive. La prima osservazione è abbastanza intuitiva. Alcune situazioni comunicative risultano essere più rilevanti di altre per le partecipanti al momento di narrare la loro biografia linguistica. La "salienza" di un contesto dipende in parte da ragioni extra-linguistiche, in parte è condizionata dalla volontà di negoziare una certa rappresentazione di sé come soggetto parlante nell'hic et nunc dell'interazione. Nello specifico, VM, DK e BV fondano il loro spazio comunicativo narrato dopo mobilità sugli usi linguistici (propri e altrui) in tre contesti diversi, ossia rispettivamente al "lavoro", in "casa" e in "università". Oltre a essere variamente posizionati lungo il continuum della vicinanza/lontananza pragmatica e sociale, tali luoghi di attività quotidiana sono associati, sia dalle tre narratrici, sia da altri intervistati del corpus, a pratiche comunicative abituali differenti e a diverse questioni (meta)linguistiche immanenti alla condizione post-mobilità. La famiglia è infatti un dominio in $\mathrm{L}$ di solito considerato centrale per il mantenimento dei codici d'origine. La messa in scena degli usi linguistici in questo ambito è inoltre spesso valutata dagli intervistati come vincolante per la negoziazione di attributi non solo linguistici, ma anche culturali o nazionali relativi alla propria persona. ${ }^{57}$ All'opposto, il lavoro e l'università sono contesti medio-alti, in cui l'io narrante rappresenta il proprio o altri personaggi al momento di interagire con altri parlanti, locali o parimenti stranieri. La frequenza di narrazioni di dialoghi ambientate in questi ultimi scenari è così possibilmente indicativa dell'importanza di prendere posizione rispetto a una propria riallocazione come soggetti sociali nella comunità d'arrivo durante il colloquio (cfr. anche $\S$ V.4).

Oltre a essere condizionate da obiettivi interazionali, le configurazioni spaziali dei repertori narrati delle partecipanti hanno, a mio avviso, un valore anche dal punto di vista presentazionale. Un loro esame permette infatti di (ri)valutare le rappresentazioni culturalmente sedimentate dei rapporti tra codici nella regione d'arrivo - discusse nel presente volume al §II.1 e seguenti - dalla prospettiva di chi, arrivato più o meno recentemente, le sta acquisendo e rimodellando sulla base di un capitale linguistico e metalinguistico diverso da quello locale. A questo proposito, si noti che gli spazi comunicativi delle tre donne sono parimenti definibili come

dirette), il contesto "riportato" (reported) nel mondo della storia e il contesto "riportante" (reporting) nel mondo dell'interazione.

57 Si confronti anche l'analisi dei glottonimi per le lingue d'origine: i nomi dei codici parlati in famiglia sono quelli più frequentemente sostituiti da denominazioni generiche in funzione "elusiva", "enfatica" o "oppositiva". 
"dissociati". Tuttavia, la portata comunicativa e le relazioni funzionali tra i codici d'origine e quelli d'arrivo non coincidono tra le partecipanti. In particolare, VM rappresenta le relazioni tra i codici conosciuti dopo mobilità come tendenzialmente dilaliche e le lingue di partenza come radicate sul territorio altoatesino. Invece, lo spazio comunicativo narrato di DK è caratterizzato da diglossia ad almeno tre elementi, ${ }^{58}$ mentre due sono i principali codici in $\mathrm{L}$ nel repertorio individuale della donna, ovvero albanese e dialetto tedesco locale. Infine, BV caratterizza i rapporti tra serbo e le lingue locali come diglottici, mentre raffigura il repertorio di parlanti italofoni e tedescofoni in Alto Adige come diacrolettico.

Gli usi linguistici comunitari nella località altoatesina di residenza hanno talvolta un influsso sulle configurazioni soggettive dei repertori narrati delle partecipanti. Tale influsso si vede, per esempio, sui modi di rendere conto della necessità di usare l'italiano in certi ambiti istituzionali da parte di VM. Rappresentazioni metalinguistiche collettive non sono tuttavia sempre determinanti. Ciò si riconosce, per esempio, dal diverso prestigio che i dialetti tedeschi locali hanno nello spazio comunicativo narrato delle tre partecipanti così come in quello di altri intervistati per la presente ricerca. Nello specifico, nel corpus si possono distinguere tre modi principali di posizionarsi nei confronti dei dialetti tedeschi locali, mentre le rappresentazioni di BV si differenziano da tutti e tre. Infatti, da un lato, c'è chi prende una posizione abbastanza negativa verso il dialetto tedesco e dichiara di non volerlo imparare, per esempio, perché "antipatico" o non così "preciso" come il tedesco standard (cfr. SV, RX, AS, DR, BL, NM, LA). Dall'altro lato, alcuni informanti, che affermano di avere competenze medio-basse o nulle nel codice, si posizionano comunque positivamente nei suoi confronti e sono favorevoli a una sua acquisizione almeno parziale. Questi ultimi intervistati tendono a giudicare il dialetto come utile in ambito lavorativo. Tuttavia, contrariamente a $\mathrm{BV}$, non lo valutano come prestigioso: infatti, il suo impiego è frequentemente attribuito, nel mondo delle storie, a clienti e/o colleghi, categorizzati come "contadini" e/o "montanari" e rappresentati, quindi, più o meno esplicitamente come di bassa estrazione sociale (cfr. la stessa VM e anche KM, NJ, RM, TF). La terza posizione è infine quella di chi conosce bene un dialetto tedesco locale, ma in conseguenza di ciò, diversamente da BV, non lo desidera né gli attribuisce solitamente un prestigio "strumentale", quanto tutt'al più "simbolico-affettivo" (cfr. la stessa DK e AK, BA, JB, TN, YF). La molteplicità, appena tratteggiata, degli atti di posizionamento dei partecipanti nei confronti delle varietà locali di tedesco è verosimilmente interconnessa con la compresenza di discorsi metalinguistici differenti sul loro conto (cfr. anche § II.1.3). A tali rappresentazioni contrastanti, diffuse nella società di arrivo, singoli intervistati (vedi, in particolare, il caso di BV) oppongono, talvolta, resistenza in modo innovativo e idiosincratico.

In aggiunta, un'altra chiave di lettura per interpretare le differenze negli spazi comunicativi soggettivi delle tre donne può essere anche quella della "diacronia apparente". In altre parole, i repertori di BV, VM e DK rappresenterebbero tre stadi, ordinati cronologicamente in relazione alla durata del soggiorno e all'età di trasfe-

58 Vale a dire i) tra varietà di tedesco, ii) tra varietà di italiano e iii) tra l'albanese e le lingue d'arrivo. 
rimento delle partecipanti, in cui si possono articolare i rapporti tra i codici di partenza e d'arrivo dopo emigrazione in provincia di Bolzano. Segnatamente, l'analisi qui condotta suggerisce che i rapporti gerarchici tra varietà linguistiche dopo mobilità in contesti istituzionalmente plurilingui, come l'Alto Adige, non tendano a semplificarsi. Questo sviluppo contrasta con quanto tendenzialmente avviene, invece, in contesti ufficialmente monolingui. ${ }^{59}$

Differenze tra le tre partecipanti si riscontrano anche nella loro messa in scena di pratiche plurilingui. Nello specifico, VM e DK caratterizzano il plurilinguismo nella regione d'arrivo non solo come un fenomeno sociale, ma anche come una risorsa comunicativa individuale: frequenti sono infatti in queste interviste i racconti di dialoghi in cui gli interattanti comunicano in varietà di contatto o di interlingua. All'opposto, la commutazione di codice non costituisce quasi mai codice di interazione tra $\mathrm{i}$ personaggi delle storie di BV. Così, il plurilinguismo altoatesino nello spazio comunicativo soggettivo della donna è il risultato di diverse abitudini linguistiche di gruppi di parlanti non sovrapponentesi tra loro. A questo riguardo, è anche importante notare che il tipo di codici menzionati, il loro status sociolinguistico e i motivi della loro presenza sul territorio non corrispondono nei repertori narrati delle tre donne. VM racconta frequentemente di dialoghi in lingue di parlanti arrivati in Alto Adige in seguito a immigrazione per lavoro, mentre BV conduce e/o sente intorno a lei conversazioni in codici, come inglese o varietà regionali di italiano e tedesco, il cui status sociolinguistico è più consolidato nella regione di arrivo. Infine, l'insieme delle varietà linguistiche autoctone e alloctone nominate da DK è composito, sia in relazione alla regione di provenienza dei parlanti, sia al prestigio dei codici menzionati.

Oltre che a essere possibilmente connesse con la composizione dei reticoli sociali delle intervistate, tali differenze sono, a mio avviso, indicative del loro diverso modo di posizionarsi rispetto a temi controversi a livello sia (meta)linguistico sia sociale. I vantaggi e gli svantaggi del "plurilinguismo" individuale e comunitario sono infatti frequentemente discussi in dibattiti sul "fenomeno immigrazione" in Alto Adige così come in altri paesi (cfr. Busch 2013: 114-116, Blackledge \& Creese 2010: 26). Inoltre, nello specifico caso studiato, tali prese di posizione si intrecciano con quelle relative a pratiche plurilingui derivanti dalla compresenza "storica" di più varietà linguistiche nella regione d'arrivo e nei paesi di provenienza. Così, al momento di mettere in scena conversazioni in lingue di antico e nuovo insediamento $\mathrm{o}$ in varietà di contatto, le partecipanti prendono anche posizione rispetto alla composizione della popolazione locale, alla legittimità di codici e parlanti alloglotti sul territorio d'arrivo e al valore strumentale o simbolico da associare a pratiche mistilingui. Il tipo di varietà linguistiche menzionate dalle intervistate può essere messo inoltre in relazione con la volontà di affiliarsi a certi gruppi di parlanti mobili e con il significato che si vuole trasmettere all'interlocutrice della propria esperienza migratoria.

Infine, nei paragrafi precedenti si è visto che alcune situazioni comunicative sono rappresentate dalle intervistate come prevalentemente monolingui e, talvolta,

59 Per una riflessione sull'evolversi ed eventuale semplificarsi dei rapporti tra codici nei repertori di comunità immigrate, si veda Fishman (1989). 
associate da parlanti diversi all'impiego di un determinato codice. Nello specifico, le interazioni con le forze dell'ordine (es. in questura, al posto di blocco) e in contesti sportivi sono caratterizzate, in alcune interviste del corpus, come necessariamente condotte in varietà di italiano. D'altro canto, pur con le precisazioni discusse sopra, la selezione del dialetto tedesco locale risulta essere la scelta di codice più vantaggiosa in altri ambiti comunicativi, sia informali, sia medio-alti. L'analisi di singole sequenze narrative ha messo in luce come nessi più o meno inamovibili tra codici, luoghi e interattanti siano istituiti, negoziati ed eventualmente tramandati in interazione. Ulteriori indagini, anche di approccio quantitativo, sarebbero a questo punto necessarie per valutare l'eventuale diffusione di tali rappresentazioni a livello di consapevolezza metalinguistica nella società altoatesina nel suo insieme. ${ }^{60}$ Oltre a essere rilevanti per meglio comprendere la situazione sociolinguistica della provincia di Bolzano in una prospettiva emica, l'individuazione di tali rapporti tra codici "ideologici" - in quanto possibilmente connessi a interessi di gruppo - è importante poiché costituisce un prerequisito per azioni di pianificazione linguistica efficaci (cfr. Dell'Aquila \& Iannàccaro 2006: 18).

\section{USI LINGUISTICI E RUOLI INTERAZIONALI}

Questa sezione del capitolo V è dedicata a un'analisi della distribuzione dei codici per ruoli interazionali nelle narrazioni di dialoghi delle tre intervistate. Per fare ciò, ho codificato il primo enunciato di discorso riportato o la prima attività comunicativa riportata in ogni narrazione di interazione a seconda del ruolo dell'io narrato nella "struttura di partecipazione" (participation framework), messa in scena nel mondo della storia (cfr. Goffman 1981). Mutuando la classificazione proposta dallo studioso, distinguo, in particolare, tra tre ruoli di produzione e ricezione che il personaggio dell'intervistata può assumere nell'evento comunicativo raccontato. In alcuni casi, l'io narrato può svolgere il ruolo di "parlante" (speaker), iniziatrice del dialogo. In altri, può essere "destinataria ratificata" (ratified addressed participant) di un atto comunicativo eseguito da altre figure. Infine, la narratrice può rappresentare il proprio personaggio in qualità di "ascoltatrice occasionale" (by-stander) di una conversazione condotta da terzi (ibidem: 131-137).

Il riesame delle nozioni di ascoltatore e parlante e il superamento di una concezione di comunicazione esclusivamente a due nella ricerca sociologica e linguistica hanno per Goffman (1981: 128) l'obiettivo di cogliere i supporti o rinforzi strutturali di tutti i cambiamenti di footings in interazione. In altre parole, mirano a rendere conto dei modi in cui gli interattanti dinamicamente si allineano e disallineano gli

60 A questo riguardo, un punto di partenza potrebbe essere fornito dall'indagine di Dell'Aquila \& Iannàccaro (2006), le cui rilevazioni si riferiscono però solamente allo spazio sociolinguistico della Ladinia Dolomitica. Nel formulare in tedesco e in ladino (ma non in italiano) il quesito 27 sugli usi linguistici con gli amici, anche i due ricercatori menzionano esplicitamente lo "sport" come un esempio di situazione comunicativa a parte. Una domanda sulle lingue parlate in questura o con le forze dell'ordine non è invece presente nel questionario. 
uni verso gli altri e verso il contenuto del loro discorso nel corso di una conversazione (cfr. anche Ribeiro 2006). Così, al momento di identificare i ruoli assunti dall'ascoltatore in un "luogo di incontro/riunione" (gathering), Goffman (1981) mette primariamente in rilievo la distinzione tra "ascoltatore ratificato" (indirizzato o non indirizzato) di un atto comunicativo, da un lato, e "ascoltatore occasionale", dall'altro. Inoltre, disarticola quest'ultimo ruolo in quelli di "origliatore" (eavesdropper) e "ascoltatore casuale" (overhearer) di una conversazione, a seconda dell'intenzionalità o meno nel seguire un dialogo condotto da sconosciuti. In modo leggermente diverso dalla tassonomia proposta da Goffman, nei prossimi paragrafi, la categoria dell'ascoltatore occasionale è usata per codificare sia dialoghi ascoltati personalmente dall'io narrato, sia dialoghi che gli sono stati riferiti da terzi. Invece, 1'io narrato è destinatario (ratificato e indirizzato) solo quando un altro personaggio si rivolge direttamente a lei (da sola o in un gruppo). Infine, come si vedrà, nel valutare gli atti di posizionamento delle narratrici, i ruoli di ascoltatrice e destinataria sono spesso considerati insieme.

Il motivo dipende dagli specifici obiettivi della presente ricerca. L'esame qui condotto intende infatti concentrarsi su un sotto-gruppo di cambiamenti di footings e di atti di posizionamento intrapresi dalle partecipanti nel raccontare la propria biografia linguistica. Questi sono quelli relativi a come le intervistate si allineano rispetto all'esecuzione di atti linguistici in determinati codici, si impegnano nel mondo della storia e dell'interazione nei confronti di specifiche identità linguistiche e/o di aspettative e pratiche discorsive connesse con queste, e attribuiscono la responsabilità dei giudizi e discorsi metalinguistici citati. Anche la decisione di codificare solo il primo enunciato o attività comunicativa riportata dei dialoghi narrati dipende da un particolare interesse di ricerca. Come già accennato, l'intenzione è quella di mettere a fuoco l'evento comunicativo (rappresentato come) quello che dà avvio all'interazione. In questo modo, è possibile, a mio avviso, risalire alle rappresentazioni e prese di posizione delle narratrici rispetto alla propria capacità di negoziazione durante i processi di selezione e alternanza di codice nel contesto d'arrivo (cfr. anche De Fina 2003: 106-112 per una decisione analoga con obiettivi diversi). Nello specifico, 1'analisi del discorso riportato rispetto alla sua struttura di partecipazione mira a rispondere alle seguenti domande di ricerca:

1) Quale ruolo interazionale è prevalentemente svolto dal personaggio dell'intervistata all'avvio dei dialoghi raccontati? In altre parole, la narratrice si rappresenta più frequentemente come parlante, destinataria ratificata o ascoltatrice occasionale degli atti comunicativi narrati?

2) Quali sono le varietà linguistiche e di contatto di cui l'io narrato si serve attivamente e quali sono quelle in cui gli viene rivolta la parola? E, connessa a questa seconda domanda, si rileva una discordanza tra le varietà a cui l'io narrato è esposto (da qui in avanti, anche codici input) e quelle usate attivamente (in seguito, anche codici output) nei dialoghi raccontati?

3) È presente una relazione tra tipo di codici e categoria di interattanti che li utilizzano nelle narrazioni delle singole partecipanti ed eventualmente tra partecipanti diverse? 
Con il fine di rispondere a questi interrogativi, una valutazione della distribuzione dei codici per ruoli interazionali in tutte le storie di dialoghi di un'intervista è combinata con un esame dettagliato di singole sequenze narrative raccontate nel corso di questa (cfr. il principio di conciliare analisi micro e macro, illustrato ai § III.2 e V.2). Inoltre, i risultati sono messi in relazione con categorie linguistico-identitarie, identificate come localmente significative in altre ricerche condotte in contesto altoatesino (cfr., per esempio, Veronesi 2008a, 2008b, 2010, 2012, Dal Negro 2011, Franceschini 2011, Medda-Windischer 2011, Wisthaler 2011 e il § II del presente volume). L'ipotesi è che tale accostamento consenta di individuare le identità linguistiche più salienti nella strutturazione della propria biografia linguistica da parte delle tre partecipanti.

Le osservazioni e le domande di ricerca appena illustrate riguardano prevalentemente la dimensione "presentazionale" delle biografie linguistiche raccolte. Nei prossimi paragrafi intendo però valutare anche la dimensione "interazionale" dei racconti del corpus. I due livelli di analisi, "presentazionale" e "interazionale", sono intrecciati tra loro. La ricostruzione della struttura di partecipazione nelle storie di dialoghi raccontati permette infatti di risalire al "formato di produzione" (production format) dell'attività narrativa in corso nel mondo dell'interazione, vale a dire dà accesso alle relazioni tra "animatore", "autore" e "responsabile" dei discorsi riportati dalle intervistate (cfr. sempre Goffman 1981 e più sotto in questo paragrafo).

A questo riguardo, sia qui ricordato che l'adozione del tipo di testo della narrazione implica sempre un'"inclusione" (embedding) (Goffman 1981: 147-152). Nel raccontare, un parlante proietta infatti un "sé", l'io narrato, ed eventualmente degli "altri", i personaggi. Questi non coincidono - neanche se formalmente si riferiscono alle stesse persone - né con l'io narrante né con gli interattanti, che nella conversazione in corso "eseguono" (perform) e co-costruiscono il racconto, talvolta, influenzati da obiettivi interazionali concreti (cfr. anche Bamberg 1997, Lucius-Hoene \& Deppermann 2004: 41-42). Inoltre, il discorso riportato, incluso in narrazioni, è frequentemente "dislocato" (displaced) in relazione al tempo e/o ai personaggi della storia così da presentare una "stratificazione di voci" (cfr. Goffman 1981: 147-152 e anche Günthner 2007, De Fina \& Georgakopoulou 2012: 169-171). Gli enunciati "costruiti” al momento di narrare (cfr. Tannen 1989/2007: 98-133) possono essere infatti ascritti a un io personaggio con cui l'io attuale non si identifica più o ad altre figure della storia, introdotte, per esempio, da nomi propri, categorie sociali e/o identitarie o pronomi personali. Perciò, Goffman (1981: 144-145) scompone la nozione di parlante/narratore in tre ruoli: 1" "animatore" (animator), ovvero l'individuo fisico impegnato nell'attività acustica; 1'“autore" (author), ossia colui che seleziona i sentimenti e le parole per codificarli; e il "responsabile" (principal), vale a dire la persona, di solito attiva in una particolare identità sociale, che si impegna per le parole dette e la cui posizione è stabilita da queste. Citando un discorso diretto o indiretto, l'animatore ha dunque la possibilità di parlare usando espressioni formulate da un altro autore e/o in nome di un altro responsabile. Tuttavia, anche nel caso sia dislocato, un enunciato riportato, oltre ad esprimere le parole del personaggio citato, lascia comunque intravedere il punto di 
vista del narratore che infatti lo "interpreta" (perform), per esempio, modificando il tono o la qualità della voce (cfr. Günthner 2007: 423). Da ciò deriva la connessione tra dimensione interazionale e presentazionale e l'intreccio tra diversi livelli di posizionamento possibili nell'interazione narrativa (cfr. Deppermann 2013 e $\S$ III.2.3.3).

Il secondo livello di analisi persegue, dunque, domande di ricerca diverse dalle prime, ma a queste correlate. Nello specifico, l'esame del discorso riportato riguardo al suo formato di produzione ha lo scopo di investigare gli atti di posizionamento dell'io narrante:

1) rispetto a varietà linguistiche, di contatto o di interlingua, mezzo di comunicazione dei dialoghi raccontati;

2) rispetto ad atti e comportamenti linguistici portati a termine dall'io narrato e dagli altri personaggi;

3) rispetto alle opinioni e giudizi metalinguistici citati.

Le prese di posizione delle partecipanti nei confronti di varietà linguistiche, comportamenti e giudizi metalinguistici sono distinte in "valutative", "affettive" ed "epistemiche" a seconda che i) mirino a esprimere una qualità o un valore che caratterizza l'oggetto della presa di posizione (cfr. l'uso di aggettivi come "brutto" o "antipatico"), ii) posizionino colui/colei che prende la posizione (stancetaker) su una scala emozionale (es. "sono felice", "mi viene male") o iii) lo/la posizionino lungo una scala di conoscenza (es. "lo so", "non ne ho idea") (cfr. Du Bois 2007: 142-143). Inoltre, particolare attenzione è posta anche agli atti di allineamento delle interattanti tra di loro, ossia agli atti che calibrano la relazione tra intervistata e intervistatrice rispetto a tali prese di posizione (si veda per esempio l'uso di enunciati come "sono d'accordo con te" o anche di segnali di feedback). Tali mosse interazionali permettono infatti di mappare come accordo o disaccordo rispetto a un tema siano costruiti sequenzialmente nel corso del colloquio (ibidem: $144-145) .{ }^{61}$

L'obiettivo finale è quello di tratteggiare le identità linguistiche più salienti delle narratrici a livello sia "agentivo" sia "epistemico", vale a dire rispettivamente a livello di ciò che uno può fare tramite determinate varietà e comportamenti linguistici e a livello di ciò che uno sente o sa nei loro confronti (cfr. anche Schiffrin 1996 e § III.2.2.3). Si noti che le partecipanti negoziano, attraverso la rappresentazione del proprio io narrato, queste identità linguistiche per il proprio io attuale vis-à-vis con la specifica ricercatrice. Al contempo, tramite la narrazione dei modi del proprio apprendimento linguistico e dei risultati conseguiti, le narratrici riescono talvolta a compiere una riallocazione sociale e morale della propria esperienza migratoria nell'hic et nunc dell'interazione. Come sarà dettagliatamente illustrato nel prossimo paragrafo, il discorso riportato fornisce il punto di ancoraggio per risalire alla struttura di partecipazione e al formato di produzione prevalente nelle storie di dialoghi. Perciò, è particolarmente rivelatore degli atti di posizionamento delle in-

61 Secondo Du Bois (2007: 144), l'allineamento è un tipo di presa di posizione che può essere definito come "the act of calibrating the relationship between two stances, and by implication between two stancetakers". 
tervistate volti a ri-elaborare, attraverso l'accettazione o il rifiuto di categorizzazioni già esistenti, le proprie identità linguistiche e sociali nel corso dei colloqui.

\subsection{Il discorso riportato}

Per investigare le prese di posizione delle partecipanti nel corso dei colloqui (cfr. le domande di ricerca formulate nel $\S$ V.4), mi baso nei prossimi paragrafi su un esame del discorso riportato per i seguenti motivi. In primo luogo, dal momento che, nelle narrazioni di dialoghi analizzate, le intervistate nominano la lingua di comunicazione tra i personaggi delle storie deliberatamente o in seguito a domanda della ricercatrice, il discorso riportato contestualizza, pur con diversi gradi di intenzionalità e consapevolezza, la funzione e l'adeguatezza di tali codici in relazione agli interlocutori e alle situazioni comunicative, personaggi e sfondo del racconto. In particolare, soprattutto nei racconti metalinguistici, le partecipanti, più o meno esplicitamente, "valutano" i codici e gli usi linguistici rappresentati nel riportare enunciati passati, ad esempio, tramite aggettivi come "perfetto" attribuito a un modo di esprimersi. Nel fare ciò, posizionano se stesse e gli altri nel mondo della storia e dell'interazione nei confronti di questi codici a livello "affettivo" o "epistemico" (cfr., per esempio, rispettivamente gli enunciati "ti viene male" e "it should be understandable for me" tratti da esempi dei prossimi paragrafi). Al contempo, le intervistate "si allineano" o "disallineano" con (altre) prese di posizione linguistiche e metalinguistiche di personaggi e di interlocutori, presenti o immaginati, al momento del colloquio. A proposito del pubblico immaginato di un'intervista, sia qui infatti ricordato che il testo interazionale delle biografie linguistiche raccolte, pur essendo calibrato rispetto alla particolare interlocutrice e alla situazione comunicativa concreta, non è completamente "decontestualizzato", ovvero non è del tutto sganciato dal contesto macro in cui l'interazione si svolge (cfr. Wortham et al. 2011: 43). Al contrario, specialmente nel momento in cui le partecipanti raccontano una storia di interazione presentata come "tipica", il loro discorso può rivelare atti di posizionamento interazionali abituali delle narratrici rispetto ai codici oggetto del racconto e/o modi diffusi a livello collettivo di dare un senso alla realtà sociolinguistica locale (cfr. anche Franceschini 2010 e Johnstone 2006). Così, la distribuzione del discorso riportato per codici e interlocutori rivela prese di posizione valutative, affettive ed epistemiche delle intervistate nei confronti delle varietà linguistiche o di contatto o di interlingua, adoperate nel mondo della storia. Inoltre consente di ricostruire le rappresentazioni - talvolta individuali, talvolta filtrate da quelle della comunità linguistica d'arrivo, talvolta parodistico-caricaturali - delle loro condizioni di utilizzo nell'ottica delle tre donne al momento del colloquio.

In secondo luogo, l'analisi del discorso riportato permette di valutare anche quali posizioni, a livello sia epistemico-morale sia agentivo, le partecipanti rivendicano come proprie o rifiutano nel rappresentare giudizi metalinguistici e comportamenti linguistici diffusi nel contesto d'arrivo (cfr. Schiffrin 1996, De Fina 2003, Relaño-Pastor \& De Fina 2005). Infatti, la possibilità di operare uno scollamento tra i ruoli di animatrice, autrice e responsabile nel citare discorsi diretti o indiretti con- 
sente, per esempio, alle intervistate di formulare giudizi metalinguistici sulle lingue del proprio repertorio individuale e di quello comunitario senza attribuirli direttamente a se stesse. In questo modo, come già illustrato, le narratrici possono esprimere giudizi senza assumere direttamente la "paternità/maternità" (authorship) di quanto detto. Inoltre, non solo la responsabilità di parole, ma anche quella di atti e comportamenti linguistici può essere addossata ad altri personaggi, condivisa con loro o lasciata indeterminata tramite lo sfruttamento, talvolta strategico, di questa peculiarità della comunicazione.

Infine, nei prossimi paragrafi, si presterà particolare attenzione all'occorrenza (o anche all'assenza) di fenomeni di "commutazione di codice" e "inserzioni" (cfr. Auer 1984, 1998), ${ }^{62}$ quali possono essere usati nel riprodurre i discorsi dei personaggi delle storie. L'idea è che tali alternanze di lingua siano funzionali alla messa in scena della vicenda e alla sua drammatizzazione. Nello stesso tempo, queste costituiscono un ulteriore indizio per ricostruire le identità linguistiche delle narratrici attraverso quelle delineate per i loro personaggi. ${ }^{63} \mathrm{Il}$ passaggio da una varietà linguistica a un'altra non ha infatti necessariamente (solo) una funzione "mimetica", vale a dire non riproduce per forza meramente un'alternanza di codice effettivamente verificatasi durante l'episodio riferito. Piuttosto, inserzioni di codice possono essere invece utilizzate (anche) in funzione di "icona" e/o di "indice" nel corso delle storie. In altre parole, possono servire per "rappresentare" un comportamento linguistico che ha caratteristiche simili, indipendentemente dall'identità linguistica di chi lo attua o dal codice che si stava usando nella conversazione riferita. In alternativa o in aggiunta a ciò, possono servire per "indicizzare" categorie identitarie relative al personaggio che sta parlando, presupponendo così una connessione più $o$ meno forte tra attributi linguistici ed identitari (per osservazioni in linea con ciò, si veda il già citato Hansen et al. 2010). Si pensi, per esempio, nel primo caso, all'uso della commutazione di codice dall'inglese all'italiano per segnalare l'immancabile rinegoziazione del tedesco in favore dell'italiano da parte di tutti i parlanti, locali e non locali, italofoni e tedescofoni, in provincia di Bolzano. Nel secondo caso, si consideri invece l'adozione di varietà di interlingua per imitare un parlante immigrato e, indirettamente, per posizionarlo come una persona con basso grado di istruzione oppure la commutazione al tedesco per riferirsi esclusivamente ai membri del

62 Secondo il modello procedurale proposto da Auer (1984: 62-67), 1"“alternanza di lingua" per citare un discorso riportato in conversazione è un' "inserzione", correlata al discorso, di grandi unità (nella terminologia proposta nel 1984, ma modificata nel 1998, "discoursed-related transfer") e non una "commutazione di codice" di un punto della conversazione. Tuttavia, più l'unità coinvolta nell'alternanza di codice è lunga, più il "punto di ritorno" alla lingua base è imprevedibile (Auer 1984: 29). Perciò in questi casi diventa incerta la distinzione tra le procedure di "inserzione" e "commutazione di codice" (cfr. gli esempi tratti dall'intervista con VM al $\S$ V.4.2 e seguenti).

63 Per l'individuazione di una stretta connessione tra commutazione di codice e cambiamenti di footings si confronti già Goffman (1981). Inoltre, per analisi della commutazione di codice in narrazioni si vedano Hansen et al. (2010) e Marra \& Holmes (2008). 
gruppo tedescofono altoatesino. ${ }^{64}$ Tali pratiche di contatto "reali" - nel senso di realmente verificatesi nel corso della conversazione - costituiscono atti di posizionamento impliciti, ma comunque significativi dell'io narrante nei confronti di categorie e comportamenti linguistici, rilevanti per sé e/o per la comunità linguistica di arrivo. La loro considerazione consente quindi di investigare ulteriormente il rapporto interattivo tra io narrato, io narrante, personaggi e intervistatore che sta alla base dell'elaborazione di una biografia linguistica.

\subsection{VM e il discorso riportato}

Nella maggior parte delle narrazioni di interazioni ambientate in Alto Adige, VM mette in scena un dialogo in cui lei come personaggio svolge il ruolo di destinataria ratificata o ascoltatrice occasionale della comunicazione (rispettivamente 16 e 13 storie su 37). Pochi sono invece i racconti di dialoghi che iniziano con un atto comunicativo intrapreso dall'io narrato in qualità di parlante (8 su 37). Nella tabella in $7 \mathrm{a}$, le narrazioni di interazioni nell'intervista con VM sono suddivise a seconda del ruolo interazionale svolto dalla donna nella conversazione oggetto del racconto, ovvero "destinataria ratificata", "ascoltatrice occasionale" e "parlante". Inoltre sono indicati il codice - ossia varietà linguistica, di contatto o di interlingua - della conversazione narrata e gli altri interattanti, personaggi del dialogo ${ }^{65}$

I due grafici $7 \mathrm{~b}$ e $7 \mathrm{c}$ presentano gli stessi dati da una prospettiva diversa. In particolare, il diagramma di sinistra (7b) raffigura i codici "input", ovvero le varietà linguistiche a cui l'io narrato è esposto nei racconti di dialoghi. Invece, il grafico di destra (7c) illustra i codici "output", ossia i codici usati attivamente dal personaggio di VM nel ruolo di parlante. Le risorse linguistiche, mezzo di comunicazione nel mondo delle storie, sono raggruppate in quattro categorie principali (cfr. anche $\S$ V.2.2). Queste sono i) i "codici d'arrivo", ulteriormente distinti in tedesco (deu), italiano (ita), dialetto tedesco locale (sdt) e dialetti italiani (dialetti ita), ii) le "varietà di contatto" (come l'alternanza di codice non reciproca o l'enunciazione mistilingue) e di "interlingua", iii) i "codici d'origine" (nel caso di VM, serbo, macedone e russo ${ }^{66}$ ) e iv) le "attività di comunicazione non verbale" (come il comunicare a gesti).

64 La distinzione tra alternanza di codice in funzione di icona e di indice può forse sembrare fin troppo sottile. Tuttavia, mi sembra euristicamente utile dal momento che non è necessariamente vero che il parlare una lingua voglia dire "avere" una caratteristica identitaria. I procedimenti attraverso cui nessi tra varietà linguistiche e caratteristiche identitarie sono istituiti, rappresentati (talvolta, addirittura come inamovibili) e tramandati in interazione sono del resto uno dei principali oggetti di analisi della presente ricerca.

65 Sia qui ricordato che le varietà linguistiche sono indicate con la sigla ISO o l'abbreviazione del codice corrispondente (es. $\mathrm{srp}=\mathrm{serbo}$; $\mathrm{sdt}=$ sudtirolese). Invece, le varietà di contatto comprendono i) l'alternanza di codice situazionale (rus e ita), ii) l'alternanza di codice non reciproca (ita \& eng), iii) la commutazione di codice volontaria ( $s r p \rightarrow$ ita), iv) l'enunciazione mistilingue involontaria (srp/ita) e v) i prestiti o inserzioni (deu (+srp)) (cfr. §V.2.2 per una legenda commentata).

66 Indico il russo tra i codici d'origine in quanto appreso a scuola nel paese di partenza. 
Tabella 7a: Narrazioni di interazione nell'intervista con VM suddivise per il ruolo interazionale svolto dall'io narrato nel mondo della storia.

\begin{tabular}{|l|l|l|}
\hline \multicolumn{2}{|c|}{ TOTALE NARAZIONI VM DESTINATARIA: 16 } \\
\hline parlante & codice & destinatario \\
\hline autista autobus & gesti & VM \\
\hline dottori & deu \& gesti & VM \\
\hline dottore (romano) & deu & VM \\
\hline collega & sdt & VM \\
\hline colleghi & ita \& deu & VM \\
\hline collega & ita & VM \\
\hline insegnante & ita & VM \\
\hline insegnante & ita & VM e classe \\
\hline sorella e nipoti & ita & VM \\
\hline amico & ita & VM \\
\hline collega (ucraina) & rus e ita & VM \\
\hline vicina (croata) & ita/srp & VM \\
\hline marito e compagni (ex-Jugoslavia) & n. i. e srp & VM \\
\hline suora (slovena) & n. i. e srp & VM \\
\hline marito & mac & VM \\
\hline collega (arabo) & interlingua in $n . i$. & VM \\
\hline
\end{tabular}

\begin{tabular}{|l|l|l|}
\hline \multicolumn{3}{|c|}{ TOTALE NARRAZIONI VM ASCOLTATRICE OCCASIONALE: 13 } \\
\hline parlante & codice & destinatario \\
\hline figlio & cercare parole in deu & conoscenti \\
\hline collega & deu \& sdt & collega (d'Africa) \\
\hline sconosciuti & srp & sconosciuti \\
\hline amica (serba) & srp/ita & marito dell'amica \\
\hline amico (serbo) & srp/ita/deu & amici \\
\hline nipote & ita e srp e deu & interlocutori indefiniti \\
\hline cugino & ita & sua figlia \\
\hline prete insegnante & ita \& eng & figlio \\
\hline figlio & eng e ita & insegnante \\
\hline figlio & siciliano & amico \\
\hline marito & gre \& n. i. (atto fallito) & polizia \\
\hline compagni (cinesi) & interlingua in ita & insegnante \\
\hline «zingari» & interlingua in ita & $\begin{array}{l}\text { intervistatore TV (VM } \\
\text { spettatrice) }\end{array}$ \\
\hline
\end{tabular}

\begin{tabular}{|l|l|l|}
\hline \multicolumn{3}{|c|}{ TOTALE NARRAZIONI VM PARLANTE: 8} \\
\hline parlante & codice & destinatario \\
\hline VM & deu & dottore (romano) \\
\hline VM & deu & capo \\
\hline VM & deu & capo \\
\hline VM & deu & collega \\
\hline VM (e sorella) & deu $(\&$ ita) & cameriere \\
\hline VM & ita & carabinieri \\
\hline VM & ita \& eng & impiegato (in U.S.A.) \\
\hline VM & rus & collega (polacco) \\
\hline
\end{tabular}




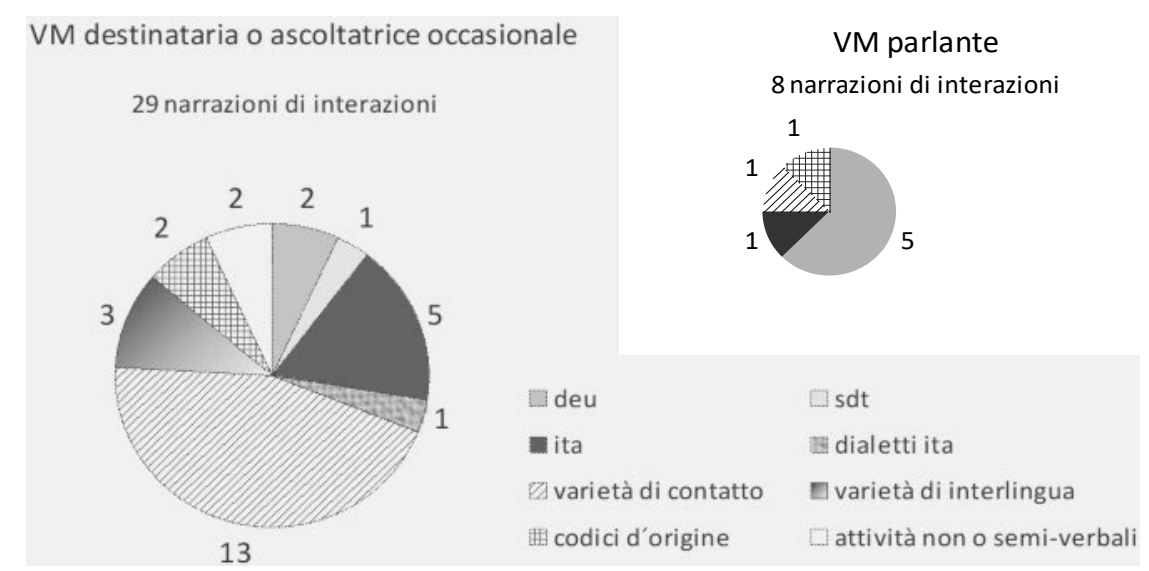

Figure 7b e 7c: Codici a cui l'io narrato è esposto (input) e codici usati attivamente (output) nelle narrazioni di interazioni nell'intervista con VM.

La distribuzione asimmetrica tra i ruoli di destinataria o ascoltatrice occasionale, da un lato, e quello di parlante, dall'altro, che emerge dalla tabella e dai grafici in 7a, b e c, punta al fatto che VM rappresenti la selezione di codice nel contesto d'arrivo come un fenomeno più frequentemente eterodiretto che determinato da lei stessa. Inoltre, sulla base dei grafici si possono riconoscere alcune differenze tra i codici usati attivamente e quelli a cui l'intervistata racconta di essere principalmente esposta. Tali differenze riguardano i) l'utilizzo mai attivo, ma solo passivo delle varietà di contatto, ii) l'uso molto frequente di tedesco da parte di VM parlante, a cui si oppone iii) l'impiego abituale di italiano e dei codici d'origine negli atti linguistici di cui l'io narrato è destinataria o ascoltatrice occasionale.

\subsubsection{L'enunciazione mistilingue come pratica involontaria}

Nelle sue narrazioni di interazioni, ambientate in Alto Adige, a VM viene rivolta la parola o ha occasione di sentir parlare in una molteplicità, in senso sia quantitativo sia qualitativo, di varietà linguistiche, di contatto e di interlingua. A questa si contrappone una relativa omogeneità e soprattutto convenzionalità dei codici di cui il suo personaggio si serve attivamente durante le storie. Così, se l'impiego di varietà di contatto risultava altamente rilevante nel repertorio narrato di VM dall'analisi per contesti (cfr. $\S$ V.3.2), un'indagine per interattanti mostra che tali pratiche e, tra queste, soprattutto l'enunciazione mistilingue involontaria (o commutazione di codice intrafrasale) siano più spesso attribuite dalla donna ad altri personaggi che a se stessa.

Nello specifico, il personaggio di VM è solo in un caso iniziatrice di un dialogo in alternanza di codice non reciproca: si tratta di una conversazione al telefono con un impiegato statunitense, in cui i due interattanti mantengono la propria lingua. Invece, la commutazione di codice intrafrasale è ascritta esclusivamente a amici e 
conoscenti, originari del paese/i di provenienza dell'intervistata. Il fenomeno del mistilinguismo in Alto Adige riguarda quindi, nelle rappresentazioni di VM, soprattutto la commutazione tra il codice d'origine e le due lingue d'arrivo, ovvero serbo e/o italiano e/o tedesco, da parte di altri cittadini stranieri conterranei. La sequenza in 4 è tratta dall'inizio dell'intervista con la donna. In questo momento, oltre a VM e alla ricercatrice, anche un'amica dell'intervistata partecipa alla conversazione.

(es. 4)

\begin{tabular}{|c|c|c|c|c|}
\hline $\mathrm{OR}$ & 1 & VM & ho una vicin[a che] è entrata in italia ha sessanta: - quattro & \\
\hline OR & 2 & $a^{67}$ & [si] & \\
\hline \multirow[t]{5}{*}{ OR } & 3 & VM & sessanta sessanta e qualcosa[ $=$ & \\
\hline & 4 & a & {$[=$ serba? } & $\leftarrow$ \\
\hline & 5 & VM & $(($ pausa $))$ no: croata de zagabria $[=-$ & \\
\hline & 6 & a & [=ua - per me è [uguale - & \\
\hline & 7 & a & ma per me è uguale $[=$ & \\
\hline EV1 & 8 & VM & [=si per noi è uguale: perché quando mi parla & $\leftarrow$ \\
\hline EV1 & 9 & VM & mi parla serbo ((pausa)) & $\leftarrow$ \\
\hline ME\& & 10 & VM & e: mi dic[e:] o ascolta ho ho: - perché mette ogni tanto la parola & \\
\hline \multirow[t]{2}{*}{ OR1 } & 11 & $\mathrm{a}$ & [ah ah] & \\
\hline & 12 & VM & italiana & \\
\hline $\mathrm{CA}$ & 13 & VM & e poi d- dai è lo stesso (h) & \\
\hline $\mathrm{mRE}$ & 14 & VM & sai dice non è: e per me è difficile perché io ho cominciato a & \\
\hline $\mathrm{mRE}$ & 15 & VM & penSA:re in italiano & \\
\hline EV2 & $\begin{array}{l}16 \\
17\end{array}$ & $\begin{array}{l}\text { VM } \\
\text { a }\end{array}$ & $\begin{array}{c}\text { - perché sposata con uno - cresciuto figlio qua ch[e è sposato con } \\
\text { [ah:::] }\end{array}$ & \\
\hline EV2 & 18 & VM & una di qua (h) è tutto: una cosa diversa - & \\
\hline \multirow[t]{3}{*}{ EV3 } & 19 & VM & un momento perdi la identità $[=$ & \\
\hline & 20 & $\mathrm{a}$ & {$[=\mathrm{ah}::$} & \\
\hline & 21 & INT & {$[=\mathrm{mh} \mathrm{mh}$} & $\leftarrow$ \\
\hline V4 & 22 & VM & ((pausa)) perché ti viene male & \\
\hline
\end{tabular}

(VM_Ser_Mer, 00:00-00:37)

Nella narrazione di interazione in 4 , la vicina di casa in qualità di parlante si rivolge al personaggio di VM, destinataria ratificata dell'atto comunicativo, in un codice misto tra italiano e serbo (ita/srp). Il contesto in cui si svolge la vicenda è il quartiere di residenza a Merano. Nella storia, il codice di interazione è nominato deliberatamente da VM e l'evento più riportabile è un fatto di lingua. Perciò considero il racconto una narrazione metalinguistica.

Le tre partecipanti nel mondo dell'interazione cooperano al processo di strutturazione della storia raccontata in 4 . La vicenda riferita da VM acquista infatti ulteriori significati in conseguenza delle domande e dei commenti dell'amica e del fatto di essere narrata vis-a-vis a una ricercatrice non originaria della ex-Jugoslavia. $\mathrm{Nel}$ "piano iniziale" di VM, l'evento più riportabile del racconto (mRE) è verosimilmente la dichiarazione della vicina di casa di avere difficoltà a parlare solo serbo a

67 Con lettere minuscole mi riferisco a persone presenti alla conversazione con cui non ho condotto un'intervista. In questo caso si tratta dell'amica di VM parimenti di origini serbe. 
causa della progressiva adozione dell'italiano come codice per la comunicazione anche interiore (cfr. righe 14-15). Questo fenomeno è valutato come una dolorosa perdita di identità dalla narratrice (EV2, EV3, EV4 alle righe 16-22). Tuttavia, durante la sezione di orientazione della storia (OR), gli interventi dell'amica elicitano indirettamente un'altra pointe nel racconto, ossia una presa di posizione di VM sulla somiglianza dei codici nello spazio linguistico slavo meridionale. L'enunciato valutativo sull'uguaglianza della lingua usata dall'io narrato e dalla vicina ("sì per noi è uguale: perché quando mi parla mi parla serbo"; righe 8-9) costituisce, infatti, una mossa di allineamento della narratrice nei confronti dell'amica. Questa ha senso soprattutto se si considera che, nell'ottica delle due donne, la ricercatrice non è necessariamente al corrente della situazione sociolinguistica di partenza.

Si noti che tale cooperazione tra le interattanti avviene all'inizio dell'intervista, ossia in un momento in cui la distribuzione dei ruoli dei partecipanti nel mondo dell'interazione è tipicamente piuttosto instabile e soggetta a negoziazioni (cfr. Lucius-Hoene \& Deppermann 2004: 200-201). In questo specifico caso, la ricercatrice aveva preso appuntamento solo con VM e, quindi, la donna si sente in diritto di detenere il banco più a lungo e tende a mantenere il ruolo di parlante principale nella conversazione. Tuttavia, anche la sua amica è di origini serbe e si è trasferita in Alto Adige recentemente. Questa dispone dunque delle competenze necessarie per collaborare e, talvolta, competere con VM nel ruolo di esperta nel racconto dell'esperienza linguistica e migratoria, esortato dall'intervistatrice in apertura del colloquio. Gli interventi dell'amica hanno effetti indiretti anche sul seguito dell'interazione. Alla fine dell'intervista, VM citerà per esempio il racconto in 4 in modo ellittico proprio per riutilizzare la presa di posizione a lei elicitata dalla conoscente. Il suo obiettivo sarà infatti quello di argomentare, questa volta esplicitamente, in favore della tesi della mutuale comprensibilità tra le varietà linguistiche parlate in Serbia, Croazia, Bosnia-Erzegovina e Montenegro.

Ai nostri fini è inoltre interessante rilevare che, nel brano in 4, VM prende posizione nei confronti della commutazione di codice interfrasale serbo e italiano (stance object) tramite il predicato affettivo "venire male" (cfr. riga 22). Si noti che il "soggetto" della presa di posizione (stance subject), riferito con il clitico "ti", non coincide né con l'io narrante né con altri personaggi del racconto. ${ }^{68}$ L'impiego del pronome di seconda persona singolare da parte di VM generalizza l'esperienza raccontata, disancorandola dalle specifiche figure del mondo della storia. Al contempo coinvolge le ascoltatrici, allineandole alla posizione affettiva espressa dall'io narrante (cfr. anche esempio 2 al § V.3.3.1 e De Fina \& Georgakopoulou 2012: 75-83).

L'enunciazione mistilingue è similmente descritta da VM in altre due narrazioni di interazione come una pratica involontaria, adottata in modo irriflesso da un'amica nei momenti di rabbia con il marito italofono e da un conoscente nel quartiere. In particolare, in questo ultimo racconto, già citato al § III.2.3.3, si riscontrano prese di posizione valutative ambivalenti della partecipante nei confronti della pratica di contatto in questione (minuti 35:15-36:27). Da un lato, l'inserzione reale di enunciati

68 Sia qui ricordato che il "soggetto" e l' "oggetto" di una presa di posizione interazionale non corrispondono alle funzioni sintattiche di soggetto e oggetto di una frase (cfr. Du Bois 2007). 
mistilingui per citare un discorso altrui svolge infatti una funzione comico-ironica, evidente, tra l'altro, dalle reazioni dell'interlocutrice che ride ("con quello di sono scherzi scherzi e signore: chef chef miei figli: cercano geld (h) - du muss du mir zahlen e: život kosta la vita costa ((riso))"). L'inserzione di materiale alloglotto costituisce così una strategia narrativa utilizzata sapientemente dall'intervistata, in questo come in altri racconti, per raggiungere determinati fini interazionali (cfr. anche i paragrafi successivi). Dall'altro lato, VM qualifica il personaggio nel ruolo di parlante come un "disastro poveraccio" (presa di posizione valutativa), incompetente anche nel parlare la lingua d'origine ("anche serbo lo parla male"). Inoltre paragona, in un enunciato orientativo incassato nell'azione complicante, la lunga durata del suo soggiorno in Alto Adige alla propria ("quanto io sono qua tredici ((pausa)) tredici pieni adesso - cominciano quattordici anni ((pausa)) (h) lui un anno prima di me è venuto"). Tramite il modo di strutturare la storia e le scelte lessicali compiute nel narrarla, l'io narrante trasmette così la sua disapprovazione e si disallinea dal comportamento mistilingue del conoscente, oggetto di scherno tra gli amici del quartiere.

Infine, sia qui menzionato che in una quarta narrazione, ambientata però nel paese d'origine e, quindi, non considerata per le figure in 7, VM racconta di praticare lei stessa, talvolta, enunciazione mistilingue involontaria. La causa di questo fenomeno è additata nell'invecchiamento, mentre la pratica è subito rimproverata dal figlio nel mondo della storia. Perciò, sebbene in alcune sequenze della sua intervista VM metta in risalto l'aspetto comico della commutazione di codice intrafrasale, le sue prese di posizione, sia valutative sia affettive, nei confronti di questa pratica sono ambivalenti, se non negative. L'enunciazione mistilingue, che non è mai descritta come un atto volontario del parlante, è infatti spesso associata a conseguenze sfavorevoli, dal punto di vista psicologico e/o pratico, per colui a cui capita di praticarla.

\subsubsection{Motivi e modi di acquisizione delle varietà di tedesco}

Sulla base delle figure in 7 si rileva un'altra asimmetria tra codici input e codici output nelle narrazioni di interazione di VM. Il numero di volte in cui VM inizia una conversazione in tedesco è infatti nettamente superiore sia rispetto alla quantità di volte in cui è ascoltatrice occasionale o destinataria di un atto linguistico in questo codice, sia rispetto all'ammontare delle occasioni in cui avvia un dialogo in un'altra lingua. Da questa divergenza risulta, a mio avviso, un auto-posizionarsi della partecipante come parlante tedescofona rispetto e nonostante il fatto che il tedesco sia raramente utilizzato dalle persone con e intorno a lei. Inoltre, sebbene la lingua dell'intervista sia prevalentemente l'italiano, VM si serve frequentemente di "inserzioni" e/o "commutazioni di codice" in tedesco per marcare il discorso riportato proprio o altrui nelle storie raccontate. ${ }^{69} \mathrm{Il}$ passaggio da una lingua a un'altra in funzione "citazionale" - ossia per citare un discorso riportato - non è sempre ado-

69 L'alternanza di lingua da parte di VM non sempre coincide con un enunciato di discorso riportato, ma talvolta prosegue oltre i suoi limiti (cfr., tre gli altri, l'esempio 5 più avanti). Perciò non 
perato dalla partecipante per scopi "mimetici", vale a dire con l'obiettivo di riprodurre fedelmente il dialogo narrato (cfr. esempio 5 più avanti e soprattutto esempio 6 al § V.4.2.3). Perciò, altre motivazioni concorrono nel determinare l'alternanza di codice nelle storie di dialoghi dell'intervistata.

Nelle narrazioni di interazioni raccontate da VM, il tedesco è un codice usato in svariati contesti, ad esempio, al lavoro, al bar, all'ospedale (cfr. anche figura 4 al $\S$ V.3.2) e con/da/tra diversi interattanti. Questi ultimi sono frequentemente categorizzati dall'intervistata facendo riferimento al loro ruolo/attività lavorativa nel contesto d'arrivo, ovvero come dottori, colleghi, capo, camerieri. Invece, gli amici e i familiari della narratrice non si servono mai esclusivamente di tedesco nelle narrazioni di interazioni. Tutt'al più sono infatti rappresentati mentre falliscono nel tentativo di comunicare in questo codice. I tipi di attività comunicative che VM porta a compimento in tedesco sono vari, mentre la loro complessità aumenta in relazione alla durata del soggiorno in Alto Adige (cfr. Franceschini 2003 per la rilevazione di un fenomeno analogo nella biografia linguistica di una parlante turcofona in Germania) ${ }^{70}$ Nelle prime narrazioni, il tedesco è infatti impiegato da VM per chiedere informazioni o aiuto, mentre con il proseguire della propria biografia linguistica VM racconta di episodi in cui questa lingua è utilizzata per scherzare, ordinare al bar o per discutere con il capo di argomenti di attualità al lavoro.

A proposito della rappresentazione del miglioramento delle proprie capacità comunicative in tedesco nel corso dell'intervista, significativa è una lunga narrazione multi-episodica ambientata in ospedale. In questa storia, uno o più dottori si rivolgono al personaggio di VM per elicitare un'auto-diagnosi su un proprio problema di salute (minuti 08:57-10:31). Nella narrazione, l'io narrato, che inizialmente è interlocutrice e successivamente assume il ruolo di parlante attiva nella conversazione, diventa con il passare del tempo sempre più abile nelle proprie competenze comunicative. All'inizio VM è infatti in grado di interagire con successo con i medici, che le chiedono di presentare i documenti e di indicare la parte del corpo dove ha dolore, ma solo a gesti e a monosillabi. Alla fine della narrazione, trascorsi due mesi, l'intervistata rappresenta invece se stessa, tornata in ospedale per lo stesso male, mentre scherza con i dottori domandando loro se hanno dimenticato qualcosa dentro al suo corpo dopo l'operazione. È importante notare che la lingua della comunicazione in ospedale è il tedesco, sebbene il dottore principale sia categorizzato come "un italiano un romano". Nonostante le iniziali difficoltà, è VM stessa a selezionare questo codice. La ragione è che, come lei stessa racconta (cfr. sotto), la donna ha competenze esclusivamente in tedesco nei primi anni di residenza in Alto Adige.

La partecipante riporta interazioni in cui le viene rivolta la parola in tedesco standard solo in questa narrazione multi-episodica nel corso dell'intera intervi-

è chiaro se debba essere definita, seguendo la tassonomia di Auer (1984), inserzione o commutazione di codice.

70 Per una proposta di classificazione, mutuata sulla tassonomia di Searle 1979, degli atti linguistici messi in scena in narrazioni si veda De Fina (2003: 93-138). 
sta. ${ }^{71}$ Inoltre, nel citare una domanda dei medici in discorso diretto e nell'introdurre la propria risposta, VM si serve della commutazione di codice: "tutti i dottori tutto personale ((pausa)) <<imitando parlato urlato frate petrović hast du verstanden was ich habe dir gesagt gemacht $>$ (h) ((pausa)) gibst du mir papier $<<$ sorridendo melanconicamente u:nd $>$ und ich - IO HO FATTO - segno ((pausa))" (tr. "tutti i dottori tutto personale ((pausa)) <<imitando parlato urlato frate petrović hai capito quello che ti ho detto fatto $>$ (h) ((pausa)) dammi i documenti $<<$ sorridendo melanconicamente e:> e io - IO HO FATTO - segno ((pausa))"). La lingua base dell'enunciato in discorso riportato concorda con la dichiarazione della narratrice di aver impiegato il tedesco per comunicare con i medici durante la vicenda narrata. Tuttavia, l'appellativo, con cui il personale dell'ospedale si rivolge al personaggio di VM, ovvero "frate petrović", rivela la funzione drammatica (e non sempre mimetica) dell'alternanza di lingua nelle storie della donna. È infatti poco probabile che i dottori abbiano interpellato l'intervistata con questo epiteto nell'interazione reale. $^{72}$

La decisione di apprendere il tedesco come primo codice dopo il trasferimento a Merano è motivata da VM nella sequenza trascritta in 5. Le affermazioni dell'intervistata nella storia in 5 sono auto-iniziate: il passo è infatti preceduto dall'illustrazione dei modi di apprendimento di competenze base in francese durante un soggiorno in Francia. Precedentemente, la partecipante ha inoltre raccontato di aver preso alcune lezioni di italiano da una professoressa di francese in Rep. di Macedonia, di aver abitato per qualche settimana a Vienna e, successivamente, di aver vissuto tre mesi in Francia, ospite di alcuni familiari. Nonostante ciò, l'io narrante non si riferisce né a esperienze migratorie precedenti né a competenze linguistiche anteriormente acquisite nel motivare la propria scelta di apprendimento del tedesco in 5 .

(es. 5)

\begin{tabular}{|c|c|c|c|c|}
\hline & 1 & VM & ((pausa)) tedesco qua ho impara cominciavo prima da par- impararlo & \\
\hline & 2 & VM & perché ((pausa)) mi da: fastidio anche che: - è normale che: un & \\
\hline & 3 & VM & straniero[co]mincia prima italiano - perché $[($ pausa $))]$ pareva & \\
\hline & 4 & INT & {$[\mathrm{mh} \mathrm{mh}]$} & \\
\hline & 5 & VM & come normale & \\
\hline $\mathrm{AB} \&$ & 6 & VM & non posso mai f- dimenticare la faccia da un collega quando è & \\
\hline EM & 7 & VM & arrivato un ragazzo di africa che parlava - tedesco PERfetto: & $\leftarrow$ \\
\hline & 8 & VM & {$[-\mathrm{m}] \mathrm{a}$} & \\
\hline & 9 & INT & {$[\mathrm{mh} \mathrm{mh}]$} & \\
\hline
\end{tabular}

71 In un altro racconto il personaggio di VM è invece destinataria di un atto linguistico in dialetto tedesco locale (cfr. sempre sotto in questo paragrafo).

72 L'appellativo "frate" è registrato nel dizionario Duden online come un prestito dall'italiano con frequenza minima nel tedesco attuale, mentre non è attestato nel Variantenwörterbuch des Deutschen (Ammon et al. 2004). Inoltre, il lemma "frate" occorre tre volte nel Korpus Südtirol, ma è usato in un solo articolo del giornale Dolomiten per riferirsi specificamente a un prete missionario (per consultare questo corpus si veda l'indirizzo $<$ http:/www.korpus-suedtirol.it/ Pages/suche_in_den_korpora.aspx $>$ (18.10.2018)). Il cognome dell'intervistata nella sequenza citata è stato sostituito con lo pseudonimo "petrović". 


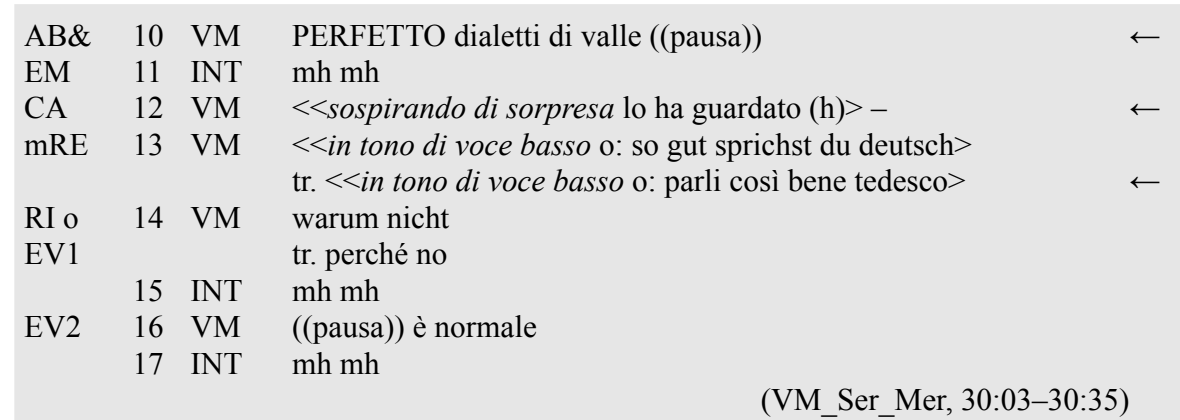

Ho codificato l'interazione raccontata in 5 come condotta alternativamente in tedesco e dialetto tedesco locale (deu \& sdt). Entrambi i codici sono infatti menzionati dall'intervistata. Il contesto, sfondo della storia, è il lavoro, mentre il personaggio di VM ha il ruolo di ascoltatrice occasionale. Come già accennato precedentemente, per la presente analisi non ho distinto i ruoli di "ascoltatore ratificato non indirizzato" e "spettatore occasionale" di un enunciato raccontato (cfr. Goffman 1981). Si osservi tuttavia che, pur non essendo la destinataria ratificata dell'atto comunicativo del parlante, VM ha più possibilità di intervenire nella conversazione riportata in 5 di quanto non avrebbe una spettatrice o origliatrice accidentale.

Nella sequenza in 5, VM esprime le ragioni della propria decisione di imparare il tedesco come prima lingua a Merano. Subito dopo, riporta una narrazione di interazione in funzione argomentativa. Lo scopo del racconto metalinguistico è infatti quello di supportare la tesi della presenza di pregiudizi e stereotipi sulle scelte e competenze linguistiche dei cittadini stranieri in Alto Adige. In particolare, VM racconta la storia in 5 per esemplificare il nesso tra lingua tedesca e autoctonicità quale, dal suo punto di vista, è spesso presupposto dalla popolazione locale nella regione di arrivo. La narratrice mette in discussione questa correlazione, riferendo della propria decisione di acquisire primariamente il tedesco dopo migrazione in Alto Adige. Nel fare ciò, l'intervistata rappresenta sé stessa come personaggio agente e figura morale nel mondo dell'interazione e ambiguamente in quello della storia. ${ }^{73}$ Entrando nei dettagli, VM trasmette indignazione morale e consegue un allineamento positivo con l'intervistatrice (cfr. i segnali di feedback di quest'ultima) attraverso il dispiegamento di una serie di "dispositivi di rappresentazione" (performance devices) a livello sia di contenuto sia di forma (cfr. Relaño-Pastor \& De Fina 2005: 41-44 e anche Günthner 1995, Bamberg 1997). Da un lato, la categorizzazione di uno dei personaggi come "ragazzo d'africa" mette in risalto le implicazioni razziste del nesso contestato (cfr. riga 7). In questo modo, VM chiama in supporto della sua tesi valori unanimemente validi e, dunque, si suppone, condivisi tra intervistatrice e intervistata. Dall'altro, VM coinvolge l'ascoltatrice e guadagna la sua approvazione tramite l'uso del discorso diretto e di un linguaggio fortemente

73 Sulla riallocazione sociale e morale portata a termine parimenti in narrazioni di conflitti linguistici, ma da donne messicane emigrate negli Stati Uniti si veda Relaño-Pastor \& De Fina (2005). 
espressivo. In particolare, l'espressività è raggiunta dalla narratrice tramite cambi repentini nella prosodia e qualità della voce (es. aumentando il volume della voce e imitando un sospiro di sorpresa), costruzioni sintattiche enfatiche e iperboliche ("non posso mai"), ripetizioni ("un tedesco perfetto, ma perfetto dialetti di valle"), metonimie per l'espressione di stati d'animo ("la faccia" per riferirsi allo sbigottimento del collega). ${ }^{74}$ Anche la procrastinazione dell'evento più riportabile tramite l'inserzione di un evento non strettamente necessario nella sequenza causale ("lo ha guardato") aumenta la suspense e, quindi, le probabilità di riuscita del racconto. ${ }^{75}$

L'evento più riportabile, ovvero l'affermazione di sorpresa del collega alla riga 13, è inoltre messo in scena drammaticamente da VM tramite l'uso del discorso diretto e della commutazione di codice che prosegue oltre ai confini dell'enunciato quotato fino alla riga 14. Adoperando una tecnica comune nel discorso di persone multilingui (cfr. Auer 1984: 62-67, Lüdi \& Py 1986/2003: 154-155, Sebba \& Wootton 1998: 282-283), l'intervistata passa dall'italiano al tedesco per citare un'altra voce in un dialogo narrato. La selezione del tedesco è in questo caso "consequenziale" (Hansen et al. 2010: 61): il "parlare tedesco" è infatti un'attività che consegue, nella rappresentazione veicolata dalla donna, all'appartenenza a una categoria saliente a livello locale, ovvero all'essere membri del gruppo tedescofono in Alto Adige. ${ }^{76}$ L'alternanza di codice svolge così la funzione di "indice". In altre parole, è strettamente connessa con l'identità del locutore nella comunità linguistica d'arrivo (ossia con il suo essere appartenente al gruppo tedescofono), mentre attribuisce, in modo velato, soprattutto ai membri di questo gruppo linguistico il "razzismo" contestato. L'uso dell'alternanza di lingua nel riportare il discorso in 5 consente a VM di formulare la suddetta recriminazione in modo implicito. Così, la donna prende una posizione senza esserne direttamente responsabile.

Il mantenimento del tedesco nell'enunciato successivo ("warum nicht", tr. "perché no"; riga 14) crea d'altra parte, in modo più o meno voluto, ambiguità rispetto alla collocazione di questa proposizione nel mondo della storia o dell'interazione e, in connessione con ciò, rispetto a quale ruolo, attivo o non attivo, svolga il personaggio di VM durante l'episodio. Non è infatti chiaro se questo enunciato costituisca la reazione/risposta dell'io narrato alla domanda retorica del collega antagonista e, quindi, sia la risoluzione del racconto (RI). In alternativa, potrebbe, invece, essere un commento dell'io narrante espresso dalla prospettiva presente e,

74 Per una panoramica delle strategie di "organizzazione vocale" solitamente impiegate in una intervista biografica e, in particolare, nella riproduzione di dialoghi, si veda Lucius-Hoene \& Deppermann (2004: 228-236 e 240-245).

75 Si confronti a questo riguardo anche Labov (2013: 29). Il ricercatore interpreta infatti l'inserzione di proposizioni strumentali nella catena causale di eventi in un racconto come uno strumento del narratore per direzionare l'assegnazione di responsabilità in favore o sfavore di determinati personaggi.

76 Si confronti il §II.1.1 per una discussione sulle possibili ragioni di natura storica, ma anche amministrativa, scolastico-educativa e demografico-abitativa della forza di identificazione esercitata dai tre gruppi linguistici locali in Alto Adige. Si ricordi comunque che tali categorizzazioni non sono assolutamente vincolanti $\mathrm{e}$, anzi, sono sempre più spesso contestate per lo meno a livello individuale. 
quindi, rappresentare la prima parte della sezione valutativa della storia (EV1). In questo modo, VM riesce a posizionarsi come figura morale, pur lasciando indeterminato il suo ruolo di personaggio agente o meno nel risolvere il conflitto di lingua riferito. Se voluta, questa ambiguità punta inoltre ancora all'uso non sempre mimetico, ma talvolta (anche) strategico della commutazione di codice per citare discorsi o pensieri propri o altrui da parte dell'intervistata.

Infine, si noti che, nella sequenza in 5 , la qualifica di "perfetto" si riferisce sia al modo di parlare tedesco (riga 7) sia ai dialetti di valle (riga 10). L'io narrante sembra, quindi, prendere una posizione valutativa positiva nei confronti di competenze nelle diverse varietà, anche locali, di questo codice. Tuttavia, il dialetto, o meglio i dialetti locali, sono raramente tema di conversazione nell'intervista con VM e non occupano una posizione centrale nel suo repertorio narrato. Queste varietà costituiscono, infatti, codice di interazione in solo un'altra narrazione, ambientata in contesto lavorativo ed elicitata da una domanda dell'intervistatrice ("INT: ma lei lo sa anche i: il dialetto di qui"). Dapprima VM risponde di avere alcune competenze in dialetto locale e ripara la formulazione al singolare della ricercatrice, sottolineandone la grande varietà di forme a livello diatopico ("VM: sì ma non so di quale valle"; cfr. per strategie di riparazione analoghe anche Schiffrin 1996: 182). Subito dopo, l'intervistata racconta la storia di un'interazione fallita sul lavoro. In questa sequenza, la donna riprende e, al contempo, tramanda il topos della proverbiale incomprensibilità delle varietà locali di tedesco, in particolare quelle della Val Passiria ("VM: perché (h) - da noi: [...] sono tanti da passeiertal"; minuti 51:53-52:44). In aggiunta, VM inserisce nel racconto alcune espressioni in dialetto tedesco locale in discorso riportato. Queste inserzioni sono, da un lato, funzionali a esemplificare iconicamente peculiarità lessicali della varietà linguistica in questione ("VM: due tre anni fa la collega una: $>$ mi ha detto $<$ da gibst du mir KANDEL [...] prima associazio- ea: che mi è arrivato è che cerca la $<<$ in tedesco kerzen kerzen $>$ candel - in $<<$ in inglese english $>0$ : - qualcosa cosi", tr. " $>$ mi ha detto $<$ da mi dai la bacinella $[\ldots]$ prima associazio- ea: che mi è arrivato è che cerca la candela candela candel - in inglese o: - qualcosa così"). ${ }^{77}$ Dall'altro lato, l'intervistata riproduce, oltre al termine "kandel", anche una forma verbale in dialetto tedesco locale "isch" nel citare la successiva risposta del proprio personaggio ("VM: cosa ti serve ((pausa)) KANDEL $-<<$ imitando parlato urlato was isch das $>$ ", tr. "cosa ti serve ((pausa)) bacinella $-<<$ imitando parlato urlato che cosa è questo $>$ "). Tramite questa appropriazione di forme dialettali, l'io narrante sembra di nuovo, indirettamente, contestare il nesso tra determinate competenze linguistiche e categorie identitarie, da lei rappresentato più volte come iconicizzato (o naturalizzato) nella comunità linguistica di arrivo (cfr. anche Bucholtz \& Hall 2005: 590-591 per esempi analoghi).

77 La traduzione di "kandel" come "bacinella" o "secchio di plastica", mi è stata fornita dall'intervistata. La voce non è riportata nel Variantenwörterbuch des Deutschen di Ammon et al. (2004). 


\subsubsection{La diffusione dell'italiano e dei codici d'origine}

Un'ultima considerazione riguardo alla tabella e alle figure in 7 concerne l'uso dell'italiano e dei codici d'origine - ossia serbo, macedone e russo - in relazione al ruolo interazionale svolto dall'io narrato nei dialoghi raccontati. Nella maggior parte delle narrazioni di interazioni dell'intervista, a VM è rivolta la parola in italiano o in una combinazione di codici di cui fa parte l'italiano. L'italiano è parlato da (e più raramente con) una grande varietà di attori locali e non locali, identificati sia tramite il loro ruolo/attività lavorativa nella società altoatesina (es. carabinieri, insegnanti, camerieri), sia tramite la loro relazione personale con l'intervistata (es. marito, sorella, colleghi, amici). Del resto, la maggior parte dei membri della famiglia nucleare e allargata di VM in Alto Adige ha competenze esclusivamente in italiano tra i codici d'arrivo. In modo analogo, l'io narrato è frequentemente destinataria o ascoltatrice occasionale di conversazioni in serbo e macedone $\mathrm{o}$ in varietà di contatto che coinvolgono questi codici. Tuttavia, ad eccezione del russo usato in Alto Adige come lingua franca per comunicare con altri migranti dall'Est Europa, VM non si serve mai attivamente dei codici di partenza nelle sue storie.

Nella sequenza in 6, già citata nel primo capitolo del presente volume (cfr. $\S$ I.2.1), VM racconta in modo scherzoso ed espressivo - usando il discorso diretto e modulando il volume e la qualità della voce - delle difficoltà di un suo insegnante di italiano a Merano nel gestire una classe con otto persone provenienti dalla "ex-Jugoslavia". Il codice dell'interazione tra i compagni di corso non è chiaramente menzionato dalla partecipante che però fa riferimento alla loro origine comune nella sezione orientativa della storia (cfr. righe 1-2). Ho categorizzato, quindi, il primo dialogo riportato in 6 come condotto alternativamente in codici non identificati e in serbo (n.i. e srp). L'autore e il responsabile dell'ultimo atto linguistico citato, che costituisce l'evento più riportabile della vicenda $(\mathrm{mRE})$, è invece l'insegnante. Questo si rivolge alla classe (VM inclusa) in italiano. La lingua di insegnamento e di conduzione delle lezioni non è il tema della storia in 6 , ma è specificata solo in seguito, in risposta a una domanda della ricercatrice, trascritta in chiusura del brano alle righe 19-25. Il racconto non costituisce quindi una narrazione metalinguistica. Non ho ulteriormente suddiviso la serie di cinque azioni complicanti che forma il nucleo centrale della narrazione, ovvero il dialogo tra i compagni di corso alle righe 9-13, per meglio rappresentare la sovrapposizione dei turni di intervistata e intervistatrice e, quindi, le reazioni divertite di questa ultima alla messa in scena della vicenda da parte di VM.

(es. 6)

$\begin{array}{llll}\text { OR } & 1 & \text { VM } & \text { poveraccio quel professore perché a una classe eravamo }(\mathrm{hh})-\text { otto } \\ \text { OR } & 2 & \text { VM } & \text { noi da ex jugoslavia }[=(\text { (riso })] \\ & 3 & \text { INT } & \\ \text { EV } & 4 & \text { VM } & <<\text { ridendo che sai cosa si }> \\ \text { ME } & 5 & \text { VM } & {[- \text { mio marito }<<\text { bisbigliando in tono basso come si dice cosa }]} \\ & 6 & \text { INT } & {[((\text { riso }))]}\end{array}$




\begin{tabular}{|c|c|c|c|}
\hline \multirow[t]{2}{*}{ ME } & 7 & VM & [cosa mi ha chiesto $>$ ] \\
\hline & 8 & INT & {$[(($ riso $))]$} \\
\hline \multirow[t]{2}{*}{$\mathrm{CA}$} & 9 & VM & - non ti dico $[-<<$ in tono basso dimmi cosa mi ha chiesto $>]$ \\
\hline & 10 & INT & {$[(($ riso $))]$} \\
\hline \multirow[t]{2}{*}{$\mathrm{CA}$} & 11 & VM & $<<$ ridendo e l'altro hai scritto $[(($ riso $))]-$ haus $=$ gabe $\left[->_{\mathrm{s}}\right]: \mathrm{i}$ \\
\hline & 12 & INT & {$[(($ riso $))]$} \\
\hline \multirow[t]{2}{*}{$\mathrm{CA}$} & 13 & VM & si mio figlio mi ha detto $<<<$ ridendo scrivilo $[($ (riso) $)]$ \\
\hline & 14 & INT & {$[(($ riso $))]$} \\
\hline \multirow[t]{2}{*}{$\mathrm{mRE}$} & 15 & VM & - dopo ha detto $>$ E:: voi[da ex jugoslavia $<<$ ridendo vi metto \\
\hline & 16 & INT & {$[(($ riso $))$} \\
\hline \multirow[t]{11}{*}{$\mathrm{mRE}$} & 17 & VM & TUTTI così che non ti potete neanche guardare> ((riso))] \\
\hline & 18 & INT & $\begin{array}{c}((\text { riso }))] \\
\text { (VM Ser Mer, 42:15-42:42) }\end{array}$ \\
\hline & & & [42 secondi dopo] \\
\hline & 19 & INT & era un corso di tedesco questo si quello che: $\mathrm{mh}::$ ((pausa)) ha \\
\hline & 20 & INT & fatto qua in qu- che: raccontava adesso era un corso di tedesco \\
\hline & 21 & VM & italiano $[=$ \\
\hline & 22 & INT & [=italiano \\
\hline & 23 & VM & - italiano $[=$ \\
\hline & 24 & INT & {$[=\mathrm{mh} \mathrm{mh}$} \\
\hline & 25 & VM & - italiano italiano ((pausa)) \\
\hline & & & (VM_Ser_Mer, 43:24-43:40) \\
\hline
\end{tabular}

Il brano in 6 è rilevante per le mie domande di ricerca sotto diversi punti di vista. Considerando il suo contenuto "presentazionale", questa narrazione con argomento extra-linguistico permette in primo luogo di individuare una situazione comunicativa, spontaneamente descritta dall'intervistata, di impiego dei codici d'origine in contesto migratorio. Inoltre, nella sequenza in 6 , la partecipante prende di nuovo implicitamente posizione rispetto al dibattito sulla mutuale comprensibilità delle varietà linguistiche parlate nei paesi successori alla Jugoslavia (cfr. anche l'esempio 4 al § V.4.2.1). È infatti la comunicazione subordinata tra partecipanti ratificati provenienti da queste regioni ("byplay" in Goffman 1981: 134), probabilmente facilitata dal fatto di parlare un codice mutualmente comprensibile come L1, a recare disturbo e a provocare la minaccia dell'insegnante.

Oltre a ciò, la sequenza offre un ulteriore esempio di inserzione dal tedesco da parte di VM per citare un discorso riportato. Nel mettere in scena il dialogo tra studenti, VM riporta infatti, alla riga 11, una delle voci in tedesco ("haus=gabe", probabilmente una forma contratta di Hausaufgabe, tr. "compito a casa"). Dal momento che non ho a disposizione ulteriori dati etnografici sugli usi linguistici della partecipante, per esempio, in conversazioni quotidiane, posso qui solo ipotizzare le motivazioni del cambio di lingua da parte di VM nel brano in 6. In particolare, non si può escludere che l'adozione del termine in tedesco alla riga 11 sia determinata da un momentaneo vuoto lessicale della narratrice, che non si ricorda la parola corrispettiva in italiano (si rammenti che VM apprende il tedesco come prima lingua dopo il trasferimento in provincia di Bolzano). A diminuire la probabilità di questa spiegazione c'è però il fatto che l'espressione "haus=gabe" in 6 non sia né segnalata esplicitamente da indicatori di correzione, né sia preceduta da esitazioni da parte 
dell'io narrante. La presenza di una breve pausa prima dell'inserzione mi sembra infatti tutt'al più da imputare al riprendere fiato di VM dopo la risata. Inoltre, il marito e il figlio di VM, personaggi della storia, non conoscono il tedesco. Così è abbastanza verosimile che la lingua, in cui è effettivamente avvenuta l'interazione raccontata in 6, sia stata il serbo, eventualmente frammisto con l'italiano. In considerazione di ciò, il passaggio al tedesco alla riga 11 potrebbe costituire un'inserzione (semi-)intenzionale della partecipante. Questa avrebbe da un lato la funzione, "correlata al discorso", di costruire un contrasto con gli altri enunciati riportati in italiano nel cotesto (cfr. Auer 1984). Dall'altro, la scelta di questo specifico codice tra quelli conosciuti dalla narratrice è verosimilmente "correlata ai partecipanti dell'interazione" e funzionale al coinvolgimento dell'interlocutrice che, infatti, conosce il tedesco, ma non il serbo (cfr. ibidem e anche Guerini 2006b).

Se l'interpretazione è giusta, è rilevante notare che VM preferisca, nella sequenza in 6 , non rinunciare a sfruttare strategicamente gli effetti drammatici e di coinvolgimento dell'inserzione di parole in un'altra lingua, sebbene questa alternanza implichi il venire meno a una riproduzione fedele del dialogo narrato. L'inosservanza del vincolo di mimeticità nella selezione del codice di un enunciato riportato non è un fenomeno per nulla inconsueto in conversazione (cfr., per esempio, Auer 1984: 62-67, Sebba \& Wootton 1998). Tuttavia, può comportare dei rischi per la parlante, come, per esempio, quello di suscitare un equivoco e, così, in parte, di "perdere la faccia" di fronte all'interlocutrice. A questo riguardo, proprio nel brano in 6 si verifica un'incomprensione tra narratrice e ricercatrice. Come dimostrano le domande di chiarimento di quest'ultima alle righe 19-25, l'intervistatrice non ha infatti inteso in quale lingua si svolgessero le lezioni al corso di lingua. Il rischio incorso da VM nel mettere in scena un discorso riportato in un codice che non è quello dell'interazione "reale" è però compensato se si considera la funzione generale che inserzioni e commutazioni in tedesco hanno nella biografia linguistica della donna. Il loro uso (di)mostra infatti le competenze dell'intervistata nella lingua in questione e permette, quindi, alla partecipante - talvolta più, talvolta meno, consapevolmente - di negoziare una rappresentazione di sé vis-à-vis con la ricercatrice come parlante tedescofona nonostante la propria origine non locale.

\subsubsection{Una parlante tedescofona nonostante il contesto sfavorevole}

Dalla discussione nei paragrafi precedenti possono essere tratte alcune osservazioni generali riguardo alla rappresentazione che VM dà della propria identità linguistica così come riguardo alle sue prese di posizione valutative, affettive ed epistemiche nei confronti degli usi linguistici propri e altrui nel contesto d'arrivo. In primo luogo, l'intervistata si rappresenta spesso nei dialoghi raccontati come destinataria indirizzata o ascoltatrice occasionale invece che parlante, iniziatrice di un dialogo. Da ciò deriva un frequente scollamento tra i ruoli di animatrice, autrice e responsabile delle affermazioni, spesso metalinguistiche, citate nelle sue narrazioni. Lo sfruttamento della possibilità di dislocazione di parole ad altri personaggi nel modo della storia libera l'io narrante dalle responsabilità verso quanto detto, in partico- 
lare, verso i giudizi e talvolta gli stereotipi linguistici riportati. Inoltre, alla dislocazione della responsabilità di parole si collega anche una tendenza alla dislocazione della responsabilità di azioni. Così, VM rappresenta la selezione e l'alternanza di codice per situazione e interlocutore nel paese d'arrivo come un fenomeno più frequentemente eterodiretto che autodeterminato. Infatti, il suo personaggio è prevalentemente destinataria o spettatrice di atti linguistici in codici pre-selezionati da altri, piuttosto che agente parlante determinante la lingua della conversazione. ${ }^{78}$

Nello stesso tempo, però, le sezioni valutative delle narrazioni e l'uso strategico di dispositivi di rappresentazione consentono all'io narrante di attribuirsi nel mondo dell'interazione caratteristiche identitarie positive e di portare a termine una propria riallocazione sociale e morale al momento dell'intervista. Infatti VM, da un lato, riesce a costruire nel corso del colloquio una propria identità interazionale come intrattenitrice esperta in grado di comunicare con successo con l'intervistatrice. In particolare, le sue abilità di narratrice risultano, per esempio, evidenti nei brani 1 e 6 (cfr. rispettivamente ai $\S$ V.3.2.1 e V.4.2.3). In queste sequenze, la donna raggiunge comicità e impatto emozionale sull'interlocutrice, tra l'altro, i) tramite il "design", talvolta ellittico, della storia, ii) tramite attività auto-riflessive meta- o extra-narrative espresse dalla prospettiva presente, così come iii) attraverso modulazioni prosodiche e variazioni nella qualità della voce (cfr. anche Deppermann 2013). Dall'altro lato, nel corso del colloquio, la partecipante riesce a posizionare il proprio io attuale, attraverso la rappresentazione del proprio io narrato, come parlante tedescofona nonostante un input linguistico sfavorevole. Infatti quest'ultimo è prevalentemente in italiano $\mathrm{o}$ in pratiche mistilingui. A questo riguardo, si noti che la donna mette spesso in scena il proprio personaggio, specie nei primi anni di residenza in Alto Adige, in situazioni semi-tragiche o disperate. Tuttavia, l'io narrante assume frequentemente un "contegno" (Haltung) ironico verso il proprio sé di allora, distanziandosi da questo e rappresentando il proprio io attuale come cambiato. Questi atti di posizionamento rispetto agli eventi passati raccontati contribuiscono alla riallocazione sociale dell'intervistata come persona che è divenuta padrona della propria esperienza migratoria e ha superato le difficoltà connesse con questa.

In secondo luogo, il personaggio di VM nel ruolo di parlante si serve prevalentemente della lingua tedesca, mentre in qualità di ascoltatrice è raramente esposta a questo codice. La singolarità della propria decisione di apprendere il tedesco come prima lingua dopo il trasferimento in Alto Adige è messa in scena dagli atti di posizionamento dei personaggi tra loro nel racconto in 5, discusso al § V.4.2.2. In questa sequenza, VM ottiene il supporto della ricercatrice e si disallinea con i sostenitori individui singoli fino a gruppi di opinione pubblica locale, assenti al momento dell'intervista, ma probabilmente evocati dal formato mediale di questa - del nesso tra competenze in dialetto tedesco locale e autoctonicità. Da ciò segue che la riallocazione portata a termine dalla partecipante per se stessa nel corso della sua biografia linguistica è sia sociale sia morale. Da un lato, VM mette infatti in discussione le caratteristiche tipiche dell'identità di "immigrata" e di "apprendente una lingua

78 Per un esempio ancora più accentuato di questa tendenza, si veda l'analisi dell'intervista con $\mathrm{BV}$ al $\S$ V.4.4 e seguenti. 
straniera" nella società di arrivo. Dall'altro, dimostra l'insostenibilità etica di pregiudizi linguistici (rappresentati come) diffusi a livello di discorso in provincia di Bolzano.

L'alternanza di codice è uno dei principali dispositivi di rappresentazione che, a livello formale, contribuisce alla riuscita dell'auto-posizionamento della partecipante come locutrice tedescofona competente nel contesto d'arrivo. Durante la conversazione, VM usa frequentemente inserzioni e commutazioni in tedesco in funzione "citazionale" (ossia per citare un discorso riportato), ma non necessariamente per scopi "mimetici" (vale a dire con l'obiettivo di riprodurre fedelmente il dialogo narrato). Queste pratiche, oltre a contribuire alla drammatizzazione della vicenda narrata e al coinvolgimento dell'ascoltatrice, hanno la funzione di (di)mostrare le competenze dell'io narrante nella lingua in questione. D'altro canto, dato questo sfondo, potrebbe sembrare singolare che VM attribuisca l'uso di varietà di contatto quasi esclusivamente ad altri personaggi nelle sue narrazioni, pur praticandole lei stessa durante l'intervista. ${ }^{79}$ La commutazione di codice, di cui VM racconta, è tuttavia enunciazione mistilingue involontaria. Invece, le proprie inserzioni o commutazioni di codice interfrasali sono solitamente strategiche, ovvero funzionali, tra l'altro, alla ricostruzione dell'identità linguistica per lei più saliente al momento di raccontare la propria biografia linguistica.

Infine, le rappresentazioni e prese di posizione rispetto alla distribuzione dei codici per tipo di interattanti nell'intervista con VM sono difficili da generalizzare. L'enunciazione mistilingue è attribuita soprattutto a persone non locali, provenienti dalle stesse regioni della partecipante. Tali pratiche sono rappresentate come diffuse nel proprio reticolo sociale. Tuttavia sono valutate come tendenzialmente svantaggiose per i loro utilizzatori. L'italiano è parlato da numerosi attori, indipendentemente dal grado di formalità della situazione comunicativa e di familiarità/ estraneità dell'interlocutore. La selezione di questo codice è inoltre talvolta associata in modo indissolubile alla comunicazione con certe figure istituzionali in determinati contesti (cfr. i carabinieri al posto di blocco nell'esempio 1 al $\S$ V.3.2.1). Sebbene impiegato più raramente dell'italiano, anche il tedesco è parlato con persone locali, tedescofoni, ma anche italofoni (cfr. il dottore nella narrazione in ospedale), e con locutori non locali. Il tedesco non è però usato nella cerchia familiare $\mathrm{e}$ costituisce frequentemente lingua di interazione con/di personaggi identificati tramite il loro ruolo/attività lavorativa nel contesto di arrivo. Così, il tedesco sembra rappresentare, malgrado tutto, una "lingua della lontananza" nello spazio comunicativo narrato della partecipante (cfr. Krefeld 2004: 19-36), ovvero una varietà linguistica (rappresentata come) talvolta usata nel proprio reticolo sociale, ma con persone socialmente distanti. Infine, i dialetti tedeschi locali, pur valutati positivamente dall'intervistata, non occupano una posizione centrale nel suo repertorio narrato.

79 Per una panoramica dei fenomeni di contatto riscontrati nell'intervista con VM si veda il $\S$ V.2.4.1. 


\subsection{DK e il discorso riportato}

La tabella in 8a mostra quali ruoli interazionali svolga il personaggio di DK nei dialoghi raccontati nel corso della sua biografia linguistica. Per ogni narrazione sono indicati il codice di comunicazione e il tipo di interattanti. Le narrazioni di interazione considerate sono solo quelle ambientate in Alto Adige. Tuttavia, si noti che l'uso di Internet può consentire ai personaggi di comunicare dall'attuale luogo

Tabella 8a: Narrazioni di interazione nell'intervista con DK suddivise per il ruolo interazionale svolto dall'io narrato nel mondo della storia.

\begin{tabular}{|l|l|l|}
\hline \multicolumn{2}{|c|}{ TOTALE NARRAZIONI DK DESTINATARIA: 6 } \\
\hline parlante & codice & destinatario \\
\hline padre & aln & DK \\
\hline attori comici & aln & DK e padre \\
\hline genitori & aln e srp & DK \\
\hline padre & aln $(+$ srp $)$ & DK \\
\hline ragazzo & deu & DK \\
\hline amica (e bambinaia) & por \& ita & DK e figli della bambinaia \\
\hline
\end{tabular}

\begin{tabular}{|l|l|l|}
\hline \multicolumn{3}{|c|}{ TOTALE NARRAZIONI DK ASCOLTATRICE OCCASIONALE: 10 } \\
\hline parlante & codice & destinatario \\
\hline fratello & aln & amici (in Kosovo) \\
\hline madre & srp \& slo & zia (slovacca) \\
\hline conoscenti & sdt & bambini \\
\hline ragazzi (locali) & hochdeu con grammatica sdt & insegnanti e compagni \\
\hline professore di letteratura & hochdeu & studenti \\
\hline bambini & deu e ita & bambini \\
\hline conoscenti italiani & deu con intonazione ita & interlocutori indefiniti \\
\hline bambini (stranieri) & ita & bambini (stranieri) \\
\hline compagni univ. (italiani) & ita & professore e compagni \\
\hline amica (bilingue) & ita "tritato" e ita/calabrese & amici \\
\hline
\end{tabular}

\begin{tabular}{|l|l|l|}
\hline \multicolumn{2}{|l|}{ TOTALE NARRAZIONI DK PARLANTE: 20 } \\
\hline parlante & codice & destinatario \\
\hline DK & aln & genitori \\
\hline DK & aln & famiglia (in Kosovo) \\
\hline DK & aln (+deu) & genitori \\
\hline DK & aln e eng & cugina (in Kosovo) \\
\hline DK & n. i. (+aln) & amici \\
\hline DK & aln/deu/ita & conoscenti (albanofoni) \\
\hline DK & srp/slo & cugina \\
\hline DK & sdt & sorelle e fratelli \\
\hline DK & sdt & sorelle e fratelli \\
\hline DK & sdt e hochdeu & compagni univ. \\
\hline DK & sdt e ita e sdt/ita & compagni (anno in L2) \\
\hline DK & hochdeu & compagni univ. (di Germania) \\
\hline DK & hochdeu & amici (di Germania) e ragazzo \\
\hline DK & hochdeu & compagni univ. (locali) \\
\hline DK & hochdeu con accento schweizerdeu & amici \\
\hline DK & ita e deu & futuro capo \\
\hline DK & ita e deu & esaminatore \\
\hline DK & ita & compagni (anno in L2) \\
\hline DK & por base & bambinaia e suoi figli \\
\hline DK & eng & cliente (in Cina) \\
\hline
\end{tabular}


di residenza con persone che si trovano in altri paesi, ad esempio, nel presente caso, in Kosovo. Nei grafici $8 \mathrm{~b}$ e $8 \mathrm{c}$, le varietà linguistiche, mezzo di comunicazione nelle storie di dialoghi, sono invece suddivise a seconda del loro costituire i) codici input, ossia codici a cui l'io narrato è esposto come destinataria indirizzata o ascoltatrice occasionale, oppure del loro essere (anche) ii) codici output, vale a dire codici di cui il personaggio dell'intervistata si serve attivamente, dando avvio a un'interazione nel mondo della storia.

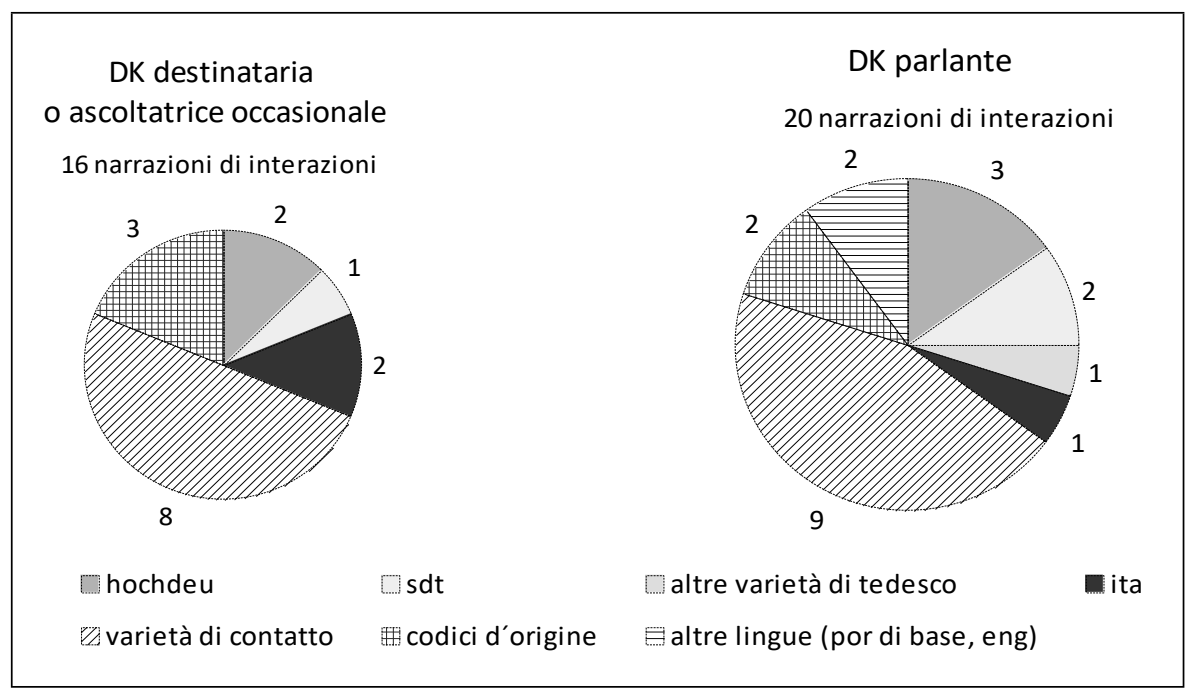

Figure 8b e 8c: Codici a cui l'io narrato è esposto (input) e codici usati attivamente (output) nelle narrazioni di interazioni nell'intervista con DK.

A differenza dell'intervista con VM, la distribuzione dei ruoli di io narrato parlante e io narrato ascoltatrice nei racconti di interazioni di DK è tendenzialmente bilanciata. Anzi il numero di narrazioni, in cui il personaggio di DK svolge il ruolo di parlante, iniziatrice del dialogo, è maggiore rispetto a quello delle storie, in cui la donna rappresenta se stessa come destinataria ratificata o ascoltatrice occasionale della conversazione (rispettivamente venti, dieci e sei racconti). Inoltre, anche la proporzione di atti linguistici condotti da DK parlante ne(le varietà de) i quattro codici "centrali" nel suo repertorio d'arrivo - ovvero albanese, dialetto tedesco locale, tedesco standard e italiano - è piuttosto equilibrata. Si noti tuttavia che, a differenza delle prime tre varietà linguistiche, l'italiano è raramente unico codice di conversazione nelle storie narrate dalla partecipante. Piuttosto, quest'ultimo codice è più frequentemente adoperato, nei racconti, in alternanza con altre lingue. 


\subsubsection{Le varietà di contatto e l'acquisizione non focalizzata}

Considerando la tabella e le figure in 8 , si riscontra almeno una differenza tra codici input e codici output nelle narrazioni di interazioni di DK. L'intervistata narra infatti di aver spesso ascoltato e di ascoltare conversazioni caratterizzate da "alternanza di codice non reciproca", vale a dire interazioni in cui i partecipanti usano rispettivamente due lingue diverse per comunicare tra loro (cfr. il modello di comunicazione interculturale "lingua receptiva"). ${ }^{80}$ In conseguenza di ciò, DK racconta di aver acquisito non intenzionalmente competenze passive nei codici relativi o di saper parlare un codice misto tra le due lingue input. In particolare, la madre parla(va) serbo con la zia che le risponde(va) in slovacco, mentre l'amica (e bambinaia) brasiliana alterna(va) tra portoghese e italiano, rivolgendosi ai propri figli e all'intervistata bambina. Come risultato, DK afferma di comunicare in un misto tra serbo e slovacco con la cugina e di aver acquisito competenze base in portoghese (oltre che in italiano) per interagire con l'amica brasiliana e i suoi figli.

Nella sequenza in 7, DK descrive questo processo di acquisizione linguistica tramite due narrazioni di interazioni, caratterizzate come iterative. Dal momento che gli episodi riferiti sono presentati come abituali, il modello di Labov \& Waletzky (1967) non è facilmente applicabile a questo tipo di storie. Perciò, sul lato destro dell'esempio, indico esclusivamente gli enunciati valutativi $(E V)$ e l'evento più riportabile del racconto (mRE).

(es. 7)

$\begin{array}{llll} & 1 & \text { DK } & \text { u:nd - da meine mutter sich ANders nicht verständigen konnte } \\ & 2 & \text { DK } & \text { [mit] meiner tante } \\ & 3 & \text { INT } & \text { [mh mh] } \\ & 4 & \text { DK } & \text { hat sie dann - serbisch genommen } \\ & 5 & \text { DK } & \text { meine tante hat slowakisch geantwortet } \\ \text { EV1 } & 6 & \text { DK } & \text { aber sie haben sich verstanden } \\ \text { EV2 } & 7 & \text { DK } & \text { weil das: mehr oder weniger so: (h) } \\ & 8 & \text { INT } & \text { mh mh } \\ \text { EV2 } & 9 & \text { DK } & \text { - basis das gleiche ist eigentlich slawische sprachen halt } \\ & 10 & \text { INT } & \text { mh mh } \\ \text { EV2 } & 11 & \text { DK } & \text { ((pause)) ähneln sich sehr viel ((pause)) } \\ & 12 & \text { INT } & \text { okay } \\ & 13 & \text { DK } & \text { - und als kind dann hört man das immer und wenn du das jeden tag } \\ & 14 & \text { DK } & \text { > } \text { hörst und hörst und hörst< irgendwann fängst=an zu verstehen du } \\ & 15 & \text { DK } & \text { redest selber auch sprichst } \\ \text { EV3 } & 16 & \text { DK } & \text { (h) aber ich vermische das jetzt } \\ & 17 & \text { DK } & \text { wenn ich s:preche mit meiner kusine oft auf s:lowakisch (h) }-\end{array}$

80 Con lingua receptiva si intende un "modo di comunicazione multilingue" in cui gli interattanti utilizzano rispettivamente lingue e/o varietà linguistiche differenti, comprendendosi vicendevolmente senza dover ricorrere a un'ulteriore lingua franca. Il termine si riferisce all'insieme delle competenze "linguistiche", "mentali", "interazionali" e "interculturali", attivate da parlanti e ascoltatori in tali interazioni (cfr. Rehbein et al. 2011: 248-249). 


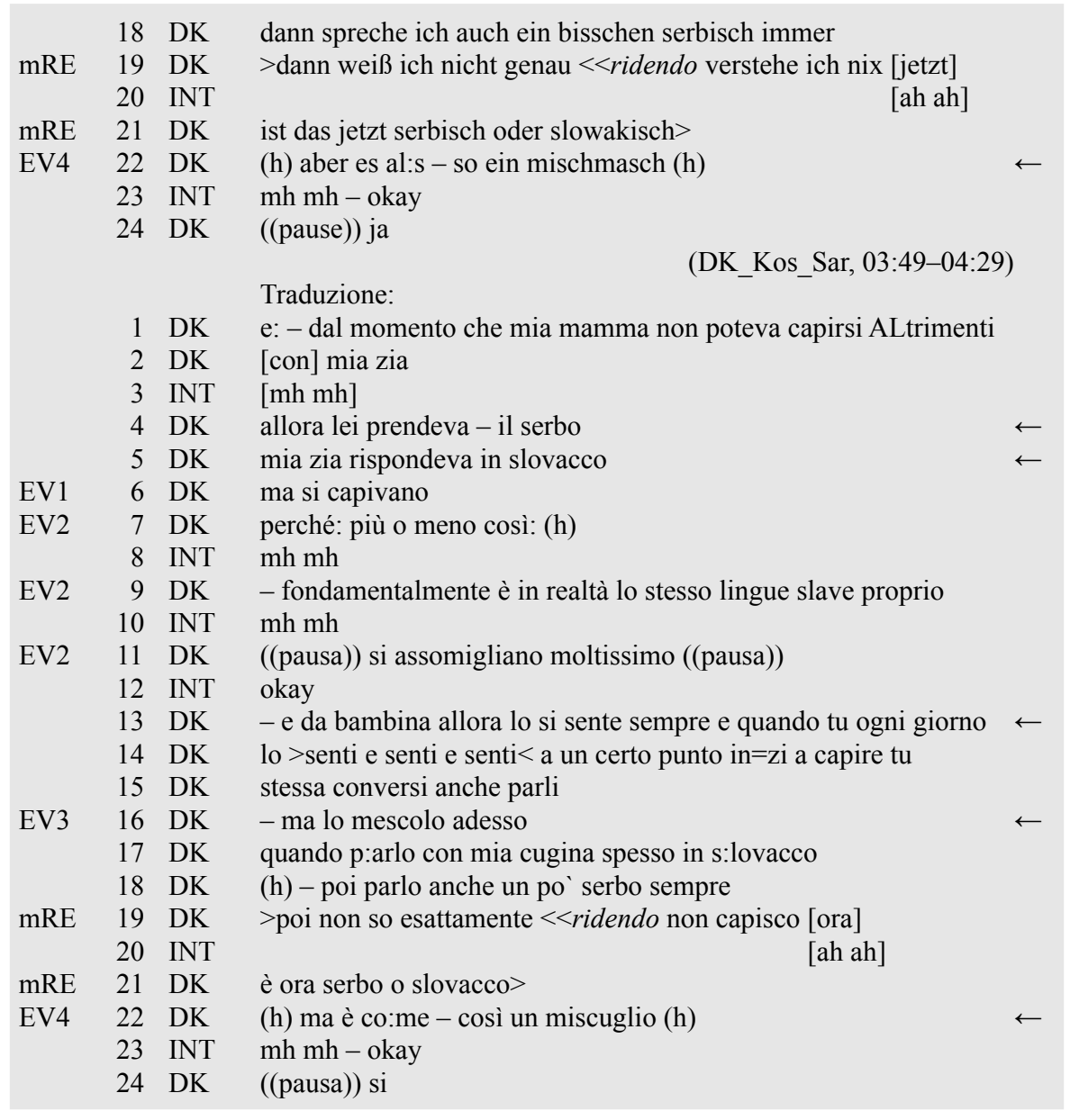

I due episodi raccontati in 7 sono posti tra loro in una relazione temporale e parzialmente causale (cfr. la congiunzione e l'avverbio "und als kind dann", tr. "e da bambina allora" alla riga 13). Nel primo racconto, DK riferisce della scelta, presa intenzionalmente da madre e zia, di parlare in due codici diversi, ma mutualmente comprensibili, in quanto unico modo per comunicare tra loro. Nel rappresentare questa decisione e la pratica comunicativa conseguente, DK non si serve del discorso diretto, ma si limita a descrivere in due azioni complicanti gli atti linguistici compiuti dai personaggi ("prendere [una lingua]" e "rispondere [in un'altra]"). La donna specifica però le varietà linguistiche dell'interazione (srp \& slo).

Nel secondo racconto metalinguistico in 7, l'enunciazione mistilingue in serbo e slovacco è invece caratterizzata come un fenomeno involontario. Questa è praticata attualmente dal personaggio di DK in qualità di parlante in interazioni con la cugina in un contesto presumibilmente familiare. L'acquisizione di competenze in serbo/slovacco è descritta dalla narratrice come una conseguenza, parzialmente 
inattesa (cfr. l'uso della congiunzione avversativa "aber", tr. "ma" alla riga 16; e Lucius-Hoene \& Deppermann 2004: 225-227) della propria esposizione da bambina ai dialoghi tra madre e zia in qualità di ascoltatrice occasionale.

In un enunciato valutativo alla riga 22 , l'io narrante si serve inoltre del termine "Mischmasch" (tr. "miscuglio") per categorizzare il risultato della propria elaborazione dell'input, ascoltato da piccola. L'espressione "Mischmasch Sprache" (lingua miscuglio) è usata anche in seguito da DK per qualificare la frequente commutazione di codice tedesco/lussemburghese, osservata durante il periodo Erasmus trascorso in Lussemburgo (minuti 45:05-45:40). In entrambe le sequenze, l'espressione è impiegata in modo neutrale, se non positivo dalla narratrice. A differenza di quanto avviene nell'intervista con VM, DK ascrive, del resto, piuttosto frequentemente al proprio personaggio nel ruolo di parlante pratiche di commutazione di codice anche intrafrasale. Si noti che tali prese di posizione non sono per nulla scontate. Infatti, il mistilinguismo in contesto migratorio e minoritario è, al contrario, frequentemente valutato come fenomeno anomalo e/o negativo da parlanti e linguisti, almeno fino agli anni ottanta (cfr. Romaine 1986 e Hinnenkamp 2000). Tuttavia, già Franceschini (2001: 118) rileva un uso dell'espressione "Mischmasch" senza sfumature peggiorative in una biografia linguistica raccolta a Basilea negli anni novanta. In aggiunta, analogamente a DK, anche un'altra giovane intervistata del corpus (BK) si serve, durante la sua biografia linguistica condotta in italiano, proprio del termine tedesco "Mischmasch", adoperandolo con una connotazione parimenti neutrale.

Ritornando alle rappresentazioni nella biografia linguistica di DK, serbo e portoghese costituiscono lingue di nuovo insediamento in Alto Adige. La prima appartiene anche al repertorio d'origine dei genitori di DK, la seconda invece no. Entrambe occupano, comunque, una posizione periferica nel repertorio narrato dell'intervistata, che acquisisce competenze in varietà mistilingui di questi codici in modo "non focalizzato", ossia non intenzionale e in contesti informali. ${ }^{81}$ Oltre a serbo e portoghese, DK racconta all'inizio dell'intervista di aver acquisito in modo non focalizzato competenze linguistiche di "base" anche in turco: parole in questa lingua sono infatti imparate dalla partecipante bambina, ascoltando le conversazioni dei vicini di casa nella città di nascita in Kosovo (cfr. anche § IV.1.4.2). La ragazza spiegherà in seguito questa propria spiccata sensibilità per le lingue e varianti linguistiche, facendo riferimento - oltre al proprio studio universitario in comunicazione - proprio al contatto fin dall'infanzia con un input linguistico variegato e plurilingue (minuti 39:02-40:26).

81 Per il concetto di competenze linguistiche "marginali" (randständig) e per una discussione sui modi di motivare l'apprendimento "non focalizzato" di codici non solo marginali in biografie linguistiche raccolte in altri contesti, si vedano Franceschini (2001) e Franceschini (2003) 


\subsubsection{L'erosione delle competenze in albanese}

Prendendo di nuovo in considerazione la tabella e le figure in 8 , una posizione centrale, equivalente a quella occupata dai codici d'arrivo, sembra essere riservata nel repertorio narrato di DK all'albanese. Questa lingua è usata quasi esclusivamente a casa e sulle reti sociali in internet con i membri della propria famiglia (cfr. anche $i$ contesti di mantenimento del codice al $\S$ V.3.3). Tuttavia, l'albanese costituisce frequentemente un codice input nelle narrazioni di interazioni della donna. Inoltre, a differenza di VM che non si serve mai attivamente di serbo nei dialoghi da lei narrati, DK racconta relativamente spesso di parlare nel codice d'origine. Così, da un lato, gli ambiti d'uso e il tipo di interlocutori rappresentati da DK come consoni all'impiego della propria lingua di partenza sono in numero inferiore e meno diversificati rispetto a nelle narrazioni di VM. Tuttavia, dall'altro lato, DK mette in scena più spesso di quest'ultima intervistata interazioni in cui il proprio personaggio è esposto o si serve in modo attivo del codice d'origine. L'importanza dell'albanese nel repertorio narrato di DK emergeva, del resto, anche dall'analisi dell'incipit della sua intervista. In apertura del colloquio, la partecipante definisce infatti questo codice come "lingua materna" e "prima lingua" per differenziarlo da "serbo" e "turco", altre varietà linguistiche parlate nella città di nascita (cfr. §IV.1.4.2 per maggiori dettagli).

Considerato questo sfondo, nel (ri-)costruire durante la propria biografia linguistica anche le proprie identità linguistiche, DK mi sembra ripetutamente posizionarsi, per lo meno nel mondo della storia, come parlante ed interlocutrice albanofona. Nel rivendicare questa rappresentazione di sé, DK non vede una contraddizione tra pratiche di commutazione di codice interfrasale, l'impiego di inserzioni o prestiti da altre lingue e la dichiarazione di una buona padronanza dell'albanese. Nei dialoghi riportati capita, infatti, spesso a diversi interattanti - all'io narrato così come ai genitori o alla cugina in Kosovo - di alternare albanese a serbo o a inglese o di prendere in prestito alcune espressioni da altre lingue conosciute, nello specifico, serbo e tedesco, in funzione espressiva. Si noti comunque che, a differenza di quelli che interessano le altre lingue di nuovo insediamento in Alto Adige (cfr. $\S$ V.4.3.1), i fenomeni di contatto che coinvolgono l'albanese non sono involontari. Questi tendono al contrario ad essere caratterizzati dalla partecipante come intenzionali in quanto funzionali a raggiungere determinati scopi interazionali.

Anche se elicitato da una domanda della ricercatrice, il racconto in 8 testimonia la rilevanza dell'albanese nel repertorio narrato di DK, per lo meno in una prospettiva emica. La narrazione è interessante dal punto di vista "presentazionale" anche perché registra un tentativo fallito della partecipante di comunicare nella lingua d'origine in contesto migratorio. Sul lato sinistro del brano sono indicati esclusivamente gli enunciati valutativi e l'evento più riportabile della storia. 
(es. 8)

\begin{tabular}{|c|c|c|c|c|}
\hline & 1 & INT & - und welche sprache möchtest du: emh ((pause)) würdest du & \\
\hline & 2 & INT & deinen kinde:rn beibringen & \\
\hline EV1 & 3 & DK & - albanisch ma- fi- ${ }^{82}$ das ist das problem weil mein freund & \\
\hline EV1 & 4 & DK & spricht nur deutsch $[=$ & \\
\hline & 5 & INT & {$[=\mathrm{ja}[=$} & \\
\hline EV2 & 6 & $\mathrm{DK}$ & {$[=>$ ALSO der kann albanisch fließend spreche } & \\
\hline EV2 & 7 & DK & auch $<$ & \\
\hline & 8 & INT & ah ja? & \\
\hline EV3 & 9 & DK & - aber automatisch mit mir spricht er deutsch & \\
\hline $\mathrm{mRE}$ & 10 & DK & - >er meint $<<<$ imitando parlato urlato ja: dann kann ich mir & \\
\hline $\mathrm{mRE}$ & 11 & DK & viel besser ausdrücken und so $>(\mathrm{h})$ & \\
\hline EV4 & 12 & $\mathrm{DK}$ & - und dann sage ich ja guck mal wenn du mal kinder hast was & $\leftarrow$ \\
\hline EV4 & 13 & DK & machst du $<<$ ridendo da $[-$ kannst $]$ du nicht immer $>[(($ riso $))]$ & $\leftarrow$ \\
\hline & 14 & INT & $\begin{array}{cc}[((\text { riso }))]] & {[((\text { riso }))]} \\
& (\text { DK_Kos_Sar, 34:33-34:5 }\end{array}$ & \\
\hline & & & Traduzione & \\
\hline & 1 & INT & - e quale lingua vorresti: emh ((pausa)) insegneresti & \\
\hline & 2 & INT & ai tuoi figli & \\
\hline EV1 & 3 & DK & - albanese ma- fi- questo è il problema perché il mio ragazzo & \\
\hline EV1 & 4 & DK & parla solo tedesco[ $=$ & \\
\hline & 5 & INT & {$[=\mathrm{si}[=$} & \\
\hline EV2 & 6 & DK & [ $>$ CIOÈ sa anche parlare albanese & \\
\hline EV2 & 7 & DK & fluentemente $<$ & \\
\hline & 8 & INT & ah si? & \\
\hline EV3 & 9 & DK & - ma automaticamente parla con me tedesco & \\
\hline $\mathrm{mRE}$ & 10 & DK & - $>$ dice $<<<$ imitando parlato urlato si: poi mi posso esprimere & \\
\hline $\mathrm{mRE}$ & 11 & DK & molto meglio e così & \\
\hline EV4 & 12 & DK & (h) - e allora io dico si guarda una volta che hai figli cosa & $\leftarrow$ \\
\hline EV4 & 13 & DK & fai $<<$ ridendo poi[ $[-$ non puoi] sempre $>$ [((riso) $)]$ & $\leftarrow$ \\
\hline & 14 & INT & [((riso $))$ uoi $]$ sempre $>[(($ riso $))]$ & \\
\hline
\end{tabular}

Nella sequenza in 8 , DK illustra le possibili difficoltà di attuazione del suo proposito di mantenimento del codice d'origine con eventuali figli futuri. Per fare ciò, mette in scena un dialogo metalinguistico presentato come abituale. Nel racconto, il ragazzo di DK si rivolge in tedesco all'io narrato nel ruolo di destinataria ratificata. In questo momento della conversazione, la ricercatrice non è ancora al corrente dell'origine kosovara del giovane, trasferitosi in Germania a sette/otto anni con la famiglia, e quindi non presuppone che quest'ultimo possa avere competenze in albanese. La sorpresa dell'interlocutrice si intuisce dai suoi segnali di ricezione e dalla richiesta di conferma alle righe 5 e $8 .{ }^{83}$

Nella sezione valutativa dell'episodio (righe 12-13), DK si disallinea dal comportamento linguistico del ragazzo e, in parte, dall'esperienza di erosione di codice di quest'ultimo. I motivi della dimenticanza di lingua del compagno sono, in parti-

82 Probabilmente si tratta una falsa partenza per "mein Freund" (tr. "il mio ragazzo").

83 Per una distinzione tra diverse attività di canale secondario (back-channel activities) dell'ascoltatore in un'intervista, si veda Norrick (2010). 
colare, ricondotti, nel prosieguo dell'intervista, alla rarità dei suoi viaggi di ritorno nel paese d'origine e all'impiego da parte dei suoi genitori, a loro volta originari del Montenegro e trasferitesi successivamente in Kosovo, di una varietà di albanese leggermente diversa e più dialettale rispetto a quella usata in quest'ultima regione. Così, analogamente ad altri intervistati albanofoni del corpus, la donna riconosce che la standardizzazione (percepita) della lingua d'origine possa avere un influsso sul suo mantenimento o sostituzione in contesto migratorio (cfr. su questo tema anche Clyne 2006, 2007 e, in questo volume, il § I.1.5).

In altre sequenze dell'intervista, DK sembra comunque paventare un rischio di erosione analogo anche per lei stessa. Così, per esempio, in una narrazione di interazione successiva, il padre ammonisce l'io narrato riguardo al pericolo di dimenticare la lingua d'origine a causa della scarsità dei suoi ambiti d'uso dopo mobilità ("mein vater sag imma: würdest du nicht zu hause sprechen dann würdest $d u=s$ [albanisch] bald vergessen", tr. "mio padre dice sempre: non parlassi a casa [albanese] lo dimenticheresti presto", minuti 49:31-50:16; cfr. anche esempio 2 al $\S$ V.3.3.1). Inoltre, in un altro brano, l'intervistata medesima si definisce, con una neoformazione occasionale, già un po" "dimenticante" ("verlorisch") del codice di partenza (minuti 35:35-36:12). Considerando questo retroscena, si può ipotizzare che l'auto-posizionamento di DK come parlante e destinataria di frequenti atti comunicativi in albanese durante le sue storie di dialoghi dipenda dalla rilevanza di tale identità linguistica non solo per lei singola, ma anche per una parte del suo reticolo sociale. In altre parole, la partecipante prenderebbe posizione, nel corso del colloquio, contro l'opinione, presentata come diffusa nella cerchia dei suoi conoscenti albanofoni, secondo cui i parlanti, emigrati da molto giovani in un paese straniero, siano soggetti, con alta probabilità, all'attrito delle proprie competenze nella lingua d'origine e a una sua eventuale sostituzione in favore dei codici d'arrivo.

\subsubsection{Il plurilinguismo "interno" in varietà di tedesco}

L'identità linguistica di interattante albanofona non è l'unica che DK ascrive al proprio personaggio durante la sua biografia linguistica. La partecipante è infatti interlocutrice (indirizzata od occasionale) e parlante in numerose narrazioni di interazioni in cui varietà linguistiche di tedesco costituiscono il codice della comunicazione. A proposito delle varietà di tedesco menzionate dall'intervistata, il parametro codici input e codici output non è rilevante per prevedere la loro distribuzione per ruolo interazionale svolto dall'io narrato. In altre parole, il personaggio di DK è esposto e si serve attivamente sia di tedesco standard, sia di dialetto tedesco locale, sia di (una sorta di) tedesco regionale nei dialoghi riportati. ${ }^{84}$ Piuttosto, le competenze in tedesco dell'io narrato si diversificano con il trascorrere del tempo, mentre la selezione di una varietà invece di un'altra varia a seconda del tipo di interlocutore

84 Per una descrizione di tali varietà nel repertorio linguistico dei parlanti tedescofoni altoatesini si confrontino i § II.1.3 e seguenti. 
e della situazione comunicativa descritta (cfr. anche l'analisi dello spazio comunicativo narrato della donna al § V.3.3). I codici di interazione con i fratelli, le sorelle, gli amici e i compagni di scuola in Alto Adige sono infatti inizialmente il dialetto locale e, da parte dei professori, una varietà di tedesco marcata regionalmente. Solo a partire dall'iscrizione all'università, frequentando persone che parlano in "Hochdeutsch" (ad esempio, studenti provenienti dalla Germania e residenti a Bolzano), l'io narrato acquisisce competenze anche in tedesco standard.

L'intervistata introduce spontaneamente differenziazioni tra le varietà di tedesco menzionate, ad esempio, tramite l'uso di glottonimi diversi e di aggettivi che rimandano a prese di posizione valutativo-epistemiche. Così, il dialetto tedesco locale è chiamato per la prima volta dall'intervistata "deutsch südtirolerisch" (tr. "tedesco altoatesino"; cfr. esempio 2 al § V.3.3.1). In seguito, la donna si riferisce al codice prevalentemente tramite l'espressione al singolare "südtirolerisch" (tr. "altoatesino"; si ricordi, invece, l'uso di una denominazione al plurale da parte di VM). Pur non coniando un nome specifico, la partecipante definisce inoltre "sehr einfach" (tr. "molto semplice") il tedesco appreso a scuola in provincia di Bolzano. Infine, l'intervistata chiama il tedesco standard "Hochdeutsch" o "Bundesdeutsch" (tr. "tedesco federale"), differenziandolo così dalle varietà locali del codice.

Nell'esempio in 9, DK riferisce alla ricercatrice del proprio graduale processo di "apprendimento" del tedesco standard. Nel racconto, la donna si posiziona come agente attiva nel conseguire la padronanza di questa varietà linguistica (cfr. più sotto in questo paragrafo). Inoltre, presenta l'avvenuta eliminazione di tratti locali dal proprio modo di parlare come un obiettivo perseguito e finalmente raggiunto: questa competenza diafasica e, in particolare, stilistica (ossia delle caratteristiche linguistiche che variano a seconda del registro e del grado di formalità della situazione comunicativa) ${ }^{85}$ le permette infatti di dissimulare la propria provenienza altoatesina, per lo meno in determinate situazioni comunicative.

(es. 9)

$\begin{array}{lrrl}\text { con } & 1 & \text { DK } & \text { ich sag das immer es heißt dann immer }<<\text { imitando un urlo di } \\ \text { tro } & 2 & \text { DK } & \begin{array}{l}\text { rifiuto nein es is:- }>- \text { ihr sagt immer südtirol- also südtiroler } \\ \text { tesi }\end{array} \\ 3 & \text { DK } & \text { könne n:- }<<\text { sorridendo nicht den richtige deutsch sprechen } \\ \& & 4 & \text { DK } & <<\text { ridendo oder so }>[-<<\text { sorridendo sa]g=ich NEIN das ist nicht } \\ \text { tesi } & 5 & \text { INT } & \text { [ah ah] } \\ & 6 & \text { DK } & \text { das aber }>\text { (h) erstens hört man zu ba- beim sprechen zum beispiel } \\ \text { ME } & 7 & \text { DK } & \text { - weil BIS ICH angefangen hab mich wirklich mit hochdeutschen } \\ \text { ME } & 8 & \text { DK } & \text { also: mit deutschen bundesdeutschen leuten zu treffen } \\ \text { CA1 } & 9 & \text { DK } & \text { mit denen viel zu sprechen } \\ \text { CA2 } & 10 & \text { DK } & - \text { mit meinem freund auch täglich ((pause)) }\end{array}$

85 La variazione stilistica è qui intesa come una sotto-dimensione della variazione diafasica e interessa il registro (dal basso/informale all'alto/formale). Le altre due sotto-dimensioni della variazione diafasica sono quella diamesica, ossia che riguarda il medium (es. scritto o orale), e quella di sotto-codice, ossia che interessa la variazione dal linguaggio comune a quello tecnico-settoriale (cfr. Berruto 1987/2012: 56). 


\begin{tabular}{|c|c|c|c|c|}
\hline & 11 & INT & $\mathrm{mh} \mathrm{mh}$ & \\
\hline CA2 & 12 & DK & hochdeutsch zu sprechen und so & \\
\hline EV1 & 13 & DK & (h) da war mein deutsch & \\
\hline mRE1 & 14 & DK & $>$ mein freund sagt das auch dass sich am anfang geahnt man hat & $\leftarrow$ \\
\hline \multirow[t]{2}{*}{$\& E V 2$} & 15 & DK & herausgehört $<$ dass ich südtirolerin ((pause)) & $\leftarrow$ \\
\hline & 16 & INT & $\mathrm{mh} \mathrm{mh}$ & \\
\hline \multirow[t]{2}{*}{ EV2 } & 17 & DK & $<<$ sorridendo bin $>($ (riso $))<<$ ridendo praktisch $>$ & $\leftarrow$ \\
\hline & 18 & INT & mh mh okay & \\
\hline EV3 & 19 & DK & $(($ pause $))$ das merkt man einfach an der sprache so & \\
\hline EV4 & 20 & DK & ((pause)) und mit der zeit hat sich das komplett irgen=wie & \\
\hline EV4 & 21 & DK & verändert auch de- aussprache & \\
\hline CA3 & 22 & DK & wenn ich sprech & \\
\hline mRE2 & 23 & DK & dann sagen viele $<<$ imitando sorpresa $\mathrm{o}$ : würde man nie denken & $\leftarrow$ \\
\hline \multirow[t]{3}{*}{ \&EV5 } & 24 & DK & dass du eigentlich aus südtiroler also da aufgewachsen bist & $\leftarrow$ \\
\hline & 25 & DK & [und] so & \\
\hline & 26 & INT & [ah ah] & \\
\hline EV6 & 27 & DK & (h) aber ((pause)) zum schreiben und so habe ich immer noch ein & \\
\hline \multirow[t]{5}{*}{ EV6 } & 28 & DK & bisschen schwierigkeiten $[-$ mi $]$ ch schön auszudrücken $[-$ abe $] \mathrm{r}$ ja & \\
\hline & 29 & INT & [okay] & \\
\hline & 30 & DK & $(($ riso $))$ & \\
\hline & & & \multicolumn{2}{|l|}{ (DK_Sar_Kos, 21:17-22:08) } \\
\hline & & & Traduzione: & \\
\hline con & 1 & $\mathrm{DK}$ & lo dico sempre si dice poi sempre $<<$ imitando un urlo di rifiuto & \\
\hline tro & 2 & DK & no è:-> - voi dite sempre gli altoatesi- cioè gli altoatesini & \\
\hline tesi & 3 & DK & $\mathrm{n}:-<<$ sorridendo non sanno parlare il tedesco vero $<<$ ridendo o & \\
\hline$\&$ tesi & 4 & DK & cose così $>[-<<$ sorridendo di $]$ co=io NO non è questo ma $>$ & \\
\hline & 5 & INT & {$[\mathrm{ah} \mathrm{ah}]$} & \\
\hline & 6 & DK & (h) prima di tutto si sente per es- quando si parla per esempio & \\
\hline ME & 7 & DK & perché FINCHÉ IO non ho iniziato veramente a incontrarmi con & \\
\hline ME & 8 & DK & tedeschi standard cioè: con tedeschi persone tedesche dalla & \\
\hline ME & $8 b$ & DK & repubblica federale & \\
\hline CA1 & 9 & DK & a parlare con loro molto & \\
\hline CA2 & 10 & DK & - con il mio ragazzo anche quotidianamente ((pausa)) & \\
\hline & 11 & INT & $\mathrm{mh} \mathrm{mh}$ & \\
\hline CA2 & 12 & DK & a parlare tedesco standard e così & \\
\hline EV1 & 13 & DK & (h) fino ad allora il mio tedesco era & \\
\hline mRE1 & 14 & DK & $>$ il mio ragazzo dice anche che all'inizio si intuiva si sentiva $<$ & $\leftarrow$ \\
\hline$\& E V 2$ & 15 & DK & che io sono $(($ pausa $))<<$ sorridendo altoatesina $>$ & $\leftarrow$ \\
\hline & 16 & INT & $\mathrm{mh} \mathrm{mh}$ & \\
\hline EV2 & 17 & DK & $(($ riso $))<<$ ridendo praticamente $>$ & $\leftarrow$ \\
\hline & 18 & INT & mh mh okay & \\
\hline EV3 & 19 & DK & ((pausa)) lo si nota semplicemente dalla lingua così & \\
\hline EV4 & 20 & DK & ((pausa)) e con il tempo è in qual=modo cambiato tutto anche $1-$ & \\
\hline EV4 & 21 & DK & pronuncia & \\
\hline CA3 & 22 & DK & quando parlo & \\
\hline mRE2 & 23 & DK & molti poi dicono $<<$ imitando sorpresa o: non si penserebbe mai & $\leftarrow$ \\
\hline \&EV5 & 24 & DK & che tu in realtà dall'alto adige cioè che sei cresciuta lì & $\leftarrow$ \\
\hline & 25 & DK & {$[\mathrm{e}]$ così } & \\
\hline & 26 & INT & [ah ah] & \\
\hline
\end{tabular}




$\begin{array}{llllcc}\text { EV6 } & 27 & \text { DK } & & \text { (h) ma ((pausa)) nello scrivere e così ho sempre ancora un po' } \\ \text { EV6 } & 28 & \text { DK } & \text { di difficoltà }[- \text { ad }] \text { esprimermi bene }[-\mathrm{m}] \text { a si } \\ & 29 & \text { INT } & & {[\mathrm{mh} \mathrm{mh}]} \\ & 30 & \text { DK } & (\text { (riso) }) & \end{array}$

Nella sequenza in 9, DK mette in scena tre dialoghi metalinguistici, il primo e l'ultimo caratterizzati come ricorrenti. Il loro tema è il condizionamento in senso geografico-regionale del modo di parlare tedesco della comunità linguistica d'arrivo e proprio. La lingua di interazione del primo e dell'ultimo dialogo non è chiaramente specificata dall'intervistata: i due racconti non sono stati quindi considerati al momento di compilare la tabella e le figure in 8 . Invece, ho codificato la seconda interazione in 9 come una narrazione metalinguistica, in cui l'io narrato in qualità di parlante si serve del tedesco standard per comunicare con gli amici provenienti dalla Germania e con il ragazzo in un contesto altoatesino non ulteriormente specificato.

Nel primo mini-dialogo in 9, il personaggio di DK in qualità di parlante cita in discorso diretto il giudizio di un gruppo di interlocutori indefiniti sulla a-grammaticalità delle varianti linguistiche locali: formalmente, un discorso diretto è quindi incluso in un altro discorso diretto (cfr. righe 1-6). L'intenzione dell'io narrante è probabilmente quella di opporre, all'affermazione riportata, una diversa valutazione del valore da attribuire a queste caratteristiche linguistiche. La partecipante infatti non considera queste ultime come assolutamente sbagliate, ma piuttosto le interpreta come marcatori (o markers) regionali. DK non formula subito la propria opinione, ma preferisce esemplificare la sua tesi tramite la narrazione di un'esperienza personale.

Nella seconda parte della sequenza, la donna riassume così brevemente gli eventi connessi con il proprio processo di apprendimento del tedesco standard (cfr. righe 7-10). Tali esperienze sono categorizzate dalla prospettiva epistemica e valutativa del presente. Tuttavia, l'uso del discorso riportato, così come il passaggio dal tempo verbale passato a quello presente al momento di introdurlo ("il mio ragazzo dice", "quando parlo molti poi dicono"), mettono, al contempo, in scena drammaticamente alcuni momenti della storia, segnalando gli apici di questa (cfr. rispettivamente le righe 14-17 e 23-24). Nel rappresentare gli eventi in 9, DK sembra quindi adottare una forma testuale intermedia tra "rappresentazione informativa" e "narrazione scenico-episodica", qualificata comunque come abituale o iterativa (cfr. Lucius-Hoene \& Deppermann 2004: 145-154 e § V.1.1.2). Oltre a costituire gli eventi più riportabili del racconto (mRE1 e mRE2), i due discorsi riportati in 9 contengono anche prese di posizione valutative, attribuite ad altri personaggi nel mondo della storia, sul modo di parlare tedesco dell'io narrato ("DK: >il mio ragazzo dice anche che all'inizio si intuiva si sentiva $<$ che io sono ((pausa)) $<<$ sorridendo altoatesina>"; "DK: molti poi dicono <<imitando sorpresa o: non si penserebbe mai che tu in realtà dall'alto adige cioè che sei cresciuta lì"). Perciò li ho doppiamente categorizzati, sia come eventi più riportabili, sia come sezioni valutative del racconto (EV2 e EV5).

Nel brano in 9, l'intervistata è prima "vittima" di critiche e poi "beneficiaria" di commenti metalinguistici positivi sul suo modo di parlare tedesco. Nonostante ciò, 
DK rappresenta, a mio avviso, se stessa nella sequenza in questione come agente attiva e prima responsabile del fatto che le valutazioni altrui nei confronti del proprio idioletto mutino. L'io narrato è infatti iniziatrice di una serie di attività comunicative con persone provenienti dalla Germania, elencate in parallelismo sintattico e tramite ripetizioni ("FINCHÉ io non ho iniziato [...] a incontrarmi con tedeschi standard $[\ldots]$ a parlare con loro $[\ldots]$ con il mio ragazzo anche quotidianamente [...] a parlare tedesco standard"; righe 7-12). Inoltre, la manifestazione di sorpresa in discorso diretto alla riga 23-24 è provocata da un atto linguistico implicito del personaggio di DK, riportato alla riga 22 ("quando io parlo molti poi dicono"). Come in altre interviste, la narratrice ascrive dunque nella sequenza in 9 giudizi, specialmente positivi, sulle proprie competenze linguistiche ad altri personaggi nel mondo della storia. Ciò non impedisce tuttavia a DK di attribuire al proprio io narrato l'avvio delle attività comunicative riferite e, in questo modo, di posizionare il proprio personaggio di allora e, al contempo, il proprio io attuale come parlante/ apprendente attivo di competenze diafasiche in tedesco.

Infine, anche le categorizzazioni negoziate da DK per gli altri e per se stessa nel brano in 9 meritano un breve commento. Tra le prime, c'è la qualifica di "tedeschi standard" per i parlanti tedescofoni provenienti dalla Germania, subito riformulata con la definizione di "persone tedesche tedesche federali" ("mit hochdeutschen also: mit deutschen bundesdeutschen leuten"; righe 7-8). All'io narrato è invece attribuita, nel primo discorso riportato, un'origine altoatesina (righe 15-17). Pur non essendo sotto la propria diretta responsabilità, l'intervistatrice sembra tuttavia sentire la necessità di negoziare questa qualifica, almeno nello specifico contesto dell'intervista. Infatti, tale affermazione di autoctonicità è preceduta da una pausa e, sebbene sia confermata dall'intervistatrice che annuisce (riga 16), è attenuata dal sorriso/riso dell'io narrante e dall'avverbio "praktisch" (tr. "praticamente"; riga 17). In modo analogo, l'attribuzione di un'origine locale, nel secondo discorso riportato, è riparata dall'io narrante con la menzione della propria esclusiva crescita in provincia di Bolzano ("non si penserebbe mai che tu in realtà dall'alto adige cioè che sei cresciuta li”; righe 23-24). L'intervistata sembra dunque riflettere in questa sequenza, vis-à-vis con l'interlocutrice, sull'interpretazione del nesso, già rilevante nella biografia linguistica di VM, tra competenze linguistiche in tedesco e autoctonicità (o non autoctonicità) del parlante.

A proposito di questa relazione, DK prende, nel corso dell'intervista, una serie di prese di posizione abbastanza particolari. L'intervistata, infatti, (ri)valuta per esempio, in una sequenza di poco precedente a quella in 9, la propria origine non locale come una "fortuna" ("Glück") dal punto di vista linguistico. Il minore periodo di tempo trascorso in Alto Adige e il fatto di non avere genitori dialettofoni sono, infatti, il motivo per cui l'io narrato è meno abituato dei suoi coetanei ad "usare [...] grammatica sudtirolese [...] in tedesco standard" (minuti 20:21-20:58). L'origine non locale e le competenze alloglotte dei genitori facilitano dunque l'io narrato nell'acquisizione di una varietà del codice d'arrivo (il tedesco standard) con prestigio overt, ossia con un valore strumentale riconosciuto come alto non solo in Alto Adige, ma anche al di fuori della nuova regione di residenza. Da ciò segue che, nella prospettiva della donna, la propria identità linguistica di "parlante albanofona" sia 
uno dei presupposti dell'altra identità linguistica rivendicata per se stessa nel corso del colloquio. Quest'ultima è appunto quella di "parlante tedescofona stilisticamente competente", vale a dire in grado di comunicare fluentemente in diverse varietà/registri di tedesco e di servirsene adeguatamente a seconda del variare (della formalità e familiarità) di contesti e interlocutori. Nel fare ciò, l'io narrante effettua, a mio avviso, una riallocazione sociale della propria vicenda biografica e una rivalutazione del codice di partenza a dispetto di opinioni metalinguistiche collettivamente diffuse. Entrambi (esperienza migratoria e padronanza dell'albanese) sono infatti presentati come estremamente vantaggiosi proprio nel contesto migratorio attuale (cfr. anche Relaño-Pastor \& De Fina 2005 per riallocazioni analoghe in altri contesti).

In conclusione, si noti che la volontà, manifestata da DK, tra l'altro, nel brano in 9, di eliminare caratteristiche linguistiche locali dalla propria pronuncia contrasta con il desiderio, espresso invece da VM nel corso della sua intervista, di non essere riconosciuta come parlante straniera e, quindi, "non locale" in Alto Adige. Nonostante questa aspirazione, le prese di posizione di DK verso le varietà locali di tedesco non sono comunque sempre negative o svalutanti. Il "dialetto" è infatti qualificato in altre sequenze del colloquio come "la propria seconda lingua" e il codice in cui la donna si sente attualmente più fluente in quanto varietà linguistica con cui è cresciuta. Inoltre, rispondendo a una domanda dell'intervistatrice, la partecipante attribuisce al tedesco (Deutsch), oltre che all'albanese (cfr. anche il §V.4.3.2), lo status di "lingua materna". Il motivo, addotto dalla donna, è che il tedesco è la lingua da lei attualmente usata più spesso. Anche in considerazione di ciò, entrambe le identità linguistiche di interattante sia albanofona, sia tedescofona stilisticamente competente, mi sembrano essere parimenti rilevanti per DK al momento di narrare la propria biografia linguistica alla specifica ricercatrice. Infine, la partecipante valuta, nel corso dell'intervista, l'apprendimento del tedesco come più difficile rispetto a quello dell'italiano. Perciò, plaude per un'iniziale acquisizione di questo codice dopo il trasferimento in Alto Adige. Al contempo, la narratrice è d'accordo con l'opinione, diffusa nella regione di arrivo, secondo cui i cittadini stranieri, soprattutto albanofoni, tendano ad apprendere l'italiano dopo il loro arrivo. Così, da un lato, DK sostiene, diversamente da VM, un'idea condivisa sui comportamenti linguistici della popolazione immigrata in Alto Adige. Dall'altro lato, similmente alla prima partecipante, quest'ultima intervistata presenta, seppur con argomenti diversi, le proprie alte competenze in tedesco come abbastanza inusuali nel gruppo dei pari. Queste le permettono infatti di distinguersi sia da persone che hanno avuto esperienze di mobilità simili alla propria, sia dai coetanei locali, nati in provincia di Bolzano.

\subsubsection{L'ascolto occasionale di varietà di italiano}

Un'ultima osservazione che può essere tratta dai dati riportati nelle figure in 8 riguarda la distribuzione delle varietà standard, non standard e di contatto di italiano nei racconti di dialoghi di DK. In queste narrazioni, la donna fa riferimento a un input molto diversificato, ma prevalentemente accidentale, di varietà di italiano nel contesto d'arrivo. Il suo personaggio ascolta infatti dialoghi in tali codici soprat- 
tutto in qualità di ascoltatrice occasionale. Inoltre, similmente a quanto avviene per il tedesco, solo con il trascorrere del tempo, DK è esposta anche a "varietà standard" della lingua in questione.

Nello specifico, a Sarentino e a lezione di italiano nella scuola di lingua tedesca, la partecipante entra inizialmente solo occasionalmente in contatto con varietà regionali (italiano/calabrese) o "tritate" ("gehackt") di italiano: queste ultime sono tali dal momento che suonano come tedesco. Tali codici sono parlati, per esempio, saltuariamente da un'amica, cresciuta in una famiglia bilingue, che però si vergogna di fronte al gruppo di conoscenti del suo accento del sud Italia. In alternativa, l'intervistata è esposta a varietà di contatto (ad es. ita \& por) o "superficiali" ("oberflächlich") del codice. Queste sono rispettivamente usate dalla bambinaia brasiliana o insegnate dai professori a scuola. Secondo i racconti della narratrice, il miglioramento delle competenze in italiano avviene, per la prima volta, in modo decisivo durante l'anno di scambio in una scuola superiore italiana a Bolzano (cfr. Veronesi 2012 per esperienze e dichiarazioni simili nelle biografie linguistiche di altri studenti altoatesini che hanno frequentato il programma di scambio "un anno in L2", organizzato dalla provincia). Tuttavia, in una breve narrazione abituale ambientata in università, gli interventi dei compagni italofoni a lezione sorprendono ancora l'io narrato, ascoltatrice non indirizzata della conversazione, per la loro ricchezza lessicale e precisione descrittiva.

In linea con l'input ricevuto, DK rappresenta se stessa in qualità di parlante come in grado di servirsi attivamente soprattutto di varietà di contatto del codice. L'italiano è infatti solitamente alternato a tedesco o a dialetto tedesco locale o frammisto a tedesco/albanese o a "altoatesino" nelle interazioni riportate dalla donna. L'unica storia in cui DK usa attivamente il codice è, invece, ambientata in passato, durante l'anno di scambio nella scuola superiore italiana. Indipendentemente dal fatto che la partecipante dichiari una buona padronanza attuale di questa lingua (cfr. $\S$ V.2.3.2), l'italiano costituisce così più raramente del tedesco standard, del dialetto tedesco locale e dell'albanese una lingua in cui l'io narrato si sente di avviare una conversazione, per lo meno nel mondo delle sue storie.

Infine, a proposito dell'alternanza situazionale tra italiano e tedesco nella regione di arrivo, l'intervistata presenta, inizialmente, la scelta tra queste due lingue come l'una escludente l'altra: o si parla italiano o si parla tedesco. Tale fenomeno è, in parte, ricondotto allo speciale sistema scolastico vigente in provincia di Bolzano, in cui gli istituti di formazione sono separati per gruppo linguistico. Competenze in entrambe le due lingue d'arrivo (sia in italiano, sia in tedesco) diventano tuttavia sempre più importanti con il passare del tempo, per lo meno nell'ottica della donna. Una padronanza di entrambi i codici è infatti, per esempio, necessaria per accedere all'università e al mondo del lavoro (cfr. anche $\S$ V.3.3). Perciò, in vista dei requisiti richiesti per proseguire gli studi e per svolgere attività professionali in provincia di Bolzano, DK giudica il mancato o lo scarso contatto con i membri dell'"altro" gruppo linguistico, durante l'infanzia e l'adolescenza, come problematici. Inoltre, presenta l'appropriazione della lingua "seconda" come un processo che deve soprattutto avvenire per iniziativa personale piuttosto che affidandosi alle lezioni di lingua a scuola. Si noti che temi analoghi sono stati individuati anche nelle biografie linguistiche di parlanti nati in Alto Adige, studiate da Veronesi (2008a, 2008b, 2010). 


\subsubsection{Una parlante tedescofona stilisticamente competente}

La discussione nei paragrafi precedenti ha permesso di individuare alcuni tratti peculiari della rappresentazione che DK dà di sé come soggetto parlante nel corso della sua biografia linguistica. In primo luogo, il rapporto tra i ruoli di io parlante e io ascoltatrice (destinataria o occasionale) nelle narrazioni dell'intervista con DK è più equilibrato rispetto a quello nei racconti di interazioni di VM. Inoltre, l'io narrato in qualità di parlante si serve sia di albanese, sia di varietà standard e locali di tedesco, sia di varietà, soprattutto di contatto, di italiano. Così, la selezione e l'alternanza tra i quattro codici "centrali" del proprio repertorio sono rappresentate dall'intervistata, al momento del colloquio, come attività che l'io narrato sa gestire attivamente e con una certa abilità, indipendentemente dalla varietà linguistica coinvolta. La distribuzione bilanciata dei ruoli interazionali nella struttura di partecipazione delle storie raccontate ha un corrispettivo, nel mondo dell'interazione, sul formato di produzione che caratterizza l'attività narrativa in via di svolgimento. In particolare, da un minore scollamento tra i ruoli di animatrice, autrice e responsabile nel riportare i discorsi dei personaggi segue, a sua volta, un maggiore accollamento di responsabilità riguardo alle affermazioni, anche metalinguistiche, citate da parte di DK rispetto a VM. Tuttavia, la possibilità di dislocare determinati enunciati ad altri responsabili è sfruttata anche durante questa intervista. Nello specifico, prese di posizione valutative rispetto alle proprie competenze linguistiche sono prevalentemente attribuite dall'io narrante ad altri personaggi nel mondo della storia.

In secondo luogo, dall'analisi della distribuzione dei codici per ruoli interazionali in tutti i racconti di dialoghi dell'intervista e dall'esame dettagliato di singole sequenze narrative emergono, a mio avviso, due identità linguistiche preponderanti che la partecipante delinea per se stessa nel co-costruire la propria biografia linguistica vis-à-vis con la ricercatrice. Da un lato, la donna si posiziona come parlante e interlocutrice albanofona che, insieme ai membri del suo reticolo sociale, ha mantenuto il codice d'origine nonostante la propria emigrazione avvenuta da giovane. Probabilmente in connessione con questa rivendicazione, commutazioni di codice, inserzioni o prestiti in albanese sono praticati dall'io narrato come da altri personaggi nel mondo dei racconti. Tuttavia, questi non sono mai involontari, ma hanno piuttosto una funzione, stilistica o referenziale. Dall'altro lato, DK si rappresenta come parlante e interlocutrice tedescofona stilisticamente competente a differenza dei coetanei, sia stranieri sia soprattutto nati nella regione di arrivo. Invece, seppur padroneggiato molto bene, l'italiano non è parimenti centrale nella rappresentazione che la donna dà di sé durante il colloquio: questa lingua è infatti utilizzata solo in concomitanza con altri codici da parte dell'io narrato parlante oppure è lingua di comunicazione in dialoghi a cui l'intervistata assiste esclusivamente come ascoltatrice occasionale.

Nel processo di acquisizione di competenze stilistiche in tedesco, DK rappresenta il proprio personaggio come agente attivo. In particolare, fattori esterni (soprattutto il luogo di residenza) la rendono primariamente parlante dialettofona di tedesco. Nonostante ciò, la propria origine non locale, le competenze alloglotte dei genitori e la successiva frequentazione di persone provenienti dalla Germania sono (ri-)valutate dall'intervistata come condizioni e iniziative personali decisive nel 
processo di diversificazione delle proprie competenze stilistiche e, in particolare, in quello di acquisizione del tedesco standard. Si noti la diversità della prospettiva di DK rispetto a quella di VM. Uno dei temi centrali nell'intervista con quest'ultima era infatti l'apprendimento del tedesco nonostante un ambiente prevalentemente alloglotto e italofono intorno a lei.

Somiglianze e differenze si possono anche individuare tra le rappresentazioni di DK e quelle di parlanti, nati in Alto Adige e intervistati da Veronesi (2008a, 2008b, 2010). In modo analogo a questi ultimi, DK valuta la preparazione linguistica fornita dalle scuole altoatesine, almeno fino all'università, come tendenzialmente insufficiente rispetto alle competenze richieste nel mondo del lavoro. La sua inadeguatezza non concerne, però, per la narratrice solo l'insegnamento della "seconda" lingua locale (nel suo caso, l'italiano), ma anche l'apprendimento di competenze stilistiche nella "prima" lingua (vale a dire, per lei, il tedesco). Inoltre, anche i campi semantici degli aggettivi usati da DK per descrivere i codici del proprio repertorio sono talvolta simili, talvolta non coincidono con quelli individuati da Veronesi (2010). In particolare, tedesco e italiano sono qualificati dall'intervistata rispettivamente come lingua piuttosto "seria" ("ernstere") e "molto sensibile" ("feinfühligste"), mentre l'albanese è definito come codice migliore per far ridere. Tali categorizzazioni seguono, pur creativamente, pattern aggettivali diffusi per descrivere i primi due codici in provincia di Bolzano e per rendere conto degli usi di una varietà linguistica in situazione minoritaria o "immigrata" (cfr. rispettivamente Veronesi 2010 e Dell'Aquila \& Iannàccaro 2006: 259, Rost 2009). D'altro canto, DK è sorpresa dalla ricchezza lessicale e dalla grande precisione descrittiva dell'italiano e dei parlanti italofoni all'università (cfr. anche BV). Tali prese di posizione valutative ed epistemico-affettive ${ }^{86} \mathrm{si}$ differenziano da atti di posizionamento più tipici, riscontrabili per esempio nella biografia linguistica di VM e in quelle degli intervistati in Veronesi (2010), per cui la "precisione" è caratteristica distintiva del tedesco.

In terzo luogo, un'asimmetria tra codici input e output si riscontra anche relativamente all'uso di varietà di contatto, sia nel mondo delle storie, sia tra quest'ultimo e quello dell'interazione. Infatti, da una parte, la ripetuta esposizione a interazioni caratterizzate da alternanza di codice non-reciproca, ad esempio in serbo e slovacco, ha come risultato l'acquisizione non intenzionale da parte dell'io narrato di competenze attive in un codice misto tra i due (srp/slo). Dall'altro lato, a differenza di quanto messo in scena nelle sue storie, l'io narrante non adopera mai l'alternanza di lingua in funzione chiaramente strategica durante l'intervista. Solo occasionalmente si rilevano infatti fenomeni di contatto nella varietà di tedesco parlata da DK: questi consistono nell'uso marginale di espressioni in inglese (es. "level"), probabilmente da ricondursi ai modi del linguaggio tra coetanei (cfr. l'alternanza tra inglese e italiano nel comunicare con la cugina) o al periodo di studio trascorso a Lussemburgo (cfr. anche $\S$ V.2.4.2). Da ciò risulta, quindi, una discrepanza tra il comportamento dell'io narrato, da un lato, e dell'io narrante, dall'altro,

86 Secondo Du Bois (2007: 175, nota a piè di pagina 4), un predicato come "essere sorpresi/stupiti" (to be amazed) incorpora una dimensione sia affettiva sia epistemica. 
riguardo alla frequenza d'uso della commutazione di codice nel mondo delle storie e a quella effettivamente praticata nel mondo dell'interazione.

Una tale asimmetria si lascia probabilmente spiegare con la situazione comunicativa: la narratrice non pratica l'alternanza di codice a causa della "formalità" del contesto "intervista", che è maggiore rispetto a quello della "conversazione spontanea". Si noti che il comportamento di DK si differenzia da quello adottato da VM nel corso del suo colloquio (cfr. $\S \mathrm{V} .4 .2 \mathrm{e} \mathrm{sgg.).} \mathrm{Questa} \mathrm{divergenza} \mathrm{potrebbe} \mathrm{puntare}$ al fatto che le due donne attribuiscano alle pratiche di contatto un diverso status. In altre parole, pur non attribuendole al suo personaggio nel mondo delle storie, VM le giudicherebbe più idonee di DK per essere usate in un contesto semi-formale come un'intervista. In aggiunta o in alternativa a ciò, potrebbe suggerire che VM giudichi più importante dimostrare di essere competente anche nella seconda lingua di arrivo (nel suo caso, il tedesco) rispetto a quanto non sia per DK dimostrare la propria padronanza dell'italiano. Infine, i comportamenti delle due partecipanti potrebbero anche dipendere da una loro diversa interpretazione della situazione interazionale in corso. Ciò potrebbe essere a sua volta determinato da altri fattori contestuali: infatti, ad esempio, l'intervista con DK si svolge nell'ufficio della ricercatrice, mentre quella con VM a casa della partecipante.

In conclusione, il tipo di interattanti è un parametro piuttosto significativo nel determinare la selezione del codice d'origine nelle narrazioni di interazioni di DK. La donna si serve infatti dell'albanese quasi esclusivamente con i componenti della famiglia nucleare e allargata. Inoltre, rappresenta la propria e l'altrui alternanza tra varietà standard, regionali o locali di tedesco come motivata, oltre che dalla formalità della situazione comunicativa, anche dal luogo di provenienza/autoctonicità dell'interlocutore. Quest'ultima rappresentazione non sorprende, soprattutto se si considera che la situazione sociolinguistica altoatesina corrisponde a una di diglossia in cui la "lingua tetto" (o Dachsprache), vale a dire il tedesco standard, non è propriamente un codice locale (cfr. anche § II.1.3.1). Perciò, i locutori dalla Germania rappresentano per DK una categoria di parlanti a se stante. Come si è visto, il contatto con loro avviene per la donna a partire dall'università e quasi esclusivamente in questo contesto. In modo parzialmente analogo, varietà linguistiche e di contatto di italiano costituiscono inizialmente lingue di comunicazione con e tra persone non originarie di Sarentino, vale a dire, ad esempio, la bambinaia brasiliana e i suoi figli, l'amica con padre calabrese e madre tedesca cresciuta in Germania, o altri bambini "stranieri". Varietà standard del codice sono impiegate successivamente con o da professori e compagni durante l'anno di scambio in una scuola superiore italiana a Bolzano. Inoltre sono attualmente usate in contesto universitario e occasionalmente lavorativo. Nel corso dell'intervista, la maggior parte degli interattanti è identificata da DK sulla base dei rapporti personali intercorrenti tra loro e il proprio io narrato (es. madre, amici, compagni), mentre narrazioni di dialoghi con personaggi istituzionali sono più rare rispetto a quelle di VM (cfr., però, l'esaminatore o il futuro capo). Infine, i bambini sia locali, sia stranieri costituiscono un'ulteriore categoria di interlocutori rilevanti nello spazio comunicativo narrato della donna. A questi è, infatti, riconosciuta la potenzialità di divenire bilingui e, nel fare ciò, di scardinare i rapporti di forza vigenti sia tra minoranze di antico, sia di nuovo insediamento. 


\subsection{BV e il discorso riportato}

A differenza di DK e in modo analogo a VM, il numero di volte in cui l'io narrato svolge il ruolo di parlante nelle narrazioni di interazioni raccontate da BV è di molto inferiore a quello dei dialoghi in cui è ascoltatrice di un atto linguistico condotto da altri. Come mostrano la tabella in $9 \mathrm{a}$ e le figure in $9 \mathrm{~b}$ e $9 \mathrm{c}$, il personaggio di BV è infatti iniziatrice di una conversazione esclusivamente in otto narrazioni. Negli altri racconti, rispettivamente quattordici e dodici storie, l'intervistata mette

Tabella 9a: Narrazioni di interazione nell'intervista con BV suddivise per il ruolo interazionale svolto dall'io narrato nel mondo della storia.

\begin{tabular}{|l|l|l|}
\hline \multicolumn{2}{|c|}{ TOTALE NARRAZIONI BV DESTINATARIA: 14 } \\
\hline parlante & codice & destinatario \\
\hline figlio & leggere in srp & BV \\
\hline persone tedesche & deu & BV \\
\hline professore (da Vienna) & deu di Vienna & BV \\
\hline compagni univ. & $\begin{array}{l}\text { hochdeu di Amburgo e deu di } \\
\text { Dresda e deu di Baviera }\end{array}$ & BV \\
\hline amico & n. i. (+ dialetto della Franconia) & BV \\
\hline compagni univ. (traduttori) & ita & BV \\
\hline compagno univ. (tedescofono locale) & ita & BV \\
\hline professore & ita di Roma & BV e classe \\
\hline professore & ita di Rimini & BV e classe \\
\hline professore & ita di Firenze & BV e classe \\
\hline professore & ita dal sud & BV e classe \\
\hline compagno univ. & lingua dal Veneto & BV \\
\hline compagno univ. & n. i. (+ lad) & BV \\
\hline insegnante di inglese & eng & BV \\
\hline
\end{tabular}

\begin{tabular}{|l|l|l|}
\hline \multicolumn{3}{|c|}{ TOTALE NARRAZIONI BV ASCOLTATRICE OCCASIONALE: 12 } \\
\hline parlante & codice & destinatario \\
\hline figlio & srp & insegnante di serbo \\
\hline presentatori TV & neologismi in hrv & amica (croata) telespettatrice \\
\hline figlio & madrelingua e deu (sogni) & $\begin{array}{l}\text { figlio (comunicazione } \\
\text { interiore) }\end{array}$ \\
\hline figlio & deu & insegnante \\
\hline conoscente (serbo) & sdt & personale ospedaliero \\
\hline conoscente (serbo) & sdt & colleghi \\
\hline sconosciuti (LORO) & sdt & sconosciuti \\
\hline bambini stranieri & ita & genitori stranieri \\
\hline presentatori TV & ita & BV telespettatrice \\
\hline insegnante di italiano & ita dal sud & figlio \\
\hline amico & $\begin{array}{l}\text { dialetto trentino \& altro dialetto } \\
\text { trentino }\end{array}$ & nonna \\
\hline marito & eng come lingua franca & colleghi di lavoro (università) \\
\hline
\end{tabular}

\begin{tabular}{|l|l|l|}
\hline \multicolumn{3}{c}{ TOTALE NARRAZIONI BV PARLANTE: 8 } \\
\hline parlante & codice & destinatario \\
\hline NOI & nostra lingua & amica (croata) \\
\hline NOI & esercizi in deu & figlio \\
\hline BV & esercitarsi in deu & insegnante e compagni \\
\hline BV & deu & insegnante del figlio \\
\hline BV & deu & classe \\
\hline BV & ita & professori e compagni \\
\hline BV & ita & polizia \\
\hline BV & eng/ita & amici \\
\hline
\end{tabular}


invece in scena un dialogo in cui l'io narrato è destinataria indirizzata (talora in un gruppo) o ascoltatrice occasionale di un'attività comunicativa. Sulla base di ciò si può ipotizzare che la dislocazione di parole ad altri personaggi sia una strategia frequentemente adoperata dalla partecipante durante la sua intervista. Inoltre sembrerebbe che la donna rappresenti frequentemente se stessa nell'atto di reagire ad atti linguistici e, quindi, a scelte di codice condotte da altri.

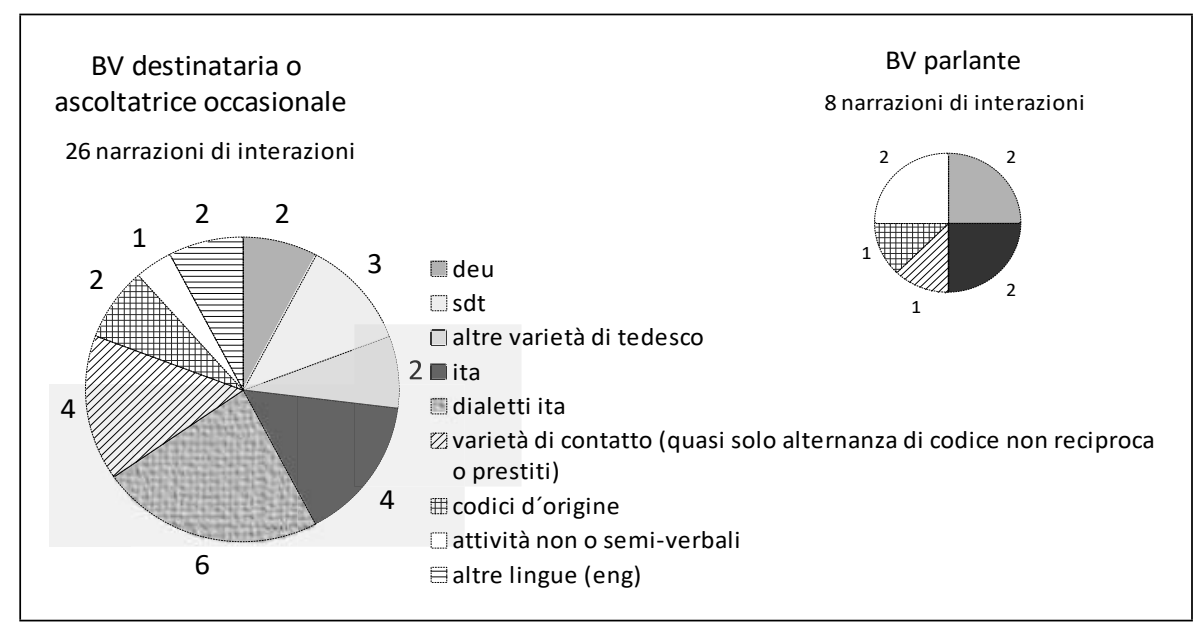

Figure $9 b$ e 9c: Codici a cui l'io narrato è esposto (input) e codici usati attivamente (output) nelle narrazioni di interazioni nell'intervista con $B V$.

\subsubsection{Le varietà locali e non locali dei codici d'arrivo}

Una caratteristica del repertorio narrato di $\mathrm{BV}$, che risultava già dall'analisi per situazioni comunicative nel $\S \mathrm{V} .3 .4$, è la differenziazione molto dettagliata tra varietà linguistiche diatopiche, locali e non locali, di italiano e tedesco portata a termine dalla partecipante durante la sua biografia linguistica. Dalla ripartizione dei codici per ruoli interazionali nella tabella e nelle figure in 9 emerge come queste varietà linguistiche costituiscano lingue in cui al personaggio di $\mathrm{BV}$ è frequentemente rivolta la parola in provincia di Bolzano. Tali codici non sono però usati attivamente dall'io narrato. Ad eccezione di un dialogo in enunciazione mistilingue italiano e inglese (cfr. §V.4.4.3), quest'ultimo si serve, infatti, esclusivamente di varietà linguistiche standard nelle narrazioni in cui è parlante.

L'intervistata distingue le varietà linguistiche di italiano e tedesco, con cui entra in contatto in Alto Adige, riferendosi primariamente alla dimensione diatopica, vale a dire alla regione o città di provenienza del parlante. Occasionalmente adotta inoltre termini che le classificano (anche) sulla dimensione socio-geografica o socio-politica e che, quindi, implicano prese di posizione riguardo al loro status sociolinguistico. Tali categorizzazioni sono tuttavia adoperate in un numero molto limitato di sequenze. In generale, i codici in questione sono solitamente definiti dalla narratrice 
dialetti ("dialects"). Eccezione costituisce invece la "language from VE:NEto" ("lingua del veneto"), espressione con cui un compagno di università di BV chiama il modo di parlare "velocissimo", "incomprensibile" e "molto brusco" ("very fast", "ununderstandable", "very ru:de") di un altro studente. Questi ultimi attributi - indicatori di una presa di posizione valutativa tendenzialmente negativa nei confronti del codice - sono espressi in una sezione valutativa della storia dall'io narrante e, quindi, ascritti alla sua diretta paternità/maternità (authorship). Il glottonimo e la classificazione della varietà come "lingua" (invece che "dialetto") sono invece assegnati, tramite discorso diretto, alla responsabilità del compagno di corso.

Come si nota dall'esempio appena citato e dalle denominazioni elencate nelle immagini in 9, BV menziona varietà sia "locali" sia "non locali" (ossia non storicamente parlate in Alto Adige) dei codici d'arrivo nelle proprie narrazioni di interazioni. Le prime sono parlate nel quartiere, al lavoro e all'ospedale, ma raramente costituiscono codice di comunicazione nelle narrazioni di BV (cfr. anche §V.3.4). Invece, le varietà non locali di tedesco e italiano sono impiegate da un numero più ristretto di interattanti e in un numero più circoscritto di luoghi, ossia quasi esclusivamente da compagni di corso e professori in università o nella scuola elementare del figlio. Tuttavia sono molto frequentemente codice di interazione nei racconti della donna. Si consideri la sequenza in 10 che segue di un paio di minuti una domanda dell'intervistatrice riguardo alle lingue sentite parlare a Bolzano (minuto 01:17:49). Dopo aver enumerato spagnolo, russo, francese, ladino e bulgaro come lingue occasionalmente udite nel quartiere, BV mette in scena due dialoghi, ambientati in università. In queste conversazioni, al personaggio di $\mathrm{BV}$, nel ruolo di destinataria in un gruppo di persone, è rivolta la parola in varietà regionali non locali di italiano. Il primo racconto riporta una vicenda usuale in funzione di esempio. La seconda storia è invece più conforme per contenuto e struttura a una narrazione scenico-episodica.

(es. 10)

\begin{tabular}{|c|c|c|c|c|}
\hline \multirow{7}{*}{ tesi } & 1 & BV & yeah spanish quite a lot of spanish people and russian people are & \\
\hline & 2 & $\mathrm{BV}$ & here mh: and ((pause)) iTALIAn from another dialect but I can not & \\
\hline & 3 & BV & recog- a: I CAN JUST SAY I ((pause)) $<<$ sorridendo I understand & \\
\hline & 4 & BV & this and I - don't understand this a:nd $>(($ pause $))$ & \\
\hline & & INT & $\mathrm{mh} \mathrm{mh}$ & \\
\hline & 6 & BV & THOse people are speaking in this way or that $>$ but $\mathrm{I}<\mathrm{I}$ don't & \\
\hline & & BV & know from which region for example & \\
\hline OR1 & 8 & BV & ((pause)) I have a:: a: $a::-$ lecturer - a: who is fro:m & \\
\hline \multirow[t]{2}{*}{ OR1 } & 9 & BV & $<<$ cambiando tono di voce rimini $>(($ pause $))$ & \\
\hline & 10 & INT & $\mathrm{mh} \mathrm{mh}$ & \\
\hline EV1\& & 11 & BV & $(($ pause $))<<$ staccato I:: HARdly can follow him> ((pause)) & \\
\hline mRE1 & 12 & INT & $\mathrm{mh} \mathrm{mh}$ & \\
\hline EV2 & 13 & BV & - I don't know he is ni:ce & $\leftarrow$ \\
\hline EV3 & 14 & BV & he is speaking o le le le o le le e:: a a - & $\leftarrow$ \\
\hline EV4 & 15 & $\mathrm{BV}$ & he's very ca:lm and nice but $(($ pause $))>$ you know $<-$ & $\leftarrow$ \\
\hline OR2 & 16 & BV & also my my professor of la:w she i:s: from $<<$ esagerando la & \\
\hline OR2 & 17 & BV & apertura della $\varepsilon$ fiREnze $>-$ & \\
\hline
\end{tabular}




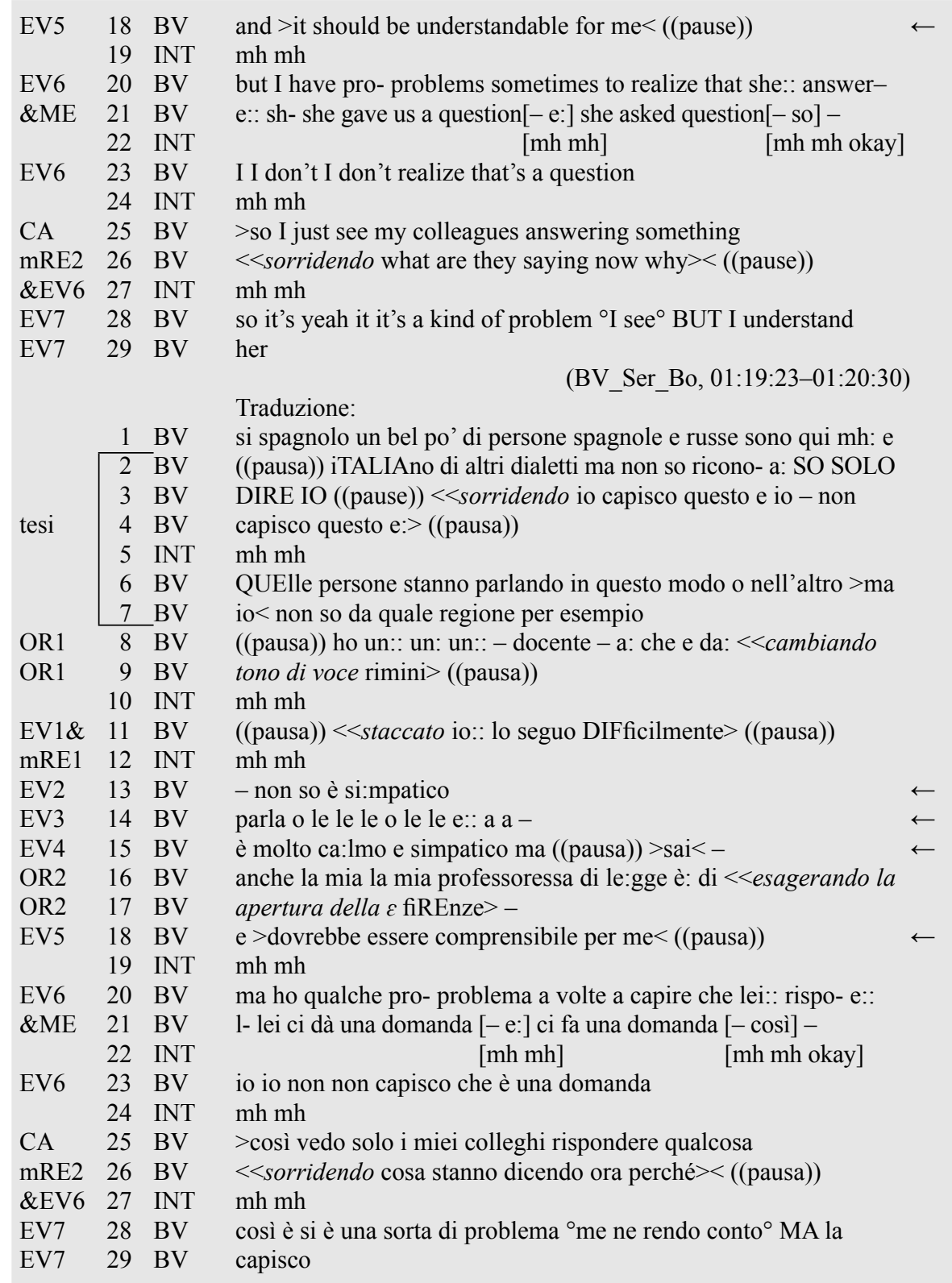

Nel "piano iniziale" di BV, la macro-funzione delle narrazioni in 10 (o almeno della prima storia raccontata) dovrebbe essere quella di esemplificare la tesi espressa in apertura della sequenza (righe 2-7). Secondo quanto da lei stessa affermato, la partecipante non sarebbe in grado di riconoscere il luogo di provenienza di un parlante "dialettofono" italiano, ma solo di valutare la comprensibilità o non comprensibilità 
della varietà linguistica usata ("> $>$ but $\mathrm{I}<\mathrm{I}$ don't know from which region for example ((pause)) I have a:: a: a:: - lecturer"). In realtà, in entrambi i racconti, l'io narrante menziona il luogo d'origine del locutore. Inoltre, la presa di posizione epistemico-valutativa "dovrebbe essere comprensibile per me" ("it should be understandable for me"; riga 18), con cui BV commenta anticipatamente il modo di parlare della professoressa di Firenze, si riferisce verosimilmente all'opinione comune per cui l'italiano standard sia simile, anche attualmente, alla varietà parlata nel capoluogo toscano. ${ }^{87}$ Tramite questa affermazione, l'intervistata si posiziona così epistemicamente nel mondo dell'interazione come persona competente nella storia sociolinguistica dell'italiano e come impegnata nel progetto conoscitivo di mapparne la variazione diatopica. Sebbene in una sequenza precedente BV avesse affermato di aver dapprincipio sottovalutato la " $<<$ commutazione dall'inglese all'italiano ricchezza linguistica $>$ " dell'italiano (minuti 19:38-20:20), l'io narrante (di) mostra quindi, nel corso dell'intervista, l'attuale interesse a supplire a questo iniziale errore di valutazione.

A questo riguardo, si noti inoltre che BV pronuncia solitamente, durante il colloquio, toponimi e glottonimi tedeschi e italiani nella lingua del paese dove i luoghi si trovano o i codici sono parlati (cfr. negli esempi di questo paragrafo "language from Veneto" e "Firenze" e negli esempi dei prossimi paragrafi "Hochdeutsch" e "Trento"). Tali termini sono verosimilmente prestiti in funzione referenziale, dovuti alla bassa frequenza o mancanza delle parole corrispondenti in inglese. Questi nomi svolgono comunque, talvolta, anche una funzione allusiva nell'interazione in corso. In altre parole, sembrano essere inseriti intenzionalmente nel discorso dall'intervistata per dimostrare le proprie competenze (meta)linguistiche (cfr., a prova di ciò, le variazioni nella qualità della voce alle righe 9 e 16-17 dell'esempio 10). In modo analogo, durante il colloquio, la partecipante inserisce occasionalmente espressioni sia dall'italiano sia dal tedesco (es. "ricchezza linguistica"), segnalandole con cambi nel tono della voce, ma senza pause ed esitazioni. Anche questi prestiti e inserzioni alludono più o meno intenzionalmente se non alle competenze plurilingui della partecipante, almeno alle conoscenze geografico-culturali da lei acquisite durante l'esperienza di mobilità.

Oltre che dal punto di vista strutturale e intertestuale, la sequenza, trascritta sopra in 10, è interessante anche a livello di analisi micro. Nel primo racconto metalinguistico, BV apre uno slot ("he is speaking") per riportare un discorso in una varietà di italiano, in questo caso quella usata a Rimini, e lo riempie con parole senza senso ("o le le le o le le e:: a a"; cfr. riga 14). L'intenzione è quella di imitare la prosodia, in particolare l'intonazione, dell'enunciato del personaggio più che riportare il contenuto del suo atto comunicativo. La presa di posizione di BV verso questo codice non è comunque svalutante come lo era, per esempio, quella veicolata dagli aggettivi usati per la "language from VE:NEto" (cfr. sopra in questo paragrafo e in generale, su questo tema, Hansen et al. 2010: 61). Prima e dopo il discorso riportato (cfr. riga 13 e 15), BV esprime infatti, per lo meno verbalmente,

87 Sull'associazione di attributi definitori dello "standard" alla "pronuncia fiorentina", si confronti, per esempio, Calamai (2011) che analizza test percettivi condotti in Toscana. 
valutazioni positive nei confronti del parlante ("he is ni:ce [...] he's very ca:Im and nice") e indirettamente della sua pronuncia, che sembra giudicare esteticamente bella. Nonostante ciò, BV difficilmente riesce a comprendere il locutore e la comunicazione frequentemente fallisce.

Il secondo esempio di atto comunicativo (semi-)fallito raccontato nella sequenza in 10 è contestualizzato più dettagliatamente da $\mathrm{BV}$, che comunque caratterizza l'episodio come ricorrente. L'interazione a lezione è infatti messa in scena tramite l'uso del tempo verbale presente (cfr. "I just see" alla riga 25) e del discorso diretto per riportare i propri pensieri alla riga 26 (" $<$ sorridendo what are they saying now why>"). Le parole degli altri personaggi non sono invece citate letteralmente dall'intervistata. Quest'ultima si limita infatti a menzionare il tipo di atto comunicativo da loro compiuto, ovvero chiedere e rispondere a una domanda. Peculiarità di intonazione costituiscono il tema anche di questa seconda narrazione metalinguistica. È infatti la mancata percezione di caratteristiche prosodiche che determina il (semi-)fallimento della comunicazione tra BV (destinataria indirizzata in un gruppo) e la professoressa di Firenze.

Considerando l'intera biografia linguistica, le prese di posizione valutative della partecipante nei confronti di varietà diatopiche, locali e non locali, sia di tedesco, sia di italiano, sia di serbo sono variabili dal punto di vista "estetico-affettivo" e ambivalenti da quello "sociale-strumentale". ${ }^{88} \mathrm{Da}$ un lato, infatti, ci sono alcune varietà che le piacciono (es. dialetto di Roma, di Belgrado, tedesco di Vienna) e altre che non le piacciono (es. dialetto da Dresda, italiano dal sud, lingua dal Veneto). Dall'altro lato, lo status sociolinguistico e il prestigio assegnato dall'intervistata ai codici "non standard" non è sempre chiaro. Varietà regionali non locali sono, infatti, frequentemente parlate in domini in $\mathrm{H}$ e da locutori con una posizione sociale riconosciuta come alta (nello specifico, studenti e professori universitari). In aggiunta, competenze nel dialetto tedesco locale sono rappresentate dalla partecipante come fondamentali per fare carriera in Alto Adige (cfr. anche esempio 3 al $\S$ V.3.4.1). Al contempo $\mathrm{BV}$ esprime, però, una certa incredulità nei confronti dei rapporti di potere tra varietà linguistiche nel macro-contesto d'arrivo. Nel fare ciò, spesso li contrappone alla situazione sociolinguistica nella sua città di nascita in Serbia, dove le persone si vergognano ("people are ashamed") di parlare con il loro accento ("their accent") da lei "adorato" (minuti 01:24:11-01:24:54). L'uso di varietà regionali non locali da parte di altri personaggi nel mondo delle storie determina, per di più, frequentemente un fallimento o un semi-fallimento della comunicazione in contesti comunicativi centrali della biografia linguistica di BV (cfr. anche $\S$ V.3.4 per l'importanza dell'ambito "università" nello spazio comunicativo narrato della donna). Perciò, l'intervistata manifesta il desiderio di acquisire competenze almeno passive in questi codici. Infine, sia qui menzionato che i racconti di interazioni, che hanno per oggetto le varietà non standard di italiano e tedesco, ricoprono talvolta un'altra macro-funzione nell'intervista con BV. In alcune sequenze del colloquio, la loro narrazione è infatti funzionale ad argomentare (più o meno esplicitamente) in favore

88 Per una recensione delle ricerche sugli "atteggiamenti linguistici" che hanno portato all'individuazione di queste due dimensioni, si confrontino, tra gli altri, Giles et al. (1987). 
della sostanziale uguaglianza delle varietà linguistiche parlate, questa volta, nelle regioni di partenza. In tali aree, la variazione diatopica è infatti valutata dalla narratrice come inferiore rispetto a quella riscontrata in Italia o in Germania.

\subsubsection{La selezione dell'italiano come "regola di default"}

Ritornando a considerare la distribuzione generale dei codici per ruoli interazionali nella tabella e figure in 9, il numero di volte in cui l'io narrato inizia un dialogo nella lingua d'origine ("serbo"/"nostra lingua"/“madrelingua"), in italiano standard $\mathrm{o}$ in tedesco standard si equivale grosso modo. Così l'intervistata posiziona se stessa, attraverso il proprio personaggio, come parlante equilibrata e "flessibile" ("flexible"; minuti 52:18-53:04) nel contesto migratorio. L'io narrato ha infatti mantenuto il codice d'origine e nello stesso tempo si adopera, a differenza di altre figure nelle sue storie (cfr., ad esempio, il comportamento del marito descritto sotto al § V.4.4.4), per utilizzare entrambi i codici d'arrivo nella nuova regione di residenza. D'altro canto, l'io narrante dichiara ripetutamente nel corso dell'intervista e, per esempio, in conclusione del brano in 11 che il suo impiego di "Hochdeutsch" è frequentemente rinegoziato in interazione dagli interlocutori in favore dell'italiano. Invece che in tedesco, le persone in Alto Adige, sia locali sia non locali, preferiscono infatti parlare a BV in italiano, sebbene questa scelta di lingua possa (talvolta) compromettere la comunicazione.

(es. 11)

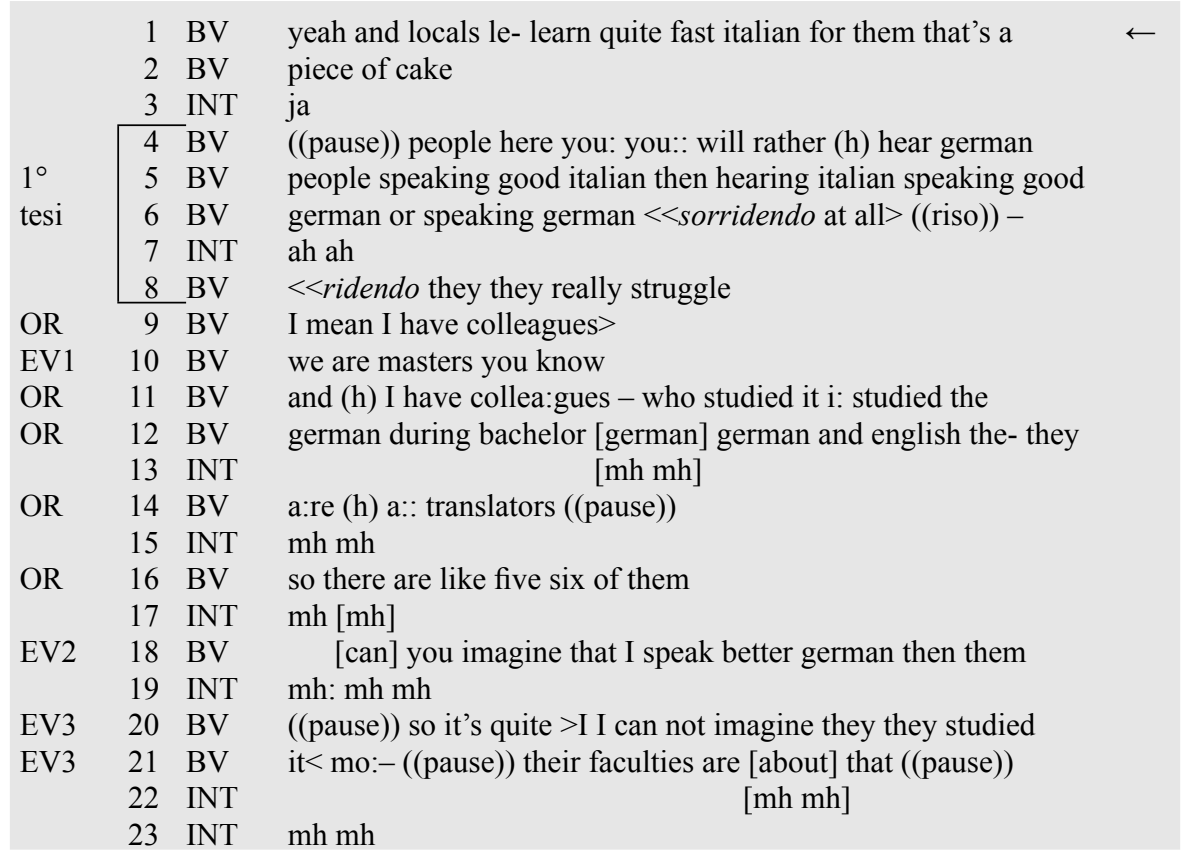




\begin{tabular}{|c|c|c|c|c|}
\hline mRE1 & 24 & BV & - so: even even for the courses they were so shy to speak & \\
\hline & 25 & BV & english german courses & \\
\hline & 26 & BV & (h) $-<<$ imitando sussurro also you know $>$ & \\
\hline ME1 & 27 & BV & (h) I I noticed that people: (came to me) when I was speaking & $\leftarrow$ \\
\hline ME1 & 28 & BV & german because & $\leftarrow$ \\
\hline mRE2 & 29 & BV & (h) a: even locals - and THOse traslators s- s- & \\
\hline mRE2 & 30 & BV & u:ao $-<<$ in italiano che bella $>(($ riso $))$ & $\leftarrow$ \\
\hline & 31 & INT & mh mh ((sorriso)) & \\
\hline EV4\& & 32 & BV & $<<$ sorridendo yeah but a: $>$ that that's means here nothing because & \\
\hline $2^{\circ}$ & 33 & BV & when I start hochdeutsch people: tend to: switch to italIAN & \\
\hline tesi & 34 & INT & $\mathrm{mh}:$ & \\
\hline & 35 & BV & $\begin{array}{l}\text { - and I am not that good in italian so ((pause)) } \\
\text { (BV_Ser_Bo, 41:25-42:43 }\end{array}$ & \\
\hline & 1 & BV & $\begin{array}{l}\text { Traduzione: } \\
\text { si e i locali imp-imparano abbastanza velocemente italiano per }\end{array}$ & \\
\hline & 2 & BV & loro è un gioco da ragazzi & \\
\hline & 3 & INT & si & \\
\hline & 4 & BV & ((pausa)) le persone qui tu: tu:: sentirai piuttosto (h) le persone & \\
\hline $1^{\circ}$ & 5 & BV & tedesche parlare bene italiano che gli italiani parlare bene & \\
\hline tesi & 6 & BV & tedesco o parlare tedesco $<<$ sorridendo del tutto $>$ ((riso)) - & \\
\hline & 7 & INT & ah ah & \\
\hline & 8 & BV & $<<$ ridendo loro loro veramente fanno fatica & \\
\hline OR & 9 & BV & intendo dire io ho dei colleghi> & \\
\hline EV1 & 10 & BV & noi siamo nella laurea magistrale sai & \\
\hline OR & 11 & BV & e (h) ho colle:ghi - che lo studiano l: hanno studiato il & \\
\hline OR & 12 & BV & tedesco durante la triennale [tedesco] tedesco e inglese 1:- & \\
\hline & 13 & INT & {$[\mathrm{mh} \mathrm{mh}]$} & \\
\hline OR & 14 & BV & loro so:no (h) a:: traduttori ((pausa)) & \\
\hline & 15 & INT & $\mathrm{mh} \mathrm{mh}$ & \\
\hline OR & 16 & BV & così ce ne sono cinque sei & \\
\hline & 17 & INT & $\mathrm{mh}[\mathrm{mh}]$ & \\
\hline EV2 & 18 & BV & [ti puoi] immaginare che io parlo tedesco meglio di loro & \\
\hline & 19 & INT & $\mathrm{mh}: \mathrm{mh} \mathrm{mh}$ & \\
\hline EV3 & 20 & BV & $(($ pausa $))$ così è abbastanza >io io non posso immaginare che loro & \\
\hline EV3 & 21 & BV & l'hanno studiato< pi:-((pausa)) le loro facoltà sono [su] questo & \\
\hline & 22 & INT & {$[\mathrm{mh} \mathrm{mh}]$} & \\
\hline & 23 & INT & $\mathrm{mh} \mathrm{mh}$ & \\
\hline mRE1 & 24 & BV & - così: anche anche per i corsi sono così timidi di parlare & \\
\hline & 25 & BV & inglese corsi di tedesco & \\
\hline & 26 & BV & (h) $-<<$ imitando sussurro anche sai $>$ & \\
\hline ME1 & 27 & BV & (venivano da me) quando & $\leftarrow$ \\
\hline ME1 & 28 & BV & stavo parlando tedesco perché & $\leftarrow$ \\
\hline mRE2 & 29 & BV & (h) a: anche I locali-e QUEi traduttori d- d- & \\
\hline mRE2 & 30 & BV & $\mathrm{u}:$ ao $-<<$ in italiano che bella $>(($ riso $))$ & 6 \\
\hline & 31 & INT & mh mh ((sorriso) $)$ & \\
\hline EV4\& & 32 & BV & $<<$ sorridendo si ma a: $>$ questo questo non significa qui nulla & \\
\hline $2^{\circ}$ & 33 & BV & perché quando inizio hochdeutsch le persone: tendono a: cambiar & \\
\hline tesi & 33 & BV & in itallANo & \\
\hline & 34 & INT & mh: & \\
\hline EV4 & 35 & BV & - e io non sono così brava in italiano quindi ((pausa)) & \\
\hline
\end{tabular}


Nella sequenza in 11, BV racconta una narrazione metalinguistica composta da due episodi. Inizialmente l'intervistata riferisce per sommi capi di come i compagni di corso "traduttori" preferiscano usare a lezione l'italiano perché si vergognano di parlare tedesco o inglese (cfr. il tipo di testo "rappresentazione informativa" o "resoconto" in Lucius-Hoene \& Deppermann 2004). Il racconto della seconda vicenda in 11 è finalizzato ad aggiungere dettagli alla situazione appena illustrata (cfr. l'enunciato "also you know" alla riga 26). Nella narrazione, il personaggio di BV nel ruolo di parlante si serve del tedesco in contesto universitario di fronte alla classe. Similmente a DK (cfr. esempio 9 al $\S$ V.4.3.3), la valutazione delle proprie abilità linguistiche è attribuita in forma di discorso diretto ad altri personaggi della storia (cfr. riga 30). Nonostante ciò, BV si posiziona comunque come parlante attiva, iniziatrice del dialogo (cfr. righe 27-28).

Gli episodi narrati in 11 hanno la macro-funzione di supportare due tesi. La prima, espressa all'inizio della sequenza (righe 4-8), consiste nell'opinione, piuttosto diffusa in Alto Adige, della scarsità o addirittura assenza di competenze linguistiche in tedesco da parte dei parlanti italofoni, sia originari della provincia di Bolzano, sia provenienti di altre regioni italiane (cfr., in questo volume, il § II.1.2.1). La seconda tesi, enunciata alla fine del brano (righe 32-33), sostiene che l'italiano sia immancabilmente scelto come lingua di comunicazione dagli interlocutori dell'intervistata, indipendentemente dal fatto che quest'ultima selezioni antecedentemente 1" "Hochdeutsch". La formulazione di quest'ultima tesi segue la narrazione di un episodio vissuto in prima persona, in cui la partecipante esemplifica il cambio di lingua in questione (cfr. righe 26-30). Si noti che la rinegoziazione di codice in favore del tedesco è spesso rappresentata come un comportamento linguistico molto comune nel contesto d'arrivo da locutori sia locali sia stranieri (cfr. Veronesi 2008a e $\S$ II.1.2.2). ${ }^{89}$

In questa seconda storia, la narratrice si serve alla riga 30 dell'alternanza di codice per citare parole altrui in discorso diretto con una funzione che definirei "iconica". Il passaggio all'italiano nell'enunciato "u:ao - che bella" può essere più o meno conforme alla realtà. Indipendentemente da ciò, l'inserzione sta in un rapporto di somiglianza con - e, quindi, rappresenta iconicamente - la tipica reazione alla selezione del tedesco standard da parte della partecipante in contesto altoatesino. Tale reazione consiste infatti nella commutazione all'italiano da parte dell'in-

89 In particolare, anche nelle biografie linguistiche discusse in Veronesi 2008a, i parlanti italofoni locali lamentano il frequente passaggio all'italiano da parte degli interlocutori tedescofoni, nonostante un loro precedente avvio della comunicazione in tedesco. Inoltre, affermano di riuscire ad imporre il tedesco come codice della comunicazione solo nelle interazioni con segretari o con clienti al telefono, ovvero, secondo l'interpretazione della ricercatrice, quando si trovano in una "posizione di forza". Per Veronesi (2008a: 145-146), tali malintesi nella comunicazione intergruppo potrebbero derivare da una diversa interpretazione del "rituale della disponibilità" ad adottare la lingua dell'altro. Infatti, i parlanti tedescofoni raccontano di commutare all'italiano per mettere a proprio agio gli interlocutori italofoni. Invece, questi ultimi narrano di sentire messe in discussione le proprie competenze nella lingua seconda da questo comportamento. 
terlocutore. Questo comportamento è attribuito esplicitamente da BV, in un'altra narrazione metalinguistica, non solo ai locutori italofoni, ma anche ai parlanti tedescofoni locali. Questi ultimi, infatti, "sono imbarazzati" ("are embarrassed") di parlare "Hochdeutsch" con l'io narrato (minuti 30:30-31:13). A differenza che nell'intervista con VM (cfr. esempio 5 al $\S$ V.4.2.2), la funzione dell'inserzione di un enunciato in italiano in 11 non è quindi quella di indicizzare l'identità linguistica del parlante, tra quelle salienti nel macro-contesto d'arrivo. Piuttosto, l'alternanza mira a rappresentare iconicamente il comportamento di tutti gli interattanti - vale a dire, i) locali italofoni, ii) locali tedescofoni e iii) non locali - al momento di comunicare con l'intervistata (cfr. anche l'impiego delle categorie "even locals - and THOse traslators" alla riga 29 e l'attribuzione della qualifica "locali" ai parlanti tedescofoni in apertura del brano alla riga 1 ).

Infine, in discorso diretto, la narratrice riporta una presa di posizione valutativa positiva dei personaggi della storia (stance subject) nei confronti dell'io narrato (stance object) e, in particolare, del suo modo di parlare tedesco ("u:ao - che bella"). L'espressione di apprezzamento colloca, almeno nello spazio comunicativo narrato di $\mathrm{BV}$, la varietà standard di questo codice come una lingua (seconda) desiderata da tutti i parlanti residenti in Alto Adige. Dal momento che l'io narrato conosce il tedesco standard, l'io narrante si posiziona così nella sequenza in 11 come parlante dalle competenze linguistiche desiderate, anche se non abbastanza autorevole per determinare la lingua a lei più favorevole in una conversazione.

\subsubsection{I prestiti in funzione iconica e il ladino}

Considerando nuovamente la distribuzione delle varietà linguistiche e di contatto nella tabella e figure in 9, la commutazione di codice ha un ruolo marginale come mezzo di comunicazione sia attivo sia ricettivo nelle narrazioni di interazioni di BV a differenza di quanto si riscontrava in quelle di VM e DK. In solo un racconto, l'intervistata attribuisce infatti l'enunciazione mistilingue in italiano/inglese al proprio personaggio nel ruolo di parlante in conversazioni con amici, apprendenti avanzati di inglese e intermediari di italiano. Nessun personaggio si rivolge invece all'io narrato, destinataria o ascoltatrice occasionale, alternando lingue diverse in uno stesso discorso. Piuttosto, BV racconta di alcune conversazioni metalinguistiche, in cui espressioni segnalate da un codice diverso da quello dell'interazione principale hanno la funzione iconica di esemplificare le sue caratteristiche lessicali o prosodiche in contrasto con altre lingue conosciute dagli interattanti.

A questo riguardo, nella sequenza in $12, \mathrm{BV}$ riporta per esempio di un dialogo metalinguistico tra il suo personaggio e un compagno di corso sulle peculiarità della lingua ladina. Tali riflessioni metalinguistiche sono inserite in una conversazione più ampia, anch'essa trascritta di seguito, in cui lo studente, iniziatore dell'interazione, argomenta i motivi della grande variazione diatopica dell'italiano. Dal momento che la lingua principale della comunicazione non è chiaramente menzionata da $\mathrm{BV}$, ho categorizzato il codice base di questo dialogo come una varietà non identificata in cui sono inseriti prestiti in ladino (n.i. (+ lad)). 
(es. 12)

\begin{tabular}{|c|c|c|c|}
\hline $\mathrm{AB} \&$ & 1 & BV & e:: the- there is colleague also who who explains me that they \\
\hline \multirow[t]{2}{*}{ OR1 } & 2 & BV & are from e: ladin origin \\
\hline & 3 & INT & $\mathrm{mh} \mathrm{mh}$ \\
\hline \multirow[t]{2}{*}{ OR1 } & 4 & BV & $(($ pause $))$ near trento he lives [ $>$ one other] colleague $<{ }^{90}$ \\
\hline & 5 & INT & {$[\mathrm{mh} \mathrm{mh}]$} \\
\hline ME & 6 & BV & so he told me oh: italy what's italy italy doesn't exist as a \\
\hline ME & 7 & BV & nation \\
\hline \multirow[t]{2}{*}{ CA1 } & 8 & BV & {$[->$ he $]$ told me } \\
\hline & 9 & INT & {$[\mathrm{mh} \mathrm{mh}]$} \\
\hline OR2 & 10 & BV & it was interesting $<$ he: he studies political science $[-$ and $]$ \\
\hline$\&$ & 11 & INT & {$[\mathrm{mh} \mathrm{mh}]$} \\
\hline EV1 & 12 & BV & I also stand on tha- on that point \\
\hline CA1 & 13 & BV & (h) $-<<$ sorridendo he said what what's that $>$ I mean $[-$ we $]$ we \\
\hline$\&$ & 14 & INT & {$[\mathrm{mh} \mathrm{mh}]$} \\
\hline \multirow[t]{2}{*}{ EV2 } & 15 & BV & are all from different origins and (h) you know I I am from a \\
\hline & 16 & BV & ladin ah:mh ((pause)) population \\
\hline $\mathrm{CA} 2$ & 17 & BV & and then he explains me so: many words fo:r \\
\hline CA2 & 18 & BV & (h) ((pause)) for example goo:d evening o:r and something to: to \\
\hline \multirow[t]{2}{*}{ CA2 } & 19 & BV & explain me that's not italian also for days you know we: can \\
\hline & 20 & INT & $\mathrm{mh} \mathrm{mh}$ \\
\hline CA3 & 21 & BV & - osoco \\
\hline CA4 & 22 & BV & $<<$ imitando parlato urlato what's that $>$ \\
\hline CA5 & 23 & BV & he said $<<$ staccato con tono di voce basso that's - my language $>$ \\
\hline CA6 & 24 & BV & $>$ but is it italian $<$ \\
\hline $\mathrm{mRE}$ & 25 & BV & no: it's not $<<$ ridendo italian $>$ \\
\hline RI\& & 26 & BV & {$[-<<$ ridendo okay - well I respect $>][(($ riso $))]$} \\
\hline EV3 & 27 & INT & $\begin{array}{l}\text { [mh mh yeah] } \\
\text { (BV_Ser_Bo, 33:32-34:23) }\end{array}$ \\
\hline $\mathrm{AB} \&$ & 1 & BV & $\begin{array}{l}\text { Traduzione: } \\
\text { e:: c- c'è un collega anche che che mi spiega che loro sono di e: }\end{array}$ \\
\hline \multirow[t]{2}{*}{ OR1 } & 2 & BV & origini ladine \\
\hline & 3 & INT & $\mathrm{mh} \mathrm{mh}$ \\
\hline \multirow[t]{2}{*}{ OR1 } & 4 & BV & $(($ pausa $))$ vicino trento vive $[>$ un altro] collega $<$ \\
\hline & 5 & INT & {$[\mathrm{mh} \mathrm{mh}]$} \\
\hline ME & 6 & BV & così mi ha detto oh: l'italia cos'è l'italia l'italia non esiste \\
\hline ME & 7 & BV & come nazione \\
\hline \multirow[t]{2}{*}{ CA1 } & 8 & BV & {$[->$ lui $]$ mi ha detto } \\
\hline & 9 & INT & {$[\mathrm{mh} \mathrm{mh}]$} \\
\hline OR2 & 10 & BV & era interessante $<$ lui: lui studia scienze politiche $[-\mathrm{e}]$ \\
\hline$\&$ & 11 & INT & {$[\mathrm{mh} \mathrm{mh}]$} \\
\hline EV1 & 12 & BV & anch'io ho que- questo punto di vista \\
\hline CA1 & 13 & BV & (h) $-<<$ sorridendo ha detto cosa cos'è questo $>$ intendo [-noi] noi \\
\hline$\&$ & 14 & INT & {$[\mathrm{mh} \mathrm{mh}]$} \\
\hline $\mathrm{EV} 2$ & 15 & BV & siamo tutti di origini diverse e $(\mathrm{h})$ sai io io sono da una ladina \\
\hline
\end{tabular}

90 BV specifica "un altro collega" perché in una narrazione di interazione precedente aveva raccontato delle difficoltà di un compagno, anch'esso proveniente da una cittadina nella provincia di Trento, a comprendere la varietà linguistica parlata dalla nonna, residente in un paese vicino. 


\begin{tabular}{|c|c|c|c|c|}
\hline & 16 & $\mathrm{BV}$ & ah:mh ((pause)) popolazione & \\
\hline CA2 & 17 & $\mathrm{BV}$ & e poi mi spiega così: molte parole pe:r & \\
\hline CA2 & 18 & BV & (h) ((pause)) per esempio buo:na sera o: e qualcosa per: per & \\
\hline \multirow{2}{*}{ CA2 } & 19 & BV & spiegarmi che non è italiano anche per i giorni sai noi: possiamo & \\
\hline & 20 & INT & $\mathrm{mh} \mathrm{mh}$ & \\
\hline CA3 & 21 & $\mathrm{BV}$ & - osoco & $\leftarrow$ \\
\hline CA4 & 22 & $\mathrm{BV}$ & $<<$ imitando parlato urlato cos'é questo $>$ & \\
\hline CA5 & 23 & $\mathrm{BV}$ & ha detto $<<$ staccato con tono di voce basso questa è - la mia & $\leftarrow$ \\
\hline CA5 & 23 & BV & lingua $>$ & $\leftarrow$ \\
\hline CA6 & 24 & BV & $>$ ma è italiano $<$ & \\
\hline $\mathrm{mRE}$ & 25 & $\mathrm{BV}$ & no: non è $<<$ ridendo italiano $>$ & \\
\hline RI\& & 26 & BV & {$[-<<$ ridendo okay - bene rispetto $>][(($ riso $))]$} & \\
\hline EV3 & 27 & INT & [mh mh si] & \\
\hline
\end{tabular}

Nella prima parte del brano, l'intervistata usa strategicamente la possibilità di dislocare parole ad altri personaggi per condividere (se non per attribuire) la responsabilità delle affermazioni citate con altre figure del racconto (cfr. righe 6-7 e 13-16). Tale strategia ha il risultato di dare autorevolezza alla sua argomentazione: infatti, il responsabile del discorso animato dall'io narrante è categorizzato come un esperto in quanto "studente di scienze politiche" (cfr. riga 10). In aggiunta, il ladino è definito da questo ultimo come "my language" (mia lingua) alla riga 23. Indipendentemente dalla fedeltà o meno di tale dichiarazione al dialogo originale, si noti che la denominazione per il codice minoritario nel contesto d'arrivo ricopre nella sequenza in 12 una funzione "enfatica" analoga a quella di espressioni simili, usate per chiamare i codici d'origine dopo esperienza migratoria nelle biografie linguistiche del corpus (cfr. $§$ IV.3 e seguenti).

Nel brano in 12, BV impiega inoltre un'espressione ladina o una parola che potrebbe essere ladina, ossia "osoco", alla riga 21 . Non è chiarissimo cosa questa espressione significhi. La donna forse cita l'interiezione ladina "òsco, oscocàn", voce senza significato usata in varie circostanze. ${ }^{91}$ In alternativa, semplicemente imita il suono di una parola ladina senza essere interessata a specificarne il contenuto lessicale (per una strategia analoga si confronti anche l'esempio 10 al $\S$ V.4.4.1). Indipendentemente dal suo significato, questa citazione è funzionale da un lato a (di)mostrare iconicamente la differenza tra il ladino e l'italiano. Infatti, l'unità lessicale e/o prosodica riportata è, in conseguenza delle sue peculiarità formali, immagine e al contempo prova, almeno per l'interlocutrice italofona, dell'alterità dei due codici. Dall'altro, in modo analogo ai riferimenti alla storia della lingua italiana nell'esempio 10 (cfr. sempre $\S$ V.4.4.1), la citazione di questa espressione dimostra l'interesse dell'io narrante - unica tra le tre partecipanti a menzionare il ladino nelle sue narrazioni di interazioni - per la situazione sociolinguistica d'arrivo. Nonostante il periodo di soggiorno piuttosto breve in Alto Adige (tre anni e cinque mesi), $\mathrm{BV}$ ha infatti acquisito conoscenze piuttosto dettagliate riguardo ai codici parlati sul territorio. Infine, a livello formale, il riportare un enunciato in ladino o in simil-la-

91 Si veda Tamburin (1997), vocabolario ladino-italiano consultabile online sul sito <http://www. istitutoladino.it $/$ index.php?option $=$ com_content\&view $=$ article\&id=151 $>$ (18.10.2018). 
dino innesca una (seconda) transizione dal discorso riportato indiretto a quello diretto (cfr. righe 22-26). Perciò si colloca tra le strategie di drammatizzazione del racconto insieme, per esempio, alle variazioni nella prosodia e nella qualità della voce usate per mettere in scena il dialogo successivo. Il passaggio da un codice a un altro, seppur limitato a una sola parola, porta dunque a termine nella sequenza in 12 diverse funzioni a vari livelli di strutturazione del racconto.

\subsubsection{L'inglese}

Un'ultima considerazione da trarre sulla base delle immagini in 9 riguarda l'allocazione dell'inglese nei racconti di interazione di BV. Come già osservato nel $\S$ V.3.4, l'inglese ha una portata comunicativa maggiore in Alto Adige per BV rispetto a per le altre due intervistate. Il codice è infatti impiegato dagli amici e dal marito anche in contesto lavorativo. Il motivo è che quest'ultimo padroneggia esclusivamente questa lingua tra quelle "parlate" nella regione d'arrivo. Al contrario, BV, pur affermando di utilizzare l'inglese abbastanza frequentemente in provincia di Bolzano (cfr. la rappresentazione del repertorio dichiarato della partecipante nella figura 3 al $\S$ V.2.4.3), ${ }^{92}$ non rappresenta il proprio personaggio come parlante attiva del codice nelle proprie narrazioni di interazioni.

Nell'attribuirsi questo comportamento linguistico, l'io narrante si disallinea in primo luogo da quello assunto dal marito $\mathrm{DV}$, anch'egli intervistato per la presente ricerca. Le mancate competenze nei codici d'arrivo, soprattutto in italiano, del consorte sono infatti per l'intervistata causa di forti limitazioni nella vita sociale della coppia. Inoltre determinano un aumento di responsabilità burocratiche e amministrative per lei stessa (minuti 57:07-58:32). La descrizione di BV concorda, almeno in parte, con la rappresentazione di sé che dà il marito nel corso della sua biografia linguistica. L'uomo afferma infatti di utilizzare quasi esclusivamente l'inglese con gli amici e al lavoro nella regione d'arrivo. Solo occasionalmente si serve invece del tedesco. Il codice, appreso tramite un corso di lingua a Vienna, è adoperato nei negozi esclusivamente quando non è possibile comunicare in inglese. Inoltre, pur sostenendo di voler iniziare a studiare l'italiano prima di lasciare l'Alto Adige, DV manifesta, al contrario della moglie, uno scarso interesse per acquisire competenze nei dialetti tedeschi locali e in varietà "non standard" dei codici di arrivo.

In secondo luogo, un'indifferenza analoga per le lingue locali e, in particolare, per l'apprendimento del tedesco è ascritta dalla narratrice anche ad altri (tipi di) personaggi nelle sue storie. Tra questi, c'è in particolare la comunità di studenti "internazionali" e delle loro famiglie. Il figlio è infatti definito dalla partecipante come un caso "unico" tra i "bambini internazionali" ("international kids") per il suo alto livello di conoscenza del tedesco (minuti 49:16-50:02). Nel prendere posizione contro questo modo di comportarsi in contesto migratorio, la narratrice rappresenta al contempo se stessa - coerentemente con quanto emerge nelle narrazioni discusse

92 Queste dichiarazioni sono confermate anche da osservazioni partecipanti della ricercatrice condotte nella mensa e nel caffè dell'università di Bolzano. 
nei paragrafi precedenti - come persona interessata ad approfondire le proprie conoscenze e a stabilire contatti con la comunità linguistica d'arrivo. Questa volontà si manifesta nella scelta di interagire nelle lingue del posto. L'uso dei codici "locali", invece dell'inglese come lingua franca, si riconnette quindi a un desiderio più ampio, espresso dalla partecipante almeno al momento dell'intervista con la specifica ricercatrice (italofona e non locale), di partecipazione alla vita sociale ed eventualmente economica del nuovo paese di residenza.

\subsubsection{Una parlante "flessibile" senza potere di negoziazione di codice}

Dall'analisi esposta nei paragrafi precedenti possono essere tratte alcune considerazioni conclusive sulle prese di posizione e gli aspetti di sé che BV mette in scena nel (co-)costruire la propria biografia linguistica vis-à-vis alla specifica ricercatrice. Il fatto che il personaggio dell'intervistata svolga prevalentemente il ruolo di ascoltatrice (destinataria o occasionale) nelle narrazioni di interazioni, ambientate in Alto Adige, ha almeno due conseguenze rispettivamente a livello "presentazionale" e "interazionale" (cfr. l'esame degli usi linguistici per interattanti nelle narrazioni di VM al §V.4.2 e sgg. per conclusioni in parte simili). Da un lato, la donna rappresenta spesso l'avvio della comunicazione e così, indirettamente, la selezione di codice in diversi contesti della regione d'arrivo come subordinati alla volontà di altri personaggi nel mondo della storia. L'io narrato è dunque raramente agente nel determinare gli usi linguistici dopo l'esperienza di mobilità. Dall'altro lato, la frequente dislocazione, talvolta anche multipla, di discorsi ad altri personaggi permette all'io narrante di tematizzare specifiche questioni, talvolta metalinguistiche, producendo distanza tra sé e le affermazioni riportate. Questa strategia ha la funzione di condividere la responsabilità per quanto detto con altre figure. Al contempo aumenta l'autorevolezza delle tesi enunciate dal momento che queste sono attribuite a personaggi qualificati come esperti. Nei casi limite consente, infine, all'io narrante di eludere completamente la paternità/maternità dei giudizi (meta)linguistici espressi o, come nell'intervista con DK, di attribuire ad altri prese di posizione valutative positive rispetto alle proprie competenze nei codici d'arrivo.

Similmente a quanto illustrato per VM e DK, l'intervistata rappresenta inoltre, durante le sue storie, gli usi linguistici del proprio io narrato e, al contempo, si allinea o disallinea rispetto agli usi linguistici di altri personaggi. Nel fare ciò, si posiziona rispetto a determinate identità linguistiche salienti per se stessa e/o per la comunità linguistica d'arrivo. Queste possono essere ulteriormente specificate sulla base dell'analisi della distribuzione dei tipi di codici per ruoli interazionali nelle narrazioni di dialoghi.

In primo luogo, l'intervistata mette in scena frequentemente conversazioni in cui è destinataria di atti comunicativi in varietà diatopiche non standard, locali o non locali, di italiano e tedesco. Il personaggio di BV ha tutt'al più competenze passive limitate in alcuni questi codici (ad es. in dialetto tedesco locale), ma non ne è mai parlante attiva. La partecipante esprime inoltre una certa incredulità nei confronti del prestigio di queste varietà linguistiche nel contesto d'arrivo, altoatesino in 
particolare e italiano in generale. Tale situazione sociolinguistica è infatti opposta a quella nel paese di provenienza. Il frequente fallimento della comunicazione, dovuto all'incomprensione dei codici in questione, non è però ricondotto, almeno discorsivamente, a una propria presa di posizione (assolutamente) negativa e svalutante nei loro confronti (cfr. esempio 10 al $\S$ V.4.4.1). Al contrario, le varietà linguistiche menzionate sono usate da interlocutori con una posizione sociale riconosciuta e in un contesto centrale nella biografia linguistica di BV, ovvero da professori e compagni di corso in università. Perciò, l'intervistata aspira ad acquisire competenze almeno passive in questi codici. Varietà linguistiche regionali e locali rappresentano quindi "lingue desiderate" nel repertorio individuale di BV (cfr. Dal Negro \& Iannàccaro 2003 per il concetto), per esempio, a differenza di quanto avviene in quello di DK.

In secondo luogo, il personaggio di BV si serve in modo bilanciato del codice d'origine e delle varietà standard dei codici d'arrivo nelle poche narrazioni di interazioni in cui è iniziatrice del dialogo. Come lei stessa afferma, la narratrice si posiziona in questo modo come "parlante flessibile" in grado di adattarsi a qualsiasi situazione comunicativa e/o scelta di lingua in contesto altoatesino (minuti 52:1853:04). Tuttavia, l'io narrante lamenta più volte la scarsità delle occasioni in cui le è possibile condurre una conversazione in tedesco standard, codice da lei idealmente preferito per la comunicazione (ma vedi più sotto in questo paragrafo). In particolare, gli interattanti italofoni, locali e non locali, e anche i parlanti tedescofoni altoatesini ammirano le competenze in "Hochdeutsch" della partecipante. L'io narrato non ha però solitamente il "potere" di decidere la lingua della conversazione. In altre parole, l'attitudine alla flessibilità di BV deve misurarsi e risulta talvolta limitata da una bassa capacità di contrattazione nei processi di negoziazione di codice in contesto migratorio.

Si noti che la rappresentazione, rivendicata da BV tanto per il proprio personaggio quanto per il proprio io attuale, di parlante flessibile (se non di parlante preferibilmente tedescofona) collide con la sua scelta di condurre l'intervista in inglese invece che in uno dei codici d'arrivo (cfr. anche $\S$ V.2.4.3). Tuttavia, la donna ha successo nel rinegoziare il significato di questa iniziale selezione di codice nel corso del colloquio. In particolare, il mancato uso dell'inglese da parte dell'io narrato nel ruolo di parlante nelle sue storie le permette, da un lato, di provare la propria volontà di entrare in contatto con la popolazione "autoctona" del nuovo contesto di residenza. Questo tentativo diventa particolarmente rilevante se si considera che il comportamento del proprio personaggio differisce, nella rappresentazione dell'intervistata, da quello assunto da altre figure nelle sue storie. Queste sono sia persone concrete (es. il marito) sia tipi ipotetico-generali (es. la comunità di studenti "internazionali" e le loro famiglie). Dall'altro lato, l'intervistata tematizza frequentemente, per esempio nelle sezioni valutative delle sue narrazioni, le proprie conoscenze riguardo alla storia della lingua italiana e tedesca o riguardo a caratteristiche prosodiche e lessicali delle varietà parlate sul territorio a livello regionale $\mathrm{o}$ nazionale. In questo modo, l'io narrante (di)mostra la sua curiosità e il suo impegno attuali nel far propri e padroneggiare norme e discorsi (meta)linguistici della comunità d'arrivo. Tale volontà di "inclusione" nel contesto di arrivo costituisce verosi- 
milmente un'altra faccia del desiderio di apprendimento di varietà linguistiche locali e del proprio posizionamento come parlante "flessibile" a livello sia agentivo sia epistemico. Questa rappresentazione di sé non è vista comunque dall'intervistata in contraddizione con la volontà di mantenere la propria lingua d'origine, non solo nel dominio familiare.

Una terza osservazione conclusiva riguarda le pratiche di commutazione e di inserzione di codice per come sono rappresentate e strategicamente utilizzate dalla partecipante al momento dell'intervista. A livello di contenuto, l'enunciazione mistilingue è marginale: questa è infatti codice di comunicazione in solo una narrazione della partecipante. L'intervistata narra, invece, piuttosto di dialoghi in cui gli interattanti citano espressioni da altre lingue per esemplificarne le caratteristiche lessicali. A livello di forma, BV si serve tuttavia di pratiche di contatto reali più frequentemente di DK, anche se più raramente di VM, nel corso del colloquio. Proprio dal confronto tra due brani in cui la commutazione o l'inserzione di codice sono impiegate per citare un discorso diretto altrui emerge, a mio avviso, una differenza nell'utilizzo di questa strategia da parte delle due intervistate. Il passaggio di VM da una lingua all'altra è infatti spesso funzionale a indicizzare una categoria identitaria locale, come, per esempio, l'appartenenza al gruppo linguistico tedescofono di uno dei suoi personaggi (cfr. es. 5 al § V.4.2.2). Al contempo, l'adozione del tedesco (di)mostra le competenze della partecipante in tale codice. Invece, l'alternanza da una lingua all'altra nell'uso di BV mi sembra avere principalmente una funzione iconica. Tramite questa strategia, l'intervistata rappresenta infatti le peculiarità (lessicali e prosodiche) delle varietà linguistiche, oggetto del racconto. In alternativa, l'alternanza di lingua sta in un rapporto di somiglianza con la tipica rinegoziazione della propria selezione del tedesco da parte di tutti gli interlocutori, indipendentemente dal gruppo linguistico a cui appartengono e, quindi, dalla loro identità linguistica nel contesto di arrivo (cfr. rispettivamente gli esempi 11 e 12 ai $\S$ V.4.4.2 e V.4.4.3). Infine, sempre funzione iconica ha, a mio avviso, l'imitazione di caratteristiche prosodiche/intonative di una varietà linguistica tramite parole senza senso da parte di BV. Questa strategia è utilizzata dalla donna in cinque narrazioni per rappresentare il modo di parlare di alcuni personaggi delle sue storie (cfr., tra queste, la sequenza in $10 \mathrm{al} \S$ V.4.4.1).

In conclusione, come già accennato sopra, varietà non locali di italiano e tedesco tendono a essere vincolate al tipo di locutore nella rappresentazione di BV. Queste sono infatti parlate esclusivamente da professori e compagni di corso in contesto universitario o a scuola. I codici "autoctoni", ovvero italiano e dialetto tedesco locale - il tedesco standard non è infatti per BV propriamente una lingua locale, mentre il ladino è raramente lingua di comunicazione a Bolzano - sono utilizzati da diversi tipi di interattanti. Tuttavia, BV qualifica nel corso della sua biografia linguistica alcuni parlanti come locutori tipici di italiano: questi sono, similmente a $\mathrm{VM}$, le forze dell'ordine. Il dialetto tedesco locale, che è acquisito anche da alcuni parlanti alloctoni, non è invece usato esclusivamente da determinati tipi di interattanti. Piuttosto il codice è rappresentato dall'intervistata, nella narrazione di interazione discussa al §V.3.4, come migliore codice possibile da usare al lavoro e/o nell'amministrazione di un ospedale per raggiungere i propri obiettivi. 


\subsection{Conclusioni: il ruolo distintivo del tedesco}

L'analisi delle narrazioni di interazione per interattanti ha permesso di tratteggiare tre tipi di parlanti "mobili", contestualizzati nella realtà sociolinguistica altoatesina. La peculiare configurazione del repertorio, rappresentata dalle tre donne nel corso delle loro interviste, è infatti strettamente interconnessa con lo specifico rapporto tra codici che vige localmente in provincia di Bolzano. VM, DK e BV conoscono entrambi i codici d'arrivo. D'altro canto, sono ancorate in maniera diversa al contesto d'arrivo per via, tra l'altro, dell'età al momento dell'emigrazione, della durata del soggiorno in Alto Adige e della causa di trasferimento. In aggiunta, le tre partecipanti portano con sé un diverso bagaglio di competenze linguistico-comunicative, acquisite nelle località di partenza. Dall'analisi dei paragrafi precedenti emerge comunque un elemento in comune. La conoscenza di varietà di tedesco, in particolare, la competenza in tedesco standard, ha per tutte e tre le intervistate un valore distintivo, per lo meno al momento di ricostruire la loro biografia linguistica insieme alla specifica ricercatrice.

In particolare, VM distingue se stessa da altri cittadini stranieri in Alto Adige in quanto parlante tedescofona e non solo italofona. Invece DK differenzia se stessa dai coetanei, sia stranieri sia soprattutto nati in Alto Adige, in quanto parlante tedescofona stilisticamente competente proprio grazie all'origine alloglotta dei genitori. $\mathrm{Nel}$ fare ciò, la donna attua una rivalutazione del proprio repertorio già plurilingue di partenza. Infine, BV distingue se stessa da altri studenti universitari sia autoctoni, sia provenienti da altre regioni italiane, sia "internazionali" per le proprie competenze in tedesco standard (oltre che per l'interesse verso le varietà linguistiche locali e per la volontà di servirsene al posto dell'inglese come lingua franca). La rilevanza delle varietà di tedesco emerge non solo contenutisticamente, ma talvolta anche formalmente nel corso delle interviste esaminate. Si confrontino, ad esempio, le frequenti commutazioni o inserzioni in tedesco da parte di VM o la proliferazione di glottonimi per indicare le diverse varietà di questo codice nell'intervista con DK.

I motivi, per cui alle varietà di tedesco è riservato un tale valore simbolico e, quasi, un maggiore prestigio nella prospettiva delle partecipanti, non sono ovviamente intrinseci al codice. Ciò è vero anche se in alcuni casi sembrano essere rappresentati come tali dalle tre narratrici e, soprattutto, da altri intervistati del corpus (cfr. più sotto in questo paragrafo). Piuttosto, il ruolo distintivo attribuito al tedesco è, a mio avviso, in larga parte determinato dal contesto interazionale e dal macrocontesto, in cui l'intervista si svolge. Da un lato, le partecipanti raccontano infatti la propria biografia linguistica a un'interlocutrice italofona non locale, che conosce il tedesco come lingua seconda e che ha un atteggiamento positivo verso questo codice. I modi e le difficoltà di apprendimento del tedesco costituiscono quindi un'esperienza condivisa tra le intervistate e la ricercatrice. La trattazione di questo tema instaura perciò un rapporto più paritario tra gli interattanti della conversazione in via di svolgimento rispetto, per esempio, a una discussione sui modi di acquisizione dell'italiano. Dall'altro lato, la preferenza per l'apprendimento dell'italiano da parte dei cittadini stranieri in Alto Adige è un argomento piuttosto dibattuto localmente a livello politico e mass-mediatico (cfr., nello specifico, § II.2.3 e II.2.4). È 
quindi probabile che le partecipanti vogliano o sentano la necessità di posizionarsi rispetto a questa questione e/o si aspettino che l'intervistatrice intenda interrogarle a riguardo. In altre parole, in conseguenza di discorsi metalinguistici diffusi nella società altoatesina, le narratrici valuterebbero, al momento di narrare la propria biografia linguistica, i modi di acquisizione e d'uso del tedesco come temi più coinvolgenti e più salienti sia per la specifica interlocutrice, sia per un pubblico immaginario più ampio. Infine, come accennato sopra, le prese di posizione riguardo a una maggiore difficoltà - in alcuni casi, dipinta addirittura come un'impossibilità fisiologica-mentale - di apprendere il tedesco rispetto all'italiano sono molto frequenti nelle interviste raccolte. Tali difficoltà sono menzionate da numerosi partecipanti sia per giustificare una mancata competenza nel codice, sia per motivare l'importanza di imparalo per primo dopo l'arrivo in provincia di Bolzano. Da queste caratteristiche, presentate come strutturali e/o connaturate alla lingua tedesca, derivano - e tramite queste sono giustificati -, nell'ottica di alcuni informanti, i vantaggi ottenuti da chi riesce finalmente ad acquisire il codice in questione. Anche quest'ultime rappresentazioni collettive hanno verosimilmente un influsso sulle prese di posizione individuali delle intervistate nel corso dei colloqui analizzati. 



\title{
CAPITOLO VI: \\ CONCLUSIONI: I REPERTORI NARRATI
}

\author{
1 TIPI DI PARLANTI NEL CONTESTO
}

L'esame delle denominazioni di lingua aveva il fine di valutare gli effetti della violenza epistemica (e anche reale) di politiche linguistiche e di discorsi metalinguistici sulle rappresentazioni dei rapporti di differenziazione tra codici d'origine da parte dei partecipanti. Gli intervistati provengono da aree, dove la variazione sia intra- sia interlinguistica è forte. ${ }^{1}$ Inoltre hanno esperito gli effetti di numerosi interventi di pianificazione, volti a codificare le varietà linguistiche da loro (ri)conosciute o a regolare le relazioni tra queste. Perciò, nel progettare il presente lavoro, si è supposto che le biografie linguistiche di cittadini originari dai paesi successori alla Jugoslavia costituissero un caso esemplare per esaminare le interrelazioni tra i significati attribuiti alla variazione linguistica da singoli individui e quelli a lei assegnati da gruppi o comunità.

L'analisi degli incipit delle interviste ha illustrato che i narratori spesso motivano, all'avvio dei colloqui, i modi, in cui e con cui hanno avuto accesso e utilizzano varietà linguistiche differenti, tramite riferimenti agli assetti e alle categorizzazioni che governano e giustificano il multilinguismo a livello sociale e istituzionale nelle località di partenza. Tale risultato non è sorprendente. Gli atti di posizionamento nelle sequenze iniziali dei colloqui costituiscono infatti i primi tentativi dei partecipanti di dare un senso al plurilinguismo proprio e altrui, quali saranno poi specificati nel prosieguo delle interviste. Inoltre, il rivolgersi a un'interlocutrice semi-sconosciuta, di cui per esempio non si conosce il grado di familiarità con la situazione sociolinguistica di partenza, può determinare la scelta di presentare i repertori individuali e comunitari nei loro tratti essenziali e più convenzionali. La sistematicità di certe categorizzazioni è comunque significativa dal momento che è indicativa dell'identità di alcuni codici usati nelle regioni di partenza degli informanti, ossia della funzione e del valore simbolico a loro comunemente assegnato da (gruppi di) parlanti. Così, ad esempio, il "serbocroato" è spesso categorizzato sulla dimensione/socio-politica/come codice usato obbligatoriamente a scuola a differenza del serbo, che è invece prevalentemente posizionato, da chi lo menziona già all'avvio del colloquio, sulla scala/emozionale-identitaria/come "nostra/mia lingua" o "lingua materna". D'altro canto, già dall'analisi degli incipit delle interviste emergono anche alcune differenze tra gli intervistati del corpus. Queste concer-

1 Ci si riferisce qui rispettivamente al continuum delle varietà slavo-meridionali e alla presenza, più o meno numerosa a seconda delle zone, di parlanti alloglotti, ad esempio, di varietà di rumeno, albanese o ungherese (cfr. $\S$ II.3.1 e II.3.2). 
nono, da un lato, i modi di qualificare e motivare l'acquisizione di alcune varietà linguistiche, vale a dire soprattutto di codici di minoranza o non riconosciuti nei paesi di partenza (es. albanese, varietà di rumeno), specialmente quando fanno parte di repertori rappresentati dai loro locutori come originariamente plurilingui. Dall'altro lato, si riscontra, già all'avvio dei colloqui, una variazione nei glottonimi adoperati, sia da parlanti diversi, sia da uno stesso parlante (ossia sia inter- sia intra-partecipante), per riferirsi a uno stesso codice così come l'adozione di denominazioni dal referente ambiguo per chiamare alcune varietà linguistiche dello spazio slavo-meridionale.

Nella seconda sezione del capitolo IV, tali questioni sono state esaminate più nel dettaglio. In particolare, dal confronto tra tre coppie di partecipanti, legati rispettivamente tra loro da legami familiari intergenerazionali, sono emersi alcuni fattori che guidano l'alternanza delle denominazioni di lingua nell'uso di singoli parlanti e che sono, in parte, generalizzabili per spiegare la loro variazione anche in interviste diverse. Tra questi, ci sono, in primo luogo, la volontà o la riluttanza nel prendere posizione rispetto alla questione dei glottonimi, ampiamente dibattuta nei paesi d'origine. In aggiunta, possono giocare un ruolo il tempo storico o biografico riferito, la situazione comunicativa e il tipo di interlocutore descritti nel mondo della storia e/o il desiderio di esprimere o meno affiliazione a una comunità linguistica (immaginata). Infine, anche la dimensione interazionale può condizionare la selezione del glottonimo appropriato e, talvolta, determinare una sua modificazione anche nel passaggio da un turno di parola ad un altro (cfr. la variazione della locuzione "nostra lingua" in "mia lingua" nell'intervista di coppia condotta con DR e FR). Quest'ultima osservazione è particolarmente rilevante in quanto conferma che le denominazioni di lingua sono, almeno nella specifica situazione studiata, strumenti impiegati strategicamente dai parlanti per negoziare la propria identità linguistica e, eventualmente, politica e nazionale, in interazione.

Nella terza sezione del capitolo IV, si è invece messo in relazione l'uso di denominazioni dal referente ambiguo (es. "nostra lingua", "mia lingua", "madrelingua") con le prese di posizione dei partecipanti riguardo al mantenimento/sostituzione di codice in contesto migratorio. Ciò ha permesso di individuare diverse funzioni dei quasi-glottonimi in interazione, ovvero "elusiva", "enfatica" e "oppositiva". In particolare, l'adozione e le modalità di impiego di quasi-glottonimi nelle conversazioni del corpus sono risultate essere interrelate a come i partecipanti si posizionano - ovvero se accettano o se oppongono resistenza - nei confronti i) dell'illegittimità (nel senso di mancato riconoscimento) di un codice da parte della comunità linguistica di partenza o di arrivo e della conseguente tendenza alla sostituzione di tale lingua per vergogna, ii) del loro essere parlanti dalle competenze delegittimate del codice d'origine (soprattutto in quanto trasferitesi da bambini in un paese straniero) e, così, del rischio di una loro possibile sostituzione di lingua per dimenticanza, iii) del loro essere parlanti delegittimati di una lingua standard che ha recentemente perso riconoscimento a livello istituzionale, ma che è talvolta ancora oggetto di identificazione da parte di singoli locutori. Perciò, l'esame di alcune interviste nella loro interezza (cfr. soprattutto i § IV.2 e IV.3) ha mostrato che le rappresentazioni iniziali dei rapporti tra i codici siano specificate e, talvolta, rinego- 
ziate dagli interattanti in sequenze successive del colloquio. Nel narrare la loro biografia linguistica gli intervistati, infatti, reinterpretano più o meno creativamente i nessi, stabiliti a livello ufficiale, tra varietà linguistiche e gruppi di parlanti così come costruiscono nuovi confini tra le lingue (ri)conosciute e tra le rispettive comunità a seconda di fini interazionali concreti.

L'analisi delle narrazioni di interazioni nel capitolo $\mathrm{V}$ ha completato il quadro offerto dall'esame delle denominazioni di lingua, ricostruendo le rappresentazioni e le prese di posizione di tre partecipanti rispetto agli usi linguistici propri e altrui in Alto Adige. In questo capitolo, si sono infatti valutati i modi in cui le narratrici mettono in scena l'agire, il sentire e il sapere del proprio io narrato o di altri personaggi con e rispetto a varietà linguistiche differenti - sia di partenza, sia di arrivo, sia di contatto, sia di interlingua - dopo emigrazione in provincia di Bolzano. Nelle loro storie, le intervistate posizionano il proprio io attuale come soggetto parlante nel contesto d'arrivo. Inoltre, in alcuni casi, portano anche a termine una riallocazione sociale e morale della propria esperienza migratoria nell'hic et nunc dell'interazione.

Nello specifico, l'analisi delle narrazioni di interazioni per contesto e per interattanti ha permesso, in primo luogo, di delineare tre rappresentazioni dello spazio sociolinguistico altoatesino singolari in quanto, pur essendo in parte condizionate da opinioni diffuse a livello collettivo, non coincidono completamente con queste. Il punto di vista preso in esame, si ricordi, è del resto quello di parlanti che hanno acquisito competenze linguistiche e comunicative nelle varietà di italiano e tedesco, parlate in provincia di Bolzano, in seguito a mobilità da un paese straniero. Queste conoscenze si sono quindi intrecciate, nei repertori narrati delle intervistate, con risorse linguistiche e metalinguistiche preesistenti.

Peculiare nei repertori narrati delle tre partecipanti è, per esempio, l'ampia portata comunicativa conferita alle lingue di nuovo insediamento in Alto Adige (prima fra tutte il serbo) così come la diffusione, riconosciuta da due intervistate su tre a pratiche plurilingui non solo in numerosi ambiti comunicativi (plurilinguismo a livello sociale), ma anche nei discorsi di singoli parlanti (plurilinguismo a livello individuale). Tuttavia, se si riconosce un certo accordo tra i partecipanti del corpus nel tratteggiare gli ambiti comunicativi informali come plurilingui, lo stesso non vale né per le prese di posizione (positive o negative) nei confronti delle pratiche di contatto, né per le rappresentazioni degli usi linguistici in domini più formali. In particolare, una rappresentazione piuttosto convenzionale è quella che concepisce l'uso di tedesco e italiano come specializzato a seconda del tipo di istituzione, ad esempio, scuola, ospedale, questura, associazioni sportive. Questa rappresentazione è probabilmente dovuta, in parte, alla regolamentazione giuridica dei rapporti tra codici in provincia di Bolzano. In parte - per esempio, quando lega indissolubilmente l'uso dell'italiano a certi tipi di interlocutori (nello specifico, i carabinieri) ricalca verosimilmente opinioni metalinguistiche diffuse nella comunità di arrivo. In aggiunta, similmente a quanto spesso sostenuto dalla popolazione italofona locale, anche certi cittadini stranieri intervistati alludono alla presenza di "regole di default" per la comunicazione tra parlanti di diverse lingue prime e, nello specifico, tra locutori locali e non locali (si vedano, tra le biografie linguistiche analizzate nel 
dettaglio, quelle di VM e BV). ${ }^{2}$ La rinegoziazione del tedesco in favore dell'italiano tende ad essere valutata negativamente da numerosi informanti in conseguenza sia delle sue (presupposte) connotazioni simboliche, sia delle sue ricadute sullo svolgimento della conversazione. Come emerge dalle biografie linguistiche raccolte da Veronesi (2008a), le intenzioni di questo cambio di lingua potrebbero però essere interpretate diversamente da chi lo attua e da chi lo subisce. Infine, gli intervistati mostrano, in generale, una consapevolezza piuttosto alta del plurilinguismo "interno" (ossia della presenza di diverse varietà e registri di tedesco e italiano), che contraddistingue la società altoatesina. A questo riguardo, si noti che l'allocazione delle varietà non standard di italiano, quale emerge dalle narrazioni di interazioni, non coincide tra le tre intervistate ed è piuttosto innovativa. Varietà regionali di italiano sono infatti raffigurate, nel caso di BV, come diffuse anche in domini formali, ad esempio, in università. Tra queste, la donna nomina anche la "lingua del veneto", conferendo quindi possibilmente a tale codice un prestigio maggiore, per lo meno a livello locale, rispetto ad altri dialetti italo-romanzi. All'opposto, varietà diatopiche di italiano sono descritte da DK come distribuite in modo diglottico rispetto all'italiano standard. La divergenza di tali rappresentazioni potrebbe puntare proprio alla presenza di opinioni discordanti riguardo alla diffusione dei dialetti italo-romanzi in provincia di Bolzano nella stessa comunità locale (cfr. anche § II.1.4). Analogamente anche le prese di posizione riguardo allo status e al prestigio dei dialetti tedeschi locali - che comunque tendono ad essere rappresentati come utilizzati anche in domini medio-alti - variano nel corpus raccolto, in parte, a seconda del grado di competenza, per lo meno dichiarata, nei codici in questione (ma si veda sempre il caso di BV per un contro-esempio). Anche tale disaccordo è verosimilmente da mettere in relazione con quello presente tra la comunità tedescofona e quella italofona autoctona (cfr. § II.1.3.2).

In secondo luogo, l'analisi delle narrazioni di interazioni ha permesso di tratteggiare tre tipi di parlanti "mobili", contestualizzati nella specifica realtà studiata ed eventualmente generalizzabili (cfr. anche più sotto in questo paragrafo). In generale, considerando tutte le interviste del corpus, il plurilinguismo della società d'arrivo è frequentemente rappresentato, dagli intervistati arrivati recentemente $\mathrm{o}$ anche dagli altri partecipanti al momento di raccontare i primi anni di residenza in Alto Adige, come una sfida (Herausforderung), ad esempio, in campo lavorativo o scolastico. Tuttavia, soprattutto per i partecipanti che conoscono entrambe le lingue, diventa poi una risorsa, per lo meno a livello simbolico. Nella maggior parte delle interviste (anche quelle condotte a Brunico o in località a prevalenza tedescofona con persone che non conoscono l'italiano), l'apprendimento e l'uso del tedesco talvolta disarticolato nell'apprendimento e nell'uso del tedesco standard e del dialetto tedesco locale - sono inoltre frequentemente valutati inter-parlante come più

2 Posizioni simili sono sostenute, per esempio, anche da BL, AC, JB e AK. In particolare, gli ultimi due intervistati, parlanti solitamente di tedesco, sostengono di dover commutare necessariamente all'italiano con gli italofoni locali per via delle loro scarse conoscenze nella lingua seconda. 
problematici rispetto all'acquisizione e all'impiego dell' italiano standard. ${ }^{3}$ Il tedesco è infatti una lingua di cui spesso si ha paura e che è giudicata come più difficile da padroneggiare. In conseguenza di ciò, un'eventuale acquisizione di questo codice è anche fonte di maggiori soddisfazioni.

Le tre partecipanti di cui ho discusso dettagliatamente le biografie linguistiche nel capitolo V padroneggiano sia l'italiano sia il tedesco. Data questa base comune, sono specialmente le conoscenze di varietà di tedesco, in particolare, le competenze in Hochdeutsch, che assumono, per lo meno durante i colloqui, un valore distintivo per le tre narratrici. Come illustrato nel corso dell'analisi, i gruppi da cui le intervistate vogliono distinguersi per delineare ex-negativo le loro identità linguistiche più salienti al momento di raccontare la loro biografia linguistica sono differenti (e tale diversità probabilmente dipende anche dalle caratteristiche socio-anagrafiche e migratorie delle tre donne). Inoltre, è forse superfluo ricordare che il valore simbolico e, quasi, il maggior prestigio attribuito alle varietà di tedesco da queste e da altri partecipanti non sono intrinseci al codice. Piuttosto, come già detto, dipendono, in larga parte, dal contesto micro e macro in cui la conversazione si svolge.

Tenuto conto di queste differenze e precisazioni, emerge comunque almeno una caratteristica comune tra le biografie linguistiche selezionate. Le tre donne ottimizzano, nel corso dei colloqui, il bilinguismo e, nel caso di DK e BV, anche la diglossia della società d'arrivo ai fini di una propria riallocazione sociale e, talvolta, morale. Questa possibilità mi sembra derivare proprio dalla complessità della situazione sociolinguistica altoatesina. In altre parole, la rivalutazione della propria esperienza biografica tramite quella linguistica è possibile proprio grazie alla compresenza di varietà linguistiche differenti sul territorio e, quindi, alla coesistenza di diversi tipi di parlanti ideali con cui ci si può identificare. Inoltre, alcuni degli intervistati per la presente ricerca si spingono talvolta oltre. Infatti, ri-interpretano a loro favore, nel corso dei colloqui, non solo il plurilinguismo del paese d'arrivo, ma anche quello del paese d'origine o dovuto a emigrazione. Così, DK presenta, per esempio, la propria origine non locale e, in particolare, le proprie competenze in una lingua di migranti, nel suo caso l'albanese, come un vantaggio proprio in contesto migratorio. Questi due fattori hanno infatti favorito l'acquisizione del tedesco standard da parte della narratrice, vale a dire di una varietà linguistica dal prestigio riconosciuto sia localmente sia globalmente, ma solitamente non padroneggiata dai parlanti autoctoni.

Alla luce di ciò si può concludere che la complessità del repertorio d'arrivo (in tutti e tre casi analizzati) e talvolta anche di quello di partenza (vedi il caso di DK) offrano un'eccedenza (o surplus) di materiale simbolico alle partecipanti. Tale materiale è utilizzabile ed è effettivamente da loro impiegato - per lo meno durante l'intervista con la specifica interlocutrice - per rivalutare la propria esperienza migratoria e la propria condizione di apprendenti una lingua straniera in un paese forestiero. Il ruolo simbolico ricoperto, in questo caso, dal tedesco potrebbe essere svolto a mio avviso da altri codici in altri contesti. Quello che conta, nel rendere

3 Ciò non vale, invece, per le varietà non standard di italiano, il cui apprendimento e uso sono parimenti valutati come difficili, per esempio, da BV. 
possibile un tale processo di riallocazione personale tramite il discorrere epilinguistico, non sono infatti tanto caratteristiche intrinseche a un codice, quanto più probabilmente la presenza di rapporti, regolati istituzionalmente, tra varietà linguistiche in una data località o, meglio, la diffusione di rappresentazioni condivise concernenti tali rapporti.

Le interviste del corpus sono state raccolte, si ricordi, non con l'intenzione di testare un'ipotesi precedentemente formulata. Piuttosto, l'obiettivo era quello di individuare, attraverso l'analisi dettagliata di casi singoli, modelli di agire linguistico e tipi di repertorio d'origine e d'arrivo così come di formulare ipotesi, tramite induzione, sui fattori che li influenzano. In linea con l'approccio qualitativo adottato, la validità e l'adeguatezza delle osservazioni esposte sopra potrebbe, a mio avviso, trarre vantaggio dall'analisi di corpora di confronto, raccolti in altri contesti (cfr. Lamnek 1988/2010: 222-224). In particolare, da un lato, sarebbe utile paragonare le interviste del corpus con le biografie linguistiche di parlanti alloglotti che abitano in comunità ufficialmente monolingui, dove però la coesistenza di codici diversi è un fenomeno riconosciuto dall'opinione pubblica (ad esempio, in metropoli come Berlino o New York). In tali contesti, i partecipanti disporrebbero sempre di materiale simbolico per rivalutare la propria origine ed esperienza migratoria attraverso il racconto dei modi di acquisizione delle loro competenze linguistiche. Tuttavia, in correlazione con la compresenza di discorsi metalinguistici differenti tra loro e della loro minore egemonia, tale rivalutazione potrebbe avvenire in modo più variabile tra gli intervistati. Inoltre, questi ultimi potrebbero tendere ad identificarsi più con pratiche di contatto, come translanguaging o multi-etnoletti, invece che con una varietà standard, come l'Hochdeutsch. ${ }^{4}$ Dall'altro lato, sarebbe a mio avviso informativo un paragone con parlanti alloglotti che vivono in comunità ufficialmente monolingui, dove il plurilinguismo non è o è poco tematizzato a livello di opinione pubblica locale. Situazioni di questo tipo si riscontrano probabilmente ancora in alcune città italiane (cfr. Bagna et al. 2003: 202-203 per una valutazione di tale questione alla data di pubblicazione dell'articolo). Questi ultimi macro-contesti offrono, infatti, un solo profilo di parlante e competenza linguistica, con cui ci si può identificare. In conseguenza di ciò, se le interpretazioni qui avanzate sono giuste, mettono a disposizione minore materiale simbolico per una rivalutazione della propria esperienza biografica tramite quella linguistica. Infine sarebbe proficuo confrontare le biografie linguistiche raccolte per il presente volume anche con storie di vita raccontate nello stesso macro-contesto, ma ad altri (tipi di) interlocutori, in particolare, a parlanti di tedesco come prima lingua. In questi casi, infatti, l'acquisizione del tedesco non costituirebbe, per esempio, più un elemento biografico in comune tra narratore e intervistatrice.

4 Per studi sul valore identitario, sebbene non specificamente biografico di queste pratiche, si confrontino del resto già Dirim \& Auer (2004), Keim (2008), Freywald et al. (2011). 


\section{OSSERVAZIONI SUL METODO}

L'analisi, esposta nel IV capitolo del presente volume, si è avvalsa di un metodo già in parte sperimentato per valutare le relazioni tra codici e tra questi e i loro parlanti da un punto di vista emico, vale a dire l'esame delle denominazioni di lingua e delle loro variazioni in interazione (cfr., per esempio, Hartley \& Preston 1999, Iannàccaro \& Dell'Aquila 2007, Tofan 2007, Dal Negro 2009, Aronin et al. 2011, Migge \& Léglise 2013, Bert \& Costa 2014). L'applicazione di tale procedura, nel presente lavoro, si fonda sull'idea che le rappresentazioni degli spazi linguistici di partenza dei partecipanti siano ricostruibili, almeno in parte, tramite l'esame dei glottonimi e delle apposizioni da loro adoperati per i codici ivi parlati. Le potenzialità di questa metodologia sono esplorabili in modo esemplare nella situazione studiata. Ciò è vero in conseguenza della pluralità delle denominazioni che circolano per le varietà linguistiche d'origine degli intervistati e del loro essere oggetto di controversie ricorrenti. $^{5}$

Nello specifico, nello svolgere l'analisi si è cercato di porre particolare attenzione alla dimensione interazionale delle interviste raccolte. Vale a dire si è esaminato come gli interattanti negozino, durante la conversazione, denominazioni di lingua situativamente e sequenzialmente - talvolta alludendo anche a prese di posizione abituali e a schemi interpretativi condivisi nelle comunità di partenza e di arrivo - per produrre senso e ordine nella propria esperienza linguistica. Come già accennato, nello sviluppare questo metodo, mi sono in parte ispirata all'"analisi delle categorie di appartenenza" (Membership Categorization Analysis o MCA; cfr. Sacks 1995 e De Fina \& Georgakopoulou 2012: 172-174). Tale approccio investiga come i locutori adoperino categorie (o collezioni di categorie) per riferirsi a oggetti o persone (in questo caso, varietà linguistiche e parlanti) e, nel fare ciò, attribuiscano loro più o meno implicitamente funzioni e connotazioni. L'esame degli incipit delle interviste ha fatto, in special modo, emergere la tensione tra innovazione e convenzionalità nell'applicazione di serie di categorie. Infatti, la scelta di una categoria (glottonimo o apposizione), tra quelle tutte ugualmente veritiere, per qualificare un codice dipende, in parte, dalla realtà sociolinguistica riferita, per come potrebbe essere descritta anche da un punto di vista etico. In parte, è influenzata dal contesto interazionale e dall'azione che si vuole realizzare con tale descrizione. Inoltre, in linea con la regola della consistenza, il primo attributo selezionato per un codice all'avvio dei colloqui lascia parzialmente prevedere e, quindi, in parte condiziona gli attributi successivi, che costituiscono appunto una collezione o serie. Al contempo ha un influsso sulla loro interpretazione da parte dell'interlocutore.

L'analisi delle narrazioni di interazione per contesti e, soprattutto, per interattanti è invece una proposta per investigare le informazioni soggettive sugli usi linguistici presentate dai partecipanti durante le loro biografie linguistiche (ossia il

5 Anche Tofan (2007), Migge \& Léglise (2013) e Iannàccaro \& Dell'Aquila (2007) conducono del resto analisi delle denominazioni di lingua in interviste o questionari con parlanti originari di Moldavia, Guyana Francese e Latgalia, ossia di spazi sociolinguistici dove più glottonimi sono usati in modo concorrente. 
"cosa" di un'intervista biografica) contemporaneamente al modo con cui queste sono messe in scena di fronte alla specifica interlocutrice (ovvero il "come" di un'intervista biografica). Nel capitolo V di questo volume, suggerisco di valutare l'interconnessione e, talvolta, lo scollamento tra la dimensione presentazionale e interazionale delle biografie linguistiche raccolte attraverso la ricostruzione della "struttura di partecipazione" degli enunciati o attività comunicative riportati nel mondo della storia e la conseguente individuazione del "formato di produzione" di tali atti linguistici nel mondo dell'interazione (cfr. Goffman 1981 per i termini). Il primo esame permette di distinguere tra le varietà linguistiche rappresentate dalle narratrici come risorse di cui l'io narrato si serve attivamente da quelle a cui è prevalentemente esposto nei racconti. La seconda analisi (strettamente interrelata con la prima) consente, invece, di valutare le prese di posizione agentive ed epistemiche dell'io narrante rispetto agli usi e discorsi (meta)linguistici riportati.

Le nozioni proposte da Goffman (1981) sono state già adoperate per analizzare le rappresentazioni della propria agentività da parte dei parlanti e/o le loro ridefinizioni da parte degli interlocutori in conversazioni condotte in svariati contesti (cfr., per esempio, He 2001, Ribeiro 2006, Clayman 2010). ${ }^{6}$ Inoltre, questi concetti sono stati applicati anche per investigare specificamente le strategie di presentazione di aspetti di sé in narrazioni in intervista (cfr. Schiffrin 1996 e De Fina \& Georgakopoulou 2012: 167-171 per ulteriori riferimenti bibliografici). Pur prendendo a modello queste ricerche, l'analisi, discussa nel capitolo $\mathrm{V}$, si è tuttavia concentrata solo su un sottoinsieme di atti di posizionamento e allineamento degli intervistati, ovvero quelli nei confronti delle varietà linguistiche del loro repertorio, delle loro norme d'uso e dei (comportamenti dei) loro parlanti. Mi sono quindi limitata ad esaminare solo alcuni aspetti della presentazione del sé in interazione, ossia quelli che riguardano la rappresentazione e costruzione dell'identità linguistica propria e altrui e dell'identità dei codici (ri)conosciuti. ${ }^{7} \mathrm{Al}$ contempo, ho esteso però l'esame a tutte le sequenze narrative delle interviste, le quali sono sistematicamente analizzate, pur con diverso grado di dettaglio, secondo la loro struttura di partecipazione e il loro formato di produzione. Il presupposto è che, sebbene una biografia linguistica sia costruita sequenzialmente in interazione, questa sia anche organizzata coerentemente intorno a identità linguistiche salienti a livello individuale e/o collettivo. La valutazione sistematica di tutte le sequenze narrative è una proposta metodologica per identificare tali punti di riferimento organizzativi del discorso.

Il metodo ha delle limitazioni. La più importante è che mi baso solo sulle narrazioni di interazioni, quando anche altre sequenze dell'intervista sono possibilmente rilevanti per valutare le prese di posizione dell'io narrante rispetto ai codici del proprio repertorio. Parimenti i modi, in cui i discorsi riportati e, quindi, la paternità e responsabilità delle opinioni riferite sono dislocati ad altri personaggi del racconto invece di essere attribuiti a se stessi, sono solo uno dei fenomeni in cui

6 I tre studiosi se ne servono, in particolare, per analizzare rispettivamente interazioni in classe, conversazioni al telefono e interviste giornalistiche.

7 Lo stesso programma è perseguito anche nel capitolo IV, pur adottando un'altra unità di analisi. 
l'interconnessione tra la dimensione presentazionale e interazionale di un'intervista biografica si manifesta e può essere studiata.

I motivi per cui ho scelto di analizzare specificamente i racconti di dialoghi sono stati già discussi nei paragrafi precedenti (cfr., in particolare, $\S$ V.1.2 e V.1.2.1). Sia qui dunque solo ricordata la ragione principale. Specialmente nelle narrazioni incentrate su fenomeni linguistici, il locutore tende spesso a esagerare e quasi a caricaturare la tipica situazione di utilizzo di un codice, probabilmente per aumentare la raccontabilità della storia (cfr. Johnstone 2006). In conseguenza delle loro caratteristiche formali e contenutistiche - ad esempio, l'adozione di strategie di coinvolgimento, come ripetizioni, discorso riportato, variazioni nella qualità della voce, o l'allusione ad opinioni o storie condivise -, i racconti "metalinguistici" hanno un impatto piuttosto forte sugli interlocutori. I nessi tra usi linguistici, contesti e interattanti, messi in scena in tali storie, sono quindi particolarmente ricordabili dai destinatari, che eventualmente li rimetteranno in scena e tramanderanno in interazioni successive.

\section{NARRAZIONI IN INTERVISTA}

Il presente lavoro contribuisce anche allo studio delle narrazioni in intervista, intesa come evento interazionale specifico, ma non per questo artificiale o innaturale (cfr. De Fina \& Perrino 2011 e gli altri contribuiti nel vol. 40 (1) di Language in Society, di cui l'articolo è la prefazione). Secondo tali ricerche, un'analisi dei modi di introduzione e delle caratteristiche formali e contenutistiche delle narrazioni permette di valutare le specificità del rapporto tra intervistatore e intervistato nella situazione comunicativa in corso, la quale non è a sua volta sganciata dal contesto macro in cui il colloquio si svolge. Così, un loro esame consente talvolta di intravedere atti di posizionamento abituali verso gli oggetti/attori di cui si sta parlando e di individuare tipiche strategie di allineamento degli interattanti tra di loro (cfr. anche De Fina 2009, De Fina \& Georgakopoulou 2012: 113-115). Inoltre, lo studio dell'attribuzione e negoziazione di ruoli e relazioni di potere in un'intervista scientifica è rilevante anche perché situazioni comunicative ad essa più o meno affini sono abbastanza diffuse nella società contemporanea, per lo meno a livello (semi-)istituzionale. Si pensi per esempio ai talkshow televisivi, agli interrogatori nei tribunali, alle interazioni medico-paziente o ai colloqui di lavoro.

Dagli studi sopra citati emerge d'altra parte che le narrazioni raccontate in intervista non svolgano tutte la stessa funzione né siano tutte dello stesso tipo. Oltre a narrazioni di esperienze personali più o meno conformi al modello di Labov \& Waletzky (1967), si riscontrano, per esempio, frequentemente racconti assimilabili al genere dei "resoconti" (account) (cfr. De Fina 2009). I resoconti possono essere, tra l'altro, definiti come "dispositivi linguistici impiegati quando un'azione è sottoposta [o è percepita come sottoposta] a un'indagine valutativa" esplicita o implicita (cfr. Scott \& Lyman 1968: 46 citato da De Fina 2009: 239; tr. della scrivente). Le storie di questo tipo sono quindi caratterizzate da una componente esplicativa e da una forte orientazione all'interlocutore (cfr. ibidem: 240). 
Nell'analizzare le biografie linguistiche del corpus raccolto, ho individuato anch'io diversi tipi di narrazioni con funzioni differenti. Tra queste ci sono racconti scenico-episodici, narrazioni abituali o generiche, storie ri-raccontate o non vissute personalmente, talvolta adoperate in funzione argomentativa-esemplare, talvolta per divertire l'interlocutrice. Nello specifico, la narrazione di VM, discussa al $\S$ V.3.2.1 ("carabinieri con la macchina"), è dal punto di vista strutturale e contenutistico abbastanza particolare. La sua funzione non è infatti quella di riferire o spiegare un comportamento linguistico. Piuttosto il racconto mira a stabilire o ribadire un terreno comune tra intervistata e intervistatrice tramite l'allusione ellittica a opinioni metalinguistiche diffuse nella società di arrivo e, quindi, conosciute da entrambe le interattanti. Ho definito perciò la narrazione in questione una "storia condivisa" non sulla base di pratiche di interazione quotidiane (cfr. Georgakopoulou 2005), ma a livello locale.

Tale narrazione o, eventualmente, tale classe di narrazioni potrebbe essere specifica di situazioni interazionali (es. interviste), che si svolgono in macro-contesti (es. la provincia di Bolzano), fortemente marcati da un punto di vista territoriale, storico e/o discorsivo. ${ }^{8}$ In particolare, l'alta consapevolezza metalinguistica diffusa tra la popolazione altoatesina - la quale è tipica di abitanti di zone (ufficialmente) plurilingui e, nel presente caso, è inoltre intensificata e complicata dalla polarizzazione della società locale riguardo a questioni di lingua ${ }^{9}$ - potrebbe costituire uno dei presupposti del fatto che narrazioni con un tale contenuto e una tale struttura siano raccontabili con successo. In altre parole, la situazione linguistica e sociolinguistica del macro-contesto locale costituirebbe una condizione della raccontabilità e buona riuscita della storia di VM. D'altra parte, si ricordi comunque che il contenuto e la struttura del racconto in questione sono anche condizionati da obiettivi interazionali perseguiti localmente dalla narratrice. Tra questi c'è il desiderio di stabilire complicità con la ricercatrice. In aggiunta, gioca anche un ruolo la volontà di rappresentarsi come parlante che conosce le norme d'uso linguistico e le rappresentazioni metalinguistiche diffuse nella società d'arrivo ed è, quindi, "inclusa" in tale comunità.

Ai fini di meglio specificare questo tipo di storie "condivise" sarebbe, tra l'altro, interessante confrontare i modi di introdurre, strutturare e negoziare le narrazioni ambientate in Alto Adige da parte degli intervistati del corpus con quelli adoperati da loro nelle storie ambientate però nei paesi di provenienza. Considerando che l'intervistatrice non è originaria e non ha (tanta) familiarità con la situazione sociolinguistica di partenza dei partecipanti, si può infatti supporre che questi due gruppi di narrazioni differiscano tra loro, per esempio, nella maggiore o minore presenza di dettagli orientativi e di sezioni valutative. Un'altra differenza potrebbe riguardare la frequenza di enunciati negativi del narratore in apertura o in chiusura dei brani così come la distribuzione dei segnali di ricezione dell'interlocutrice. Queste caratteristiche segnalerebbero, infatti, disparità nelle aspettative degli interattanti e/o nelle presupposizioni sulle loro conoscenze reciproche (cfr. sempre De Fina 2009: 244 e Norrick 2010, riferito però non specificamente allo studio di narrazioni).

8 Ringrazio la Professoressa R. Franceschini per il suggerimento.

9 Si pensi al sistema della proporzionale etnico-linguistica e si confronti, in particolare, il § II.1.1. 


\section{I REPERTORI NARRATI}

Come già accennato nel $\S$ V.1., definisco le rappresentazioni dei rapporti tra varietà linguistiche sia di origine sia d'arrivo e le prese di posizione nei loro confronti i "repertori narrati" dei partecipanti al momento dei colloqui con la specifica interlocutrice. Sebbene entrambi siano rappresentazioni emiche dell'allocazione dei codici (ri)conosciuti, i repertori narrati non coincidono con quelli che potrebbero essere definiti i "repertori dichiarati" degli intervistati. Con quest'ultimo termine mi riferisco alle informazioni sugli usi e sui comportamenti linguistici che sono ricavabili dall'analista, decontestualizzando le dichiarazioni dei partecipanti. La presenza di un disaccordo tra le configurazioni dei repertori ricavate tramite i due metodi non è comunque necessariamente indicativa della portata o significatività del concetto di repertorio narrato. Piuttosto, la rilevanza di quest'ultima nozione emerge a mio avviso dal fatto che il repertorio narrato offre una rappresentazione peculiare dei rapporti tra codici in quanto integra alcuni aspetti, parzialmente interconnessi gli uni agli altri.

La prima caratteristica è quella della "salienza". Dall'analisi esposta nel presente volume è infatti emerso che alcuni contesti/interattanti siano più rilevanti di altri per un narratore al momento di raccontare la propria biografia linguistica. La maggiore o minore rilevanza di contesti e interattanti non coincide tra gli intervistati (anche) perché questa è strettamente connessa con la loro rappresentazione delle identità linguistiche più salienti al momento dell'intervista. Da ciò segue che contesti e interattanti non siano distinguibili solo su una scala gerarchica da alto a basso e/o da informale a formale, ma anche a seconda del loro valore simbolico e, quindi, su una scala emozionale-identitaria. Nello specifico, la "famiglia" è, per esempio, un "dominio" 10 particolarmente sensibile a questioni di identità. La rappresentazione degli usi linguistici in questo contesto è perciò frequentemente valutata dai partecipanti come vincolante per la rappresentazione delle loro identità linguistiche. Ciò risulta per esempio dall'esame delle denominazioni di lingua. I glottonimi dei codici parlati in famiglia sono infatti quelli più frequentemente sostituiti da quasi-glottonimi in funzione elusiva, enfatica, oppositiva. Nonostante ciò o forse proprio per questo, l'analisi dei repertori narrati ha anche messo in luce strategie di resistenza a tali categorializzazioni. Così, alcune narratrici scelgono di fondare la rappresentazione del proprio spazio comunicativo narrato dopo l'esperienza di mobilità su altri contesti ideologicamente meno carichi di quello familiare o, meglio, marcati sì, ma da altre connotazioni identitarie. Tra questi ci sono, in particolare, il lavoro e l'università.

In secondo luogo, i repertori narrati sono peculiari rispetto a quelli dichiarati in quanto rendono conto della "sequenzialità" e "contestualizzazione" delle rappresentazioni dei rapporti tra codici. Come ripetutamente osservato, le relazioni tra varietà linguistiche, messe in scena dalle narratrici nelle loro storie di dialoghi, non

10 Con "dominio", sia qui ricordato, si intende un insieme di situazioni sociolinguistiche relative a uno stesso campo di esperienza, nello specifico a determinati luoghi, rapporti tra interattanti e temi (cfr. Mioni 1987, Berruto 1995). 
sono infatti date o esclusivamente vincolate dalle rappresentazioni metalinguistiche ufficiali (cfr. anche sotto in questo paragrafo), ma sono anche negoziate nell'hic et nunc dell'interazione. I processi, attraverso cui le rappresentazioni e prese di posizione dei partecipanti emergono nel corso delle conversazioni e sono condivise con l'interlocutrice, sono particolarmente evidenti dall'analisi dell'alternanza delle denominazioni per le lingue d'origine intra- e inter-parlante (cfr. § IV.2). In aggiunta, sono anche osservabili dall'esame di singole sequenze narrative delle interviste del corpus (cfr., ad esempio, il brano 4 al $\S$ V.4.2.1 sulla "commutazione di codice involontaria della vicina croata" di VM).

Infine, il terzo aspetto peculiare dei repertori narrati è quello della "soggettività" (cfr. Busch 2013: 13-79, Kramsch 2009: 16-22). In un repertorio narrato la distinzione netta tra repertorio individuale e comunitario sfuma. Senza mettere in dubbio l'utilità di una differenziazione tra il repertorio individuale e quello comunitario dei partecipanti, la soggettività del repertorio narrato non costituisce una commistione tra queste due dimensioni, quanto piuttosto una terza dimensione. Il tentativo è quello di registrare l'interazione tra gli usi e i comportamenti linguistici idiosincratici dei singoli parlanti, da un lato, e quelli abituali in una collettività, dall'altro (cfr. anche Blommaert 2013 per i concetti in parte affini di "policentricità" e "stratificazione" del repertorio individuale). In particolare, tramite la considerazione della dimensione soggettiva del repertorio narrato è possibile investigare il ruolo singolare che varietà linguistiche non solo conosciute, ma anche riconosciute - in quanto usate da altri locutori nell'ambiente circostante - o desiderate in quanto connesse con funzioni o apparentamenti etnico-nazionali con un fascino speciale (cfr. Dal Negro \& Iannàccaro 2003: 437) - acquisiscono per un narratore nel corso dei colloqui.

Uno dei capisaldi, che emerge dalla ricerca discussa in questo volume, è dunque quello che invita a concepire la configurazione dei repertori narrati come il risultato dell'interazione tra diversi fattori. Le rappresentazioni dei rapporti tra codici sono infatti, in parte, condizionate dal i) micro-contesto locale in cui si svolge l'interazione e, quindi, come ricordato sopra, dalle aspettative attribuite dai narratori all'interlocutrice e/o dagli obiettivi interazionali concreti da loro perseguiti. In parte, sono determinate dalle ii) esperienze biografico-personali più salienti dei partecipanti, tra cui giocano un ruolo particolare per gli intervistati del corpus quelle conseguenti alla migrazione in un paese straniero. A riguardo di questa influenza, si ricordino, per esempio, le difficoltà attraversate da $\mathrm{BV}$ per raggiungere i requisiti di accesso all'ateneo bolzanino e il suo conseguente attuale desiderio di acquisizione delle varietà linguistiche non standard, locali e non locali, usate dai professori e compagni di corso in università. In alternativa, si rammenti l'influsso del tempo biografico riferito sull'alternanza dei glottonimi nell'intervista con NM e, quindi, sulla rilevanza o meno di una distinzione netta tra "serbo" e "croato". In terzo luogo, la configurazione di un repertorio narrato si lascia in parte ricondurre anche al modo di posizionarsi rispetto alle iii) rappresentazioni e interpretazioni collettive di fenomeni storico-sociali, avvenuti più o meno recentemente nei paesi di origine e di arrivo. Tra questi avvenimenti, hanno una grande importanza, nella situazione studiata, le rotture nell'uso linguistico, conseguenti agli interventi di pianificazione 
linguistica intrapresi "dall'alto" nei paesi di provenienza dei partecipanti. Inoltre, giocano un ruolo le interpretazioni, che circolano in provincia di Bolzano, del plurilinguismo "storico" e delle sue interrelazioni con il "nuovo" plurilinguismo dovuto ai flussi migratori più o meno recenti. Nei repertori e spazi comunicativi narrati degli intervistati del corpus, l'influenza di tali avvenimenti e delle loro rappresentazioni si riconosce, per esempio, da un lato, nelle diverse funzioni assunte dai quasi-glottonimi per le lingue d'origine, dall'altro, nei modi di mettere in scena la selezione di codice in determinati contesti istituzionali altoatesini. In aggiunta, anche il ruolo distintivo attribuito al tedesco in numerose biografie linguistiche raccolte si lascia in parte ricondurre a tali rappresentazioni condivise, in parte è determinato dal micro-contesto interazionale in cui la conversazione si svolge.

Infine, fattori più generali, come i motivi di emigrazione, possono talvolta correlare con le scelte di mantenimento o sostituzione di lingua dopo il trasferimento in un paese straniero. Tuttavia, solitamente, la loro influenza non è decisiva, ma si intreccia a fattori più soggettivi, come quelli delineati sopra. Così, per esempio, TF, emigrata a causa della guerra, sostituisce il serbo dopo l'arrivo in Italia negli anni novanta: il motivo sono le stigmatizzazioni a cui, dal suo punto di vista, è soggetta l'identità indicizzata da tale codice nel paese d'arrivo (cfr. § IV.3.2). Invece, i fratelli più giovani di DK imparano l'albanese e quindi mantengono il codice d'origine, seppur si siano trasferiti anche loro in Alto Adige per sfuggire a un conflitto e per di più da molto giovani. Similmente, anche la scelta di mantenimento/sostituzione di una lingua minoritaria per i parlanti con repertori originariamente plurilingui varia considerevolmente a seconda di come i locutori stessi concepiscano soggettivamente questo codice, spesso in relazione con la lingua dominante. Infatti certi parlanti di lingue di minoranza nel paese d'origine si rifiutano di comunicare in serbocroato come lingua seconda a causa delle esperienze negative connesse con questo codice. Per converso, altri partecipanti mantengono, dopo l'arrivo in Alto Adige, solo il serbocroato o il serbo a discapito di altre varietà linguistiche precedentemente parlate in famiglia nei paesi di provenienza in quanto queste ultime sono, per esempio, considerate "dialetti" privi di una grammatica specifica (cfr. DL e le dichiarazioni di DB, discusse sempre al § IV.3.2).

D'altro canto, in modo non del tutto sorprendente, l'essere emigrati da bambini/ragazzi e il fatto di aver frequentato parte del percorso scolastico in provincia di Bolzano tendono a correlare con un maggiore grado di sicurezza (mostrata) in uno dei codici d'arrivo. Quale questo codice sia (italiano o tedesco), dipende spesso, ma non esclusivamente, dalla prima località di residenza in Alto Adige dell'intervistato; scelta che, a sua volta, è in parte condizionata da catene migratorie precedenti. ${ }^{11}$ Tuttavia, il fattore età al momento dell'emigrazione non è necessariamente in-

11 Non sembra giocare invece un ruolo sulla scelta di apprendere italiano o tedesco come primo codice dopo l'emigrazione - per lo meno per la popolazione studiata (emigrata tuttavia in larga parte prima della promulgazione della norma) - la necessità di superare un test di lingua italiana per ottenere un permesso di soggiorno di lunga durata. Infatti, a parte BV, nessuno degli intervistati fa riferimento alla prova. Piuttosto, alcuni partecipanti lamentano la validità prettamente locale delle certificazioni di lingua altoatesine e la mancata accettazione, almeno fino a qualche anno fa, di certificati acquisiti in altri paesi. 
terrelato con l'acquisizione da parte dei partecipanti di competenze bilingui in italiano e tedesco. Infatti, gli intervistati più giovani (indipendentemente dal tipo di scuola frequentata) si sentono spesso insicuri - o raccontano di essersi sentiti insicuri - nell'adoperare l'altro codice locale (cfr. DK e anche, tra gli altri, DL, LP, AP, SP). Nel favorire l'apprendimento di entrambe le lingue d'arrivo (e, eventualmente, del dialetto tedesco locale), gioca piuttosto un ruolo maggiore l'entrata nel mondo del lavoro, accompagnata dalla volontà di "inclusione" o meglio di non essere esclusi dalla società locale (si comparino a questo riguardo le prese di posizione opposte dei consorti BV e DV sul desiderio di acquisizione delle varietà linguistiche d'arrivo, italiano standard compreso). Infatti, l'apprendimento di competenze plurilingui avviene spesso soprattutto per motivi professionali e in ambito lavorativo. Dicendo ciò, non si intende, tuttavia, assolutamente sostenere che chi tra gli intervistati non abbia acquisito competenze in entrambi i codici di arrivo (o dichiari di non averlo fatto), non abbia una reale volontà di apprenderli. Nè tantomeno si intende sostenere che la responsabilità dell'apprendimento linguistico dipenda esclusivamente dalla volontà dei singoli. Altri fattori, come quelli legati alle condizioni socio-economiche dei cittadini stranieri così come alle rappresentazioni metalinguistiche diffuse sul loro conto, hanno infatti frequentemente un influsso negativo sui risultati dell'apprendimento linguistico (e, per quanto possibile, dovrebbero essere quindi tenuti da conto al momento di pianificare attività di inclusione linguistica nella provincia autonoma, in particolare, e in altre regioni istituzionalmente plurilingui, in generale). Così, per esempio, i ritmi serrati di molti lavoratori immigrati impediscono spesso loro di frequentare corsi di lingua, mentre la già citata opinione, per cui "uno straniero, specie se proveniente da paesi a basso reddito, non potrai mai parlare bene il tedesco" (cfr. la storia di VM, citata al §V.4.2.2), sicuramente scoraggia i nuovi arrivati a cimentarsi nello studio del codice. L'effetto deterrente di questi ultimi fattori non è comunque stato decisivo sulle scelte e sui risultati di apprendimento linguistico degli intervistati per la presente ricerca. Contrariamente a quanto spesso paventato da alcuni gruppi e mass media locali, la maggior parte dei partecipanti a questo studio (28 su 38) dichiara infatti di avere competenze almeno base in entrambe le varietà standard dei codici di arrivo, mentre più di un quarto padroneggia, oltre ai codici standard, anche uno dei dialetti tedeschi locali. 


\section{ALLEGATI}

Allegato 1: Sezione della tabella dei metadati dei 38 intervistati del corpus.

I partecipanti sono ordinati per anno di prima emigrazione. La durata delle interviste di coppia è posta tra partentesi quadre.

\begin{tabular}{|c|c|c|c|c|c|c|c|c|c|c|}
\hline SPK & $\begin{array}{l}\text { Paese } \\
\text { origine }\end{array}$ & Sesso & Età & $\begin{array}{l}\text { Lingua } \\
\text { intervista }\end{array}$ & $\begin{array}{l}\text { Prima } \\
\text { residenza in } \mathbf{A} \text {. } \\
\text { A. }\end{array}$ & $\begin{array}{l}\text { Anno di } \\
\text { emigr. }\end{array}$ & $\begin{array}{l}\text { Anno di } \\
\text { arrivo in } \\
\text { A. A. }\end{array}$ & $\begin{array}{l}\text { Altri luoghi di } \\
\text { residenza precedenti }\end{array}$ & $\begin{array}{l}\text { Occupazione } \\
\text { attuale }\end{array}$ & $\begin{array}{l}\text { Durata } \\
\text { intervista }\end{array}$ \\
\hline BA & Ser & $\mathrm{m}$ & 45 & ita & Merano & 1970 & 1994 & Austria & portiere di notte & $00: 52: 19$ \\
\hline YF & Ser & $m$ & 52 & deu & Brunico & 1987 & 2002 & Germania & camionista & {$[00: 26: 43]$} \\
\hline $\mathrm{XF}$ & Ser & $f$ & 48 & deu & Brunico & 1987 & 2002 & Germania & in azienda & [00:26:43] \\
\hline IP & Mac & $m$ & 50 & ita & Merano & 1988 & 2014 & $\begin{array}{l}\text { Abruzzo, Trentino, } \\
\text { Lombardia }\end{array}$ & ristoratore & $00: 21: 44$ \\
\hline$A C$ & Kos & $m$ & 41 & ita & Brunico & 1992 & 1994 & Campania & panettiere & $00: 32: 42$ \\
\hline RM & Mon & $m$ & 42 & ita & Bolzano & 1992 & 2011 & $\begin{array}{l}\text { Roma, Trento, } \\
\text { Svizzera }\end{array}$ & ristoratore & 01:03:51 \\
\hline $\mathrm{AF}$ & Bos & $f$ & 32 & ita & Vipiteno & 1992 & 1992 & - & $\begin{array}{l}\text { insegnante di } \\
\text { tedesco }\end{array}$ & $01: 12: 46$ \\
\hline KS & Mon & $f$ & 40ca. & deu & Brunico & 1992 & 2000 & Austria & $\begin{array}{l}\text { impresa } \\
\text { frutticola }\end{array}$ & {$[00: 25: 21]$} \\
\hline LA & Cro & $f$ & 53 & deu & Bolzano & 1992 & 1998 & Belgrado, Innsbruck & $\begin{array}{l}\text { mediatrice } \\
\text { interculturale }\end{array}$ & 01:01:03 \\
\hline $\mathrm{JB}$ & Ser & $m$ & 45 & deu & San Lorenzo & $1992-93$ & 1999 & Austria & in azienda & $00: 40: 18$ \\
\hline ZT & Kos & $m$ & 43 & ita & Laives & 1993 & 1996 & Grecia, Abruzzo & operaio & $00: 26: 06$ \\
\hline NJ & Mac & $m$ & 40 & ita & Lana & 1993 & 1993 & - & tassista & $01: 07: 48$ \\
\hline TF & Ser & $f$ & 49 & ita & Falzes & 1994 & 2002 & Roma & $\begin{array}{l}\text { costruttrice di siti } \\
\text { web }\end{array}$ & $00: 33: 21$ \\
\hline SM & Mon & $\mathrm{m}$ & 19 & ita & Bolzano & $1994-95$ & 2011 & Roma, Trento & ristoratore & $00: 26: 51$ \\
\hline AK & Kos & $f$ & 20 & deu & Bolzano & 1995 & 2002 & Germania & scolara & $00: 25: 31$ \\
\hline KM & Bos & $m$ & $42 \mathrm{ca}$. & ita & Bolzano & 1995 & 1995 & - & $\begin{array}{l}\text { venditore di } \\
\text { piastrelle }\end{array}$ & 01:03:43 \\
\hline RX & Mon & $\mathrm{m}$ & 45 & ita & Bolzano & 1996 & 1997ca. & Puglia, Lombardia & commerciante & $01: 45: 28$ \\
\hline $\mathrm{BL}$ & Kos & $f$ & 18 & ita & Appiano & 1997 & 1997 & - & scolara & $00: 33: 07$ \\
\hline $\mathrm{DL}$ & Ser & $m$ & 26 & ita & Renon & 1997 & 1997 & Ravenna & cameriere & $00: 51: 22$ \\
\hline \begin{tabular}{|l}
$L P$ \\
\end{tabular} & Kos & $f$ & 28 & ita & Bolzano & 1998 & 1999 & Croazia & studentessa & $01: 16: 40$ \\
\hline $\mathrm{ML}$ & Kos & $f$ & 35 & ita & Merano & 1998 & 1998 & Montenegro & $\begin{array}{l}\text { raccoglitrice } \\
\text { mele }\end{array}$ & $00: 32: 07$ \\
\hline AP & Kos & $f$ & 22 & ita & Bolzano & 1998 & 1999 & Croazia & studentessa & [01:23:02] \\
\hline SP & Kos & $f$ & 24 & ita & Bolzano & 1998 & 1999 & Croazia & studentessa & [01:23:02] \\
\hline DK & Kos & $f$ & 23 & deu & Sarentino & $1998-99$ & $1998-99$ & Svizzera & studentessa & $01: 00: 20$ \\
\hline VM & Ser & $f$ & 46 & ita & Merano & 2001 & 2001 & Macedonia & $\begin{array}{l}\text { cameriera in } \\
\text { mensa }\end{array}$ & $01: 13: 34$ \\
\hline FK & Kos & $f$ & 27 & ita & Bolzano & 2002 & 2002 & Albania & studentessa & $00: 24: 11$ \\
\hline DR & Ser & $f$ & 59 & ita & Merano & 2002 & 2002 & - & cameriera & [01:18:21] \\
\hline $\begin{array}{l}F R \\
\end{array}$ & Ser & $f$ & 35 & ita & Merano & 2002 & 2002 & - & lavandaia & [01:18:21] \\
\hline \begin{tabular}{|l}
$\mathrm{PB}$ \\
\end{tabular} & Ser & $f$ & $35-40$ & deu & Brunico & 2002 & 2002 & - & in azienda & {$[00: 25: 21]$} \\
\hline MG & Mac & $f$ & $35-40$ & ita & Bolzano & 2003 & 2003 & - & $\begin{array}{l}\text { insegnante di } \\
\text { inglese }\end{array}$ & $00: 44: 26$ \\
\hline DB & Ser & $f$ & 42 & ita & San Vigilio & 2004 & 2004 & - & $\begin{array}{l}\text { cameriera ai } \\
\text { piani }\end{array}$ & $00: 35: 21$ \\
\hline NM & Cro & $f$ & 29 & ita & Bolzano & 2004 & 2004 & Serbia & casalinga & $00: 49: 03$ \\
\hline SV & Ser & $f$ & 41ca. & ita & Merano & 2006 & 2006 & - & $\begin{array}{l}\text { cameriera ai } \\
\text { piani }\end{array}$ & $00: 26: 05$ \\
\hline AS & Mac & $f$ & 24 & ita & Bolzano & 2006 & 2006 & - & pulizie in ufficio & 00:33:09 \\
\hline $\mathrm{TN}$ & Ser & $m$ & 22 & deu & Vandoies & 2006 & 2006 & - & disoccupato & $00: 32: 24$ \\
\hline OV & Ser & $f$ & $36 \mathrm{ca}$. & ita & Merano & 2007 & 2007 & - & disoccupata & $00: 24: 26$ \\
\hline BV & Ser & $m$ & 29 & eng & Bolzano & 2009 & 2010 & Vienna & studentessa & $02: 04: 16$ \\
\hline DV & Ser & $m$ & 29 ca. & eng & Bolzano & 2009 & 2010 & Vienna & dottorando & $00: 38: 03$ \\
\hline
\end{tabular}


Allegato 2: Sezione del protocollo di ascolto dell'intervista con VM. Alla prima parte del colloquio è presente oltre alla ricercatrice anche un'amica della partecipante.

\begin{tabular}{|c|c|c|c|}
\hline Tema & Tipo di testo & Note linguistiche & Minuti \\
\hline $\begin{array}{l}\text { VM: vicina croata e l'italiano } \\
\text { VM: perdita dell'identità } \\
\text { VM: difficoltà e stereotipi } \\
\text { linguistici del primo periodo in } \\
\text { Rep. di Macedonia } \\
\text { VM: ottime competenze in } \\
\text { macedone dopo tre mesi, uso di } \\
\text { serbo nei momenti di rabbia } \\
\text { VM: differenze di suoni tra serbo e } \\
\text { macedone }\end{array}$ & $\begin{array}{l}\text { narrazione } \\
\text { episodica }\end{array}$ & & $\begin{array}{l}00: 00-00: 32 \\
00: 32-00: 37 \\
00: 37-01: 09 \\
01: 09-01: 44 \\
01: 44-02: 04\end{array}$ \\
\hline $\begin{array}{l}\text { Amica: essere nati per le lingue: } \\
\text { differenze individuali nella } \\
\text { capacità di apprendimento }\end{array}$ & & & $02: 04-02: 25$ \\
\hline $\begin{array}{l}\text { VM: marito e figlio in questura } \\
\text { VM: abitudine al plurilinguismo } \\
\text { degli altoatesini } \\
\text { VM: scarse capacità linguistiche } \\
\text { dei francesi autoctoni versus } \\
\text { non-autoctoni }\end{array}$ & $\begin{array}{l}\text { narrazione } \\
\text { episodica }\end{array}$ & $\begin{array}{l}\text { discorso diretto } \\
\text { discorso diretto }\end{array}$ & $\begin{array}{l}02: 25-03: 34 \\
03: 34-03: 56 \\
03: 56-04: 40\end{array}$ \\
\hline $\begin{array}{l}\text { Amica: presenza di molti stranieri } \\
\text { a Merano }\end{array}$ & & & 04:40-05:01 \\
\hline $\begin{array}{l}\text { VM: la prima volta in pullman a } \\
\text { Merano } \\
\text { Amica: problema della vergogna } \\
\text { di non saper parole } \\
\text { VM: volontà di avere una rela- } \\
\text { zione è sufficiente per capirsi } \\
\text { VM: in ospedale }\end{array}$ & $\begin{array}{l}\begin{array}{l}\text { narrazione } \\
\text { episodica }\end{array} \\
\text { narrazione } \\
\text { multi-episodica } \\
\text { con funzione } \\
\text { argomentativa } \\
\text { (1 episodio) }\end{array}$ & $\begin{array}{l}\text { inserzione di } \\
\text { parola in tedesco } \\
\text { (Gallenstein, } \\
\text { tr. calcolo biliare) }\end{array}$ & $\begin{array}{l}05: 01-07: 07 \\
07: 07-07: 45 \\
07: 45-07: 56 \\
07: 56-08: 47\end{array}$ \\
\hline interruzione per breve telefonata & & & $08: 47-08: 57$ \\
\hline $\begin{array}{l}\text { VM: gentilezza del dottore } \\
\text { VM: excursus: severità dell'inse- } \\
\text { gnante di russo alle elementari } \\
\text { VM: seconda operazione in } \\
\text { ospedale }\end{array}$ & $\begin{array}{l}\text { proseguimento } \\
\text { narrazione } \\
\text { multi-episodica } \\
\left(2^{\circ} \text { episodio }\right) \\
\text { narrazione } \\
\text { multi-episodica } \\
\left(3^{\circ} \text { episodio) }\right.\end{array}$ & $\begin{array}{l}\text { inserzione di frase } \\
\text { in tedesco e } \\
\text { discorso diretto }\end{array}$ & $\begin{array}{l}08: 57-09: 13 \\
09: 13-09: 41 \\
09: 41-10: 31\end{array}$ \\
\hline
\end{tabular}




\begin{tabular}{|l|l|l|c|}
\hline \multicolumn{1}{|c|}{ Tema } & Tipo di testo & Note linguistiche & Minuti \\
\hline $\begin{array}{l}\text { Intervistatrice: parlavano in } \\
\text { tedesco i medici? }\end{array}$ & & & $10: 31-10: 34$ \\
\hline $\begin{array}{l}\text { VM: tedesco per VM anche se il } \\
\text { dottore era italiano }\end{array}$ & & & $10: 34-10: 48$ \\
\hline interruzione per telefonata & & & $10: 48-11: 07$ \\
\hline$\ldots$ & $\ldots$ & $\ldots$ & $\ldots$ \\
\hline
\end{tabular}

Allegato 3: Esempio di un protocollo di situazione (intervista con VM).

\begin{tabular}{|l|l|}
\hline Data e luogo & 07.02 .2014$, Merano \\
\hline Ora & Dalle 17:30 alle 19:00 circa \\
\hline Ambiente & Soggiorno dell'appartamento dell'intervistata \\
\hline Partecipanti & $\begin{array}{l}\text { Ricercatrice e VM. Un'amica di origini serbe e il } \\
\text { marito della partecipante sono rispettivamente } \\
\text { presenti all'inizio e alla fine del colloquio }\end{array}$ \\
\hline Durata & $01: 13: 34$ \\
\hline Compilazione del protocollo & Febbraio 2014 \\
\hline Registratore & Zoom H2next \\
\hline
\end{tabular}

\begin{tabular}{|l|l|}
\hline Modo del contatto & $\begin{array}{l}\text { Appuntamento fissato il giorno prima da DR in } \\
\text { presenza della ricercatrice per telefono }\end{array}$ \\
\hline Incontri prima dell'intervista? & No \\
\hline Rapporti con altri intervistati & Amica di DR, conoscente di FR, conoscente di BA \\
\hline
\end{tabular}

\begin{tabular}{|l|l|}
\hline Intervistato & VR_Ser_Mer \\
\hline Mimica e gesti & Gestualità pronunciata \\
\hline Atmosfera durante l'intervista & Ottima, anche se al termine un po' malinconica \\
\hline Qualità audio & Ottima \\
\hline Tipo di intervista & Intervista episodico-narrativa \\
\hline Lingua dell'intervista & Italiano \\
\hline
\end{tabular}

\begin{tabular}{|l|l|}
\hline $\begin{array}{l}\text { Comunicazione al di fuori } \\
\text { dell'intervista }\end{array}$ & [omesse] \\
\hline Altri incontri dopo l'intervista & No \\
\hline
\end{tabular}


Allegato 4: Sigle ISO-639-2 e altre abbreviazioni utilizzate per le varietà linguistiche.

\begin{tabular}{|l|l|}
\hline aln & albanese \\
\hline bos & bosniaco \\
\hline bul & bulgaro \\
\hline deu & tedesco \\
\hline chi & cinese \\
\hline eng & inglese \\
\hline fra & francese \\
\hline gre & greco moderno \\
\hline hochdeu & tedesco standard (Hochdeutsch) \\
\hline hrv & croato \\
\hline hrv-srp & croatoserbo \\
\hline ita & italiano \\
\hline lad & ladino \\
\hline lat & latino \\
\hline mac & macedone \\
\hline nep & nepalese \\
\hline ukr & ucraino \\
\hline por & portoghese \\
\hline rum & rumeno \\
\hline rus & russo \\
\hline schweizerdeu & tedesco svizzero (Schweizerdeutsch) \\
\hline slo & slovacco \\
\hline slv & sloveno \\
\hline spa & spagnolo, castigliano \\
\hline srp & serbo \\
\hline srp-hrv & serbocroato \\
\hline sdt & dialetti tedeschi locali (sudtirolese) \\
\hline tur & turco \\
\hline
\end{tabular}


Allegati 5a e 5b: Esempi di articoli di giornale in cui si tratta del tema della violazione del "diritto alla madre lingua" da parte dei carabinieri secondo alcuni esponenti politici locali. Nel secondo articolo, alle forze di sicurezza è attribuito un enunciato in italiano in discorso diretto.

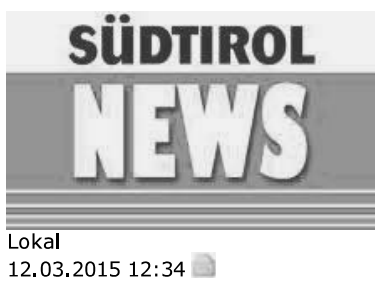

\section{STF: "Carabinieri verweigern Recht auf Gebrauch der Muttersprache"}

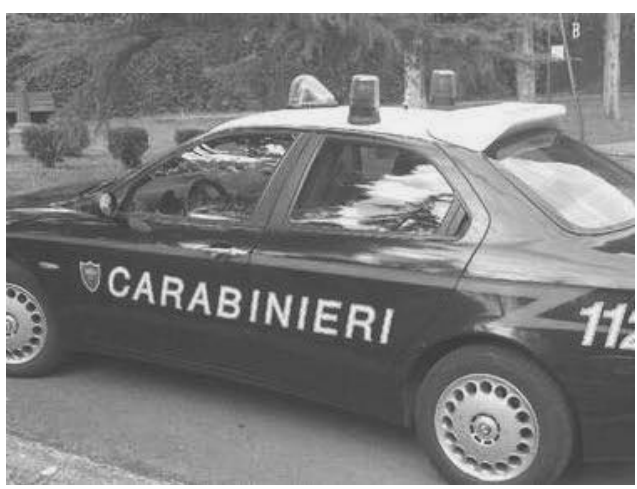

Bewegung spricht von einer „unendlichen Geschichte“

Foto: ansa

Bozen - Die Süd-Tiroler Freiheit kritisiert, dass das Recht auf Gebrauch der Muttersprache bei den Carabinieri häufig immer noch ignoriert werde. „Dies bestätigte vor kurzer Zeit ein Fall im Unterland. Als ein besorgter Bürger drei mutmaßliche Betrüger melden wollte, welche sich aufdringlich als ENEL-Vertreter ausgaben, traf er am anderen Ende der Leitung nur einen italienischsprachigen Beamten an. Der Beamte der Notrufstelle 112 leitete ihn an einen weiteren italienischsprachigen Beamten in Neumarkt weiter."

„Auf den Hinweis des Bürgers, er hätte das Recht, seine deutsche Muttersprache zu gebrauchen, reagierte der Beamte der Station in Neumarkt gereizt und gab ihm zu verstehen, dass er das Gespräch entweder in Italienisch oder gar nicht führen werde", schreibt die Süd-Tiroler Freiheit.

Für die Bewegung ist dies ein „absolutes Unding und ein weiterer Beweis dafür, welche Vorteile zum Beispiel eine eigene Landespolizei hätte. Trotz aller beschwichtigenden Rhetorik seitens der Carabinieri kommt es immer wieder zu Verletzungen der Zweisprachigkeitspflicht“, kritisiert Landtagsabgeordneter Sven Knoll.

„Eine Südtiroler Landespolizei, anstelle von Carabinieri und Staatspolizei, könnte sich wesentlich besser in die lokalen Realitäten einfügen und mit den geographischen, historischen, kulturellen und gesellschaftlichen Verhältnissen besser umgehen“, ergänzt Fraktionssekretär Stefan Zeiger.

Fonte: <http://www.suedtirolnews.it/d/artikel/2015/03/12/stf-carabinieri-verweigern-recht-aufgebrauch-der-mutter sprache\#.VVO8vpNwwqI> (13.05.2015). Ora l'articolo si può trovare con un nuovo titolo e grafica all'URL: https://www.unsertirol24.com/2015/03/12/carabinieriund-recht-auf-gebrauch-der-muttersprache-die-unendliche-geschichte/ (10.10.2018). 


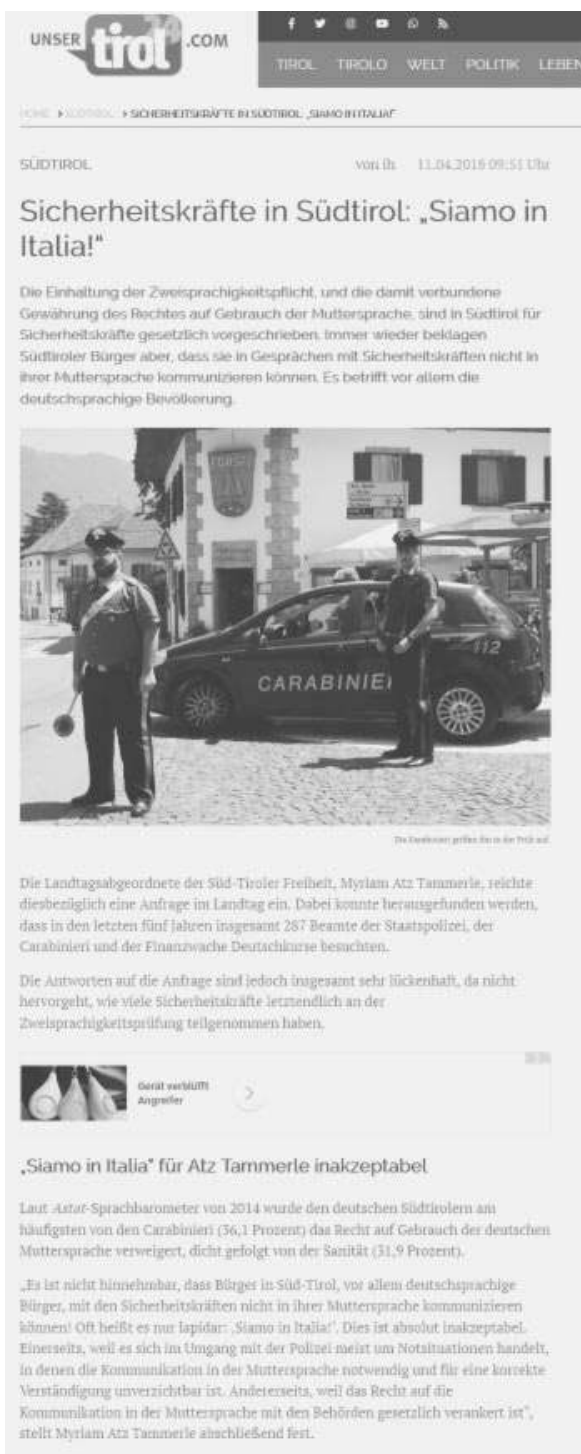

Fonte: <https://www.unsertirol24.com/2018/04/11/sicherheitskraefte-in-suedtirol-siamo-initalia/> (18.10.2018). 


\section{BIBLIOGRAFIA}

Ahrenholz, Bernt (a cura di) (2009): Empirische Befunde zu DaZ-Erwerb und Sprachförderung: Beiträge aus dem 3. Workshop "Kinder mit Migrationshintergrund". Freiburg im Breisgau: Fillibach, 273-289.

Akin, Salih (2000): Pour une typologie des processus redénominatifs. In: S. Akin (a cura di): Noms et re-noms: la dénomination des personnes, des populations, des langues et des territoires. Rouen: Publ. de l'Univ. de Rouen, 33-60.

Ambrosini, Maurizio (2005): Sociologia delle migrazioni. Bologna: Il mulino.

Ammon, Ulrich; Dittmar, Norbert; Mattheier, Klaus (a cura di) (1987): Sociolinguistics/Soziolinguistik. An International Handbook of the Science of Language and Society/Ein internationales Handbuch zur Wissenschaft von Sprache und Gesellschaft. Berlin: de Gruyter.

Ammon, Ulrich; Kyvelos, Rhea; Nyffenegger, Regula (2004): Variantenwörterbuch des Deutschen. Die Standardsprache in Österreich, der Schweiz und Deutschland sowie in Liechtenstein, Luxemburg, Ostbelgien und Südtirol. Berlin, New York: de Gruyter.

Anderson, Benedict R. O'G (1983/1991): Imagined communities. Reflections on the origin and spread of nationalism. Edizione riveduta e ampliata. London, New York: Verso.

Andorno, Cecilia M. \& Interlandi, Grazia M. (2004): Gli arabofoni fra le comunità immigrate a Torino: un rilevamento sociolinguistico. In: M. Vedovelli et al. (a cura di): Lingue e culture in contatto. L'italiano come L2 per gli arabofoni. Milano: FrancoAngeli, 233-267.

Androutsopoulos, Jannis (2007): Ethnolekte in der Mediengesellschaft. Stilisierung und Sprachideologie in Performance, Fiktion und Metasprachdiskurs. In: C. Fandrych \& R. Salverda (a cura di): Standard, Variation und Sprachwandel in germanischen Sprachen/Standard, variation and language change in Germanic languages. Tübingen: Narr., 113-155.

Androutsopoulos, Jannis (2011): Die Erfindung ‘des' Ethnolekts. Inventing 'the' Ethnolect. In: Zeitschrift für Literaturwissenschaft und Linguistik (164), 93-120.

Aronin, Larissa \& Singleton, David (2010): Affordances and the diversity of multilingualism. In: International Journal of the Sociology of Language 205, 105-129.

Aronin, Larissa; Laoire, Muiris'o; Singleton, David (2011): The multiple faces of multilingualism: Language nominations. In: Applied Linguistics Review 2, 169-190.

Arvinte, Vasile (2003): Désignations des langues de la Romania du Sud-Est. In: A. Burkhardt et al. (a cura di), 156-163.

ASTAT (2003): Demographisches Handbuch für Südtirol 2002/ Manuale demografico della provincia di Bolzano 2002. Bolzano: Provincia Autonoma di Bolzano-Alto Adige - ASTAT.

ASTAT (2006): Südtiroler Sprachbarometer - 2004/ Barometro linguistico dell'Alto Adige - 2004. Sprachgebrauch und Sprachidentität in Südtirol/ Uso della lingua e identità linguistica in provincia di Bolzano. Bolzano: Provincia Autonoma di Bolzano-Alto Adige - ASTAT. URL: < http://astat.provinz.bz.it/de/aktuelles-publikationen-info.asp?news_action=4\&news_article_ id $=131260>$, (18.10.2018).

ASTAT (2012): Immigration in Südtirol 2011/ Immigrazione in Alto Adige 2011. Lebensumstände und Sichtweisen der in- und ausländischen Bevölkerung/Stili di vita ed opinioni della popolazione altoatesina e straniera. Bolzano: PRINTEAM. URL: < http://astat.provinz.bz.it/ de/aktu elles-publikationen-info.asp?news_action=4\&news_article_id=394791>, (18.10.2018).

ASTAT (2013): Statistisches Jahrbuch für Südtirol 2012/ Annuario statistico della provincia di Bolzano 2012. Bolzano: PRINTEAM. URL: <http://astat.provinz.bz.it/downloads/jahrbuch_2012.pdf>, (18.10.2018).

ASTAT (2015): Ausländische Wohnbevölkerung 2014/ Popolazione straniera residente 2014. Bolzano: Provincia Autonoma di Bolzano-Alto Adige - ASTAT. URL: <http://astat.provinz.bz. 
it/de/aktuelles-publikationen-info.asp?news_action=4\&news_article_id=499734>, (18.10.2018).

Auer, Peter (1984): Bilingual conversation. Amsterdam, Philadelphia: J. Benjamins.

Auer, Peter (a cura di) (1998a): Code-switching in conversation. Language, interaction and identity. London, New York: Routledge.

Auer, Peter (1998b): Introduction: Bilingual Conversation revisited. In: P. Auer (a cura di), 1-24.

Auer, Peter (2005): A postscript: code-switching and social identity. In: Journal of Pragmatics 37, 403-410.

Bagna, Carla; Machetti, Sabrina; Vedovelli, Massimo (2003): Italiano e lingue immigrate: verso un plurilinguismo consapevole o verso varietà di contatto? In: A. Valentini (a cura di), 201-222.

Baker, Colin (1992): Attitudes and language. Clevedon, Philadelphia: Multilingual Matters.

Bamberg, Michael G. W. (1997): Positioning Between Structure and Performance. In: Journal of Narrative and Life History 7 (1-4), 335-342.

Bamberg, Michael G. W. \& Georgakopoulou, Alexandra (2008): Small stories as a new perspective in narrative and identity analysis. In: Text and Talk 28 (3), 377-396.

Bamberg, Michael G. W.; Fina, Anna de; Schiffrin, Deborah (a cura di) (2007): Selves and identities in narrative and discourse. Amsterdam, Philadelphia: J. Benjamins.

Banfi, Emanuele (2003): Evoluzione delle frontiere delle lingue romanze: Romania del Sud-Est. Entwicklung der romanischen Sprachgrenzen: Südostromania. In: A. Burkhardt (a cura di), 622-631.

Barbarić, Philipp (2015): Che storia che gavemo qua. Sprachgeschichte Dalmatiens als Sprechergeschichte (1797 bis heute). Stuttgart: Steiner (Spazi Comunicativi, 12).

Barni, Monica (2008): Le lingue immigrate in Italia. In: Caritas/Migrantes (a cura di): Immigrazione. Dossier statistico 2008. XVIII Rapporto. ROMA: Centro Studi e Ricerche IDOS.

Bauman, Richard (1986): Story, performance, and event. Contextual studies of oral narrative. Cambridge, New York: Cambridge University Press.

Baur, Siegfried (2000): Die Tücken der Nähe. Kommunikation und Kooperation in Mehrheits-/ Minderheitssituationen: Kontextstudie am Beispiel Südtirol. Meran (Bozen): Alpha \& Beta.

Baur, Siegfried (2011): Die Sprache der Anderen. Was erschwert und was erleichtert den Zweitspracherwerb in Südtyrol?. In: G. Grote \& B. Siller (a cura di), 167-175.

Baur, Siegfried; Giorgio Mezzalira; Walter Pichler (a cura di) (2008): La lingua degli altri. Aspetti della politica linguistica e scolastica in Alto Adige-Südtirol dal 1945 ad oggi. Milano: FrancoAngeli.

Baynham, Mike (2005): Network and Agency in the Migration Stories of Moroccan Women. In: M. Baynham \& A. De Fina (a cura di), 11-35.

Baynham, Mike \& De Fina, Anna (a cura di) (2005): Dislocations/Relocations. Narratives of displacement. Manchester: St. Jerome Pub.

Berić, Vesna (1986): Zur Diachronie der deutschen Bezeichnung "Muttersprache”. In: Grazer Linguistische Studien 27, 15-20.

Bernhard, Stefan (2014): Identitätskonstruktionen in narrativen Interviews. Ein Operationalisierungsvorschlag im Anschluss an die relationale Netzwerktheorie. In: Forum Qualitative Sozialforschung/ Forum: Qualitative Social Research 15 (3), URL: $<\mathrm{http}: / / w w w . q u a l i t a t i v e-r e$ search.net/index.php/fqs/article/view/2130> (18.10.2018).

Berruto, Gaetano (1995): Fondamenti di sociolinguistica. Roma: Laterza.

Berruto, Gaetano (1987/2012): Sociolinguistica dell'italiano contemporaneo. Roma: Carocci.

Berruto, Gaetano; Brincat, Joseph; Caruana, Sandro; Andorno, Cecilia (a cura di) (2008): Lingua cultura e cittadinanza in contesti migratori. Europa e area mediterranea: Malta, 21-22 febbraio 2008: atti dell' 8 . Congresso dell'Associazione italiana di linguistica applicata. Perugia: Guerra.

Bert, Michel \& Costa, James (2014): What Counts as a Linguistic Border, for Whom and with What Implications? Exploring Occitan and Francoprovençal in Rhône-Alpes, France. In: D. Watt \& C. Llamas (a cura di): Language, Borders and Identities. Edinburgh: Edinburgh University Press, 186-205. 
Betten, Anne (a cura di) (1995): Sprachbewahrung nach der Emigration - das Deutsch der 20er Jahre in Israel. Teil I: Transkripte und Tondokumente. Tübingen: Niemeyer.

Betten, Anne (2010): Sprachbiographien der 2. Generation deutschsprachiger Emigranten in Israel. Zur Auswirkung individueller Erfahrungen und Emotionen auf die Sprachkompetenz. In: Zeitschrift für Literaturwissenschaft und Linguistik 40 (Sprache und Biographien 160), 29-57.

Betten, Anne \& Du-nour, Miryam (a cura di) (2000): Sprachbewahrung nach der Emigration: das Deutsch der 20er Jahre in Israel. Teil II: Analysen und Dokumente. Tübingen: Niemeyer.

Biber, Douglas (1993): Representativeness in Corpus Design. In: Literary and Linguistic Computing 8 (4), 243-257.

Blackledge, Adrian \& Creese, Angela (2010): Multilingualism. A critical perspective. London, New York: Continuum.

Bletzer, Keith V. (2013): Mexican Trans-Migrants and Their Experience on Both Sides of the Border: Intimacy and Distance Through Use of Deictic Referents. In: The Open Anthropology Journal 6, 1-10.

Blommaert, Jan (1999): The debate is open. In: J. Blommaert (a cura di): Language ideological debates. Berlin, New York: de Gruyter, 1-38.

Blommaert, Jan (2008): Language, asylum, and the national order. In: Urban Language \& Literacies 50, 2-21.

Blommaert, Jan (2010): The sociolinguistics of globalization. Cambridge, UK, New York: Cambridge University Press.

Blommaert, Jan (2013): Citizenship, language and superdiversity: towards complexity. In: Journal of Language, Identity and Education, Forum on 'citizenship' 12 (3),193-196.

Blommaert, Jan \& Backus, Ad (2012): Superdiverse repertoires and the individual. In: Tilburg Papers in Culture Studies, paper 24, 1-32.

Boario, Anna (2008): Community of practice e diffusione di un fenomeno alloctono a Torino trasmesso a parlanti immigrati non nativi. In: G. Berruto et al. (a cura di), 165-190.

Bochmann, Klaus \& Dumbrava, Vasile (a cura di) (2007): Sprachliche Individuation in mehrsprachigen Regionen Osteuropas. 1. Republik Moldova. Leipzig: Leipziger Universitätsverlag.

Bochmann, Klaus \& Dumbrava, Vasile (a cura di) (2009): Sprachliche Individuation in mehrsprachigen Regionen Osteuropas. 2. Ukraine. Leipzig: Leipziger Universitätsverlag.

Bourdieu Pierre (1982/2005): Was heißt sprechen? Die Ökonomie des sprachlichen Tausches. 2. edizione riveduta e ampliata. Wien: Braumüller.

Breu, Walter (2002), Moliseslawisch. In: M. Okuka \& G. Krenn (a cura di): Wieser. Enzyklopädie des europäischen Ostens. vol. 10, Wieser Verlag: Klagenfurt, 315-317. URL: <http://wwwg. uni-klu.ac.at/eeo/Moliseslawisch.pdf> (18.10.2018).

Brozović, Dalibor (1992): Serbo-Croatian as a pluricentric language. In: M. Clyne (a cura di), $347-380$.

Bucholtz, Mary \& Hall, Kira (2005): Identity and interaction: a sociocultural linguistic approach. In: Discourse Studies 7, 585-614.

Bugarski, Ranko (1990): The social basis of language conflict and language attitudes. In: P.H. Nelde (a cura di): Language attitudes and language conflict. Spracheinstellungen und Sprachkonflikte. Bonn: Dümmler (Plurilingua, 9), 41-48.

Bugarski, Ranko (2004): What's in a name: the case of Serbo-Croatian. In: Revue des études slaves 75 (1), 11-20.

Bugarski, Ranko (2012): Language, identity and borders in the former Serbo-Croatian area. In: Journal of Multilingual and Multicultural Development 33 (3), 219-235.

Bugarski, Ranko \& Hawkesworth, Celia (a cura di) (2004): Language in the former Yugoslav lands. Bloomington, IN: Slavica Publishers.

Burkhardt, Armin; Ernst, Gerhard; Ungeheuer, Gerold (a cura di) (2003): Romanische Sprachgeschichte/ Histoirè linguistique de la Romania. Ein internationales Handbuch zur Geschichte der romanischen Sprachen/Manuel international d'histoire linguistique de la Romania. Berlin: de Gruyter. 
Busch, Brigitta (2004a): Debate. In: B. Birgitta \& H. Kelly-Holmes (a cura di): Language, discourse and borders in the Yugoslav successor states. Clevedon: Multilingual Matters Ltd, 50-66.

Busch, Brigitta (2004b): Sprachen im Disput. Medien und Öffentlichkeit in multilingualen Gesellschaften. Klagenfurt: Drava.

Busch, Brigitta (2006): Bosnisch, Kroatisch, Serbisch, Serbokroatisch, Romani oder Vlachisch? Heteroglossie und 'muttersprachlicher' Unterricht in Österreich. In: P. Cichon (a cura di): Gelebte Mehrsprachigkeit. Akten des Wiener Kolloquiums zur individuellen und sozialen Mehrsprachigkeit, 5.-6.XI.2005. Wien: Praesens, 12-27.

Busch, Brigitta (2012): The Linguistic Repertoire Revisited. In: Applied Linguistics 33 (5), 503-523.

Busch, Brigitta (2013): Mehrsprachigkeit. Stuttgart: UTB.

Busch, Brigitta \& Schick, Jürgen (2007): Educational Materials Reflecting Heteroglossia: Disinventing Ethnolinguistic Differences in Bosnia-Herzegovina. In: S. Makoni \& A. Pennycook (a cura di), 216-232.

Byron, Janet (1985): An overview of language planning achievements among the Albanians of Yugoslavia. In: International Journal of the Sociology of Language (52), 59-92.

Calamai, Silvia (2011): Per una storia della pronuncia degli italiani: opinioni e atteggiamenti intorno alla pronuncia fiorentina. In: A. Nesi et al. (a cura di): Storia della lingua italiana e storia dell'Italia unita. L'italiano e lo stato nazionale: atti del IX Convegno ASLI, Associazione per la storia della lingua italiana (Firenze, 2-4 dicembre 2010). Firenze: F. Cesati, 175-184.

Carlà, Andrea (2015): Tensions and Challenges between New and Old Minorities: Political Party Discourses on Migration in South Tyrol. In: R. Medda-Windischer \& A. Carlà (a cura di): Migration and autonomous territories. The case of South Tyrol and Catalonia. Boston: Brill Nijhoff, 65-99.

Carli, Augusto \& Guardiano, Cristina (2005): Lingua percepita e costruzione identitaria. In: G. Banti et al. (a cura di): Atti del $4^{\circ}$ congresso di studi dell 'Associazione Italiana di Linguistica Applicata. Modena, 19-20 febbraio 2004. Perugia: Guerra, 385-413.

Carranza, Isolda E. (1998): Low-Narrativity Narratives and Argumentation. In: Narrative Inquiry 8 (2), 287-317.

Cashman, Holly R. (2008): Conversation and Interactional Analysis. In: W. Li \& M. G. Moyer (a cura di): The Blackwell guide to research methods in bilingualism and multilingualism. Malden, MA: Blackwell, 275-296.

Castellotti, Véronique \& Moore, Danièle (2002): Représentations sociales des langues et enseignement. Etude de référence pour le guide pour le développement de politiques linguistiqueséducatives en Europe. Strasbourg: Conseil de l'Europe, Conseil pour la coopération culturelle. URL: $<$ https://rm.coe.int/representations-sociales-des-langues-et-enseignements/168087458d > (18.10.2018).

Chafe, Wallace (1990): Some Things That Narratives Tell Us About the Mind. In: B. K. Britton \& A.D. Pellegrini (a cura di): Narrative Thought and narrative Language. A publication of the Cognitive Studies Group and the Institute for Behavioral Research at the University of Georgia. Hillsdale, N. J: L. Erlbaum, 79-98.

Chini, Marina (2003): Rapporti fra l'italiano e le lingue d'origine nel repertorio di immigrati in area lombarda: un sondaggi qualitativo. In: A. Valentini (a cura di), 223-246.

Chini, Marina (a cura di) (2004): Plurilinguismo e immigrazione in Italia. Un 'indagine sociolinguistica a Pavia e Torino. Milano: FrancoAngeli.

Chini, Marina (2009): L'italiano L2 nel repertorio delle nuove comunitá alloglotte: riflessioni su alcune dinamiche in atto. In: C. Consani (a cura di), 279-315.

Chini, Marina (2011): New linguistic minorities: repertoires, language maintenance and shift. In: International Journal of the Sociology of Language 2011 (210), 47-69.

Ciccolone, Simone (2010): Lo standard tedesco in Alto Adige. L'orientamento alla norma dei tedescofoni sudtirolesi. Milano: LED. 
Clayman, Steven (2010): Questions in Broadcast Journalism. In: A. F. Freed \& S. Ehrlich (a cura di): Why do you ask? The function of questions in institutional discourse. Oxford, New York: Oxford University Press, 256-278.

Clyne, Michael (a cura di) (1992): Pluricentric Languages: Differing Norms in Different Nations. Berlin \& New York: de Gruyter.

Clyne, Michael (2006): Some exploratory comments relating sociolinguistic typology to language shift. In: G. Gilbert et al. (a cura di): Studies in contact linguistics. Essays in Honor of Glenn G. Gilbert. New York: P. Lang, 207-230.

Clyne, Michael (2007): Sociolinguistic continuity from old to new homeland: factors in language maintenance and shift seen from the Australian situation. In: J. Darquennes (a cura di): Contact linguistics and language minorities. Kontaktlinguistik und Sprachminderheiten. Linguistique de contact et minorites linguistiques. St. Augustin: Asgard (Plurilingua, 30), 91-102.

Clyne, Michael \& Kipp, Sandra (1999): Pluricentric languages in an immigrant context. Spanish, Arabic and Chinese. Berlin, New York: de Gruyter, 1-62.

Clyne, Michael \& Kipp, Sandra (2006): Tiles in a multilingual mosaic. Macedonian, Filipino and Somali in Melbourne. Canberra: Pacific Linguistics.

CNEL (2013): IX Rapporto sugli indici di integrazione degli immigrati in Italia. URL: <http:// www.cnel.it/29?s hadow_ultimi_aggiornamenti=3484> (01.06.2016).

Coletti, Vittorio; Cordin, Patrizia; Zamboni, Alberto (1996): Il Trentino e l'Alto Adige. In: F. Bruni (a cura di): L'italiano nelle regioni. Milano: Garzanti, 262-318.

Condrea, Irina (2007): Der Terminus Muttersprache - Symbole und Mythen der Identität. In: K. Bochmann \& V. Dumbrava (a cura di), 57-69.

Consani, Carlo (a cura di) (2009): Alloglossie e comunità alloglotte nell'Italia contemporanea. Teorie, applicazioni e descrizioni, prospettive. Roma: Bulzoni.

Cortinovis, Enrica (2011): Lingua, etnicita e stile. Usi linguistici di adolescenti albanofoni a Bolzano. Tesi di dottorato non pubblicata.

Czernilofsky, Barbara (2010): "Zweisprachig unter Einsprachig" - vier sprachbiographische Erzählung. In: P. Cichon (a cura di): Sprachen - Sprechen - Schreiben. Blicke auf Mehrsprachigkeit. Wien: Praesens, 97-113.

D’Agostino, Mari; Amenta, Luisa; Amoruso, Chiara; Paternostro, Giuseppe (2003): Spazio pensato, vissuto, parlato. Comunità immigrate a Palermo. In: A. Valentini (a cura di), 261-279.

Dal Negro, Silvia (2009): La costruzione dell'altro: La definizione dei gruppi etnolinguistici in contesto plurilingue. In: C. Consani et al. (a cura di): Oralità/Scrittura. In memoria di Giorgio Raimondo Cardona (Atti del IX Congresso AItLA). Perugia: Edizioni Guerra, 195-216.

Dal Negro, Silvia (2011): Notes on the Mother Tongue ideology: Evidence from multilingual environments. In: W. Wiater \& G. Videsott (a cura di): New theoretical perspectives in multilingualism research. Frankfurt am Main, New York: P. Lang, 185-202.

Dal Negro, Silvia (2015), Sprache und Nation in Italien: Zur Dekonstruktion eines Zusammenhangs. In: N. Thoma \& M. Knappik (a cura di): Sprache und Bildung in Migrationsgesellschaften: Machtkritische Perspektiven auf ein prekarisiertes Verhältnis. Bielefeld: Transcript, 27-43.

Dal Negro, Silvia \& Molinelli, Piera (a cura di) (2002): Comunicare nella torre di Babele. Repertori plurilingui in Italia oggi. Roma: Carocci.

Dal Negro, Silvia \& Iannàccaro, Gabriele (2003): "Qui parliamo tutti uguale, ma diverso". Repertori complessi e interventi sulle lingue. In: A. Valentini (a cura di), 431-450.

Daniel, Erich; Egger, Kurt; Lanthaler, Franz (2001): Sprachnormautoritäten in Südtirol. In: K. Egger \& F. Lanthaler (a cura di), 208-231.

Bres, Julia de (2013): Language ideologies for constructing inclusion and exclusion: Identity and interest in the metalinguistic discourse of cross-border workers in Luxembourg. In: E. Barát et al. (a cura di): Ideological conceptualizations of language. Discourses of linguistic diversity. Frankfurt am Main [i.a.]: P. Lang, 57-83. 
De Fina, Anna (2003): Identity in narrative. A study of immigrant discourse. Amsterdam, Philadelphia: J. Benjamins.

De Fina, Anna (2008): Who tells which story and why? Micro and macro contexts in narrative. In: Text and Talk 28 (3), 421-442.

De Fina, Anna (2009): Narratives in interview - The case of accounts. For an interactional approach to narrative genres. In: Narrative Inquiry 19 (2), 233-258.

De Fina, Anna \& Perrino, Sabina (2011): Introduction: Interviews vs. 'natural' contexts: a false dilemma. In: Language in Society 40 (1), 1-11.

De Fina, Anna \& Georgakopoulou, Alexandra (2012): Analyzing narrative. Discourse and sociolinguistic perspectives. Cambridge, New York: Cambridge University Press.

Dell'Aquila, Vittorio \& Iannàccaro, Gabriele (2004): La pianificazione linguistica. Lingue, società e istituzioni. Roma: Carocci.

Dell'Aquila, Vittorio \& Iannàccaro, Gabriele (2006): Survey Ladins. Usi linguistici nelle Valli Ladine. Trento: Regione autonoma Trentino-Alto Adige.

Dell'Aquila, Vittorio \& Iannàccaro, Gabriele (2007): Metodi statistici per la misurazione del plurilinguismo sociale e dei rapporti tra i codici. In: J. Darquennes (a cura di): Contact linguistics and language minorities. Kontaktlinguistik und Sprachminderheiten. Linguistique de contact et minorités linguistiques. St. Augustin: Asgard (Plurilingua, 30), 77-89. Citazioni dalla versione online, URL: <https://www.academia.edu/1267868/Metodi_statistici_per_la_misurazione_del_ plurilin guismo_sociale_e_dei_rapporti_tra_i_codici $>(18 . \overline{10} .2018)$.

Deppermann, Arnulf (2013): Positioning in narrative interaction. Editorial. In: Narrative Inquiry 23 (1), 1-15.

Deppermann, Arnulf \& Lucius-Hoene, Gabriele (2006): Argumentatives Erzählen. In: A. Deppermann \& M. Hartung (a cura di): Argumentieren in Gesprächen. Gesprächsanalytische Studien. Tübingen: Stauffenburg Verlag, 130-144.

Dirim, İnci \& Auer, Peter (2004): Türkisch sprechen nicht nur die Türken. Über die Unschärfebeziehung zwischen Sprache und Ethnie in Deutschland. Berlin, New York: de Gruyter.

Dittmar, Norbert (2004): Transkription. Ein Leitfaden mit aufgaben für Studenten, Forscher und Laien. 2. edizione. Wiesbaden: Verlag für Sozialwissenschaften.

Du Bois, W. John (2007): The stance triangle. In: R. Englebretson (a cura di): Stancetaking in discourse. Subjectivity, evaluation, interaction. Amsterdam, Philadelphia: J. Benjamins, $139-182$.

Duranti, Alessandro (1997): Linguistic anthropology. New York: Cambridge University Press.

Edwards, John (1996): Language, prestige and stigma. In: H. Goebl et al. (a cura di), vol. 1., $703-708$.

Edwards, John (2012): Multilingualism. Understanding Linguistic Diversity. London: Bloomsbury Publishing.

Egger, Kurt (1990): Sprachenlernen in Südtirol: Antrieb und Zugang. In: A. M. Mioni et al. (a cura di), 37-55.

Egger, Kurt (2001): Sprachlandschaft im Wandel: Südtirol auf dem Weg zur Mehrsprachigkeit; soziolinguistische und psycholinguistische Aspekte von Ein- und Mehrsprachigkeit. Bozen: Verl.-Anst. Athesia.

Egger, Kurt \& Lanthaler, Franz (a cura di) (2001): Die deutsche Sprache in Südtirol. Einheitssprache und regionale Vielfalt. Wien: Folio.

Ehrich, Veronika (1992): Hier und jetzt. Studien zur lokalen und temporalen Deixis im Deutschen. Tübingen: Niemeyer.

Eichinger, Ludwig M. (2001): Die soziolinguistische Situation der deutschen Sprachgruppe in Südtirol. In: K. Egger \& F. Lanthaler (a cura di), 121-136.

Eichinger, Ludwig M.; Plewnia, Albrecht; Steinle, Melanie (a cura di) (2011): Sprache und Integration. Über Mehrsprachigkeit und Migration. Tübingen: Narr (Studien zur deutschen Sprache, 57). 
Eichler, Ernst; Burkhardt, Armin; Ungeheuer, Gerold; Wiegand, Herbert Ernst; Steger, Hugo; Brinker, Klaus (a cura di) (1995): Namenforschung: ein internationales Handbuch zur Onomastik/ Name studies: An International Handbook of Onomastics. Berlin: de Gruyter.

Evans Davies, Catherine (2007): Language and Identity in discourse in the American South: Sociolinguistic repertoire as expressive resource in the presentation of self. In: M.G.W. Bamberg et al. (a cura di): Selves and identities in narrative and discourse. Amsterdam, Philadelphia: J. Benjamins, 71-88.

Extra, Guus \& Yagmur, Kutlay (2008): Immigrant minority language in Europe: cross-national and cross-linguistic perspectives. In: G. Extra \& D. Gorter (a cura di): Multilingual Europe. Facts and policies. Berlin, New York: de Gruyter, 315-336.

Fincati, Veronica (a cura di) (2007): Gli immigrati serbi e montenegrini in Italia e in Veneto. Report realizzato nell'ambito del Progetto Interreg 3A DILMA. URL: < http://bancadati. italialavoro.it/bdds/download?fileName=C_21_Strumento_5442_documenti_itemName_0_documento.pdf\&uid=1082bc89-fde7-41c5-8774-ad0ea6d53a83 $>$ (18.10.2018).

Fishman, Joshua A. (1972/1975): Soziologie der Sprache. München: Max Hueber Verlag.

Fishman, Joshua A. (1989): Language and ethnicity in minority sociolinguistic perspective. Clevedon, Avon, England, Philadelphia: Multilingual Matters, Ltd.

Fix, Ulla (2010): Sprachbiographien als Zeugnisse von Sprachgebrauch und Sprachgebrauchsgeschichte. Rückblick und Versuch einer Standortbestimmung. In: Zeitschrift für Literaturwissenschaft und Linguistik 40 (Sprache und Biographien 160), 10-28.

Franceschini, Rita (1998): Riflettere sull'interazione. Un'introduzione alla metacomunicazione e all'analisi conversazionale. Milano: FrancoAngeli.

Franceschini, Rita (2001): Sprachbiographien randständiger Sprecher. In: R. Franceschini (a cura di): Biographie und Interkulturalität. Diskurs und Lebenspraxis: eingeleitet durch ein Interview mit Jacques Le Goff. Tübingen: Stauffenburg Verlag, 111-125.

Franceschini, Rita (2003): Unfocussed Language Acquisition? The Presentation of Linguistic Situations in Biographical Narration. In: Forum Qualitative Sozialforschung/Forum: Qualitative Social Research 4 (3). URL: <http://www.qualitative-research.net/index.php/fqs/article/view/667/ $1442>(18.10 .2018)$.

Franceschini, Rita (2004): Sprachbiographien: das Basel-Prag-Projekt (BPP) und einige mögliche Generalisierungen bezüglich Emotion und Spracherwerb. In: R. Franceschini \& J. Miecznikowski (a cura di), 121-145.

Franceschini, Rita (2010): Einleitung. In: Zeitschrift für Literaturwissenschaft und Linguistik 40 (Sprache und Biographien 160), 7-9.

Franceschini, Rita (2011a): Die `mehrsprachigsten’ Bürger Europas. Sprecher von historischen und neuen Minderheitensprache und ihr Beitrag. In: L. M. Eichinger et al. (a cura di), $29-53$.

Franceschini, Rita (2011b): The potentiality of Multilingualism: Four Scenarios for a Multilingual Country. In: W. Wiater e G. Videsott (a cura di): New theoretical perspectives in multilingualism research. Frankfurt am Main, New York: P. Lang, 135-153.

Franceschini, Rita (2012): Unfokussierter Spracherwerb in Kontaktsituationen: Sprachexposition als Teil des Sprachwandels. In: Sociolinguistica 26, 41-57.

Franceschini, Rita (2014): Language Acquisition: Italy and the Italian-Speaking Regions. In: C. Fäcke (a cura di): Language Acquisition in the Romance Speaking World. Berlin: de Gruyter, $529-554$.

Franceschini, Rita (2016): Multilingualism research. In: V. Cook \& W. Li (a cura di): The Cambridge handbook of linguistic multi-competence. Cambridge, New York: Cambridge University Press.

Franceschini, Rita \& Miecznikowski, Johanna (a cura di) (2004): Leben mit mehreren Sprachen/ Vivre avec plusieurs langues: Sprachbiographien/ Biographies langagières. Bern: P. Lang.

Franceschini, Rita; Müller, Myriam; Schmid, Stephan (1984): Comportamento linguistico e competenza dell'italiano in immigrati di seconda generazione: Un'indagine a Zurigo. In: Rivista Italiana di Dialettologia. Scuola società territorio VIII, 41-72. 
Freywald, Ulrike; Mayr, Katharina; Özcelik, Tiner; Wiese, Heike (2011): Kiezdeutsch as a multiethnolect. In: F. Kern \& M. Selting (a cura di): Ethnic styles of speaking in European metropolitan areas. Amsterdam: J. Benjamins, 47-73.

Fricke, Ellen (2007): Origo, Geste und Raum. Lokaldeixis im Deutschen. Berlin, New York: de Gruyter.

Friedman, Victor A. (2004): Language planning and status in the Republic of Macedonia and in Kosovo. In: R. Bugarski \& C. Hawkesworth (a cura di), 197-231.

Gal, Susan (1979): Language shift. Social determinants of linguistic change in bilingual Austria. New York: Academic Press.

Gal, Susan (1987): Linguistic Repertoire. In: U. Ammon et al. (a cura di), 286-292.

Gal, Susan (1993): Diversity and contestation in linguistic ideologies: German speakers in Hungary. In: Language in Society 22, 337-359.

Gal, Susan (1996): Language shift. In: H. Goebl et al. (a cura di), vol. 1, 584-593.

Georgakopoulou, Alexandra (2005): Same old story?: On the interactional dynamics of shared narratives. In: U. M. Quasthoff \& T. Becker (a cura di), 223-241.

Giddens, Anthony (2009): Race, Ethnicity and Migration. In: A. Giddens e P. W. Sutton (a cura di): Sociology. 6. edizione. Cambridge, UK, Malden, MA: Polity, 629-671.

Giles, Howard; Hewstone, Miles; Ryan, Ellen B.; Johnson, Patricia (1987): Research on Language Attitudes. In: U. Ammon et al. (a cura di), vol. 1, 585-597.

Girardi, Rainer (2011): Cenni storici e dati demografici sulle migrazioni in Alto Adige. In: G. Hetfleisch et al. (a cura di), 78-94.

Goebl, Hans (1979): Glottonymie, glottotomie und Schizoglossie. Drei sprachpolitisch bedeutsame Begriffe. In: Ladinia III, 7-38.

Goebl, Hans (1986): Der 'Muttersprache Not' in der Romania. Eine begriffsgeschichtliche Betrachtung zum Beizeichnungstyp 'Langage maternel français'. In: Grazer Linguistische Studien 27, 69-88.

Goebl, Hans; Nelde, Peter H.; Zdeněk, Starý; Wölck, Wolfgang (a cura di) (1996-1997): Kontaktlinguistik. Ein internationales Handbuch zeitgenoessischer Forschung/Contact linguistics : an international handbook of contemporary research/Linguistique de contact : manuel international des recherches contemporaines. Berlin [i. a.]: de Gruyter.

Goffman, Erving (1974): Frame analysis. An essay on the organization of experience. Cambridge, Mass.: Harvard University Press.

Goffman, Erving (1981): Footing. In: E. Goffman (a cura di): Forms of talk. Philadelphia: University of Pennsylvania Press, 124-159.

Grassi, Corrado (1981): Il concetto di spazio e la geografia linguistica. In: B. Schlieben-Lange (a cura di): Logos semantikos. Histoire et architecture des langues. Berlin: de Gruyter, 59-69.

Greenberg, Robert D. (2004/2008): Language and identity in the Balkans: Serbo-Croatian and its disintegration. Oxford: Oxford University Press.

Gröschel, Bernhard (2009): Das Serbokroatische zwischen Linguistik und Politik. Mit einer Bibliographie zum postjugoslavischen Sprachenstreit. München: Lincom Europa.

Grote, Georg \& Siller, Barbara (a cura di) (2011): Südtirolismen. Erinnerungskulturen - Gegenwartsreflexionen - Zukunftsvisionen. Innsbruck: Wagner.

Guerini, Federica (2003): Immigrazione e repertori plurilingui in Italia: il repertorio della comunità di immigrati di origine ghanese in provincia di Bergamo. In: A. Valentini (a cura di), 295-307.

Guerini, Federica (2006a): Repertori complessi e comunicazione plurilingue: la comunità degli immigrati ghanesi in provincia di Bergamo. In: A. Carli (a cura di): Le sfide della politica linguistica di oggi: fra la valorizzazione del multilinguismo migratorio locale e le istanze del plurilinguismo europeo. Milano: FrancoAngeli, 119-246.

Guerini, Federica (2006b): Transfer e prestiti nel repertorio della comunità ghanese in provincia di Bergamo: una prospettiva funzionale. In: E. Banfi \& G. Iannàccaro (a cura di): Lo spazio linguistico italiano e le "lingue esotiche": rapporti e reciproci influssi; atti del XXXIX 
Congresso internazionale di studi della Società di Linguistica Italiana (SLI); Milano, 22-24 settembre 2005/Società di Linguistica Italiana. Roma: Bulzoni, 565-578.

Guerini, Federica (2008): Atteggiamenti e consapevolezza linguistica in contesto migratorio: qualche osservazione sugli immigrati ghanesi a Bergamo. In: G. Berruto et al. (a cura di), $133-163$.

Gumperz, John J. (1964): Linguistic and Social Interaction in Two Communities. In: American Anthropologist 66 (6), The Ethnography of Communication (Special Issue), 137-153.

Günthner, Susanne (1995): Exemplary stories: the cooperative construction of moral indignation. In: VERSUS quaderni di studi semiotici 70/71, 147-175.

Günthner, Susanne (2007): The construction of otherness in reported dialogues as a resource for identity work. In: P. Auer (a cura di): Style and social identities. Alternative approaches to linguistic heterogeneity. Berlin: de Gruyter, 419-443.

Gustavsson, Sven (2004): Serbo-Croatian and its successors in the Nordic countries. In: R. Bugarski \& C. Hawkesworth (a cura di), 251-257.

Hansen, Alan D.; Moissinac, Luke; Renteria, Cristal; Razzo, Elena (2010): Chapter 5. "Ay Ay Vienen Estos Juareños": On the Positioning of Selves through Code Switching by SecondGeneration Immigrant College Students. In: D. Schiffrin et al. (a cura di): Telling stories. Language, narrative, and social life. Washington, DC: Georgetown University Press, 57-68.

Hartley, Laura C. \& Preston, Dennis R. (1999): The names of us english: valley girl, cowboy, yankee, normal, nasal and ignorant. In: T. Bex \& R. J. Watts (a cura di): Standard English. The widening debate. London, New York: Routledge, 207-238.

Haugen, Einar (1966): Language Conflict and Language Planning. The case of modern Norwegian. Cambridge, Massachusetts: Harvard University Press.

Hausendorf, Heiko \& Quasthoff, Uta M. (2005): Sprachentwicklung und Interaktion. Eine linguistische Studie zum Erwerb von Diskursfähigkeiten. Radolfzell: Verl. für Gesprächsforschung.

He, Agnes Weiyun (2001): The Language of Ambiguity. Practices in Chinese Heritage Language classes. In: Discourse Studies 3 (1), 75-96.

Heller, Monica \& Duchêne, Alexandre (2012): Pride and profit: changing discourses of language, capital and nation-state. In: A. Duchêne \& M. Heller (a cura di): Language in late capitalism. Pride and profit. New York: Routledge, 1-21.

Hetfleisch, Gerhard; Meyer, Maren; Medda-Windischer, Roberta (a cura di) (2011): La migrazione in Alto Adige e Tirolo. Analisi e prospettive multidisciplinari. Bolzano: Eurac research. URL: < http://webfolder.eurac.edu/EURAC/Publications/Institutes/autonomies/minrig/Migration_Sued tirol_2011_it.pdf $>(18.10 .2018)$.

Hinnenkamp, Volker (2000): "Gemischt sprechen" von Migrantenjugendlichen als Ausdruck ihrer Identität. In: Der Deutschunterricht 5/2000, 96-107.

Holmes, Janet (1993): Immigrant women and language maintenance in Australia and New Zealand. In: International Journal of Applied Linguistics 3 (2), 159-179.

Iannàccaro, Gabriele (2002): Il Dialetto Percepito. Sulla reazione di parlanti di fronte al cambio linguistico. Alessandria: Ed. dell'Orso.

Iannàccaro, Gabriele \& Dell'Aquila, Vittorio (2000): Alla ricerca della comunità linguistica: spunti dal concetto di "lingua madre". In: G. Marcato (a cura di): "Isole linguistiche? Per un'analisi dei sistemi in contatto". Atti del Convegno, Sappala/ Plodn, Belluno, 1-4 luglio 1999. Padova: CLUEP, 361-371.

Iannàccaro, Gabriele \& Dell'Aquila, Vittorio (2001): Mapping languages from inside: notes on perceptual dialectology. In: Social \& Cultural Geography 2 (3), 265-280.

Iannàccaro, Gabriele \& Dell'Aquila, Vittorio (2002): Italienisch oder Dialekt? Die Wahrnehmung des romanischen Sprachkontinuums seitens der Molisekroate. In: H. Weydt (a cura di): Langue, communauté, signification. Approches en linguistique fonctionnelle: actes du XXVème Colloque international de linguistique fonctionnelle. Frankfurt am Main, New York: P. Lang, 175-181. 
Iannàccaro, Gabriele \& Dell'Aquila, Vittorio (2007): La lingua è l'italiano, il dialetto è il dialetto, perché ogni paese ha la sua usanza. Nomi delle lingue e situazioni sociolinguistiche. In: Bollettino linguistico campano 9 (10), 59-95. Citazioni dalla versione online, URL: $<$ http:// www.academia.edu/1528351/_La_lingua_\%C3\%A8_litaliano_il_dialetto_\%C3\%A8_il_dialetto_perch\%C3\%A9_ogni_paese_ha_la_sua_usanza_nomi_delle_lingue_e_situazioni_sociolinguistiche $>(18.10 .2018)$.

Iannàccaro, Gabriele \& Dell'Aquila, Vittorio (2011): Numeri soggettivi. Spunti sulla vitalità linguistica da inchieste e trattamenti quantitativi. In: B. Moretti et al. (a cura di): Vitalità di una lingua minoritaria. Aspetti e proposte metodologiche/Vitality of a minority language. Aspects and methodological issues. Atti del Convegno, Bellinzona, 15-16 ottobre 2010. Bellinzona: Osservatorio Linguistico della Svizzera Italiana, 152-192.

Irvine, Judith T. \& Gal, Susan (2000): Language Ideology and Linguistic Differentiation. In: P.V. Kroskrity (a cura di): Regimes of language. Ideologies, polities, and identities. Santa Fe, NM, Oxford: School of American Research Press, 35-83.

ISTAT (2011): La popolazione straniera residente in Italia. 1 Gennaio 2011. URL: < https://www. istat.it/it/files/2011/09/ReportStranieriResidenti.pdf> (18.10.2018).

ISTAT (2013): Cittadini non comunitari regolarmente soggiornanti. Anni 2012-2013. URL: < https: //www.istat.it/it/files//2013/07/Cittadini-non-comunitari.pdf> (18.10.2018).

Ivić, Pavle (2001): Language planning in Serbia today. In: International Journal of the Sociology of Language 151, 7-17.

Jefferson, Gail (1984): Transcript notation. In: J.M. Atkinson \& J. Heritage (a cura di): Structures of social action: studies in conversation analysis. Cambridge: Cambridge University Press, IX-XVI.

Johnstone, Barbara (1996): The linguistic individual. Self-expression in language and linguistics. New York: Oxford University Press.

Johnstone, Barbara (2006): A new role of narrative in variationist sociolinguistics. In: Narrative Inquiry $16(1), 46-55$.

Kalogjera, Damir (1985): Attitudes toward Serbo-Croatian language varieties. In: International Journal of the Sociology of Language 52, 93-109.

Kämper, Heidrun (2008): Sprachgeschichte - Zeitgeschichte - Umbruchgeschichte. Sprache im 20. Jahrhundert und ihre Erforschung. In: H. Kämper \& L. M. Eichinger (a cura di): Sprache, Kognition, Kultur. Sprache zwischen mentaler Struktur und kultureller Prägung. Berlin; New York: de Gruyter, 198-224.

Karadža, Mevlida (2004): Serbo-croate et situation sociolinguistique de l'espace ex-Yougoslave. In: Revue des études slaves 75 (1), 21-30.

Keim, Inken (2008): Die "türkischen Powergirls". Lebenswelt und kommunikativer Stil einer Migrantinnengruppe in Mannheim. 2. edizione. Tübingen: Narr.

Kelle, Udo (2008): Computergestützte Analyse qualitativer Daten. In: U. Flick et al. (a cura di): Qualitative Forschung: ein Handbuch. 6. edizione. Reinbek bei Hamburg: Rowohlt Taschenbuch-Verl., 485-502.

King, Kendall A. \& De Fina, Anna (2010): Language Policy and Latina Immigrants: An Analysis of Personal Experience and Identity in Interview Talk. In: Applied Linguistics 31 (5), 651-670.

Kordić, Snježana (2004): Le serbo-croate aujourd'hui: entre aspirations politiques et faits linguistiques. In: Revue des études slaves 75 (1), 31-43.

Kordić, Snježana (2009): Plurizentrische Sprachen, Ausbausprachen, Abstandsprachen und die Serbokroatistik. In: Zeitschrift für Balkanologie 45 (2), 210-215.

Kramsch, Claire J. (2009): The multilingual subject. What foreign language learners say about their experience and why it matters. Oxford, New York: Oxford University Press.

Krefeld, Thomas (2002): Per una linguistica dello spazio vissuto. In: T. Krefeld (a cura di): Spazio vissuto e dinamica linguistica. Varietà meridionali in Italia e in situazione di extraterritorialità. Frankfurt am Main: P. Lang, 11-24.

Krefeld, Thomas (2004): Einführung in die Migrationslinguistik: von der Germania italiana in die Romania multipla. Tübingen: Narr. 
Krefeld, Thomas \& Pustka, Elissa (2010): Für eine perzeptive Varietätenlinguistik. In: T. Krefeld (a cura di): Perzeptive Varietätenlinguistik. Frankfurt am Main: P. Lang, 9-28.

Krefeld, Thomas \& Pustka, Elissa (2014): Einleitung. In: T. Krefeld \& E. Pustka (a cura di): Perzeptive Linguistik. Phonetik, Semantik, Varietäten. Stuttgart: Franz Steiner Verlag, 9-18.

Labov, William (1972): The Transformation of Experience in Narrative. Capitolo 9. In: W. Labov: Language in the inner city. Studies in the Black English vernacular. Oxford: Blackwell, 354-396.

Labov, William (1997): Some Further Steps in Narrative Analysis. In: The Journal of Narrative and Life History 7 (1-4), 395-415.

Labov, William (2006): Narrative pre-construction. In: Narrative Inquiry 16 (1), 37-45.

Labov, William (2013): The language of life and death. The transformation of experience in oral narrative. Cambridge: Cambridge University Press.

Labov, William \& Waletzky, Joshua (1967): Narrative Analysis: Oral Version of Personal Experience. In: J. Helm (a cura di): Essays on the verbal and visual arts. Proceedings of the 1966 annual spring meeting of the American Ethnological Society. Seattle, London: American Ethnological Society; Distributed by the University of Washington Press, 12-44.

Lainati, Chiara \& Saltarelli, Salvatore (2007): Migrazioni in Alto Adige. Migration in Südtirol. Storie migratorie, lavoro, famiglie e percorsi di integrazione. Social Survey. Migrationsgeschichten, Erwerbstätigkeit, Familie und Integrationsmuster. Social Survey. Bolzano: Praxis3.

Lamnek, Siegfried (1988/2010): Qualitative Sozialforschung. Lehrbuch. 5. edizione riveduta. Weinheim, Basel: Beltz, PVU.

Lanthaler, Franz (1990): Dialekt und Zweisprachigkeit in Südtirol. In: A. M. Mioni et al. (a cura di), 59-81.

Lanthaler, Franz (2001): Zwischenregister der deutschen Sprache in Südtirol. In: K. Egger \& F. Lanthaler (a cura di), 137-152.

Lawson, Sarah \& Sachdev, Itesh (2004): Identity, Language Use, and Attitudes: Some SylhetiBangladeshi Data from London, UK. In: Journal of Language and Social Psychology 23 (1), 49-69.

Lazarenko, Liubov (2009): Die sprachliche Selbstidentifikation im Milieu der ethnischen Minderheiten. Das Dilemma der Kontinuität. In: K. Bochmann \& V. Dumbrava (a cura di), 34-61.

László, Marácz \& Adamo, Silvia (2017): Multilingualism and Social Inclusion. In: Social Inclusion 5 (4), 1-4.

Léglise, Isabelle \& Migge, Bettina (2006): Towards a comprehensive description of language varieties: A consideration of naming practicies, ideologies and linguistic practicies. In: Language in Society 3 (35), 313-339.

Le Page, Robert B. \& Tabouret-Keller, Andrée (1985): Acts of identity. Creole-based approaches to language and ethnicity. Cambridge, New York: Cambridge University Press.

Linde, Charlotte (1993): Life stories. The creation of coherence. New York: Oxford University Press.

Linde, Charlotte (1997): Narrative: Experience, Memory, Folklore. In: Journal of Narrative and Life History, 281-289.

Linde, Charlotte (2000): The Acquisition of a Speaker by a Story: How History Becomes Memory and Identity. In: Ethos 28 (4), 608-632.

Linde, Charlotte (2009): Working the past. Narrative and institutional memory. Oxford, New York: Oxford University Press.

LINEE (2010): Challenges of Multilingualism in Europe. Core findings of the LINEE Network of Excellence. Bern: LINEE, Institut für Sprachwissenschaft der Universität Bern. URL: < http:// ecspm.org/wp-content/uploads/2018/01/LINEE_final-report_2010-1.pdf>, (18.10.2018).

Lucius-Hoene, Gabriele \& Deppermann, Arnulf (2004): Rekonstruktion narrativer Identität. Ein Arbeitsbuch zur Analyse narrativer Interviews. Wiesbaden: VS, Verl. für Sozialwiss.

Lüdi, Georges (1996): Migration and Mehrsprachigkeit. In: H. Goebl et al. (a cura di), vol. 1, 320-327.

Lüdi, Georges \& Py, Bernard (1986/2003): Etre bilingue. 3. edizione. Bern: P. Lang. 
Lupoli, Nicola (2009): La formazione e le sfide della globalizzazione. Politiche formative e migranti adulti in Alto Adige. Milano: FrancoAngeli.

Lupica Spagnolo, Marta (2016): Language Nominations and Experienced Linguistic Repertoire in Biographical Interviews. In: D. Cailleux et al. (a cura di), Situations de plurilinguisme et politiques du multilinguisme en Europe. Bruxelles: P. Lang, 43-60.

Macioti, Maria Immacolata \& Pugliese, Enrico (2003/2010): L'esperienza migratoria. Immigrati e rifugiati in Italia. Roma: Laterza.

Mackey, William (1989): Determining the Status and Function of Languages in Multinational Societies. In: U. Ammon (a cura di): Status and function of languages and language varieties. Berlin, New York: de Gruyter.

Makoni, Sinfree \& Pennycook, Alastair (a cura di) (2007a): Disinventing and reconstituting languages. Clevedon: Multilingual Matters.

Makoni, Sinfree \& Pennycook, Alastair (2007b): Disinventing and reconstituting languages. In: S. Makoni \& A. Pennycook (a cura di), 1-41.

Manzelli, Gianguido (2012): Dall'aggregazione alla disgregazione: frammenti di storia della lingua e della letteratura serbocroata (bosniaca, croata, montenegrina e serba). In: I. Putzu et al. (a cura di): Lingue, letterature, nazioni. Centri e periferie tra Europa e Mediterraneo. Milano: FrancoAngeli, 371-420.

Marra, Meredith \& Holmes, Janet (2008): Constructing ethnicity in New Zealand workplace stories. In: Text and Talk 28 (3), 397-419.

Måwe, Marie (2011): Zur Varietätenwahl in Südtirol unter besonderer Berücksichtigung von Begrüßungsformen. In: G. Grote \& B. Siller (a cura di), 177-193.

Medda-Windischer, Roberta (2011): Gestione della diversità delle "nuove minoranze" in Alto Adige/Süd Tirol. In: G. Hetfleisch et al. (a cura di), 19-32.

Medda-Windischer, Roberta \& Girardi, Rainer (a cura di) (2011): Jahresbericht über Einwanderung in Südtirol 2010/Rapporto annuale sull'immigrazione in Alto Adige 2010. Bolzano/ Bozen: Eurac research.

Medda-Windischer, Roberta; Flarer, Heidi; Girardi, Rainer; Grandi, Francesco (2011): Condizione e prospettive di integrazione degli stranieri in Alto Adige: relazioni sociali, lingua, religione e valori. Bolzano: Eurac research. URL: $<$ http://aei.pitt.edu/32518/1/Ricerca_analitica.pdf $>$ (18.10.2018).

Melchior, Luca (2008): Udin: historisches Sprachprofil und erlebte Sprachräume. In: T. Krefeld (a cura di): Sprachen und Sprechen im städtischen Raum. Frankfurt am Main: P. Lang, 195-211.

Melchior, Luca (2009): Sù pes Gjermaniis. Zwischen Dissoziation und Integration: Kommunikationsräume friaulischer Einwanderer in Bayern. Frankfurt am Main: P. Lang.

Meluzzi, Chiara (2014): Italiano e tedesco a Bolzano: la percezione degli italofoni. In: A. De Meo et al. (a cura di): Varietà dei contesti di apprendimento linguistico. Bologna: AItLA - Associazione Italiana di Linguistica Applicata (studi AItLA 1), 91-104.

Meluzzi, Chiara (2015): Dialects and linguistic identity of Italian speakers in Bozen. In: Globe: A Journal of Language, Culture and Communication 1, 1-16.

Migge, Bettina \& Léglise, Isabelle (2013): Exploring language in a multilingual context. Variation, interaction and ideology in language documentation. Cambridge, New York: Cambridge University Press.

Migliorini, Bruno (1927): Il nome proprio e il nome comune. Tentativi di delimitazione. In: B. Migliorini: Dal nome proprio al nome comune: studi semantici sul mutamento dei nomi propri di persona in nomi comuni negli idiomi romanzi. Genève: Olschki, 1-14.

Milroy, Lesley \& Gordon, Matthew J. (2003): Sociolinguistics. Method and interpretation. Malden, Oxford, Melbourne: Blackwell.

Mioni, Alberto M. (1987): Domain. In: U. Ammon et al. (a cura di), vol. 1, 170-178.

Mioni, Alberto M. (1990): Bilinguismo intra- e intercomunitario in Alto Adige/Südtirol: Considerazioni sociolinguistiche. In: A. M. Mioni et al. (a cura di), 13-35. 
Mioni, Alberto M. (2001): L'italiano nelle tre comunità linguistiche tirolesi. (con particolare riguardo per la pronuncia). In: K. Egger \& F. Lanthaler (a cura di), 65-76.

Mioni, Alberto M.; Egger, Kurt; Lanthaler, Franz (a cura di) (1990): Mehr als eine Sprache. Zu einer Sprachstrategie in Südtirol. Più di una lingua. Per un progetto linguistico in Alto Adige. Meran: Alpha \& Beta Verlag.

Moser, Hans (1982): Methodische Überlegungen zur Untersuchung des gesprochenen Deutsch in Südtirol. In: O. Putzer \& H. Moser (a cura di), 75-90.

Nedeljkovic, Dubravka Valic (2004): Education and mass media in the languages of ethnic communities in Vojvodina. In: R. Bugarski \& C. Hawkesworth (a cura di), 243-249.

Nekvapil, Jiři (2003): Language biographies and the analysis of language situations: on the life of the German community in the Czech Republic. In: International Journal of the Sociology of Language 162, 63-83.

Nekvapil, Jiri (2004): Zur Situation der Deutschen in der Tschechischen Republik. In: R. Franceschini \& J. Miecznikowski (a cura di), 147-172.

Nelde, Peter Hans (2007): Le conflit linguistique: un Aperçu. In: J. Darquennes (a cura di): Contact linguistics and language minorities. Kontaktlinguistik und Sprachminderheiten. Linguistique de contact et minorites linguistiques. St. Augustin: Asgard (Plurilingua, 30), 29-35.

Neweklowsky, Gerhard (1997): Jugoslawien/ Jugoslavia/ Yougoslavie. In: H. Goebl et al. (a cura di), 1407-1416.

Neweklowsky, Gerhard (2004): Serbo-Croatian and its successors in Austria. In: R. Bugarski \& C. Hawkesworth (a cura di), 41-51.

Nicolaisen, Wilhelm F.H. (1995): Name and Appellative. In: E. Eichler et al. (a cura di), 384-393.

Norrick, Neal R. (2000): Conversational narrative: storytelling in everyday talk. Amsterdam: J. Benjamins.

Norrick, Neal R. (2005): The dark side of tellability. In: Narrative Inquiry 15 (2), 323-343.

Norrick, Neal R. (2010): Listening practices in television celebrity interviews. In: Journal of Pragmatics 42 (2), 525-543.

Ochs, Elinor \& Capps, Lisa (1997): Narrative Authenticity. In: Journal of Narrative and Life History 7 (1-4), 83-89.

Ochs, Elinor \& Capps, Lisa (2001): Living narrative. Creating lives in everyday storytelling. Cambridge, MA: Harvard University Press.

Orioles, Vincenzo (2007): 'Nuove minoranze'. Come cambia lo spazio comunicativo. In: E. Pistolesi (a cura di): Lingua, scuola e società. I nuovi bisogni comunicativi nelle classi multiculturali; atti del convegno organizzato dall'Istituto Gramsci del Friuli Venezia Giulia con il patrocinio dell'Università degli studi di Trieste; Trieste, 6-7 ottobre 2006. Fagagna (UD): Graphis di Roberto Tomai \& C. snc, 69-77.

Osservatorio del Mercato del Lavoro (2009): Conoscenze linguistiche, patentino e mercato del lavoro. Novembre 2009. URL: <www.provinz.bz.it/arbeit-wirtschaft/arbeit/statistik/arbeitsmarktnews.asp?641_action=300\&641_image_id $=159533>,(18.10 .2018)$.

Pallaoro, Alessandro \& Colletti, Micaela (2013): 'Nuove' minoranze in Alto Adige/Südtirol: impatto sugli strumenti a tutela delle 'vecchie' minoranze. In: R. Medda-Windischer \& A. Carlà (a cura di): Politiche migratorie e autonomie territoriali. Nuove minoranze, identità e cittadinanza in Alto Adige e Catalogna/ Migrationspolitik und territoriale Autonomie: neue Minderheiten, Identität und Staatsbürgerschaft in Südtirol und Katalonien. Bolzano: Accademia europea (Eurac research), 115-159.

Pallotti, Gabriele (2007): Conversation Analysis: Methodology, machinery and application to specific settings. In: H. Bowles \& P. Seedhouse (a cura di): Conversation Analysis and Language for Specific Purposes. Bern: P. Lang, 37-57.

Pan, Christoph (2011): Einführung in die Minderheitenproblematik Europas. In: G. Grote \& B. Siller (a cura di), 27-39. 
Pani, Pandeli (2006): Some differences between varieties of Albanian with special reference to Kosovo. In: International Journal of the Sociology of Language 178, 55-73.

Pasch, Renate; Brauße, Ursula; Breindl, Eva; Waßner, Ulrich Hermann (a cura di) (2003): Handbuch der deutschen Konnektoren: linguistische Grundlagen der Beschreibung und syntaktische Merkmale der deutschen Satzverknüpfer (Konjunktionen, Satzadverbien und Partikeln). Berlin: de Gruyter.

Paternostro, Giuseppe (2013a): Discorso, interazione, identità. Studiare il parlato attraverso $i$ parlanti. Frankfurt am Main: P. Lang.

Paternostro, Giuseppe (2013b): Narrative and argumentative discourse between Dialect and Italian. Analysis of the Linguistic Atlas of Sicily (ALS) Corpus. Presentazione alla conferenza: Lingue Migranti: The Global Languages of Italy and the Diaspora. New York, 25-27 aprile 2013. URL: $<\mathrm{http} / /$ www.academia.edu /3625655/Narrative_and_Argumentative_Discourse_betwe en_Dia lect_and_Italian._Analysis_of_the_Linguistic_Atlas_of_Sicily_corpus $>(11.11 .2015)$.

Pavlenko, Aneta (2007): Autobiographic Narratives as Data in Applied Linguistics. In: Applied Linguistics 28 (2), 163-188.

Pavlinić-Wolf, Andrina (1986): The Definition of a Mother Tongue and some Related Questions. In: Grazer Linguistische Studien 27, 167-182.

Pelusi, Simonetta (2008): Voci dalle periferie dell'Europa. Lingua e identità: la moltiplicazione degli idiomi nella ex-Jugoslavia. In: Cives 7, 126-140.

Pichler, Walter (2008a): La cornice istituzionale per l'insegnamento della lingua seconda: 1945-72. In: S. Baur et al. (a cura di), 51-67.

Pichler, Walter (2008b): Tra istanze di cambiamento ed "emergenza linguistica": gli anni '70. In: S. Baur et al. (a cura di), 108-149.

Provenzano, Claudia \& Dal Negro, Silvia (a cura di) (2012): Un anno in L2/Zweitsprachjahr/N ann te L2 y L3. Strumenti e metodi per la ricerca. Bergamo: Junior.

Putzer, Oskar \& Moser, Hans (a cura di) (1982): Zur Situation des Deutschen in Südtirol. Sprachwissenschaftliche Beiträge zu den Fragen von Sprachnorm und Sprachkontakt. Innsbruck: Institut für Germanistik.

Py, Bernard (2000): Représentations sociales et discours. Questions épistémologiques et méthodologiques. In: Tranel 32, 5-20.

Quasthoff, Uta M. \& Becker, Tabea (a cura di) (2005): Narrative interaction. Amsterdam, Philadelphia: J. Benjamins.

Rehbein, Jochen; Thije, Jan D. ten; Verschik, Anna (2011): Lingua receptiva (LaRa) - remarks on the quintessence of receptive multilingualism. In: International Journal of Bilingualism 16 (3), $248-264$.

Reiffenstein, Ingo (2003): Bezeichnungen der deutschen Gesamtsprache. In: W. Besch et al. (a cura di): Sprachgeschichte. Ein Handbuch zur Geschichte der deutschen Sprache und ihrer Erforschung. 2. edizione riveduta e ampliata. Berlin [i. a.]: de Gruyter, Vol. 3., 2191-2205.

Relaño-Pastor, Anna Maria \& De Fina, Anna (2005): Contesting Social Place. Narrative of Language Conflict. In: M. Baynham \& A. De Fina (a cura di), 36-58.

Redder, Angelika (2011): 'Ethnizität' und Mehrsprachigkeit. In: Zeitschrift für Literaturwissenschaft und Linguistik (164), 71-92.

Ribeiro, Branca Telles (2006): Footing, positioning, voice. Are we talking about the same things? In: A. De Fina et al. (a cura di): Discourse and identity. Cambridge, UK, New York: Cambridge University Press, 48-82.

Rindler Schjerve, Rosita (1996): Domänenuntersuchungen. In: H. Goebl et al. (a cura di), vol. 1, 796-804.

Romaine, Suzanne (1986): Sprachmischung und Purismus: Sprich mir nicht von Mischmasch. In: Zeitschrift für Literaturwissenschaft und Linguistik 62, 92-107.

Romaine, Suzanne (1989): Bilingualism. Oxford, OX, UK, New York, NY, USA: Blackwell.

Rosenthal, Gabriele (2005): Interpretative Sozialforschung. Eine Einführung. Weinheim: Juventa. 
Rosenthal, Gabriele (2006): The Narrated Life Story: On the Interrelation Between Experience, Memory and Narration. In: K. Milnes et al. (a cura di): Narrative, Memory \& Knowledge: Representations, Aesthetics, Contexts. Huddersfield: University of Huddersfield, 1-16. URL: $<$ http://eprints.hud.ac.uk/id/eprint/4894/2/Chapter_1___Gabriele_Rosenthal.pdf $>$ (18.10.2018).

Rost, Dietmar (2009): Sprachpraxis und Sprachbedeutungen aus der Perspektive von Jugendlichen mit Migrationshintergrund. Ergebnisse aus einer qualitativen Begragung. In: B. Ahrenholz (a cura di), 291-309.

Sacks, Harvey (1995): “The baby cried. The mommy picked it up”. In: G. Jefferson (a cura di): Harvey Sacks. Lectures on conversation. Oxford, UK, Cambridge, Mass., USA: Blackwell.

Saxalber-Tetter, Annemarie (1982): Einschätzung des Dialekts bei Eltern und Lehrern. Ergebnisse einer Umfrage. In: O. Putzer \& H. Moser (a cura di), 179-200.

Schader, Basil (2009): Albadeutsch und Shqipanisht: Untersuchungen zum albanisch-deutschen Sprachkontakt und Codeswitching. In: B. Ahrenholz (a cura di), 273-289.

Schiffrin, Deborah (1996): Narrative as self-portrait: Sociolinguistic constructions of identity. In: Language in Society 25 (2), 167-203.

Schmid, Monika (2002): First language attrition, use and maintenance. The case of German Jews in anglophone countries. Amsterdam [i.a.]: J. Benjamins.

Schmid, Monika (2011): Language attrition. New York: Cambridge University Press.

Schubert, Gabriella (1997): Diskurs der Eliten in Ex-Jugoslawien um Sprachnomination und Standardsprache. In: W. W. Moelleken \& P. J. Weber (a cura di): Neue Forschungsarbeiten zur Kontaktlinguistik. Bonn: Dümmler (Plurilingua, 19), 458-466.

Schütze, Fritz (1983): Biographieforschung und narratives Interview. In: Neue Praxis 13 (3), 283-293. URL: < https://www.ssoar.info/ssoar/bitstream/handle/document/5314/ssoar-np1983-3-schutze-biographieforschung_und_narratives_interview.pdf $>$ (18.10.2018).

Schwitalla, Johannes (1997): Zum Textsortenfeld narrativer mündlicher Texte. In: F. Simmler (a cura di): Textsorten und Textsortentraditionen. Bern [i. a.]: P. Lang, 41-62.

Sebba, Mark \& Wootton, Tony (1998): We, they and identity: Sequential versus identity-related explanation in codeswitching. In: P. Auer (a cura di), 262-286.

Selinker, Larry (1972): Interlanguage. In: International Review of Applied Linguistics in Language Teaching 10 (1-4), 209-231.

Sériot, Patrick (1997): Le cas du macédonien: faut-il nommer les langues? In: A. Tabouret-Keller (a cura di), 167-190.

Serra, Cecilia (2000): Traitement discursif et conversationnel des représentations sociales. In: Tranel 32, 77-90.

Sinner, Carsten (2014): Varietätenlinguistik. Eine Einführung. Tübingen: Narr Francke Attempto.

Slembrouck, Stef (2015): The Role of the Researcher in Interview Narrative. In: A. De Fina \& A. Georgakopoulou (a cura di): The Handbook of Narrative Analysis. Oxford: Blackwell, 237-254.

Stevenson, Patrick (2006): 'National' Languages in Trasnational Contexts: Language, Migration and Citizenship in Europe. In: C. Mar-Molinero \& P. Stevenson (a cura di): Language Ideologies, Policies and Practices. Language and the Future of Europe. Basingstoke [i. a.]: Palgrave Macmillan, 147-161.

Stevenson, Patrick (2011) Migration und Mehrsprachigkeit in Europa: Diskurse über Sprache und Integration. In: L. M. Eichinger et al. (a cura di), 13-27.

Stewart, George R. (1975): Names on the globe. New York: Oxford University Press.

Strauss, Anselm L. \& Corbin, Juliet M. (1990/1996): Grounded theory. Grundlagen qualitativer Sozialforschung. Weinheim: Beltz, PsychologieVerlagsUnion.

Tabouret-Keller, Andrée (a cura di) (1997a): Le nom des langues. Louvain-la-Neuve: Peeters.

Tabouret-Keller, Andrée (1997b): Les enjeux de la nomination des langues. Présentation. In: A. Tabouret-Keller (a cura di), 5-20.

Tamine, Michel (2013): Les noms propres ont-ils un sens? In: J.C. Bouvier (a cura di): Le nom propre a-t-il un sens? Actes du XVe colloque d'onomastique, Aix-en-Provence, 2010. Aix-enProvence: Presses universitaires de Provence, 5-13. 
Tannen, Deborah (1989/2007): Talking voices. Repetition, dialogue, and imagery in conversational discourse. 2. edizione. Cambridge: Cambridge University Press.

Tofan, Alina (2007): Narrative Sprachautobiographie, soziolinguistische Individuation und der Name der Sprache. In: K. Bochmann \& V. Dumbrava (2007), 70-89.

Tollefson, James W. (1993): Language policy and power: Yugoslavia, the Philippines, and Southeast Asian refugees in the United States. In: International Journal of the Sociology of Language 103, 73-95.

Tollefson, James W. (2002): The language debates: preparing for the war in Yugoslavia, 19801991. In: International Journal of the Sociology of Language 154, 65-82.

Tracy, Karen \& Robles, Jessica (2009): Questions, questioning, and institutional practices: an introduction. In: Discourse Studies 11 (2), 131-152.

Trovesi, Andrea (2009): La codificazione della lingua montenegrina. Storia di un'idea. In: Studi Slavistici VI, 197-223.

Valentini, Ada (a cura di) (2003): Ecologia linguistica. Atti del 36. Congresso internazionale di studi della Società di linguistica italiana (SLI): Bergamo, 26-28 settembre 2002. Roma: Bulzoni.

Vanelli, Laura \& Renzi, Lorenzo (2001): La deissi. In: L. Renzi et al. (a cura di) (2001): Grande grammatica italiana di consultazione. III. Tipi di frase, deissi, formazione delle parole. Nuova ed. Bologna: Il Mulino, 261-375.

Veiter, Theodor (1983): Mehrsprachigkeit in Jugoslawien. In: P. H. Nelde (a cura di): Vergleichbarkeit von Sprachkontakten. Comparability of language contacts. Bonn: Dümmler, 155-170.

Veronesi, Daniela (2001): Riunioni di lavoro nel contesto plurilingue altoatesino: tra comunicazione 'internazionale', comunicazione 'intergruppo' e regole di default. In: S. Cigada et al. (a cura di): Comunicare in ambiente professionale plurilingue. Atti del convegno VALS/ASLA tenuto a Lugano dal 14 al 16 settembre 2000. Lugano: USI, 303-324.

Veronesi, Daniela (2008a): Geschichte, Sprachpolitik und Lebenserzählung: Erste Gedanken zur Sprachbiographie in Südtirol. In: T. Keller \& G. Lüdi (a cura di): Biographien und Staatlichkeit/Biographies et pratiques de l'etat. Akten des 5. Kolloquiums des EUCOR-Forschungsverbunds Interkulturalität in Theorie und Praxis vom 21. bis 22. April 2005, Villa Castelen, Augst, Schweiz. Berlin: Berliner Wissenschafts-Verlag, 123-154.

Veronesi, Daniela (2008b): Rappresentazioni di lingue e di percorsi di apprendimento: la metafora nelle biografie linguistiche di parlanti in Alto Adige-Südtirol. In: C. Casadio (a cura di), Vie della metafora: linguistica, filosofia, psicologia. Chieti: Prime Vie, 120-145.

Veronesi, Daniela (2010): >>Zu wem ghör i jetz? $<<$ bzw. $>>$ due lingue che sono entrambe mie $<<$. Sprachbiographien ein- und zweisprachiger Sprecher aus einem Grenzgebiet. In: Zeitschrift für Literaturwissenschaft und Linguistik 40, 83-106.

Veronesi, Daniela (2012): La biografia linguistica come strumento di monitoraggio e ricercazione: aspetti metodologici e risvolti applicativi. In: C. Provenzano \& S. Dal Negro (a cura di), 63-90.

Vietti, Alessandro (2005): Come gli immigrati cambiano l'italiano. L'italiano di peruviane come varietà etnica. Milano: FrancoAngeli.

Vietti, Alessandro (2008): Contesti d'uso in repertori linguistici complessi. Tentativi di descrizione multidimensionale dei dati della Survey Ladins. In: G. Iannàccaro \& V. Dell'Aquila (a cura di): Survey Ladins. Atti del convegno (Vigo di Fassa 14-16.9.2006). Mondo Ladino 31, 239-266.

Vietti, Alessandro (2009): Selezione di codice in contesto bilingue: un'indagine quantitativa in Alto Adige/Südtirol. In: C. Consani (a cura di), 199-214.

Vietti, Alessandro (2012): Le reti sociali nella ricerca sociolinguistica. In: C. Provenzano \& S. Dal Negro (a cura di), 41-61.

Voß, Christian (2007): Zum Problem der Sprachgrenzen im (ex-)jugoslawischen Raum. In: F. Otten et al. (a cura di): Beiträge zur slawischen Philologie. Festschrift für Fred Otten. Frankfurt am Main, New York: P. Lang, 193-211. 
Vučo, Julijana (2003): L'italiano nel sud-est dell'Europa - una lingua "ecologica". Storia, attualità e prospettive didattiche. In: A. Valentini (a cura di), 381-389.

Weisgerber, Bernard (1990): Das Verhältnis von Dialekt und Standardsprache als Problem sprachlicher Minderheiten. In: P. Nelde (a cura di): Language conflict and minorities. Sprachkonflikte und Minderheiten, (Plurilingua X). Bonn: Dümmler, 23-32.

Wiesinger, Peter (1985): Die Entwicklung des Verhältnisses von Mundart und Standardsprache in Österreich. In: W. Besch et al. (a cura di): Sprachgeschichte. Ein Handbuch zur Geschichte der deutschen Sprache und ihrer Erforschung. Berlin [i. a.]: de Gruyter, vol. 2, 1939-1949.

Wisthaler, Verena (2011): Migration - Chance und Herausforderung für das Südtirol des 21. Jahrhunderts. In: G. Grote \& B. Siller (a cura di), 241-258.

Woolard, Kathryn Ann (1998): Introduction. Language Ideology as a Field of Inquiry. In: B. B. Schieffelin et al. (a cura di): Language ideologies. Practice and theory. New York: Oxford University Press, 3-47.

Wortham, Stanton; Mortimer, Katherine; Lee, Kathy; Allard, Elaine; White, Kimberly Daniel (2011): Interviews as interactional data. In: Language in Society 40 (1), 39-50.

Zanolla, Giovanna (2011): Uno studio qualitativo sulla condizione dei migranti in Alto Adige. In: G. Hetfleisch et al. (a cura di), 169-268. 



\section{REGISTRO DEI LUOGHI E DEI NOMI}

Abruzzo 120, 215

Austria 55, 60, 66-67, 105, 120, 151, 181, 187-188, 207, 228, 232, 268, 276, 303

Bachtin, Michail Michailowitsch $(* 1895$ $\dagger 1975) 253$ nota 14

Bassa Atesina (Südtiroler Unterland) 41, 46, 53, 58 nota $16,61-62,66,71$

Baviera 55, 302-303, 350

Belgrado 88, 94-96, 154, 172-174, 181-182, $187,218,274,355$

Benelux 67

Berlino 374

Bosnia-Erzegovina 35, 69-70, 87-88, 92-93, 95, 100-104, 115, 117, 119-120, 130, 268, 270-274, 217, 232, 276, 321

Brennero (Brenner) 54, 66

Bressanone (Brixen) 41, 46, 50, 58, 80

Brozović, Dalibor (*1927 - †2009) 94, 96, 102, 105

Brunico (Bruneck, Bornech) 46, 71, 79-80, 83, 111 nota $3,113-115,130,218,372$

Campania 120

Croazia 69-70, 80, 87, 89, 91, 92-93, 95, 100-101, 103, 115, 117, 119-120, 130, 154, $171,181,191,201,303,321$

Dalmazia 181-182, 187, 190

Emilia Romagna 61 nota 21, 66 nota 24

Federazione di Jugoslavia $(F R J)$ 91, 95-96, 103

Firenze 302-303, 350, 352-355

Fortezza (Franzensfeste) 41, 66

Francia 67, 269, 324

Franconia 302, 350

Friuli-Venezia Giulia 67, 268

Gaj, Ljudevit $(* 1809-\dagger 1872) 88$

Germania 142 nota 2, 223 nota 44, 225, 269, 272, 294, 296, 303, 306 nota 55, 323, 333, $339,341,343-344,347,349,356$

Grecia 97, 159, 268

Grimm, Jacob $(* 1785-\dagger 1863) 100$

Istria (istriano) 89, 303

Ivić, Pavle $(* 1924-\dagger 1999) 96,103$

Karadžič, Vuk $(* 1787$ - †1864) 88, 100

Kopitar, Jernej $(* 1780-\uparrow 1844) 100$

Kosovo 66-67, 69-70, 73, 89-91, 97-99, $116-120,130,144$ nota $3,153,161-163$, 214, 219, 221-222, 225, 267, 272-274, 294-296, 333-334, 337-338, 340
Ladinia (valli ladine) 40, 43, 47 nota 10, 57, 58 nota 18,311 nota 60

Laives (Leifers) 41, 219, 221-222

Lana (Lana) 71

Lazio 61 nota 21, 64

Lombardia 61 nota $21,64,215$

Lussemburgo 272, 294, 337, 348

Macedonia, Rep. di 66-67, 69, 87, 91, 97-98, 118-120, 130, 157-161, 170, 198, 212-214, $217,234,267-270,292,324$

Merano (Meran) 40-42, 46, 54, 66, 71, 79-83, $111,113-115,121,130,182,187,220,223$, 267-268, 271, 283-284, 287, 295, 320, 324-325, 328

Montenegro 69-70, 86-87, 90-92, 95-97, 103-104, 111 nota $3,118-120,130$, 169-171, 181-182, 193, 195-197, 207, 212, 215, 225, 228-230, 234, 236, 274, $276,321,340$

Nikčević, Vojislav P. (*1935 - †2007) 96

Novi Sad 88, 95-96, 101-102

Podgorica 196

Pristina 99

Repubblica Federale di Jugoslavia (FRJ) 91, 95-97, 104, 106

Repubblica Socialista Federale di Jugoslavia (SFRJ) 67, 89-94, 97, 101, 103-104, 179, 190, 208

Roma 181, 193, 197, 218, 234, 302, 350, 355

Russia 160, 352

Sarajevo 172, 175, 225, 227, 231

Sarentino (Sarntal) 130, 267, 272-273, 293-294, 296-297, 299, 346, 349

Saussure, Ferdinand de $(* 1857-\dagger 1913) 253$ nota 14

Serbia 36, 69, 80, 87, 89-92, 95-97, 100-101, 103, 117-120, 130, 151-152, 160, 164-165, 169-170, 172, 178, 181, 187, 190-192, 201, 215, 217, 223-224, 228-230, 234, 236-237, 267-270, 274-276, 303-305, 321,355

Serbia e Montenegro, Unione Statale di 69, 97

Slavonia 89

Srpska, Republika 95, 104

Svezia 67, 105

Svizzera 56, 59, 67, 72, 120, 181, 193, 197, 272 
Trentino 61 nota 21,215

Trentino-Alto Adige 43, 67, 289

Trento 40 nota 1, 70, 181, 193, 197, 219, 354, 360

Triveneto 67

Ungheria 268

Val Badia (Gadertal, Val Badia) 40 nota 1, 41

Val Gardena (Grödnertal, Gherdëina) 40 nota 1,41

Valli ladine $c f r$. Ladinia
Val Passiria (Passeiertal) 54, 327

Veneto $61,67,120,258-259,302,350,352$, 354-355, 372

Vienna 88, 100, 188, 217 nota 41, 268, 272, 274, 276, 302-303, 324, 350, 355, 362

Voivodína 89-91, 118-119, 164, 166, 179, 215, 217

Zadar 182 nota 182,320

Zagabria $88,171,320$ 


\section{INDICE ANALITICO}

A

Accordo di Novi Sad 88, 101-102

Accordo Letterario di Vienna 88, 100

acquisizione linguistica cfr. apprendimento linguistico

acroletto $c f r$. codice in $H$

adattamento linguistico 49

adeguatezza dei dati 115,374

agentività $158,282,376$

allineamento (disallineamento), strategia di 22 , 139, 250, 300, 314, 321, 325, 376, 377

alsaziano, glottonimo 207

alternanza di codice non reciproca 260, 284, $317,319,335,348,351$

ambito comunicativo cfr. dominio d'uso

analessi 244

analisi della conversazione $21,128,130,138$

animatore, come ruolo nel formato di produzione $313,315,330,347$

apposizione, come nome di lingua generico

33-34, 38, 102-106, 130, 138, 141-179,

190, 195, 197-199, 202-205, 215, 375

apprendimento linguistico (acquisizione

linguistica)

- autonomo 81

- globale 295

- in contesto formale 45, 79-80, 90, 164, 218, 273, 276

- in contesto informale $45,80,83,178,187$, 271, 273, 276, 295, 337

- in contesto non formale 80

- non focalizzato $16,37,337$

- non guidato 178,270

- ragione per l'apprendimento linguistico

- geografica/geografico-urbanistica 159, $163,170,179$

- pseudo-storica 159, 179

appropriazione (induction) di una trama 291 argomento demografico e di potere 76 arumeno, codice 89, 91, 98, 159 nota 12, 206

ascoltatore, come ruolo interazionale 128 , 311-312

- non indirizzato $312,325,346$

- occasionale $139,256,258,311-312$, 317-319, 322, 325, 328, 330-331, 333-334, $337,340,346-347,350-351,359,363$ atteggiamento durante la raccolta dati 122, 126 atteggiamento linguistico

- della/verso la popolazione straniera in Alto Adige 65 nota 23, 71-72, 74, $77-78,80,85,120-121$

- in sociolinguistica $17,26,117,180,266$, 355 nota 88

- dell'intervistatrice 366

- verso i codici d'arrivo $39,45-46,48$, 51-52, 55-56, 63, 72

- verso i codici d'origine 92-93, 106, 218

- vs rappresentazione linguistica 21,112 , $126,133,240$

attitudine alla ricostruzione 126

attività non verbale o paraverbale 125,129 , 254-256, 258, 261, 283, 317

attrito $c$ fr. erosione linguistica

austro-bavarese, dialetto $39,50-53,58-60,62$, $64,72,124$

autenticità 264, 291-292, 306

autore, come ruolo nel formato di produzione

$244,313,315,328,330,347$

autorialità, come dimensione di narratività 244

- attribuzione di autorialità 159, 291, 316, $352,362,376$

azione complicante, come unità narrativa

263-264, 300, 322, 328, 336

B

basiletto $c f r$. codice in $L$

bilinguismo $c$ fr. plurilinguismo

biografico, approccio 15, 18, 22 nota 7, 25, 37, $110,132,243$

biografico-acquisizionale, dimensione 147-148, 151, 154-155, 157, 166, 171, 176,199

bosgnacco/bosniano, glottonimo 35, 103-104, 207

bosniaco-croato-serbo, glottonimo 79, 105, 189-190, 192, 236

$\mathrm{C}$

čakavo, codice $87-88,92,94$

campionamento, modi di 84, 109-115, 122

- a valanga $109-111,113$

- teorico 109, 111-112 
catalano, glottonimo 207

categoria identitaria $c f r$. identità

categorie di appartenenza, analisi di (membership categorization analysis) 138, 142, 375

catena migratoria $67,73,381$

centratura dei/sui dati 126

clausola

- narrativa 242, 261-264, 287 nota 37, 299, 301

- orientativa 263,306

coda, come unità narrativa 122,265

codice (varietà linguistica, lingua)

- accettato 167, 173-174

- bersaglio 261

- colloquiale 50, 54-59, 211, 225, 301

- della lontananza vs vicinanza $c f r$. dominio d'uso

- desiderato cfr. ideologia linguistica

- di eredità 105, 303

- di minoranza 17, 23-24, 90-91, 95, 98, 118-119, 154, 160, 176, 370, 381

- di nuovo insediamento 258 nota 18,284 , 295, 310, 337-338, 371

- endocomunitario e esocomunitario $c f r$. comunicazione in-group e out-group

- ideologico cfr. ideologia linguistica

- illegittimo, non riconosciuto cfr. illegittimità

- immigrato $v s$ di migranti 82,259 nota 18 , 285,373

- in H (acroletto) 19, 51, 50, 55, 61, 89, 147, 166, 173, 178, 206, 278, 280, 286, 297, 355

- in L (basiletto) 19, 24, 57, 60-61, 147, 166, 178, 280, 297, 308-309

- istituzionale 177

- misto cfr. mistilinguismo

- nazionale, dello stato 32 nota $14,86,89$, $90,101,103,148,154,156-157,207$

- parlato con la madre 209, 225

- per distanza (Abstand) 52, 105

- per elaborazione (Ausbau) 37 nota 16, 105

- pluricentrico cfr. pluricentricità

- territoriale 278

- tetto 56, 349

coerenza 264, 292, 306 nota 54

- principio della coerenza del testo 129

coinvolgimento 254-255, 263, 282, 307, 330, 332,377

commutazione di codice $16,20,30,51,164$, 193, 257, 260-261, 271, 310, 319-324, 326-327, 337-338, 349, 354, 358-359, 365,380

- in funzione mimetica $316,323-324,327$, 330,332
- in funzione di indice $v$ s icona 316-317, 326

- in funzione citazionale 322,332

comunicazione in-group e out-group 58

- codice endocomunitario 142, 146, 148, 157, 180, 195-196, 200, 206, 217

- codice esocomunitario 146, 180, 196, 198, 200, 206

comunicazione intergruppo 46, 48, 50-52, 54, 358 nota 89

comunità di discorso 78, 139, 288

comunità di locutori 17-18, 133, 226

comunità linguistica $15,17-18,30-31,37$

- di origine $88,95,117,150,207,213,223$

- frammentazione di 149

- immaginata $23,31,170,195,370$

- di arrivo 40, 42-44, 46, 48, 52-53, 73, 78, $185,315,317,322,327,343$

- legittima, riconosciuta 31, 184, 211, 236

- negoziazione, affiliazione a $107,133,142$, 146, 148-149, 185, 199-200, 209, 212, $221,224,227,230,232,235,248,363$

- riconoscimento da parte di 199, 201, 210, $226,235,370$

configurazione di dominanza tra codici 19

conflitto linguistico naturale $v$ s artificiale 92-93, 95, 98, 143

contestualizzazione 241,379

credibilità 263-264, 306 nota 54

$\mathrm{D}$

dacu-rumeno, codice $91,118-119,165$ nota $16,203,234$

dal basso (bottom-up) 44, 99, 149, 182 nota 24

dall'alto (top-down) 92, 95, 99, 133, 201, 227, 236, 381

dalmatino/dalmata, codice 100, 154

deissi 299 nota 49

- deittici, uso dei 126, 199, 254, 294, 299

- origo deittico 294, 299

destinatario, come ruolo interazionale 139 , $256,258,311-312,317-321,324$ nota 71 , $325,328,330-331,333-334,339-340$, $347,350-352,355,359,363$

diacrolettia (diacrolettico) 19, 158, 161, 178, 267, 304, 309

dialettalità percepita, indice di 209, 225 nota 45

dialettia 94-95

dialettologia percettiva $c f$ r. percezione

dialogo costruito $c f r$. discorso riportato

dichiarazione di appartenenza o di aggregazione 42,76 
differenziale semantico 21

diglossia (diglottico) 19, 23

- disglotizzazione 53

- dopo migrazione 278

- e repertori narrati 296-297, 304, 309, 372-373

- in Alto Adige 53, 59, 349

- incomprensione diglottica 51

- nei paesi d'origine $98,161,166,178$, 267

- triglossia 59, 297, 309

dilalia (dilalico) 19, 164, 178, 181-182, 267, 286, 309

diritto linguistico personale $v s$ territoriale 89

disallineamento $c f r$ allineamento

discorso riportato

- alternanza di codice nel 193, 257, 260, 271, 316, 322-324, 327, 329-330, 332

- come dialogo costruito $254,257,307$ nota 56,313

- funzione del 126, 135, 263, 315-316, $343-344,354,362$, 376-377

- inclusione e dislocazione del 250 nota 10 , 313

- modo di codifica del 256, 263, 311-316

dominio d'uso (ambito comunicativo) 19, 269 , 280

- della vicinanza $v s$ lontananza o anonimia 258, 280, 285, 296, 304, 308

- codice della lontananza 332

- codice della vicinanza 278, 285

- istituzionale (contesto istituzionale) 63, 104, 118, 207, 278, 281, 284-286, 296, $301,304,309,381$

drammatizzazione, strategia di 316, 332, 362

\section{E}

ecologico, approccio 277

egemonia (egemonico) 197, 246, 374

ekavismo 96

ekavo, codice 87-88, 95-95, 102-103, 147, 150, 154, 166-167, 173-174, 189

elisione 134, 290

elusiva, funzione $107,184,195,202,210-218$, $227,234,259,308$ nota $57,370,379$

emico $v$ s etico 15, 34, 149-150, 192, 256-259, 281,375

- categoria emica 21, 143, 146-147, 153, 255-259

empowerment 253 nota 13

enfatica, funzione 184-186, 192, 201-202, 208 nota $35,209-212,214$ nota $39,215-216$,
218-219, 221, 223-224, 227, 235, 259, 308

nota $57,361,370,379$

erosione linguistica (attrito) 32, 117, 219-121, $152,223,227,235,338-340$

espressivo, linguaggio 129, 134, 254, 264, 290, 295, 326

estratto, come unità narrativa 263,287 nota 37

etnicità 31 nota $12,43,93,131$

evento matrice $263,285,299-300$

evento più riportabile 244-245, 249, 263-265, 287, 292, 307, 320, 326

evitamento, strategia di 207

$\mathrm{F}$

feedback, segnale di cfr. segnale di ricezione

femminilizzazione dei flussi migratori 266

footing 139, 311-312, 316 nota 63

fossilizzazione

- fenomeno di 261

- fossilizzato 205, 208, 211-212, 227, 237, 271

fused lect 16

G

Gastarbeiter (lavoratore ospite) 67-68, 223 nota 44,225

ghego, codice 97-99, 203-204

giuntura temporale $242,262,287$

glossotopo 278

glottonimo

- concorrente vs semi-concorrente 144, 155. $167-178,182,188,207,375$ nota 5

- e dimensione interazionale $180,182,370$, 232,370

glottotomia 31 nota $11,101,149$

greco

- codice 90, 97, 159, 206, 283, 287, 292

- parlanti grecofoni 97, 282

grounded theory 26,128

I

iconicizzazione 134, 216, 290

identità

- della varietà linguistica (della lingua, del codice) $25,30,92,107,174$

- dimensione temporale, sociale e autoreferenziale dell' $28,32,131-132$

- epistemica vs agentiva 138,314-315, 365

- in narrazione o in interazione 130

- lavoro identitario 30, 37, 131, 135, 143, 290

- metodo della ricostruzione dell'identità narrativa $26,30,126$

- narrativa 28-30, 126, 131-133 
ideologia linguistica (pratica di significazione) 24, 134, 197, 255, 286, 290

- codice ideologico (codice desiderato, Wunschsprache) 56, 73, 85, 147, 223, 226, $240,304,311,359,364,380$

- puristica 24

idioma/espressione, apposizione (izraz) 88, 94-96, 102-104

ikavo, codice 87-88, 95

illegittimità (non riconoscimento) 18, 209-210, 370

- codice illegittimo (non riconosciuto) 18 , 20, 36, 40, 118-119, 163, 209, 214, 217, 231, 233-236, 370

- parlante illegittimo (non riconosciuto) 18 , 32, 222, 226-227, 235-236, 370

impersonale $c f$ r. spersonalizzazione, strategia di

implicatura 214

inclusione (integrazione)

- indice di integrazione potenziale 78 nota 36

- legge provinciale per l'integrazione 76

- linguistica o sociale $64,74,77-79,81,364$, 382

inclusione (embeddedness), come dimensione di narratività 244,250 nota 10,313

indessicalità (indessicale) 34, 37, 139, 255

induttivo, approccio 242

inserzione di codice 28,185 nota $26,257,273$, 277,316 nota $62,321-323,329-330$, 358-359, 365

integrazione $c f r$. inclusione interazionale $v s$ presentazionale, dimensione $27-28,130,132,314,375-377$

interdiscorsività 250, 251-253

interlingua (varietà di apprendimento) 52, 212 , 216, 256, 261, 271, 283-284, 292, 295, 297, 310, 314-319, 371

intertestualità $250,251-253$

- intertestuale, rinvio 290, 354

intersoggettività 250 nota 9

intervista

- di coppia 123, 144 nota 3, 180, 182, 193, 44 nota $44,228,370$

- focus group 20, 77, 123, 133

- morbida 122

- narrativa in profondità $19,110,123$

- qualitativa cfr. qualitativo

- semi-strutturata 20,122, 144, 203 nota 32

- episodico-narrativa 123, 144, 180, 203 nota $32,272-273$

io attuale cfr. io narrante io narrante (io attuale) 137, 250, 279 nota 31 , 313-314, 317, 371, 376

io narrato $137,379,314,317,371$

istrioto, codice 89

istrorumeno, codice 91

$\mathrm{J}$

jekavo (ijekavo), codice 87-88, 95-96, 102-103, 147, 166-167, 173-174, 189

jugoslavo, glottonimo 102, 114, 213

K

kajkavo, codice 87-88, 92, 94

kosovaro, glottonimo 114, 147, 151, 160, 163, 166, 219-223

L

Labov \& Waletzky, modello di 242-244, 261-263, 269, 335, 377

ladino

- codice 22, 40, 45, 47, 49, 259 nota 18,281 , 288, 302, 352, 359-361, 365

- popolazione 37 nota $16,40-44,47,49-50$, $53,74-76,271,273,276$

lavoro svolto, come fattore sociolinguistico $72-73$

lineare $v s$ circolare e dialogica, raccolta dati 112

linearità, come dimensione di narratività 244

lingua $c f r$. codice

lingua franca $90,216.236,328,335$ nota 80

- inglese come 85, 302, 350, 363, 366

lingua e immigrazione 74,278

lingua receptiva 335

località di residenza

- come fattore sociolinguistico $62,72-73$, 159,381

- come parametro raccolta dati 115, 130, 146

$\mathrm{M}$

macro vs micro

- approccio 23, 126-127, 280-282, 313

- contesto 22, 34-35, 107, 208, 210-211, 244, 251, 373-374, 377-378, 380-381

- fattore 68 nota $25,73,180$

macro-dialetto $87-88$

macro-lingua 87

mantenimento del banco 253

mantenimento/sostituzione di lingua

- e biografie linguistiche 25-26

- e denominazioni di lingua 209-210,212, 223, 227, 230-231, 234, 370 
- e repertorio narrato 259 nota $18,281,285$, 295, 297, 308, 338-340

- fattori sociolinguistici per 85-86, 111, 266, 340,381

- in contesto migratorio $23-24,26,220$ nota 43, 266

- in contesto minoritario 23, 36

- iniziative in Alto Adige per 79-80, 83-84

marcatore di struttura 127,146

marginalizzazione, strategia di 215, 234

- competenza linguistica marginale 337 nota 81

Matica Srpska 96, 103

meglenorumeno, codice 91

memoria 247

mistilinguismo 320, 337

- mistilingue, enunciazione 137, 252, 256, 260, 283-284, 303, 310, 317, 319-322, 331-332, 336-337, 351, 359, 365

- codice misto 54, 159 nota 11,213 , 225-226, 320, 330, 335, 337, 346, 348

mobilità vs migrazione 16

modello migratorio 68

moldavo, glottonimo 207

monolinguismo, diritto al 45, 281

montenegrino, codice 86-88, 92-93, 96-97,

101-105, 116-118, 151-152, 166, 168-171,

177, 181, 183, 194-201, 207, 225,

229-230, 235-236, 259, 276

multi-etnoletto 374

multilinguismo cfr. plurilinguismo

N

narratività 242, 244

narrazione (storia, racconto)

- abituale (iterativa) 179, 245-246, 254, 272 , 294, 297-301, 307, 343, 335, 378

- aneddoto 257, 306 nota 53

- argomentativo-esemplare (argomentativoillustrativa) 251, 275, 294, 297, 300-301, 307,378

- come modo di conoscenza 251

- condivisa 247-248, 286-292, 306 nota 53, 377-378

- contro-fattuale 245-246, 254, 290

- di conflitti linguistici 325 nota 73

- di esperienza personale 29, 222, 242-243, 252, 262, 291-292, 300, 306, 377

- di incontri linguistici 255

- familiare 247

- generica 246, 254, 272, 294, 297-301, 378

- grande (big) 139, 243, 279
- in interazione 243,263 , nota 19

- in intervista $27,125,243,248,376-377$

- in seconda persona $282,300,321$

- in terza persona $135,222-223,244$ nota 4, 247, 275, 304-305

- ipotetica 245-246, 254, 264

- metalinguistica $v s$ con argomento extralinguistico 34-35, 249, 251, 253, 255, 292, 315,377

- non-partecipata (non vissuta personalmente) 247-248, 304-308, 378

- piccola (small) 243, 264, 279

- preferita 291 nota 44

- prototipo (di default) 244-245, 247, 253, 269, 288 nota 38

- rappresentazione in forma di cronaca 248

- rappresentazione informativa 248, 343, 358

- resoconto (account) 248, 272, 358, 377

- ri-raccontata 246-247, 254, 275, 288 nota 38,305 nota 53,378

- scenico-episodica 127, 179, 247-248, 254, 272, 291, 294, 343, 378

- sul pericolo di morte 243 nota 3

naš jezik 106, 184, 206-207

naški 106, 206

negativa, frase 264, 289-290, 378

Neo-Vukovita 96-97

\section{$\mathrm{O}$}

obiettivo interazionale $21,33,143,292,308$, $313,378,380$

onomastico

- contenuto 141, 203, 232

- diatriba (disputa) 100, 104

- insicurezza (incertezza) 104, 194, 201, 230

- processo 206 nota 33

- uso 101

oppositiva, funzione 184, 192, 202, 210-212, $216,227-230,235-236,259,308$ nota 57 , 370,379

orientazione all'interlocutore (recipient design) $27,248,252$ nota 12,377

orientazione narrativa, sequenza con 243,245 , 251

orientazione, come unità narrativa 263, 297, 299, 306, 321

- orientativo

- clausola (enunciato) 262-263, 306, 322

- dettaglio 378

- sezione $263,300,306,328$ 
$\mathrm{P}$

paesaggio linguistico 83

partecipazione, creazione di $247,254-255$, 282,307

partecipazione, struttura di 139, 258, 311-314, 347,376

percezione

- della presenza di un codice 270, 274, 276

- linguistica percettiva delle varietà (dialettologia percettiva) 22, 277

- riguardo alla lingua $21-22,42,55,83,126$, 133, 240, 279

- test percettivo 354 nota 87

performance 132, 313, 325

pianificazione linguistica

- in Alto Adige 43, 50, 52, 59, 311

- nelle regioni di provenienza 25, 31, 34, 86, 93, 95, 98-99, 101, 107, 117, 181, 183, 201, 149, 152, 211, 226-227, 235-237, $303,369,380$

pluricentricità 105

- codice pluricentrico 17,37 nota $16,105-106$ plurilinguismo (bilinguismo, multilinguismo)

- bicomunitario e/o intercomunitario 46

- e rivalutazione dell'esperienza biografica 373-374

- in Alto Adige 46-48, 50, 52-53, 62, 78, 281, 286

- in contesto migratorio $35,63,73-74,78$, $268,310,373-374,381$

- interno e/o esterno 59-60, 63, 340, 372

- istituzionale $31,45,74,95,119,158$

- nelle regioni di partenza $24,31,33,88$, 181-182, 289

- patentino di bilinguismo (attestato, certificazione di) 43-45, 48, 273

- rappresentazioni del plurilinguismo di arrivo 284, 289, 295, 303, 306, 310, 371-373

- rappresentazioni del plurilinguismo di partenza 142, 152, 157-159, 161, 170, 178, 198, 201, 234, 373

- sociale e/o individuale $31,36,39,46-48$, $86,161,369,371$

- trilingue tricomunitario 178

policentricità (policentrico) 278, 380

polifonia (polifonico) 241, 250-251

portata comunicativa $278,281,285,295-296$, $303,309,362,371$

posizionamento, atto di (presa di posizione, stance) 21-22, 135-139, 240-243, 312, 314-317, 331, 376

- abituale 135, 257, 315, 375, 377
- oggetto vs soggetto di un atto di posizionamento $139,321,359$

- stancetaker 139, 314

- triangolo della presa di posizione 139

- valutativo cfr. valutazione, nell'atto di prendere una posizione

- valutativo, affettivo e/o epistemico 139, $300,315,321,348,354$

- verso se stessi e gli altri 135

posizionamento, livelli di 135-139, 314

posizionamento morale, come dimensione di narratività 244,253

pratica di significazione $c f$ r. ideologia linguistica

presa di posizione cfr. posizionamento, atto di prestigio manifesto $v s$ occulto o interno 39-40, $58,199,278,309,344$

prestito

- in funzione referenziale $261,273,277,317$ nota 65,324 nota $72,338,347,351,354$, 359

- nelle varietà d'origine 92, 97

- nelle varietà di tedesco in Alto Adige 52, 55

- (o inserzione) in funzione iconica 327, 358-359, 361, 365

primavera croata $93,102,105$ nota 62

pronome personale, alternanza di 139, 195, $254,282,300$

produzione, formato di 139, 313-314, 347, 376 profitto $v s$ orgoglio 197 nota 31

prolessi 244

pronuncia, apposizione (izgovor) 88, 95, 102-103, 174

proporzionale etnico-linguistica $42-44,53,76$, 378 nota 9

prosodia (caratteristica prosodica) 30 , 128-129, 135, 137, 254, 264, 290-291, 326, 331, 354-355, 359, 361-362, 364-365

prosodica, caratteristica $c f$ r. prosodia

protocollo di ascolto e di situazione 127, 384-385

Q

qualitativo

- analisi qualitativa assistita dal computer 128

- approccio (analisi) 20, 36 nota 15, 47, 109-112, 125, 186, 374

- intervista 73, 121, 266

- sociologia 25-26

quantificatore iperbolico 254, 264, 302

quantitativo, approccio (inchiesta, analisi) 20 , $29,42,47,109,311$ 
quasi-glottonimo $33,38,141,150-152,170$ nota $18,184-185,189,192,195,201$, 201-237, 259, 370, 379, 381

\section{$\mathrm{R}$}

raccontabilità 244-245, 253, 263-264, 272, 306 nota $54,377-378$

racconto $c f$ r. narrazione

rappresentanza 267

rappresentatività $111,115,267$

rappresentazione

- collettiva (comunitaria) 13, 86, 118, 133, 277, 292, 367

- di sé $23,25,27,30,34,114,131,134,137$, 220, 230, 239, 243, 264, 268, 275, 279-280, $285,290,293,308,330,338,362,365$

- dispositivi di 325

- individuale 18-19, 26, 32, 277, 279

- informativa o in forma di cronaca $c f r$. narrazione

- in uso 133

- modo di cfr. tipo di testo

- sociale 21-22, 25, 131-134

realtà del soggetto, del testo e della storia 28-30

recipient design cfr. orientazione all'interlocutore

referenziale $v s$ valutativa, funzione 242

regime linguistico $24,31,158$

regola di default 49, 63, 74, 371

repertorio

- individuale $v s$ comunitario $17-18,24,30$, 107, 109, 138, 142-143, 166, 178, 199, $214,235,278,369,380$

- narrato $v s$ dichiarato 240-241, 295, 303 nota 52,262

- tipo di 19, 23, 61, 112, 178, 281, 374

- verbale 15

responsabile, come ruolo nel formato di produzione $313,315,326,328,330,347$, 361

responsabilità, modulazione di $159,275,282$, $307-308,312,316,326$ nota $75,330-331$, $344,347,352,361,363,376$

rete sociale $c$ fr. reticolo sociale

reticolo sociale (rete sociale) 23-24, 68, 71, $111,113-114,246,252,266$ nota 22,310 , 332,340

riallocazione

- dei codici 15

- sociale e/o morale $253,308,314,325$ nota 73, 331, 345, 371, 373-374 riconoscimento, non cfr. illegittimità

ricordare 292

ricorsività frattale 134

ripetizione, strategia di coinvolgimento 253-254, 264, 291, 302, 306, 326, 344, 377

riportabilità 249 nota 7, 253, 263-264, 272, 290, 306

risoluzione, come unità narrativa 265, 326

rituale della disponibilità 358 nota 89

ruolo interazionale $128,139,256,312$, $317-318,333-334,350-351$

russo, codice $80-81,90,152,160,183,186$, 270-271, 283-284, 303 nota 52, 317, 328, 352

\section{$\mathrm{S}$}

salienza 241, 308, 379

- saliente 20, 25, 139, 240-241, 254, 260, 313-314, 326, 332, 359, 363, 367, 373, $376,379-380$

schizoglossia (schizoglottico) 31 nota 11, 149, 166-168, 179, 207, 236

Secondo Statuto di Autonomia per il TrentinoAlto Adige 43, 45, 48, 77

segnale di canale secondario $c f r$ segnale di ricezione

segnale di ricezione (segnale di feedback, segnale di canale secondario) 125, 130, $244,255,306,314,325,339,378$

sequenzialità 241,379

- sequenziale (sequenzialmente) 22, 30, 127, 130-131, 135, 155, 185, 194, 200, 205, 220, 239-241, 314, 375-376

siciliano, codice 271, 283, 294, 318

sistema scolastico altoatesino $39,43,46,53$, $63,74-76,80,118,286,326$ nota 76,346 , 381

slang di Bolzano 62

slavonico, codice 100,105

slovacco, codice 169, 271, 273, 293, 295, 335-336, 348

sociolinguistica della migrazione $17,23,266$, 277

soggettività 241,380

- approccio soggettivista (prospettiva soggettiva) 13, 19, 26, 381

- esperienza soggettiva 36

- informazione soggettiva 28,375

- repertorio soggettivo 241, 279, 309, 380

- spazio comunicativo soggettivo 285 , 309-310

- uso linguistico soggettivo 296, 308 
spazio comunicativo narrato 240,256 , 280-282, 285-285, 292-297, 299, 301, 303, 308-309, 332, 341, 349, 355, 359, 379,381

- dissociato 278, 285, 296, 309

spazio comunicativo vissuto $277-278$

spersonalizzazione, strategia di 195, 234

- forma verbale impersonale 158, 195-196, 215, 234, 282, 300

stance cfr. posizionamento, atto di stereotipo linguistico 51, 92, 110, 133, 288, 325,331

stigma (stigmata)

- verso gruppi di parlanti 110, 210, 218, 234, 381

- verso varietà linguistiche o di contatto 20 , $52,93,142$ nota $2,199,214-215,235,253$ nota 13

stile 131

štokavo, codice $87-88,92$

storia cfr. narrazione

storico-collettiva, dimensione 15, 25, 30, 239

strumentale e/o simbolico, valore dei codici 16 , $30,34,58,63,88,164,166,199-200,214$, 309-310, 355

storia migratoria, come fattore sociolinguistico 61 nota $21,64,69-70$

sudtirolese

- etnonimo 44-45

- glottonimo 53, 84 nota 44, 204, 283, 293, 296, $298299,302,317$ nota 65,344

\section{$\mathrm{T}$}

tabù (tabuizzazione) 149, 207, 210

tedesco austriaco, codice 56 tempo della narrazione cfr. tempo del racconto tempo del racconto (tempo della narrazione) 187 nota 27

tempo della storia $122,180,187-193$

tipo di testo (modo di rappresentazione) 35, 122, 127, 241-242, 247, 250, 313, 358 topos 176,327

- topos ad hominem 176 transfer 228, 261, 271

- discoursed-related transfer 316 nota 62

- time-out transfer 271

tosco, codice 98

trentino, codice 302,350

tropo 254

turco

- codice 89, 92, 98-99, 162-163, 206, 273, 337-338
- popolazione 90 nota 50,323

- prestiti dal 92,97, 153

turno di parola 27, 49, 129-130, 135, 145, 151, 184, 186, 194, 203, 214, 216, 229, 231, $273,328,370$

U

unità intonativa 262

unità narrativa $242,261-265,287$ nota 37

uso linguistico

- esibito 83

- individuale $v s$ abituale $15,279,286,290$, 300

- reale $v s$ rappresentato $v s$ dichiarato 18,20 , $28,59,116-117,126,220,255,279$

- rottura nell' $26,30,96,226,380$

- soggettivo 296, 308

V

valenziano, glottonimo 207

valutazione, come unità narrativa 263-264, 287 nota 37

- esterna $v s$ inclusa 264

- valutativo

- attività 241,290 nota 41

- enunciato 137, 263-264, 289, 300, 306-307, 321, 335, 337-338

- informazione 244,263

- sezione $327,331,339,343,352,378$

valutazione, nell'atto di prendere una posizione 139

- valutativo, atto di posizionamento 254,300 , 306, 314-315, 321-322, 327, 330, 341, $343,347-348,352,354-355,359,363$

variante, apposizione (varijanta) $88,95,102$, $105,147,150,154,166,174,188-190$, 192, 237

varietà di apprendimento $c f$ r. interlingua varietà linguistica $c f$ r. codice

variazione

- diacronica 15, 42, 46, 54, 57, 141, 208

- diacronia apparente 239, 309

- diafasica 54, 58, 60, 148, 301, 341, 344

- diamesica 341 nota 85

- diatopica 41-42, 46, 54, 57-58, 61, 94-95, 152, 173-174, 303, 327, 351, 354-356, $359,365,372$

- stilistica 261, 273, 341, 347

valacco/vlacco (vlaso, vlasco)

- codice 160, 165-166, 179, 216-217, 234

- popolazione $91,159,206$

verbalizzazione riguardo alle lingue $21-22$ 
vergogna $18,210-212,216-218,223,227$, $231,234,346,355,358,370$

vernacolare, parlato 243 nota 3

violenza epistemica 31,369 vitalità linguistica 58, 83, 91, 119, 163

vlaso, vlasco cfr. valacco/vlacco

W

weil, subordinata introdotta da 301 
CAROLIN PATZELT

in modernen Migrationsgesellschaften

Romanische Sprachen und

romanisch-basierte Kreolsprachen

in Französisch-Guayana

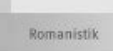

Franz Steiner Verlag

\section{Sprachdynamiken}

Carolin Patzelt

\section{Sprachdynamiken in modernen Migrationsgesellschaften}

Romanische Sprachen und romanisch-basierte Kreolsprachen in Französisch-Guayana

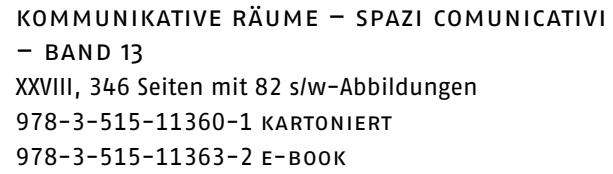

Plurilinguale, von komplexem ethnischen Miteinander geprägte Gesellschaften, wie man sie oftmals außerhalb Europas und in Zeiten zunehmender Mobilität in immer höherem Maße findet, gelten gemeinhin als chaotische, nicht vorhersagbare sprachliche Konglomerate. Obwohl die gängigen, aus eurozentrischem Blickwinkel konzipierten Sprachwandeltheorien ihnen starke Konvergenzprozesse prognostizieren, lässt sich hier häufig eine erstaunliche Stabilität der Vielsprachigkeit beobachten.

Carolin Patzelt zeigt am Beispiel der hochkomplexen Sprachsituation Französisch-Guayanas, wie die Stabilität der Mehrsprachigkeit gerade durch eine hohe Dynamik in der Kultivierung sprachlicher Identitäten befördert wird. Auf Basis einer umfassenden empirischen Studie zur Sprachselektion in Französisch-Guayana analysiert sie den

\begin{abstract}
Ablauf soziolinguistischer Dynamiken in modernen Migrationsgesellschaften. Mit ihrem multidimensionalen Ansatz leistet die Autorin einen wichtigen Beitrag für die Theoriebildung der modernen Sozio- und Migrationslinguistik.

\section{AUS DEM INHALT}

Französischguayana als multilinguale Migrationsgesellschaft | Mobilität und Diversität in der Migrationsgesellschaft | Modelle von Sprachdynamiken im plurilingualen Raum | Methodischer Ansatz | ,Central Accents“ im plurilingualen Raum | ,Central Accents‘ im plurilingualen Individuum | Pragmatische Sprachselektion im plurilingualen Raum | Sprachliche Integration von Migranten: Diagenerationelle Dynamiken | Zusammenfassung und Ausblick | Bibliographie
\end{abstract}




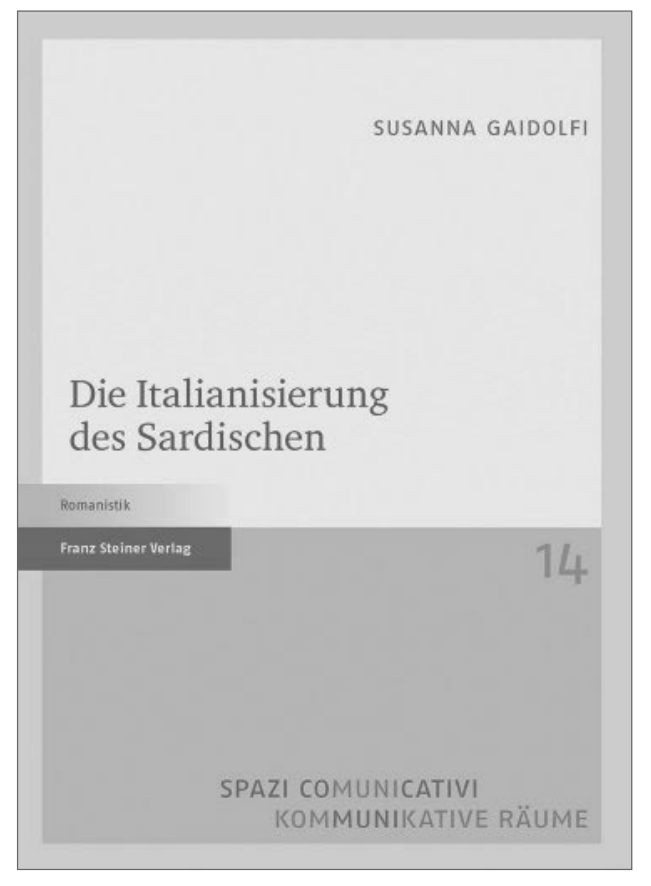

Obwohl das Sardische als eigenständige Sprache anerkannt ist, bleibt sein Wert in der Gesellschaft häufig hinter dem des Italienischen zurück. Susanna Gaidolfi leistet mit dieser Studie einen Beitrag zur Erforschung der gegenwärtigen Situation der gesprochenen sardischen Sprache. Die Arbeit fügt sich damit in das aktuelle Interesse für Minderheitensprachen ein, das in den letzten Jahren nicht nur auf romanischem Territorium als Gegenbewegung zur Globalisierung in gesteigertem Maße zu beobachten war.

Im Fokus steht die Italianisierung des Sardischen. Grundlage der Untersuchung bildet eine empirische Studie, die die Autorin in zwei Orten auf Sardinien durchgeführt hat. Das Fortschreiten der Italianisierung untersucht Gaidolfi anhand verschiedener Themen der Lexik und der Morpho-Syntax, die sie auf Veränderungen gegenüber grammatischen
Susanna Gaidolfi

\section{Die Italianisierung des Sardischen}

KOMMUNIKATIVE RÄUME - SPAZI COMUNICATIVI

- BAND 14

265 Seiten mit 27 s/w-Abbildungen und 97 Tabellen

978-3-515-11559-9 KARTONIERT

978-3-515-11563-6 E-BOOK

Beschreibungen dahingehend analysiert, ob sie den Angaben in Lexika und deskriptiven Grammatiken des Sardischen entsprechen oder sich den Gegebenheiten des Italienischen angepasst haben. Im Bereich der Lexik werden Monatsnamen, Verwandtschaftsbezeichnungen und Gesprächswörter untersucht, in der Morpho-Syntax die Konditionalformen, die Differentielle Objektmarkierung und Possessivphrasen.

\section{AUS DEM INHALT}

Einleitung | Sprachkontakt | Die sprachliche Situation Sardiniens | Bisherige Forschungen zu Sardisch und Italienisch in Kontakt | Die vorliegende Studie | Untersuchung lexikalischer Felder | Untersuchung morpho-syntaktischer Felder | Dimensionen der Italianisierung | Zusammenfassung und Ausblick | Bibliographie | Anhang 
VINCENZO PINELLO

\section{Raccontare e rappresentare le lingue e lo spazio}

L'esperienza dell'Atlante Linguistico della Sicilia (ALs)

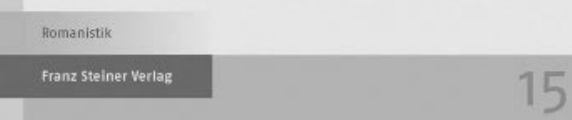

SPAZI COMUNICATIVI KOMMUNIKATIVE RÄUME

La Dialettologia Percettiva, disciplina che si occupa dello studio delle opinioni dei parlanti sulle varietà di lingua, nell'ultimo decennio ha rinnovato i propri fondamenti. Il volume da un lato intende ripercorrere criticamente tali profonde innovazioni, dall'altro propone una serie di modelli originali per l'analisi e l'interpretazione dei dati. Il corpus della ricerca è costituito dalle risposte di circa 900 informatori distribuiti in 60 punti d'inchiesta a tre domande del questionario dell'Atlante Linguistico della Sicilia (ALS) pensate per rilevare la percezione e rappresentazione della differenza linguistica. Una mole imponente di dati che sono stati trattati con un approccio quanti-qualitativo dimensionato al corpus e dialogando con un complesso eterogeneo di settori di studio che in un modo o nell'altro riguardano le scienze del linguaggio. Il volume offre anche un quadro completo dei principali
Vincenzo Pinello

\section{Raccontare e rappresentare le lingue e lo spazio}

L'esperienza dell'Atlante Linguistico della Sicilia (ALS)

KOMMUNIKATIVE RÄUME - SPAZI COMUNICATIVI

- BAND 15

315 Seiten mit 29 s/w-Abbildungen, 14 Tabellen und

7 Farbkarten

978-3-515-11871-2 KARTONIERT

978-3-515-11872-9 E-BOOK

fenomeni linguistici che caratterizzano l'articolato repertorio della Sicilia contemporanea. Di quest'ultimo vengono analizzate pure le dinamiche di contatto italiano vs. dialetto e le implicazioni ideologiche e identitarie. In appendice, un apparato cartografico a colori.

\section{CONTENUTO}

Modelli costruzionisti ed interazionali per un atlante della percezione | Dialettologia percettiva: modelli cognitivi e della costruzione sociale | Dialettologia percettiva e atteggiamenti | Consapevolezza e non consapevolezza nelle interazioni metalinguistiche | Salienze, stereotipi: le rappresentazioni degli spazi fisici, sociali e di lingua | Categorie, dicotomie, ideologia, spazi | Spazio vissuto I dati quantitativi nella dimensione metalinguistica | Bibliografia | Appendici 
Oggetto del volume sono le biografie linguistiche di persone trasferitesi in Alto Adige (Südtirol) dai paesi successori alla Jugoslavia dal 1985 al 20I5. Esaminando a livello contenutistico e formale i discorsi epilinguistici di parlanti che hanno vissuto e vivono in spazi sociolinguistici altamente complessi, la ricerca si propone di contribuire allo studio della ristrutturazione dei repertori in situazioni di contatto. Due sono le unità di analisi specifiche, identificate tramite i metodi della sociolinguistica interpretativa. Da un lato, si analizzano i glottonimi e le apposizioni usate per riferirsi alle varietà linguistiche d'origine. Ne emerge un quadro dei modi di posizionarsi dei partecipanti nei confronti dei recenti interventi di pianificazione linguistica in area balcanica. Dall'altro, si ricostruiscono gli spazi comunicativi narrati di tre intervistate attraverso l'esame delle loro storie di dialoghi. Questi racconti mostrano come le narratrici, attingendo a schemi interpretativi circolanti nella società altoatesina o resistendo loro, diano un senso vis-à-vis con la ricercatrice al cristallizzarsi di nessi più o meno inamovibili tra codici, luoghi e interlocutori nella regione d'arrivo.

ISBN 978-3-515-12290-0 